UNIVERSIDADE DE BRASÍLIA

FACULDADE DE TECNOLOGIA DEPARTAMENTO DE ENGENHARIA MECÂNICA

\title{
TÉCNICA DE OTIMIZAÇÃO APLICADA EM PROJETO CONCEITUAL DE MÍSSEIS TÁTICOS
}

\author{
RODRIGO QUEIROZ NEIVA
}

ORIENTADOR: CARLOS ALBERTO GURGEL VERAS

DISSERTAÇÃO DE MESTRADO EM CIÊNCIAS MECÂNICAS

$$
\begin{gathered}
\text { PUBLICAÇÃO: ENM.DM - } 245 \text { A/2016 } \\
\text { BRASÍLIA/DF: AGOSTO - } 2016
\end{gathered}
$$


UNIVERSIDADE DE BRASÍLIA

FACULDADE DE TECNOLOGIA DEPARTAMENTO DE ENGENHARIA MECÂNICA

TÉCNICA DE OTIMIZAÇÃO APLICADA EM PROJETO CONCEITUAL DE MÍSSEIS TÁTICOS

RODRIGO QUEIROZ NEIVA

DISSERTAÇÃO SUBMETIDA AO DEPARTAMENTO DE ENGENHARIA MECÂNICA DA FACULDADE DE TECNOLOGIA DA UNIVERSIDADE DE BRASÍLIA COMO PARTE DOS REQUISITOS NECESSÁRIOS PARA A OBTENÇÃO DO GRAU DE MESTRE EM CIÊNCIAS MECÂNICAS.

APROVADA POR:

Prof. Carlos Alberto Gurgel Veras, Dr. (ENM-UnB)

(Orientador)

Prof. Marcus Vinícius Girão de Morais, Dr. (ENM-Unb)

(Examinador Interno)

Ademir Luiz Xavier Júnior, Dr. (Agência Espacial Brasileira)

(Examinador Externo)

BRASÍLIA/DF, 17 DE AGOSTO DE 2016 


\section{FICHA CATALOGRÁFICA}

\section{NEIVA, RODRIGO QUEIROZ}

Técnica de Otimização Aplicada em Projeto Conceitual de Mísseis Táticos [Distrito Federal] 2016.

xxv, 300p., 210 x 297 mm (ENM/FT/UnB, Mestre, Ciências Mecânicas, 2016).

Dissertação de Mestrado - Universidade de Brasília. Faculdade de Tecnologia.

Departamento de Engenharia Mecânica.

1.Mísseis táticos

3.Otimização

I. ENM/FT/UnB
2.Projeto conceitual

4.Algoritmo genético

II. ENM.DM - 245 A/2016

\section{REFERÊNCIA BIBLIOGRÁFICA}

NEIVA, R. Q. (2016). Técnica de Otimização Aplicada em Projeto Conceitual de Mísseis

Táticos. Dissertação de Mestrado em Ciências Mecânicas, Publicação, Departamento de Engenharia Mecânica, Universidade de Brasília, Brasília, DF, 300p.

\section{CESSÃO DE DIREITOS}

AUTOR: Rodrigo Queiroz Neiva.

TÍTULO: Técnica de Otimização Aplicada em Projeto Conceitual de Mísseis Táticos.

GRAU: Mestre

ANO: 2016

É concedida à Universidade de Brasília permissão para reproduzir cópias desta dissertação de mestrado e para emprestar ou vender tais cópias somente para propósitos acadêmicos e científicos. $\mathrm{O}$ autor reserva outros direitos de publicação e nenhuma parte desta dissertação de mestrado pode ser reproduzida sem autorização por escrito do autor.

Rodrigo Queiroz Neiva

rodrigo.q.neiva@gmail.com 


\section{DEDICATÓRIA}

Ao meu sobrinho Samuel Araújo Neiva (in memoriam) que ainda cedo Deus chamou para si.

Rodrigo Queiroz Neiva 


\section{AGRADECIMENTOS}

A Deus, Pai de nosso Senhor Jesus Cristo, que permitiu que esse trabalho fosse realizado. Agradeço à minha esposa, Cristiane, pela compreensão nos momentos de ausência, incentivo quando me abateu o cansaço e pela efetiva participação na elaboração e revisão dessa dissertação.

Aos meus pais, Cleitus e Rosa, pelo apoio à conclusão de mais uma etapa acadêmica. Ao Professor Gurgel pela sugestão do tema e orientações em decisões importantes durante essa jornada.

Aos amigos que fiz na graduação e no mestrado.

Rodrigo Queiroz Neiva 


\section{RESUMO}

\section{TÉCNICA DE OTIMIZAÇÃO APLICADA EM PROJETO CONCEITUAL DE MÍSSEIS TÁTICOS}

O projeto conceitual de mísseis táticos impõe o desafio de lidar com uma ampla gama de variáveis e parâmetros de projeto e atender a determinados requisitos operacionais. Além disso, a limitação de recursos e a competitividade estabelece que seja obtida não somente uma solução que atenda aos requisitos, mas uma concepção mais vantajosa. Nesse contexto surge a necessidade de uma ferramenta de auxilio ao projetista, na fase de projeto conceitual de mísseis táticos, que empregue técnica de otimização multiparamétrica e multiobjetiva.

O presente trabalho visa o desenvolvimento de uma ferramenta computacional para auxílio no projeto conceitual de mísseis táticos, mediante a otimização da configuração geral do míssil. O programa desenvolvido, denominado Scorpio 1.0, incorpora modelos teóricos simplificados e de rápida avaliação nas áreas de aerodinâmica, propulsão, peso e trajetória de voo. Para o processo de otimização é empregada técnica de algoritmos genéticos.

O Scorpio 1.0 foi avaliado em diferentes etapas. Inicialmente foi verificada sua capacidade de otimizar a solução de uma função de teste. Em seguida foi averiguada a precisão dos modelos teóricos utilizados ao se comparar a previsão de desempenho e características, dada pelo programa, com os valores reais de um míssil de cruzeiro existente. Os resultados indicados pelo programa apresentaram boa aproximação dos dados do míssil real. Posteriormente foi verificada a capacidade de repetibilidade de resultados em execuções com configurações idênticas, quando o programa indicou soluções próximas nos diferentes casos. Por fim, o programa foi utilizado demonstrativamente para otimização de um míssil em fase de desenvolvimento no Brasil. Os resultados obtidos indicaram um míssil com massa de lançamento de aproximadamente $68 \%$ da previsão inicial dos participantes do projeto, atendendo aos requisitos e restrições de projeto, demonstrando assim a viabilidade do uso do programa Scorpio 1.0 para otimização de mísseis táticos em fase de projeto conceitual. 


\section{ABSTRACT \\ OPTIMIZATION TECHNIQUE APPLIED IN CONCEPTUAL DESIGN OF TACTICAL MISSILES}

Conceptual design of tactical missiles imposes the challenge of dealing with a wide range of design variables and parameters and fulfilling certain operational requirements. In addition, limited resources and competitiveness requires not only a solution that meets the requirements, but a more advantageous design. In this context, the need for a tool to aid the designer in the conceptual design of tactical missiles arises, making use of multiparametric and multiobjective optimization techniques.

The objective of this work is to develop a computational tool to assist in the conceptual design of tactical missiles, by the optimization of the general configuration of the missile. The developed program, called Scorpio 1.0, incorporates simplified theoretical models and rapid assessment in areas such aerodynamics, propulsion, weight and flight trajectory. For the optimization process is employed technique of genetic algorithms.

The Scorpio 1.0 was evaluated in difentes steps. Initially it was verified its ability to optimize the solution of a test function. Then has been investigated the accuracy of the theoretical models used comparing the prediction of performance and features, foreseen by the program, with the data of an existing cruise missile. The results indicated by the program showed good approximation to the reference missile data. It was later verified the program's results repeatability capacity at different executions with identical configurations, when the program indicated close solutions in different cases. Finally, the program was used demonstratively for optimization of a missile under development at Brazil. The results indicated a missile with launch mass of approximately $68 \%$ of the initial value, foreseen by the project participants, while still meeting the requirements and restrictions, thus demonstrating the feasibility of using the Scorpio 1.0 for optimization of tactical missiles in conceptual design phase. 


\section{SUMÁRIO}

1 - INTRODUÇÃ

1.1 - IMPORTÂNCIA ATUAL DOS MÍSSEIS TÁTICOS ...................................... 1

1.2 - FASES DO PROJETO DE ENGENHARIA........................................................ 3

1.2.1 - Projeto conceitual ............................................................................................................4 4

1.2.2 - Projeto preliminar ...................................................................................................... 4

1.2.3 - Projeto detalhado ..............................................................................................5

1.3 - PROJETO CONCEITUAL DE MÍSSEIS TÁTICOS ......................................... 5

1.4 - DEFINIÇÃO DO PROBLEMA...................................................................9

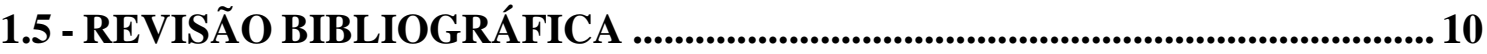

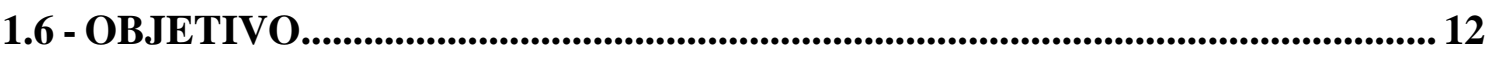

1.6.1 - Objetivo geral .................................................................................................................. 12

1.6.2 - Objetivos específicos ............................................................................................ 13

1.7 - ORGANIZAÇÃO DA DISSERTAÇÃO ........................................................... 15

2 - MODELOS MATEMÁTICOS .................................................................................. 17

2.1 - CONFIGURAÇÃO BÁSICA DOS MÍSSEIS TÁTICOS ...................................... 17

2.2 - AERODINÂMICA ........................................................................................................ 18

2.2.1 - Coeficiente de arrasto parasita ...................................................................... 18

2.2.1.1 - Coeficiente de arrasto parasita no corpo do míssil....................................... 18

2.2.1.2 - Coeficiente de arrasto parasita nas superfícies planas do míssil ................... 25

2.2.2 - Coeficiente de força normal .................................................................................227

2.2.2.1 - Coeficiente de força normal no corpo do míssil ........................................... 27

2.2.2.2 - Coeficiente de força normal nas superfícies planas do míssil....................... 29

2.2.3 - Centro aerodinâmico.................................................................................................... 33

2.2.3.1 - Posição longitudinal do centro aerodinâmico do corpo do míssil................. 33

2.2.3.2 - Posição longitudinal do centro aerodinâmico das superfícies planas do míssil

2.2.4 - Relação sustentação / arrasto ............................................................................. 36

2.2.5 - Geometria e características das superfícies planas do míssil ....................... 38

2.2.6 - Dimensionamento das superfícies de cauda do míssil..................................... 42

2.2.7 - Tipos de configuração e controle ................................................................45 


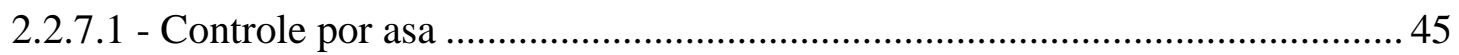

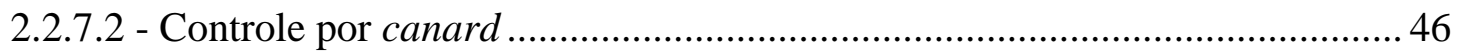

2.2.7.3 - Controle por superfície de cauda................................................................. 47

2.2.8 - Equilíbrio estático e estabilidade ............................................................... 48

2.2.9 - Manobrabilidade ................................................................................................49

2.2.10 - Equilíbrio em voo ..........................................................................................................50

2.2.11 - Margem de estabilidade estática....................................................................5 57

2.2.12 - Fator de carga em voo..............................................................................................5 57

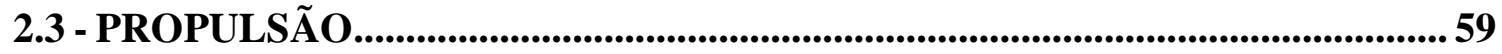

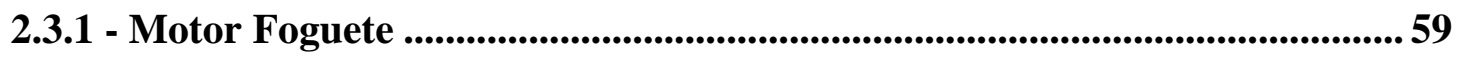

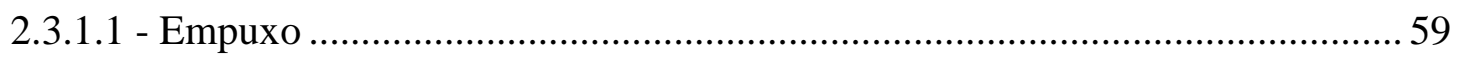

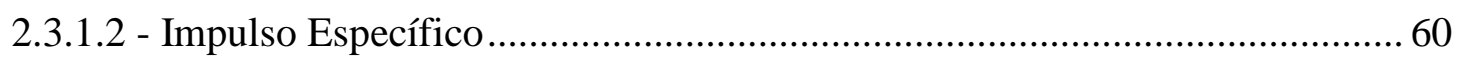

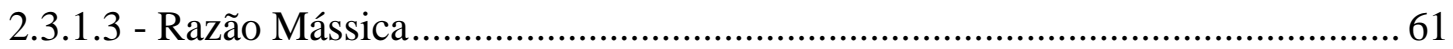

2.3.1.4 - Fração Mássica de Propelente ........................................................................... 61

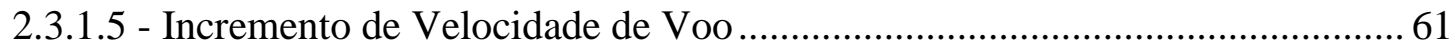

2.3.1.6 - Câmara de Empuxo de Foguetes Químicos ................................................. 64

2.3.2 - Ramjet ................................................................................................................................... 73

2.3.2.1 - Ramjet ideal - análise do ciclo termodinâmico............................................. 75

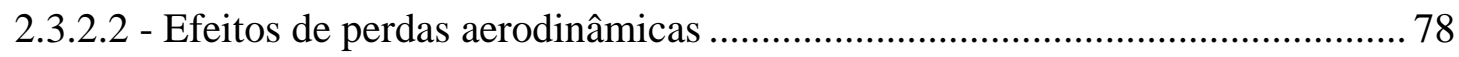

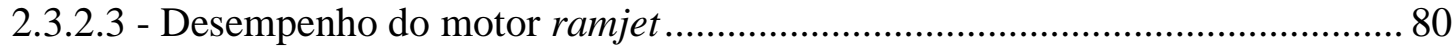

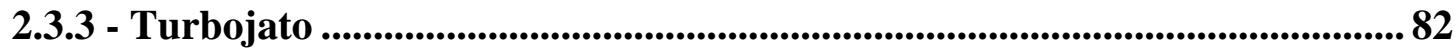

2.3.3.1 - Turbojato ideal - análise do ciclo termodinâmico ....................................... 82

2.3.3.2 - Considerações a respeito do bocal de exaustão............................................. 90

2.3.3.3 - Desempenho do motor turbojato ................................................................ 92

2.3.3.4 - Considerações a respeito da temperatura de combustão ............................... 97

2.3.3.5 - Considerações a respeito da relação de pressões no compressor ................... 98

2.4 - VOLUME E PESO................................................................................................................... 99

2.4.1 - Benefícios de um míssil com baixo peso ............................................................... 99

2.4.2 - Estimativa do peso do míssil.................................................................................99

2.4.3 - Massa específica média de mísseis táticos ................................................. 101

2.4.4 - Estimativa do peso dos componentes do míssil............................................. 103

2.4.4.1 - Estimativa do peso do motor foguete (booster) ......................................... 103

2.4.4.2 - Estimativa do peso de propelente do motor foguete (booster) .................... 104 
2.4.4.3 - Componentes com massa constante (dado de entrada) .............................. 104

2.4.4.4 - Estimativa de massa do combustível de cruzeiro........................................ 105

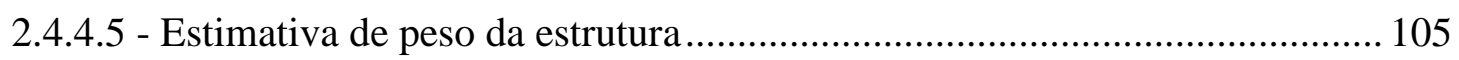

2.4.4.6 - Estimativa de peso das superfícies aerodinâmicas ...................................... 109

2.4.4.7 - Estimativa de peso do motor de cruzeiro ................................................. 111

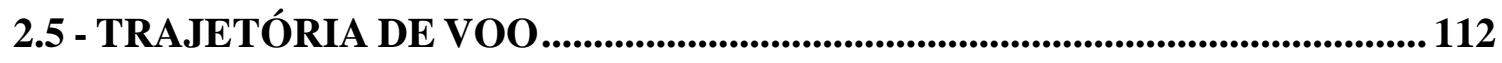

2.5.1 - Equações de modelagem de movimento .................................................... 112

2.5.2 - Perfis de voo ............................................................................................ 114

2.5.2.1 - Perfil do tipo aceleração inicial - planeio (boost - coast) ........................... 114

2.5.2.2 - Perfil do tipo aceleração inicial - sustain (boost - sustain) ........................ 115

2.5.2.3 - Perfil do tipo aceleração inicial - cruzeiro - coast .................................... 115

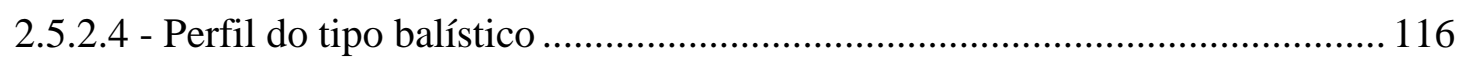

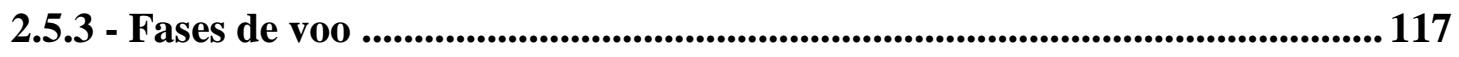

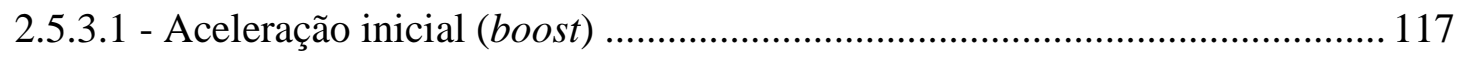

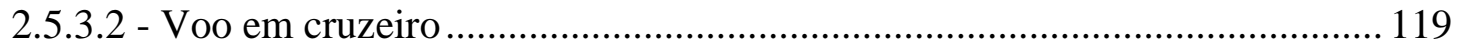

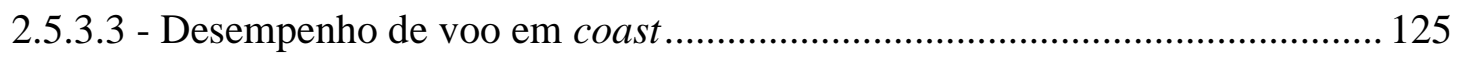

2.5.3.4 - Desempenho em voo balístico ............................................................. 127

3 - METODOLOGIA ……........................................................................................................... 129

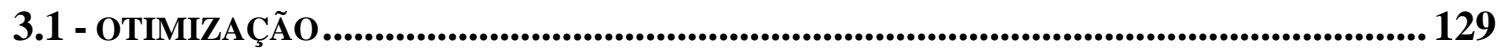

3.1.1 - Variáveis de projeto ............................................................................... 129

3.1.2 - Parâmetros de projeto ................................................................................................. 129

3.1.3 - Funções de projeto .......................................................................................................... 130

3.2 - ALGORITMOS GENÉTICOS................................................................................ 130

3.2.1 - Algoritmos genéticos ....................................................................................... 130

3.2.2 - Características de AG's .............................................................................. 132

3.3 - FUNCIONAMENTO DE UM ALGORITMO GENÉTICO............................. 133

3.3.1 - Esquema básico de um AG .............................................................. 133

3.3.2 - Representação cromossomial ......................................................................... 134

3.3.3 - Escolha da população inicial ................................................................................. 135

3.3.4 - Função de avaliação .......................................................................................... 135

3.3.5 - Seleção de pais ............................................................................................ 136

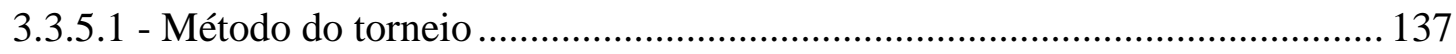


3.3.6 - Operadores genéticos ............................................................................................ 138

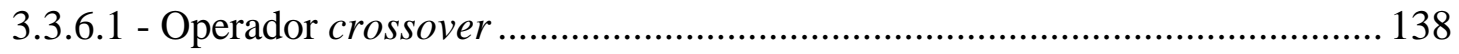

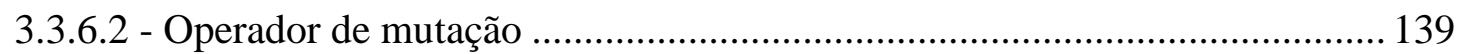

3.3.7 - Módulo de população ......................................................................................... 140

3.3.8 - Tamanho da população......................................................................................... 140

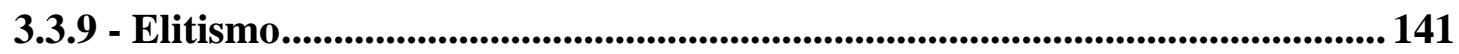

3.4 - O PROGRAMA SCORPIO 1.0......................................................................... 142

3.4.1 - O AG incorporado no programa Scorpio 1.0 …........................................... 142

3.4.2 - A função de avaliação no programa Scorpio 1.0 ............................................ 146

3.4.2.1 - Cromossomo de um míssil ......................................................................... 147

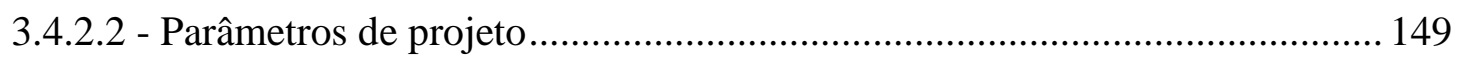

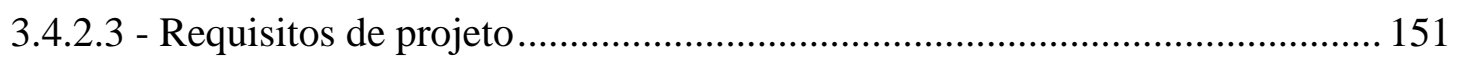

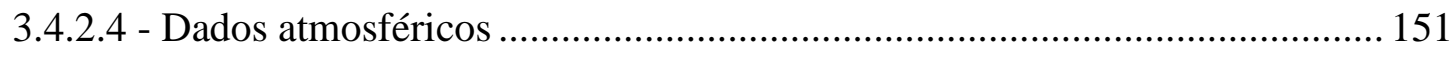

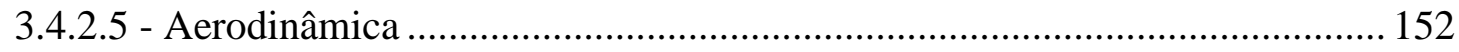

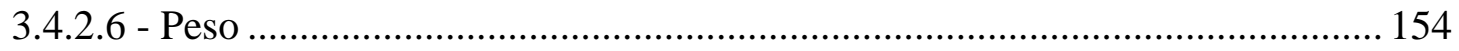

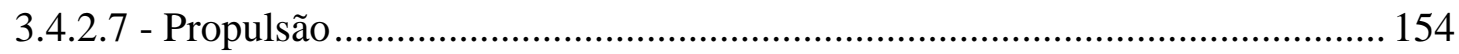

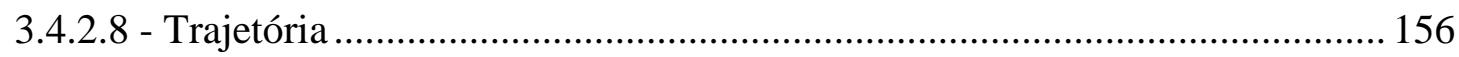

3.4.2.9 - Função de avaliação ……………………………………………………..... 157

4 - RESULTADOS E DISCUSSÃO .............................................................................. 163

4.1 - VERIFICAÇÃO DO ALGORITMO GENÉTICO IMPLEMENTADO ......... 164

4.1.1 - A função de Rastrigin ................................................................................. 164

4.1.2 - Aplicação do AG desenvolvido para busca do mínimo global da função de Rastrigin ..................................................................................................................... 167

4.2 - VERIFICAÇÃO DAS EQUAÇÕES DE MODELAGEN PARA O CASO DE UM MÍSSIL DE CRUZEIRO SUBSÔNICO................................................................. 180

4.2.1 - O míssil Harpoon................................................................................................. 180

4.2.2 - Previsão de desempenho do míssil Harpoon pelo programa Scorpio 1.0183 4.3 - VERIFICAÇÃO DE REPETIBILIDADE DE RESULTADOS ........................ 191

4.3.1 - Testes de repetibilidade ................................................................................. 191

4.3.2 - Configurações iniciais do Scorpio 1.0 para os testes de repetibilidade ... 191

4.3.3 - Resultados dos testes de repetibilidade .......................................................... 197 
4.4 - DEMONSTRAÇÃO DO USO DO SCORPIO 1.0 PARA O CASO DE UM MÍSSIL DE CRUZEIRO SUBSÔNICO EM DESENVOLVIMENTO .................... 216

4.4.1 - Míssil Tático de Cruzeiro para o Sistema ASTROS 2020 ........................... 216

4.4.2 - Configurações iniciais do Scorpio 1.0 para o caso do Míssil Tático de

Cruzeiro do Sistema ASTROS

4.4.3 - Resultados do caso do Míssil Tático de Cruzeiro do Sistema ASTROS $2020 \quad 222$

5 - CONCLUSÕES 236

REFERÊNCIAS BIBLIOGRÁFICAS 243

ANEXOS 248

A - FORMAS DE CLASSIFICAÇÃO DE MÍSSEIS 249

B - CONTROLE E PROLIFERAÇÃO DE MÍSSEIS. 254

C - CÁlCULO DE MOMENTO FLETOR NO CORPO DO MÍSSIL 256

D - PROBLEMAS INTRATÁ VEIS 263

E - ELEMENTOS DE BIOLOGIA FUNDAMENTAL 265

F - ATMOSFERA PADRÃO 268

G - ESTIMATIVA DE CUSTOS DE MÍSSEIS TÁTICOS 269

H - RELATÓRIO DE EXECUÇÃO DO SCORPIO 1.0: MÍSSIL HARPOON ........ 271

I - RELATÓRIO DE EXECUÇÃO DO SCORPIO 1.0: MÍSSIL ASTROS 2020 .... 286 


\section{LISTA DE TABELAS}

Tabela 2.1 - Características de diferentes tipos de controle aerodinâmico.......................... 48

Tabela 2.2 - Configurações em voo para equilíbrio aerodinâmico...................................... 56

Tabela 2.3 - Valores típicos de eficiência de componentes de motor turbojato (Hill \&

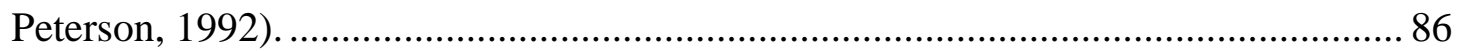

Tabela 2.4 - Parâmetros de cálculo para o motor turbojato .............................................. 93

Tabela 2.5 - Relação Empuxo/Peso para diferentes tipos de motor.................................. 111

Tabela 3.1 - Características do AG incorporado no programa Scorpio 1.0....................... 144

Tabela 3.2 - Genes componentes do cromossomo de um míssil. ..................................... 147

Tabela 3.3 - Dados de entrada e saída da função ATMOSFERA_ICAO. .......................... 151

Tabela 3.4 - Dados de entrada e saída da função AERODINAMICA. .............................. 153

Tabela 3.5 - Dados de entrada e saída da função ESTRUTURA..................................... 154

Tabela 3.6 - Dados de entrada e saída da função PROPULSÃO. ..................................... 155

Tabela 3.7 - Dados de entrada e saída da função TRAJETORIA. .................................... 156

Tabela 3.8 - Dados de entrada e saída da função FUNCAO_DE_AVALIACAO............. 157

Tabela 3.9 - Valores dos coeficientes da equação de avaliação parcial. ............................ 158

Tabela 3.10 - Verificação do atendimento aos requisitos de voo na equação de avaliação

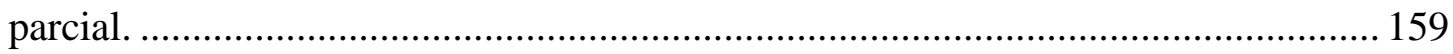

Tabela 3.11 - Valores dos coeficientes da equação de bonificações. ................................ 159

Tabela 3.12 - Verificação do atendimento aos requisitos de voo na equação de

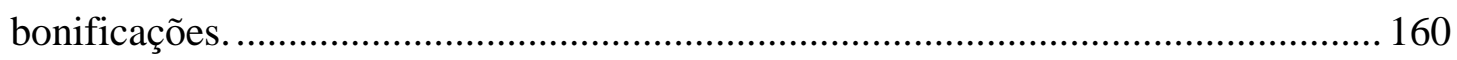

Tabela 3.13 - Valores dos coeficientes da equação de penalizações................................. 161

Tabela 3.14 - Verificação dos critérios da equação de penalizações.................................. 162

Tabela 4.1 - Dados da solução final de execução do algoritmo genético para minimização da função de Rastrigin dos casos representados nas Figuras 4.4 e 4.5 ...................... 170

Tabela 4.2 - Dados médios e desvio padrão de 200 execuções do AG. ............................. 177

Tabela 4.3 - Variáveis de projeto para dimensionamento do míssil AGM-84D Harpoon. 181

Tabela 4.4 - Parâmetros de projeto para simulação do míssil AGM-84D Harpoon.......... 183

Tabela 4.5 - Dados de desempenho do AGM-84D Harpoon conforme calculado pelo

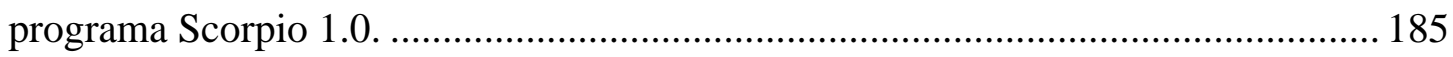

Tabela 4.6 - Centro aerodinâmico do míssil Harpoon (estimado pelo Scorpio 1.0). ........ 189

Tabela 4.7 - Dados de voo do míssil Harpoon (estimado pelo Scorpio 1.0)..................... 189 
Tabela 4.8 - Massa dos componentes do míssil Harpoon (estimado pelo Scorpio 1.0).... 189

Tabela 4.9 - Dados do motor de cruzeiro do míssil Harpoon (estimado pelo Scorpio 1.0).

Tabela 4.10 - Configurações de ajuste do AG para testes de repetibilidade.

Tabela 4.11 - Requisitos de voo para testes de repetibilidade.

Tabela 4.12 - Variáveis de projeto para testes de repetibilidade.

Tabela 4.13 - Variáveis de projeto para testes de repetibilidade (continuação 1).

Tabela 4.14 - Variáveis de projeto para testes de repetibilidade (continuação 2). 196

Tabela 4.15 - Parâmetros de projeto para os testes de repetibilidade.

Tabela 4.16 - Dados da execução do Scorpio 1.0 para os casos de teste de repetibilidade.

Tabela 4.17 - Dados de desempenho em voo para os casos de teste de repetibilidade..... 210

Tabela 4.18 - Dados dimensionais do corpo do míssil dos casos de teste de repetibilidade.

Tabela 4.19 - Dados dimensionais da asa do míssil dos casos de teste de repetibilidade. 211

Tabela 4.20 - Dados dimensionais da cauda do míssil dos casos de teste de repetibilidade.

Tabela 4.21 - Centro aerodinâmico do míssil dos casos de teste de repetibilidade.

Tabela 4.22 - Dados de voo do míssil dos casos de teste de repetibilidade.

Tabela 4.23 - Massa do míssil dos casos de teste de repetibilidade.

Tabela 4.24 - Massa dos componentes dos casos de teste de repetibilidade.

Tabela 4.25 - Dados do booster dos casos de teste de repetibilidade

Tabela 4.26 - Dados do motor de cruzeiro dos casos de teste de repetibilidade.

Tabela 4.27 - Características iniciais do míssil tático de cruzeiro

Tabela 4.28 - Configurações de ajuste do AG para o caso do míssil tático de cruzeiro do sistema ASTROS 2020.

Tabela 4.29 - Requisitos de voo para o caso do míssil tático de cruzeiro do sistema ASTROS 2020.

Tabela 4.30 - Variáveis de projeto para o caso do míssil tático de cruzeiro do sistema ASTROS 2020.

Tabela 4.31 - Variáveis de projeto para o caso do míssil tático de cruzeiro do sistema ASTROS 2020. (continuação 1). 
Tabela 4.32 - Variáveis de projeto para o caso do míssil de cruzeiro do sistema ASTROS

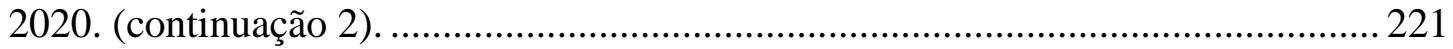

Tabela 4.33 - Parâmetros de projeto para o caso do míssil de cruzeiro ASTROS 2020... 221 Tabela 4.34 - Dados da execução do Scorpio 1.0 para o caso do sistema ASTROS 2020.

Tabela 4.35 - Dados de desempenho em voo para o caso do sistema ASTROS 2020...... 231

Tabela 4.36 - Dados dimensionais do corpo do míssil do caso do sistema ASTROS 2020.

Tabela 4.37 - Dados dimensionais da asa do míssil do caso do sistema ASTROS 2020..232 Tabela 4.38 - Dados dimensionais da cauda do míssil do caso do sistema ASTROS 2020.

Tabela 4.39 - Centro aerodinâmico do míssil do caso do sistema ASTROS 2020 ........... 233

Tabela 4.40 - Dados de voo do míssil do caso do sistema ASTROS 2020....................... 233

Tabela 4.41 - Massa do míssil do caso do sistema ASTROS 2020.................................. 233

Tabela 4.42 - Massa dos componentes do caso do sistema ASTROS 2020..................... 234

Tabela 4.43 - Dados do booster do caso do sistema ASTROS 2020 .............................. 234

Tabela 4.44 - Dados do motor de cruzeiro do caso do sistema ASTROS 2020................ 235 


\section{LISTA DE FIGURAS}

Figura 1.1 - Fluxograma típico de projeto conceitual de míssil tático baseado em um míssil

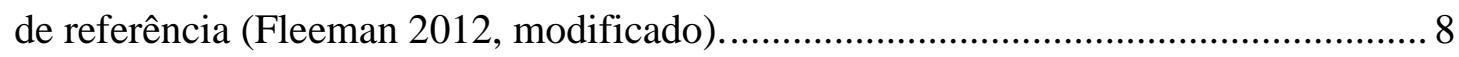

Figura 2.1 - Composição básica de um míssil tático. Adaptada de (TPUB, 2016) ............. 17

Figura 2.2 - Definição de parâmetros geométricos do corpo de um míssil......................... 19

Figura 2.3 - Coeficiente de arrasto de onda em função do número de Mach. .................... 21

Figura 2.4 - Arrasto e coeficiente de arrasto parasita teóricos em função do número de

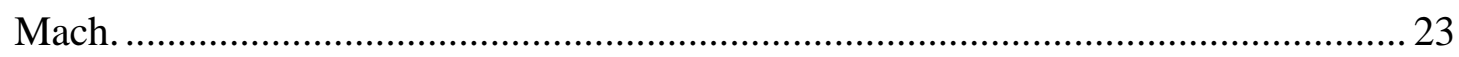

Figura 2.5 - Comparação de coeficientes de arrasto parasita obtidos teórica e

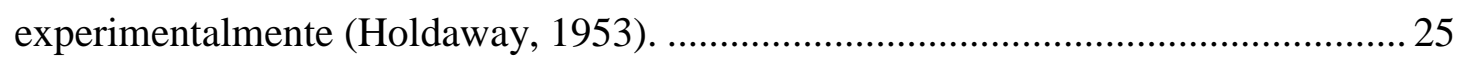

Figura 2.6 - Definição de parâmetros geométricos de superfícies aerodinâmicas de um

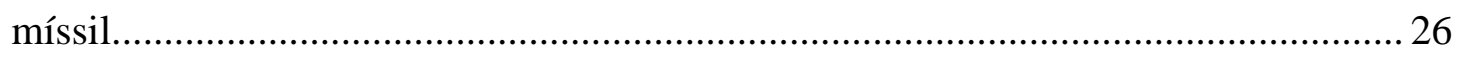

Figura 2.7 - Coeficiente de força normal no corpo em função do ângulo de ataque........... 28 Figura 2.8 - Coeficiente de força normal em superfície plana em função do ângulo de

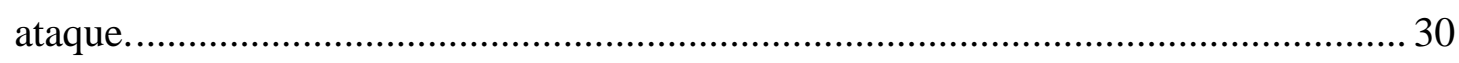

Figura 2.9 - Derivada do coeficiente de força normal em superfície plana, com relação ao ângulo de ataque, em função do número de Mach. ..................................................... 32

Figura 2.10 - Centro aerodinâmico do corpo em função do ângulo de ataque.................... 35

Figura 2.11 - Decomposição da força aerodinâmica resultante........................................ 36

Figura 2.12 - Relação sustentação/arrasto em função do ângulo de ataque. ........................ 38

Figura 2.13 - Características de diferentee superficies planas (Fleeman 2012, modificado).

Figura 2.14 - Tipos de controle aerodinâmico (Chin 1961, modificado). 45

Figura 2.15 - Atitude de voo de um míssil. Adaptada de (Bureau of Naval Personnel, 1959).... .49

Figura 2.16 - Forças atuantes sobre um míssil em voo (normal e arrasto parasita)........... 51

Figura 2.17 - Forças atuantes sobre um míssil em voo (sustentação e arrasto)................... 52

Figura 2.18 - Manobra em voo com velocidade constante ..............................................5 58

Figura 2.19 - Balanço de pressões em câmara de empuxo de motor foguete (Sutton \&

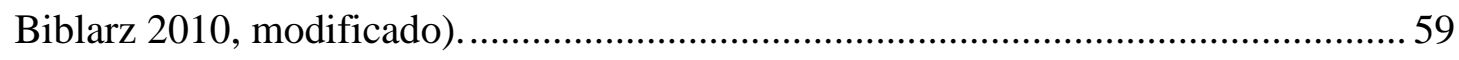

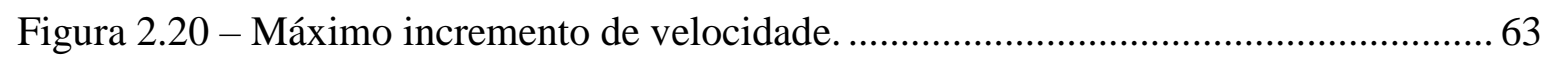

Figura 2.21 - Diagramas esquemáticos de foguetes químicos. ....................................... 65 
Figura 2.22 - Câmara de empuxo de motor foguete (Hill \& Peterson 1992, modificado) . 66

Figura 2.23 - Diagrama esquemático do motor ramjet ...................................................... 74

Figura 2.24 - Empuxo e consumo específico de combustível do ramjet ideal..................... 78

Figura 2.25 - Empuxo e consumo específico de combustível do motor ramjet considerando o efeito das perdas aerodinâmicas

Figura 2.26 - Diagrama esquemático de motor turbojato. .83

Figura 2.27 - Consumo específico e empuxo do motor turbojato (Mach = 0; nível do mar).

Figura 2.28 - Consumo específico e empuxo do motor turbojato (Mach = 0,85; $12200 \mathrm{~m}$ altitude)

Figura 2.29 - Consumo específico e empuxo do motor turbojato (Mach = 2,00; $18300 \mathrm{~m}$ altitude). 95

Figura 2.30 - Consumo específico e empuxo do motor turbojato (Mach = 3,00; $24400 \mathrm{~m}$ altitude) .95

Figura 2.31 - Peso de lançamento em função do alcance de mísseis balísticos. 101

Figura 2.32- Massas específicas típicas de subsistemas de mísseis (Fleeman 2012, modificado).

Figura 2.33 - Peso adimensional das superfícies planas em função da razão de aspecto. 110 Figura 2.34 - Comparação de modelos de trajetória de voo para projeto, baseado nos graus de liberdade do movimento (Fleeman 2012, modificado).

Figura 2.35 - Diagramas de força para diferentes condições de equilíbrio e voo (Chin 1961, modificado)

Figura 2.36 - Perfis de voo do tipo boost - coast. (Fleeman 2012, modificado). 115

Figura 2.37 - Perfil de voo de cruzeiro 116

Figura 2.38 - Perfil de voo balístico. 117

Figura 2.39 - Definições de parâmetros de voo. 119

Figura 2.40 - Diagrama de corpo livre de míssil em voo de cruzeiro. 120

Figura 2.41 - Variação do alcance de voo para mísseis típicos com diferentes tipos de propulsão (Fleeman 2012, modificado) 125

Figura 3.1 - Função hipotética com máximos e mínimos locais e globais - método do gradiente.

Figura 3.2 - Função hipotética com máximos e mínimos locais e globais - algoritmo genético. 
Figura 3.3 - Algoritmo genético genérico.

Figura 3.4 - Diagrama esquemático da seleção de pais pelo método do torneio

Figura 3.5 - Diagrama esquemático do funcionamento dos operadores crossover e mutação do algoritmo genético.

Figura 3.6 - Fluxograma do algoritmo genético implementado no programa Scorpio 1.0.

Figura 3.7 - Fluxograma da função de avaliação implementada no programa Scorpio 1.0.

Figura 3.8 - Cromossomo de um míssil tático.

Figura 4.1 - Função de Rastrigin.

Figura 4.2 - Contornos (curvas de nível) da função de Rastrigin. 166

Figura 4.3 - Contornos da função de Rastrigin. Caminho de busca típico percorrido pelo melhor indivíduo da população durante execução do algoritmo genético. População composta por 80 indivíduos. 168

Figura 4.4 - Variação da avaliação ao longo de gerações para minimização da função de Rastrigin, através da maximização de seu inverso Rasx - 1. População com 80 indivíduos, taxa de mutação de $2 \%$.

Figura 4.5 - Variação da avaliação ao longo de gerações para minimização da função de Rastrigin, através da maximização de seu inverso $\operatorname{Ras} x-1$. População com 80 indivíduos, taxa de mutação de $30 \%$.

Figura 4.6 - Variação da avaliação ao longo de gerações para minimização da função de Rastrigin, através da maximização de seu inverso Rasx - 1. População com 3000 indivíduos, taxa de mutação de $2 \%$.

Figura 4.7 - Contornos da função de Rastrigin. Caminho de busca típico percorrido pelo melhor indivíduo da população durante execução do algoritmo genético. População composta por 3000 indivíduos 173

Figura 4.8 - Contornos da função de Rastrigin. Caminho de busca típico percorrido pelo melhor indivíduo da população durante execução do algoritmo genético. População composta por 3000 indivíduos

Figura 4.9 - Resultados compilados para 210 execuções do AG para avaliação da função de Rastrigin. Cada ponto representa a média de 10 execuções com configurações iniciais idênticas com exceção da população utilizada. 175 
Figura 4.10 - Variação da avaliação ao longo de gerações para minimização da função de Rastrigin, através da maximização de seu inverso Rasx - 1. População com 40 indivíduos, taxa de mutação de $2 \%$. O melhor indivíduo permanece inalterado nas últimas 65 gerações, devido, possivelmente, à baixa diversidade genética presente na população.

Figura 4.11 - O míssil AGM-84 Harpoon em dois momentos. À esquerda o lançamento a partir de um navio (US Navy, 2015). Notar o booster na parte posterior do míssil. A imagem à direita mostra o míssil em voo de cruzeiro, sem booster (Kopp, 2014)... 181

Figura 4.12 - Imagens representativas do míssil AGM-84D Harpoon. 184

Figura 4.13 - Gráficos da primeira execução do Scorpio 1.0 para os testes de repetibilidade.

Figura 4.14 - Gráficos da segunda execução do Scorpio 1.0 para os testes de repetibilidade. 198

Figura 4.15 - Gráficos da terceira execução do Scorpio 1.0 para os testes de repetibilidade. 198

Figura 4.16 - Gráficos da quarta execução do Scorpio 1.0 para os testes de repetibilidade. 199

Figura 4.17 - Gráficos da primeira execução do Scorpio 1.0 para os testes de repetibilidade (diferentes escalas). 201

Figura 4.18 - Gráficos da segunda execução do Scorpio 1.0 para os testes de repetibilidade (diferentes escalas). 201

Figura 4.19 - Gráficos da terceira execução do Scorpio 1.0 para os testes de repetibilidade (diferentes escalas). 202

Figura 4.20 - Gráficos da quarta execução do Scorpio 1.0 para os testes de repetibilidade (diferentes escalas). .202

Figura 4.21 - Imagens representativas dos melhores mísseis a partir das configurações mostradas nas Tabelas 4.10 a 4.15. Primeira execução do programa Scorpio 1.0... 204 Figura 4.22 - Imagens representativas dos melhores mísseis a partir das configurações mostradas nas Tabela 4.10 a Tabela 4.15. Segunda execução do programa Scorpio 1.0 205

Figura 4.23 - Imagens representativas dos melhores mísseis a partir das configurações mostradas nas Tabelas 4.10 a 4.15. Terceira execução do programa Scorpio 1.0. ... 206 
Figura 4.24 - Imagens representativas dos melhores mísseis a partir das configurações mostradas nas Tabelas 4.10 a 4.15. Quarta execução do programa Scorpio 1.0....... 207

Figura 4.25 - Unidade lançadora do sistema ASTROS no momento do disparo de um

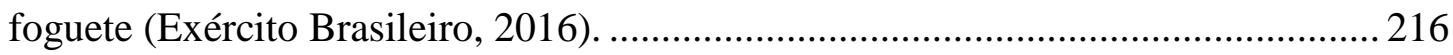

Figura 4.26 - Gráficos da execução do Scorpio 1.0 para o caso do sistema ASTROS 2020.

Figura 4.27 - Gráficos da execução do Scorpio 1.0 para o caso do sistema ASTROS 2020 (diferentes escalas).

Figura 4.28 - Imagens representativas dos melhores mísseis a partir das configurações mostradas nas Tabelas 4.28 a 4.33 . 226 


\section{LISTA DE SÍMBOLOS, NOMENCLATURA E ABREVIAÇÕES}

\section{Letras Latinas}

A

A

A

a

$a_{a}$

$A_{e}$

$a_{e}$

$\mathrm{A}_{L E}$

$a_{N}$

$A^{*}$

$b_{e}$

$c_{d}$

$C_{D}$

$C_{D_{0}}$

$\left(C_{D_{0}}\right)_{\text {avg }}$

$C_{L}$

$c_{\text {mac }}$

$C_{N}$

$C_{N_{\alpha}}$

$c_{p}$

$c_{p c}$

$c_{\text {ponta }}$

$c_{p t}$

$c_{\text {raiz }}$

$C_{\mathfrak{J}}$
Arrasto parasita

Área de referência

$\left[\mathrm{m}^{2}\right]$

Razão de aspecto da superfície

Velocidade do som

$[\mathrm{m} / \mathrm{s}]$

Velocidade do som ambiente

$[\mathrm{m} / \mathrm{s}]$

Área de exaustão do motor

$\left[\mathrm{m}^{2}\right]$

Velocidade do som nos gases de exaustão do motor

$[\mathrm{m} / \mathrm{s}]$

Ângulo de enflechamento das superfícies aerodinâmicas

Graus

Aceleração do míssil normal à sua trajetória.

$\left[\mathrm{m} / \mathrm{s}^{2}\right]$

Área da garganta da tubeira

$\left[\mathrm{m}^{2}\right]$

[m]

Coeficiente de descarga da tubeira

Coeficiente de Arrasto

Coeficiente de arrasto parasita total

Coeficiente de arrasto médio

Coeficiente de sustentação

Corda aerodinâmica média

[m]

Coeficiente de força normal

Derivada do coeficiente de força normal com relação ao

$\operatorname{rad}^{-1}$ ângulo de ataque

Calor específico a pressão constante

[J/kg.K]

Calor específico a pressão constante dos gases no

[J/kg.K]

compressor do turbjato

Corda aerodinâmica da ponta da asa

[m]

Calor específico a pressão constante dos gases na

[J/kg.K]

turbina do turbjato

Corda aerodinâmica da raiz da superfície

[m]

Coeficiente de empuxo da tubeira 


\begin{tabular}{|c|c|c|}
\hline$c^{*}$ & Velocidade característica & {$[\mathrm{m} / \mathrm{s}]$} \\
\hline $\mathrm{D}$ & Arrasto & {$[\mathrm{N}]$} \\
\hline$d$ & Diâmetro do míssil & {$[\mathrm{m}]$} \\
\hline$D_{\text {avg }}$ & Arrasto médio durante voo & {$[\mathrm{N}]$} \\
\hline$d_{i}$ & Diâmetro interno do corpo & {$[\mathrm{m}]$} \\
\hline$E$ & Módulo de elasticidade & GPa \\
\hline$f$ & Relação combustível/ar & - \\
\hline$g, g_{e}$ ou $g_{c}$ & Aceleração da gravidade & {$\left[\mathrm{m} / \mathrm{s}^{2}\right]$} \\
\hline$h$ & Entalpia & {$[\mathrm{J} / \mathrm{kg}]$} \\
\hline$h_{\max }$ & Altitude máxima & {$[\mathrm{m}]$} \\
\hline$h_{0}$ & Entalpia de estagnação & {$[\mathrm{J} / \mathrm{kg}]$} \\
\hline$I$ & Impulso total devido ao sistema de propulsão & {$[\mathrm{N} . \mathrm{s}]$} \\
\hline$I_{s p}$ & Impulso específico & {$[\mathrm{s}]$} \\
\hline $\mathrm{L}$ & Sustentação & {$[\mathrm{N}]$} \\
\hline 1 & Comprimento do míssil & {$[\mathrm{m}]$} \\
\hline$l_{n}$ & Comprimento do nariz & {$[\mathrm{m}]$} \\
\hline M & Número de Mach & - \\
\hline $\mathrm{m}$ & Massa & {$[\mathrm{kg}]$} \\
\hline$M_{\mathrm{A}_{L E}}$ & Número de Mach perpendicular ao bordo de ataque & - \\
\hline$M_{e}$ & Número de Mach de exaustão do ramjet & - \\
\hline$m_{f}$ & Massa final do foguete & {$[\mathrm{kg}]$} \\
\hline$M_{p}$ & Massa total de propelente & {$[\mathrm{kg}]$} \\
\hline$m_{p}$ & Massa de propelente & {$[\mathrm{kg}]$} \\
\hline$M R$ & A razão mássica & - \\
\hline$m_{0}$ & Massa inicial do foguete & {$[\mathrm{kg}]$} \\
\hline$\dot{m}$ & Taxa de fluxo mássico & {$[\mathrm{kg} / \mathrm{s}]$} \\
\hline$\dot{m}_{a}$ & Fluxo mássico de ar & [kg.s] \\
\hline$\dot{m}_{a c}$ & Fluxo mássico de ar frio & {$[\mathrm{kg} / \mathrm{s}]$} \\
\hline$\dot{m}_{a H}$ & Fluxo mássico de ar quente & {$[\mathrm{kg} / \mathrm{s}]$} \\
\hline$\dot{m}_{c}$ & Fluxo mássico através do compressor do turbojato & {$[\mathrm{kg} / \mathrm{s}]$} \\
\hline$\dot{m}_{f}$ & Fluxo mássico de combustível & {$[\mathrm{kg} / \mathrm{s}]$} \\
\hline$\dot{m}_{t}$ & Fluxo mássico através da turbina do turbojato & {$[\mathrm{kg} / \mathrm{s}]$} \\
\hline
\end{tabular}




$\begin{array}{llc}M^{*} & \text { Número de Mach na garganta da tubeira } & - \\ N & \text { Força normal } & {[\mathrm{N}]} \\ \mathrm{n} & \text { Fator de carga em voo } & - \\ n_{\text {sup }} & \text { Número de superfícies planas (painéis) } & - \\ \mathrm{p} & \text { Pressão } & {[\mathrm{Pa}]} \\ p_{a} & \text { Pressão ambiente } & {[\mathrm{Pa}]} \\ p_{c} & \text { Pressão crítica } & {[\mathrm{Pa}]} \\ p_{e} & \text { Pressão de exaustão do motor } & {[\mathrm{Pa}]} \\ p_{r c} & \text { Razão de pressões do compressor } & - \\ p_{0} & \text { Pressão de estagnação } & {[\mathrm{Pa}]} \\ \mathrm{q} & \text { Pressão dinâmica do ar } & {[\mathrm{Pa}]} \\ Q_{R} & \text { Poder calorífico do combustível (base mássica) } & {[\mathrm{J} / \mathrm{kg}]} \\ \mathrm{R} & \text { Alcance de voo balístico } & {[\mathrm{m}]} \\ \mathrm{r} & \text { Raio da estrutura do míssil } & {[\mathrm{m}]} \\ r_{c} & \text { Razão de pressão de estagnação no combustor do } \text { ramjet } & - \\ r_{d} & \text { Razão de pressão de estagnação no difusor do } \text { ramjet } & - \\ r_{n} & \text { Razão de pressão de estagnação no bocal do ramjet } & {[} \\ \bar{R} & \text { Constante universal dos gases } & - \\ s & \text { Distância de voo } & {[\mathrm{J} / \mathrm{kg} . \mathrm{K}]} \\ S_{\text {asa }} & \text { Área da superfície da asa } & {[\mathrm{m}]} \\ S_{\text {Cauda }} & \text { Área da superfície de cauda } & {\left[\mathrm{m}^{2}\right]} \\ S_{e} & \text { Área planiforme de superfície exposta } & {[\mathrm{s}]} \\ S_{\text {nosetip }} & \text { Área da parcela abaulada do nariz do míssil } & {\left[\mathrm{m}^{2}\right]} \\ S_{\text {ref }} & \text { Área de referência (seção transversal do míssil) } & {\left[\mathrm{m}^{2}\right]} \\ S_{\text {superfície }} & \text { Área planiforme da superfície } & {\left[\mathrm{m}^{2}\right]} \\ \mathrm{T} & \text { Temperatura } & {\left[\mathrm{m}^{2}\right]} \\ \mathfrak{J} & \text { Empuxo } & {\left[\mathrm{m}^{2}\right]} \\ \mathrm{t} & \text { Espessura } & {[\mathrm{K}]} \\ t & \text { tempo instantâneo } & {[\mathrm{N}]} \\ T_{a} & \text { Temperatura ambiente } & {[\mathrm{m}]} \\ t_{\text {mac }} & \text { Espessura máxima da corda aerodinâmica média } & {[\mathrm{s}]} \\ t_{\text {max }} & \text { Tempo máximo de voo } & {[\mathrm{K}]} \\ & & {[\mathrm{m}]} \\ & & \end{array}$




$\begin{array}{llc}t_{p} & \text { Tempo de funcionamento do motor foguete } & {[\mathrm{s}]} \\ t_{\text {raiz }} & \text { Espessura da raiz da superfície } & {[\mathrm{m}]} \\ T_{0} & \text { Temperatura de estagnação } & {[\mathrm{K}]} \\ u & \text { Velocidade de voo } & {[\mathrm{m} / \mathrm{s}]} \\ u_{e} & \text { Velocidade de exaustão do motor } & {[\mathrm{m} / \mathrm{s}]} \\ u_{e q} & \text { Velocidade de exaustão equivalente (ou efetiva) } & {[\mathrm{m} / \mathrm{s}]} \\ u_{i} & \text { velocidade inicial } & {[\mathrm{m} / \mathrm{s}]} \\ u_{p} & \text { Máxima velocidade do míssil no fim da queima do } & {[\mathrm{m} / \mathrm{s}]} \\ & \text { propelente } & \\ \overline{u_{e}} & \text { Velocidade de exaustão média } & {[\mathrm{m} / \mathrm{s}]} \\ \mathrm{V} & \text { Velocidade } & {[\mathrm{m} / \mathrm{s}]} \\ \mathrm{X}_{A C} & \text { Localização do centro aerodinâmico } & {[\mathrm{m}]} \\ \mathrm{X}_{C G} & \text { Localização do centro de massa } & {[\mathrm{m}]} \\ y_{c p} & \text { Afastamento lateral entre a raiz e o centro de pressão de } & {[\mathrm{m}]} \\ & \text { uma superfície aerodinâmica } & \\ W & \text { Peso do míssil. } & {[\mathrm{N}]} \\ W_{a v g} & \text { Peso médio durante voo } & {[\mathrm{N}]} \\ W_{B S} & \text { Peso da estrutura do corpo } & {[\mathrm{N}]} \\ W_{i} & \text { Peso inicial do míssil } & {[\mathrm{N}]} \\ W_{L} & \text { Peso de lançamento } & {[\mathrm{N}]} \\ W_{M} & \text { Peso do motor foguete } & {[\mathrm{N}]} \\ W_{p} & \text { Peso de propelente } & {[\mathrm{N}]}\end{array}$

\section{Letras Gregas}

$\begin{array}{llc}\alpha & \text { Ângulo de ataque } & \text { Graus } \\ \alpha^{\prime} & \text { Ângulo de ataque efetivo local } & \text { Graus } \\ \gamma & \text { Razão de calores específicos } & - \\ \gamma_{c} & \text { Razão de calores específicos no compressor do turbojato } & - \\ \gamma_{d} & \text { Razão de calores específicos no difusor do turbojato } & - \\ \gamma_{n} & \text { Razão de calores específicos no bocal do turbojato } & - \\ \gamma_{t} & \text { Razão de calores específicos dos gases na turbina } & -\end{array}$




$\begin{array}{llc}\delta_{L E} & \text { Ângulo total da seção do bordo de ataque } & \text { Graus } \\ \Delta u & \text { Incremento na velocidade de voo } & {[\mathrm{m} / \mathrm{s}]} \\ \zeta & \text { Fração mássica de propelente } & - \\ \eta_{b} & \text { Eficiência de combustão } & - \\ \eta_{c} & \text { Eficiência adiabática do compressor do turbojato } & - \\ \eta_{d} & \text { Eficiência adiabática do difusor do turbojato } & - \\ \eta_{n} & \text { Eficiência adiabática do bocal de exaustão do turbojato } & - \\ \eta_{t} & \text { Eficiência adiabática da turbina do turbojato } & - \\ \eta_{0} & \text { Eficiência global do sistema de propulsão } & - \\ \theta_{i} & \text { Ângulo de lançamento ótimo } & \mathrm{Graus} \\ \lambda & \text { Razão entre a corda de ponta e corda de raiz da } & - \\ \rho & \text { superfície (taper ratio) } & {\left[\mathrm{kg} / \mathrm{m}^{3}\right]} \\ \rho_{a v g} & \text { Massa específica } & {\left[\mathrm{kg} / \mathrm{m}^{3}\right]} \\ \rho_{c} & \text { Massa específica média } & {\left[\mathrm{kg} / \mathrm{m}^{3}\right]} \\ \sigma & \text { Massa específica crítica } & \mathrm{MPa} \\ \phi & \text { Tensão admissível } & \mathrm{Graus}\end{array}$

\section{Siglas}

CG

Centro de Massa

DNA

Ácido Desoxirribonucleico

DOS

Disk Operating System

FS

Fator de Segurança

AG

Algoritmo Genético

GDL

Graus de Liberdade

MFPH

Motor Foguete a Propelentes Híbridos

MFPL

Motor Foguete a Propelentes Líquidos

MFPS

Motor Foguete a Propelente Sólido

MTCR

Regime de Controle de Tecnologia de Mísseis

RCS

Radar Cross-Section

TSFC

Consumo específico de combustível (thrust specific fuel consumption) 


\section{1 - INTRODUÇÃO}

\section{1 - IMPORTÂNCIA ATUAL DOS MÍSSEIS TÁTICOS}

Mísseis são veículos aéreos não tripulados que contêm uma cabeça-de-guerra explosiva, dotados de sistemas de propulsão própria, com sistemas de orientação e controle de voo embarcados (Bureau of Naval Personnel, 1966). Os mísseis foram uma arma inteiramente nova na Segunda Guerra Mundial. Eles ofereciam as vantagens dos foguetes (alcance, velocidade, poder de fogo, baixo peso, recuo e exposição) e eliminavam a maior desvantagem destes (imprecisão). Mesmo quando disparados contra alvos distantes ou em movimento, os mísseis ofereciam probabilidade razoável de sucesso. Essa tecnologia estava ainda em seu início quando a Segunda Guerra Mundial teve fim, mas em 1945 estava claro que os novos mísseis representariam uma revolução no campo militar (Mindling \& Bolton, 2011).

A bipolarização mundial nos anos seguintes à Segunda Guerra Mundial promoveu o desenvolvimento de mísseis balísticos capazes de transportar não apenas explosivos convencionais mas também artefatos nucleares. A opção por mísseis balísticos para ataque a longas distâncias ocorreu por disponibilidade tecnológica referentes ao sistema de propulsão bem como do sistema de guiamento e controle. Em 1955 tanto a União Soviética como os Estados Unidos já dispunham em seus arsenais de mísseis balísticos capazes de transportar ogivas nucleares. O desenvolvimento desse tipo de armamento continuou nos anos subsequentes, com o incremento do alcance e capacidade de carga, resultando na disponibilidade de mísseis balísticos intercontinentais já no início da década de 1960 (Van Riper, 2004).

Após a Segunda Guerra Mundial, os primeiros projetos de mísseis de cruzeiro utilizavam motores aeronáuticos comuns e piloto-automático para guiamento e controle. Em seguida, estes foram substituídos por guiamento por comando e sistemas de navegação inercial, enquanto propelentes sólidos e motores turbojato (e posteriormente turbofan) substituíram os motores iniciais. Contudo, o longo tempo de voo dos primeiros mísseis de cruzeiro fazia 
com que os sistemas inerciais acumulassem erros de navegação inaceitáveis do ponto de vista operacional.

O advento de tecnologias como guiamento por comparação de terreno ${ }^{1}$, correlação digital de imagem ${ }^{2}$ e navegação por GPS $^{3}$ permitiu superar obstáculos relacionados à navegação de mísseis de cruzeiro por longas distâncias. Outra barreira significativa para implementação de mísseis de cruzeiro é a necessidade de um sistema de propulsão de alta eficiência, capaz de levar o míssil até alvos além de $300 \mathrm{~km}$. No início da década de 1980 os Estados Unidos e a União Soviética detinham mísseis de cruzeiro capazes de transportar ogivas nucleares e convencionais por distâncias superiores a $1500 \mathrm{~km}$, atingindo alvos com grande precisão.

Mísseis balísticos representaram uma ferramenta de pressão política e militar durante a segunda metade do século XX. As diversas tensões políticas desse período, ainda que não tenham resultado em conflitos armados, incentivaram o desenvolvimento de mísseis balísticos em países de todos os continentes. Todavia, a análise dos principais conflitos armados desde o fim da Segunda Guerra Mundial até o início do século XXI mostra um decréscimo do uso de mísseis balísticos e o incremento do uso de mísseis de cruzeiro (Gormley, 2008).

Avanços tecnológicos nas últimas décadas têm permitido que barreiras pontuais sejam superadas, disseminando a capacidade de produção de mísseis de cruzeiro por diversos países do mundo. Atualmente a ênfase no uso desse tipo de armamento tem sido o ataque de alvos específicos, onde é requerida grande precisão e furtividade no ataque, de forma a dificultar ou mesmo impedir a capacidade de reação do oponente, com o mínimo de danos colaterais possíveis.

Estima-se que os custos do ciclo de vida completo de um míssil de cruzeiro sejam menores que custos correspondentes de aeronaves tripuladas de ataque (Nicholls, 2000). Esse é um importante fator a ser considerado quando se leva em conta a capacidade de sobrevivência

\footnotetext{
${ }^{1}$ Uma tradução livre do inglês Terrain Contour-Matching (TERCOM).

${ }^{2}$ Uma tradução livre do inglês Digital Scene-Matching Area Correlation (DSMAC).

${ }^{3}$ Do inglês Global Positioning System.
} 
de aeronaves em situações de combate. Dadas estas vantagens relativas dos mísseis de cruzeiro aliadas ao fato que eles permitem conduzir campanhas militares estratégicas sem a necessidade de inicialmente obter superioridade aérea, é possível concluir que, num futuro próximo, haverá um interesse crescente na aquisição desse tipo de armamento por parte de diferentes nações (Gormley, 2008).

\section{2 - FASES DO PROJETO DE ENGENHARIA}

Qualquer produto de engenharia, inclusive um míssil tático, é projetado e construído para desempenhar funções específicas servindo a determinados fins. Este ciclo de vida total inclui três etapas principais:

\footnotetext{
i. $\quad$ Projeto de Engenharia;

ii. Fabricação;

iii. Operação.
}

Projeto de Engenharia é essencialmente um processo de tomada de decisões por meio do qual um produto pode ser fabricado com um custo razoável, atendendo aos requisitos de projeto. Diferenças no projeto de um dado produto, que refletem em seu desempenho, podem ser relacionadas à extensão da análise de engenharia que precede qualquer decisão tomada pelo projetista. Incluem-se em tal análise parâmetros como (a) geometria e dimensões de diferentes partes, (b) tipos de materiais usados na fabricação e suas especificações técnicas, (c) técnicas de fabricação e montagem, e (d) condições de operação (Tawancy, Ul-Hamid \& Abbas, 2004).

Tipicamente, o projeto se inicia com uma ideia ou um conceito desenvolvido para satisfazer determinadas necessidades, sejam elas necessidades de mercado por um novo produto ou pelo incremento no desempenho de um produto existente. Antes desse conceito se materializar em um produto, o Projeto de Engenharia passa por fases distintas, que podem ser classificadas em:
i. Projeto conceitual;
ii. Projeto preliminar; 
iii. Projeto detalhado (Projeto de produção).

\subsection{1 - Projeto conceitual}

O projeto conceitual se atém primariamente com requisitos funcionais do produto e como eles podem ser atendidos. Nesta fase, diversas concepções ou ideias que podem atender aos requisitos iniciais são avaliadas (por exemplo: configuração, dimensões principais, peso, desempenho). Posteriormente uma decisão é tomada a respeito da viabilidade de determinada concepção. Após a aprovação da mesma, ela é selecionada para desenvolvimento posterior. Além disso, são feitas considerações acerca da disponibilidade de materiais estruturais cujas propriedades satisfaçam aos requisitos de projeto. Assim, o projeto conceitual contém muito mais do que é visto no esboço do produto apresentado no fim dessa etapa (Raymer, 2004). Um bom projeto conceitual é submetido às avaliações das etapas de projeto subsequentes sem que grandes mudanças sejam necessárias. Isso decorre da abrangência e precisão dos modelos teóricos utilizados para elaboração do projeto conceitual.

\subsection{2 - Projeto preliminar}

Para que a fase de projeto preliminar seja iniciada, as grandes modificações no projeto conceitual devem ser finalizadas. Alterações posteriores, de menor impacto no projeto conceitual selecionado, caso ocorram, resultam em um projeto razoavelmente maduro durante a fase de projeto preliminar. A configuração geral do produto permanecerá inalterada, embora pequenas alterações possam ocorrer. Num estágio próximo do fim do projeto preliminar, mesmo as alterações menores serão finalizadas. O objetivo final dessa etapa é a preparação para a fase de projeto detalhado. No fim geralmente é feito um modelo em escala real do produto (Raymer, 2004). Nessa fase é estabelecida a viabilidade da fabricação do produto, atendendo, além dos requisitos técnico-operacionais, ao cronograma e ao custo estimado. 


\subsection{3 - Projeto detalhado}

Considerando uma decisão favorável ao desenvolvimento da escala real do produto, a fase de projeto detalhado se inicia, na qual são projetadas as peças e os componentes a serem fabricados. Outra atividade importante dessa fase é o projeto de produção, onde se determina como o produto será fabricado, desde as partes mais simples até a montagem completa do produto. Portanto, nesta etapa são desenvolvidos desenhos técnicos de engenharia para especificar os diversos componentes, suas dimensões, procedimentos de montagem, bem com os materiais que deverão ser utilizados. Isso permite a conversão do projeto em um protótipo de teste e avaliação, que pode demandar alterações adicionais no projeto para melhorar o desempenho do produto.

Durante a etapa de projeto detalhado são intensificados os testes de cada subsistema do produto. Esta etapa termina com a fabricação do produto. É importante que todas as mudanças necessárias sejam feitas antes que o produto entre em fase de projeto de produção. É possível que a fase de projeto detalhado revele a necessidade de mudanças adicionais no projeto. Alterações no projeto do produto após avanços na produção podem ser muito onerosas. Portanto, as mudanças requeridas devem ser realizadas durante a fase de projeto detalhado (Tawancy, Ul-Hamid \& Abbas, 2004).

\section{3 - PROJETO CONCEITUAL DE MÍSSEIS TÁTICOS}

Segundo Fleeman (2006), o projeto conceitual de mísseis táticos é um processo iterativo, que requer um número de iterações de projeto para atingir um equilíbrio entre diversos parâmetros de entrada e saída. As principais atividades do projeto conceitual são:

i. Definição da missão e cenário de operação;

ii. Definição dos requisitos do armamento, estudos de compromisso e análise de sensibilidade;

iii. Estudo de integração física do míssil com a plataforma de lançamento;

iv. Elaboração do conceito do míssil;

v. Avaliação tecnológica e roteiro de desenvolvimento tecnológico. 
O processo inicial de projeto começa com uma definição geral da missão e cenário de operação do míssil. Os dados de entrada são as capacidades desejáveis pelo operador do sistema (míssil), que idealmente não mudam durante o processo, mas que podem ser alteradas, por exemplo, por se descobrir que as metas iniciais não podem ser atingidas ou pela decisão de adoção de uma tecnologia que não estava disponível no início do projeto.

A segunda etapa, definição dos requisitos do armamento, estudos de compromisso e análise de sensibilidade, fornece os requisitos técnico-operacionais do míssil tais como alcance, tempo de voo até o alvo e outras figuras de mérito.

A terceira etapa, estudo de integração física do míssil com a plataforma de lançamento, estabelece a existência de restrições físicas tais como comprimento, envergadura e peso. Esta etapa é orientada no sentido de integração dos diferentes sistemas (Fleeman, 2006).

A quarta etapa, elaboração do conceito do míssil, é a mais iterativa e indiscutivelmente a mais criativa (Fleeman, 2006). Nela, tradicionalmente, são avaliadas características como forma aerodinâmica, massa e tipo de propelente ou combustível, alcance de voo, tempo até o alvo, manobrabilidade, alcance de detecção do alvo, precisão, letalidade e custo; e o míssil é redimensionado e reconfigurado em um processo iterativo. Por exemplo, os estabilizadores de cauda e superfícies de controle aerodinâmico podem ser redimensionados para incrementar a estabilidade e manobrabilidade. Outro exemplo é a adição de propelente ou combustível para atingir o alcance de voo desejado. Ao passo que o projeto amadurece e é melhor definido através das iterações, o número de soluções alterativas é reduzido de uma vasta gama de possibilidades para um pequeno grupo de alternativas preferidas que é mais razoável e com melhor relação custo-benefício. Com o amadurecimento do projeto, obtém-se informações mais abrangentes para o projeto dos subsistemas (Fleeman, 2012).

Por fim, uma etapa de avaliação tecnológica permite uma definição ainda mais profunda dos subsistemas e a seleção das melhores tecnologias aplicáveis. Os estudos de tecnologia levam a um grupo de tecnologias preferidas. Um roteiro de desenvolvimento tecnológico documenta o desenvolvimento para o amadurecimento de tecnologias necessárias (Fleeman, 2012). 
A Figura 1.1 apresenta o fluxograma típico de avaliação de alternativas e o processo iterativo usado para composição do projeto conceitual de mísseis táticos proposta na obra de Fleeman (2012). Nesse fluxograma, a partir dos requisitos da missão, estabelece-se um ponto de partida com um míssil de referência (existente), dotado de sistema de propulsão similar ao desejado. O míssil de referência é utilizado para acelerar a convergência do projeto. As vantagens do uso do míssil de referência incluem a consideração de um sistema balanceado e o uso de um referencial preciso a respeito de dados de teste existentes (p.ex. dados de túnel de vento). O míssil de referência sofre modificações em sua aerodinâmica, propulsão, peso e trajetória de voo para atender aos novos requisitos do novo míssil. O novo projeto conceitual é avaliado a partir de seus requisitos de voo (p.ex. alcance de voo, tempo de voo até o alvo, manobrabilidade).

A rotina aerodinâmica do processo de projeto conceitual abrange uma investigação das alternativas de configuração geométrica. Informações de saída dos cálculos aerodinâmicos são então utilizados como dados de entrada para o dimensionamento do sistema de propulsão. Esse dimensionamento inclui a previsão de suficiente quantidade de propelente ou combustível para atender aos requisitos de alcance e tempo de voo. O próximo passo é a estimativa de peso do novo míssil com sua aerodinâmica e propulsão modificada. Boa parte dessa atividade é focada no projeto estrutural, que é sensível às mudanças do desempenho de voo (Fleeman, 2012). Após a estimativa de peso, a trajetória de voo do novo míssil é computada. O alcance, velocidade terminal, manobrabilidade, e outros parâmetros de desempenho de voo são então comparados com o desempenho de voo requerido pela missão. Se o míssil não atender aos requisitos de desempenho de voo, ele é redimensionado e o processo reiterado. Após completar um número suficiente de reiterações, o próximo passo é avaliar novo míssil a partir de outras figuras de mérito e restrições. Se o míssil não atende a estes últimos requisitos, o projeto é alterado (configurações alternativas, subsistemas, tecnologia) e redimensionado para a próxima iteração e avaliação (Fleeman, 2012). ${ }^{4}$

\footnotetext{
${ }^{4}$ Esse é o processo tradicional de projeto conceitual de mísseis táticos apresentado por Fleeman (2012). Como será visto adiante, neste trabalho será adotada uma rotina diferente, não sendo adotado um míssil como referência, tampouco serão aplicadas iterações para alterações consecutivas de um mesmo míssil. O fluxograma de processos adotado neste trabalho está representado pelas Figuras 3.6 e 3.7 .
} 


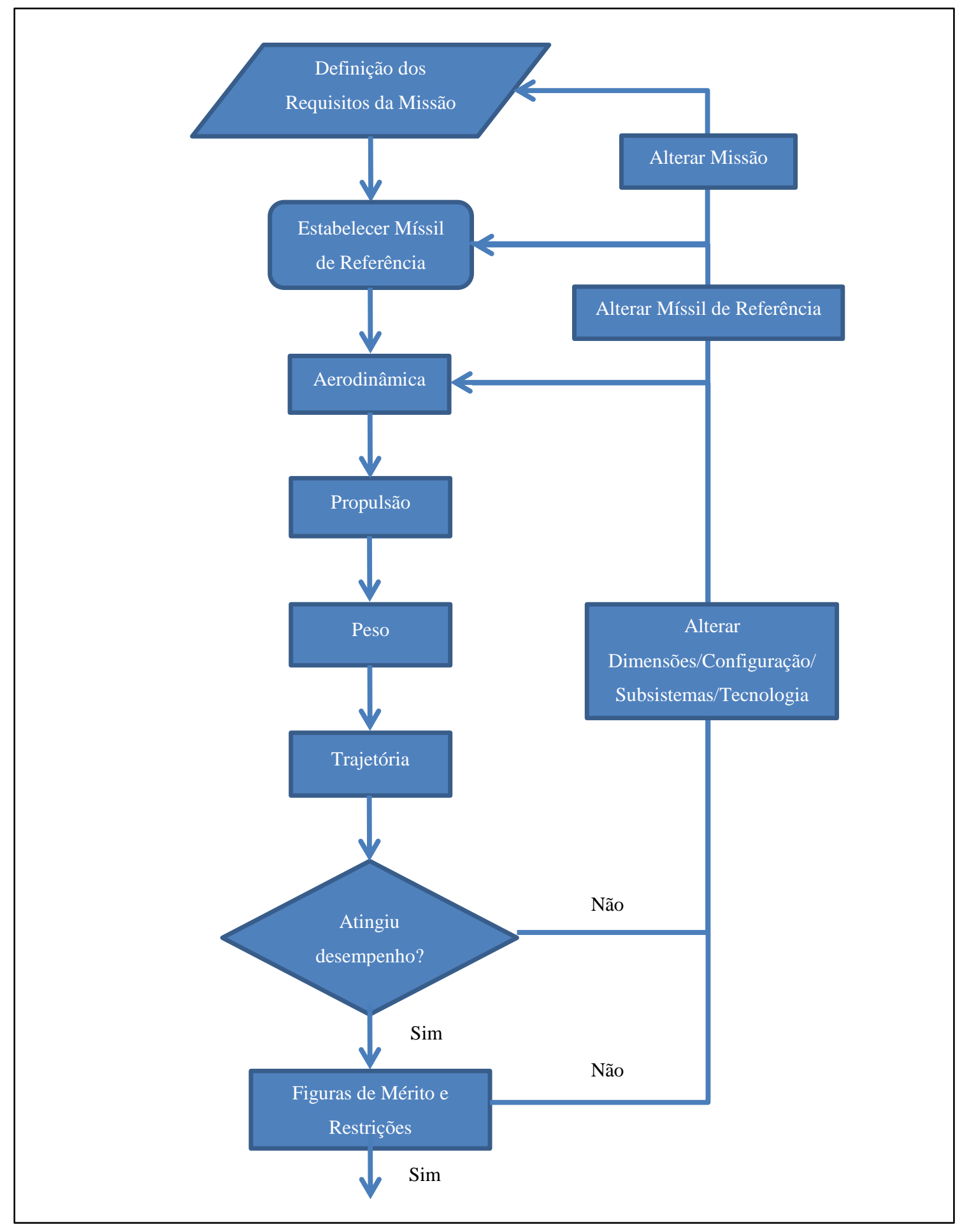

Figura 1.1 - Fluxograma típico de projeto conceitual de míssil tático baseado em um míssil de referência (Fleeman 2012, modificado).

Após ser submetido ao fluxo de processos apresentado, o míssil final diferirá do míssil de referência em muitos aspectos. Por exemplo, a área da asa pode ter sido redimensionada para atender aos requisitos de manobrabilidade. A área das superfícies de cauda pode ter 
sido redimensionada para atender aos requisitos de margem de estabilidade estática e máximo ângulo de ataque para voo trimado. O motor foguete ou ramjet pode ter sido alterado para aumentar sua eficiência na altitude e velocidade de voo selecionadas. Adicionalmente, o comprimento do sistema de propulsão pode ter sido alterado para acomodar a quantidade adicional de propelente/combustível necessária para satisfazer o requisito de alcance de voo. As mudanças de projeto se refletem em revisões da massa, geometria, perfil de empuxo e trajetória de voo do míssil. Com esse processo, tipicamente, são necessárias de 3 a 6 iterações de projeto antes que o míssil alterado convirja e atenda aos requisitos de desempenho de voo (Fleeman, 2006).

Embora o projeto de um míssil possa atender ao requisitos de desempenho e satisfazer a outras figuras de mérito e restrições da plataforma de lançamento, esse não é necessariamente um projeto otimizado. De acordo com Fleeman (2012), é uma boa prática de projeto avaliar o maior número possível de alternativas de projeto durante a duração desta etapa.

\section{4 - DEFINIÇÃO DO PROBLEMA}

Durante o projeto conceitual de um míssil tático é necessário estimar, de forma rápida e econômica, o desempenho de uma grande variedade de possíveis configurações. Portanto, o emprego de uma ferramenta computacional de auxílio ao projetista é fundamental.

Dois requisitos básicos para programas de computador empregados em projeto conceitual de mísseis táticos são: curto tempo de resposta e facilidade de uso. Curto tempo de resposta é necessário para realizar uma busca em uma ampla gama de soluções com um número de iterações suficientes para a convergência do projeto para uma solução adequada. Por esta razão devem ser utilizados métodos simples baseados em modelos matemáticos incorporando apenas os parâmetros mais importantes (Fleeman, 2006).

Além disso, a limitação de recursos e a competitividade estabelecem que seja obtida não somente uma solução que atenda aos requisitos, mas uma concepção mais vantajosa. Nesse contexto surge a necessidade de uma ferramenta de auxilio ao projetista, na fase de projeto 
conceitual de mísseis táticos, que empregue técnica de otimização multiparamétrica e multiobjetiva, com vista à redução de custos do produto.

\section{5 - REVISÃO BIBLIOGRÁFICA}

Projeto conceitual de míssil tático é geralmente baseado em previsões de características aerodinâmicas nas quais são utilizados métodos simples, sem os benefícios de dados de testes para novas configurações (Fleeman, 2012). Exemplos de ferramentas de previsão com relação a projeto conceitual é o código ADAM e a planilha eletrônica TDM.

O código ADAM (Advanced Design of Aerodynamic Missiles) opera em DOS e utiliza, para previsões aerodinâmicas, métodos propostos por Pitts, Nielsen \& Kaatari (1957) e Jorgensen (1973). Os métodos aerodinâmicos cobrem de regimes subsônicos a hipersônicos e ângulos de ataque de até 180 graus. O modulo de aerodinâmica do programa ADAM calcula coeficientes de força e momento, derivadas de estabilidade estática e dinâmica, condições de trimagem, efetividade de controle e localização de centros de pressão. Equações de movimento incluem modelos de três a seis graus de liberdade. O programa possui uma base de dados de mísseis existentes. No módulo de propulsão o empuxo é modelado como um perfil com dois níveis, de determinados tempos de duração. A massa de propelente de cada fase de empuxo também pode ser especificada. O alvo do míssil pode ser modelado como fixo ou móvel. A distância, altitude e velocidade do alvo são especificados, bem como as condições de lançamento do míssil, incluindo altitude, velocidade e ângulo de lançamento (Hindes, 1993).

Uma outra ferramenta computacional adequada para projeto conceitual é a planilha eletrônica denominada TDM (Tactical Missile Design), baseada na metodologia de dimensionamento proposta por Fleeman (2006). A planilha TDM utiliza a plataforma Windows Excel. Nessa planilha, as propriedades aerodinâmicas do corpo do míssil utilizam as teorias de Pitts, Nielsen \& Kaatari (1957) e Jorgensen (1973). Previsões aerodinâmicas para as superfícies fixas e móveis são baseadas nos trabalhos de Pitts, Nielsen \& Kaatari (1957), Jorgensen (1973) e Hoak (1978). Os métodos são aplicáveis para configurações de asa de baixa razão de aspecto, com ângulo de ataque de até 90 graus e regime de voo subsônico a hipersônico. 
A planilha TDM possui capacidade de estimar dados de motor ramjet, fornecendo valor de recuperação de pressão de admissão, impulso específico e empuxo, conforme Ashley (1974), Kinroth \& Anderson (1980) e North American Rockwell Corporation (1970). O empuxo e impulso específico de motor foguete são baseados em equações de escoamento isentrópico, ajustadas com a variação de razão de calores específicos em função da temperatura. O empuxo é modelado como um perfil com dois níveis, de determinados tempos de duração. A massa de propelente de cada nível de empuxo também pode ser especificada. A planilha TDM tem a capacidade de estimar a massa dos componentes do míssil. Previsões de trajetória de voo são baseadas em métodos analíticos. Uma descrição detalhada das funcionalidades da planilha TDM é feita por Frits et al (2002).

Além dessas duas ferramentas existem outras que incorporam códigos mais sofisticados, uma vez que utilizam dados de túnel de vento ou dados de desempenho de mísseis existentes. Como exemplo de tais códigos, cita-se, por exemplo, o Missile DATCOM, MISL3 e o AP09.

O programa de previsões aerodinâmicas Missile DATCOM (DATa COMpendium) é um programa de computador complexo, com 405 subrotinas, escrito em FORTRAN 90, que foi desenvolvido com patrocínio do Air Force Research Laboratory (EUA). Os métodos generalizados são aplicáveis a configurações de asa-corpo-cauda com corpo de seção transversal circular e não-circular, com qualquer ângulo de ataque (Bruns, Moore, Stoy, Vukelich, \& Blake, 1991). O código pode modelar admissão de ar e outras protuberâncias. Superfícies aerodinâmicas podem estar situadas em posições arbitrárias. Segundo Fleeman (2012), este programa é mais adequado para o projeto preliminar devido ao grande número de parâmetros de entrada e ao tempo necessário para preparar dados de entrada e analisar dados de saída.

O código aerodinâmico MISL3 do Nielsen Engineering and Research (NEAR) é baseado em ângulos de ataque equivalente desenvolvido pelo NEAR (NEAR Inc, 2016). O programa inclui desprendimento de vórtices, configurações geométricas e número de Mach. O MISL3 é aplicável a configurações asa-corpo-cauda em grandes ângulos de ataque, ângulo de rolagem e deflexão de superfícies de controle arbitrário. As saídas do programa incluem forças e momentos, carregamentos, momentos fletores e derivadas de 
estabilidade dinâmica. O programa é mais adequado para projeto preliminar dado que ele não transfere automaticamente as informações de saída para um código de trajetória de voo, requerendo um longo tempo de entrada de dados.

O Aeroprediction Incorporated Code AP09 inclui, além dos usuais dados de entrada, corpos com seção transversal elíptica e grandes ângulos de ataque. Dados de saída incluem forças e momentos, derivadas de estabilidade dinâmica, distribuição de pressão, temperatura superficial e simulação de trajetória de voo com três graus-de-liberdade (Moore \& Moore, 2009).

\section{6 - OBJETIVO}

\subsection{1 - Objetivo geral}

O presente trabalho consiste no desenvolvimento de uma ferramenta computacional para auxílio ao projetista no projeto de mísseis táticos, especificamente na fase de projeto conceitual, mediante a otimização da configuração geral do míssil, a partir de requisitos de desempenho (alcance, estabilidade estática, manobrabilidade etc), parâmetros de projeto (perfil de voo, tipo de motor, tipo de controle etc) e restrições informadas pelo usuário do programa (massa de lançamento máxima, limitações dimensionais superiores e inferiores de componentes do míssil etc). O procedimento de otimização empregado no programa tem como objetivo principal a minimização da massa de lançamento, paralelamente à maximização do alcance do míssil. Uma vez que esses objetivos são conflitantes, é adotado um critério de avaliação das soluções de acordo com a aplicação de pesos a cada um dos objetivos individualmente. Para a otimização multiobjetivo imposta pela natureza do problema, o programa desenvolvido utilizará técnica de algoritmos genéticos.

O programa proposto visa suprir uma necessidade da fase de projeto conceitual de mísseis táticos, apresentando-se como uma ferramenta que incorpora modelos teóricos simplificados e de rápida avaliação nas áreas de aerodinâmica, propulsão, peso e trajetória de voo, abrangendo uma ampla gama de configurações técnico-operacionais possíveis, 
conjugada com a capacidade de otimização de mísseis para determinada missão. A simplicidade dos modelos utilizados aliada à sua razoável precisão permite a análise de um grande número de configurações de mísseis, explorando o espaço de soluções possíveis, indicando configurações mais adequadas para suprir as necessidades do operador do sistema de arma.

\subsection{2 - Objetivos específicos}

Os objetivos específicos deste trabalho são:

1. Implementação de algoritmo genético (AG) e sua verificação. $O$ AG implementado no programa desenvolvido deverá ser verificado pelo uso de uma função de teste amplamente utilizada, a função de Rastrigin (Rastrigin, 1974), que contém diversos máximos e mínimos locais. Essa função não está relacionada com mísseis táticos, mas permite a verificação das funcionalidades do AG. O objetivo desta etapa é demostrar a capacidade evolutiva e de busca de boas soluções do AG implementado, com uso de uma função da qual se conhece o espaço de busca e o mínimo global (ou máximo, como será discutido), antes que se inicie a aplicação deste $\mathrm{AG}$ com os modelos teóricos adequados para mísseis táticos.

2. Implementação de rotina de dimensionamento de míssil tático conforme modelos matemáticos adotados. Deverá ser implementada rotina de dimensionamento conforme modelo matemático para dimensionamento de características aerodinâmicas, de propulsão, volume/peso e trajetória de voo, com precisão e simplicidade suficientes para previsões em fase de projeto conceitual de mísseis táticos. Os modelos matemáticos adotados deverão possuir capacidade de modelar os seguintes parâmetros:

a. Aerodinâmica: coeficiente de arrasto parasita, coeficiente de força normal e centro aerodinâmico para o corpo do míssil e suas superfícies aerodinâmicas; relação sustentação/arrasto; regime de voo subsônico e supersônico; controle por canard, asa ou cauda; cálculo da margem de estabilidade estática e máximo fator de carga em voo. 
b. Propulsão: motores do tipo foguete, ramjet e turbojato. Cálculo das principais caraterísticas técnico-operacionais do motor de interesse em projeto conceitual.

c. Volume/Peso: estimativa de volume e peso para os principais componentes do míssil, bem como de todo o conjunto.

d. Trajetória de voo: estimativa para o alcance de voo de acordo com perfis de voo dos tipos boost-coast, boost-sustain, cruzeiro e balístico.

3. Implementação de função de avaliação de mísseis táticos para procedimento de otimização com múltiplos objetivos.

4. Verificação ${ }^{5}$ das equações de modelagem apresentadas e rotina de dimensionamento para o caso de míssil de cruzeiro subsônico. O programa desenvolvido deverá ser utilizado para o dimensionamento de um míssil de cruzeiro existente, a partir do uso de informações relativas a este míssil como dado de entrada. $\mathrm{O}$ desempenho informado pelo programa deverá ser comparado com o desempenho do míssil existente declarado pelo fabricante. O objetivo desta etapa é a verificação do funcionamento da rotina de cálculo e da precisão dos modelos matemáticos apresentadas para previsão do desempenho de um míssil.

5. Verificação de repetibilidade de resultados para casos com os mesmos parâmetros e variáveis de projeto. Devido à natureza aleatória dos algoritmos genéticos, os resultados obtidos após sucessivas execuções do programa desenvolvido não serão idênticos, mesmo para iguais dados de entrada. Contudo, uma medida da confiabilidade dos resultados fornecidos pelo programa é a capacidade de produzir resultados próximos, para execuções diferentes com dados de entrada iguais. Esta etapa objetiva demonstrar esta capacidade do programa desenvolvido.

\footnotetext{
${ }^{5}$ Ressalta-se que o escopo deste trabalho prevê a implementação e verificação dos algoritmos citados acima, não a sua validação. Segundo Fleeman (2012), o processo de verificação de um código computacional de dimensionamento inclui a depuração (“debugging”) do código fonte, comparação do código fonte com os algoritmos originais, comparação dos resultados com outro programa de computador e, quando possível, comparação dos resultados com pelo menos um conjunto de dados de testes. Ainda segundo Fleeman (2012), o processo de validação de um código computacional de dimensionamento confirma que o código modela a realidade com precisão. Validação é a comparação dos resultados do código com os dados do sistema real, o que, idealmente, incluem dados de teste de voo.
} 


\section{Utilização demonstrativa do programa para o caso de um míssil de cruzeiro}

subsônico em desenvolvimento. O programa desenvolvido deverá ser utilizado para o estudo do caso de um míssil que se encontrava em fase de desenvolvimento à época da elaboração deste trabalho. Para isso serão utilizados dados preliminares divulgados pelos participantes do projeto (fabricante e operador).

\section{7 - ORGANIZAÇÃO DA DISSERTAÇÃO}

De modo a permitir uma visão panorâmica dessa dissertação, descreve-se a seguir sua estrutura.

Essa dissertação é composta por cinco capítulos. No primeiro (e corrente) é feita uma Introdução à temática do trabalho, com comentários sobre a diferença básica entre foguetes e mísseis, a composição básica de mísseis táticos e da importância de mísseis táticos na guerra moderna. Faz-se uma breve exposição das diferentes fases de um projeto de engenharia (projeto conceitual, projeto preliminar e projeto detalhado). Comenta-se ainda sobre as atividades que fazem parte do projeto conceitual de mísseis táticos, bem como a tradicional rotina de dimensionamento utilizada. Por fim, são declarados os objetivos do atual trabalho.

No capítulo dois faz-se uma exposição dos Modelos Matemáticos utilizados nas áreas de aerodinâmica, propulsão, peso e trajetória. A seção que trata de Aerodinâmica mostra como é calculada a força de arrasto parasita e força normal em cada componente aerodinâmico do míssil (corpo, asa, superfícies de cauda) e posterior decomposição em forças de sustentação e arrasto, para diferentes regimes de voo e configuração de cada componente. São feitos comentários sobre a geometria das superfície aerodinâmicas do míssil, dimensionamento das superfícies de cauda e sobre tipos de configuração de controle. Trata-se brevemente sobre equilíbrio estático em voo e estabilidade, manobrabilidade, margem de estabilidade estática e fator de carga em voo. Em sequência trata-se do tema Propulsão onde são abordados os principais tipos de motor utilizados em mísseis táticos: motor foguete, ramjet e turbojato. Posteriormente apresenta-se as considerações empregadas para estimativa de Volume e Peso para os principais 
componentes de um míssil tático. A seção seguinte trata de Trajetória de Voo e aborda as equações de modelagem de movimento para as diferentes fases do voo.

O capítulo de número três apresenta a Metodologia utilizada no presente trabalho. Lá são comentados alguns conceitos fundamentais os algoritmos genéticos. É feita uma exposição dos principais tópicos relacionados ao funcionamento de um algoritmo genético. Nesse capítulo é descrito o programa criado no âmbito dessa dissertação, o qual foi denominado Scorpio 1.0. Lá também é possível obter detalhes relacionados ao algoritmo genético implementado para otimização e a rotina de dimensionamento e avaliação de mísseis táticos.

Sob o título Resultados e Discussão, o quarto capítulo apresenta e discute de forma gradual os resultados obtidos segundo a estrutura a seguir.

1. Verificação do algoritmo genético.

2. Verificação das equações de modelagem apresentadas para o caso de míssil de cruzeiro subsônico.

3. Verificação de repetibilidade de resultados para casos com os mesmos parâmetros e variáveis de projeto.

4. Utilização demonstrativa do programa para o caso de um míssil de cruzeiro subsônico em desenvolvimento.

O quinto e último capítulo contém as Conclusões dessa dissertação. 


\section{2 - MODELOS MATEMÁTICOS}

\section{1 - CONFIGURAÇÃO BÁSICA DOS MÍSSEIS TÁTICOS}

Mísseis são diferentes de outros veículos aeroespaciais e por esse motivo eles formam uma especialidade técnica por si só (Fleeman, 2006). Mísseis podem ser caracterizados como táticos ou estratégicos. A distinção entre mísseis táticos e estratégicos inclui o tipo de cabeça de guerra (convencional ou nuclear), alcance de voo (relativamente curto ou longo), custo (relativamente baixo ou alto), tamanho do arsenal (inventário grande ou pequeno) e frequência de uso (Fleeman, 2012). Logicamente, a diversidade tecnológica de mísseis táticos é muito maior que uma breve discussão possa sugerir. A gama de funções nas quais eles têm sido utilizados também é grande. O Anexo A - apresenta formas de classificação de mísseis com base em diferentes parâmetros.

Mísseis táticos apresentam grande variação em tamanho, peso, perfil de voo, plataforma de lançamento, método de guiamento, função etc. Eles são projetados para uma grande variedade de missões. Ainda assim, eles têm muitas características em comum. Praticamente todos, por exemplo, têm a mesma estrutura básica: um corpo cilíndrico, equipado com superfícies aerodinâmicas para estabilidade e controle de direção de voo, equipado com um sistema de propulsão, sistemas de guiamento e controle e uma cabeçade-guerra (Figura 2.1). Os modelos matemáticos das seções seguintes serão aplicados a essa concepção básica.

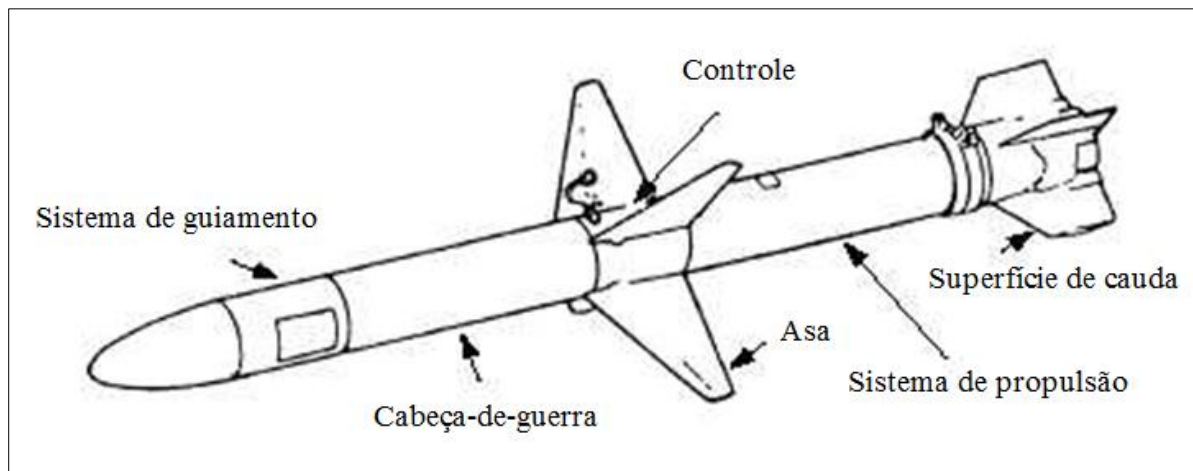

Figura 2.1 - Composição básica de um míssil tático. Adaptada de (TPUB, 2016) 


\section{2 - AERODINÂMICA}

\subsection{1 - Coeficiente de arrasto parasita}

Considere-se um corpo com dois planos de simetria ortogonais um ao outro. A linha de intersecção destes planos é um eixo de simetria. Se este corpo se move na direção deste eixo em um meio fluido, as tensões normais e de cisalhamento que o fluido exerce em suas superfícies geram uma força resultante cuja linha de ação coincide com o eixo de simetria. Esta força tem direção oposta à velocidade do corpo relativa ao meio fluido e se chama arrasto parasita (Von Mises, 1944). O arrasto parasita $\left(D_{0}\right)$ de um corpo qualquer pode ser escrito como:

$$
D_{0}=C_{D_{0}} \frac{\rho}{2} V^{2} A
$$

onde o coeficiente de arrasto parasita $C_{D_{0}}$ depende do número de Reynolds e da forma do corpo, mas independe de seu tamanho.

De acordo com (Pitts, Nielsen \& Kaatari, 1957), o coeficiente de arrasto parasita total $C_{D_{0}}$ de um míssil pode ser considerado, com aceitável nível de aproximação, como a soma das

contribuições de coeficiente de arrasto parasita do corpo $\left(C_{D_{0}}\right)_{C o r p o}$, da asa $\left(C_{D_{0}}\right)_{A s a}$ e da superfície de cauda $\left(C_{D_{0}}\right)_{\text {Cauda }}$. Essa consideração despreza interferências aerodinâmicas entre asa e corpo, corpo e asa, superfície de cauda e corpo, corpo e superfície de cauda e entre asa e superfície de cauda. Assim, $C_{D_{0}}$ pode ser computado conforme:

$$
C_{D_{0}}=\left(C_{D_{0}}\right)_{\text {Corpo }}+\left(C_{D_{0}}\right)_{A s a}+\left(C_{D_{0}}\right)_{\text {Cauda }} .
$$

2.2.1.1 - Coeficiente de arrasto parasita no corpo do míssil

Considerando a Figura 2.2, define-se os seguintes parâmetros:

i. Comprimento do corpo do míssil, $l$; 
ii. Comprimento do nariz do míssil, $l_{n}$;

iii. Diâmetro do corpo do míssil, $d$.

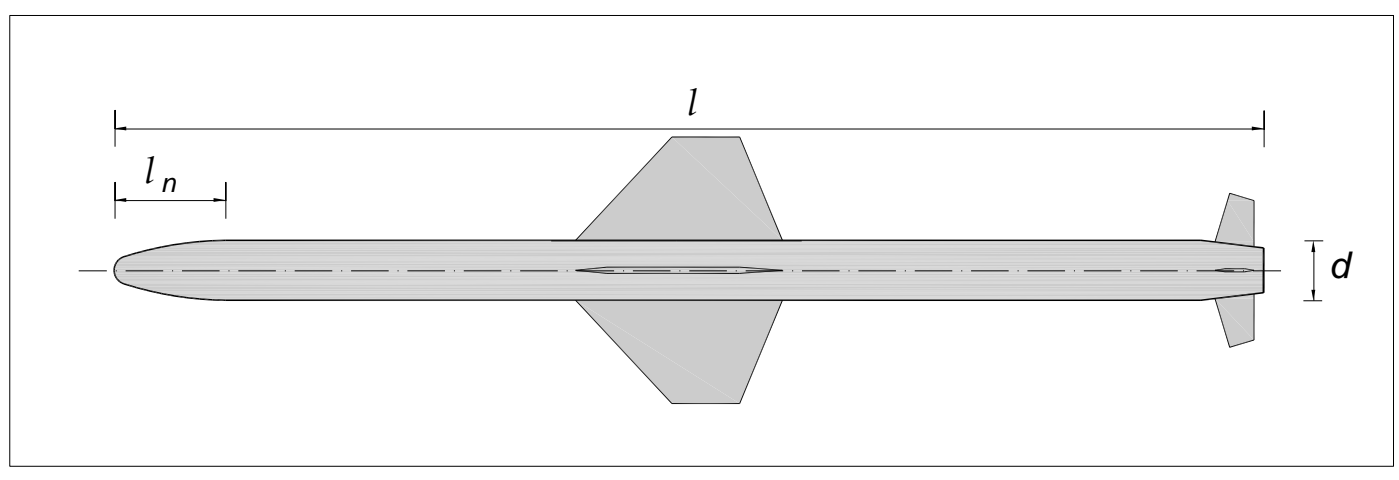

Figura 2.2 - Definição de parâmetros geométricos do corpo de um míssil.

O coeficiente de arrasto parasita do corpo pode ser estimado pela combinação do arrasto de fricção superficial - $\left(C_{D_{0}}\right)_{\text {Corpo,Fricção }}$, arrasto de base (gerado pela esteira turbulenta de baixa pressão à jusante do corpo) $-\left(C_{D_{0}}\right)_{B a s e}$ e, caso o voo seja supersônico, arrasto de onda - $\left(C_{D_{0}}\right)_{\text {Corpo,Onda }}$. Portanto o coeficiente de arrasto parasita do corpo pode, então, ser expresso por:

$$
\left(C_{D_{0}}\right)_{\text {Corpo }}=\left(C_{D_{0}}\right)_{\text {Corpo,Friç̧ão }}+\left(C_{D_{0}}\right)_{\text {Base }}+\left(C_{D_{0}}\right)_{\text {Corpo,Onda }} .
$$

O arrasto de onda é um fenômeno aerodinâmico existente somente em escoamentos supersônicos e está associado com a energia irradiada a partir do veículo na forma de ondas de pressão, de maneira semelhante a uma embarcação que se desloca em grande velocidade, causando ondas na superfície da água (Ashley \& Landahl, 1956).

Segundo (Bonney et al., 1956) a expressão matemática utilizada para estimar o coeficiente de arrasto de corpo devido à(s) onda(s) de choque em voo supersônico $\left(C_{D_{0}}\right)_{\text {Corpo,Fricção' }}$, para mísseis, é dada por: 


$$
\left(C_{D_{0}}\right)_{\text {Corpo, Onda-sharp nose }}=\left(1,583+\frac{1,834}{M^{2}}\right)\left\{\tan ^{-1}\left[\frac{0,5}{\frac{l_{n}}{d}}\right]\right\}^{1,69}
$$

Na Equação ( 2.4), $M$ é o número de Mach do voo, $l_{n}$ é o comprimento do nariz e $d$ o diâmetro do míssil. ${ }^{6} \mathrm{O}$ valor de $\tan ^{-1}$ é dado em radianos. De acordo com Fleeman (2012), para mísseis supersônicos, o arrasto devido a ondas de choque no nariz do míssil é comparável ou mesmo maior que o arrasto de fricção superficial e o arrasto de base. Devido à natureza desta parcela de arrasto, $\left(C_{D_{0}}\right)_{\text {Corpo,onda }}$ só deve ser considerado em voos sônicos e supersônicos.

Para um míssil com relação entre o comprimento do nariz e seu diâmetro igual a $1 / 2$, ou seja, um míssil com nariz hemisférico, a Equação ( 2.4) se reduz a:

$$
\left(C_{D_{0}}\right)_{\text {Corpo,Onda-Hemi nose }}=0,665\left(1,583+\frac{1,834}{M^{2}}\right) .
$$

De acordo com Fleeman (2012) é possível estimar o coeficiente de arrasto supersônico no nariz de um míssil com geometria alongada e ponta abaulada (ver Figura 2.6), fazendo uma composição entre as Equações ( 2.4) e ( 2.5), levando em consideração a área de cada parcela, através da Equação ( 2.6). Nessa equação $S_{r e f}$ é a área da seção transversal do míssil e $S_{\text {nosetip }}$ representa a área da parcela abaulada do nariz do míssil:

$$
\begin{gathered}
\left(C_{D_{0}}\right)_{\text {Corpo,Onda-Blunt }}= \\
\left(C_{D_{0}}\right)_{\text {sharp nose }}\left(\frac{S_{\text {ref }}-S_{\text {nosetip }}}{S_{\text {ref }}}\right)+\left(C_{D_{0}}\right)_{\text {hemi nose }}\left(\frac{S_{\text {nosetip }}}{S_{\text {ref }}}\right) .
\end{gathered}
$$

A Figura 2.3 mostra valores de coeficiente de arrasto de corpo devido à formação de onda(s) de choque em voo supersônico em função do número de Mach de voo, para diferentes geometrias de nariz. Em detalhe nesta figura são mostrados perfis ogivais de nariz de míssil para algumas relações $l_{n} / d$. Infere-se que, do ponto de vista aerodinâmico,

\footnotetext{
${ }^{6}$ Esta equação é valida independentemente do sistema de unidades utilizado para expressar $l_{n}$ e $d$ (SI ou IP), conquanto sejam utilizadas a mesma unidade para as duas dimensões.
} 
para voo supersônico é desejável que o míssil possua nariz alongado (alta relação $l_{n} / d$ ). Cabe salientar que para Mach inferior a 1 essa parcela de arrasto não é computada e será considerada nula sempre que o voo for subsônico.

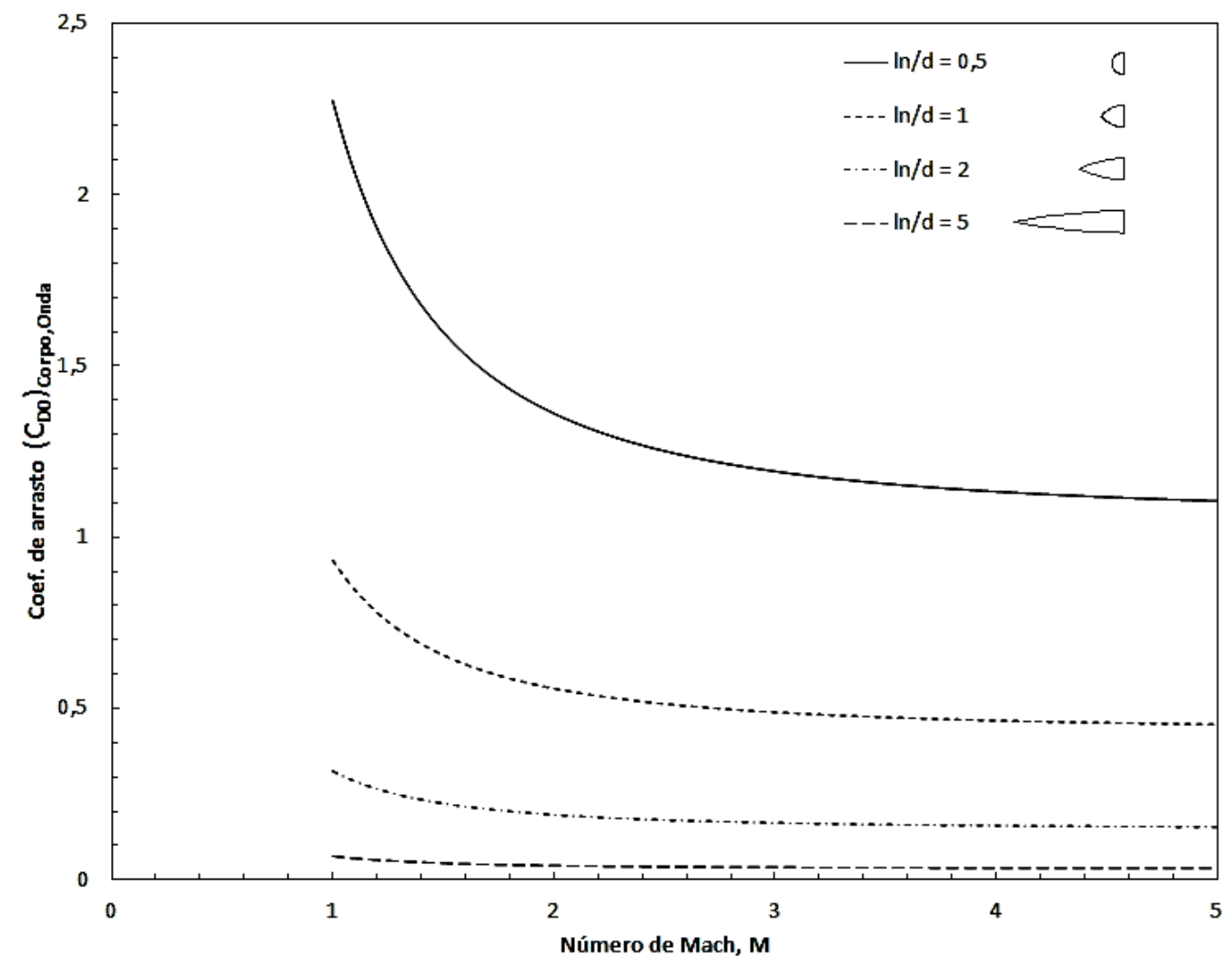

Figura 2.3 - Coeficiente de arrasto de onda em função do número de Mach.

Ainda conforme Fleeman (2012), o arrasto de base para voo supersônico não propelido pode ser estimado pela Equação (2.7). Na hipótese de voo subsônico, o arrasto de base deve ser estimado pela Equação (2.8). Durante voo propelido (aceleração inicial ou cruzeiro) o arrasto de base é reduzido pelo fator $\left(1-A_{e} / S_{r e f}\right)$, onde $A_{e}$ é a área de exaustão do motor e $S_{r e f}$ a área da seção transversal do corpo do míssil. Se a área de saída da tubeira (ou descarga do motor) possuir aproximadamente a mesma área da base do míssil, o arrasto de base pode desprezado durante voo propelido. Esse autor também afirma que o arrasto de base do corpo do míssil pode ser um dos principais contribuintes para o arrasto total durante voo não-propelido, devido à esteira de baixa pressão que se forma à jusante do míssil: 


$$
\begin{gathered}
\left(C_{D_{0}}\right)_{\text {Base }}=\left(C_{D_{0}}\right)_{\text {Base, }, \text { coast }}=\frac{0,25}{M}, \\
\left(C_{D_{0}}\right)_{\text {Base }}=\left(C_{D_{0}}\right)_{\text {Base,Coast }}=0,12+0,13 M^{2} .
\end{gathered}
$$

Por fim, o arrasto de fricção superficial, $\left(C_{D_{0}}\right)_{\text {Corpo,Friçãoo }}$ é uma importante parcela do arrasto de um míssil em voo subsônico. O valor de $\left(C_{D_{0}}\right)_{\text {Corpo,Friç̧ão }}$ é fundamentalmente dependente da razão de afilamento do corpo (relação $l / d$ ). Além disso, sofre leve influência do número de Mach, pressão dinâmica e comprimento do corpo. Conforme Jerger (1960), a Equação (2.9) pode ser utilizada para estimar, com razoável precisão, o coeficiente de arrasto de friç̧ão superficial no corpo principal de mísseis ${ }^{7}$ :

$$
\left(C_{D_{0}}\right)_{\text {Corpo,Friç̧ão }}=0,053\left(\frac{l}{d}\right)\left[\frac{M}{(q l)}\right]^{0,2} .
$$

Assumiu-se que:

- a área molhada (área superficial exposta ao escoamento) de um míssil com corpo sustentante $^{8}$ e seção transversal não-circular pode ser aproximada pela aérea molhada de um cilindro de seção transversal circular equivalente,

- a variação da velocidade do som e viscosidade, do escoamento livre, com altitude é relativamente pequena,

- o escoamento sobre o corpo tem camada limite turbulenta e o corpo não possui afilamento posterior (boattail).

\footnotetext{
${ }^{7}$ Nesta equação Jerger (1960) utilizou, para pressão dinâmica do ar (q), unidades de libra por pé quadrado (psf), enquanto que para o comprimento total do míssil ( $l$ ), utilizou unidades de pés (ft). Por coerência, nesta equação, o diâmetro do míssil também deve ser dado em pés. No presente trabalho, apesar da adoção do Sistema Internacional de Unidades (SI), optou-se pelo uso das equações originais propostas pela literatura referenciada, fazendo-se, no presente trabalho, a conversão das unidades das grandezas de interesse antes e depois do uso destas equações, do Sistema Internacional para o sistema de unidades inglesas e vice-versa.

${ }^{8}$ Um corpo sustentante (lifting body) é um dispositivo na qual a configuração do próprio corpo produz sustentação. Isso pode ser alcançado, por exemplo, com a adoção de um corpo com seção transversal alongada no sentido horizontal (seção elíptica). Em contraste com uma asa voadora, que é uma asa sem fuselagem ou corpo principal, um corpo sustentante é uma fuselagem que gera sustentação sem a forma de uma estrutura fina e plana típica de uma asa.
} 
Segundo Fleeman (2012), a consideração de camada limite turbulenta é menos aplicável a situações de voo com baixo número de Reynolds como mísseis de menor comprimento, voando a baixo número de Mach (p. ex.: $M<0,2$ ) e em grandes altitudes (p. ex.: $h>$ 24.000 metros). Para as mesmas condições, um corpo com seção transversal circular possuiria menor arrasto de fricção superficial que um corpo sustentante equivalente, pois ele possuiria menor área molhada.

Na Figura 2.4 é exposta a previsão de coeficiente de arrasto parasita total do corpo de um míssil $\left(C_{D_{0}}\right)_{\text {Corpo }}$, composto pelas parcelas de coeficientes de arrasto parasita de onda, fricção superficial e de base, com a variação do número de Mach de voo. É mostrada também a força de arrasto desse corpo em função do número de Mach. Os dados dimensionais do corpo de míssil utilizado para os cálculos e de altitude de voo estão expostos na figura. Considerou-se, para elaboração da Figura 2.4, voo não-propelido e $A_{e}=S_{r e f}$ (área de base igual à área da seção transversal do corpo).

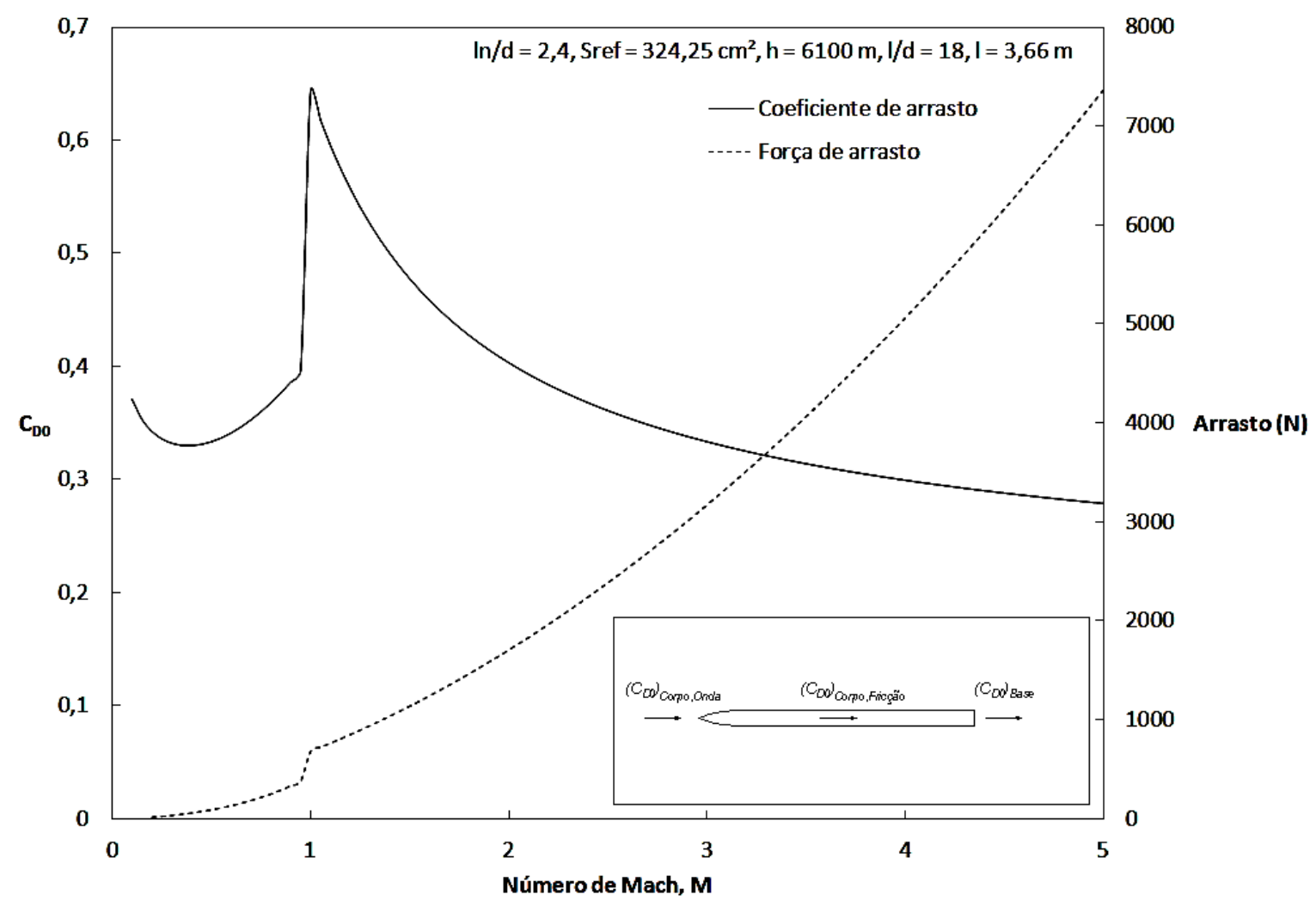

Figura 2.4 - Arrasto e coeficiente de arrasto parasita teóricos em função do número de Mach. 
Da análise da Figura 2.4, infere-se, que o valor de $\left(C_{D_{0}}\right)_{\text {Corpo }}$, calculado a partir das equações apresentadas, sofre um expressivo aumento na região de voo transônico, atingindo um pico próximo a Mach igual a 1. Nessa região de voo que ocorre um forte incremento na força de arrasto. É possível verificar ainda que o arrasto de corpo é continuamente crescente com o aumento do número de Mach, apesar do decréscimo do coeficiente de arrasto parasita após Mach unitário.

A Figura 2.5 (Holdaway, 1953) mostra uma comparação do aumento do coeficiente de arrasto de onda próximo de Mach 1, feita com dados experimentais e previsões teóricas. Em geral, os cálculos teóricos garantem boa previsão dos valores experimentais. Limitações da teoria resultaram apenas em concordância qualitativa sendo obtida entre teoria e medições experimentais em números de Mach abaixo de 1,02. Para números de Mach maiores que este, o efeito das limitações da teoria diminui e o nível do aumento do arrasto é previsto quantitativamente. $\mathrm{O}$ autor ainda afirma que, nas configurações utilizadas por ele, em geral, para valores acima de $M=1,02$, suas previsões de arrasto estão contidas em uma faixa de erro de cerca de $20 \%$, com desvio máximo entre teoria e experimentação de $26 \%{ }^{9}$.

Vale esclarecer que as equações utilizadas para previsão de arrasto de onda só se aplicam para voo com Mach 1 ou superior. Todavia, conclui-se, da análise dos dados experimentais de Holdaway (1953), que mesmo antes de Mach 1 ocorre aumento do arrasto parasita. Segundo Anderson (2001), o aumento do arrasto em voo transônico está relacionado a regiões de escoamento supersônico sobre o corpo, mesmo com este se deslocando com velocidade subsônica próximo de Mach 1, culminando na formação de ondas de choque após estas regiões. Estas ondas de choque usualmente causam intensas perturbações no escoamento à jusante das mesmas, acompanhadas de grande aumento no arrasto. Dessa forma, espera-se boas estimativas de coeficiente de arrasto parasita a partir das Equações ( 2.3) a (2.9), com exceção da região próximo de Mach 1 (região transônica).

\footnotetext{
${ }^{9}$ O trabalho de Holdaway (1953) apresentou resultados de estudos com diferentes combinações de asa-corpocauda, diferentemente da configuração utilizada para elaborar a Figura 2.4, onde foi considerado apenas o corpo. Portanto não há que se fazer uma comparação quantitativa entre as Figuras 2.4 e 2.5, somente qualitativa.
} 


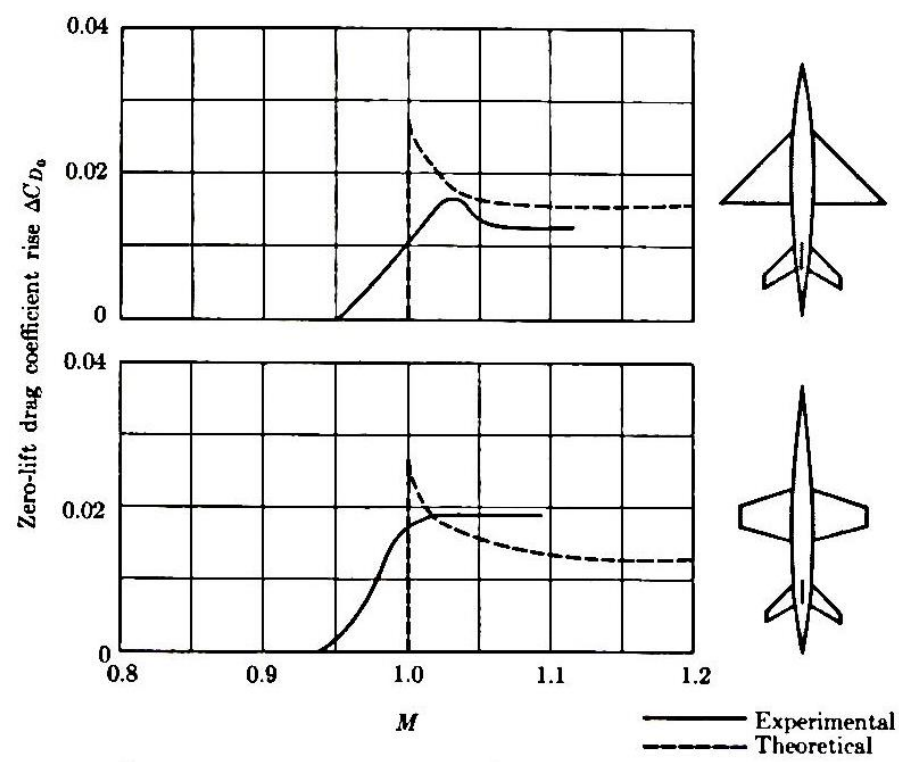

Figura 2.5 - Comparação de coeficientes de arrasto parasita obtidos teórica e experimentalmente (Holdaway, 1953).

\subsubsection{2 - Coeficiente de arrasto parasita nas superfícies planas do míssil}

Superfícies planas de um míssil são aquelas adicionadas ao corpo principal para gerar sustentação e/ou proporcionar estabilidade e permitir controle de voo, a exemplo de asas e estabilizadores de cauda. Para uma superfície plana de um míssil em voo subsônico, o contribuinte dominante para o coeficiente de arrasto total é a fricção superficial (Fleeman, 2012). Para uma superfície em regime supersônico o arrasto é composto principalmente por fricção superficial e arrasto de onda (onda de choque). Um terceiro contribuinte em potencial é o arrasto de base devido ao descolamento do escoamento de ar do bordo de fuga da superfície. Porém, para uma superfície com bordo de fuga afinado, o descolamento do escoamento é pequeno. Assim, de acordo esse autor, o arrasto de base pode ser desprezado da análise aerodinâmica da maioria das superfícies planas de mísseis, pois com frequência são superfícies de baixa espessura.

Considerando a Figura 2.6, define-se os seguintes parâmetros:

i. Ângulo total da seção do bordo de ataque, $\delta_{L E}$;

ii. Comprimento da corda aerodinâmica média, $c_{m a c}$;

iii. Ângulo de enflechamento do bordo de ataque, $\mathrm{A}_{L E}$;

iv. Espessura máxima da corda aerodinâmica media, $t_{\text {mac }}$; 
v. Envergadura da superfície exposta, $b_{e}$;

vi. Área planiforme de superfície exposta, $S_{e}$;

vii. Razão de aspecto da superfície exposta, $A_{e}=b_{e}{ }^{2} / S_{e}$.

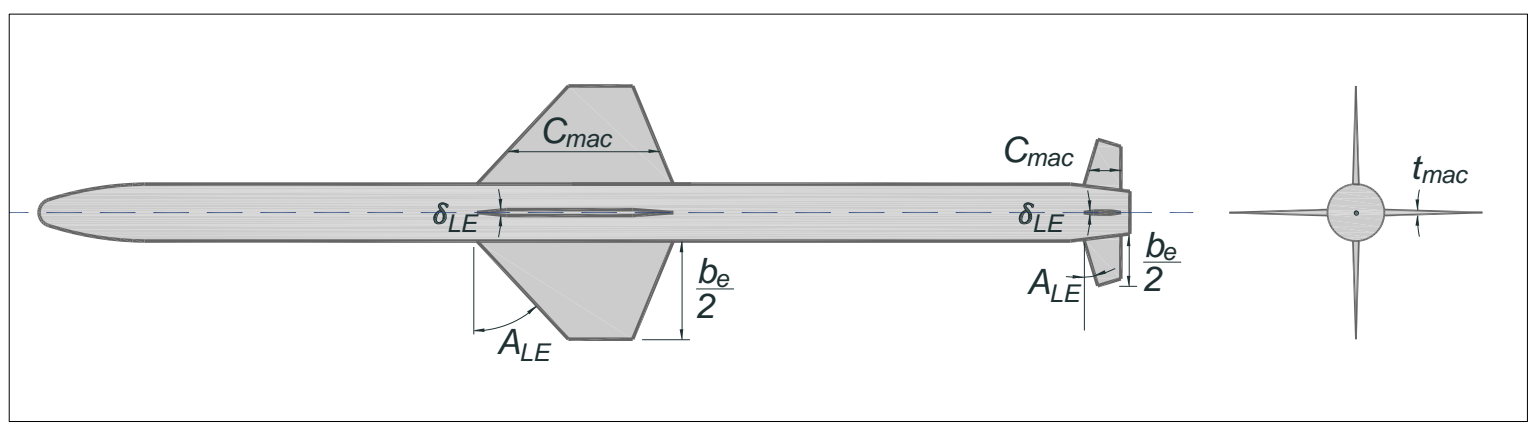

Figura 2.6 - Definição de parâmetros geométricos de superfícies aerodinâmicas de um míssil.

Jerger (1960) propôs uma forma de prever o valor do coeficiente de arrasto de fricção superficial em superfícies planas de mísseis, descrita pela Equação (2.9) ${ }^{10}$. Os principais responsáveis pelo coeficiente de arrasto de fricção superficial são o número de superfícies planas (painéis) $n_{\text {sup }}$ e a área plana (planiforme) da superfície $S_{\text {sup }}{ }^{11}$. A área total de superfície molhada é igual a $2 n_{\text {sup }} S_{\text {sup }}$. O coeficiente $\left(C_{D_{0}}\right)_{\text {Superfície,Fricção }}$ é pouco influenciado pelo número de Mach, pressão dinâmica e o comprimento da corda média aerodinâmica. $\mathrm{O}$ contribuinte dominante é a área total de superfície molhada. Para a Equação ( 2.10) considerou-se relativamente pequena a variação da velocidade do som do escoamento livre e viscosidade com a altitude, e camada limite turbulenta. Assim como utilizado anteriormente $S_{\text {ref }}$ representa a área da seção transversal do míssil, usada como referência para cálculo dos coeficientes e forças sobre o míssil.

\footnotetext{
${ }^{10}$ Nesta equação Jerger (1960) utilizou, para pressão dinâmica do ar $(q)$, unidades de libra por pé quadrado (psf), enquanto que para a corda média aerodinâmica $\left(c_{m a c}\right)$, utilizou unidades de pés ( $\mathrm{ft}$ ). No presente trabalho, apesar da adoção do Sistema Internacional de Unidades (SI), optou-se pelo uso das equações originais propostas pela literatura referenciada, fazendo-se, no presente trabalho, a conversão das unidades das grandezas de interesse antes e depois do uso destas equações, do Sistema Internacional para o sistema de unidades inglesas e vice-versa.

${ }^{11}$ Uma asa simples (com 2 painéis) possui $n_{\text {sup }}=1$, ao passo que uma asa cruciforme (com 4 painéis) possui $n_{\text {sup }}=2 \mathrm{e}$ assim por diante.
} 


$$
\left(C_{D_{0}}\right)_{\text {Superfície,Friç̧̃̃o }}=n_{\text {sup }}\left\{0,0133\left[\frac{M}{\left(q c_{\text {mac }}\right)}\right]^{0,2}\right\}\left(\frac{2 S_{\text {sup }}}{S_{\text {ref }}}\right) .
$$

Um outro contribuinte para o arrasto das superfícies planas é o arrasto de onda de choque. A previsão do arrasto de onda é baseada na teoria de impacto newtoniana modificada, descrita por Jorgensen (1973) através da Equação ( 2.11). A teoria newtoniana é modificada pelo cálculo da pressão através da onda de choque normal como função do número de Mach. Substituindo o valor da razão de calores específicos $\gamma=1,4$ para o ar resulta na Equação ( 2.11). Nessa equação $M_{\mathrm{A}_{L E}}=M \cos \mathrm{A}_{L E}$.

$$
\begin{gathered}
\left(C_{D_{0}}\right)_{\text {Superfície,onda }}= \\
n_{\text {sup }}\left[\frac{2}{\gamma M_{\mathrm{A}_{L E}}^{2}}\right]\left\{\left\{\left[\frac{\left.(\gamma+1) M_{\mathrm{A}_{L E}}^{2}\right]}{2}\right\}^{\frac{\gamma}{\gamma-1}}\left\{\frac{\gamma+1}{\left[2 \gamma M_{\mathrm{A}_{L E}}^{2}-(\gamma-1)\right]}\right\}^{\frac{1}{(\gamma-1)}}-\right.\right. \\
1\} \sin ^{2} \delta_{L E} \cos \mathrm{A}_{L E} t_{\text {mac }} \frac{b}{S_{r e f}} .
\end{gathered}
$$

\subsection{2 - Coeficiente de força normal}

2.2.2.1 - Coeficiente de força normal no corpo do míssil

Como mostrado na Figura 2.7, a máxima força normal atuante sobre um corpo sustentante (por exemplo, um corpo com seção transversal elíptica) é maior que aquela de um corpo axissimétrico (seção transversal circular). A equação para o coeficiente de força normal no corpo do míssil é:

$$
\left|C_{N}\right|_{\text {Corpo }}=\left[\left(\frac{a}{b}\right) \cos ^{2} \phi+\left(\frac{b}{a}\right) \sin ^{2} \phi\right]\left[\left|\sin (2 \alpha) \cos \left(\frac{\alpha}{2}\right)\right|+1,3\left(\frac{l}{d}\right) \sin ^{2} \alpha\right] .
$$

Nessa equação, generalizada para um corpo com seção transversal elíptica, a relação $a / b$ representa a razão entre os semieixos maior e menor, $\phi$ o ângulo de rolagem do corpo, $\alpha$ o 
ângulo de ataque do corpo e $l / d$ a relação entre o comprimento e o diâmetro do míssil. A Figura 2.7 foi plotada considerando a relação $l / d=10$ para todos os casos.

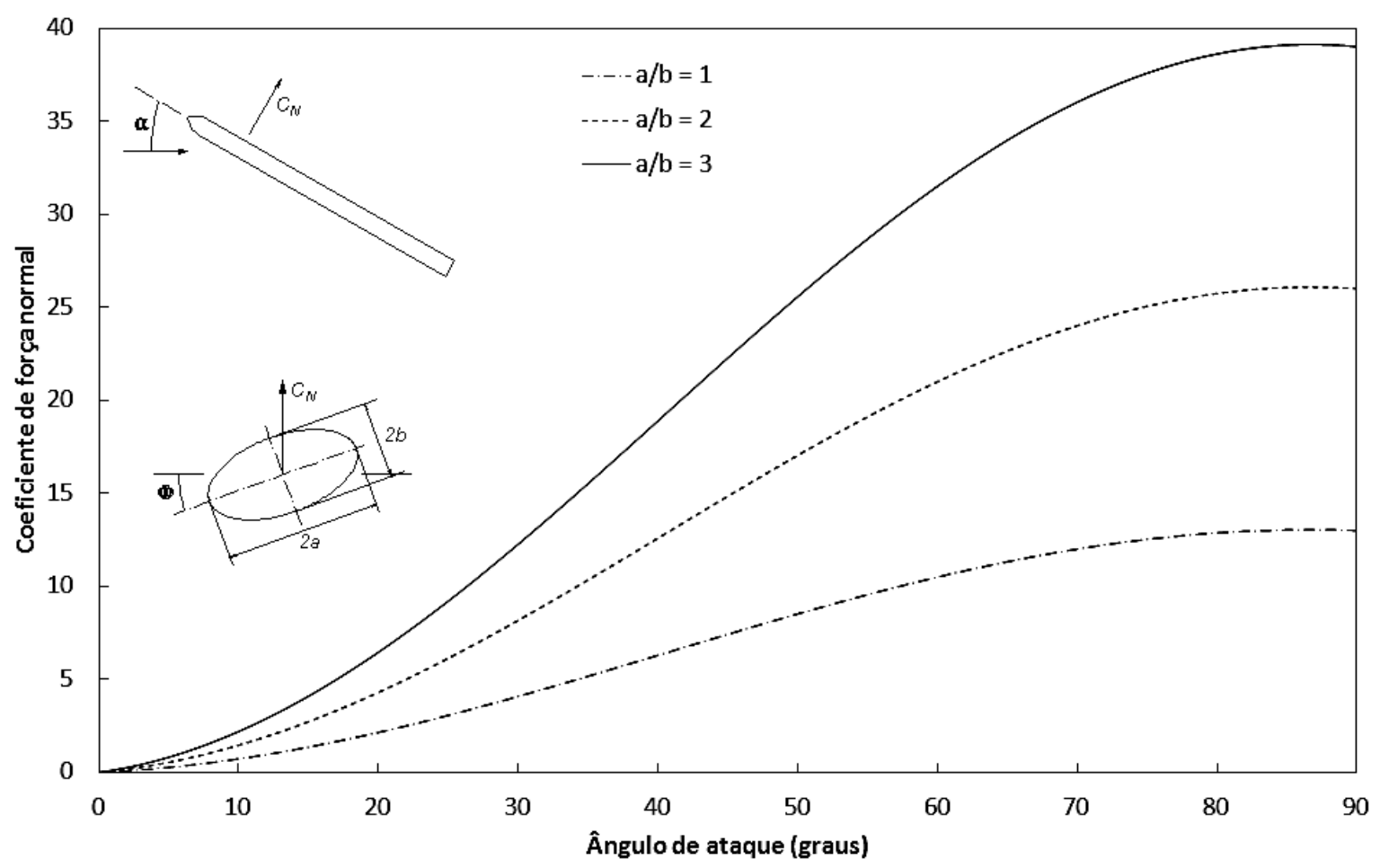

Figura 2.7 - Coeficiente de força normal no corpo em função do ângulo de ataque.

O coeficiente de força normal de um corpo esbelto é, teoricamente, uma função apenas do ângulo de ataque e geometria do corpo e independente dos números de Mach e Reynolds. A estimativa da força normal é baseada na combinação da teoria de corpo esbelto ${ }^{12}$ (Pitts, Nielsen \& Kaatari, 1957) e da teoria de escoamento cruzado em um corpo ${ }^{13}$ (Jorgensen, 1973). Com baixo ângulo de ataque o cálculo da força normal no corpo tem grande influência da teoria do corpo esbelto. Com grandes ângulos de ataque $\left(\alpha \rightarrow 90^{\circ}\right)$ o cálculo da força normal é dominado pela teoria do escoamento cruzado, representado pelo arrasto de fluxo cruzado em um cilindro. Para um cilindro circular longo (por exemplo: $l / d=10$ ) com $\alpha=90^{\circ}$, o coeficiente de arrasto varia de aproximadamente 1,2 a 1,5 vezes $l / d$, dependendo do número de Mach. O coeficiente de arrasto de fluxo cruzado é maior para número de Mach transônico $(0,8<M<1,2)$. Para números de Mach subsônico $(M<$

\footnotetext{
${ }^{12}$ Do inglês slender body theory.

${ }^{13}$ Do inglês cross flow theory.
} 
0,8) e supersônico $(M>1,2)$ um valor médio de $\left(C_{N_{\alpha=90^{\circ}}}=1,3 \mathrm{l} / \mathrm{d}\right)$ tem, usualmente, suficiente precisão para a etapa de projeto conceitual (Fleeman, 2012).

A Equação (2.12) para coeficiente de força normal é válida para razões $l / d>5$. Para seção transversal elíptica, um diâmetro equivalente é baseado em uma seção transversal circular de mesma área. A Figura 2.7 indica que o coeficiente de força normal aumenta com o ângulo de ataque (até $\alpha=90^{\circ}$ ) e $a / b$.

A inclinação da curva de força normal ao corpo com ângulo de ataque é usada no dimensionamento das superfícies de cauda para estabelecer requisitos de estabilidade estática, como exposto mais adiante. Logo $\left(C_{N_{\alpha}}\right)_{\text {Corpo }}$ é a derivada do coeficiente de força normal no corpo. A unidade de $\left(C_{N_{\alpha}}\right)_{\text {Corpo }}$ é $\mathrm{rad}^{-1}$. Com baixo ângulo de ataque,

$$
\left(C_{N_{\alpha}}\right)_{\text {Corpo }}=2\left[\left(\frac{a}{b}\right) \cos ^{2} \phi+\left(\frac{b}{a}\right) \sin ^{2} \phi\right] .
$$

2.2.2.2 - Coeficiente de força normal nas superfícies planas do míssil

A asa, a superfície de cauda e o canard podem ser caracterizados pelas suas posições relativas ao centro de massa $(\mathrm{CG})$ do míssil. Asas são instaladas próximas ao centro de massa, enquanto superfícies de cauda são instaladas à jusante do CG e canard, à montante do CG (próximo ao nariz do míssil). Os painéis da asa, as superfícies de cauda e do canard podem ser fixos ou móveis (ou seja, superfícies de controle). A metodologia proposta por Hoak (1978) para prever a força normal na asa também é aplicável para outras superfícies, tais como superfície de cauda e canard. 


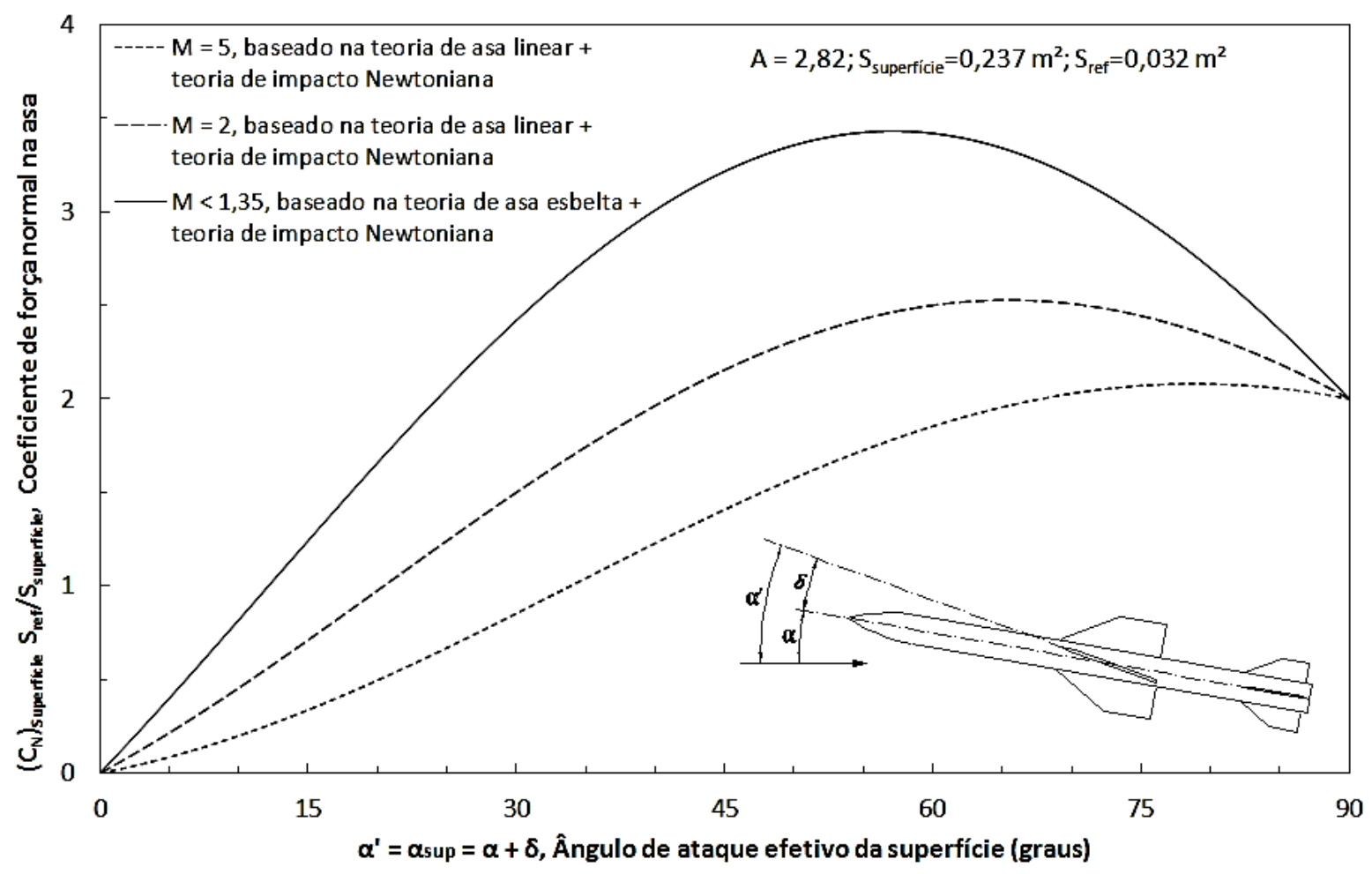

Figura 2.8 - Coeficiente de força normal em superfície plana em função do ângulo de ataque.

As equações de Hoak (1978) para a derivada do coeficiente de força normal em superfícies planas, baseadas na teoria de asa $\operatorname{linear}^{14}$ e teoria de asa esbelta ${ }^{15}$, são dadas pelas Equações (2.14) e (2.15), respectivamente.

$$
\frac{d C_{N}}{d \alpha} \approx\left[\frac{4}{\left(M^{2}-1\right)^{\frac{1}{2}}}\right]\left(\frac{S_{\text {superfície }}}{S_{\text {ref }}}\right)
$$

A equação (2.14) é válida para:

- $\quad \alpha<\approx 10^{\circ}$

- $\quad M>\left\{1+\left[\frac{8}{(\pi A)}\right]^{2}\right\}^{\frac{1}{2}}$.

\footnotetext{
${ }^{14}$ Do inglês linear wing theory.

${ }^{15}$ Do inglês slender wing theory.
} 


$$
\frac{d C_{N}}{d \alpha} \approx\left(\frac{\pi A}{2}\right)\left(\frac{S_{\text {superfície }}}{S_{\text {ref }}}\right)
$$

A equação (2.15) é válida para:

- $\quad \alpha<\approx 10^{\circ}$

- $\mathrm{A}<3$;

- $\quad M<\left\{1+\left[\frac{8}{(\pi A)}\right]^{2}\right\}^{\frac{1}{2}}$.

Fleeman (2012) destaca que a teoria da asa esbelta tem excelente precisão para baixa razão de aspecto (p.ex.: $A=1$ ) com escoamento incompressível (p.ex.: $M<0,5$ ) e superfície sem enflechamento. Com alta razão de aspecto (p.ex.: $A=3$ ) e escoamento incompressível, a equação da teoria da asa esbelta sobre-estima o efeito da razão de aspecto. Com número de Mach transônico, o efeito da compressibilidade tende a compensar esse erro (Fleeman, 2012). A teoria da asa esbelta não contabiliza os efeitos de enflechamento de asa e razão de afilamento ${ }^{16}$. Para $A>2$, o aumento do enflechamento da superfície diminui significativamente a força normal sobre a superfície.

A Figura 2.9 indica que superfícies aerodinâmicas são mais efetivas em voo subsônico se elas possuírem alta razão de aspecto. Como efeito de primeira ordem, duplicando-se a razão de aspecto, duplica-se a força normal em voo subsônico. Entretanto, uma vantagem de uma superfície de baixa razão de aspecto é a menor mudança nas características aerodinâmicas com o número de Mach. Para voo com alto número de Mach, existe um efeito desprezível da razão de aspecto na força normal.

\footnotetext{
${ }^{16}$ Razão de afilamento é a relação entre a corda de ponta e corda de raiz da superfície $\left(\lambda=c_{\text {ponta }} / c_{\text {raiz }}\right)$
} 


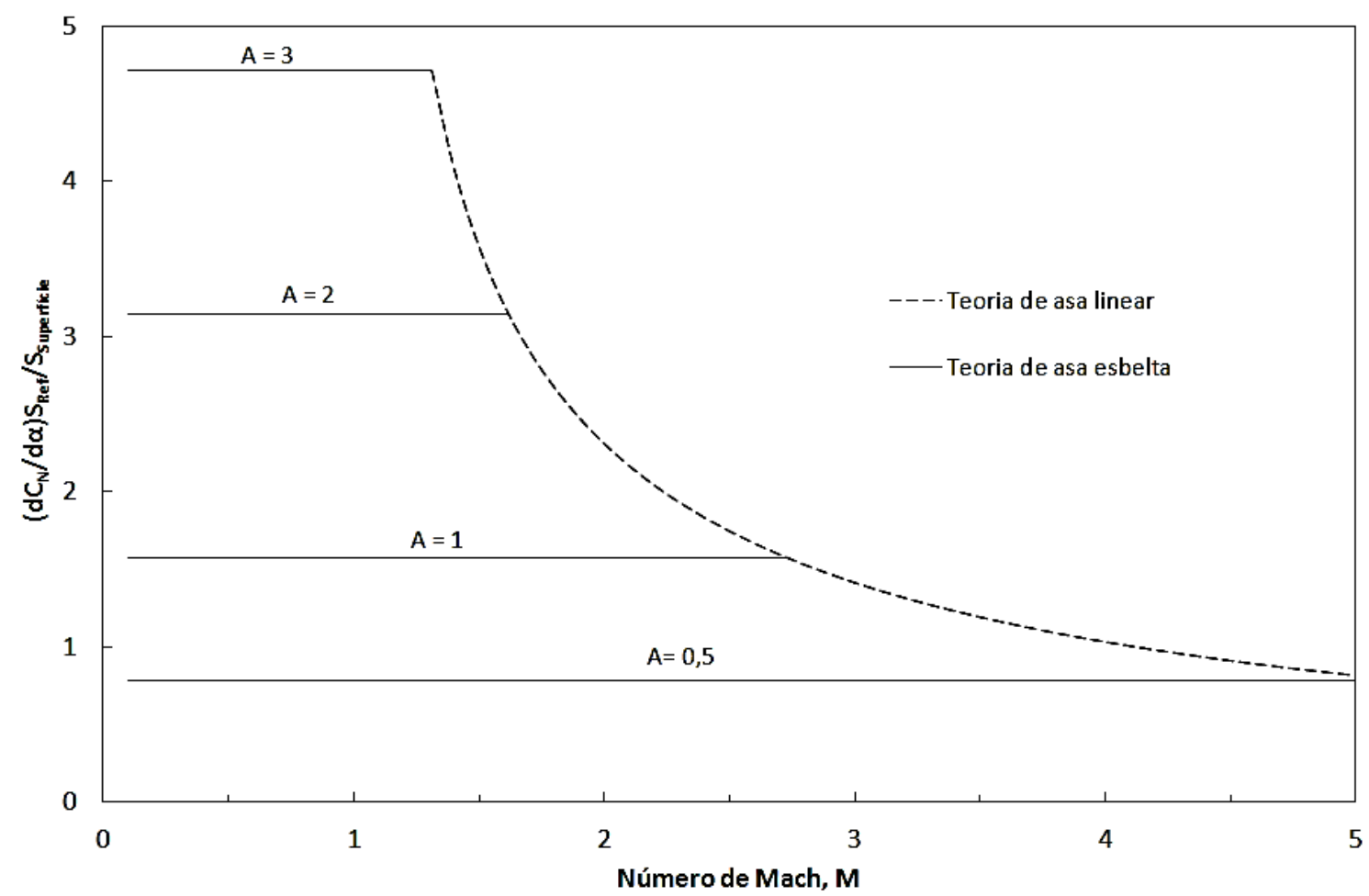

Figura 2.9 - Derivada do coeficiente de força normal em superfície plana, com relação ao ângulo de ataque, em função do número de Mach.

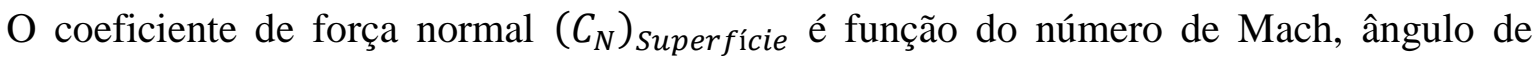
ataque local, razão de aspecto e área planiforme da superfície (Figura 2.8). Nota-se que $\left(C_{N}\right)_{\text {Superfície }}$ decresce com o aumento do número de Mach e aumenta com o ângulo de ataque e área de superfície. Na Figura 2.8, a teoria de asa linear (Hoak, 1978) juntamente com a teoria newtoniana de impacto ${ }^{17}$ (Jorgensen, 1973) são aplicadas em voo supersônico, com a condição:

$$
M>\left\{1+\left[\frac{8}{(\pi A)}\right]^{2}\right\}^{\frac{1}{2}}
$$

A Equação (2.17) calcula o valor do coeficiente de força normal na superfície, conforme a teoria de asa linear e a teoria de impacto newtoniana.

\footnotetext{
${ }^{17}$ Do inglês Newtonian impact theory.
} 


$$
\left|\left(C_{N}\right)_{\text {Superfície }}\right|=\left(\frac{4\left|\sin \alpha^{\prime} \cos \alpha^{\prime}\right|}{\left(M^{2}-1\right)^{\frac{1}{2}}}+2 \sin ^{2} \alpha^{\prime}\right)\left(\frac{S_{\text {superficie }}}{S_{\text {ref }}}\right)
$$

Nota-se que $\left(C_{N}\right)_{\text {Superfície }}$ baseado na teoria de asa linear é independente da razão de aspecto da superfície. Como uma abordagem alternativa, a teoria de asa esbelta associada à teoria newtoniana de impacto (Jorgensen, 1973) é mais aplicável para números de Mach menores e pouco acima de 1 (Fleeman, 2012), com o a necessidade que seja satisfeita a seguinte condição:

$$
M<\left\{1+\left[\frac{8}{(\pi A)}\right]^{2}\right\}^{\frac{1}{2}}
$$

A combinação das teorias de asa esbelta e de impacto newtoniana resulta na Equação

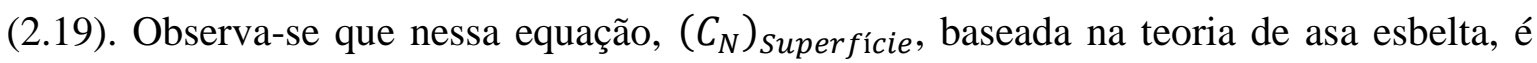
independente do número de Mach. Fleeman (2012) afirma que essa teoria é precisa para superfícies com baixas razões de aspecto $(A<\approx 3)$. Para razão de aspecto $\mathrm{A}=3$, a teoria de asa esbelta superestima a força normal atuante sobre a superfície.

$$
\left|\left(C_{N}\right)_{\text {Superfície }}\right|=\left[\left(\frac{\pi A}{2}\right)\left|\sin \alpha^{\prime} \cos \alpha^{\prime}\right|+2 \sin ^{2} \alpha^{\prime}\right]\left(\frac{S_{\text {superfície }}}{S_{\text {ref }}}\right) .
$$

Segundo Fleeman (2012) a previsão de força normal tende a ser otimista para número de Mach muito baixo (p.ex.: $M<0,2$ ) e para altitudes muito grandes (p. ex.: $h>26.000$ metros). Para essas condições de voo, a transição de camada limite laminar pra turbulenta é atrasada, resultando em uma camada limite mais espessa. A espessura da camada limite na região posterior do corpo pode cobrir uma porção significante da superfície de cauda, reduzindo a estabilidade e efetividade de controle da mesma.

\subsection{3 - Centro aerodinâmico}

2.2.3.1 - Posição longitudinal do centro aerodinâmico do corpo do míssil 
Centro aerodinâmico é definido como a posição no corpo do míssil que promove margem de estabilidade estática neutra ${ }^{18}$. Se o centro de massa $(C G)$ é posicionado no centro aerodinâmico, não existe tendência de mudança de ângulo de ataque com a variação do próprio ângulo de ataque ${ }^{19}$. A localização do centro aerodinâmico do corpo $\left(\mathrm{X}_{A C}\right)_{\text {Corpo }}$ depende principalmente de três parâmetros, quais sejam: ângulo de ataque $(\alpha)$, comprimento de nariz $\left(l_{n}\right)$ e comprimento total do corpo $\left(l_{\text {corpo }}\right)$. Para projeto conceitual, o efeito do numero de Mach em $\left(\mathrm{X}_{A C}\right)_{\text {Corpo }}$ pode ser desprezado (Fleeman, 2012).

Para a previsão da posição longitudinal do centro aerodinâmico do corpo do míssil, tal como anteriormente, combinando-se a teoria de corpo esbelto (Pitts, Nielsen \& Kaatari, 1957) com teoria de escoamento cruzado em um corpo (Jorgensen, 1973), chega-se à Equação (2.20).

$$
\frac{\left(\mathrm{X}_{A C}\right)_{\text {Corpo }}}{l_{n}}=0,63\left(1-\sin ^{2} \alpha\right)+0,5\left(\frac{l_{\text {corpo }}}{l_{n}}\right) \sin ^{2} \alpha
$$

Por meio do uso da Equação (2.20), obtém-se os dados da Figura 2.10. Como visto nesta figura, para um corpo sem estabilizadores e em baixo ângulo de ataque, $\left(\mathrm{X}_{A C}\right)_{\text {Corpo }}$ está posicionado a aproximadamente $63 \%$ do comprimento do nariz do míssil. Com ângulos de ataque se aproximando de $\alpha=90^{\circ},\left(\mathrm{X}_{A C}\right)_{\text {Corpo }}$ aproxima-se do centro do corpo. Os resultados da Figura 2.10 estão mostrados em função da razão $l_{c o r p o} / l_{n}$ (comprimento total do corpo / comprimento do nariz) e $\alpha$ (ângulo de ataque).

\footnotetext{
${ }^{18}$ Margem de estabilidade estática, como mostrado adiante no texto, é um conceito usado para caracterizar a estabilidade estática e manobrabilidade de aeronaves e mísseis. Para mísseis, a margem de estabilidade estática é definida como a distância entre o centro de pressão e o centro de massa (Chin, 1961). Geralmente, essa margem de estabilidade é escrita, de forma adimensional, em termos do diâmetro do corpo do míssil. Por sua vez, a estabilidade estática está relacionada com a capacidade da aeronave ou míssil retornar para sua direção original com relação ao meio em que se move, quando desviado de sua direção original.

${ }^{19}$ Centro de pressão em um corpo sujeito a um escoamento externo, é o ponto onde a força resultante atua e o momento aerodinâmico é nulo. Centro aerodinâmico é o ponto onde o momento aerodinâmico é independente do ângulo de ataque, ou seja, é constante (Anderson, 2001).
} 


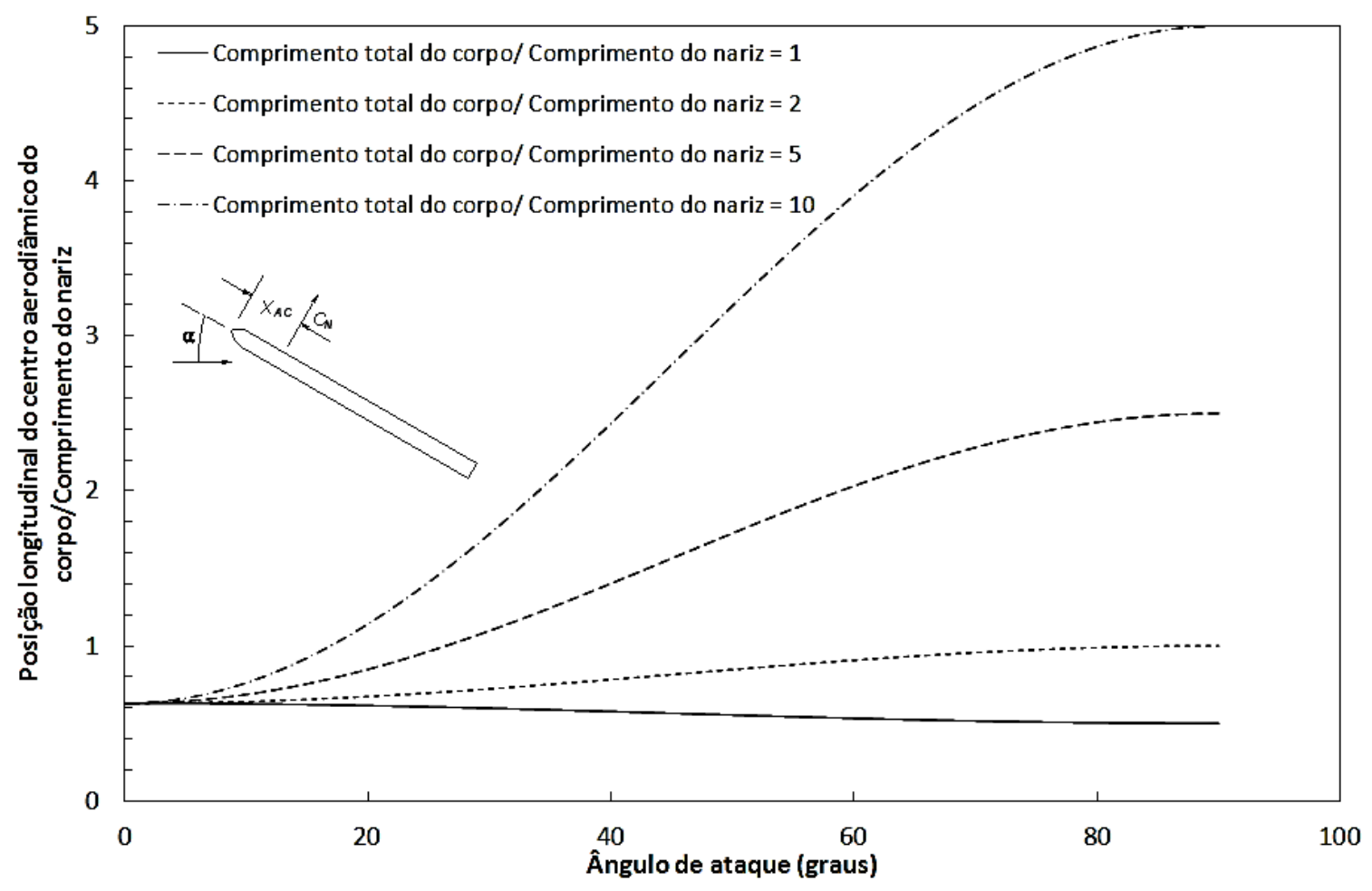

Figura 2.10 - Centro aerodinâmico do corpo em função do ângulo de ataque.

2.2.3.2 - Posição longitudinal do centro aerodinâmico das superfícies planas do míssil

Segundo Fleeman (2012), com baixo número de Mach, $\left(\mathrm{X}_{A C}\right)_{\text {Superfície }}$ está localizado a aproximadamente $25 \%$ da corda média aerodinâmica $\left(C_{m a c}\right)$. Em voo hipersônico (alto número de $\mathrm{Mach}),\left(\mathrm{X}_{A C}\right)_{\text {Superfície }}$ move-se para aproximadamente $50 \%$ da corda média aerodinâmica.

$$
\frac{\left(\mathrm{X}_{A C}\right)_{\text {Superfície }}}{C_{\text {mac }}}=\frac{A\left(M^{2}-1\right)^{\frac{1}{2}}-0,67}{2 A\left(M^{2}-1\right)^{\frac{1}{2}}-1} .
$$

A Equação ( 2.21) aplica-se caso M > 2.

$$
\frac{\left(\mathrm{X}_{A C}\right)_{\text {Superfície }}}{C_{\text {mac }}}=0,25
$$

A Equação ( 2.22) é aplicável caso $\mathrm{M}<0,7$. 


\subsection{4 - Relação sustentação / arrasto}

A força normal $(N)$ e a força de arrasto parasita $(A)$ compõem uma força resultante $(R)$ sobre este corpo. Por conveniência, pode-se decompor novamente esta força resultante em componentes horizontal - arrasto - $(D)$, e perpendicular - sustentação - $(L)$ à velocidade do escoamento livre $(V)$, de acordo com o indicado na Figura 2.11.

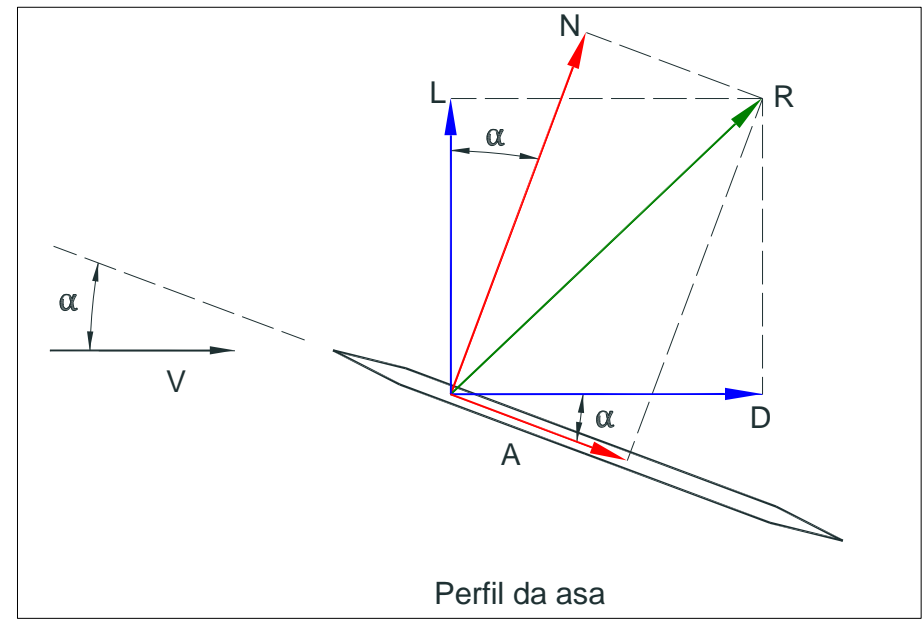

Figura 2.11 - Decomposição da força aerodinâmica resultante.

Por definição, a sustentação $L$ de um corpo é a componente perpendicular da força resultante, ao passo que o arrasto $D$ é a componente da força resultante paralela à velocidade do escoamento livre (Anderson, 2001). Escrevendo estas componentes em termos de coeficientes adimensionais de força, a relação geométrica entre estas duas componentes é dada por:

$$
C_{L}=C_{N} \cos \alpha-C_{D_{0}} \sin \alpha
$$

e

$$
C_{D}=C_{N} \sin \alpha+C_{D_{0}} \cos \alpha
$$

Uma medida de eficiência aerodinâmica é a razão sustentação / arrasto $(L / D)$. A equação para eficiência aerodinâmica é dada pela Equação ( 2.25). 


$$
\frac{L}{D}=\frac{C_{L}}{C_{D}}=\frac{C_{N} \cos \alpha-C_{D_{0}} \sin \alpha}{\left(C_{N} \sin \alpha+C_{D_{0}} \cos \alpha\right)}
$$

Como mostrado na Figura 2.12, um aumento na relação $L / D$ é obtido pela redução do coeficiente de arrasto parasita $\left(C_{D_{0}}\right)$, aumento da relação $l / d$ ou através da adoção de configuração de corpo que gere maior sustentação $(a / b)$. Também mostrado é que com a obtenção de uma maior relação $L / D$, decresce o ângulo de ataque no qual ocorre $(L / D)_{\text {máximo. }}$ Percebe-se que outras considerações de projeto, restrições laterais e de comprimento de plataforma de lançamento, podem limitar a configuração aerodinâmica praticável. Ainda, em voo em altitude constante e fator de carga de 1-g, o ângulo de ataque é usualmente muito menor que o ângulo de ataque no qual ocorre $(L / D)_{\text {máximo. Como }}$ resultado, a relação $L / D$ durante voo para a maioria dos mísseis é geralmente muito menor que $(L / D)_{\text {máximo }}\left(\right.$ Fleeman, 2012) ${ }^{20}$.

Embora uma configuração de corpo com $a / b>1$ tenha maior valor de $(L / D)_{\text {máximo que }}$ uma configuração de seção transversal circular, para voo em 1-g com baixo ângulo de ataque e alta pressão dinâmica, a configuração circular pode fornecer relação $L / D$ comparável. A adição de superfícies planas (p.ex.: asa) também aumenta $(L / D)_{\text {máximo }}$, e reduz o ângulo de ataque e pressão dinâmica nos quais ocorre $(L / D)_{\text {máximo }}$.

\footnotetext{
${ }^{20} \mathrm{O}$ fator de carga, como mostrado adiante no texto, é definido como a razão entre a sustentação e o peso do míssil (instantâneos). Uma vez que o fator de carga é uma relação de duas forças, ele é um termo adimensional. Porém, tradicionalmente, refere-se a ele em unidades de "g" (múltiplos da aceleração da gravidade) devido à relação entre o fator de carga e a aparente aceleração da gravidade a bordo do míssil. Um fator de carga de 1-g representa condições de voo nivelado e em linha reta. Fatores de carga maiores ou menores que 1-g são resultados de manobras de voo e rajadas de vento.
} 


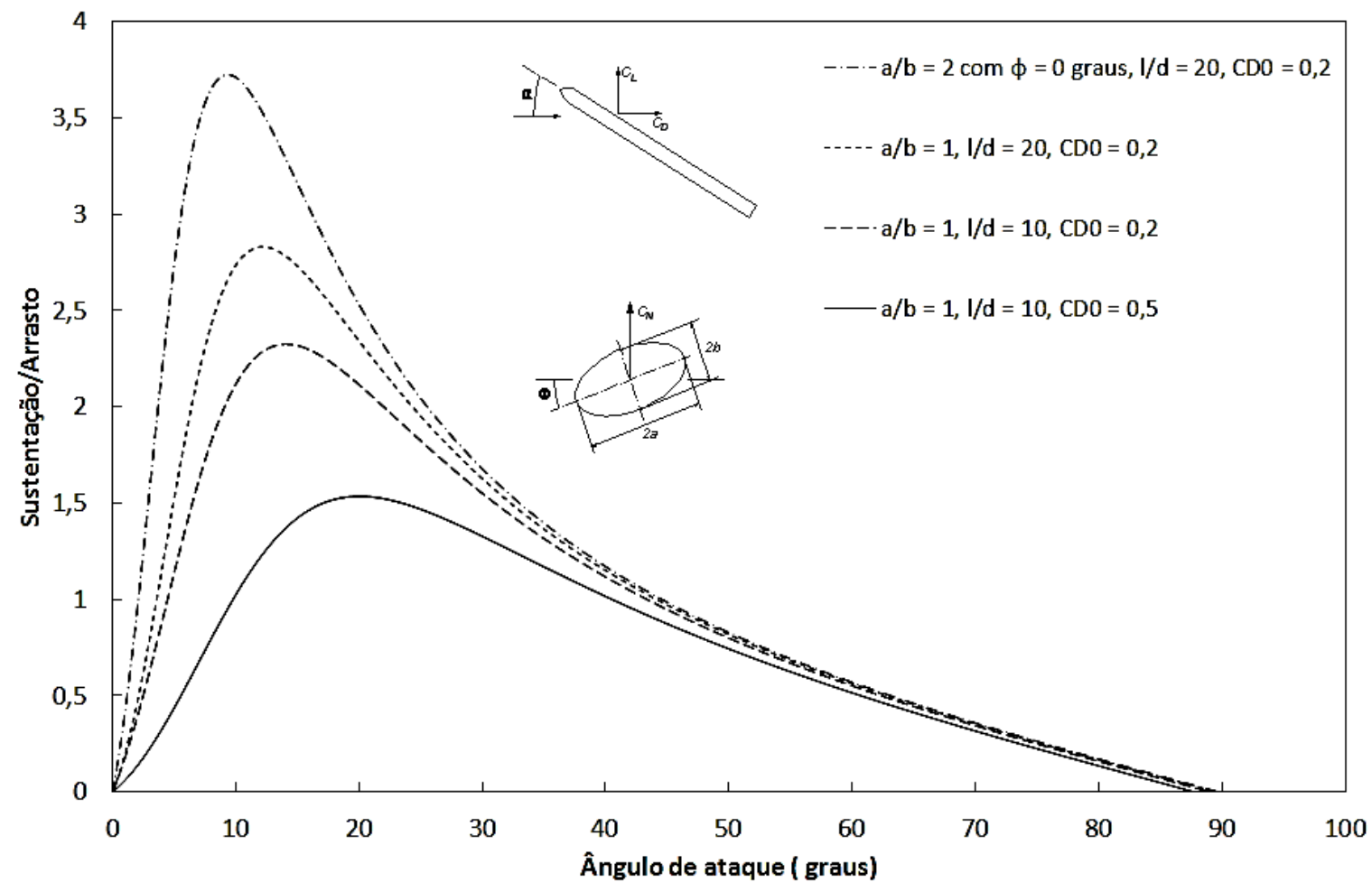

Figura 2.12 - Relação sustentação/arrasto em função do ângulo de ataque.

\subsection{5 - Geometria e características das superfícies planas do míssil}

A Figura 2.13 (Fleeman, 2012) mostra exemplos de diferentes geometrias para os painéis das superfícies planas de mísseis, como asa, superfície de cauda e canard. ${ }^{21}$ Essa figura compara qualitativamente as formas 1) triangular (delta), 2) trapezoidal convencional com bordo de ataque com enflechamento positivo, 3) trapezoidal "gravata borboleta", com bordo de ataque com enflechamento negativo e bordo de fuga com enflechamento positivo, 4) bordo de ataque com duplo enflechamento, e 5) superfície com geometria retangular. A comparação é baseada na mesma área plana, pois aproximadamente a mesma área é necessária para promover a mesma estabilidade estática e manobrabilidade (Fleeman, 2012). A comparação também considera que pode existir uma restrição de envergadura, situação frequente para compatibilidade do míssil com a plataforma de lançamento.

\footnotetext{
${ }^{21}$ Canard é um dispositivo semelhante a uma pequena asa ou placa utilizada em aeronaves e mísseis na região anterior de seu corpo, geralmente para fins de controle de voo, podendo também ser utilizado para aumento da sustentação total da aeronave.
} 


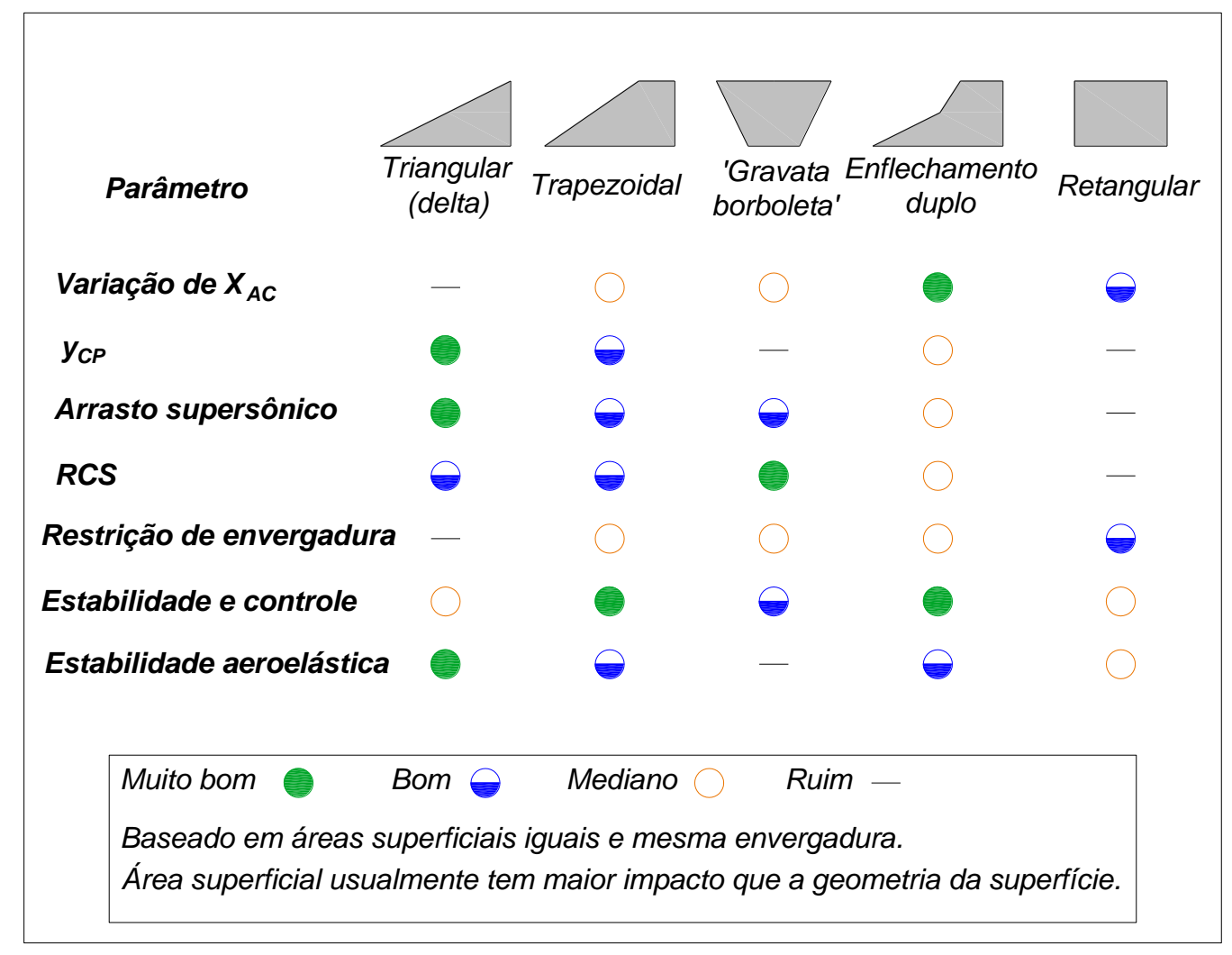

Figura 2.13 - Características de diferentee superficies planas (Fleeman 2012, modificado).

Depreende-se da Figura 2.13 que uma superfície com geometria triangular (delta) se destaca nos quesitos de baixo momento de flexão / baixa espessura requerida para integridade estrutural (o que resulta em menor peso), baixo arrasto supersônico (devido ao maior ângulo de enflechamento), relativamente baixo $\mathrm{RCS}^{22}$ e alta rigidez estrutural. Desvantagens da geometria em delta são maior envergadura, o que pode ser um problema para integração com plataforma de lançamento, e grande variação do centro aerodinâmico da superfície (Fleeman, 2012).

Uma segunda alternativa de geometria, trapezoidal convencional com bordo de ataque com enflechamento positivo, é frequentemente selecionada para os painéis das superfícies planas de mísseis, como asa, superfície de cauda e canard. De acordo com a avaliação de (Fleeman, 2012) isso ocorre devido à sua alta efetividade de controle e também por não possuir nenhum fator que desabone os demais atributos.

\footnotetext{
${ }^{22}$ RCS é o acrônimo para Radar Cross-Section, que é uma medida de quão detectável por um radar é determinado objeto.
} 
Outro exemplo de forma plana das superfícies é a geometria trapezoidal "gravata borboleta", com bordo de ataque com enflechamento negativo e bordo de fuga com enflechamento positivo. Essa geometria "gravata borboleta" é adequada para superfícies planas de mísseis que requerem baixos RCS frontal e posterior. Essa característica vem do fato dos bordos de ataque e fuga causarem difusão de parte das ondas eletromagnéticas emitidas pela ameaça ao míssil. Além de baixo RCS, essa geometria também proporciona baixo arrasto supersônico e boa efetividade de controle, especialmente controle de rolagem. Uma desvantagem inerente da superfície em forma de "gravata borboleta" é o aumento do potencial de instabilidade aeroelástica ${ }^{23}$. Outra desvantagem é o grande afastamento entre a raiz da superfície e o centro de pressão da superfície $\left(y_{c p}\right)$. Um grande valor de $y_{c p}$ resulta em um maior momento fletor, o que aumenta a fricção do eixo de controle de voo e requer maior torque do atuador de comando da superfície de controle. Um grande valor de momento fletor também requer uma estrutura mais espessa, o que aumenta o peso da mesma.

A geometria com bordo de ataque com duplo enflechamento (duplo delta) tem como maior vantagem sua capacidade de minimizar a variação do centro aerodinâmico $\left(\left(\mathrm{X}_{A C}\right)_{\text {Superfície }}\right)$ (Fleeman, 2012). Para asa, essa geometria promove margem estática aproximadamente constante. Para superfície de controle, a geometria com duplo delta gera reduzido torque de atuação, permitindo o uso de atuadores de comando da superfície com menor peso, tamanho e custo. Além da baixa variação de $\left(\mathrm{X}_{A C}\right)_{\text {Superfície }}$, a geometria de duplo delta tem efetividade de controle superior (especialmente em voo subsônico), boa estabilidade aeroelástica e nenhuma desvantagem maior nos demais pontos de consideração de projeto. Um aspecto que faz com que esse tipo de geometria não seja mais popular é o custo adicional de desenvolvimento e fabricação dessa superfície mais complexa.

\footnotetext{
23 Aeroelasticidade é um ramo da Engenharia que trata das interações entre forças inerciais, elásticas e aerodinâmicas que ocorrem quando um corpo elástico é exposto a um escoamento. Fenômenos aeroelásticos podem causar deflexões estáticas e dinâmicas ou movimentos oscilatórios de componentes de aeronaves ou mísseis, que por sua vez podem levar à redução da vida estrutural de componentes, problemas associados a controle e até violentas falhas estruturais.
} 
Por fim, superfícies retangulares têm muitas desvantagens e são utilizadas com menor frequência. Uma característica superior da superfície retangular é que ela tem a maior área superficial que pode ser acomodada se existirem restrições da plataforma de lançamento quanto à envergadura e corda aerodinâmica da superfície do míssil. Uma superfície retangular também tem relativamente baixa mudança no centro aerodinâmico, devido à corda aerodinâmica necessária, relativamente baixa. As principais desvantagens das superfícies retangulares são maior fricção / momento de flexão do eixo de controle da superfície, maior arrasto supersônico e maior RCS.

Os parâmetros da geometria das superfícies aerodinâmicas incluem razão de afilamento, razão de aspecto, afastamento entre a raiz da superfície e o centro de pressão da superfície e corda média aerodinâmica. A geometria planificada é baseada em dois painéis unidos na corda de raiz. Lembrando que a razão de afilamento é a relação entre a corda de ponta e corda de raiz da superfície $\left(\lambda=c_{\text {ponta }} / c_{\text {raiz }}\right)$. Razão de aspecto é definida como o quadrado da envergadura da superfície dividido pela área de superfície $\left(A=b^{2} / S\right)$. Para uma superfície convencional, com bordos de ataque e fuga retilíneos, a razão de aspecto pode ser calculada como:

$$
A=\frac{2 \mathrm{~b}}{\left[(1+\lambda) C_{\text {raiz }}\right]}
$$

O afastamento entre a raiz e o centro de pressão ou corda média aerodinâmica de uma superfície com bordos de ataque e fuga retilíneos é dado por:

$$
y_{c p}=\frac{\left(\frac{\mathrm{b}}{6}\right)(1+2 \lambda)}{(1+\lambda)}
$$

É possível notar, a partir da Equação (2.27) que para $\lambda=0$ (asa em delta) obtém-se o beneficio de baixo valor de $y_{c p}(b / 6)$, resultando em menor momento fletor no eixo de controle da superfície, enquanto que $\lambda=1$ (asa retangular) fornece o efeito adverso de um maior valor de $y_{c p}(b / 4)$ e um maior momento fletor na raiz da superfície.

A equação para o comprimento da corda média aerodinâmica de uma área trapezoidal é dada pela Equação (2.28). 


$$
C_{m a c}=\frac{2}{3} C_{\text {raiz }} \frac{\left(1+\lambda+\lambda^{2}\right)}{(1+\lambda)}
$$

O centro aerodinâmico de uma superfície (que coincide com o centro de pressão para uma superfície com uma seção transversal simétrica não arqueada) está posicionado na corda média aerodinâmica. De acordo com (Fleeman, 2012), comumente, a área de superfície tem maior impacto na estabilidade aerodinâmica, controle e desempenho que a geometria da superfície. Considerando que mísseis têm, com frequência, limitações na envergadura, eles usualmente não podem tirar proveito de geometrias com alta razão de aspecto.

\subsection{6 - Dimensionamento das superfícies de cauda do míssil}

Parte importante do processo de dimensionamento da configuração de projeto conceitual é orientada no sentido da estimativa da área das superfícies de cauda do míssil. Uma vez que geralmente impõe-se a mísseis limitações de volume e, dado o fato dos subsistemas que os compõem possuírem massas específicas próximas, o centro de massa (CG) do míssil está, geralmente, localizado próximo de 50\% do comprimento do míssil (Fleeman, 2012). Dado que o nariz do míssil e qualquer superfície à montante do CG tem efeito desestabilizador, superfícies de cauda precisam ser adicionadas e dimensionadas para gerar a estabilidade estática requerida. A contribuição das superfícies de cauda para a tendência de mudança de ângulo de ataque é promovida pela efetividade da força normal na superfície de cauda

$\left(C_{N_{\alpha}}\right)_{\text {Cauda }}\left(S_{\text {Cauda }} / S_{R e f}\right)$ multiplicado por sua distância até o CG $\left(\left(\mathrm{X}_{A C}\right)_{\text {Cauda }}-\mathrm{X}_{C G}\right)$. Assim, considerando somatório de momento igual a zero $(\Sigma M=0)$ no centro aerodinâmico, resulta na Equação (2.29). 


$$
\begin{gathered}
\left(C_{N_{\alpha}}\right)_{\text {Corpo }}\left\{\frac{\left[\mathrm{X}_{C G}-\left(\mathrm{X}_{A C}\right)_{\text {Corpo }}\right]}{d}\right\}+\left(C_{N_{\alpha}}\right)_{\text {Asa }}\left\{\frac{\left[\mathrm{X}_{C G}-\left(\mathrm{X}_{A C}\right)_{\text {Asa }}\right]}{d}\right\} \frac{S_{\text {asa }}}{S_{\text {ref }}}+\left(C_{N_{\alpha}}\right)_{\text {Cauda }}\left\{\frac{\left[\mathrm{X}_{C G}-\left(\mathrm{X}_{A C}\right)_{\text {Cauda }}\right]}{d}\right\} \frac{S_{\text {Cauda }}}{S_{\text {ref }}}= \\
-\left[\left(C_{N_{\alpha}}\right)_{\text {Corpo }}+\left(C_{N_{\alpha}}\right)_{\text {Asa }} \frac{S_{\text {asa }}}{S_{\text {ref }}}+\left(C_{N_{\alpha}}\right)_{\text {Cauda }} \frac{S_{\text {Cauda }}}{S_{\text {ref }}}\right]\left[\frac{\left(\mathrm{X}_{A C}-\mathrm{X}_{C G}\right)}{d}\right] .
\end{gathered}
$$

A Equação (2.30) pode ser utilizada para calcular a margem de estabilidade estática para uma área de superfície de cauda especificada. Esta equação será utilizada no algoritmo desenvolvido neste trabalho (descrito adiante no texto).

$$
\begin{gathered}
\frac{\left(\mathrm{X}_{A C}-\mathrm{X}_{C G}\right)}{d}= \\
-\frac{\left\{\left(C_{N_{\alpha}}\right)_{\text {Corpo }}\left\{\frac{\left[\mathrm{X}_{C G}-\left(\mathrm{X}_{A C}\right)_{\text {Corpo }}\right]}{d}\right\}+\left(C_{N_{\alpha}}\right)_{\text {Asa }}\left\{\frac{\left[\mathrm{X}_{C G}-\left(\mathrm{X}_{A C}\right)_{\text {Asa }}\right]}{d}\right\} \frac{S_{\text {asa }}}{S_{\text {ref }}}+\left(C_{N_{\alpha}}\right)_{\text {Cauda }}\left\{\frac{\left[\mathrm{X}_{C G}-\left(\mathrm{X}_{A C}\right)_{\text {Cauda }}\right]}{d}\right\} \frac{S_{\text {Cauda }}}{S_{\text {ref }}}\right\}}{\left[\left(C_{N_{\alpha}}\right)_{\text {Corpo }}+\left(C_{N_{\alpha}}\right)_{\text {Asa }} \frac{S_{\text {asa }}}{S_{\text {ref }}}+\left(C_{N_{\alpha}}\right)_{\text {Cauda }} \frac{S_{\text {Cauda }}}{S_{\text {ref }}}\right] .}
\end{gathered}
$$

A área da superfície de cauda para um valor especificado de margem estática é dada pela Equação (2.31).

$$
\frac{s_{\text {Cauda }}}{s_{\text {ref }}}=\left(C_{N_{\alpha}}\right)_{\text {Corpo }}\left\{\frac{\left[\mathrm{x}_{C G}-\left(\mathrm{x}_{A C}\right)_{\text {Corpo }}\right]}{d}\right\}+\left(C_{N_{\alpha}}\right)_{A s a}\left\{\frac{\left[\mathrm{x}_{C G}-\left(\mathrm{x}_{A C}\right)_{A s a}\right]}{d}\right\} \frac{s_{\text {asa }}}{S_{\text {ref }}}+\frac{\left\{\left[\left(C_{N_{\alpha}}\right)_{\text {Corpo }}+\left(C_{N_{\alpha}}\right)_{A s a} \frac{s_{a s a}}{s_{\text {ref }}}\right]\left[\frac{\left(\mathrm{x}_{A C}-\mathrm{x}_{C G}\right)}{d}\right]\right\}}{\left\{\left(C_{N_{\alpha}}\right)_{\text {Cauda }} \frac{\left[\left(\mathrm{x}_{A C}\right)_{C a u d a}-\mathrm{x}_{C G}\right]}{d}-\frac{\left(\mathrm{x}_{A C}-\mathrm{x}_{C G}\right)}{d}\right\}}
$$


Estabilidade neutra ocorre quando o centro aerodinâmico do míssil coincide com o centro de massa do míssil. Assim,

$$
\frac{\left(\mathrm{X}_{A C}-\mathrm{X}_{C G}\right)}{d}=0
$$

A área requerida para estabilidade neutra é:

$$
S_{\text {Cauda }}=\left\{\left(C_{N_{\alpha}}\right)_{\text {Corpo }} \frac{\left[\mathrm{X}_{C G}-\left(\mathrm{X}_{A C}\right)_{\text {Corpo }}\right]}{d}+\left(C_{N_{\alpha}}\right)_{A s a}\left\{\frac{\left[\mathrm{X}_{C G}-\left(\mathrm{X}_{A C}\right)_{A s a}\right]}{d}\right\} \frac{S_{\text {asa }}}{S_{\text {ref }}}\right\}\left\{\frac{d}{\left[\left(\mathrm{X}_{A C}\right)_{\text {Cauda }}-\mathrm{X}_{C G}\right]}\right\} \frac{S_{\text {Ref }}}{\left(C_{N_{\alpha}}\right)_{\text {Cauda }}}
$$




\subsection{7 - Tipos de configuração e controle}

Naturalmente, o tipo de superfície de controle adotado está diretamente relacionado ao tipo de configuração do míssil. As principais configurações e suas respectivas formas de controle aerodinâmico são mostradas na Figura 2.14, cada uma possuindo características favoráveis e desfavoráveis.

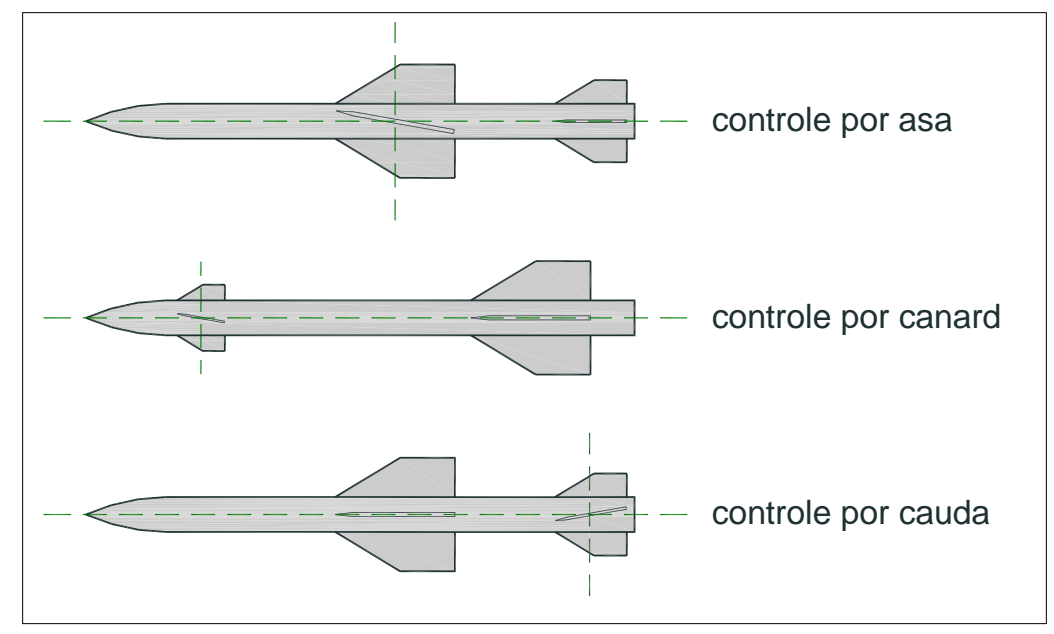

Figura 2.14 - Tipos de controle aerodinâmico (Chin 1961, modificado).

\subsubsection{1 - Controle por asa}

Uma configuração de controle por asa consiste de uma asa relativamente grande localizada próximo ao centro de massa do míssil e um conjunto de superfícies de cauda ou estabilizadores na parte posterior do míssil. Este tipo de controle permite características de resposta extremamente rápidas. Sustentação instantânea é produzida como resultado da deflexão da asa para proporcionar sustentação para manobras em voo. Sustentação adicional é desenvolvida enquanto o ângulo de ataque do míssil aumenta. Contudo, de acordo com Chin (1961), diversas características indesejáveis relacionadas a este tipo de controle devem ser cuidadosamente consideradas antes de sua seleção para uma aplicação particular. Dentre estas caraterísticas destacam-se: (1) perda relativamente grande da efetividade das superfícies de cauda na contribuição para a estabilidade estática, devido ao 
downwash ${ }^{24}$ produzido pela asa; (2) aerodinâmica não linear resultante do downwash decorrente da deflexão da asa e ao ângulo de ataque e (3) severos momentos de rolagem adversos induzidos nas superfícies de cauda por efeitos combinados do ângulo de ataque e deflexão diferencial dos painéis da asa (Chin, 1961).

\subsubsection{2 - Controle por canard}

Uma configuração de controle por canard consiste de um grupo de pequenas superfícies de controle localizado na parte anterior do corpo do míssil e um grupo de superfícies maiores (asa ou cauda) instalado na parte mediada ou posterior do míssil. Opostamente ao controle por asa, devido às pequenas dimensões do canard, este não produz intenso downwash, o que não gera o efeito adverso na estabilidade do míssil. Assim, margens de estabilidade estática relativamente grandes podem ser obtidas com simples mudanças na localização da asa (ou cauda). A sustentação resultante neste tipo de configuração é produzida quase que inteiramente pelo corpo uma vez que a sustentação gerada pelo canard é anulada pela carga negativa sobre a asa ou cauda devido ao downwash do canard (Chin, 1961). Uma característica atrativa do canard é o pequeno volume inerente dos atuadores de controle e sua instalação na parte anterior do míssil. Além disso, mudanças na posição do centro de massa devido a alterações do projeto conceitual podem facilmente ser acomodadas por simples realocação da asa ou superfície de cauda. Uma vez que a área total de superfícies de sustentação é geralmente menor, o arrasto total e peso do míssil são reduzidos.

As principais desvantagens da configuração com canard são: (1) difícil (se não impossível) estabilização de rolagem com uso de canard em decorrência dos efeitos de seu tamanho e downwash sobre a asa, requerendo um método mais complexo para garantir controle de rolagem (por exemplo, adoção de ailerons na asa) e (2) relativamente altas taxas de variação da superfície de controle são necessárias para obter a taxa de resposta desejada. Como consequência. Demanda-se um aumento da potência dos atuadores das superfícies de controle. Porém, a potência requerida pelo atuador do canard é usualmente menor que aquela necessária para atuação de um controle por asa (Chin, 1961).

\footnotetext{
${ }^{24}$ Em aerodinâmica, downwash é a mudança na direção do ar defletido pela ação de uma asa ou aerofólio.
} 


\subsubsection{3 - Controle por superfície de cauda}

Com este tipo de controle a deflexão das superfícies de cauda deve ser em uma direção oposta ao ângulo de ataque do míssil. Esta característica resulta em respostas relativamente lentas, uma vez que a sustentação inicial gerada pela cauda está em uma direção oposta à desejada. Todavia, esta configuração mostra-se vantajosa porque a carga da cauda e o torque do eixo de controle são mantidos em níveis relativamente baixos com a diminuição do ângulo de ataque total da superfície. Isto, por sua vez, reduz a flexão do corpo para um valor mínimo, dado que a maior parte da carga resultante está concentrada na asa principal, instalada próximo ao centro de massa do míssil. Ainda, os efeitos da interferência asa cauda são reduzidos, pois a principal superfície de sustentação é fixa, não produzindo downwash. Portanto, as características aerodinâmicas são mais lineares que aquelas de uma configuração de controle por asa. As principais desvantagens associadas a este tipo de configuração são: (1) espaço limitado, na parte posterior do míssil, para um mecanismo de controle caso seja utilizado um motor foguete e (2) deficiências da superfície de cauda para prover controle lateral desejado (Chin, 1961).

Um caso especial de controle por cauda é um que não é utilizada asa. Este tipo de configuração é restrito a mísseis que podem possuir manobrabilidade relativamente baixa. O corpo, neste caso, promove grande parte da sustentação com a adoção um grande ângulo de ataque. Outro caso especial de controle por cauda é um que uma asa de baixa razão de aspecto é utilizada. A superfície de controle neste caso é a parte posterior da asa, articulada para garantir controle. $\mathrm{O}$ ângulo de ataque neste caso geralmente é grande. 
Tabela 2.1 - Características de diferentes tipos de controle aerodinâmico.

\begin{tabular}{|c|c|c|}
\hline Tipo de controle & Vantagens & Desvantagens \\
\hline Asa & $\begin{array}{l}\text { Respostas rápidas } \\
\text { Ângulo de trimagem pequeno } \\
\text { Relativamente fácil acomodação dos } \\
\text { atuadores }\end{array}$ & $\begin{array}{l}\text { Alto torque no eixo de controle } \\
\text { Requer alta potência para atuação das } \\
\text { superfícies } \\
\text { Forte arrasto } \\
\text { Forte downwash - diminui a contribuição } \\
\text { da cauda para a estabilidade estática } \\
\text { Muita sensibilidade ao passeio do CG } \\
\text { Forte momento de rolagem induzido }\end{array}$ \\
\hline Canard & $\begin{array}{l}\text { Fácil acomodação dos atuadores } \\
\text { Baixo torque no eixo de controle } \\
\text { Aerodinâmica aproximadamente linear } \\
\text { Pouca sensibilidade ao passeio do CG } \\
\text { Facilidade de alterações no projeto } \\
\text { Baixo arrasto }\end{array}$ & $\begin{array}{l}\text { Controle lateral mais complexo } \\
\text { Momento fletor no corpo relativamente } \\
\text { grande } \\
\text { Requer taxas de atuação relativamente altas } \\
\text { Ângulo de trimagem relativamente alto }\end{array}$ \\
\hline Cauda & $\begin{array}{l}\text { Baixa carga na cauda } \\
\text { Baixo torque no eixo de controle } \\
\text { Baixo momento fletor no corpo } \\
\text { Aerodinâmica aproximadamente linear }\end{array}$ & $\begin{array}{l}\text { Respostas lentas } \\
\text { Força de atuação inicial oposta à direção } \\
\text { desejada } \\
\text { Dificuldade de acomodação dos atuadores } \\
\text { Controle lateral ruim } \\
\text { Ângulo de trimagem relativamente alto }\end{array}$ \\
\hline
\end{tabular}

\subsection{8 - Equilíbrio estático e estabilidade}

Equilíbrio estático ocorre sempre que o míssil não sofre aceleração em voo. Ausência de aceleração requer que o somatório de forças e momentos atuantes sobre o míssil seja nulo. Dessa forma, em voo nivelado e em regime permanente, com o vetor empuxo alinhado com a direção de voo, o empuxo deve ser igual ao peso, e o empuxo deve ser igual ao arrasto (ver Figura 2.40). Equilíbrio estático também implica que a força lateral sobre o míssil seja nula. Esta condição usualmente ocorre como resultado da simetria do míssil. Além disso, os somatórios de momentos em relação ao centro de massa (CG), nas três dimensões espaciais, devem ser nulos para voo trimado. A simetria do míssil geralmente implica em momentos de guinagem e rolagem nulos, mas o momento de arfagem é geralmente anulado com a atuação das superfícies de controle (Figura 2.15). Quando as superfícies de controle são ajustadas de modo que as forças e momentos resultantes sobre o centro de massa são todos nulos, diz-se que o míssil está trimado, o que simplesmente significa equilíbrio estático (Phillips, 2010). 


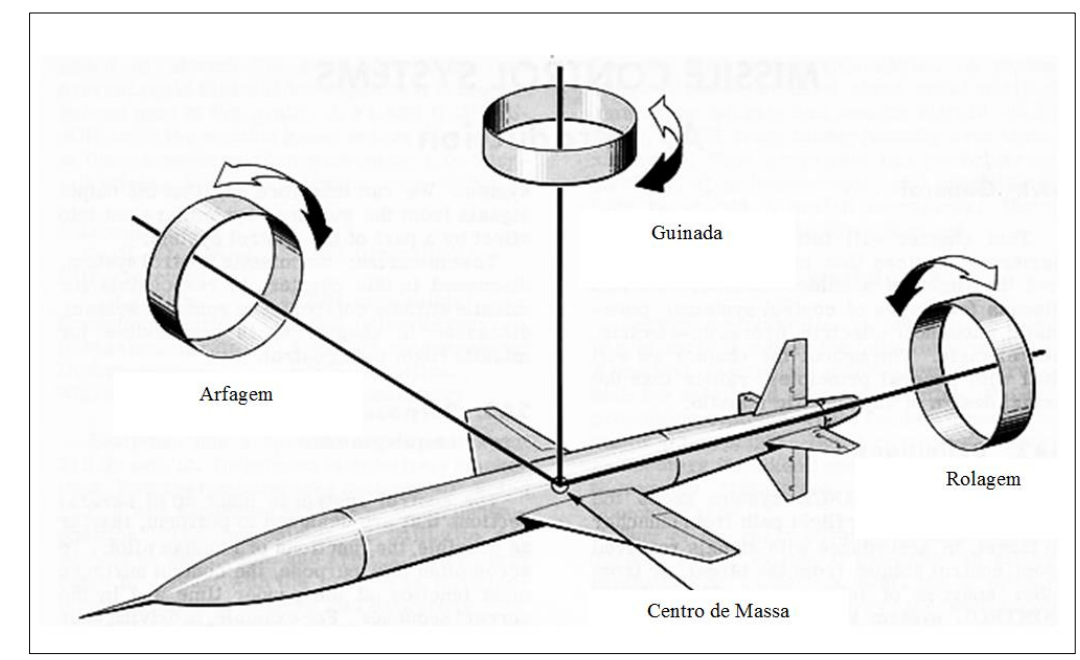

Figura 2.15 - Atitude de voo de um míssil. Adaptada de (Bureau of Naval Personnel, 1959)

A facilidade em manter o equilíbrio estático está relacionada a uma propriedade do estado de equilíbrio, que é conhecida por estabilidade estática. A estabilidade estática de qualquer estado de equilíbrio está relacionada com a resposta do sistema a um pequeno distúrbio que tente o afastar daquele estado de equilíbrio. Se um sistema em um estado de equilíbrio retorna ao equilíbrio após um pequeno distúrbio, diz-se que o que este é um equilíbrio estável. Por outro lado, se o sistema diverge do equilíbrio quando levemente perturbado, o estado é dito ser um equilíbrio instável.

A efetividade de um míssil, em termos de precisão e probabilidade de destruição, depende fortemente das características de resposta do conjunto, composto pela configuração aerodinâmica e pelos sistemas de guiamento e controle. Uma das tarefas mais importantes na etapa de configuração do míssil, ou seja, da fase de projeto conceitual, é prever que estabilidade estática suficiente seja garantida pela configuração escolhida para o míssil. Feito isso, são necessários menos componentes adicionais para atender a requisitos de resposta em voo (Chin, 1961).

\subsection{9 - Manobrabilidade}

A operação em voo de um míssil em voo nivelado e em regime permanente é uma consideração muito importante no projeto desse dispositivo, mas também é preciso 
compreender como as superfícies de controle do míssil são usadas para acelerá-lo de um estado de equilíbrio para outro. A força que produz quase toda aceleração tipicamente usada para manobrar um míssil é a sustentação. ${ }^{25}$ Em grande parte, as superfícies de controle aerodinâmico são projetadas para mudar a magnitude e direção dessa força. $\mathrm{O}$ ângulo de ataque controla a magnitude da sustentação, ao passo que e as superfícies de cauda (ou canard) controlam o ângulo de ataque.

Consequentemente, é preciso conceber uma configuração externa com fator de carga (ou manobrabilidade) suficiente de modo que o míssil possa executar curvas de pequeno raio, para interceptação do alvo ou correção de trajetória de voo. Contudo, estes dois requisitos de projeto, isto é, estabilidade e manobrabilidade, são conflitantes, uma vez que a manobrabilidade diminui com o aumento da estabilidade (Chin, 1961).

Para determinar o ângulo de ataque das superfícies de controle necessário para voo trimado, deve-se ser considerar o somatório de forças normal e de momentos de arfagem iguais a zero. Essas duas equações acopladas são solucionadas para o ângulo de ataque de equilíbrio e deflexão das superfícies de controle. Obviamente, as superfícies de controle devem ser suficientes para permitir voo trimado para qualquer condição de operação possível. Porém, simplesmente ser capaz de trimar o míssil não é suficiente. As superfícies de controle devem ser grandes o bastante para manobrar o míssil adequadamente sobre toda a faixa de condições de operação.

\subsubsection{0 - Equilíbrio em voo}

A análise de um modelo com dois graus de liberdade (um movimento rotacional e um translacional) é conveniente para estudar a estabilidade estática longitudinal e as características de controle de um míssil. Conforme afirmado anteriormente, se um míssil voa nivelado e em regime permanente, a soma das forças bem como dos momentos dessas forças que atuam sobre o míssil, deve ser nula.

\footnotetext{
${ }^{25}$ Uma exceção é a técnica de Controle por Empuxo Vetorado (Thrust Vectoring Control).
} 
A Figura 2.16 mostra um diagrama esquemático da força normal e de arrasto parasita atuantes sobre o míssil em voo e seus respectivos pontos de atuação. As forças mostradas são simplificações da realidade uma vez que as forças reais de superfície atuantes sobre um míssil são resultado de distribuição de tensão (normal e cisalhante) nas superfícies do míssil (corpo, asa, cauda, motor etc). Mas, considerando que a distribuição de tensão no corpo produza forças distribuídas conforme o indicado na Figura 2.16 é possível realizar o balanço de forças e momentos para determinar a condição de equilíbrio em voo.

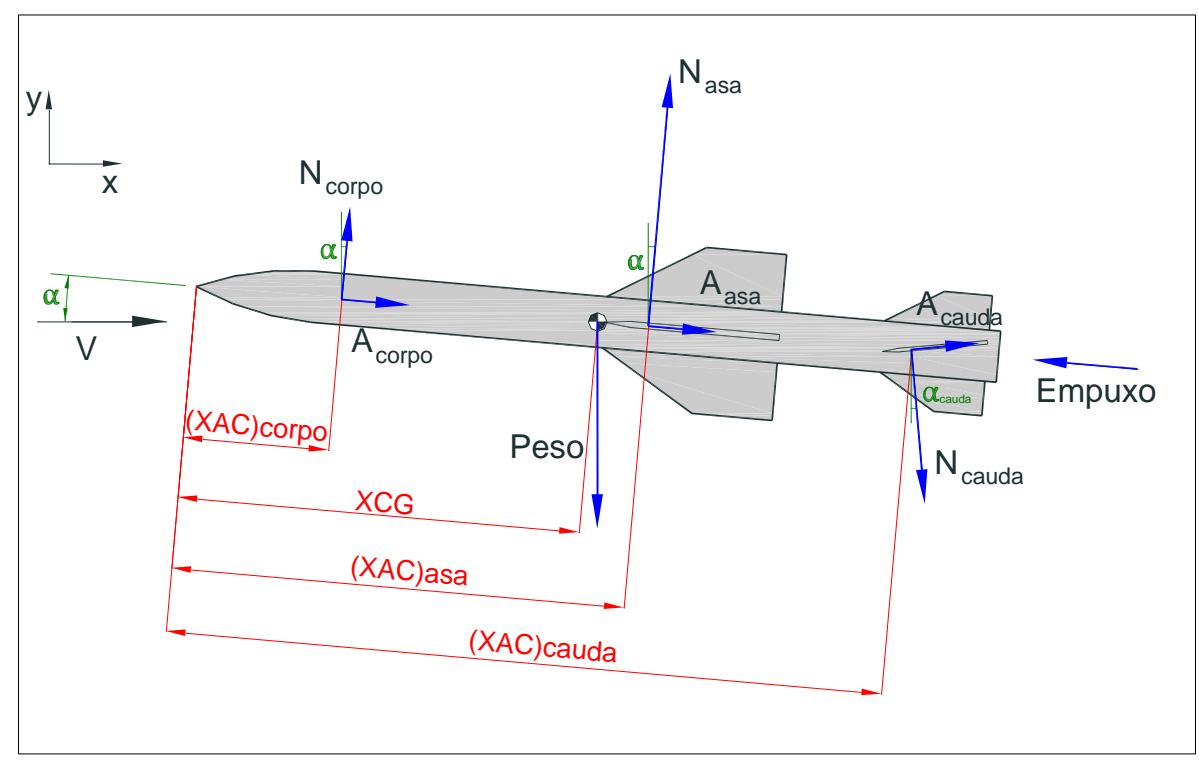

Figura 2.16 - Forças atuantes sobre um míssil em voo (normal e arrasto parasita).

Seguindo as definições anteriores

$\left(\mathrm{X}_{A C}\right)_{C o r p o}=$ localização do centro aerodinâmico do corpo do míssil;

$\left(\mathrm{X}_{A C}\right)_{A s a}=$ localização do centro aerodinâmico da asa;

$\left(\mathrm{X}_{A C}\right)_{\text {Cauda }}=$ localização do centro aerodinâmico da cauda;

$\left(\mathrm{X}_{C G}\right)_{M i ́ s s i l}=$ localização do centro de massa do míssil;

Por conveniência, para que a condição de equilíbrio em voo seja avaliada, a força normal e de arrasto parasita mostradas na Figura 2.16 poder ser transformadas em componentes horizontal e vertical. A Figura 2.17 mostra o diagrama esquemático das forças de sustentação e de arrasto atuantes sobre o míssil em voo e seus respectivos pontos de atuação. Nas Figuras 2.16 e 2.17, adotou-se a mesma nomenclatura utilizada na Figura 2.11 . 


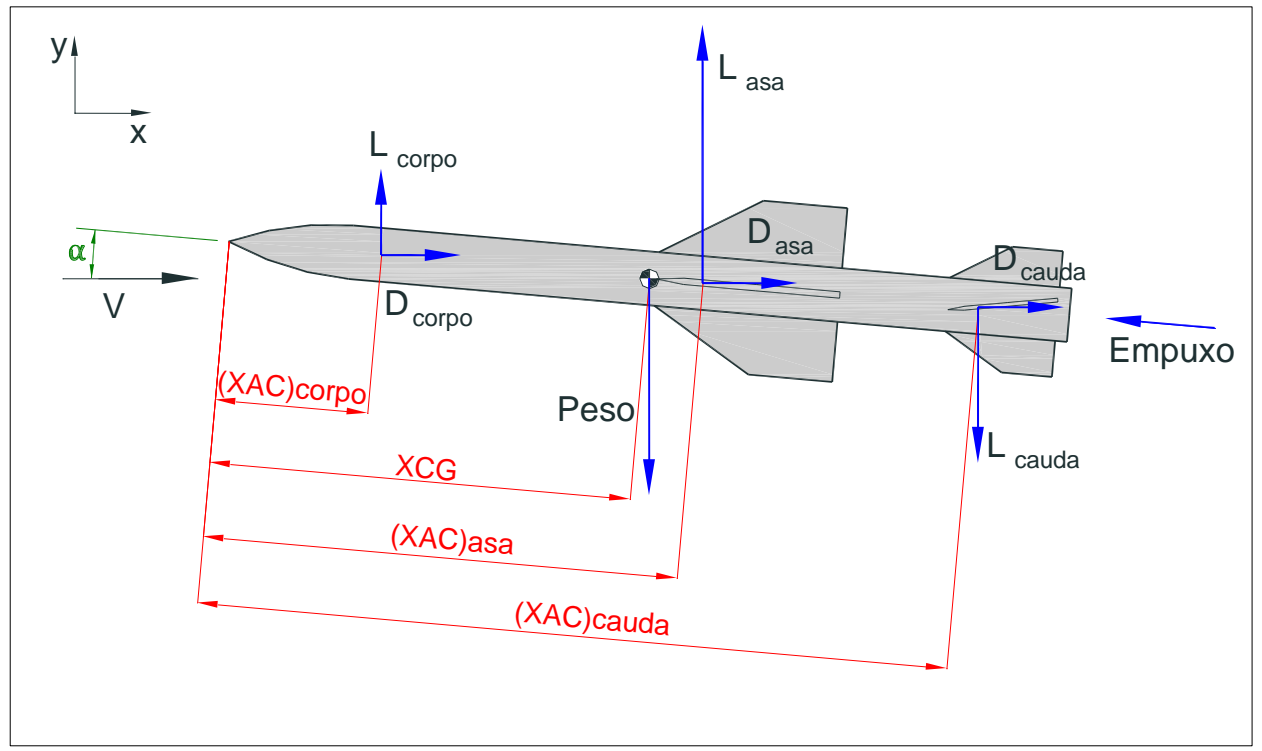

Figura 2.17 - Forças atuantes sobre um míssil em voo (sustentação e arrasto).

A força normal e de arrasto parasita nos elementos do míssil são calculadas na forma que se segue. $^{26}$

Cálculo da força de normal no corpo $\left(N_{\text {Corpo }}\right)$, asa $\left(N_{\text {Asa }}\right)$ e cauda $\left(N_{\text {Cauda }}\right)$ :

$$
\begin{gathered}
N_{\text {Corpo }}=\left|C_{N}\right|_{\text {Corpo }} S_{\text {ref }} \frac{1}{2} \gamma p_{a} M^{2}, \\
N_{\text {Asa }}=\left|\left(C_{N}\right)_{\text {Asa }}\right| S_{\text {ref }} \frac{1}{2} \gamma p_{a} M^{2}, \\
N_{\text {Cauda }}=\left|\left(C_{N}\right)_{\text {Cauda }}\right| S_{\text {ref }} \frac{1}{2} \gamma p_{a} M^{2} .
\end{gathered}
$$

Onde $\gamma$ representa a relação de calores específicos do ar, $p_{a}$ a pressão estática ambiente e $M$ o número de Mach do voo.

\footnotetext{
${ }^{26}$ Por coerência, nessas equações aplica-se, como área de referência para o cálculo das forças normal e de arrasto parasita, o valor da área da seção transversal do míssil $S_{r e f}$, uma vez que o valor dos coeficientes de força normal e de arrasto parasita, mesmo para as superfícies planas, considera o uso dessa área (ver as Equações ( 2.10), ( 2.11), (2.17) e (2.19)).
} 
Cálculo da força de arrasto parasita no corpo $\left(A_{\text {Corpo }}\right)$, asa $\left(A_{\text {Asa }}\right)$ e cauda $\left(A_{\text {Cauda }}\right)$ :

$$
\begin{aligned}
A_{\text {Corpo }} & =\left(C_{D_{0}}\right)_{\text {Corpo }} S_{\text {ref }} \frac{1}{2} \gamma p_{a} M^{2}, \\
A_{\text {Asa }} & =\left(C_{D_{0}}\right)_{\text {Asa }} S_{\text {ref }} \frac{1}{2} \gamma p_{a} M^{2}, \\
A_{\text {Cauda }} & =\left(C_{D_{0}}\right)_{\text {Cauda }} S_{\text {ref }} \frac{1}{2} \gamma p_{a} M^{2} .
\end{aligned}
$$

Cálculo da força de sustentação no corpo $\left(L_{\text {Corpo }}\right)$, asa $\left(L_{\text {Asa }}\right)$ e cauda $\left(L_{\text {Cauda }}\right)^{27}$ :

$$
\begin{gathered}
L_{\text {Corpo }}=N_{\text {Corpo }}\left(\cos \alpha_{\text {Corpo }}\right)-A_{\text {Corpo }}\left(\sin \alpha_{\text {Corpo }}\right), \\
L_{\text {Asa }}=N_{\text {Asa }}\left(\cos \alpha_{\text {Asa }}\right)-A_{\text {Asa }}\left(\sin \alpha_{\text {Asa }}\right), \\
L_{\text {Cauda }}=N_{\text {Cauda }}\left(\cos \alpha_{\text {Cauda }}\right)-A_{\text {Cauda }}\left(\sin \alpha_{\text {Cauda }}\right) .
\end{gathered}
$$

Cálculo da componente vertical do empuxo:

$$
F_{y_{\text {Empuxo }}}=\operatorname{Empuxo}\left(\sin \alpha_{\text {Corpo }}\right) \text {. }
$$

Cálculo da força de arrasto no corpo $\left(D_{\text {Corpo }}\right)$, asa $\left(D_{\text {Asa }}\right)$ e cauda $\left(D_{\text {Cauda }}\right)$ :

$$
\begin{gathered}
D_{\text {Corpo }}=N_{\text {Corpo }}\left(\sin \alpha_{\text {Corpo }}\right)+A_{\text {Corpo }}\left(\cos \alpha_{\text {Corpo }}\right), \\
D_{\text {Asa }}=N_{\text {Asa }}\left(\sin \alpha_{\text {Asa }}\right)+A_{\text {Asa }}\left(\cos \alpha_{\text {Asa }}\right), \\
D_{\text {Cauda }}=N_{\text {Cauda }}\left(\sin \alpha_{\text {Cauda }}\right)+A_{\text {Cauda }}\left(\cos \alpha_{\text {Cauda }}\right) .
\end{gathered}
$$

\footnotetext{
27 Equações válidas considerando ângulo de ataque $(\alpha)$ positivo. Deve-se ter cautela ao avaliar sin $\alpha$ e aplicar essas equações caso o ângulo de ataque de algum elemento do míssil (corpo, asa, cauda) seja negativo.
} 
O balanço de forças verticais resulta na equação de equilíbrio (2.47). Para a configuração mostrada na Figura $2.17\left(\alpha_{\text {Corpo }}\right.$ e $\left.\alpha_{\text {Asa }}>0, \alpha_{\text {Cauda }}<0\right)$ o somatório de forças verticais resulta em:

$$
\sum F_{y}=0=L_{\text {Corpo }}+L_{\text {Asa }}-L_{\text {Cauda }}-\text { Peso }+F_{y_{\text {Empuxo }}} .
$$

As forças de sustentação e arrasto descritas nas Equações (2.40) a (2.42) e (2.44) a (2.46) produzem momentos em relação ao centro de massa do míssil que podem ser calculadas na forma que segue $\mathrm{e}^{28}$.

Momento produzido pela força de sustentação do corpo em relação ao CG:

$$
M_{L_{\text {Corpo }}}=\left|\left(\mathrm{X}_{C G}-\left(\mathrm{X}_{A C}\right)_{\text {Corpo }}\right) L_{\text {Corpo }}\left(\cos \alpha_{\text {Corpo }}\right)\right|
$$

Momento produzido pela força de sustentação da asa em relação ao CG:

$$
M_{L_{A s a}}=\left|\left(\left(\mathrm{X}_{A C}\right)_{A s a}-\mathrm{X}_{C G}\right) L_{A s a}\left(\cos \alpha_{\text {Corpo }}\right)\right|
$$

Momento produzido pela força de sustentação da cauda em relação ao CG:

$$
M_{L_{\text {Cauda }}}=\left|\left(\left(\mathrm{X}_{A C}\right)_{\text {Cauda }}-\mathrm{X}_{C G}\right) L_{\text {Cauda }}\left(\cos \alpha_{\text {Corpo }}\right)\right|
$$

Momento produzido pela força de arrasto do corpo em relação ao CG:

\footnotetext{
${ }^{28} \mathrm{O}$ uso do módulo para cálculo dos momentos ocorre por questão de conveniência e simplificação da rotina para o programa desenvolvido neste trabalho (descrito mais adiante). Os motivos são: i) possibilidade da ocorrência de ângulo de ataque ( $\alpha$ ) negativo durante a avaliação dos mísseis, tendo como resultado um valor negativo para $\sin \alpha$; a possibilidade de ocorrência de inversão das posições relativas entre os centros aerodinâmicos dos elementos e o CG do míssil.
} 


$$
M_{D_{\text {Corpo }}}=\left|\left(\mathrm{X}_{C G}-\left(\mathrm{X}_{A C}\right)_{\text {Corpo }}\right) D_{\text {Corpo }}\left(\sin \alpha_{\text {Corpo }}\right)\right|
$$

Momento produzido pela força de arrasto da asa em relação ao CG:

$$
M_{D_{A s a}}=\left|\left(\left(\mathrm{X}_{A C}\right)_{A s a}-\mathrm{X}_{C G}\right) D_{A s a}\left(\sin \alpha_{C o r p o}\right)\right| .
$$

Momento produzido pela força de arrasto da cauda em relação ao CG:

$$
M_{D_{\text {Cauda }}}=\left|\left(\left(\mathrm{X}_{A C}\right)_{\text {Cauda }}-\mathrm{X}_{C G}\right) D_{\text {Cauda }}\left(\sin \alpha_{\text {Corpo }}\right)\right|
$$

Arrasto total do míssil:

$$
D_{\text {Míssil }}=D_{\text {Corpo }}+D_{\text {Asa }}+D_{\text {Cauda }} \text {. }
$$

Empuxo instantâneo necessário para voo em equilíbrio:

$$
\text { Empuxo }=\frac{D_{\text {Missil }}}{\cos \alpha_{\text {Corpo }}} .
$$

A condição de voo em equilíbrio requer que o somatório dos momentos aerodinâmicos em relação ao centro de massa do míssil seja nulo, então:

$$
\begin{aligned}
\sum M_{C G}= & 0=\left(M_{L_{\text {Corpo }}}+M_{L_{\text {Cauda }}}+M_{D_{\text {Corpo }}}\right)- \\
& \left(M_{L_{\text {Asa }}}+M_{D_{\text {Asa }}}+M_{D_{\text {Cauda }}}\right) .
\end{aligned}
$$

Destaca-se que as Figuras 2.16 e 2.17 mostram um míssil com controle por cauda ( $\alpha_{\text {Corpo }}$ $=\alpha_{A s a}>0$ ) e uma configuração onde:

$$
\begin{gathered}
\left(\mathrm{X}_{A C}\right)_{A s a}>\mathrm{X}_{C G}, \\
\left(\mathrm{X}_{A C}\right)_{\text {Cauda }}>\mathrm{X}_{C G}, \\
\mathrm{X}_{C G}>\left(\mathrm{X}_{A C}\right)_{\text {Corpo }} .
\end{gathered}
$$


Além de considerar um balanço de equilíbrio de tal forma que demande $\alpha_{\text {Cauda }}<0$ (superfície de cauda com sustentação negativa).

Obviamente essas condições não são atendidas para qualquer míssil. Portanto, as Equações (2.47) e ( 2.56) devem ser modificadas para cada caso específico.

Em linhas gerais e para os fins do presente trabalho, considerar-se-á a possibilidades de ocorrência das situações descritas na Tabela 2.2. Para fins de concisão, serão omitidas as equações de equilíbrio para cada uma das situações indicadas na Tabela 2.2. A forma geral das equações para cada caso específico é semelhante às Equações (2.40) a ( 2.56), tendo como variação o sinal de alguns termos, em função da posição relativa entre os elementos do míssil e de seus ângulos de ataque. Não obstante, o devido equacionamento foi incluído no programa desenvolvido neste trabalho.

Tabela 2.2 - Configurações em voo para equilíbrio aerodinâmico.

\begin{tabular}{|c|c|c|}
\hline Tipo de Controle & Posição de $\left(\mathbf{X}_{A C}\right)_{A s \boldsymbol{a}}$ e de $\mathbf{X}_{C G}$ & Ângulos de ataque \\
\hline Cauda & $\left(\mathrm{X}_{A C}\right)_{A s a}>\mathrm{X}_{C G}$ & $\alpha_{\text {Corpo }}=\alpha_{\text {Asa }}>0, \alpha_{\text {Cauda }}<0$ \\
\hline Cauda & $\left(\mathrm{X}_{A C}\right)_{A s a}<\mathrm{X}_{C G}$ & $\alpha_{\text {Corpo }}=\alpha_{\text {Asa }}>0, \alpha_{\text {Cauda }}>0$ \\
\hline Asa ou Canard & $\left(\mathrm{X}_{A C}\right)_{A s a}>\mathrm{X}_{C G}$ & $\alpha_{\text {Asa }}>0, \alpha_{\text {Corpo }}=\alpha_{\text {Cauda }}<0$ \\
\hline Asa ou Canard & $\left(\mathrm{X}_{A C}\right)_{A s a}<\mathrm{X}_{C G}$ & $\alpha_{\text {Asa }}>0, \alpha_{\text {Corpo }}=\alpha_{\text {Cauda }}>0$ \\
\hline Cauda & $\left(\mathrm{X}_{A C}\right)_{A s a}=\mathrm{X}_{C G}$ & $\alpha_{\text {Corpo }}=\alpha_{\text {Asa }}>0, \alpha_{\text {Cauda }}>0$ \\
\hline Asa ou Canard & $\left(\mathrm{X}_{A C}\right)_{A s a}=\mathrm{X}_{C G}$ & $\alpha_{\text {Asa }}>0, \alpha_{\text {Corpo }}=\alpha_{\text {Cauda }}<0$ \\
\hline Cauda & $\left(\mathrm{X}_{A C}\right)_{A s a}>\mathrm{X}_{C G}$ & $\alpha_{\text {Corpo }}=\alpha_{\text {Asa }}>0, \alpha_{\text {Cauda }}>0$ \\
\hline Asa ou Canard & $\left(\mathrm{X}_{A C}\right)_{A s a}>\mathrm{X}_{C G}$ & $\alpha_{\text {Asa }}>0, \alpha_{\text {Corpo }}=\alpha_{\text {Cauda }}>0$ \\
\hline Asa ou Canard & $\left(\mathrm{X}_{A C}\right)_{A s a}<\mathrm{X}_{C G}$ & $\alpha_{\text {Asa }}<0, \alpha_{\text {Corpo }}=\alpha_{\text {Cauda }}>0$ \\
\hline
\end{tabular}

No âmbito deste trabalho dois instantes de voo do míssil merecem destaque. O primeiro é a condição de equilíbrio em voo no momento do início do voo de cruzeiro (se houver voo em cruzeiro), ou seja, voo nivelado com máxima massa de voo em cruzeiro, e o momento de máximo fator de carga possível nas condições de voo do início do cruzeiro(descrito adiante). 
Para a avaliação dos ângulos de ataque do corpo, asa e cauda necessários no início do voo de cruzeiro, é preciso satisfazer as condições de equilíbrio de forças verticais e de momentos em relação ao CG do míssil (Equações (2.47) e (2.56)).

Para a avaliação dos ângulos de ataque do corpo, asa e cauda necessários para máximo fator de carga possível, é preciso satisfazer a condição de equilíbrio de momentos em relação ao CG do míssil (Equação ( 2.56)), com os máximos ângulos de ataque possíveis.

\subsubsection{1 - Margem de estabilidade estática}

A margem de estabilidade estática de um míssil é definida como a distância entre o centro aerodinâmico e o centro de massa de um míssil (Chin, 1961). Usualmente, a margem de estabilidade é definida em termos do diâmetro do corpo do míssil, uma vez que, para mísseis, o fator utilizado para tornar a margem estática um termo adimensional é o diâmetro do corpo (Equação (2.57)).

$$
\text { Margem de estabilidade estática }=\frac{\left(\mathrm{X}_{A C}-\mathrm{X}_{C G}\right)}{d}
$$

\subsubsection{2 - Fator de carga em voo}

A manobrabilidade (ou controlabilidade) de um míssil é definida como a magnitude do fator de carga que ele pode executar em sua condição trimada ou condição de equilíbrio. $O$ fator de carga $n$ é definido como a razão entre força normal total (em voo trimado) e o peso do míssil.

A análise da posição das superfícies de controle em condição de voo trimado é baseada no equilíbrio estático. Para a análise de manobrabilidade, deve-se considerar voo com aceleração. As superfícies de controle são utilizadas para acelerar o míssil em uma direção normal ao vetor velocidade. A Figura 2.18 representa uma manobra com velocidade constante. Nessa manobra, a velocidade do ar $V$, é mantida constante, mas o míssil tem 
uma aceleração $a_{N}$, que é normal à sua trajetória. Esta aceleração normal requer a produção de sustentação superior ao peso do míssil.

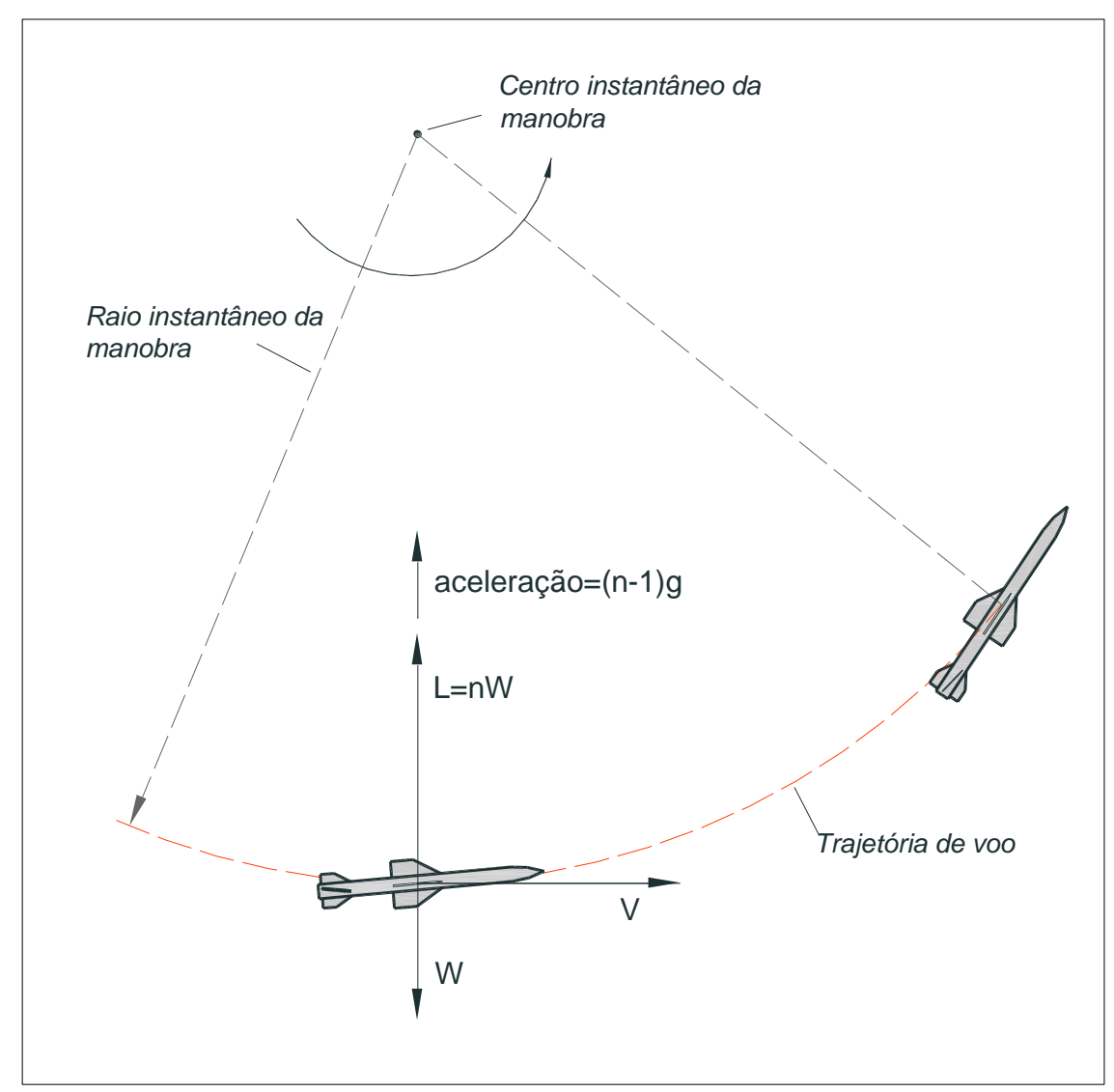

Figura 2.18 - Manobra em voo com velocidade constante.

A partir da segunda lei de Newton é possível escrever

$$
\frac{W}{g} a_{N}=L-W
$$

$\mathrm{ou}$

$$
a_{N}=\left(\frac{L}{W}-1\right) g \text {. }
$$

A relação entre a sustentação gerada durante uma manobra e o peso do míssil é conhecida como fator de carga em voo. Ou seja:

$$
n \equiv \frac{L}{W}
$$


Onde:

$L=$ força de sustentação durante a manobra;

$W=$ peso do míssil.

Portanto, o fator de carga máximo de um míssil é um importante parâmetro a ser avaliado por ser uma medida da capacidade de manobra em voo, decorrente da necessidade de realizar curvas em voo com grande aceleração centrípeta, como resultado, por exemplo, do estabelecimento de pontos de passagem (waypoints) predeterminados pelo operador do sistema ou mesmo para interceptação de alvos móveis.

\section{3 - PROPULSÃO}

\subsection{1 - Motor Foguete}

\subsubsection{1 - Empuxo}

Motores foguete se distinguem dos motores a ar-aspirado pelo fato dos primeiros carregarem com eles todo o seu propelente. Eles desenvolvem empuxo ao transmitir energia e momentum ao propelente enquanto este é expelido do motor.

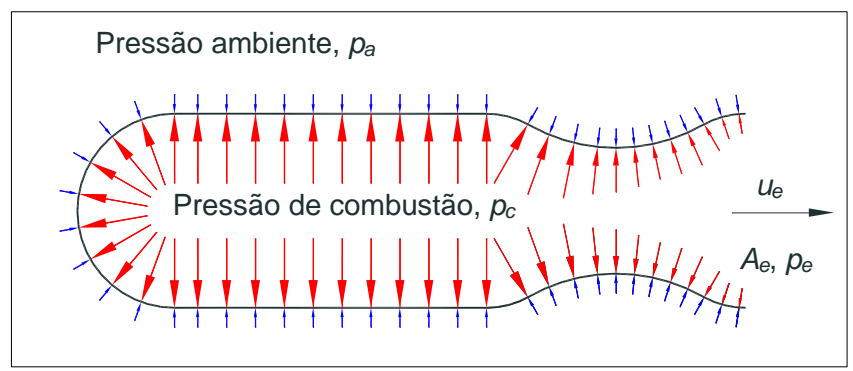

Figura 2.19 - Balanço de pressões em câmara de empuxo de motor foguete (Sutton \& Biblarz 2010, modificado).

O empuxo gerado sobre um motor foguete se manifesta como a força resultante da pressão ou distribuição de tensões sobre as superfícies interiores e exteriores da câmara de empuxo, como mostrado no diagrama de um foguete químico típico na Figura 2.19. O empuxo em 
termos das condições no plano de saída da tubeira pode ser calculado pela equação a seguir:

$$
\mathfrak{I}=\dot{m} u_{e}+\left(p_{e}-p_{a}\right) A_{e}
$$

Se a pressão no plano de saída for igual à pressão atmosférica, o empuxo é dado por $\mathfrak{I}=\dot{m} u_{e}$.

Esta condição, qual seja, $p_{e}=p_{a}$ é chamada de expansão ótima ou correta porque ela corresponde ao máximo empuxo para dadas condições da câmara de empuxo. É conveniente definir uma velocidade de exaustão equivalente (ou efetiva), $u_{e q}$, tal que:

$$
u_{e q}=u_{e}+\left(\frac{p_{e}-p_{a}}{\dot{m}}\right) A_{e} .
$$

Com essa definição pode-se escrever a equação de empuxo como:

$$
\mathfrak{I}=\dot{m} u_{e q}
$$

\subsubsection{2 - Impulso Específico}

O impulso por unidade de massa de propelente é uma importante variável na análise do desempenho de um motor foguete. O termo impulso específico, $I_{s p}$, em geral é definido como o impulso total por unidade de peso de propelente. Matematicamente é definido como

$$
I_{s p}=\frac{I}{M_{p} g_{e}}=\frac{u_{e q}}{g_{e}}
$$

onde $g_{e}$ é a aceleração devido à gravidade na superfície da terra. A presença de $g_{e}$ nesta definição é arbitrária, mas ela tem a vantagem de que, em todos os sistemas de unidades comuns, o impulso específico é expresso em segundos. 
O impulso específico é um importante parâmetro do desempenho de um motor foguete. Uma vez que a massa de propelente é, frequentemente, uma grande parte da massa total do sistema de propulsão, deseja-se obter o maior impulso específico possível. Sendo assim, quanto maior seu valor, melhor o desempenho do motor.

\subsubsection{3 - Razão Mássica}

A razão mássica $\boldsymbol{M} \boldsymbol{R}$ de um míssil ou de um estágio de um motor é definida como a massa final $m_{f}$ (após o consumo de todo o propelente útil do motor foguete) dividido pela massa inicial $m_{0}$ (antes da operação do foguete).

$$
\boldsymbol{M} \boldsymbol{R}=m_{f} / m_{0}
$$

\subsubsection{4 - Fração Mássica de Propelente}

A fração mássica de propelente $\zeta$ indica a fração da massa de propelente $m_{p}$ com relação à massa inicial $m_{0}$.

$$
\zeta=m_{p} / m_{0}
$$

A relação entre a razão mássica $\boldsymbol{M R}$ e a fração mássica de propelente $\zeta$ :

$$
\zeta=1-\boldsymbol{M R}=1-m_{f} / m_{0}=m_{p} / m_{0} .
$$

Quando aplicados a um sistema de propulsão, a razão mássica e a fração mássica de propelente são diferentes de quando aplicados ao míssil completo. Quando aplicados a um sistema de propulsão, o valor de $\zeta$ indica a qualidade do projeto do motor. Altos valores de $\zeta$ são desejados, como será mostrado a seguir.

\subsubsection{5 - Incremento de Velocidade de Voo}


A análise de voo no espaço profundo, distante de qualquer estrela, onde não existe arrasto aerodinâmico e essencialmente nenhuma atração gravitacional significativa, possibilita a extração de informações que permitem compreender os parâmetros fundamentais do desempenho de voo de mísseis propelidos com motor foguete. ${ }^{29}$

Aplicando-se a segunda lei de Newton a um míssil, é possível demonstrar que:

$$
u_{p}=u_{e q} \ln \left(m_{0} / m_{f}\right)
$$

onde $u_{p}$ é o máximo incremento de velocidade que pode ser obtido no vácuo, livre de gravidade, com fluxo constante de propelente, partindo-se do repouso (Sutton \& Biblarz, 2010). A Figura 2.20 mostra os efeitos da variação em $u_{e q}, I_{s p}$ e $\zeta$ no incremento de velocidade do vôo. O conceito de máximo incremento de velocidade que pode ser obtido no vácuo, livre de gravidade é útil para entender a influência dos parâmetros básicos no desempenho de voo do míssil. Ele é usado para comparar diferentes sistemas de propulsão, mísseis, missões de voo ou alternativas de projeto.

\footnotetext{
${ }^{29}$ Apesar de mísseis táticos não se enquadrarem nessas condições de voo, dado que quase sempre voam dentro da atmosfera terrestre, com influência da gravidade terrestre e arrasto aerodinâmico, o motor foguete utilizado como booster (motor de aceleração inicial) de mísseis táticos geralmente possuem empuxo muito maior que o arrasto e o peso do míssil, sendo possível adotar as considerações apresentadas com razoável precisão.
} 


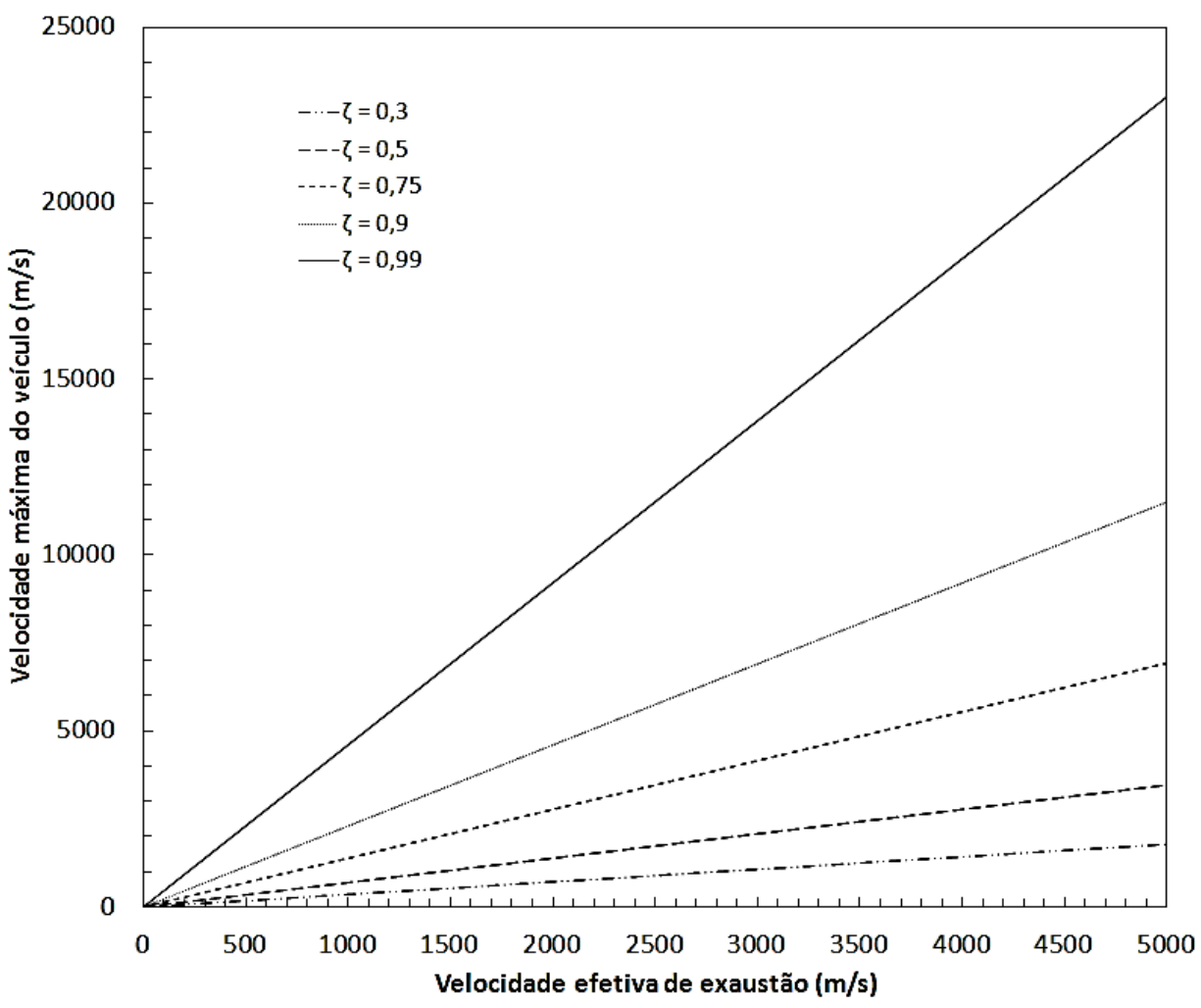

Figura 2.20 - Máximo incremento de velocidade.

Pode ser visto que a fração mássica de propelente $\zeta$ tem efeito logarítmico na velocidade do míssil. Aumentando-se esta razão de 0,8 para 0,9 , a velocidade máxima no vácuo e na ausência de gravidade é acrescida de 43\%. Uma fração mássica $\zeta$ igual a 0,8 indica que apenas $20 \%$ da massa total do míssil é composta pela estrutura, fuselagem, carga-paga, sistema de propulsão, sistema de comunicação, sistema de guiamento, superfícies aerodinâmicas, e assim por diante; os $80 \%$ restantes são compostos pela massa de propelente. $^{30}$

$\mathrm{O}$ incremento de velocidade de voo $u_{p}$ é proporcional à velocidade de exaustão equivalente $u_{e q}$ e, assim, ao impulso específico. Desta forma qualquer aumento em $I_{s p}$ (tal como o uso de melhores propelentes, razão de área de tubeira mais favorável, ou pressão de câmara maior) reflete-se em melhor desempenho do míssil, contanto que tal incremento

\footnotetext{
${ }^{30}$ Mísseis táticos apresentam valores de fração mássica de propelente muito menor (por exemplo, $\zeta=0,1$ ), como será visto nos capítulos posteriores e resultados apresentados.
} 
não implique em aumento excessivo da massa inerte, o que logicamente causa a diminuição da fração mássica de propelente.

\subsubsection{6 - Câmara de Empuxo de Foguetes Químicos}

A Figura 2.21 mostra esquematicamente três tipos de foguetes químicos, o Motor Foguete a Propelente Sólido (MFPS), o Motor Foguete a Propelentes Líquidos (MFPL) e o Motor Foguete a Propelentes Híbridos (MFPH).

No MFPL (Figura 2.21) tanto o combustível como o oxidante são armazenados na forma líquida a baixa pressão, em tanques separados. O motor propriamente dito consiste de uma ou mais câmara de empuxo, um mecanismo de alimentação (bombas) para suprir continuamente a câmara de empuxo com propelente oriundo dos tanques, uma fonte de potência de eixo (turbina) para acionar o mecanismo de alimentação, tubulações para transferir os propelentes do tanque à câmara de empuxo, uma estrutura para transmitir a força de empuxo e os dispositivos de controle (incluindo válvulas) para controlar o fluxo de propelentes e, consequentemente, o empuxo.

O MFPS (Figura 2.21) consiste de um grão propelente composto por uma combinação prémisturada de combustível e oxidante, no estado sólido, que queima quando é suficientemente aquecido. O grão propelente é posto dentro da própria câmara de combustão. A combustão ocorre na superfície do grão a uma taxa que é função da temperatura e pressão na câmara de combustão e também da geometria da superfície do grão. Excetuando um possível mecanismo de controle do vetor empuxo, o MFPS não possui partes móveis, sendo de grande simplicidade de operação. Este é o tipo de motor foguete usualmente adotado para propulsão de mísseis táticos (como booster e sustainer).

O MFPH (Figura 2.21) utiliza propelentes armazenados em diferentes estados físicos, daí o nome híbrido. Em um motor foguete híbrido clássico o combustível é armazenado na fase sólida (ou condensada) e o oxidante, na fase líquida. Assim como no MFPL, deve existir um tanque de armazenamento do oxidante, um mecanismo de alimentação, uma fonte de potência para acionar o mecanismo de alimentação, tubulações para transferir os propelentes do tanque à câmara de empuxo, uma estrutura para transmitir a força de 
empuxo e os dispositivos de controle para controlar o fluxo de propelentes. De modo semelhante ao MFPS, o MFPH armazena o grão combustível diretamente na câmara de combustão. A combustão ocorre quando a superfície do grão combustível pirolisa e se mistura com oxidante proveniente do tanque.

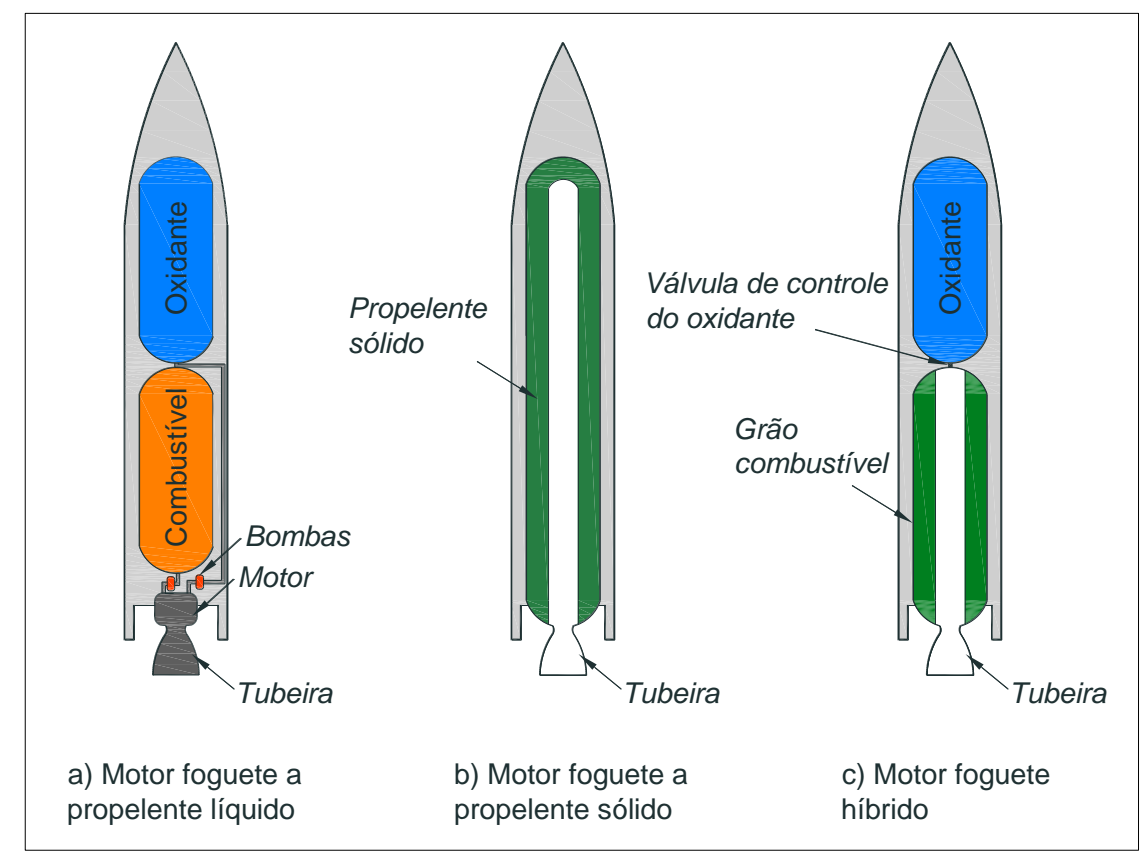

Figura 2.21 - Diagramas esquemáticos de foguetes químicos.

\section{A) Velocidade de exaustão e empuxo}

Com o intuito de simplificar a análise da câmara de empuxo - que engloba a câmara de combustão, a tubeira e dispositivos para montagem - utiliza-se o conceito de foguete ideal. Este conceito é útil porque os princípios termodinâmicos básicos relevantes podem ser expressos como relações matemáticas simples. Estas equações descrevem teoricamente o escoamento quase-unidimensional na tubeira, que corresponde a uma idealização e simplificação das equações bi e tridimensionais e do comportamento aerotermoquímico real. Porém, com o uso das considerações e simplificações listadas abaixo, essas equações se tornam adequadas para se obter dimensionamento para vários parâmetros de projeto preliminar de sistemas de propulsão. Segundo Sutton \& Biblarz (2010), para foguetes químicos, o desempenho real medido, em geral, encontra-se entre 1 e $6 \%$ abaixo do valor ideal calculado. Um foguete ideal é aquele em que as seguintes considerações são válidas (Hill \& Peterson, 1992): 
1. O fluido de trabalho (ou produtos da reação química) se comporta como um gás perfeito de composição constante;

2. O fluido de trabalho é homogêneo;

3. Todas as espécies do fluido de trabalho estão no estado gasoso. Qualquer fase condensada (líquido ou sólido) representa parcela desprezível da massa total;

4. Não existe transferência de calor pelas superfícies do foguete; portanto o escoamento é adiabático;

5. Não existe fricção apreciável e efeitos de camada limite são desprezados;

6. Não existem ondas de choque ou descontinuidades no escoamento na tubeira;

7. O escoamento de propelente é permanente e constante. A expansão do fluido de trabalho é uniforme, permanente, unidimensional, isentrópica e sem vibrações. Efeitos transientes têm curta duração e podem ser desprezados;

8. Todos os gases de exaustão saem do foguete com velocidade puramente axial;

9. A velocidade, pressão, temperatura e massa específica do gás são todos uniformes através de qualquer seção normal ao eixo da tubeira;

10. O equilíbrio químico é estabelecido dentro da câmara de combustão e a composição do gás não muda na tubeira;

11. Propelentes armazenados estão na temperatura ambiente;

12. A reação química é equivalente a um processo de aquecimento a pressão constante.

Com estas hipóteses, pode-se descrever a câmara de empuxo esquematicamente como na Figura 2.22 e obter uma expressão para a velocidade de descarga:

$$
u_{e}=\sqrt{2 c_{p} T_{02}\left[1-\left(\frac{p_{e}}{p_{02}}\right)^{\frac{(\gamma-1)}{\gamma}}\right]} .
$$

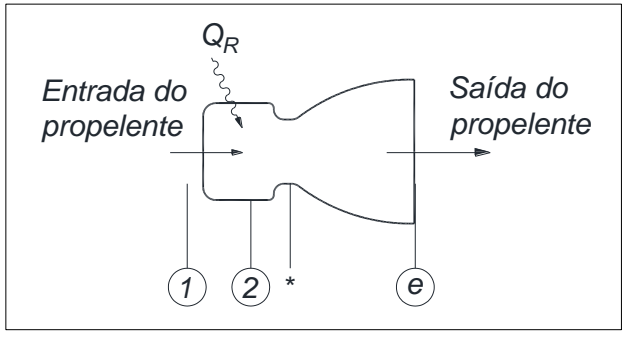

Figura 2.22 - Câmara de empuxo de motor foguete (Hill \& Peterson 1992, modificado) . 
Expressando $c_{p}$ em termos de $\gamma$, da constante universal dos gases $\bar{R}$, e da massa molecular do propelente $\bar{M}$, tem-se que:

$$
u_{e}=\sqrt{\frac{2 \gamma \bar{R}}{(\gamma-1) \bar{M}} T_{02}\left[1-\left(\frac{p_{e}}{p_{02}}\right)^{\frac{(\gamma-1)}{\gamma}}\right]}
$$

Assim, para dada $T_{02}$, é vantajoso empregar propelentes com baixa massa molecular de maneira a se obter alto $u_{e}$.

Em termos do poder calorífico $Q_{R}$ por unidade de massa de propelente, rearranjando-se as equações anteriores, resta que:

$$
u_{e}=\sqrt{2 c_{p}\left(T_{01}+\frac{Q_{R}}{c_{p}}\right)\left[1-\left(\frac{p_{e}}{p_{02}}\right)^{\frac{(\gamma-1)}{\gamma}}\right]} \approx \sqrt{2 Q_{R}\left[1-\left(\frac{p_{e}}{p_{02}}\right)^{\frac{(\gamma-1)}{\gamma}}\right]} .
$$

A expressão acima assume que $T_{01} \ll Q_{R} / c_{p}$, o que geralmente ocorre na prática, em motores foguete (Hill \& Peterson, 1992).

Expressando $Q_{R}$ em termos do poder calorífico por $m o l$ de propelente, $\overline{\bar{Q}_{R}}$, obtém-se ${ }^{31}$

$$
u_{e} \approx \sqrt{2 \frac{\bar{Q}_{R}}{\bar{M}}\left[1-\left(\frac{p_{e}}{p_{02}}\right)^{\frac{(\gamma-1)}{\gamma}}\right]}
$$

\footnotetext{
${ }^{31}$ Depreende-se dessa equação que misturas de propelentes com alta relação $\bar{Q}_{R} / \bar{M}$ são desejáveis. Tanto $\bar{Q}_{R}$ como $\bar{M}$ dependem da razão oxidante / combustível. Em muitos casos misturas ricas em combustível (tendo como resultado combustão incompleta e moléculas mais leves) são usadas, pois a redução em $\bar{M}$ justifica a redução do valor de $\bar{Q}_{R}$ (Sutton \& Biblarz, 2010).
} 
Considerando que o número de Mach na garganta da tubeira é igual a um $\left(M^{*}=1\right)$, a taxa de fluxo mássico de propelente $\dot{m}$ é dada em termos do fluido no interior da câmara de combustão e da área da garganta da tubeira pela equação abaixo:

$$
\dot{m}=\frac{A^{*} p_{02}}{\sqrt{R T_{02}}} \sqrt{\gamma\left(\frac{2}{\gamma+1}\right)^{\frac{(\gamma+1)}{(\gamma-1)}}},
$$

onde $A^{*}$ = área da garganta da tubeira e $R=\overline{\bar{R}} / \bar{M}$.

Substituindo as expressões (2.70) e ( 2.73) para $u_{e}$ e $\dot{m}$ na equação do empuxo mostrada anteriormente:

$$
\mathfrak{I}=\dot{m} u_{e}+\left(p_{e}-p_{a}\right) A_{e}
$$

em que $p_{a}=$ pressão ambiente, chega-se a (Hill \& Peterson, 1992 e Sutton \& Biblarz, 2010):

$$
\frac{\mathfrak{I}}{A^{*} p_{0}}=\sqrt{\frac{2 \gamma^{2}}{\gamma-1}\left(\frac{2}{\gamma+1}\right)^{\frac{(\gamma+1)}{(\gamma-1)}\left[1-\left(\frac{p_{e}}{p_{0}}\right)^{\frac{(\gamma-1)}{\gamma}}\right]}}+\left(\frac{p_{e}}{p_{0}}-\frac{p_{a}}{p_{0}}\right) \frac{A_{e}}{A^{*}}
$$

Sendo $p_{0}$ a pressão de estagnação na câmara de combustão ${ }^{32}$.

Alternativamente, Fleeman (2012) apresenta a relação a seguir, incluindo o termo $c_{d}$ (coeficiente de descarga) no denominador do lado esquerdo da expressão.

\footnotetext{
32 É notável que não exista menção nesta equação sobre a temperatura de estagnação e massa molecular do propelente (ambos afetam fortemente a velocidade de exaustão). Uma vez que o empuxo ideal depende somente das forças de pressão, é razoável que a equação acima contenha somente as variáveis que controlam a geometria e distribuição de pressão (Hill \& Peterson, 1992).
} 


$$
\frac{\mathfrak{J}}{c_{d} A^{*} p_{0}}=\sqrt{\frac{2 \gamma^{2}}{\gamma-1}\left(\frac{2}{\gamma+1}\right)^{\frac{(\gamma+1)}{(\gamma-1)}}\left[1-\left(\frac{p_{e}}{p_{0}}\right)^{\frac{(\gamma-1)}{\gamma}}\right]}+\left(\frac{p_{e}}{p_{0}}-\frac{p_{a}}{p_{0}}\right) \frac{A_{e}}{A^{*}}
$$

O mesmo autor assume um valor referencial constante de $c_{d}=0,96$ para previsões de projeto conceitual. A expressão acima bem como o mesmo valor referencial de $c_{d}$ apresentado por Fleeman (2012) será emprego no presente trabalho para o cálculo da área da garganta da tubeira $\left(A^{*}\right)$.

\section{B) Velocidade Característica}

O foguete ideal, além de servir como um simples modelo analítico, fornece a base para a comparação e avaliação de foguetes reais (Hill \& Peterson, 1992). De modo a descrever separadamente o desempenho de cada componente da câmara de empuxo (câmara de combustão e tubeira), dois coeficientes devem ser definidos.

Para a câmara de combustão, a velocidade característica $c^{*}$ é definida como

$$
c^{*} \equiv \frac{p_{0} A^{*}}{\dot{m}} .
$$

Utilizando-se as equações anteriores, obtém-se

$$
c^{*}=\sqrt{\frac{1}{\gamma}\left(\frac{\gamma+1}{2}\right)^{(\gamma+1) /(\gamma-1)} \frac{\bar{R} T_{0}}{\bar{M}}}
$$

para o foguete ideal (Sutton \& Biblarz, 2010). Assim, $c^{*}$ é essencialmente uma função das propriedades da câmara de combustão, pois está relacionada com a eficiência da combustão e independe das características da tubeira (Hill \& Peterson, 1992). Porém, o impulso específico $I_{s p}$ e a velocidade de exaustão equivalente (ou efetiva), $u_{e q}$, são também funções da geometria da tubeira, tal como a relação de áreas $A_{e} / A^{*}$. 
A determinação da composição dos gases de combustão e de suas propriedades termodinâmicas pode ser feita a partir do cálculo de equilíbrio das concentrações de produtos químicos de um conjunto específico de propelentes segundo, por exemplo, a metodologia descrita por Gordon \& McBride (1994).

Entretanto, a adoção de métodos como o descrito por Gordon \& McBride (1994) para a determinação da composição dos gases de combustão e de suas propriedades termodinâmicas e, consequentemente, da velocidade característica na câmara de combustão, resultaria em relativa lentidão em um processo no qual seja necessária avaliar rapidamente um grande número de soluções, como é o caso do presente trabalho.

Não obstante, é possível adotar na fase de projeto conceitual um valor constante para a velocidade característica. Fleeman (2012) afirma que a velocidade característica de um conjunto propelente de baixo desempenho pode ser inferior a $1460 \mathrm{~m} / \mathrm{s}$, enquanto que para um propelente de alto desempenho tipicamente utilizado em mísseis táticos pode ser superior a $1700 \mathrm{~m} / \mathrm{s}$. No âmbito deste trabalho, será adotado o valor referencial de $c^{*}=$ $1560 \mathrm{~m} / \mathrm{s}$.

C) Coeficiente de Empuxo

O coeficiente de empuxo da tubeira $C_{\mathfrak{J}}$ é definido como (Hill \& Peterson, 1992):

$$
C_{\mathfrak{J}} \equiv \frac{\mathfrak{I}}{p_{0} A^{*}}
$$

Usando a Equação ( 2.74), tem-se

$$
C_{\Im}=\sqrt{\frac{2 \gamma^{2}}{\gamma-1}\left(\frac{2}{\gamma+1}\right)^{(\gamma+1) /(\gamma-1)}\left[1-\left(\frac{p_{e}}{p_{0}}\right)^{(\gamma-1) / \gamma}\right]}+\frac{p_{e}-p_{a}}{p_{0}} \frac{A_{e}}{A^{*}}
$$

para o foguete ideal (Sutton \& Biblarz, 2010). Pode-se notar que $C_{\mathfrak{J}}$ é uma função apenas da geometria da tubeira, pois a variável $\left(p_{e}-p_{a}\right) / p_{0}$ pode ser interpretada como uma medida de quão adequada é a geometria da tubeira para a razão de pressões real (Hill \& 
Peterson, 1992). Combinando-se as Equações ( 2.76) e ( 2.77), encontra-se que o empuxo de um foguete é dado por

$$
\mathfrak{I}=\dot{m} c^{*} C_{\mathfrak{J}}
$$

em que $c^{*}$ e $C_{\mathfrak{J}}$ caracterizam o desempenho da câmara de combustão e bocal de descarga, respectivamente. Para um foguete real, a comparação entre $c^{*}$ e $C_{\mathfrak{J}}$, calculados a partir das Equações ( 2.76) e ( 2.78), com os valores ideais das Equações ( 2.77) e (2.79), indica a eficiência de cada componente da câmara de empuxo real (Hill \& Peterson, 1992).

D) Razão de expansão ideal da tubeira

A previsão da razão de expansão ideal da tubeira é dada pela equação abaixo (Fleeman, 2012).

$$
\frac{A_{e}}{A^{*}}=\frac{\left(\frac{2}{\gamma+1}\right)^{\frac{1}{\gamma-1}} \sqrt{\frac{\gamma-1}{\gamma+1}}}{\left(\frac{p_{e}}{p_{0}}\right)^{\frac{1}{\gamma}} \sqrt{1-\left(\frac{p_{e}}{p_{0}}\right)^{\frac{\gamma-1}{\gamma}}}}
$$

Nessa equação, $\gamma$ representa a razão de calores específicos. Embora os gases da combustão experimentem uma grande variação de temperatura e, portanto, do valor de $\gamma$ ao longo da câmara de empuxo, para as estimativas de projeto conceitual deste trabalho, foi adotado o valor médio de $\gamma=1,18$ durante a expansão dos gases pela tubeira, conforme proposto por Fleeman (2012).

\section{E) Empuxo requerido para o motor de aceleração}

A estimativa do empuxo requerido para o motor de aceleração (booster) neste trabalho é feita a partir da massa de lançamento do míssil e do fator de aceleração (múltiplos da 
gravidade). A massa de lançamento é um dado calculado pelo programa desenvolvido e o fator de aceleração é um parâmetro de projeto definido pelo usuário. Assim:

$$
\mathfrak{I}=\text { Fat }_{\text {acel }} W_{L}
$$

Onde $W_{L}$ representa o peso de lançamento do míssil e Fat acel representa o fator de aceleração durante boost.

F) Impulso Específico

O impulso específico pode ser calculado pela equação abaixo.

$$
I_{s p}=\frac{\Im c^{*}}{g_{e} p_{0} A^{*}}
$$

Relembrando que $g_{e}$ representa a aceleração da gravidade.

G) Fluxo mássico de propelente

A determinação do fluxo mássico de propelente pode ser feita a partir da Equações (2.73) e (2.76) . Assim:

$$
\dot{m}=\frac{p_{0} A^{*}}{c^{*}} .
$$

H) Massa de propelente necessária

O método de estimativa da massa de propelente necessária será mostrado na Seção 2.5.3.1 -Aceleração inicial (boost), deste trabalho. 


\subsection{2 - Ramjet}

O mais simples de todos os motores a ar-aspirado é o ramjet (Hill \& Peterson, 1992) ${ }^{33}$. Como a Figura 2.23 mostra esquematicamente, o ramjet consiste de um difusor, uma câmara de combustão e um bocal de descarga ou tubeira. Ar entra pelo difusor, onde é comprimido antes de ser misturado com combustível e queimado na câmara de combustão. Os gases quentes são então expelidos pelo bocal de exaustão por meio do aumento de pressão no difusor, posto que o ar de admissão é desacelerado da velocidade de voo para uma velocidade relativamente baixa dentro da câmara de combustão. Consequentemente, embora ramjets possam operar em velocidade de voo subsônico, o crescente aumento de pressão que acompanha maiores velocidades de voo faz com que o ramjet seja mais adequado para voo supersônico.

A Figura 2.23 é típica de ramjets supersônicos, que empregam parcialmente difusão supersônica através de um sistema de ondas de choque. Uma vez que a câmara de combustão requer número de Mach em sua entrada de aproximadamente 0,2 a 0,3, o aumento de pressão em voo com velocidade supersônica pode ser substancial. Por exemplo, para desaceleração isentrópica de $M=3$ para $M=0,3$, a razão de pressões estática entre pressão ambiente e a pressão da câmara de combustão seria de aproximadamente 34. Entretanto apenas uma fração da razão de pressões isentrópica é atingível na prática porque, especialmente com alto número de Mach, as perdas de pressão de estagnação associadas a ondas de choques são significativas (Hill \& Peterson, 1992). Após o processo de compressão, o ar escoa ao redor dos injetores de combustível, que pulverizam um fluxo de finas gotículas de combustível de modo que ar e combustível se misturem rapidamente. A mistura então flui pela câmara de combustão, que normalmente contém um dispositivo para estabilização de chama (flameholder). A combustão eleva a temperatura da mistura para cerca de $3000 \mathrm{~K}$ (valor variável), antes dos produtos da combustão expandirem para altas velocidades no bocal de exaustão. A reação ao aumento de momentum dos produtos da combustão é empuxo no motor, conforme a Equação (2.85). Este empuxo é aplicado por pressão de forças de cisalhamento distribuídas sobre as superfícies internas do motor.

\footnotetext{
${ }^{33}$ Optou-se por adotar neste trabalho a expressão "ramjet" ao invés do termo "estato-reator".
} 


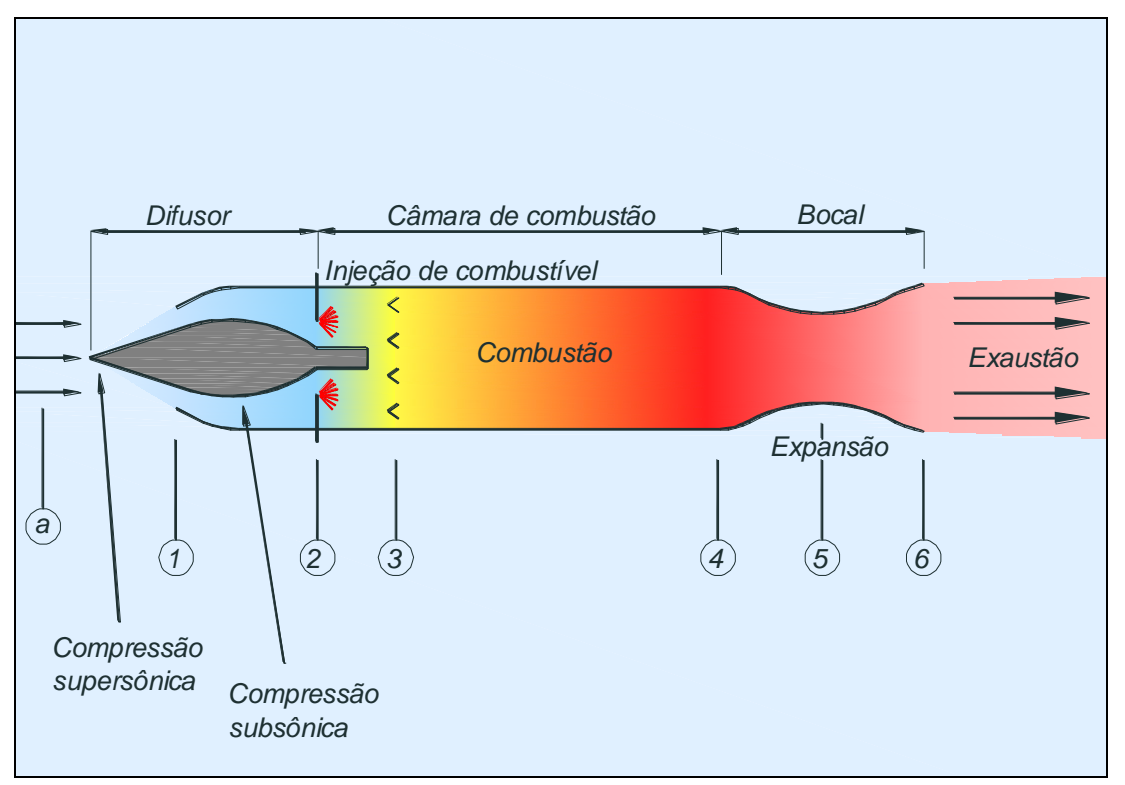

Figura 2.23 - Diagrama esquemático do motor ramjet.

Os materiais utilizados atualmente para as superfícies da câmara de combustão e bocal de exaustão não podem tolerar temperaturas muita acima de 1200 K (Hill \& Peterson, 1992), mas eles podem ser mantidos com temperaturas menores que o fluxo principal por meio de dispositivo de injeção de combustível que mantém uma camada protetora de ar relativamente frio próximos às superfícies.

Este pico de temperatura relativamente alto do ramjet permite operação em voos com alto número de Mach. A medida que o número de Mach é aumentado, a temperatura de entrada na câmara de combustão também aumenta, e em algum número de Mach limite, ela irá se aproximar da temperatura limite imposta pelos materiais das superfícies e métodos de arrefecimento. Por exemplo, em voo com Mach igual a 8 em uma atmosfera com temperatura de $225 \mathrm{~K}$, a temperatura de estagnação é cerca é $2500 \mathrm{~K}$.

Em temperaturas acima de $2500 \mathrm{~K}$, dissociação de produtos da combustão pode ser significante. A altas temperaturas, o principal efeito de injeção adicional de combustível é dissociação adicional ao invés de aumento de temperatura real. Se os produtos da combustão dissociados se recombinarem enquanto expandem pelo bocal de exaustão, a energia de combustão pode ser parcialmente transformado em energia cinética do propelente. Caso contrário, a ocorrência de dissociação química pode penalizar severamente o desempenho do motor (Hill \& Peterson, 1992). 
Uma desvantagem do ramjet é que a razão de pressões é estritamente limitada pela velocidade de voo e desempenho do difusor. A consequência mais séria disto é o fato de que ramjets não podem desenvolver empuxo estático e, portanto, não podem acelerar um míssil a partir do repouso. Além disso, o difusor, cujo desempenho é tão importante para o motor como um todo, é difícil de ser projetado para alto desempenho. Isto ocorre devido ao comportamento prejudicial da camada limite em gradientes de pressão adversos, especialmente na presença de ondas de choque, que são praticamente inevitáveis durante operação supersônica. Difusores supersônicos projetados para melhor desempenho a um dado número de Mach usualmente tem baixa eficiência em outros números de Mach ao menos que sua geometria seja variável. O desenvolvimento de um difusor supersônico grande, com desempenho e faixa de operação razoáveis, requer extenso trabalho experimental e substanciais instalações de testes (Hill \& Peterson, 1992).

\subsubsection{1 - Ramjet ideal - análise do ciclo termodinâmico}

Para entender o desempenho do ramjet, é útil realizar uma análise termodinâmica de um modelo simplificado. Para isso admite-se que os processos de compressão e expansão no motor sejam reversíveis e adiabáticos, e que o processo de combustão ocorra a pressão constante. Estas considerações não são, obviamente, realistas. No difusor real, sempre existe irreversibilidades devido às ondas de choque, mistura e fricção nas superfícies. Além disso, ao menos que a combustão ocorra em escoamento com muito baixa velocidade, tanto a pressão estática como a pressão dinâmica diminuirão, devido à adição de calor. Afastamentos do escoamento isoentrópico em um bocal de exaustão real ocorrem devido à fricção e transferência de calor. Entretanto, o conceito de ramjet ideal é útil posto que seu desempenho é o maior que as leis da termodinâmica permitem, e é o limite do qual motores reais irão se aproximar se suas irreversibilidades forem reduzidas.

Utilizando a notação dos pontos da Figura 2.23, o processo do ar pelo ramjet ideal se processa da seguinte forma. O processo de compressão leva isentropicamente o ar da sua condição no ponto "a" para seu estado de estagnação "02" na estação " 2 ". O processo de combustão é representado por um processo de adição de calor e massa a pressão constante “02" para "04” até a máxima temperatura $T_{04}$. O bocal de exaustão faz com que os produtos de combustão expandam isentropicamente até a pressão ambiente. 
O empuxo do ramjet ideal pode ser obtido da Equação (2.85):

$$
\mathfrak{I}=\dot{m}_{a}\left[(1+f) u_{e}-u\right]
$$

Com processos de compressão e expansão isentrópicos, a adição de calor e massa em baixa velocidade e pressão constante, segue que a pressão de estagnação deve ser constante através do motor. Portanto $p_{0 a}=p_{06}$.

Se variações de propriedades do fluido de trabalho $(R, \gamma)$ pelo motor forem ignoradas para este caso ideal, então:

$$
\frac{p_{0 a}}{p_{a}}=\left(1+\frac{\gamma-1}{2} M^{2}\right)^{\gamma /(\gamma-1)}
$$

$\mathrm{e}$

$$
\frac{p_{06}}{p_{e}}=\left(1+\frac{\gamma-1}{2} M_{e}^{2}\right)^{\gamma /(\gamma-1)}
$$

onde $M$ é o número de Mach do voo e $M_{e}$ é o número de Mach no plano de exaustão. Portanto, com a consideração de $p_{e}=p_{a}$,

$$
\frac{p_{0 a}}{p_{a}}=\frac{p_{06}}{p_{e}}
$$

e

$$
M_{e}=M_{a}
$$

Assim é possível determinar a velocidade de exaustão por meio da Equação (2.90):

$$
u_{e}=\frac{a_{e}}{a_{a}} u
$$

onde $a$ é a velocidade do som. Uma vez que $a=\sqrt{\gamma R T}$, então $a_{e} / a_{a}=\sqrt{T_{e} / T_{a}}$. Todavia, para o caso $M_{e}=M_{a}, T_{e} / T_{a}=T_{06} / T_{0 a}$ e se $T_{04}=T_{06}$, então: 


$$
u_{e}=\sqrt{T_{04} / T_{0 a}} u
$$

Se a entalpia do combustível injetado for desprezada, a equação de energia aplicada ao processo de combustão idealizado será:

$$
(1+f) h_{04}=h_{02}+f Q_{R}
$$

onde $f$ é a relação combustível/ar e $Q_{R}$ é o poder calorífico do combustível. Se o calor específico for considerado constante, então a Equação (2.92) pode ser escrita isolando-se $f$, conforme a Equação (2.93).

$$
f=\frac{\left(T_{04} / T_{0 a}\right)-1}{\left(Q_{R} / c_{p} T_{0 a}\right)-T_{04} / T_{0 a}}
$$

As Equações (2.85) e (2.91) podem ser combinadas para fornecer o empuxo por unidade de fluxo mássico de ar, na forma da Equação (2.94).

$$
\frac{\Im}{m_{a}}=M \sqrt{\gamma R T_{a}}\left[(1+f) \sqrt{T_{04} / T_{a}}\left(1+\frac{\gamma-1}{2} M^{2}\right)^{-1 / 2}-1\right]
$$

onde $f$ é dado pela Equação (2.93). Segundo Hill \& Peterson (1992), o consumo específico de combustível (thrust specific fuel consumption) é dado por:

$$
T S F C=\frac{\dot{m}_{f}}{\Im}=\frac{f}{\Im / m_{a}}
$$

A Figura 2.24 mostra, para o ramjet ideal, a dependência do empuxo específico e relação combustível/ar sobre o número de Mach do voo e temperatura máxima. Os resultados são aproximados, pois:

1. As variações da razão de calores específicos $(\gamma)$ com a temperatura foram desprezadas;

2. Não foram consideradas perdas por fricção ou ondas de choques; 
3. Não foi considerada dissociação dos produtos da combustão.

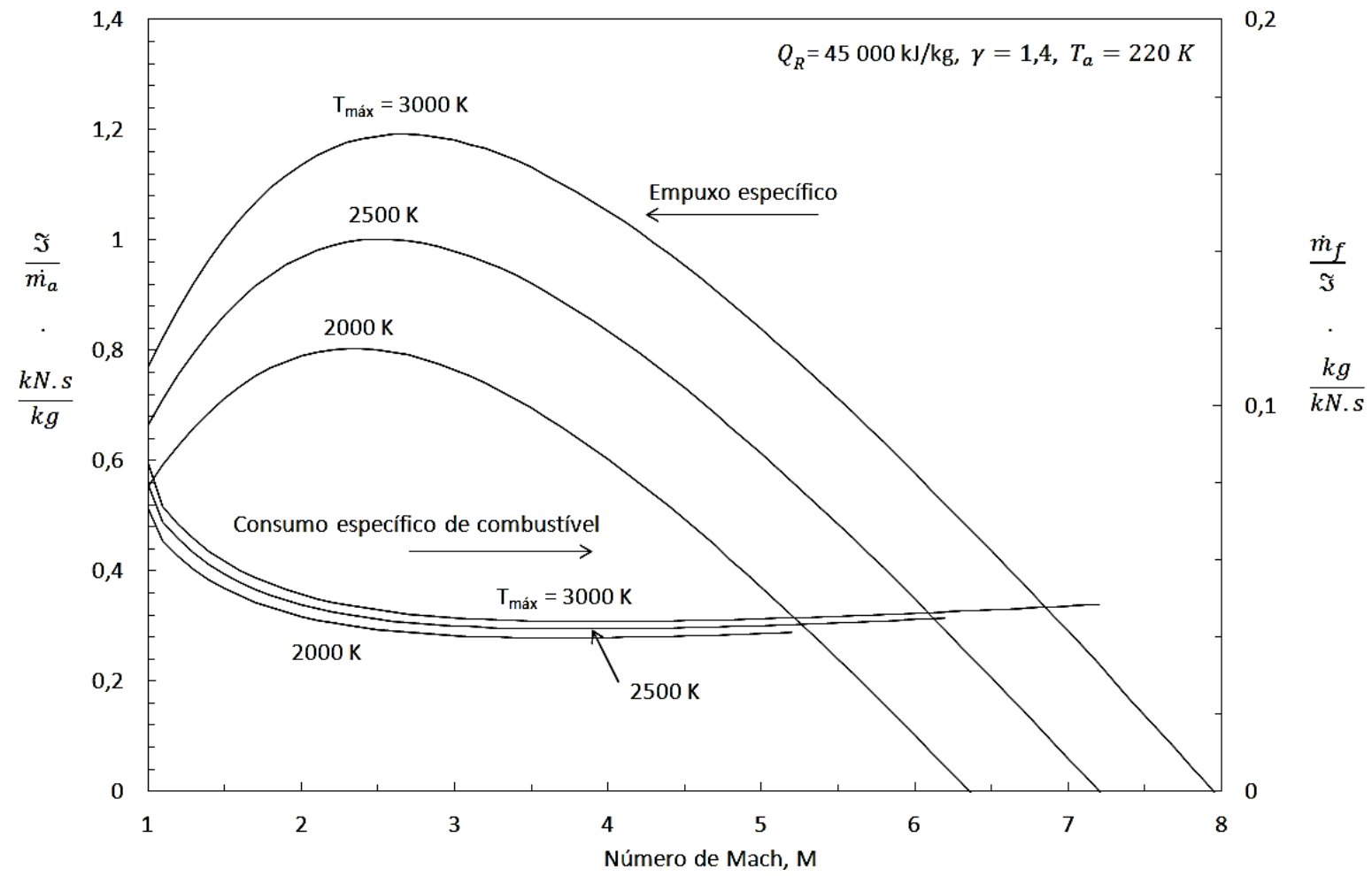

Figura 2.24 - Empuxo e consumo específico de combustível do ramjet ideal.

Apesar dessas aproximações, a Figura 2.24 mostra qualitativamente o mesmo comportamento que ramjets reais, que requerem velocidade de voo supersônico para empuxo específico aceitável e razoavelmente baixo consumo específico de combustível.

As tendências da Figura 2.24 indicam que o consumo específico de combustível permanece finito enquanto o empuxo específico se aproxima de zero.

\subsubsection{2 - Efeitos de perdas aerodinâmicas}

O propelente em um motor ramjet real, obviamente, sofre perdas na pressão de estagnação enquanto se move pelo motor. O processo de compressão no ramjet real não é isoentrópico. A pressão de estagnação ao fim do processo é menor do que seria se a compressão fosse isentrópica. O desempenho do difusor pode ser caracterizado por uma razão de pressões de estagnação $r_{d}$ definida pela Equação ( 2.96): 


$$
r_{d}=\frac{p_{02}}{p_{0 a}}
$$

Similarmente, razão de pressões de estagnação pode ser definida para combustor $\left(r_{c}\right)$ e bocal de exaustão $\left(r_{n}\right)$, conforme, respectivamente, as Equações ( 2.97) e ( 2.98):

$$
\begin{aligned}
& r_{c}=\frac{p_{04}}{p_{02}}, \\
& r_{n}=\frac{p_{06}}{p_{04}} .
\end{aligned}
$$

A razão de pressões de estagnação global é, portanto

$$
\frac{p_{06}}{p_{0 a}}=r_{d} r_{c} r_{n}
$$

Além disso, a pressão de exaustão real $\mathrm{p}_{\mathrm{e}}$ ou $\mathrm{p}_{6}$ não pode ser igual à pressão ambiente $\mathrm{p}_{\mathrm{a}}$. Porém, para $\gamma$ com valor constante, é possível escrever o número de Mach da exaustão na forma da Equação ( 2.100):

$$
M_{e}^{2}=\frac{2}{\gamma-1}\left[\left(1+\frac{\gamma-1}{2} M^{2}\right)\left(\frac{p_{06}}{p_{0 a}} \frac{p_{a}}{p_{e}}\right)^{(\gamma-1) / \gamma}-1\right] .
$$

Assim, em termos da razão de pressões de estagnação dos componentes,

$$
M_{e}^{2}=\frac{2}{\gamma-1}\left[\left(1+\frac{\gamma-1}{2} M^{2}\right)\left(r_{d} r_{c} r_{n} \frac{p_{a}}{p_{e}}\right)^{(\gamma-1) / \gamma}-1\right]
$$

Se a transferência de calor a partir do motor for considerada desprezível (por unidade de massa de fluido de trabalho), então a velocidade de exaustão é dada por $u_{e}=M_{e} \sqrt{\gamma R T_{e}}$ ou, em termos da temperatura de estagnação de exaustão: 


$$
u_{e}=M_{e} \sqrt{\gamma R T_{04} /\left(1+\frac{\gamma-1}{2} M_{e}^{2}\right)}
$$

Uma vez que irreversibilidades não têm efeito sobre a temperatura de estagnação através do motor, a relação combustível/ar necessária para produzir $T_{04}$ desejada é dada por uma forma modificada da Equação (2.93), resultando na Equação ( 2.103).

$$
f=\frac{\left(T_{04} / T_{0 a}\right)-1}{\left(\eta_{b} Q_{R} / c_{p} T_{0 a}\right)-T_{04} / T_{0 a}}
$$

Onde $\eta_{b}$ é a eficiência de combustão e $\eta_{b} Q_{R}$ é a liberação de calor real por unidade de massa de combustível. O empuxo por unidade de taxa de fluxo mássico então se torna na Equação ( 2.104):

$$
\frac{\widetilde{J}}{\dot{m}_{a}}=\left[(1+f) u_{e}-u\right]+\frac{1}{\dot{m}_{a}}\left(p_{e}-p_{a}\right) A_{e}
$$

Ou, combinando as Equações ( 2.101) e (2.102), chega-se a (Hill \& Peterson, 1992):

$$
\frac{\mathfrak{I}}{\dot{m}_{a}}=(1+f) \sqrt{\frac{2 \gamma R T_{04}(m-1)}{(\gamma-1) m}}-M \sqrt{\gamma R T_{a}}+\frac{p_{e} A_{e}}{\dot{m}_{a}}\left(1-\frac{p_{a}}{p_{e}}\right) .
$$

Sendo que,

$$
m=\left(1+\frac{\gamma-1}{2} M^{2}\right)\left(r_{d} r_{c} r_{n} \frac{p_{a}}{p_{e}}\right)^{(\gamma-1) / \gamma}
$$

Lembrando que o consumo específico de combustível (TSFC) é dado pela Equação (2.95).

\subsubsection{3 - Desempenho do motor ramjet}

Com as equações acima é possível verificar os efeitos das perdas aerodinâmicas assumindo-se $r_{d}=0,7, r_{c}=0,95, r_{n}=0,98$ (Hill \& Peterson, 1992). O efeito das razões de pressões de estagnação se manifesta na mudança em $m$ (Equação ( 2.106)). A Figura 
2.25 mostra esse efeito. Comparando-se esta com a Figura 2.24 observa-se uma redução de 10\% no empuxo específico máximo e também no consumo específico de combustível.

É irrealista assumir que estes coeficientes de perdas, especialmente $r_{d}$, sejam independentes do número de Mach do voo. Presume-se que perdas no difusor sejam fortemente dependentes de sua geometria; para voo eficiente sobre uma ampla faixa de número de Mach, a tomada de ar supersônica deveria ter geometria variável (e possivelmente complexa), para evitar excessivas perdas por ondas de choque. Em parte, capacidade de variação é necessária para manterem-se baixas as perdas por choque, uma combinação de ondas de choque oblíquas seria necessária, e o ângulo de uma onda de choque oblíqua é dependente do número de Mach do voo.

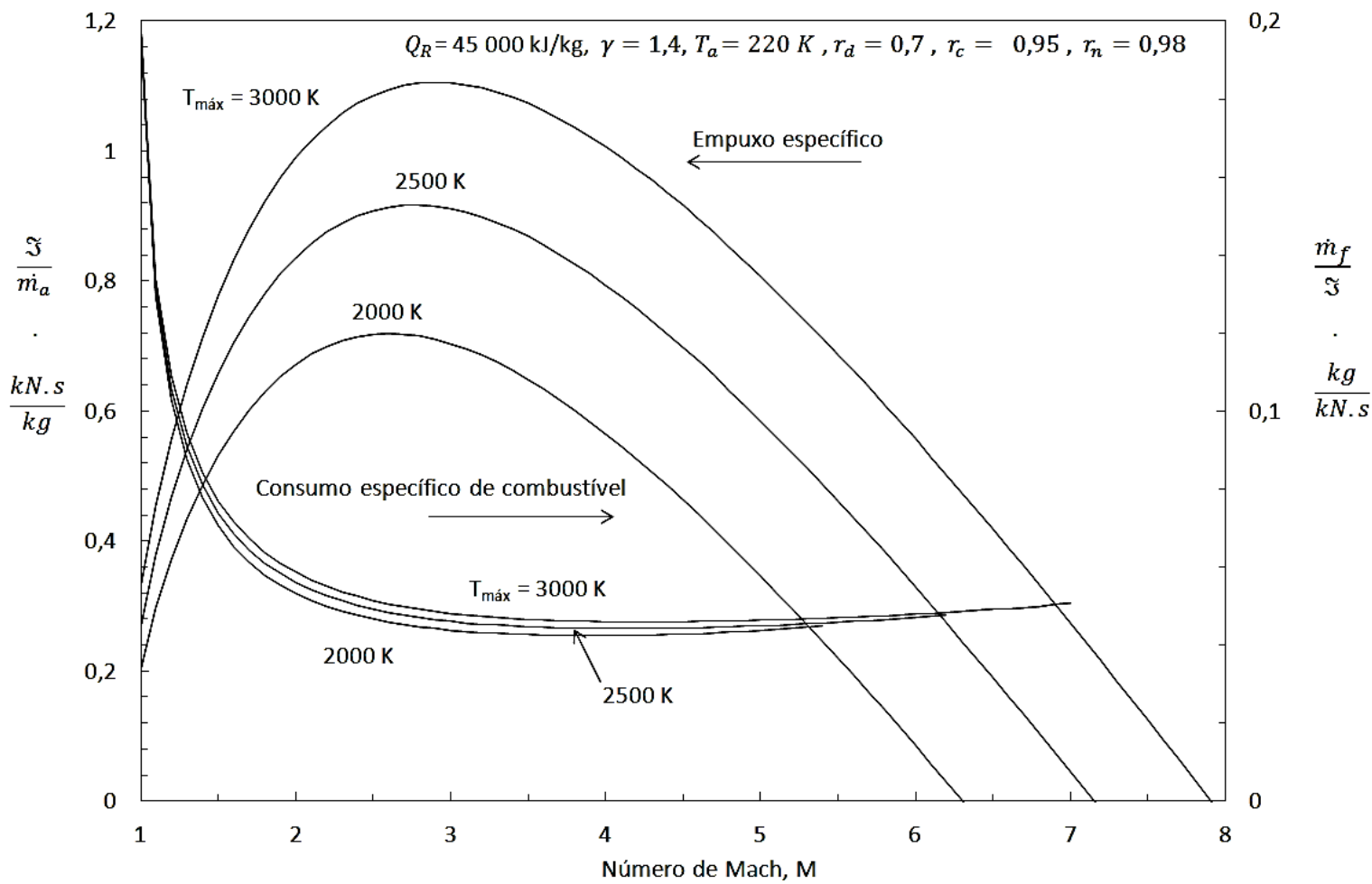

Figura 2.25 - Empuxo e consumo específico de combustível do motor ramjet considerando o efeito das perdas aerodinâmicas. 


\subsection{3 - Turbojato}

Como mencionado, uma das desvantagens do ramjet é que a razão de pressões do motor depende do número de Mach do voo. Ele também não pode desenvolver empuxo estático (velocidade de voo nula) e, na realidade, ele não tem bom desempenho até que a velocidade de voo esteja consideravelmente acima da velocidade do som. Um modo de solucionar esta desvantagem é por meio da instalação de um compressor no duto de entrada, de modo que, mesmo em velocidade nula, ar poderia ser admitido pelo motor, sofrer aumento de temperatura e ser expandido pelo bocal de exaustão. Porém, isto introduz a necessidade de uma fonte de potência para acionar o compressor. Se uma turbina for conectada ao compressor e movida pelos gases quentes provenientes da câmara de combustão, em seu caminho até ao bocal de exaustão, o ramjet se transforma em um turbojato. A adição destas turbomáquinas, todavia, muda completamente as características de desempenho do motor.

\subsubsection{1 - Turbojato ideal - análise do ciclo termodinâmico}

O arranjo interno do turbojato está mostrado esquematicamente na Figura 2.26. Ao escoar pela máquina, o ar passa pelos seguintes processos.

1. $a \rightarrow 1$. Do escoamento não perturbado, onde a velocidade do ar relativa ao motor é a velocidade de voo, o ar é trazido à tomada de ar, geralmente com alguma aceleração ou desaceleração;

2. $1 \rightarrow 2$. A velocidade do ar é diminuída enquanto o ar é transferido do difusor de entrada e sistema de duto até a entrada do compressor;

3. 2 $\rightarrow 3$. O ar é comprimido em um compressor dinâmico;

4. 3 3 4. O ar é "aquecido" pela mistura e queima de combustível no ar;

5. $4 \rightarrow 5$. O ar é expandido através da turbina para obter potência para acionar o compressor;

6. 5 5 - 6 . O ar pode ou não ser "aquecido" adicionalmente pela injeção e queima de mais combustível no pós-combustor;

7. $6 \rightarrow 7 . \mathrm{O}$ ar é acelerado e exaurido pelo bocal de exaustão. 


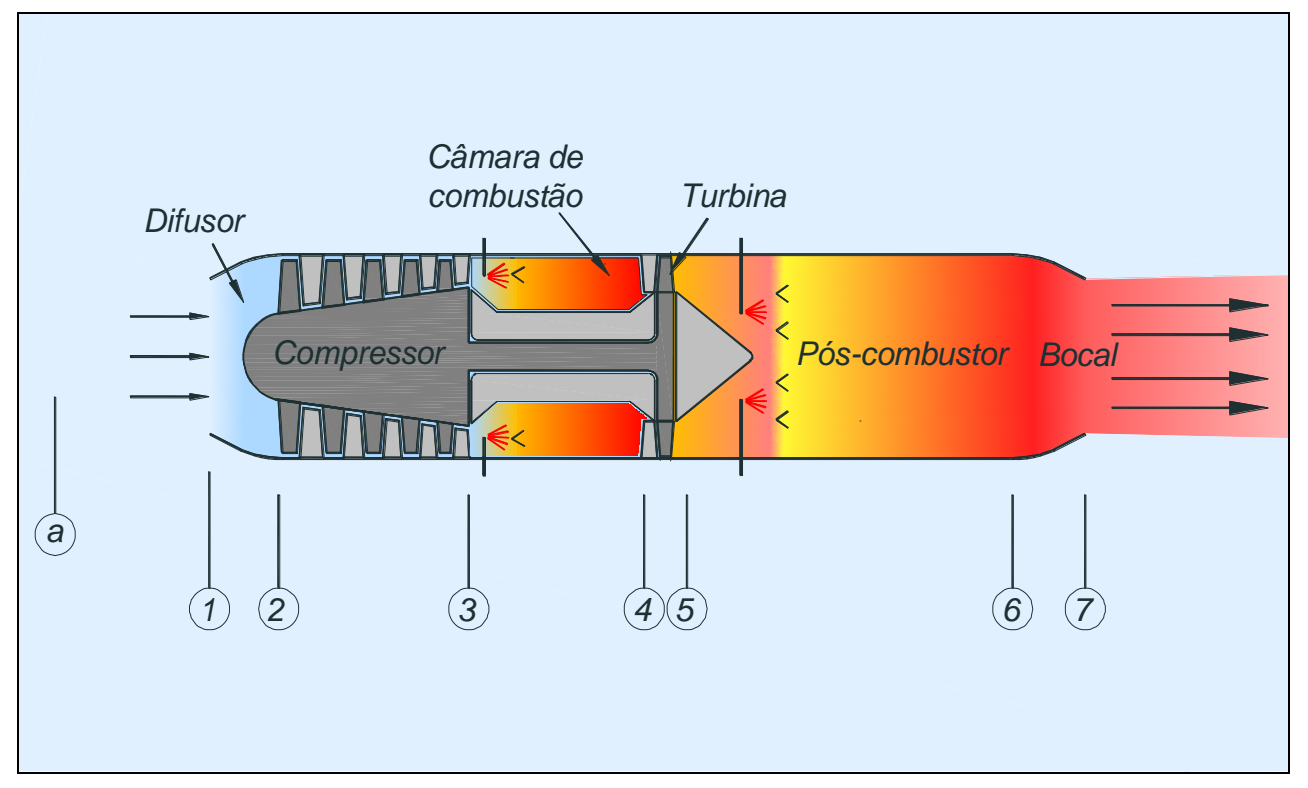

Figura 2.26 - Diagrama esquemático de motor turbojato.

Para desenvolver uma melhor compreensão do processo global, é útil inicialmente estudar um modelo altamente simplificado. Por esta razão assume-se que todos os componentes, exceto os combustores (câmara de combustão) sejam reversíveis e adiabáticos, que os combustores possam ser substituídos por simples aquecedores sem perdas de pressão e que a velocidade nas seções 2 e 6 sejam desprezíveis.

No caso ideal, a pressão se eleva de a -1 , e ainda mais de $1-2$, ao passo que o ar é desacelerado relativamente ao motor. Uma vez que se assume que a velocidade no ponto 2 é nula e a desaceleração é isentrópica, $p_{2}$ é a pressão de estagnação para os pontos a, 1 , e 2 . Ainda, $T_{2}$ é a temperatura de estagnação nesses pontos. A potência consumida pela compressão (processo $2-3$ ) deve ser suprida pela turbina através da expansão de $4-5$. Assim, se o fluxo mássico pelo compressor e turbina forem iguais, resta que $h_{3}-h_{2}=$ $h_{4}-h_{5}$, e se o calor específico for constante, as correspondentes diferenças de temperatura também serão iguais. No caso de não emprego de pós-combustor, os estados 5 e 6 serão idênticos e a queda de entalpia do ponto 5 até o ponto 7 é proporcional ao quadrado da velocidade de exaustão. Na hipótese do uso de pós-combustor, o ar é "reaquecido" na estação $6, \operatorname{logo}$, a velocidade de exaustão será maior nesse caso. De fato a ausência de materiais altamente solicitados no pós-combustor permite que $T_{6}$ seja muito 
maior que $T_{4}$, de maneira que o aumento na velocidade de exaustão seja da ordem de $50 \%$ (Hill \& Peterson, 1992).

Embora bastante simplificado, este modelo ilustra a função dos diversos componentes e a relação entre eles. Ele mostra claramente que a energia cinética do fluido de exaustão é, de certo modo, o remanescente após a extração de potência do fluido de trabalho para acionamento do compressor.

Um motor real difere desse modelo ideal em vários aspectos. Primeiro, e mais importante, nenhum componente é realmente reversível, apesar de ser razoável considera-los adiabáticos. Segundo, os combustores não são simples aquecedores, e a composição do fluido de trabalho varia durante o processo de combustão. Terceiro, as velocidades do fluido dentro do motor não são desprezíveis. Se a velocidade do escoamento no interior do combustor fosse realmente nula (como requer esse processo sob pressão constante), seria impossível obter uma chama estável, dado que a chama se propaga em relação ao fluido como velocidades bastante altas (Turns, 2000). Uma quarta diferença é que a taxa de fluxo mássico no compressor e turbina podem não ser iguais, pois, por um lado, combustível é injetado entre eles, e por outro, ar pode ser extraído em várias posições para fins de resfriamento.

Para dada razão de pressões no compressor, irreversibilidades aumentam a necessidade de potência do compressor, enquanto ao mesmo tempo aumenta a queda de pressão necessária na turbina. Ambos os efeitos decrescem a energia cinética de exaustão, de forma que é presumível que a eficiência global seja sensível ao desempenho do compressor e turbina.

Usando o fato que os processos de compressão e expansão no motor turbojato são quase adiabáticos, é possível fazer estimativas realísticas do desempenho do motor definindo-se as eficiências de componentes adiabáticos como segue.

Para o difusor de entrada, uma eficiência adiabática $\eta_{d}$ pode ser definida como a razão das mudanças de entalpia ideal e real durante o processo de difusão (para a mesma relação de pressão $\left.p_{02} / p_{1}\right)$, ou 


$$
\eta_{d}=\frac{h_{02}-h_{a}}{h_{02}-h_{a}}
$$

Alternativamente, a razão de pressões de estagnação como definida para o ramjet (Equação ( 2.97)) pode ser usada.

De modo correspondente, para o compressor, uma definição útil de uma eficiência adiabática $\eta_{c}$ é a razão do trabalho requerido em um processo isentrópico para aquele requerido em um processo real, para uma mesma razão de pressões de estagnação e estado de entrada no compressor, conforme a Equação (2.108).

$$
\eta_{c}=\frac{h_{03_{S}}-h_{02}}{h_{03}-h_{02}}
$$

Para a turbina, a eficiência adiabática pode ser definida conforme a Equação (2.109), que é a razão de trabalho real na turbina para aquele que seria obtido durante uma expansão isentrópica para a mesma pressão de estagnação de exaustão.

$$
\eta_{t}=\frac{h_{04}-h_{05}}{h_{04}-h_{05_{s}}}
$$

A eficiência adiabática do bocal de exaustão pode ser definida pela Equação (2.110).

$$
\eta_{n}=\frac{h_{06}-h_{07}}{h_{06}-h_{07_{s}}}
$$

Além dessas quatro eficiências adiabáticas, um quinto tipo de eficiência é frequentemente empregado: a eficiência do combustor (ou eficiência de combustão) $\eta_{b}$, que é simplesmente a fração da energia química do combustível que é liberada no combustor (Saravanamuttoo, Rogers, Cohen \& Straznicky, 2008).

Segundo Hill \& Peterson (1992), para motores com bom projeto, as eficiências mencionadas geralmente variam próximo dos valores indicados na Tabela 2.3. Lembrando 
que a eficiência adiabática do difusor $\left(\eta_{d}\right)$ dependendo fortemente do número de Mach do voo.

Tabela 2.3 - Valores típicos de eficiência de componentes de motor turbojato (Hill \& Peterson, 1992).

\begin{tabular}{|cc|}
\hline $\begin{array}{c}\text { Componente } \\
\text { Difusor }\end{array}$ & $\begin{array}{c}\text { Eficiência adiabática } \\
0,70<\eta_{d}<0,90\end{array}$ \\
\hline Compressor & $0,85<\eta_{c}<0,90$, \\
\hline $\begin{array}{c}\text { Câmara de } \\
\text { combustão }\end{array}$ & $0,97<\eta_{b}<0,99$ \\
\hline Turbina & $0,90<\eta_{t}<0,95$ \\
\hline Bocal & $0,95<\eta_{n}<0,98$ \\
\hline
\end{tabular}

Nota-se que essas definições utilizaram valores de entalpia de estagnação. Geralmente é mais conveniente do ponto de vista experimental medir valores de estagnação, ao invés de valores estáticos, para pressão e temperatura em um escoamento. Valores de estagnação são convenientes analiticamente, posto que eles contêm termos de energia cinética.

O objetivo dessas discussões é mostrar como o desempenho global do motor depende do desempenho dos componentes e, em particular, da máxima relação de pressão e temperatura.

Duas questões de considerável importância dizem respeito à magnitude do empuxo por unidade de fluxo mássico do motor $\left(\mathfrak{I} / \dot{m}_{a}\right)$ e ao consumo de combustível por unidade de empuxo (TSFC). Considerando que um motor de um dado diâmetro é limitado quanto ao fluxo mássico para determinadas condições de admissão, a relação $\mathfrak{J} / \dot{m}_{a}$ governa a relação entre empuxo e tamanho do motor.

Considerando a hipótese de que a pressão no plano de exaustão seja igual à atmosférica, o empuxo por unidade de fluxo se torna: 


$$
\frac{\Im}{m_{a}}=\left[(1+f) u_{e}-u\right]
$$

e o consumo específico de combustível pode ser calculado pela Equação (2.112).

$$
T S F C=\frac{m_{f}}{\mathfrak{J}}=\frac{f}{(1+f) u_{e}-u}
$$

Dada a velocidade de voo $u$, as condições ambientais $p_{a}$ e $T_{a}$, a razão de pressões do compressor $p_{03} / p_{02}$, e a temperatura de entrada na turbina $T_{04}$, a tarefa é determinar a relação combustível/ar $f$ e velocidade de exaustão $u_{e}$. Então, é possível avaliar o empuxo e consumo específico de combustível do motor a partir das Equações (2.111) e (2.112). O procedimento ao longo do motor é como se segue (Hill \& Peterson, 1992).

1. Condições de entrada no compressor. Com o número de Mach do voo $M=$ $u / \sqrt{\gamma R T_{a}}$, onde $\gamma$ é a razão de calores específicos (considerado constante para o processo de difusão), avalia-se a temperatura de estagnação $T_{02}$ com:

$$
T_{02}=T_{a}\left(1+\frac{\gamma-1}{2} M^{2}\right)
$$

Pela definição da eficiência adiabática do difusor $\eta_{d}$, é possível calcular a pressão de estagnação correspondente como:

$$
p_{02}=p_{a}\left[1+\eta_{d}\left(\frac{T_{02}}{T_{a}}-1\right)\right]^{\gamma_{d} /\left(\gamma_{d}-1\right)} .
$$

2. Condições de saída do compressor. Uma vez que a razão de pressões do compressor $\left(p_{r c}=p_{03} / p_{02}\right)$ está especificada, determina-se a pressão de estagnação da saída do compressor pela Equação(2.115).

$$
p_{03}=p_{02} p_{r c}
$$


E a temperatura de estagnação da saída pela Equação (2.116). Nesta equação $\gamma_{c}$ é a razão de calores específicos (considerado constante) para o processo de compressão e $\eta_{c}$ é a eficiência adiabática do compressor.

$$
T_{03}=T_{02}\left[1+\frac{1}{\eta_{c}}\left\{p_{r c}\left(\gamma_{c}-1\right) / \gamma_{c}-1\right\}\right]
$$

3. Relação combustível/ar para o combustor. Com a temperatura de saída do combustor $T_{04}$ especificada, é possível determinar a relação combustível/ar por meio da Equação (2.117), que é obtida da mesma forma da Equação (2.93).

$$
f=\frac{\left(T_{04} / T_{03}\right)-1}{\left(Q_{R} / c_{p} T_{03}\right)-T_{04} / T_{03}}
$$

4. Pressão de entrada na turbina. Conhecida a relação de pressão $p_{04} / p_{03}$ através do combustor, determina-se a pressão de estagnação da turbina com o emprego da Equação (2.118).

$$
p_{04}=p_{03}\left(p_{04} / p_{03}\right)
$$

5. Condições de saída da turbina. Considerando que a turbina deve fornecer a potência requerida pelo compressor, escreve-se (para escoamento em regime permanente e adiabático em ambos componentes):

$$
\dot{m}_{t}\left(h_{04}-h_{05}\right)=\dot{m}_{c}\left(h_{03}-h_{02}\right) \text {, }
$$

$\mathrm{Ou}$

$$
\dot{m}_{t} c_{p t}\left(T_{04}-T_{05}\right)=\dot{m}_{c} c_{p c}\left(T_{03}-T_{02}\right)
$$

As taxas de fluxo mássico $\dot{m}_{t}$ e $\dot{m}_{c}$ não são exatamente iguais, posto que combustível é adicionado ao escoamento na câmara de combustão e ar pode ser extraído do compressor para resfriamento da turbina. Nem são iguais, os calores específicos $c_{p t}$ e $c_{p c}$. Para taxas 
modestas de extração de ar de resfriamento do compressor, pode-se dizer, como uma aproximação, que é válida a Equação (2.121).

$$
\dot{m}_{t} c_{p t} \cong \dot{m}_{c} c_{p c}
$$

De modo que

$$
T_{05} \cong T_{04}-\left(T_{03}-T_{02}\right)
$$

Logo, da definição da eficiência adiabática da turbina, pode-se calcular a pressão de estagnação $p_{05}$, a partir da Equação (2.123), onde $\gamma_{t}$ é a razão de calores específicos (considerado constante) para o processo de expansão na turbina.

$$
p_{05}=p_{04}\left[1-\frac{1}{\eta_{t}}\left(1-\frac{T_{05}}{T_{04}}\right)\right]^{\gamma_{t} /\left(\gamma_{t}-1\right)} .
$$

6. Condições de entrada no bocal de exaustão. Sem o emprego de pós-combustor ${ }^{34}$, as condições de entrada no bocal de exaustão são

$$
T_{06}=T_{05} \quad \text { e } \quad p_{06}=p_{05} .
$$

7. Condições de saída do bocal de exaustão. A energia cinética de descarga é, por definição, expressa pela Equação (2.125), na qual $\eta_{n}$ é a eficiência adiabática do bocal de exaustão.

$$
\frac{u_{e}^{2}}{2}=h_{07}-h_{7}=\eta_{n}\left(h_{07}-h_{7 s}\right) .
$$

Em regime permanente com escoamento adiabático no bocal de exaustão $h_{07}=h_{06}$, logo:

\footnotetext{
${ }^{34}$ A adoção de pós-combustor não é usual em motores turbojato para mísseis.
} 


$$
u_{e}=\sqrt{2 \eta_{n} \frac{\gamma_{n}}{\gamma_{n}-1} R T_{06}\left[1-\left(\frac{p_{a}}{p_{06}}\right)^{\left(\gamma_{n}-1\right) / \gamma_{n}}\right]} .
$$

A Equação (2.126) considera que não existe onda de choque na garganta do bocal de exaustão.

Com a relação combustível/ar $(f)$, determinada pela Equação (2.117), e também com a velocidade de exaustão $\left(u_{e}\right)$, é possível estabelecer o empuxo e consumo específico do motor pelas Equações (2.111) e (2.112), respectivamente (Hill \& Peterson, 1992).

\subsubsection{2 - Considerações a respeito do bocal de exaustão}

A Equação (2.126) assume que a pressão no plano de escape do turbojato (ponto 7) é igual à pressão ambiente, ou seja, ocorre expansão completa dos gases pelo bocal de exaustão. Surge a necessidade de determinar se se deve empregar um simples bocal de exaustão convergente ou um bocal convergente - divergente. Mesmo com relações de pressão no compressor moderadas, a relação $\frac{p_{06}}{p_{a}}$ pode ser maior que a razão de pressões crítica quando se atinge velocidade sônica em algum ponto do bocal. Embora um bocal convergentedivergente possa parecer necessário, deve-se lembrar que deseja-se obter empuxo e não a máxima velocidade de exaustão (Saravanamuttoo, Rogers, Cohen \& Straznicky, 2008). Pode-se mostrar que, para uma expansão isentrópica, o empuxo produzido é máximo quando ocorre expansão completa até $p_{a}$, pois a parcela de empuxo gerada pela pressão dos gases no plano de escape, a saber, $A_{7}\left(p_{7}-p_{a}\right)$, não compensa completamente a perda de empuxo gerado pela variação do momentum devido à menor velocidade de exaustão. Entretanto, o uso de um bocal de exaustão convergente - divergente resultaria em aumento significativo no peso, comprimento e diâmetro do motor, que resultaria em maiores complicações de instalação e aumento do peso total do míssil.

Segundo experimentos, para valores de $\frac{p_{06}}{p_{a}}$ até cerca de 3 , o empuxo produzido por um bocal de exaustão convergente é equivalente ao produzido por um bocal convergente divergente, mesmo quando o último tem razão de expansão adequada para a razão de pressões (Ashwood, 1957). Com razões de pressão de operação menores que os valores de 
projeto, como em carga parcial, por exemplo, um bocal de exaustão convergente divergente, de geometria fixa, seria menos eficiente devido à formação de ondas de choque na região divergente. Por essas razões, motores turbojato geralmente empregam bocal de exaustão convergente (Saravanamuttoo, Rogers, Cohen \& Straznicky, 2008).

Neste trabalho, para motores turbojato, será sempre considerado bocal de exaustão convergente, ainda que a pressão de exaustão seja maior que a pressão atmosférica. Para isso, será utilizada a razão de pressões crítica. A razão de pressões crítica $\frac{p_{06}}{p_{c}}$ é a razão de pressões $\frac{p_{06}}{p_{7}}$ que resulta em $M_{7}=1$. A pressão crítica é dada por:

$$
p_{c}=p_{06}\left[1-\frac{1}{\eta_{n}}\left(1-\frac{T_{c}}{T_{06}}\right)\right]^{\gamma /(\gamma-1)} .
$$

E a razão de pressões crítica é dada por:

$$
\frac{p_{06}}{p_{c}}=\frac{1}{\left[1-\frac{1}{\eta_{n}}\left(\frac{\gamma-1}{\gamma+1}\right)\right]^{\gamma /(\gamma-1)}} .
$$

Este método de usar $\eta_{n}$ para determinar a razão de pressões crítica fornece resultados consistentes com uma análise mais detalhada, que envolve equações de momentum (Saravanamuttoo, Rogers, Cohen \& Straznicky, 2008).

Nas situações onde a pressão no plano de saída do bocal de exaustão não é igual à pressão atmosférica, existirá uma parcela de empuxo devido à pressão. Para isso, é preciso conhecer a área $A_{7}$. Para um dado fluxo mássico $m$, ela é dada aproximadamente por:

$$
A_{7}=\frac{m}{\rho_{c} C_{c}}
$$

com $\rho_{c}$ obtido de $p_{c} / R T_{c}$ e $C_{c}$ a partir de $\left[2 c_{p}\left(T_{06}-T_{c}\right)\right]^{1 / 2}$ ou $\left(\gamma R T_{c}\right)^{1 / 2}$. Este é apenas um valor aproximado da área de exaustão, pois, em escoamentos reais, a presença da camada limite demandará uma maior área de exaustão. Na prática, a área de exaustão necessária para proporcionar as condições operacionais do motor é encontrada por 
tentativa e erro durante testes de desenvolvimento (Saravanamuttoo, Rogers, Cohen \& Straznicky, 2008).

Não obstante, para cálculo do empuxo do turbojato no âmbito deste trabalho, será considerado sempre o uso de bocal convergente e, caso a relação de pressão $\frac{p_{06}}{p_{c}}$ seja superior a $\frac{p_{06}}{p_{a}}$, será considerado o efeito da pressão no plano de exaustão para cálculo do empuxo, sendo a área de exaustão calculada conforme a Equação (2.129).

\subsubsection{3 - Desempenho do motor turbojato}

Para compreender a influência de alguns dos fatores apresentados até agora, a seguir serão considerados exemplos de variação de empuxo e consumo de combustível com a razão de pressões no compressor do turbojato, temperatura de entrada da turbina e número de Mach de voo. Para os cálculos, são arbitrados valores de eficiência de componentes, propriedades do fluido de trabalho e condições do motor, conforme mostrados na Tabela 2.4. Considerase que cada número de Mach de voo corresponde a diferentes altitudes e, assim, a diferentes valores de pressão e temperatura ambientes $\left(p_{a}\right.$ e $\left.T_{a}\right)$. Nestes cálculos assumese, como anteriormente, que o produto $\dot{m} c_{p}$ é o mesmo na turbina e compressor.

As Figuras 2.27 a 2.30 mostram empuxo e consumo específico de combustível, calculados sob estas condições, para três valores de temperatura de entrada na turbina e quatro valores de número de Mach. Estes parâmetros, bem como a razão de pressões do compressor, fortemente influenciam o desempenho do motor (nestas cruvas, considerou-se expansão completa dos gases no bocal de exaustão, desde a pressão na saída da turbina até a pressão atmosférica). 
Tabela 2.4 - Parâmetros de cálculo para o motor turbojato

\begin{tabular}{lcc}
\multicolumn{1}{c}{ Componente } & Eficiência adiabática & Razão de calores específicos média \\
\hline Difusor & $\eta_{\mathrm{d}}=0,97$ & 1,40 \\
\hline Compressor & $\eta_{\mathrm{c}}=0,85$ & 1,37 \\
\hline Câmara de combustão & $\eta_{\mathrm{b}}=1,00$ & 1,35 \\
\hline Turbina & $\eta_{\mathrm{t}}=0,90$ & 1,33 \\
\hline Bocal & $\eta_{\mathrm{n}}=0,98$ & 1,36 \\
\hline
\end{tabular}

Poder calorífico do combustível: $45000 \mathrm{~kJ} / \mathrm{kg}$

\begin{tabular}{lcc}
\hline \multicolumn{1}{c}{ Altitude de voo (Mach) } & Pressão ambiente (kPa) & Temperatura ambiente (K) \\
\hline Nível do mar (0) & 101,3 & 288,2 \\
\hline $\mathbf{1 2} \mathbf{2 0 0}$ m (0,85) & 18,75 & 216,7 \\
\hline $\mathbf{1 8 3 0 0}$ m (2,0) & 7,17 & 216,7 \\
\hline $\mathbf{2 4 ~ 4 0 0 ~ m ~ ( 3 , 0 )}$ & 2,097 & 216,7 \\
\hline
\end{tabular}




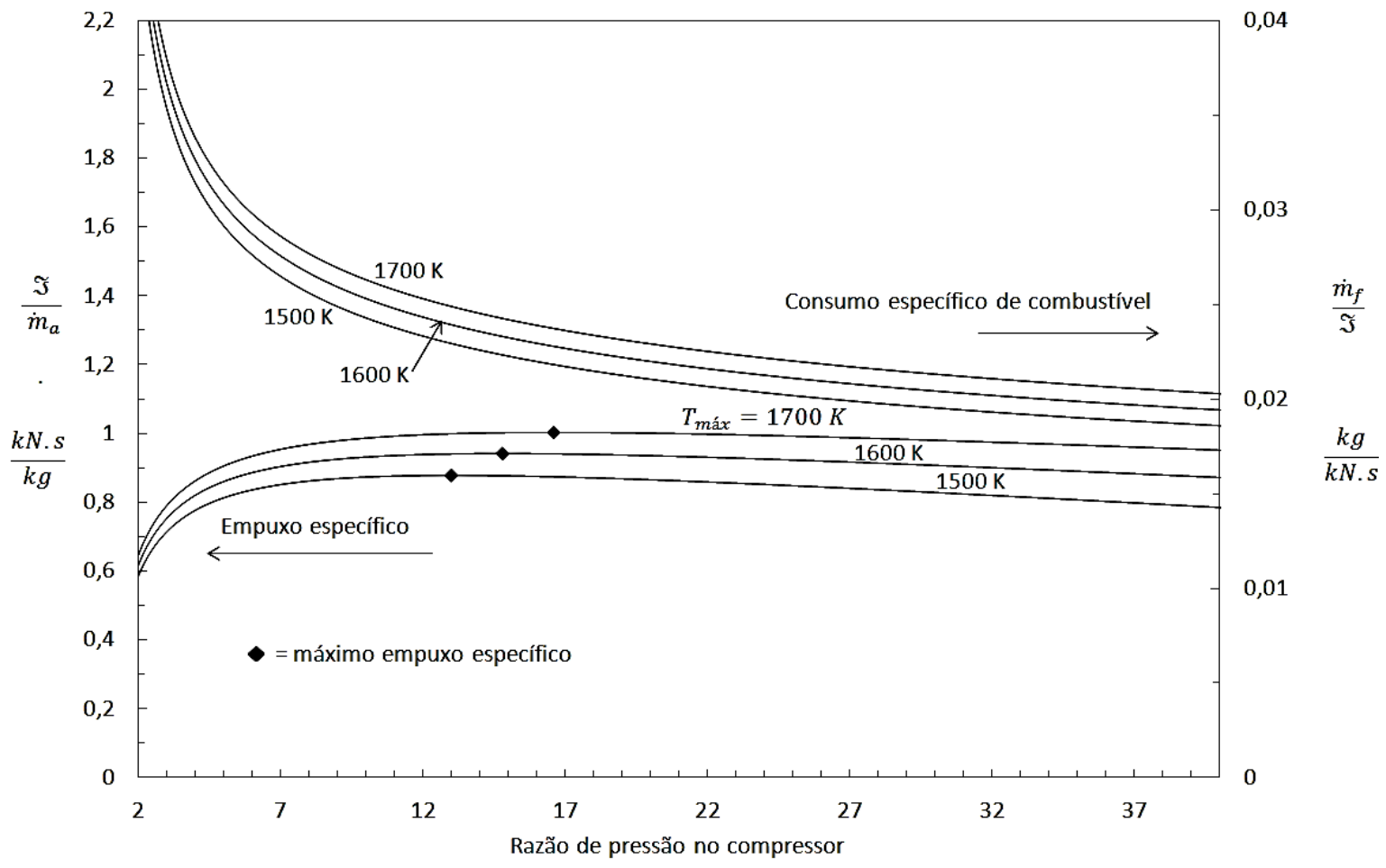

Figura 2.27 - Consumo específico e empuxo do motor turbojato (Mach = 0; nível do mar).

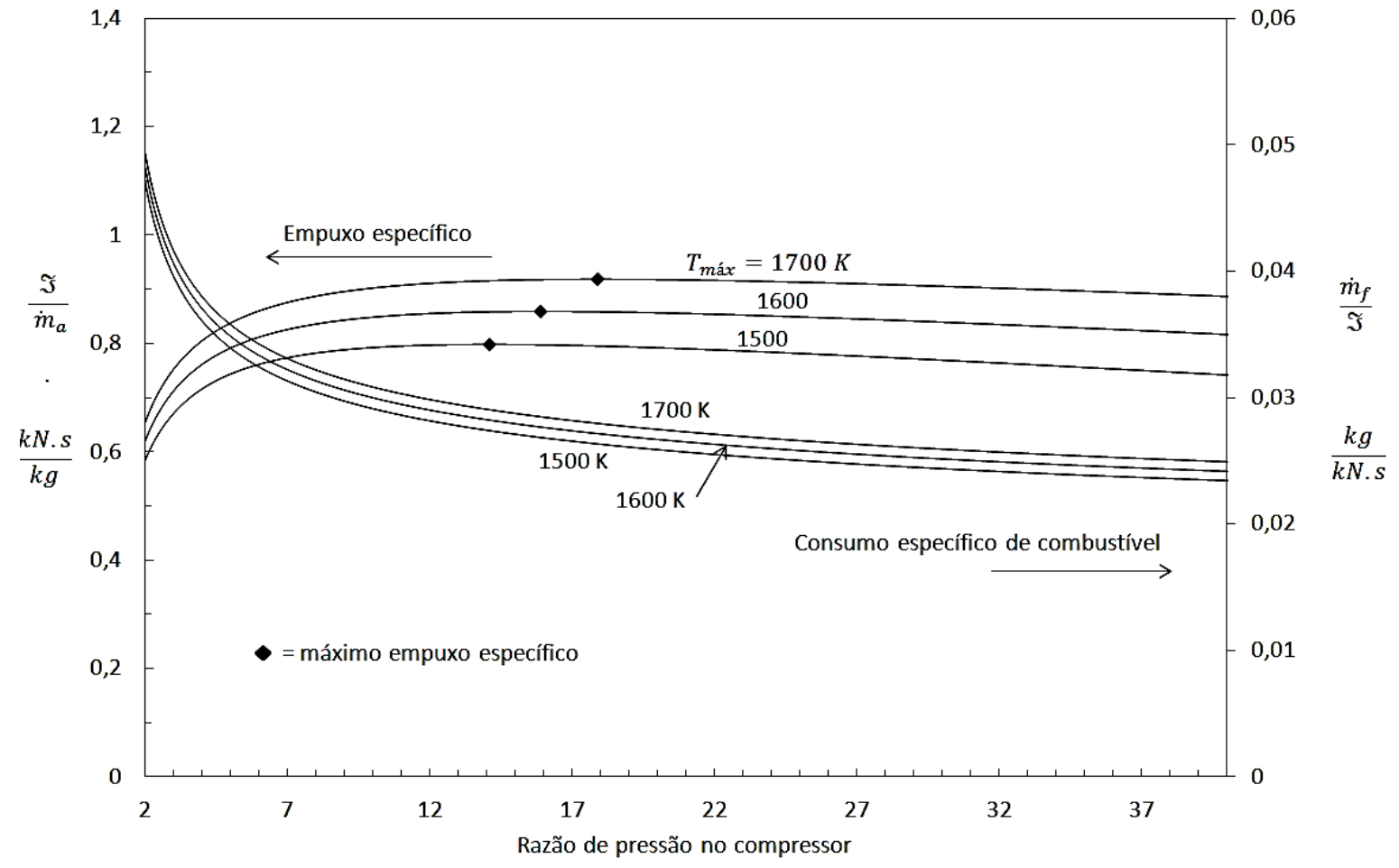

Figura 2.28 - Consumo específico e empuxo do motor turbojato $($ Mach $=0,85 ; 12200 \mathrm{~m}$ altitude). 


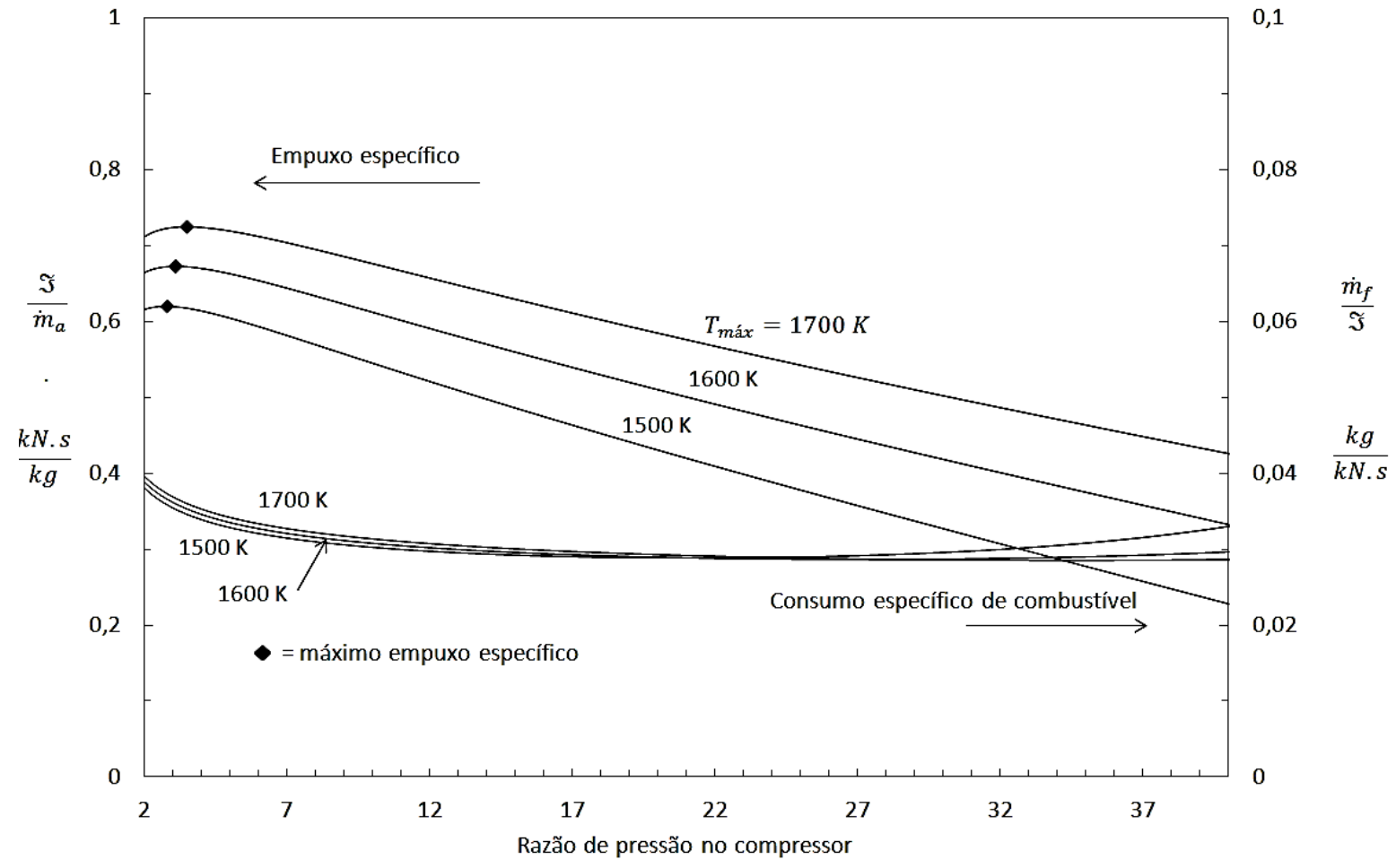

Figura 2.29 - Consumo específico e empuxo do motor turbojato (Mach =2,00; $18300 \mathrm{~m}$ altitude).

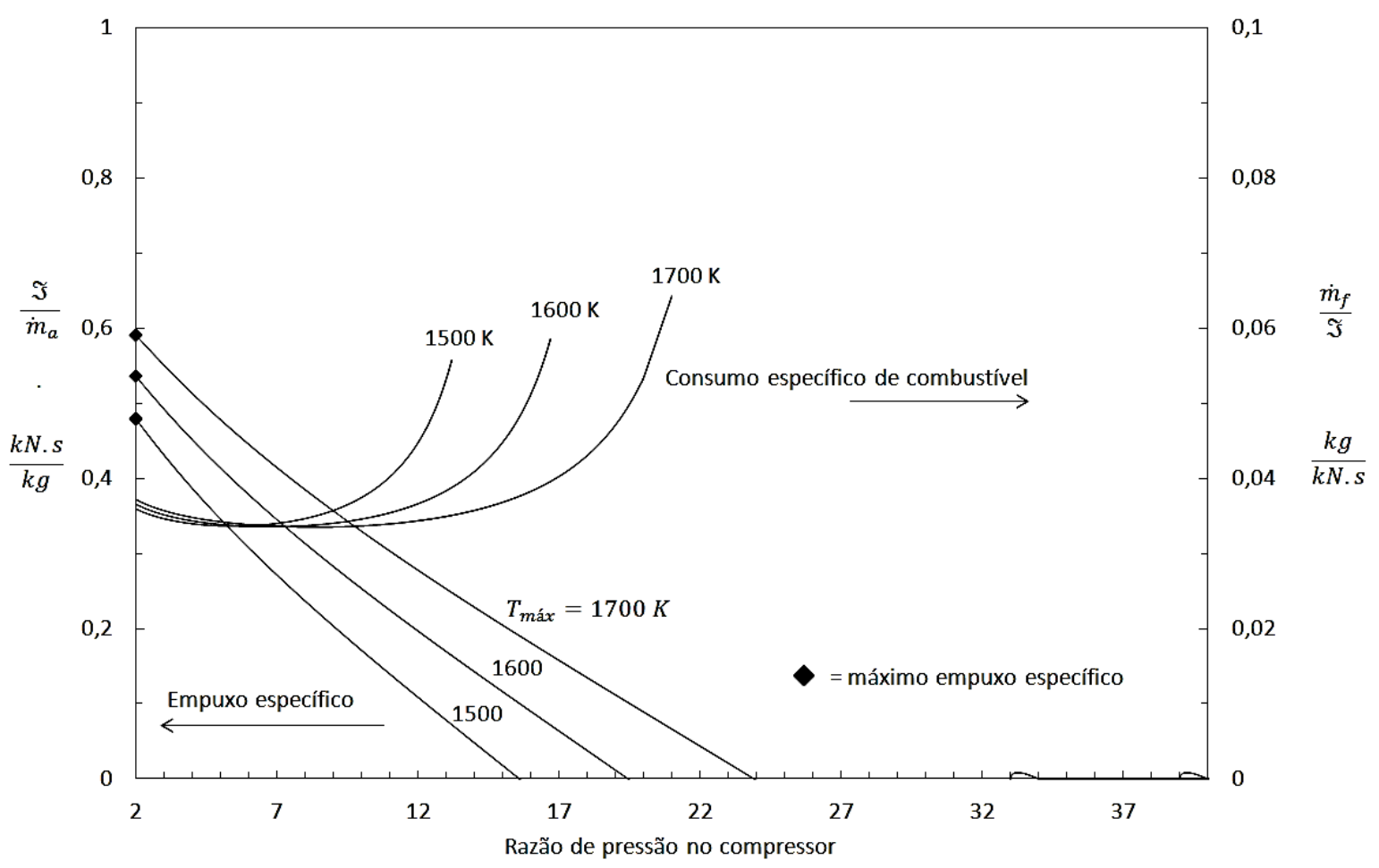

Figura 2.30 - Consumo específico e empuxo do motor turbojato (Mach = 3,00; $24400 \mathrm{~m}$ altitude). 
Destes gráficos é possível concluir que:

1. Em determinado número de Mach e dada temperatura de entrada na turbina, a razão de pressões que maximiza o empuxo específico não fornece consumo mínimo de combustível. Uma vez que o peso do motor depende fortemente da taxa de fluxo de ar e substancialmente afeta a capacidade de transporte (carga-paga) do míssil, tanto o empuxo específico como o consumo específico de combustível devem ser considerados durante a seleção da melhor relação de pressão do compressor (Hill \& Peterson, 1992). A escolha da relação de pressão para melhor autonomia de voo em cruzeiro requer um compromisso que leve em consideração as características do motor e do míssil.

2. Aumentando-se a temperatura de entrada na turbina pode-se aumentar significativamente o empuxo específico. A temperatura máxima mostrada, $1700 \mathrm{~K}$, está muito abaixo da máxima temperatura de queima estequiométrica de combustíveis hidrocarbonetos, mas requer não apenas ligas metálicas que suportem altas temperaturas para o rotor da turbina, mas também intenso resfriamento das pás do rotor.

3. Com dada razão de pressões no compressor, elevando-se a temperatura de entrada na turbina é possível ou não aumentar o consumo de combustível por unidade de empuxo. Para razões de pressão associadas ao mínimo consumo de combustível, o aumento da temperatura na entrada da turbina pode reduzir um pouco o consumo específico de combustível.

4. A razão de pressões no compressor necessária para minimizar o consumo específico de combustível é muito menor para voo supersônico que para voo subsônico. Em Mach 3, o pico de empuxo específico ocorre com uma razão de pressões no compressor igual a um; neste caso, não existe necessidade de compressor e/ou turbina, e o turbojato de torna um ramjet. O ramjet poderia, obviamente, tolerar temperaturas máximas muito superiores, por não possuir pás de turbina altamente solicitadas expostas aos gases quentes.

As Figuras 2.27 a 2.30 não mostram a sensibilidade do desempenho do motor às eficiências dos componentes. Todavia, logicamente existe um grande incentivo para obter 
processos de compressão, combustão e expansão os mais eficientes possíveis (Hill \& Peterson, 1992).

\subsubsection{4 - Considerações a respeito da temperatura de combustão}

Assim como em qualquer aplicação aeronáutica, com mísseis também existe interesse em minimizar o peso do motor, atendendo aos requisitos de empuxo, consumo específico de combustível, restrições dimensionais etc. Isso leva a componentes altamente solicitados, bem como altos picos de temperatura. De acordo com Hill \& Peterson (1992), grande parte das tensões nas pás da turbina é devida à pseudoforça centrífuga, sendo que a tensão admissível nestas pás está diretamente relacionada à temperatura na qual estas devem operar. Dessa forma, é preciso um compromisso entre as tensões nas pás da turbina e a temperatura de combustão. Ainda segundo esses autores, com materiais disponíveis atualmente, a temperatura de estagnação máxima dos gases que entram na turbina está limitada em aproximadamente $1200 \mathrm{~K}$ para pás não resfriadas. Se as pás forem resfriadas internamente por meio de pequenas passagens de ar no interior das mesmas, é possível utilizar temperaturas de estagnação iguais ou superiores a $1700 \mathrm{~K}$. A operação do motor em tais temperaturas, entretanto, pode requerer que consideráveis frações do fluxo de ar do compressor (tal como $10 \%$ ou mais) sejam desviadas para o resfriamento da turbina ao invés de entrar na câmara de combustão. Isso acarreta em maior complexidade, volume, peso e custo do motor. Logo, é preciso avaliar cuidadosamente os benefícios reais de se adotar esse tipo de tecnologia em motores para mísseis táticos.

Conforme observado nas Figuras 2.27 a 2.30, o aumento da temperatura exerce efeito benéfico sobre o empuxo, enquanto o oposto é verdadeiro a respeito do consumo específico de combustível. Um compromisso para determinar o nível necessário de empuxo (por exemplo, para superar o arrasto do míssil ou prover aceleração para maior velocidade de voo) é o estabelecimento da relação combustível/ar $(f)$. Um alto valor de $f$ garante altas temperaturas de combustão, com o benefício de alto empuxo com um pequeno diâmetro de admissão, mas eleva o consumo específico de combustível e um potencial problema com os materiais da turbina. Um baixo valor de $f$ promove baixa temperatura de combustão com o benefício de baixo consumo específico de combustível e menor risco associado aos materiais, mas requer maior diâmetro de admissão de ar para 
atender ao requisito de empuxo, com os efeitos adversos de admissão de ar de maior peso e maior empuxo.

\subsubsection{5 - Considerações a respeito da relação de pressões no compressor}

Conforme Fleeman (2012), um típico míssil de cruzeiro subsônico com motor turbojato de curto alcance (p.ex. $90 \mathrm{~km}$ ) usualmente tem compressor com relação de pressões relativamente baixa (por exemplo, $p_{r c}=p_{03} / p_{02} \sim 5$ ) e poucos estágios de compressão (por exemplo, 2 a 4). Isso permite empuxo quase máximo com vantagens associadas a relativamente baixo peso, baixo comprimento, baixo custo, alta eficiência e alta confiabilidade.

Um típico míssil de cruzeiro subsônico com motor turbojato de longo alcance (por exemplo, $900 \mathrm{~km})$ geralmente tem compressor com relação de pressões maiores $\left(p_{r c}=\right.$ $p_{03} / p_{02} \sim 10$ ) e maior número de estágios de compressão (por exemplo, 8 ), permitindo valores maiores de $I_{s p}$ com maior alcance de voo, como será mostrado na seção 2.5 -(que tratará de Trajetória de Voo).

Por fim, um míssil de cruzeiro subsônico de muito longo alcance (por exemplo, maior que $1800 \mathrm{~km}$ ) costuma ter um motor turbofan ao invés de um motor turbojato, devido ao maior valor de $I_{s p}$ do turbofan quando comparado ao turbojato. ${ }^{35}$ Para essa situação específica, o requisito de desempenho de muito longo alcance permite o maior custo, complexidade e maior diâmetro do motor turbofan. (Fleeman, 2012).

\footnotetext{
${ }^{35} \mathrm{O}$ motor turbofan foi concebido como uma forma de aumentar a eficiência de propulsão do motor a jato ao reduzir a velocidade média do fluido de trabalho, particularmente em operação em alta velocidade subsônica. No turbofan uma parte do escoamento total de ar é desviada e não passa por parte do compressor, câmara de combustão, turbina e bocal de exaustão, antes de ser exaurida por um bocal distinto. Assim, o empuxo é formado por dois componentes, um devido aos gases frios (fan) e um devido aos gases quentes (turbina) (Saravanamuttoo, Rogers, Cohen \& Straznicky, 2008).
} 


\section{4 - VOLUME E PESO}

\subsection{1 - Benefícios de um míssil com baixo peso}

Embora mísseis sofram maiores restrições quanto ao seu volume do que em relação ao peso, os benefícios de mísseis com baixo peso são numerosos (Fleeman, 2012). Estas vantagens incluem custos de produção e logísticos mais baixos, menor tamanho, maior poder de fogo para uma plataforma de lançamento com peso e volume limitados, menor propensão à detecção por parte de uma ameaça, melhor flexibilidade de missão devido à capacidade de ser transportado em múltiplas plataformas de lançamento (como bombardeiros, aviões de caça, helicópteros, veículos aéreos de combate não tripulados, navios, submarinos, veículos terrestres) e maior sinergia com guerra expedicionária. O requisito de rápido emprego de força em guerra expedicionária requer mísseis de baixo peso.

\subsection{2 - Estimativa do peso do míssil}

Fleeman (2012) apresenta uma abordagem de primeira ordem para predição de peso de um míssil balístico, baseada na equação de velocidade incremental (Equação ( 2.68)).

$$
V \approx-g I_{s p} \ln \left(1-\frac{W_{p}}{W_{L}}\right)
$$

A equação acima considera que o arrasto é desprezível, o que promove um resultado otimista.

Os parâmetros que definem a velocidade após a aceleração inicial do míssil são o peso de propelente $W_{p}$, o peso de lançamento $W_{L}$ e o impulso específico $I_{s p}$. Integrando a equação de velocidade, ela fornece uma estimativa de primeira ordem do respectivo alcance de voo balístico, máxima altitude e máximo tempo de voo na forma, respectivamente, das Equações abaixo. 


$$
\begin{gathered}
R \approx \frac{u^{2} \sin \left(2 \theta_{i}\right)}{g}, \\
h_{\max }=\frac{u^{2} \sin ^{2} \theta_{i}}{2 g}, \\
t_{\max }=\frac{2 u \sin \theta_{i}}{g} .
\end{gathered}
$$

Assumindo ângulo de lançamento ótimo $\theta_{i}=45^{\circ}$, resulta em uma estimativa (otimista) de primeira ordem para o máximo alcance em voo balístico.

$$
R \approx \frac{u^{2}}{g}
$$

As equações acima consideram arrasto desprezível e superfície da Terra plana e nãorotativa.

A Figura 2.31 foi elaborada conforme as equações acima. Ela mostra o peso de lançamento em função do máximo alcance balístico do míssil, baseada em valores típicos de peso de carga-paga $\left(W_{\text {carga-paga }}=2,3 ; 22,6 \text { e 226,4 kgf }\right)^{36}$, típico impulso específico de propelentes sólidos $\left(I_{s p}=250 \mathrm{~s}\right)$ e típica relação de peso da estrutura do corpo / peso de lançamento para um míssil tático $W_{B S} / W_{L}=0,22$ (Fleeman, 2012). Peso de carga-paga é definido como sendo a porção do peso do míssil que é relativamente insensível a variações no alcance de voo. A modelagem para projeto conceitual de carga-paga de um míssil balístico tipicamente inclui a cabeça de guerra (explosivo), dispositivo acionador do detonador, sistemas de guiamento e controle, e sistema de enlace de dados. A estrutura do corpo é sensível ao alcance de voo e considera-se que ela seja composta pelo invólucro do motor foguete e estrutura da fuselagem.

\footnotetext{
${ }^{36}$ Valores típicos de peso de carga-paga no sistema inglês $\left(W_{\text {carga-paga }}=5,50,500 \mathrm{lb}\right)$.
} 


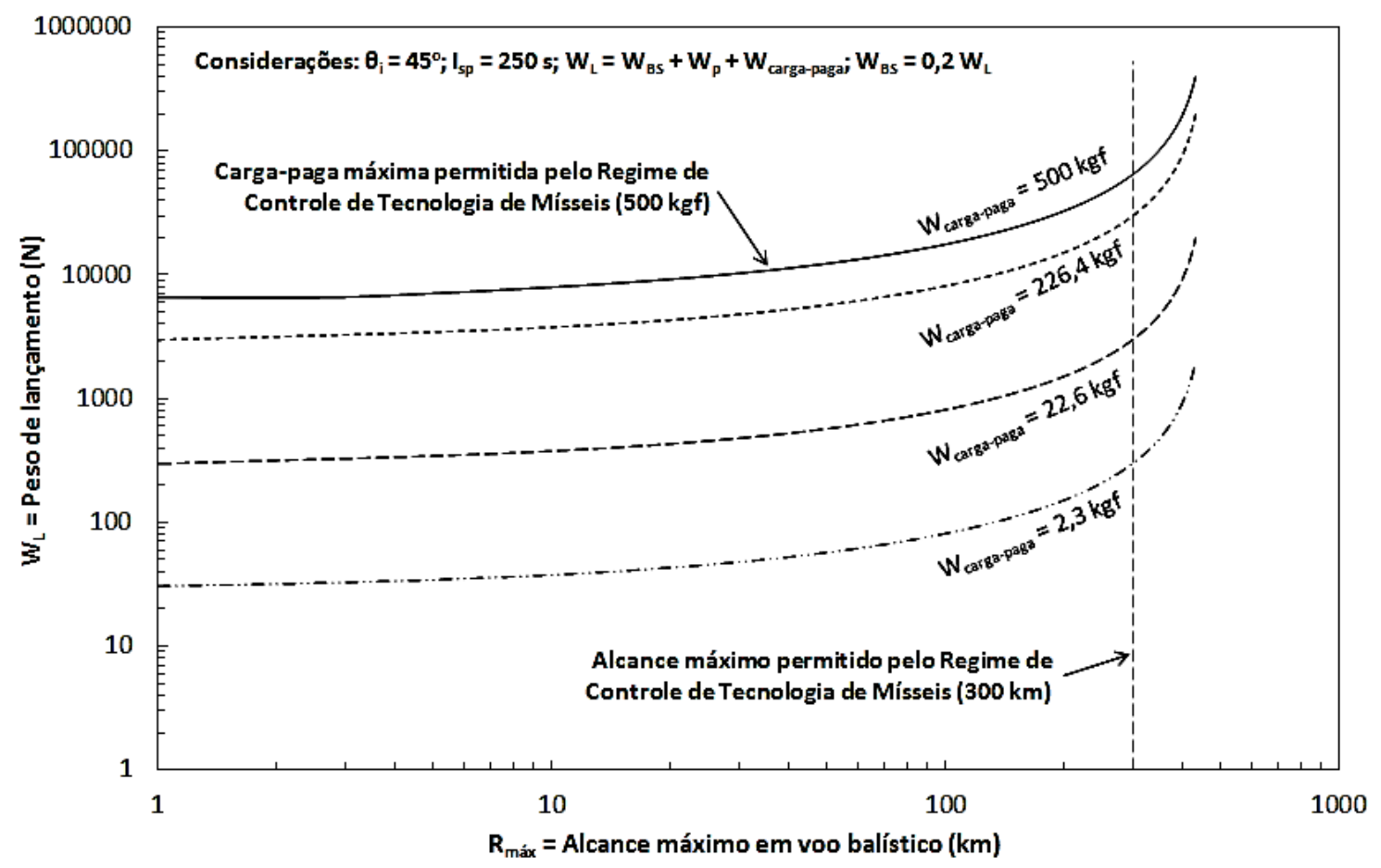

Figura 2.31 - Peso de lançamento em função do alcance de mísseis balísticos.

Na Figura 2.31 estão indicados ainda os limites de carga-paga e alcance máximo permitido segundo o Regime de Controle de Tecnologia de Mísseis (MTCR). ${ }^{37}$

\subsection{3 - Massa específica média de mísseis táticos}

Segundo Fleeman (2012), a massa específica média dos subsistemas de um míssil é de aproximadamente $1384 \mathrm{~kg} / \mathrm{m}^{3}\left(0,05 \mathrm{lbm} / \mathrm{pol}^{3}\right)$. Este é o resultado estatístico apresentado pelo autor para 48 mísseis, sendo uma boa aproximação para a fase de projeto conceitual.

Exceto pela seção do nariz, a maioria dos corpos de mísseis podem ser representados por um cilindro de diâmetro $d$ e comprimento $l$. Usando a equação para determinar o volume

\footnotetext{
${ }^{37}$ O MTCR é uma parceria internacional informal (da qual o Brasil participa) cujos países membros se comprometem a limitar o comércio de mísseis e seus componentes. Segundo o MTCR o termo "míssil" abrange qualquer veículo aéreo não tripulado capaz de exceder os limites de $300 \mathrm{~km}$ de alcance e $500 \mathrm{kgf}$ de carga-paga. Algumas informações adicionais encontram-se no Anexo B - CONTROLE E PROLIFERAÇÃO DE MÍSSEIS.
} 
de um cilindro, desprezando a diferença entre a geometria do nariz do míssil e um cilindro e desconsiderando a massa das superfícies planas do míssil (asa e cauda), a massa de lançamento do míssil $W_{L}$ pode ser estimada pela Equação (2.135).

$$
W_{L}=1087 l d^{2}
$$

Na equação acima $W_{L}$ é expressa em $\mathrm{kg}$, ao passo que a unidade de $d$ e $l$ é o metro.

Uma correlação mais detalhada da massa do míssil ao nível dos subsistemas é mostrada na Figura 2.32. São mostrados valores típicos de massa específica dos subsistemas para mísseis com motor foguete. Exceto para os componentes monolíticos (sólidos), tais como estrutura, invólucro do motor foguete, superfícies aerodinâmicas monolíticas, a variação de massa específica dos subsistemas é pequena, entre 870 e $1900 \mathrm{~kg} / \mathrm{m}^{3}$, o que corrobora com o valor médio do conjunto em torno de $1384 \mathrm{~kg} / \mathrm{m}^{3}$. Isto implica que o centro de massa do míssil no momento do lançamento esteja localizado próximo do centro do míssil.

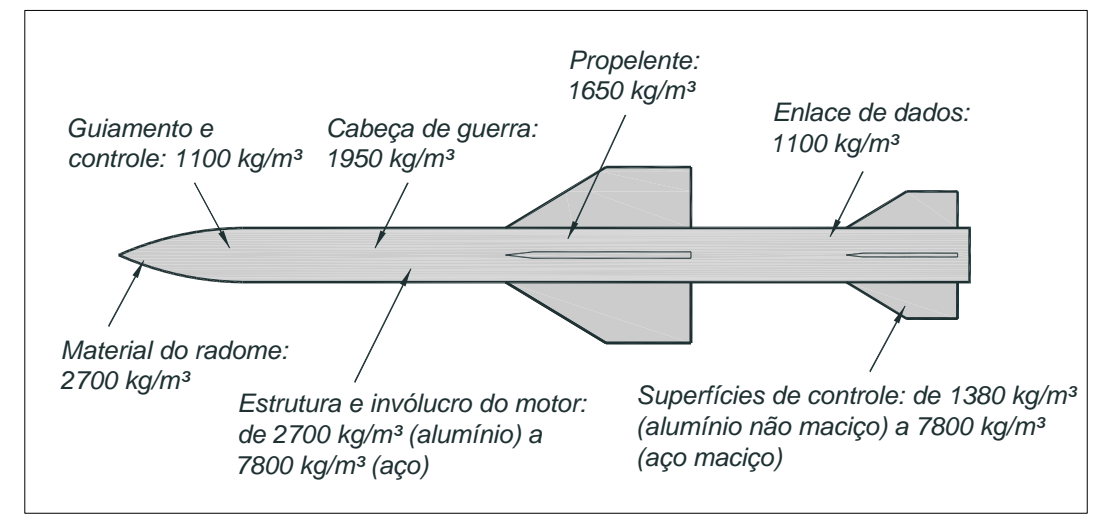

Figura 2.32- Massas específicas típicas de subsistemas de mísseis (Fleeman 2012, modificado).

Assim, neste trabalho será utilizado como valor referencial a massa específica média de mísseis o valor de de $1384 \mathrm{~kg} / \mathrm{m}^{3}$ como parâmetro para avaliar os mísseis dimensionados no programa desenvolvido (descrito adiante no texto), a partir das dimensões dos componentes externos (corpo e superfícies aerodinâmicas) do míssil e da massa dos componentes individuais. Além disso, será sempre considerado que o centro de massa do 
míssil no início do voo em cruzeiro se localiza a 50\% do comprimento do voo de cruzeiro (após a ejeção do booster).

\subsection{4 - Estimativa do peso dos componentes do míssil}

Para a avaliação do peso total de lançamento do míssil, no âmbito deste trabalho, serão consideradas o peso dos seguintes componentes:

1. Booster sem propelente (calculado pelo programa);

2. Propelente do booster (calculado pelo programa);

3. Cabeça de Guerra (dado de entrada);

4. Sistemas de Guiamento, Controle e Enlace de dados (dado de entrada);

5. Combustível de cruzeiro (calculado pelo programa);

6. Estrutura do corpo do míssil (calculado pelo programa);

7. Asa (calculado pelo programa);

8. Cauda (calculado pelo programa);

9. Motor de cruzeiro (calculado pelo programa);

10. Atuadores das superfícies de controle (dado de entrada);

11. Fonte de energia - power supply - (dado de entrada);

\subsubsection{1 - Estimativa do peso do motor foguete (booster)}

Fleeman (2012) apresenta os resultados de uma análise estatística para determinar uma correlação que estabelece um valor típico de peso de propelente $\left(W_{P}\right)$ como uma fração do peso do motor foguete $\left(W_{M}\right)$. O peso total do motor inclui o peso do propelente, invólucro do motor foguete, tubeira e isolamento térmico. Neste caso ocorre uma relação estatística equivalente a $W_{P} / W_{M} \approx 0,65$. Ressalta-se que esta relação é válida para mísseis táticos. Além disso, essa relação foi encontrada considerando-se mísseis com motor foguete que empregam invólucro de motor foguete construído com material metálico (por exemplo, aço). 
Um motor foguete com alta fração mássica de propelente (ou seja, maior que 65\%) tenderia a ter alto carregamento volumétrico de propelente, invólucro do motor de alta resistência, baixa pressão de combustão, baixas cargas de voo e pequeno tempo de queima. Correspondentemente, baixa fração mássica de propelente é resultado de baixo carregamento volumétrico, involucro do motor de baixa resistência, alta pressão de combustão, carga de voo alta e tempo de queima longo.

Portanto, para que seja feita uma estimativa do peso do motor foguete (booster) sem o propelente $\left(W_{M}-W_{P}\right)$, neste trabalho, será necessário primeiramente conhecer o peso de propelente necessário $\left(W_{P}\right)$ e, então, aplicar a relação $W_{P} / W_{M} \approx 0,65$.

\subsubsection{2 - Estimativa do peso de propelente do motor foguete (booster)}

A estimativa do peso de propelente $\left(W_{P}\right)$ requerido pelo motor foguete (booster) utiliza procedimentos descritos na seção que tratou de Motor Foguete (seção2.3.1 -) e na seção que tratará de Trajetória de Voo (seção2.5 -), encontrada mais adiante neste texto.

\subsubsection{3 - Componentes com massa constante (dado de entrada)}

Conforme declarado anteriormente, os componentes com peso constante, neste trabalho, são a Cabeça de Guerra, dos Sistemas de Guiamento, Controle e Enlace de Dados, atuadores das superfícies de controle e a fonte de energia (power supply).

O peso da Cabeça de Guerra (elemento explosivo), um dos parâmetros de projeto, é um dado de entrada e valor constante para o dimensionamento de um míssil.

O peso dos Sistemas de Guiamento, Controle e Enlace de Dados, é um dado de entrada e valor constante para o dimensionamento de um míssil. Sempre que possível será utilizado um valor semelhante ao de mísseis de referência (com configuração, requisitos operacionais e dimensões próximas ao do míssil sendo dimensionado). Logicamente esses valores serão aproximados, sendo necessária uma melhor avaliação nas fases posteriores de projeto (projeto preliminar e detalhado) ou a utilização de dados precisos a partir do 
conhecimento, a priori, dos detalhes técnicos dos Sistemas de Guiamento, Controle e Enlace de Dados que de fato serão empregados em determinado projeto.

Apesar de o peso dos atuadores ser dependente da tecnologia empregada, do torque e velocidade de atuação e do fato do peso da fonte de energia ser dependente da tecnologia utilizada, potência requerida e tempo de voo (Fleeman, 2012), ambos serão considerados constantes em cada processo de otimização deste trabalho.

\subsubsection{4 - Estimativa de massa do combustível de cruzeiro}

Neste trabalho a estimativa de massa do combustível de cruzeiro ( $\left.m_{\text {combustível }}\right)$ é feita através de associação de um dado de entrada (fração mássica de combustível de cruzeiro, $\zeta_{\text {cruzeiro }}$ ) com dados calculados pelo programa (massa do início do voo em cruzeiro, $m_{1}$ ), na forma das Equações abaixo.

$$
\begin{gathered}
\zeta_{\text {cruzeiro }}=\frac{m_{\text {combustível }}}{m_{1}}, \\
m_{\text {combustível }}=\zeta_{\text {cruzeiro }} m_{1} .
\end{gathered}
$$

\subsubsection{5 - Estimativa de peso da estrutura}

A estimativa de peso da estrutura do míssil é uma das principais atividades do projeto conceitual. Fleeman (2012) faz uma análise estatística para determinar uma correlação que estabelece um valor típico de peso da estrutura do corpo em relação ao peso de lançamento do míssil. Segundo essa correlação, o peso médio da estrutura $W_{B S}$ equivale a $22 \%$ do peso de lançamento $W_{L}$. Cabe ressaltar que essa relação é válida, com boa aproximação, para mísseis táticos. Dado que para mísseis estratégicos existe uma ênfase maior na maximização do alcance de voo, estes últimos têm, tipicamente, estruturas mais eficientes e relativamente de baixo peso (resultando em maiores custos de produção). Isto pode ser alcançado com, por exemplo, uso de múltiplos estágios, conforme explicado anteriormente no tópico sobre motores foguete. Mísseis estratégicos atingem valores de $W_{B S} / W_{L}=0,10$. 
Nesta correlação, $W_{B S}$ não inclui o peso da superfície de cauda, asa ou outras superfícies planas. Outro ponto a se destacar é que os 11 mísseis utilizados pelo autor (Fleeman, 2012) para encontrar essa relação, possuem estrutura fabricada em material metálico. Uma estrutura de material compósito seria mais leve, com menor fração de peso estrutural.

Essa correlação $\left(W_{B S}=0,22 W_{L}\right)$ será utilizada apenas como estimativa inicial do peso da estrutura, sendo que os procedimentos apresentados a seguir serão utilizados para uma melhor avaliação desse peso.

Diversos fatores influenciam o projeto da estrutura da fuselagem do míssil. Eles incluem processos de fabricação, transporte, armazenamento, movimentação na plataforma de lançamento, lançamento, manobras iniciais, cargas em voo e manobras terminais. Todavia, para projeto conceitual, as considerações mais importante quanto ao projeto estrutural são, normalmente, cargas de lançamento, flambagem da estrutura do míssil, pressão interna do motor foguete, cargas de manobras iniciais e cargas de manobras terminais.

Fleeman (2012) apresenta equações simplificadas para estimar a espessura necessária para diferentes considerações de projeto, para uma estrutura cilíndrica convencional. A seguir serão apresentadas as equações para espessura de parede necessária para considerações de

1. Bitola mínima para fabricação;

2. Flambagem localizada devido a flexão;

3. Flambagem localizada devido a compressão axial;

4. Força de empuxo;

5. Momento fletor devido a manobras em voo;

6. Pressão interna.

A primeira consideração, bitola mínima para fabricação, requer espessura suficiente para suportar operações de fabricação tais como usinagem e flexão. Estas operações podem ser representadas como uma sobrepressão externa equivalente, em torno de 10 psi $(68,9 \mathrm{kPa})$. A equação ${ }^{38}$ para bitola mínima é:

\footnotetext{
${ }^{38}$ A equação apresentada tem unidades no sistema inglês ( $r$ em polegadas, $\sigma$ e $E$ em psi).
} 


$$
t_{\text {bitola mínima }}=0,7 d\left[\left(\frac{p_{\text {ext }}}{E}\right) \frac{l}{d}\right]^{0,4}
$$

Para uma sobrepressão externa equivalente $p_{\text {ext }} \approx 10 p s i$, a espessura mínima para materiais usuais em estrutura de mísseis (alumínio, aço etc) é:

$$
t_{\text {bitola mínma }} \approx 1,524 \mathrm{~mm} \text {. }
$$

A equação ${ }^{39}$ para espessura requerida para suportar flambagem localizada devido a flexão é:

$$
t_{\text {flambagem }_{\text {flexão }}}=\frac{2,9 r \sigma}{E} .
$$

A equação ${ }^{40}$ para espessura requerida para suportar flambagem localizada devido a compressão axial (empuxo) é:

$$
t_{\text {flambagem }} \text { compressão }_{E}=\frac{4,0 r \sigma}{E} .
$$

A equação para espessura requerida para suportar carregamento axial ( $\mathfrak{I}=$ empuxo $)$ é:

$$
t_{\text {carregamento axial }}=\frac{\mathfrak{I}}{2 \pi \sigma r} \text {. }
$$

A equação para espessura requerida para suportar esforços devido a momento fletor ${ }^{41}$ é:

$$
t_{f l e x a ̃ o}=\frac{M}{\pi \sigma r^{2}}
$$

\footnotetext{
${ }^{39}$ A equação apresentada tem unidades no sistema inglês ( $r$ em polegadas, $\sigma$ e $E$ em psi).

${ }^{40} \mathrm{~A}$ equação apresentada tem unidades no sistema inglês ( $r$ em polegadas, $\sigma$ e $E$ em psi).

${ }^{41} \mathrm{O}$ procedimento utilizado para determinação do máximo momento fletor no corpo encontra-se disponível no Anexo C - CÁLCULO DE MOMENTO FLETOR NO CORPO DO MÍSSIL.
} 
A espessura necessária para um corpo cilíndrico acomodar carregamento interno devido a pressão (por exemplo, pressão de combustão do motor foguete) é:

$$
t_{\text {pressão interna }}=\frac{p r}{\sigma} \text {. }
$$

A condição de projeto crítica é geralmente uma combinação de diferentes tipos de carregamentos estruturais. Porém, pode não haver tempo hábil suficiente em fase de projeto conceitual para determinar a combinação crítica de carregamentos, resultando em incertezas de projeto. Fleeman (2012) apresenta três abordagens simplificadas para estabelecer a espessura da estrutura do míssil, levando em consideração os diferentes tipos de solicitações mencionadas.

A primeira abordagem pode ser considerada uma abordagem de alto risco, desconsidera efeitos dos esforços combinados. A espessura é o fator de segurança (FS) multiplicado pelo máximo valor da maior espessura considerando cada condição de carregamento.

$$
\begin{gathered}
t=F S \times \operatorname{Max}\left(t_{\text {bitola mínma }}, t_{\text {flambagem }}{ }_{\text {flexão }}, t_{\text {flambagem }} \text { compressão },\right. \\
\left.t_{\text {carregamento axial }}, t_{\text {flexão }}, t_{\text {pressão interna }}\right) .
\end{gathered}
$$

A segunda abordagem é de risco moderado e utilizada a raiz da soma dos quadrados para estabelecer a espessura da estrutura do míssil

$$
\begin{gathered}
t=F S \times\left(t_{\text {bitola mínma }}^{2}+t_{\text {flambagem }}^{2} \text { flexão }_{\text {flambagem }}+t_{\text {compressão }}^{2}+\right. \\
\left.t_{\text {carregamento axial }}^{2}+t_{\text {flexão }}^{2}+t_{\text {pressão interna }}^{2}\right)^{\frac{1}{2}} .
\end{gathered}
$$

A terceira abordagem é de baixo risco, mas que resulta em estruturas sobredimensionadas (pesadas). Ela assume que a espessura necessária é a soma das espessuras requeridas por cada um dos carregamentos. 


$$
\begin{aligned}
t=F S \times & \left(t_{\text {bitola mínma }}+t_{\text {flambagem }_{\text {flexão }}+t_{\text {flambagem }}} \text { compressão }+\right. \\
& \left.t_{\text {carregamento axial }}+t_{\text {flexão }}+t_{\text {pressão interna }}\right) .
\end{aligned}
$$

A segunda abordagem (Equação (2.146)) é usada com frequência para projeto conceitual (Fleeman, 2012) e por isso será utilizada no presente trabalho.

Tendo sido determinadas as dimensões da estrutura (comprimento, diâmetro externo, espessura) e o material utilizado no dimensionamento, é possível determinar o peso da estrutura.

$$
\begin{gathered}
d_{i}=d-2 t \\
W_{\text {estrutura }}=\frac{\pi}{4}\left(d^{2}-d_{i}{ }^{2}\right) l \rho_{\text {material }} .
\end{gathered}
$$

Onde $\rho_{\text {material }}$ é massa específica do material, $l$ é o comprimento do corpo, $d$ e $d_{i}$ os diâmetro externo e interno do corpo, respectivamente.

2.4.4.6 - Estimativa de peso das superfícies aerodinâmicas

A Equação (2.150) mostra a relação entre peso estrutural adimensional de superfícies planas (p.ex.: asa, cauda, canard), apresentada por Fleeman (2012).

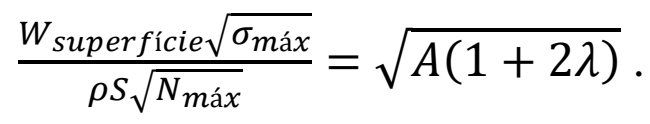

Os termos nessa equação são a carga máxima $\left(N_{\text {máx }}\right)$, razão de aspecto $(A)$, taper ratio $(\lambda)$, limite de resistência à tração $\left(\sigma_{\text {máx }}\right)$, massa da superfície $\left(W_{\text {superfície }}\right)$, massa específica do material $(\rho)$ e área planiforme da superfície $(S)$. 
Para a obtenção dessa equação, considera-se que as superfícies planas sejam compostas por dois painéis monolíticos (sólidos), sob carregamento uniforme e que sua espessura é determinada por tensão devido ao momento fletor. Nota-se que na Figura 2.33, formada com base na Equação (2.150), superfícies com baixa razão de aspecto com formato em delta $(\lambda=0)$ tem o menor massa.

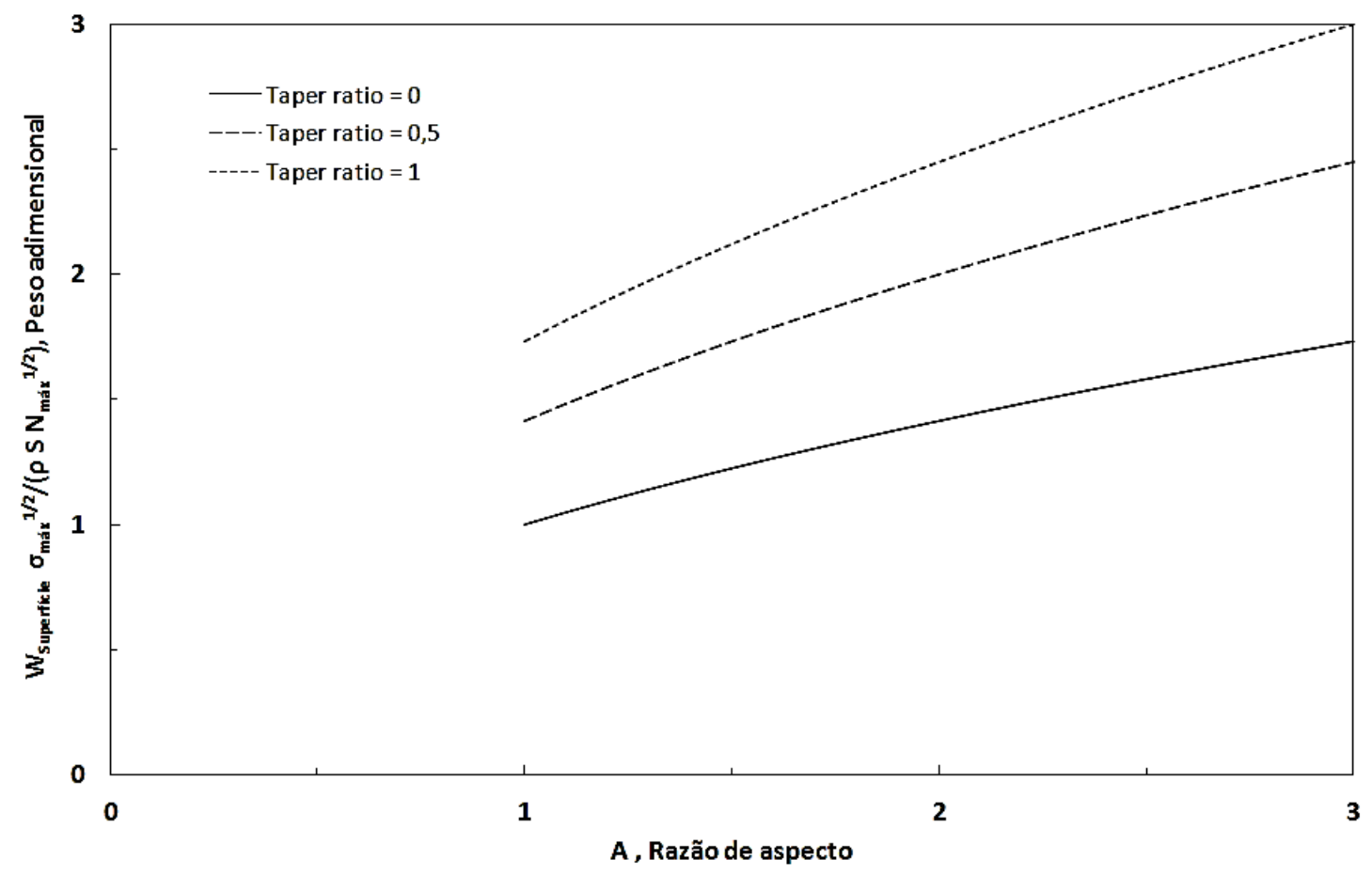

Figura 2.33 - Peso adimensional das superfícies planas em função da razão de aspecto.

O peso da superfície pode ser expressa como:

$$
W_{\text {superfície }}=\rho S t_{\text {mac }} g \text {. }
$$

$\mathrm{Na}$ Equação (2.151), a espessura da corda média aerodinâmica $\left(t_{m a c}\right)$ é representada pela espessura média da superfície.

A equação para a espessura da corda da raiz da superfície é dada por:

$$
t_{\text {raiz }}=\sqrt{\frac{(F S) N_{\text {máx }} A(1+2 \lambda)}{\sigma_{m a ́ x}}} .
$$


Nessa equação, $F S$ representa o fator de segurança em projeto.

2.4.4.7 - Estimativa de peso do motor de cruzeiro

Na seção deste trabalho que trata de Propulsão, foram apresentados alguns aspectos fundamentais a respeito de motor foguete, turbojato e ramjet. Está além do alcance e objetivos presentes o dimensionamento pormenorizado desses tipos de motores e consequentemente a determinação precisa do peso dos mesmos. Apesar disso, para que sejam atingidos os objetivos deste trabalho, é preciso ter uma estimativa do peso dos motores (booster e cruzeiro) dos mísseis avaliados. Por este motivo, e considerando que para o motor foguete já é feita uma estimativa do peso do mesmo, neste trabalho serão utilizadas as relações Empuxo/Peso para os motores Turbojato e Ramjet, apresentada por Sutton \& Biblarz (2010) e apresentada na Tabela 2.5. Reitera-se que esses valores são apenas referenciais.

Tabela 2.5 - Relação Empuxo/Peso para diferentes tipos de motor.

\begin{tabular}{|cc|}
\hline Tipo de motor & Empuxo / Peso do motor (adimensional) \\
\hline Foguete & $75: 1$ \\
\hline Turbojato & $5: 1$ \\
\hline Ramjet & $7: 1$ (Mach 3, 9144 m de altitude) \\
\hline
\end{tabular}




\section{5 - TRAJETÓRIA DE VOO}

\subsection{1 - Equações de modelagem de movimento}

A atividade de avaliação de trajetória de voo do míssil durante a fase de projeto conceitual requer considerações acerca dos graus de liberdade (GDL) a serem simulados. A Figura 2.34 compara modelos de graus de liberdade para simulação que são geralmente usados em projeto conceitual com os graus de liberdade que são apropriados para projeto preliminar (Fleeman, 2012).

\begin{tabular}{|c|c|}
\hline Modelagem de forças e momentos para projeto conceitual & $\begin{array}{l}\text { Forças e momentos } \\
\text { aerodinâmicos }\end{array}$ \\
\hline 1 GDL [força axial $\left(\mathrm{C}_{\mathrm{D} 0}\right)$, empuxo, peso] & $C_{D 0^{-}}$ \\
\hline 2 GDL [força normal, força axial, empuxo, peso] & $C_{A}$ \\
\hline 2 GDL [sustentação $\left(\mathrm{C}_{\mathrm{L}}\right)$, arrasto $\left(\mathrm{C}_{\mathrm{D}}\right)$, empuxo, peso] & \\
\hline $\begin{array}{l}3 \text { GDL - massa pontual [3 forças aerodinâmicas (normal, } \\
\text { axial, lateral), empuxo, peso] }\end{array}$ & \\
\hline $\begin{array}{l}3 \text { GDL [2 forças aerodinâmicas (normal, axial), } 1 \text { momento } \\
\text { aerodinâmico, empuxo, peso] }\end{array}$ & $C_{A^{-}}^{C}$ \\
\hline $\begin{array}{l}4 \text { GDL [2 forças aerodinâmicas (normal, axial), } 2 \\
\text { momentos aerodinâmicos, empuxo, peso] }\end{array}$ & $P c_{1}$ \\
\hline Modelagem de forças e momentos para projeto preliminar & $\begin{array}{l}\text { Forças e momentos } \\
\text { aerodinâmicos }\end{array}$ \\
\hline $\begin{array}{l}5 \text { GDL [3 forças aerodinâmicas (normal, axial, lateral), } 2 \\
\text { momentos aerodinâmicos, empuxo, peso] } \\
6 \text { GDL [3 forças aerodinâmicas (normal, axial, lateral), } 3 \\
\text { momentos aerodinâmicos, empuxo, peso] }\end{array}$ & $c_{C_{A}}^{C_{C_{n}} C_{C_{Y}}}$ \\
\hline
\end{tabular}

Figura 2.34 - Comparação de modelos de trajetória de voo para projeto, baseado nos graus de liberdade do movimento (Fleeman 2012, modificado). 
Como exposto anteriormente, na fase de projeto conceitual, deve-se proceder com uma rápida avaliação de uma grande gama de alternativas de soluções. Isto requer que os métodos de avaliação sejam rápidos, simples de usar e tenham larga faixa de aplicabilidade (Fleeman, 2012). O modelo de trajetória de voo mais simples, frequentemente aceitável para projeto conceitual de mísseis de alta velocidade, é o modelo com um grau de liberdade (1 GDL). A trajetória de voo com 1 GDL requer a modelagem apenas das forças de arrasto parasita, empuxo e peso. Equações analíticas podem ser usadas para modelar uma trajetória com 1 GDL. Outros modelos usados para projeto conceitual são:

i. Ponto material com dois graus de liberdade (2 GDL) com força normal, força axial, empuxo e peso;

ii. Ponto material com 2 GDL com força de sustentação, força de arrasto, empuxo e peso;

iii. Ponto material com 3 GDL com forças normal, axial e lateral, empuxo e peso;

iv. Corpo sólido com 3 GDL com força normal, força axial, modelagem de momento de arfagem (rotação sobre o eixo horizontal que passa pelas asas), empuxo e peso;

v. Corpo sólido com 4 GDL com forças normal e axial, modelagem de momentos de arfagem e rolagem, empuxo e peso;

Por fim, simulações mais avançadas durante projeto preliminar geralmente são modeladas considerando 5 ou 6 - GDL. Uma simulação com 5 - GDL inclui três forças aerodinâmicas (normal, axial e lateral), dois momentos aerodinâmicos, empuxo e peso. A simulação com 6 - GDL é o padrão para o desenvolvimento de mísseis em fases posteriores ao projeto conceitual. Ela inclui a modelagem de todos os eixos ortogonais. Ela inclui todos os movimentos de rotação e translação de um corpo rígido. Para isso ela computa três forças aerodinâmicas, três momentos aerodinâmicos, empuxo e peso.

Neste trabalho será utilizada a modelagem ponto material com 2 GDL e forças de sustentação, arrasto, empuxo e peso, a partir das metodologias já apresentadas. 


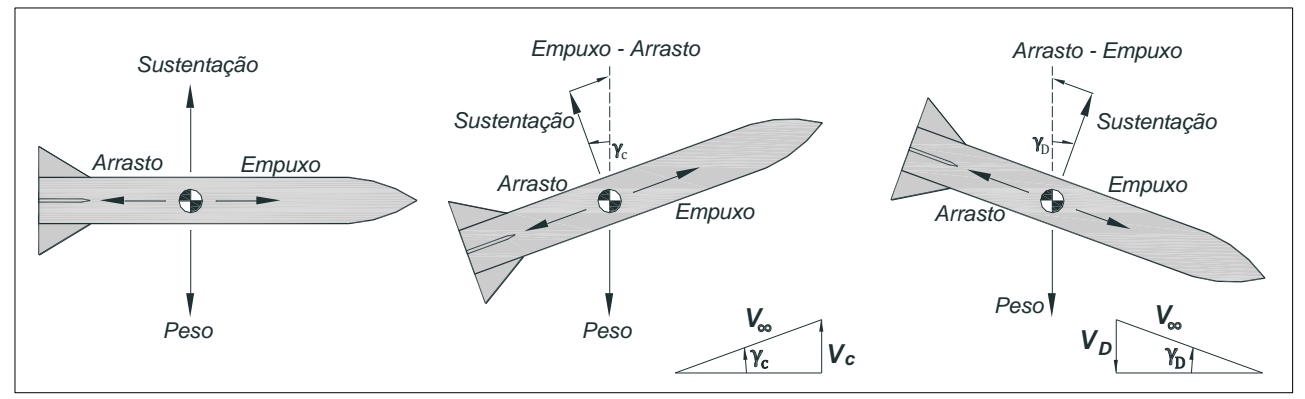

Figura 2.35 - Diagramas de força para diferentes condições de equilíbrio e voo (Chin 1961, modificado).

Uma vez que as forças atuantes sobre o míssil (empuxo, arrasto, peso) e condições de voo forem determinadas ou especificadas na forma mostrada na Figura 2.35, as características de desempenho em voo de um míssil podem ser determinadas (Chin, 1961). Métodos de cálculo de parâmetros de desempenho tais como velocidade máxima e razão de subida para mísseis de cruzeiro são idênticos àqueles utilizados para aeronaves tripuladas. Para mísseis com propulsão a motor foguete, particularmente aqueles que são acelerados até determinada velocidade e então desaceleram ou planeiam até seu destino, uma abordagem um pouco diferente é necessária para a avaliação de desempenho.

\subsection{2 - Perfis de voo}

\subsubsection{1 - Perfil do tipo aceleração inicial - planeio (boost - coast)}

Uma trajetória do tipo aceleração inicial - planeio é definida como aquela em que o míssil é rapidamente acelerado até sua velocidade máxima e então planeia (sem propulsão), o restante de sua trajetória (Figura 2.36). Para mísseis de alcance relativamente curto, este tipo de trajetória é muito comum. A principal vantagem desse tipo de trajetória de voo é sua inerente simplicidade. É possível calcular o alcance e velocidade empregando este tipo de trajetória através da solução das equações de movimento, como será descrito mais adiante. 


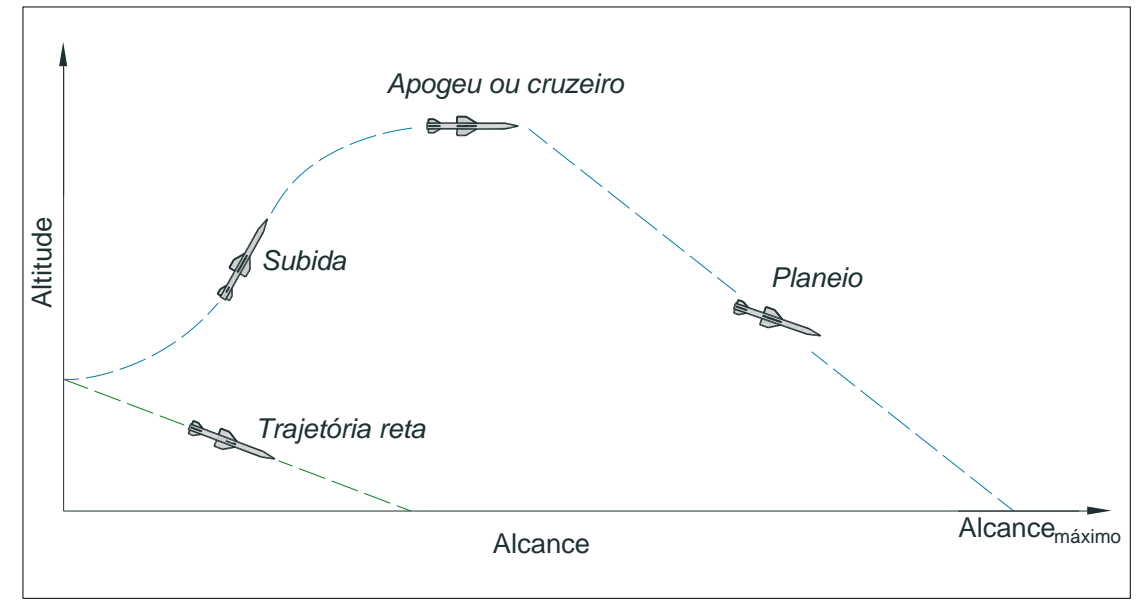

Figura 2.36 - Perfis de voo do tipo boost - coast. (Fleeman 2012, modificado).

\subsubsection{2 - Perfil do tipo aceleração inicial - sustain (boost-sustain)}

Este tipo de trajetória consiste de um período de aceleração inicial relativamente curto seguido por um voo propelido (sustained). Geralmente a velocidade da segunda fase de voo é constante, trajetória é que denominada boost - constant sustained.

Para certas aplicações, este tipo de trajetória é mais vantajosa que o tipo aceleração inicial - planeio. De acordo com Chin (1961), suas principais vantagens são: a) redução do máximo número de Mach necessário para dado alcance; b) atenuação do problema de aquecimento aerodinâmico; c) melhor desempenho aerodinâmico do míssil ao ser operado em menor nível de arrasto; d) simplificação do sistema de controle, visto que as características aerodinâmicas do míssil são mantidas praticamente constantes.

\subsubsection{3 - Perfil do tipo aceleração inicial - cruzeiro - coast}

Um míssil de cruzeiro usualmente tem uma trajetória composta por um período de aceleração inicial, que leva o míssil da velocidade de lançamento até a velocidade de cruzeiro ou uma velocidade suficiente para que o motor de cruzeiro comece a operar. $\mathrm{O}$ motor de cruzeiro permanece em operação até o ponto de impacto ou é desativado e o míssil entra em um período de voo em planeio ou balístico até chegar ao alvo. A Figura 2.37 mostra esquematicamente este perfil de voo. 


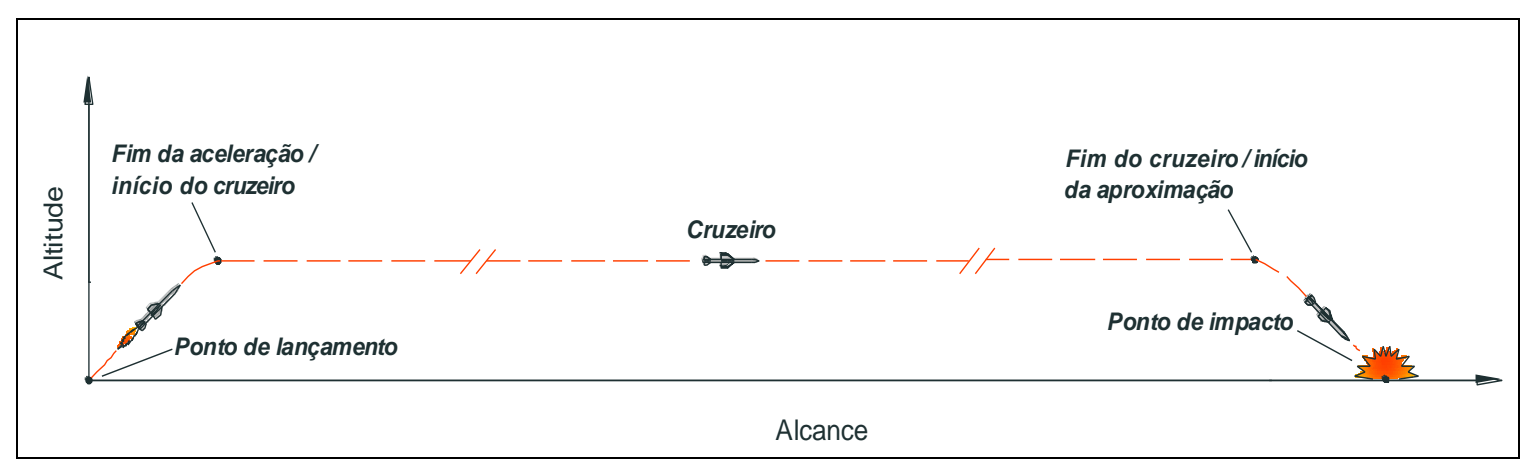

Figura 2.37 - Perfil de voo de cruzeiro.

Conforme mencionado anteriormente, métodos utilizados para determinar as características de desempenho de mísseis de cruzeiro são os mesmos utilizados para aeronaves tripuladas. Portanto, é necessário conhecer as características do motor de cruzeiro (por exemplo: empuxo, consumo de combustível, etc), arrasto e condições da altitude de operação para determinar parâmetros de desempenho como alcance máximo.

\subsubsection{4 - Perfil do tipo balístico}

A natureza geral da trajetória descrita por um míssil balístico é mostrada na Figura 2.38. A principal característica desse tipo de voo é que durante um período de aceleração relativamente curto o míssil é acelerado para altas velocidades, após isto o míssil ou um veículo de reentrada, contento a cabeça de guerra, então percorre uma trajetória balística até o ponto de impacto ${ }^{42}$.

\footnotetext{
${ }^{42}$ A Figura 2.38 não mostra em detalhe a trajetória do voo durante a fase de aceleração inicial. O perfil de voo balístico só ocorre após a desativação do motor, ponto indicado na figura como 'fim da aceleração'. Chin (1961) destaca que, para mísseis balísticos de longo alcance, durante a fase de aceleração neste tipo de voo, o míssil ascende verticalmente após o lançamento, logo em seguida inicia uma trajetória curvilínea, gradualmente diminuindo seu ângulo de atitude e então assume um trecho de voo com ângulo de atitude constante, mantendo-se dessa forma até o fim da aceleração e início da trajetória balística. Assim, após a desativação do motor de aceleração o míssil é posto em determinada posição e velocidade que praticamente determinam a posição do ponto de impacto.
} 


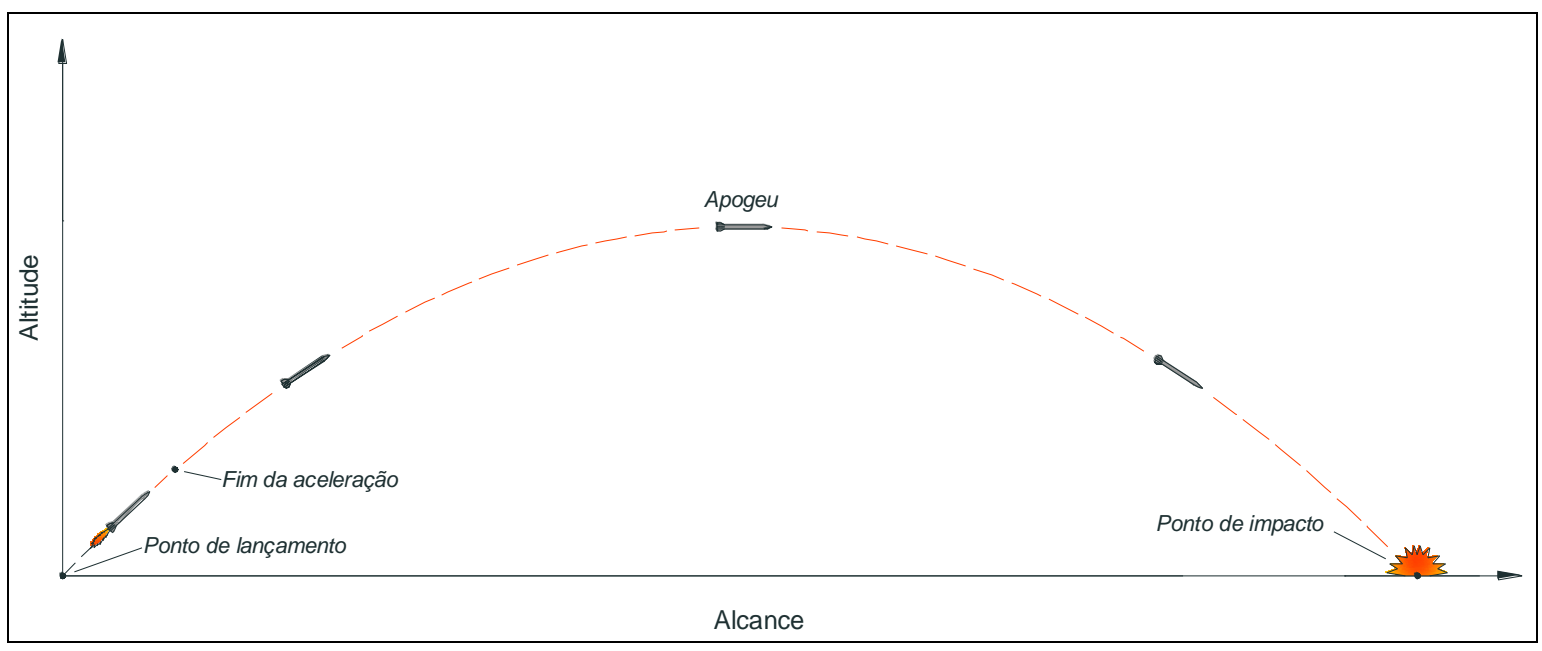

Figura 2.38 - Perfil de voo balístico.

\subsection{3 - Fases de voo}

De modo a analisar os diferentes perfis de voo apresentados, convém dividir o voo conforme suas diferentes fases e então aplicar as equações de modelagem do movimento. Serão utilizadas três fases distintas: boost, cruzeiro e coast (aproximação final). Esta última poderá ter perfil balístico ou de planeio.

\subsubsection{1 - Aceleração inicial (boost)}

Com base nas hipóteses de voo com baixo ângulo de ataque $\left(\alpha \approx 0^{\circ}\right)$, ângulo de trajetória de voo $(\gamma)$ constante, e empuxo maior que a componente do peso que atua ao longo do eixo de empuxo $(\mathfrak{I}>W \sin \gamma)$, o incremento de velocidade proveniente do acionamento do motor foguete pode ser modificado (Equação ( 2.68)) para incluir a força de arrasto e peso do míssil, resultando na forma da Equação (2.154).

$$
u_{p}=u_{e q} \ln \left(m_{0} / m_{f}\right)
$$

Nessa equação: 
$m_{0}=$ massa de lançamento;

$m_{f}=$ massa após queima completa do propelente do booster (burnout);

$u_{e q}=$ velocidade de exaustão equivalente (ou efetiva).

Lembrando que

$$
I_{s p}=\frac{u_{e q}}{g}
$$

$\mathrm{e}$

$$
\frac{\Delta u}{\left(g I_{s p}\right)}=-\left[1-\left(\frac{D_{a v g}}{\mathfrak{I}}\right)-\left(\frac{W_{a v g} \sin \gamma}{\mathfrak{I}}\right)\right] \ln \left(1-\frac{W_{p}}{W_{i}}\right),
$$

onde:

$\Delta u=$ incremento na velocidade de voo;

$g$ = aceleração da gravidade;

$I_{s p}=$ impulso específico;

$D_{a v g}=$ arrasto médio durante o processo de aceleração;

$\mathfrak{I}=$ empuxo;

$W_{\text {avg }}=$ peso médio do míssil durante o processo de aceleração;

$\gamma=$ ângulo de trajetória de voo;

$W_{p}=$ peso do míssil no início do processo de aceleração;

$W_{i}=$ peso do míssil no fim do processo de aceleração.

Portanto alto incremento de velocidade é promovido pelo acionamento do motor foguete se existe alta fração mássica de combustível (conforme demonstrado na seção 2.3.1.5 -, que trata de Propulsão), baixo arrasto médio $D_{a v g}$, alto empuxo $\mathfrak{I}$, alto impulso específico $I_{s p} \mathrm{e}$ trajetória de voo em mergulho $(\gamma<0)$. 


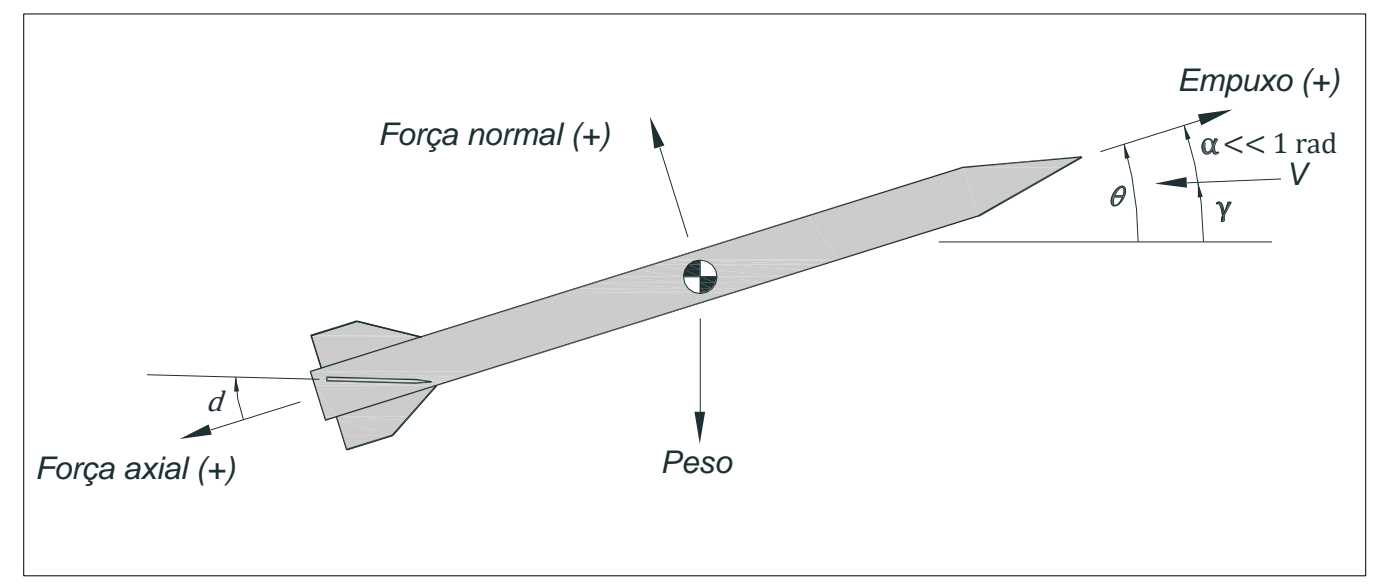

Figura 2.39 - Definições de parâmetros de voo.

A distância percorrida durante voo propelido pelo booster é dada pela Equação (2.155).

$$
s_{\text {Booster }}=\left(u_{i}+\frac{\Delta u}{2}\right) t_{b}
$$

Na equação acima $u_{i}$ é a velocidade inicial e $t_{b}$ o tempo de queima do motor foguete.

\subsubsection{2 - Voo em cruzeiro}

Em muitos casos, a distância que um míssil pode percorrer com dada massa de combustível é um importante critério de excelência de desempenho da combinação entre motor e o restante do míssil. Ignorando-se o trecho de subida para, e o trecho de descida da altitude de cruzeiro, e assumindo que todas as características do míssil e motor, exceto a massa total do sistema de propulsão, são constantes durante o cruzeiro, pode-se obter facilmente uma estimativa de autonomia ou alcance. 


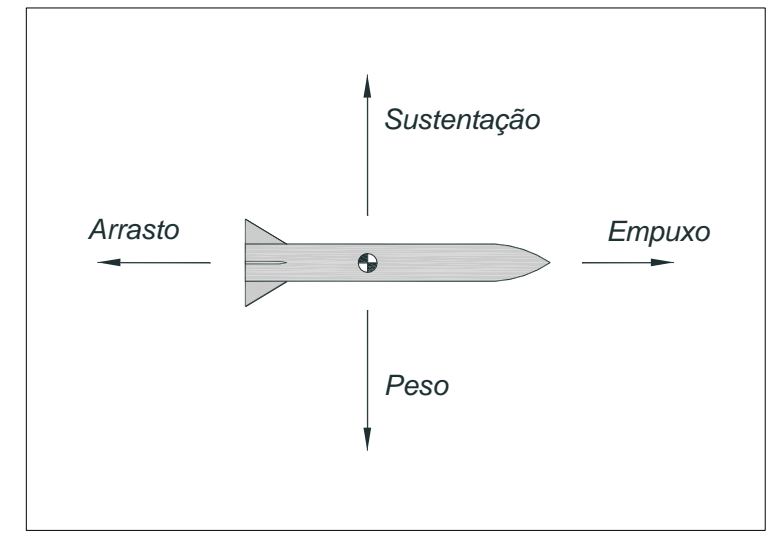

Figura 2.40 - Diagrama de corpo livre de míssil em voo de cruzeiro.

Considerando o diagrama de corpo livre de um míssil em voo de cruzeiro (nivelado e com velocidade constante) representado pela Figura 2.40, é possível desenvolver a Equação (2.156), onde m é a massa instantânea do míssil, $g$ é a aceleração devido à gravidade, $D$ é a força de arrasto e $L / D$ é a razão sustentação - arrasto.

$$
\mathfrak{I}=D=L\left(\frac{D}{L}\right)=\frac{m g}{\frac{L}{D}}
$$

A potência de empuxo é então dada pela Equação (2.157).

$$
\mathfrak{I} u=\frac{m g u}{\frac{L}{D}}
$$

Onde $u$ é a velocidade de voo.

Modificando a expressão acima e incluindo o conceito de eficiência de propulsão (Hill \& Peterson, 1992), obtém-se:

$$
\dot{m}_{f}=\frac{m g u}{\eta_{0} Q_{R}\left(\frac{L}{D}\right)}
$$


Nessa equação, $Q_{R}$ representa o poder calorífico do combustível e $\eta_{0}$ é a eficiência global do sistema de propulsão. Porém, uma vez que a massa combustível $\left(\dot{m}_{f}\right)$ faz parte da massa total do míssil $m$,

$$
\dot{m}_{f}=-\frac{d m}{d t} \quad \text { ou } \quad \dot{m}_{f}=-u \frac{d m}{d s},
$$

onde $s$ representa a distância percorrida na trajetória de voo. Substituindo a Equação (2.159) na Equação (2.158), segue que:

$$
\frac{d m}{d s}=-\frac{m g}{\eta_{0} Q_{R}\left(\frac{L}{D}\right)} .
$$

Se, como uma aproximação, o denominador $\eta_{0} Q_{R}(L / D)$ for considerado constante, o alcance $s$ do míssil pode ser obtido integrando-se a Equação (2.160) para obter a equação de alcance de Breguet (Equação (2.161)).

$$
s=\eta_{0}\left(\frac{L}{D}\right) \ln \frac{m_{1}}{m_{2}} \frac{Q_{R}}{g}
$$

Onde $m_{1}$ e $m_{2}$ são as massas inicial e final do míssil (durante o voo de cruzeiro), sendo que a diferença entre os dois é a massa de combustível consumido. Assim, o alcance é diretamente proporcional à eficiência global do sistema de propulsão $\eta_{0}$.

A importância desse termo estabelece um interesse em sua variação com a velocidade de voo e variáveis do motor. Se a razão combustível/ar $(f)$ for muito menor que um (o que geralmente ocorre) e o termo de pressão na equação de empuxo (Equação ( 2.104)) for desprezado, e se, por simplicidade, novamente for considerado fluxo de um único propelente, segue que:

$$
\eta_{0}=\frac{\left(u_{e}-u\right) u}{f Q_{R}}
$$

E que, para dado valor de $u_{e}, \eta_{0}$ é máximo para $u=u_{e} / 2$. 
É possível mostrar que isso pode ser modificado para expressar a eficiência global de um motor com fluxo de dois propelentes. É necessário apenas substituir a velocidade de exaustão $u_{e}$, pela velocidade de exaustão média $\overline{u_{e}}$, que é definida pela Equação (2.163).

$$
\overline{u_{e}}=\frac{\dot{m}_{a H}(1+f) u_{e H}+\dot{m}_{a C} u_{e C}}{\dot{m}_{a H}(1+f)+\dot{m}_{a C}}
$$

E substituir a razão combustível/ar $f$ pelo termo $f /\left[1+\left(\dot{m}_{a c} / \dot{m}_{a H}\right)\right]$; a razão combustível /ar é definida por $f=\dot{m}_{f} / \dot{m}_{a H}$. Portanto:

$$
\eta_{0}=\left(1+\frac{\dot{m}_{a C}}{\dot{m}_{a H}}\right) \frac{\left(\overline{u_{e}}-u\right) u}{f Q_{R}}
$$

Para dada razão $\dot{m}_{a c} / \dot{m}_{a H}$ e determinada velocidade de exaustão $\overline{u_{e}}$, a eficiência global do sistema de propulsão é aproximadamente maximizada para $u=\overline{u_{e}}, / 2$, uma generalização do resultado anterior.

Na seção 2.3.3 - Turbojato, são mostradas as razões e o modo como ocorre a variação da velocidade de exaustão $u_{e}$ e a razão combustível/ar $f$ com a velocidade de voo (ou o número de Mach do voo, $M$ ). Com os materiais disponíveis atualmente para emprego em motores e com as melhores configurações de projeto, o valor de $\eta_{0}$ tipicamente aumenta continuamente com o número de Mach do voo (Hill \& Peterson, 1992).

Entretanto, esses autores ressaltam que isso não significa que, para máximo alcance, o míssil deva voar com máximo número de Mach; a razão sustentação - arrasto $(L / D)$ também depende do número de Mach do voo como mostrado na seção 2.2 - Aerodinâmica. A razão $L / D$ comumente é muito menor para voo supersônico que para voo subsônico, e o produto $\eta_{0}(L / D)$ atinge um pico em voo subsônico, com número de Mach próximo de 1 . Por esta razão a maioria dos mísseis de cruzeiro de longo alcance é projetada para voar em número de Mach subsônico.

Para voo supersônico, quanto maior o número de Mach, melhor será o valor de $\eta_{0}(L / D)$. Mas maximizar $\eta_{0}(L / D)$ não basta por si só, pois quanto maior o número de Mach do voo, maior será a temperatura de superfície do míssil e, portanto, mais pesada poderá ser a 
estrutura para manter as tensões em níveis seguros. Logo a razão $m_{1} / m_{2}$ também tem que ser considerada na determinação da velocidade supersônica de voo mais econômica.

A equação de alcance em voo (Equação (2.165)) mostra que, para determinada velocidade de voo, o alcance do míssil é diretamente proporcional à relação entre empuxo e taxa de fluxo de combustível:

$$
s=\left(\frac{L}{D}\right) \ln \frac{m_{1}}{m_{2}} \frac{\mathfrak{I}}{\dot{m}_{f}} \frac{u}{g}
$$

Lembrando que o consumo específico de combustível (TSFC) - amplamente utilizado como indicador da qualidade do motor - é definido como:

$$
T S F C=\frac{\dot{m}_{f}}{\mathfrak{J}}
$$

Então, substituindo na Equação (2.165):

$$
s=\left(\frac{L}{D}\right) \ln \frac{m_{1}}{m_{2}} \frac{1}{T S F C} \frac{u}{g} .
$$

Alternativamente Fleeman (2012) apresenta a equação do alcance do míssil em função não de TSFC, mas sim de $I_{s p}$ (o significado físico de $I_{s p}$ for explicado na seção 2.3.1.2 Impulso Específico). Usando a relação de equivalência apresentada na Equação (2.168),

$$
I_{s p}=\frac{1}{T S F C} \frac{1}{g}
$$

Modifica-se a Equação (2.167) para obter a Equação (2.169):

$$
s=u I_{s p}\left(\frac{L}{D}\right) \ln \frac{m_{1}}{m_{2}} .
$$

A equação de alcance em voo de cruzeiro (Equação (2.169)) é função da massa do míssil no início do cruzeiro $\left(m_{1}\right)$, massa de propelente $\left(m_{1}-m_{2}\right)$, eficiência aerodinâmica $(L /$ 
$D)$, impulso específico $\left(I_{s p}\right)$ e velocidade de voo $(u)$. A Figura 2.41, adaptada do trabalho de Fleeman (2012), compara o alcance máximo em cruzeiro para um típico míssil com motor foguete, um com motor ramjet e um míssil subsônico com motor turbojato dotado de asas. A curva mais abaixo da figura refere-se ao motor foguete. É baseada é um valor típico máximo de propelente solido

$$
u I_{s p}\left(\frac{L}{D}\right)=610 \mathrm{~km}
$$

A curva intermediária é o alcance típico de um míssil com o motor ramjet. Utiliza parâmetros comuns deste tipo de motor, com uma estrutura axissimétrica (baixo $L / D$ ) de

$$
u I_{s p}\left(\frac{L}{D}\right)=3050 \mathrm{~km}
$$

Por fim, a curva superior representa o alcance com propulsor turbojato. É fundamentada também em valores e considera o uso de asas.

$$
u I_{s p}\left(\frac{L}{D}\right)=7625 \mathrm{~km}
$$




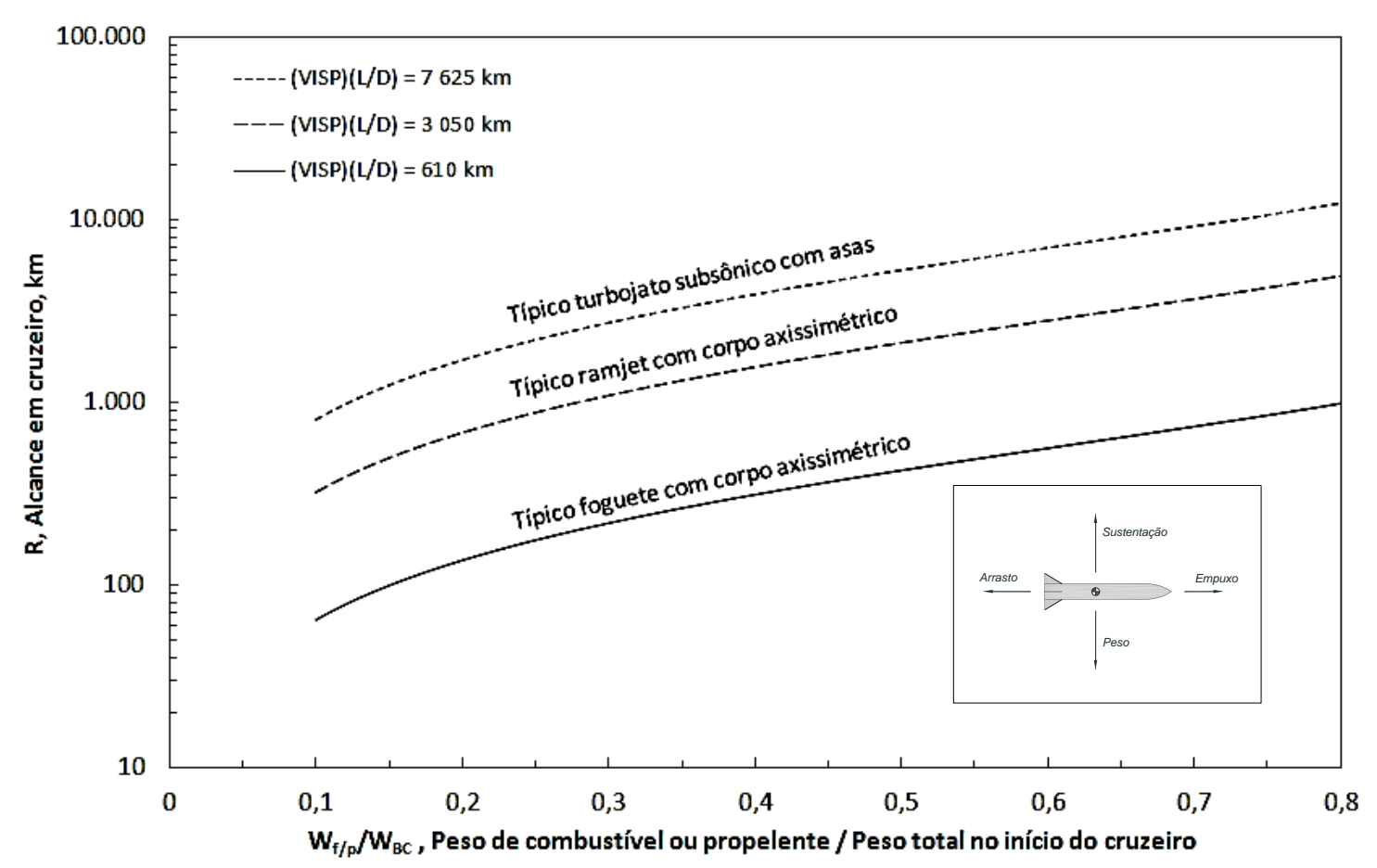

Figura 2.41 - Variação do alcance de voo para mísseis típicos com diferentes tipos de propulsão (Fleeman 2012, modificado).

As curvas estão mostradas em função da fração mássica de propelente ou combustível (em relação à massa de lançamento do míssil). Nota-se que, para um mesmo valor de fração mássica, o turbojato com asas promove o maior alcance, enquanto o motor foguete, $\mathrm{o}$ menor. Contudo, o foguete, em trajetória balística ou semibalística provavelmente teria um maior alcance que uma trajetória de voo em cruzeiro (Fleeman, 2012). Além disso, para o mesmo peso total do míssil, o foguete provavelmente teria uma maior fração mássica de propelente que o ramjet ou turbojato.

\subsubsection{3 - Desempenho de voo em coast}

Velocidade de coast e alcance são funções do tempo de coast do míssil, peso, massa específica do ar ambiente, área de referência do míssil (p.ex. área da seção transversal do corpo do míssil), coeficiente de arrasto parasita e velocidade inicial. Fleeman (2012) baseia-se na equação de movimento com um grau de liberdade (1 - GDL), com a consideração de ângulo de trajetória de voo $(\gamma)$ constante e baixo ângulo de ataque $(\alpha \approx$ 
$0^{\circ}$ ) para a obtenção de uma expressão para as condições de voo em coast, o que implica em $C_{D} \approx C_{D_{0}}$. A equação de movimento mais simples é:

$$
\frac{d u}{d t}=\frac{-g C_{D_{0}} S_{r e f} q}{W-g \sin \gamma}
$$

Integrando a Equação (2.170), chega-se à Equação (2.171) para a velocidade de coast do míssil.

$$
u=u_{i} \frac{\left\{1-\left[\frac{(g \sin \gamma)}{u_{i}}\right] t\right\}}{\left\{1+\left\{\frac{\left[g_{c} \rho_{\text {avg }} S_{R e f}\left(c_{D_{0}}\right)_{\text {avg }} u_{i}\right]}{(2 W)}\right\} t\right\}}
$$

Integrando novamente, o incremento de alcance durante voo em coast é dado pela Equação (2.172).

$$
\begin{gathered}
s=\left\{\frac{2 W}{\left[g_{c} \rho_{\text {avg }} S_{R e f}\left(C_{D_{0}}\right)_{\text {avg }}\right]}\right\} \ln \left\{1-\left[\frac{g_{c}^{2} \rho_{\text {avg }} S_{\text {Ref }}\left(C_{D_{0}}\right)_{\text {avg }}}{(2 W)}\right][\sin \gamma] t^{2}+\right. \\
\left.\left\{\frac{\left[g_{c} \rho_{\text {avg }} S_{\text {Ref }}\left(C_{D_{0}}\right)_{\text {avg }} u_{i}\right]}{(2 W)}\right\} t\right\} .
\end{gathered}
$$

O exame da equação acima mostra que os fatores que contribuem para voo em coast com longo alcance incluem uma alta velocidade inicial, baixo coeficiente de arrasto parasita e voo em grande altitude (atmosfera de baixa densidade).

O coeficiente de arrasto parasita $C_{D_{0}}$ varia durante a trajetória de voo em coast, devido a variações no número de Mach do voo. Uma abordagem para estimar o valor médio do coeficiente de arrasto parasita $\left(C_{D_{0}}\right)_{\text {avg }}$ é inicialmente calcular a condição de fim de coast, baseando-se no valor inicial de $C_{D_{0}}$. $\left(C_{D_{0}}\right)_{\text {avg }}$ é a média das estimativas de $C_{D_{0}}$ no início e no fim do voo em coast. Similarmente, a massa específica da atmosfera $\rho$ irá variar com mudanças de altitude. Considera-se que a massa específica média $\rho_{a v g}$ é a média da massa específica estimada entre o início e o fim do voo em coast. 
A velocidade de coast calculada pode ser decomposta em componentes horizontal e vertical pelas Equações abaixo:

$$
u_{x}=u \cos \gamma
$$

e

$$
u_{y}=u \sin \gamma
$$

Analogamente, o alcance do voo em coast por ser decomposto em:

$$
s_{x}=s \cos \gamma
$$

e

$$
s_{y}=s \sin \gamma
$$

\subsubsection{4 - Desempenho em voo balístico}

Segundo Fleeman (2012), velocidade e alcance de míssil em voo balístico são funções do tempo de voo do míssil, densidade atmosférica, área de referência do míssil, coeficiente de arrasto parasita, velocidade inicial e ângulo de trajetória inicial de voo. Para a obtenção de uma expressão para as condições de voo balístico, deve-se basear na equação de movimento com um grau de liberdade (1 - GDL) sob a consideração de ausência de empuxo $(\mathfrak{I}=0)$, ângulo de ataque nulo $\left(\alpha=0^{\circ}\right)$, força de arrasto maior que a componente do peso ao longo do eixo de arrasto $(D>W \sin \gamma)$ e erro devido à curvatura da terra desprezível. A equação simplificada para a componente horizontal de velocidade é:

$$
u_{x}=\frac{u_{i} \cos \gamma_{i}}{\left\{1+\left\{\frac{\left[g_{c} \rho_{a v g} S_{R e f}\left(c_{D_{0}}\right)_{a v g} V_{i}\right]}{(2 W)}\right\} t\right\}}
$$

A componente vertical de velocidade é dada pela Equação (2.178).

$$
u_{y}=\frac{u_{i} \sin \gamma_{i}}{\left\{1+\left\{\frac{\left[g_{c} \rho_{a v g} S_{R e f}\left(c_{D_{0}}\right)_{a v g} V_{i}\right]}{(2 W)}\right\} t\right\}-g_{c} t} .
$$


A distância horizontal percorrida (alcance) durante voo balístico é dada pela Equação ( 2.179). A posição vertical (altitude) durante voo balístico é dada pela Equação (2.180):

$$
\begin{gathered}
s_{x}=\left\{\frac{2 W \cos \gamma_{i}}{\left[g_{c} \rho_{a v g} S_{R e f}\left(C_{D_{0}}\right)_{\text {avg }}\right]}\right\} \ln \left\{1+\left\{\frac{\left[g_{c} \rho_{\text {avg }} S_{\text {Ref }}\left(C_{D_{0}}\right)_{\text {avg }} u_{i}\right]}{(2 W)}\right\} t,\right. \\
h=h_{i}+\left\{\frac{\left(2 W \sin \gamma_{i}\right)}{\left[g_{c} \rho_{a v g} S_{R e f}\left(C_{D_{0}}\right)_{\text {avg }}\right]}\right\} \ln \left\{1+\left\{\frac{\left[g_{c} \rho_{\text {avg }} S_{\text {Ref }}\left(C_{D_{0}}\right)_{\text {avg }} u_{i}\right]}{(2 W)}\right\} t-\right. \\
\left.g_{c} \frac{t^{2}}{2}\right\} .
\end{gathered}
$$

A análise das Equações acima mostra que os fatores que contribuem para voo balístico de longo alcance incluem alta velocidade inicial (velocidade após desativação do motor), baixo valor de coeficiente de arrasto parasita, ângulo de lançamento ótimo e voo em grande altitude (baixa densidade atmosférica).

O coeficiente de arrasto parasita $C_{D_{0}}$ varia durante voo balístico, devido às variações do número de Mach do voo. Uma abordagem que permite estimar o valor médio do coeficiente de arrasto parasita $\left(C_{D_{0}}\right)_{a v g}$ é, inicialmente, calcular a condição de fim de voo baseado no valor inicial de $C_{D_{0}}$. $\left(C_{D_{0}}\right)_{a v g}$ é a média do $C_{D_{0}}$ no número de Mach inicial e do $C_{D_{0}}$ no número de Mach do fim de voo. De modo análogo, a massa específica da atmosfera $(\rho)$ varia com mudanças de altitude (ver modelo atmosférico no Anexo $\mathrm{F}$ ATMOSFERA PADRÃO) de forma que a massa específica média $\rho_{a v g}$ é a média das massas específicas na altitude de voo inicial e altitude final. Para grandes variações de altitude, uma abordagem mais precisa seria um cálculo baseado na soma das mudanças incrementais nas equações acima para mudanças menores de altitude (Fleeman, 2012). 


\section{3 - METODOLOGIA}

\section{1 - OTIMIZAÇÃO}

Otimização é, em essência, a busca pelo resultado ótimo quando se trabalha dentro de um grupo de restrições (Venkataraman, 2008). Ela pressupõe o conhecimento das regras e relações de projeto do problema específico, principalmente a capacidade de descrever o projeto em termos matemáticos. Esses termos incluem variáveis de projeto, parâmetros de projeto e funções de projeto.

\subsection{1 - Variáveis de projeto}

Variáveis de projeto são entidades que definem um projeto específico. Os valores de um grupo completo dessas variáveis estabelecem um projeto particular. $\mathrm{Na}$ busca pelo projeto ótimo, os valores dessas entidades variam dentro de uma determinada faixa, por isso o uso do termo variáveis (Venkataraman, 2008).

O grupo de variáveis de projeto é identificado como vetor de projeto. O comprimento desse vetor $n$ é o número de variáveis de projeto no problema. As variáveis de projeto podem expressar diferentes grandezas dimensionais no problema, mas no modelo matemático eles são referenciados como $x$ para a variável e por $X$ para o vetor.

$$
X=\left\{x_{1}, x_{2}, \ldots, x_{n}\right\}
$$

\subsection{2 - Parâmetros de projeto}

Parâmetros de projeto identificam constantes que não variam enquanto diferentes projetos são gerados e comparados durante a otimização. Expressar o projeto e suas propriedades requer mais que variáveis de projeto. São exemplos de parâmetros as propriedades de materiais, cargas aplicadas, aceleração devido à gravidade etc. 


\subsection{3 - Funções de projeto}

As funções de projeto definem informações significativas sobre o projeto. Elas são calculadas usando as variáveis de projeto e parâmetros de projeto e definem o modelo matemático do problema. Essas funções podem representar objetivos e restrições do projeto. O objetivo do projeto é aquilo que motiva a busca pelas configurações ideais para o objeto. $\mathrm{O}$ cumprimento das restrições estabelece a validade do projeto.

\section{2 - ALGORITMOS GENÉTICOS}

\subsection{1 - Algoritmos genéticos}

Algoritmos genéticos (AG's) são técnicas de otimização inspirados na teoria da evolução como uma ferramenta para resolver problemas ${ }^{43}$. Eles empregam o conceito de simulação da evolução das espécies através da seleção, mutação e reprodução, processos estes que dependem do "desempenho" dos indivíduos desta espécie dentro do "ambiente" em que estão inseridos.

Os algoritmos genéticos funcionam mantendo uma população de estruturas (vetores de projeto) denominadas indivíduos ou cromossomos ${ }^{44}$. Opera-se sobre essas estruturas de forma semelhante à evolução das espécies. A estas estruturas são aplicados os chamados operadores genéticos, como crossover (recombinação) e mutação, entre outros. Cada indivíduo recebe uma avaliação, que é uma quantificação da sua qualidade como solução do problema em questão. Com base nesta avaliação são aplicados os operadores genéticos de forma a simular a sobrevivência do mais apto. Esse processo tende a gerar um processo

43 O Anexo E - ELEMENTOS DE BIOLOGIA FUNDAMENTAL contém algumas informações sobre os fundamentos da teoria da evolução.

$44 \mathrm{Na}$ área dos AG's, os termos cromossomo e indivíduo (denominado também vetor de variáveis de projeto) são sinônimos. 
de evolução natural destes indivíduos que eventualmente deve produzir um indivíduo caracterizando uma boa solução para o problema em estudo (talvez a melhor possível).

Os operadores genéticos consistem em aproximações computacionais de fenômenos vistos na natureza, como a reprodução, a mutação genética e quaisquer outros processos que possam ser modelados computacionalmente.

A reprodução (que neste trabalho será chamada de crossover) e a mutação são aplicadas em indivíduos selecionados dentro da população. A seleção deve ser feita de tal forma que os indivíduos mais aptos sejam selecionados mais frequentemente do que aqueles menos aptos, de forma que as boas características daqueles passem a predominar dentro da nova população de soluções ${ }^{45}$. A reprodução é a principal responsável pela evolução da população. A mutação cria diversidade, mudando aleatoriamente genes dentro de indivíduos e, assim como na natureza, é aplicada de forma menos frequente que a recombinação, que é o fruto da reprodução

A codificação da informação em cromossomos (vetor de variáveis de projeto) é um ponto crucial dentro do AG, e é, juntamente com a função de avaliação, o que liga o AG ao problema a ser resolvido.

Os algoritmos genéticos são extremamente dependentes de fatores estocásticos (probabilísticos), tanto na fase de inicialização da população quanto na fase de evolução, principalmente durante a seleção dos pais. Isto faz com que os seus resultados raramente sejam perfeitamente reprodutíveis. Ademais, os algoritmos genéticos, não asseguram a obtenção do melhor resultado possível em todas as suas execuções.

\footnotetext{
45 De forma alguma os indivíduos menos aptos têm que ser descartados da população reprodutora. Isto causaria uma rápida convergência genética de todas as soluções para um mesmo conjunto de características e evitaria uma busca mais ampla pelo espaço de soluções. A convergência genética se traduz em uma população com baixa diversidade genética que, por possuir genes similares, não consegue evoluir, a não ser pela ocorrência de mutações aleatórias que sejam favoráveis. Isto pode ser traduzido em outro conceito interessante que é a perda da diversidade, que pode ser definida como sendo o número de indivíduos que nunca são escolhidos pelo método de seleção de pais. Quando maior for a perda de diversidade, mais rápida será a convergência genética do AG (Blickle \& Thiele, 1997).
} 
Os algoritmos genéticos (AG's) são técnicas de otimização global. A questão da otimização global opõe os AG's aos métodos como gradiente (hill climbing), que seguem a derivada de uma função de forma a encontrar o máximo de uma função. O método do gradiente fica facilmente retido em máximos locais, como é possível ver na figura seguinte.

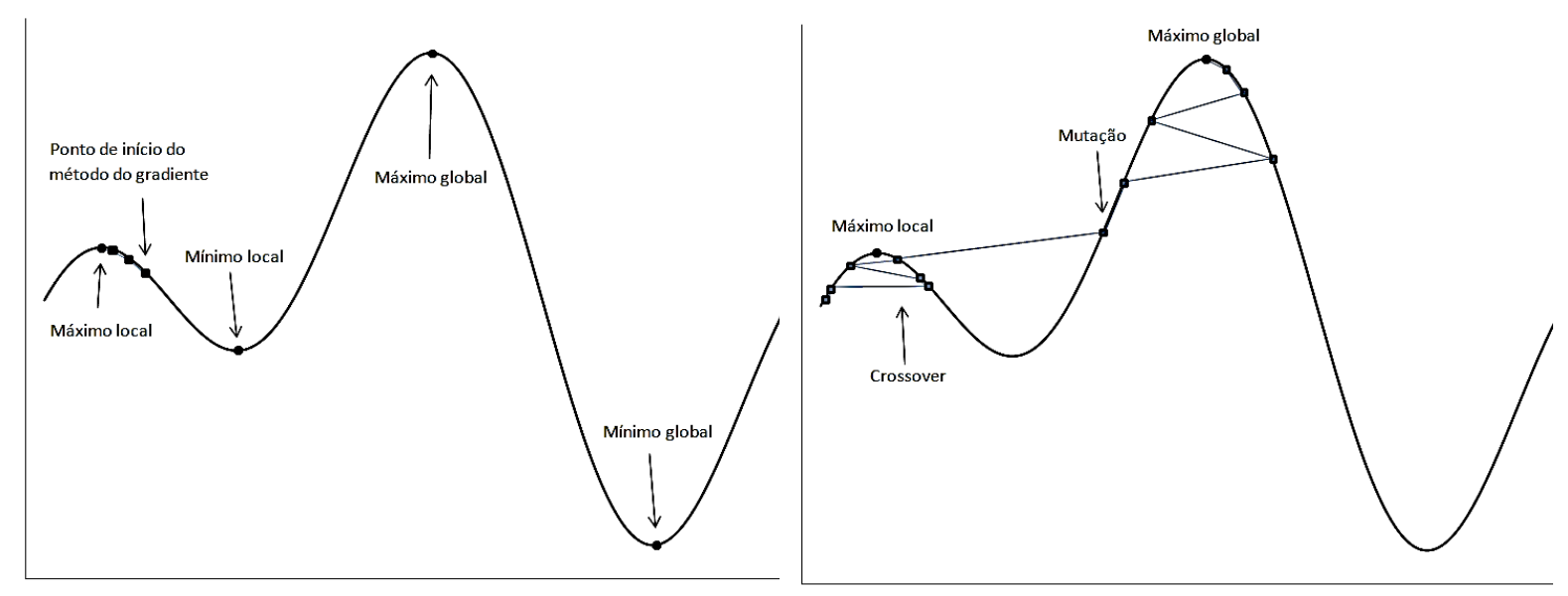

Figura 3.1 - Função hipotética com máximos e mínimos locais e globais método do gradiente.
Figura 3.2 - Função hipotética com máximos e mínimos locais e globais algoritmo genético.

\subsection{2 - Características de AG's}

De forma geral, AG’s são técnicas probabilísticas e não técnicas determinísticas. Assim sendo, um AG com a mesma população inicial e o mesmo conjunto de parâmetros de projeto pode encontrar soluções diferentes cada vez que é executado.

Os algoritmos genéticos trabalham com uma grande população de cromossomos, sendo uma técnica de busca no espaço de soluções. Um AG diferencia-se dos esquemas enumerativos pelo fato de não procurar em todos os pontos possíveis mas sim em um (espera-se, pequeno) subconjunto desses pontos. Além disso, os AG's diferenciam-se de esquemas aleatórios por utilizar informação pertinente ao problema durante o processo de busca, equivalente ao processo natural. Isto quer dizer que, apesar de determinar o 
conjunto de pontos a ser percorrido de forma aleatória, os algoritmos genéticos não podem ser chamados de buscas aleatórias não-direcionadas, pois exploram informações históricas para encontrar novos pontos de busca, onde são esperados bons desempenhos (Carvalho, Braga \& Ludermir, 2003).

Essa exploração é feita através do uso da função de avaliação como guia na escolha dos elementos reprodutores (pais). Existem fatores estocásticos associados ao processo, entretanto, busca-se usar as características existentes no instante atual para tentar caminhar na direção mais adequada. Isto quer dizer que os AG's não são processos puramente estocásticos, mas sim uma busca direcionada no espaço de soluções.

É importante salientar também que os algoritmos genéticos trabalham com uma forma codificada dos parâmetros a serem otimizados e não com os parâmetros propriamente ditos. Assim, deve ser definido um esquema de codificação e decodificação destes parâmetros. Isto equivale à representação cromossomial citada anteriormente.

Por outro lado, não importa ao AG como é codificada ou decodificada a informação dos parâmetros. Ele só se importa com a representação em si. Toda a informação relativa ao problema está contida na função de avaliação do problema, que embute os módulos de codificação e decodificação dos parâmetros. Assim, um mesmo AG pode ser utilizado para uma infinidade de problemas, necessitando-se apenas que seja mudada a função de avaliação.

\section{3 - FUNCIONAMENTO DE UM ALGORITMO GENÉTICO}

\subsection{1 - Esquema básico de um AG}

O funcionamento de um algoritmo genético pode ser resumido algoritmicamente através dos seguintes passos (Gen \& Cheng, 1997): 
Passo 1 Estabelecer uma população inicial $P(0)$ - um conjunto inicial de soluções ou cromossomos;

Passo 2 Avaliar as soluções iniciais para aptidão, comparar e atribuir um valor a cada uma delas;

Passo 3 Índice da geração $t=0$;

Passo 4 Elitismo - Selecionar grupo preservado para a próxima geração;

Passo 5 Seleção - Selecionar os pais por meio de processo seletivo para gerar novos cromossomos;

Passo 6 Utilizar os operadores genéticos (crossover, mutação) para gerar o conjunto de filhos;

Passo 7 Apagar os velhos membros da população;

Passo 8 Acrescentar um grupo de população randomicamente gerado (imigrantes);

Passo 9 Reavaliar a aptidão da população;

Passo 10 Se o número de gerações atingiu um máximo determinado ou o melhor cromossomo satisfaz os requerimentos e desempenho, retorne-o, caso contrário, índice da geração $t \leftarrow t+1$ e volte para o Passo 4 .

Figura 3.3 - Algoritmo genético genérico.

\subsection{2 - Representação cromossomial}

A representação cromossomial consiste em uma maneira de codificar a informação do problema de forma viável a ser tratada pelo computador. Cada parte indivisível desta representação é chamada de gene, por analogia com as partes fundamentais que compõem um cromossomo biológico.

Linden (2012) afirma que a representação cromossomial é completamente arbitraria, ficando sua definição de acordo com aquele que programa o $\mathrm{AG}$ e com a adequação ao problema. Todavia, é interessante que algumas regras gerais sejam seguidas:

1. A representação deve ser a mais simples possível;

2. Se houver soluções proibidas ao problema, então é preferível que elas não tenham uma representação; 
3. Se o problema impuser condições de algum tipo, estas devem estar implícitas dentro da representação.

\subsection{3 - Escolha da população inicial}

A inicialização da população é feita fazendo-se uma escolha aleatória independente para cada indivíduo (ou genes dos indivíduos) da população inicial. A lei das probabilidades sugere que teremos uma distribuição cobrindo praticamente todo o espaço de soluções. Mas isto não pode ser garantido pois a população tem tamanho finito. Caso o número de amostras seja pequeno, a distribuição de valores pode não ser muito homogênea.

Linden (2012) declara que a prática da área de AG é usar a estratégia mais simples de inicialização. Isto consiste em simplesmente escolher $n$ indivíduos de forma aleatória. A inicialização aleatória de forma geral produz uma boa distribuição das soluções no espaço de busca e o uso do operador de mutação de forma eficaz garante uma boa exploração do todo o espaço de busca.

\subsection{4 - Função de avaliação}

A função de avaliação é a maneira utilizada pelos AG's para determinar a qualidade de um indivíduo como solução do problema em questão. A função de avaliação calcula um valor numérico que reflete quão bem os parâmetros representados no cromossomo resolvem o problema. Isto é, ela usa todos os valores armazenados no cromossomo e retorna um valor numérico, cujo significado é uma métrica da qualidade da solução obtida usando-se aqueles parâmetros.

A função de avaliação deve embutir todo o conhecimento sobre o problema a ser resolvido, tanto suas restrições quanto seus objetivos de qualidade. A função de avaliação também deve diferenciar entre duas soluções quaisquer, deixando claro qual delas está mais próxima da solução procurada. 
O mais importante conceito é que a função de avaliação deve refletir os objetivos a serem alcançados na resolução de um problema e é derivada diretamente das condições impostas por ele.

Quando se trabalha com funções com múltiplos objetivos, é preciso estabelecer uma forma de determinar o vetor de projeto que representa uma solução de qualidade superior. Isso ocorre pois é difícil obter um vetor que garanta a maximização (ou minimização) de todos os objetivos, especialmente em problemas que têm funções com objetivos mutuamente excludentes.

Como já explicado, algoritmos genéticos trabalham transformando uma representação cromossomial em um número representativo da qualidade da solução, a função de avaliação. Quando são considerados múltiplos objetivos, pode-se considerar que existe um vetor de funções de avaliação, $f(X)=\left\{f_{1}(X), f_{2}(X), \ldots, f_{k}(X)\right\}$. Portanto, é possível transformar este vetor em um único escalar através da aplicação de pesos a cada um dos objetivos, obtendo uma função de avaliação com o formato da Equação ( 3.1).

$$
g(X)=\sum_{i=1}^{k} w_{i} f_{i}(X)
$$

\subsection{5 - Seleção de pais}

O método de seleção de pais deve simular o mecanismo de seleção natural que atua sobre as espécies biológicas, em que os pais mais capazes geram mais filhos, ao mesmo tempo em que permite que os pais menos aptos também gerem descendentes.

Conforme Linden (2012), o conceito fundamental é que deve-se privilegiar os indivíduos com função de avaliação alta, sem desprezar completamente aqueles indivíduos com função de avaliação extremamente baixa. Essa decisão é razoável porque até indivíduos com péssima avaliação podem ter características genéticas que sejam favoráveis à criação de um indivíduo que seja a melhor a solução para o problema sob análise, características estas que podem não estar presentes em nenhum outro cromossomo da população. 
É importante destacar que permitir que apenas os melhores indivíduos se reproduzam faz com que a população tenda a ser composta de indivíduos cada vez mais semelhantes, o que resulta em perda de diversidade a esta população, efeito denominado convergência genética. Selecionando também os indivíduos menos aptos da população pode-se evitar ou pelo menos minimizar esse efeito.

Existem diversos métodos de seleção de pais em algoritmos genéticos. Cita-se como exemplo, dentre outros, o método da roleta viciada e método do torneio. Neste trabalho optou-se pelo método do torneio, pele fato deste apresentar algumas vantagens em relação aos demais métodos.

\subsubsection{1 - Método do torneio}

O método do torneio, como o próprio nome indica, consiste em selecionar uma série de indivíduos da população e fazer com que eles entrem em competição direta pela oportunidade de gerarem filhos, competindo através dos valores de suas avaliações.

Neste método existe um parâmetro denominado tamanho do torneio que define quantos indivíduos são selecionados aleatoriamente dentro da população para competir. Uma vez definidos os competidores, aquele dentre eles que possuir a melhor avaliação será selecionado para a aplicação dos operadores genéticos.

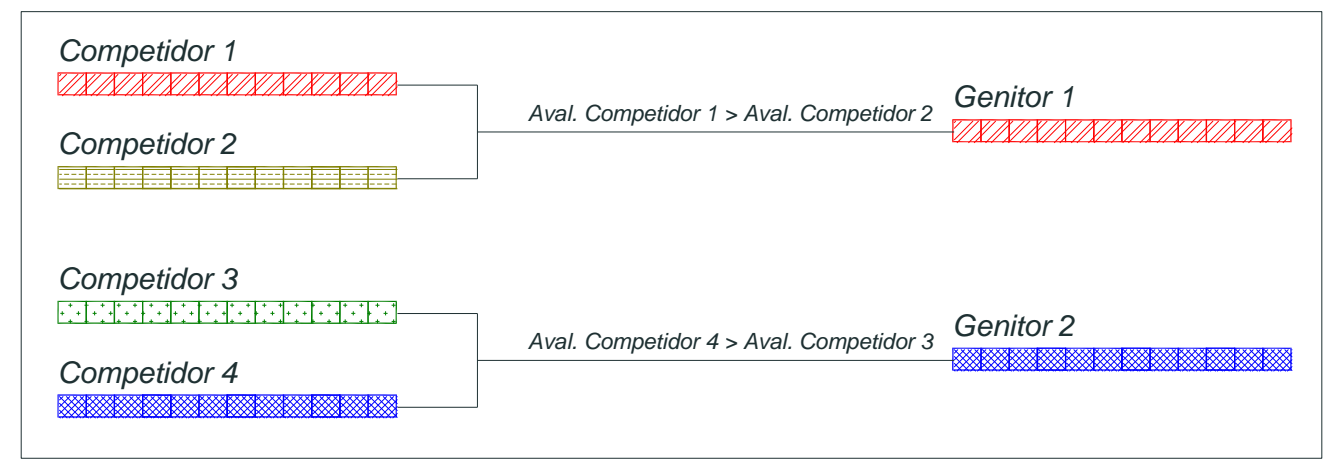

Figura 3.4 - Diagrama esquemático da seleção de pais pelo método do torneio.

O valor mínimo do tamanho do torneio é igual a dois, pois com menos que dois indivíduos não haverá competição. O valor máximo é o tamanho da população. Contudo, se for 
escolhido o valor igual ao tamanho da população, o vencedor será sempre o mesmo (o melhor de todos os indivíduos). Se forem escolhidos valores próximos do tamanho da população, um dado grupo de indivíduos tenderá a predominar, uma vez que sempre um destes será o vencedor do torneio.

Os indivíduos são selecionados para participar do torneio de forma completamente aleatória. Não existe nenhum favorecimento para os melhores indivíduos, como no caso da roleta viciada. A única vantagem que os melhores indivíduos da população têm é que, se selecionados, eles vencerão o torneio.

\subsection{6 - Operadores genéticos}

\subsubsection{1 - Operador crossover}

O operador crossover mais simples é chamado de operador crossover de um ponto. Este operador tem um funcionamento da seguinte forma: após a seleção de dois pais (genitores) pelo módulo de seleção, um ponto de corte é selecionado. Um ponto de corte constitui uma posição entre dois genes de um cromossomo. Cada indivíduo com $n$ genes contém $n-1$ pontos de corte, e este ponto de corte é o ponto de separação entre cada um dos genes que compõem o material genético de cada pai.

Depois de selecionado o ponto de corte, separa-se os genitores em duas partes: uma à esquerda do ponto de corte e outra à direita. O primeiro filho será formado através da concatenação da parte do primeiro pai à esquerda do ponto de corte com a parte do segundo pai (mãe) à direita do ponto de corte. O segundo filho é composto através da concatenação das partes que sobraram (a metade do segundo pai (mãe) à esquerda do ponto de corte com a metade do primeiro pai à direita do ponto de corte).

É simples entender o motivo pelo qual este operador é denominado crossover de um ponto. Afinal, só é utilizado um ponto de corte. Evidentemente, se fossem selecionados dois pontos de corte haveria um crossover de dois pontos. A Figura 3.5 descreve esse processo com dois pontos de corte. 


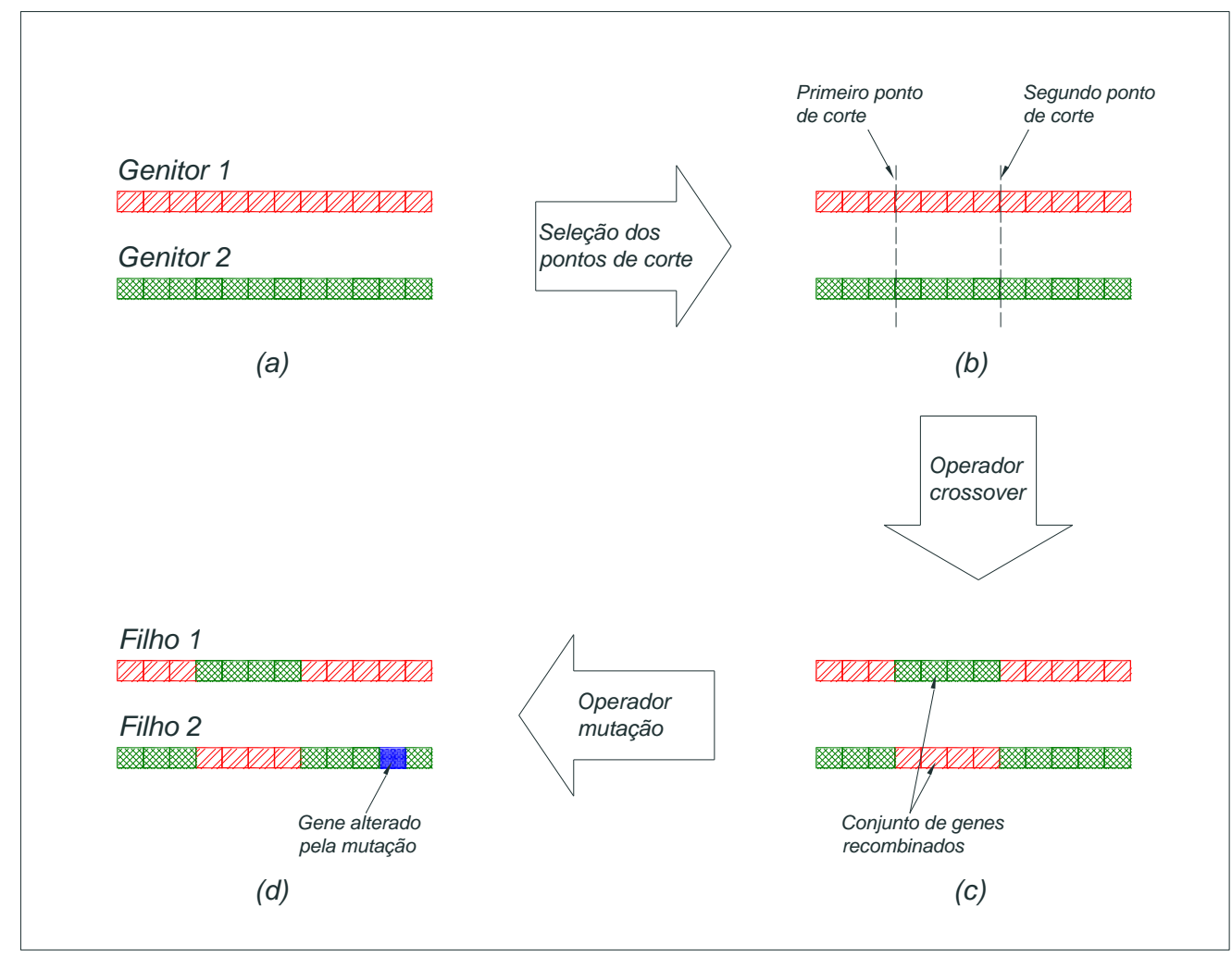

Figura 3.5 - Diagrama esquemático do funcionamento dos operadores crossover e mutação do algoritmo genético.

\subsubsection{2 - Operador de mutação}

Depois de compostos os filhos, aplica-se sobre eles o operador de mutação. Este opera da seguinte forma: a ele é associada uma probabilidade extremamente baixa (da ordem de $0,5 \%)$ e é gerado um número aleatório entre 0 e 1 . Se este número for menor que a probabilidade predeterminada então o operador atua sobre o gene em questão, alterando o valor aleatoriamente. Repete-se então o processo para todos os genes componentes dos filhos.

O conceito fundamental quanto ao valor da probabilidade de mutação é que ele deve ser baixo. Se ele for muito alto, o algoritmo genético se comportará como uma técnica de busca aleatória, na qual a solução é determinada de forma estocástica (simplesmente sorteando-se elementos sem usar informações correntes ou passadas). 
O operador de mutação é fundamental para um AG, pois garante a continuidade da existência de diversidade genética na população ao passo que o operador de crossover contribui fortemente para a igualdade entre os indivíduos (convergência genética). Tecnicamente, é possível dizer que o operador de mutação é uma técnica exploratória, que insere novos genes na população e permite que o AG busque soluções fora dos limites definidos pela população inicial (Vose, 2004).

\subsection{7 - Módulo de população}

O módulo de população é responsável pelo controle da população de indivíduos do AG. Por uma questão de simplicidade, assume-se que esta população não possa crescer, o que permite que a população seja armazenada em um vetor de tamanho constante. Logo, os pais têm que ser substituídos conforme os filhos vão sendo gerados.

O módulo de população utilizado é extremamente simples. Cada atuação dos operadores genéticos criam-se dois filhos. Estes vão sendo armazenados em um espaço auxiliar até que o número de filhos criados seja igual ao tamanho da população. Em seguida os pais são descartados e os filhos tornam-se os indivíduos da nova geração.

\subsection{8 - Tamanho da população}

O desempenho do algoritmo genético é extremamente sensível ao tamanho da população. Esse parâmetro deve ser definido com muito cuidado. Caso este número seja pequeno demais, não haverá espaço para existir uma variedade genética suficientemente grande dentro da população, o que fará com que o algoritmo genético seja incapaz de encontrar boas soluções. Caso este número seja grande demais, o algoritmo será muito lento e a característica evolutiva diminuirá, fazendo com que o método se pareça com uma busca aleatória.

Linden (2012) afirma ser difícil prever com precisão o tamanho mínimo para o qual o AG ainda terá um bom desempenho, pois este limite varia com o número de genes presentes 
em cada individuo. O mesmo autor declara que a capacidade de armazenamento de estados de um AG é exponencialmente proporcional ao número de indivíduos presentes. Consequentemente, há um limite para o tamanho da população onde ainda verifica-se melhora do desempenho conforme o tamanho da população aumenta.

O número de indivíduos avaliados em uma execução do $\mathrm{AG}$ é igual ao número de indivíduos na população multiplicado pelo número de gerações executadas pelo algoritmo. Logicamente este número não é preciso pois podem ocorrer repetições nos indivíduos em diferentes gerações. Este número serve como um ponto de partida para uma estimativa de população necessária. É interessante considerar este número total e verificar o percentual do espaço de busca coberto pela execução total do AG. Se a porcentagem de soluções avaliadas for muito alta deve-se considerar alguma técnica alternativa de resolução do problema. Por outro lado, a dificuldade da função de avaliação deve ser um fator que afete a escolha destes dois parâmetros.

\subsection{9 - Elitismo}

Elitismo é uma pequena modificação no módulo de população que quase não altera o tempo de processamento garantindo o desempenho crescente do AG com o decorrer das gerações. A ideia básica do elitismo é preservar um determinado número de melhores indivíduos de cada geração e manter seus cromossomos inalterados para a próxima geração.

A manutenção do melhor individuo da geração atual na próxima geração garante que o melhor individuo da próxima geração seja pelo menos igual ao melhor indivíduo da geração atual (na hipótese de nenhum indivíduo melhor ser criado). 


\section{4 - O PROGRAMA SCORPIO 1.0}

Para o estudo e solução do problema proposto foi desenvolvido um programa ${ }^{46}$ com a capacidade de prever o desempenho de representações de mísseis táticos de acordo com os modelos discutidos neste trabalho. O programa desenvolvido é capaz de produzir processo de busca de mísseis aptos ${ }^{47}$ a cumprir determinados requisitos técnico-operacionais. $\mathrm{O}$ programa, que emprega algoritmo genético como técnica de otimização, foi nomeado Scorpio 1.0 (primeira versão) ${ }^{48}$.

Para fins de esclarecimento acerca do funcionamento do Scorpio 1.0, serão comentadas separadamente as partes relativas ao algoritmo genético (AG) e aquela correspondente à função de avaliação (dimensionamento e avaliação do míssil), na forma que se segue.

\subsection{1 - O AG incorporado no programa Scorpio 1.0}

O programa criado para a solução do problema proposto utiliza representação cromossomial com números reais (em contraste com representação binária). As soluções proibidas são evitadas pela adequada definição dos limites de cada variável de projeto (gene). Soluções indesejáveis ou tecnicamente inviáveis são evitadas através de imposição de penalizações na avaliação dessas soluções.

Para o problema específico da previsão de desempenho de mísseis táticos, foram identificadas 22 variáveis de projeto com grande influência e independência linear. Estas variáveis serão discutidas com mais detalhes na próxima seção.

\footnotetext{
${ }^{46}$ O programa desenvolvido foi escrito na linguagem MATLAB R2013a.

${ }^{47}$ Nas seções anteriores foi discutida brevemente a questão de resultados ótimos ou próximos dele. Como foi dito e será mostrado, um algoritmo genético não necessariamente produz o melhor resultado possível todas as vezes que ele é executado. Todavia o programa desenvolvido foi capaz de fornecer resultados "evoluídos" em todas execuções a que foi submetido.

${ }^{48}$ Scorpio era um tipo de peça de artilharia romana que foi descrito em detalhes por Vitruvius (80-70 a.C 15 d.C.) (Warry, 1995).
} 
A população inicial é escolhida de forma randômica pelo algoritmo e é composta por genes possíveis existentes entre os limites superiores e inferiores estabelecidos pelo usuário. $\mathrm{O}$ usuário tem também a possibilidade de definir o espaçamento disponível entre os genes (incremento das variáveis de projeto), aumentando ou diminuindo o número de soluções (e possivelmente a qualidade da solução) dentro do espaço delimitado inferior e superiormente. A escolha do tamanho da população faz parte das atribuições do usuário. Durante a elaboração, testes e verificação do programa, não foi identificado um limite superior para este valor que, possivelmente existe e está relacionado com a memória disponível para a execução do algoritmo. O tamanho da população deve ser um número par maior que 2 .

A seleção de pais para gerar filhos para a geração seguinte é feita pelo método do torneio, com dois participantes, de acordo com a Figura 3.4. Cada par de pais gera 2 filhos que são inseridos na população da geração seguinte. Para a geração dos filhos é utilizado crossover de dois pontos, conforme ilustrado na Figura 3.5.

A taxa de mutação, definida pelo usuário, pode assumir valor constante ou variável ao longo das gerações (valores distintos no início e fim da execução do programa). A variação da taxa de mutação ao longo da execução é feita através da definição de uma taxa de mutação inicial e uma taxa de mutação final. Na hipótese de elas serem iguais no início e fim da execução, a taxa de mutação se manterá inalterada. A vantagem da taxa de mutação variável (crescente) foi apresentada anteriormente e, como será visto, foi adotada em alguns casos neste trabalho.

Para preservar um grupo de indivíduos possuidores das melhores avaliações é utilizada a estratégia de elitismo. O número de indivíduos que compõem este grupo é definido pelo usuário, tendo limite inferior igual a um e limite superior igual ao número total da população menos o número do grupo de migrantes (descrito a seguir).

Para a preservação da diversidade de genética, paralelamente à taxa de mutação, é utilizado ainda o conceito de imigrantes na população, sendo que o número de imigrantes, também constante ao longo das gerações, é definido pelo usuário e deve ser igual ou menor que o tamanho total da população menos o tamanho do grupo de elite. 
No programa desenvolvido, a função de avaliação aplicada é mantida constante ao longo das gerações na execução do AG. A Tabela 3.1 apresenta resumidamente as características do algoritmo genético implementado no programa Scorpio 1.0.

Tabela 3.1 - Características do AG incorporado no programa Scorpio 1.0.

\begin{tabular}{ll}
\hline Quantidades de genes & 22 \\
\hline Representação do cromossomo & Real (valores discretos) \\
\hline População inicial & Gerada aleatoriamente dentro dos limites informados \\
\hline Função de avaliação & Pesos definidos pelo usuário \\
\hline Método de seleção de pais & Método do torneio (2 indivíduos) \\
\hline Operador Crossover & 2 pontos \\
\hline Taxa de mutação & Fixa ou variável \\
\hline Tamanho da população & Determinado pelo usuário (fixo durante execução) \\
\hline Número de gerações & Determinado pelo usuário \\
\hline Critério de parada & Número máximo de gerações/Avaliação suficiente \\
\hline Avaliação Suficiente & Determinado pelo usuário \\
\hline Tamanho do grupo de elite & Determinado pelo usuário \\
\hline Tamanho grupo de imigrantes & Determinado pelo usuário \\
\hline
\end{tabular}

Tal como descrição contida na seção 3.3.1 -Esquema básico de um AG, a Figura 3.6 contém o fluxograma de funcionamento do algoritmo genético desenvolvido. O símbolo de ponto de decisão representa um loop no programa onde são verificadas duas condições que podem interromper a execução do AG na geração em que se encontra, a saber, atingimento de número máximo de gerações ou obtenção de melhor indivíduo com avaliação suficiente. Caso uma destas condições seja satisfeita, o loop é encerrado. Tanto o número máximo de gerações como a avaliação considerada suficiente, são dados fornecidos pelo usuário.

Uma vez que um AG é um programa genérico de otimização e que as únicas relações dele com o problema a ser otimizado ocorrem através da função de avaliação e das variáveis de projeto, o AG desenvolvido pode ser utilizado para otimizar não apenas mísseis táticos, mas qualquer problema que possa ser expresso na forma de uma função de avaliação ${ }^{49}$.

49 Essa característica será utilizada no próximo capítulo durante a verificação do algoritmo genético desenvolvido. 


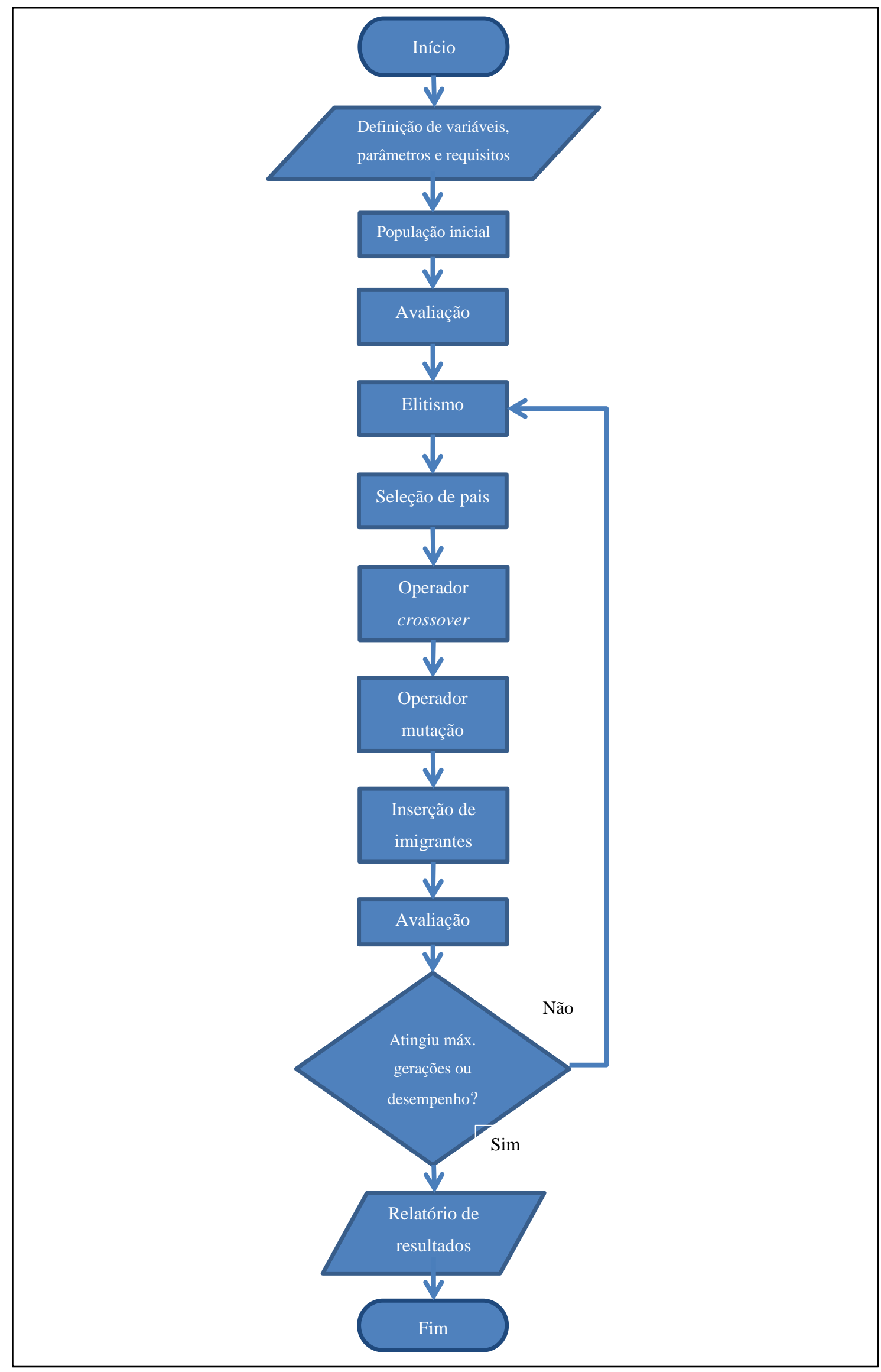

Figura 3.6 - Fluxograma do algoritmo genético implementado no programa Scorpio 1.0. 


\subsection{2 - A função de avaliação no programa Scorpio 1.0}

O conjunto de rotinas do bloco Avaliação (Figura 3.6) é a parte que consome maior parcela do tempo de execução do Scorpio 1.0. Apesar de esse conjunto ser denominado simplesmente Avaliação, ele é na verdade formado pelo grupo de atividades descrito no fluxograma da Figura 3.7 que inclui não somente a Função de Avaliação, mas também as rotinas relacionadas aos dados atmosféricos, propriedades aerodinâmicas, sistemas de propulsão, peso e trajetória do míssil.

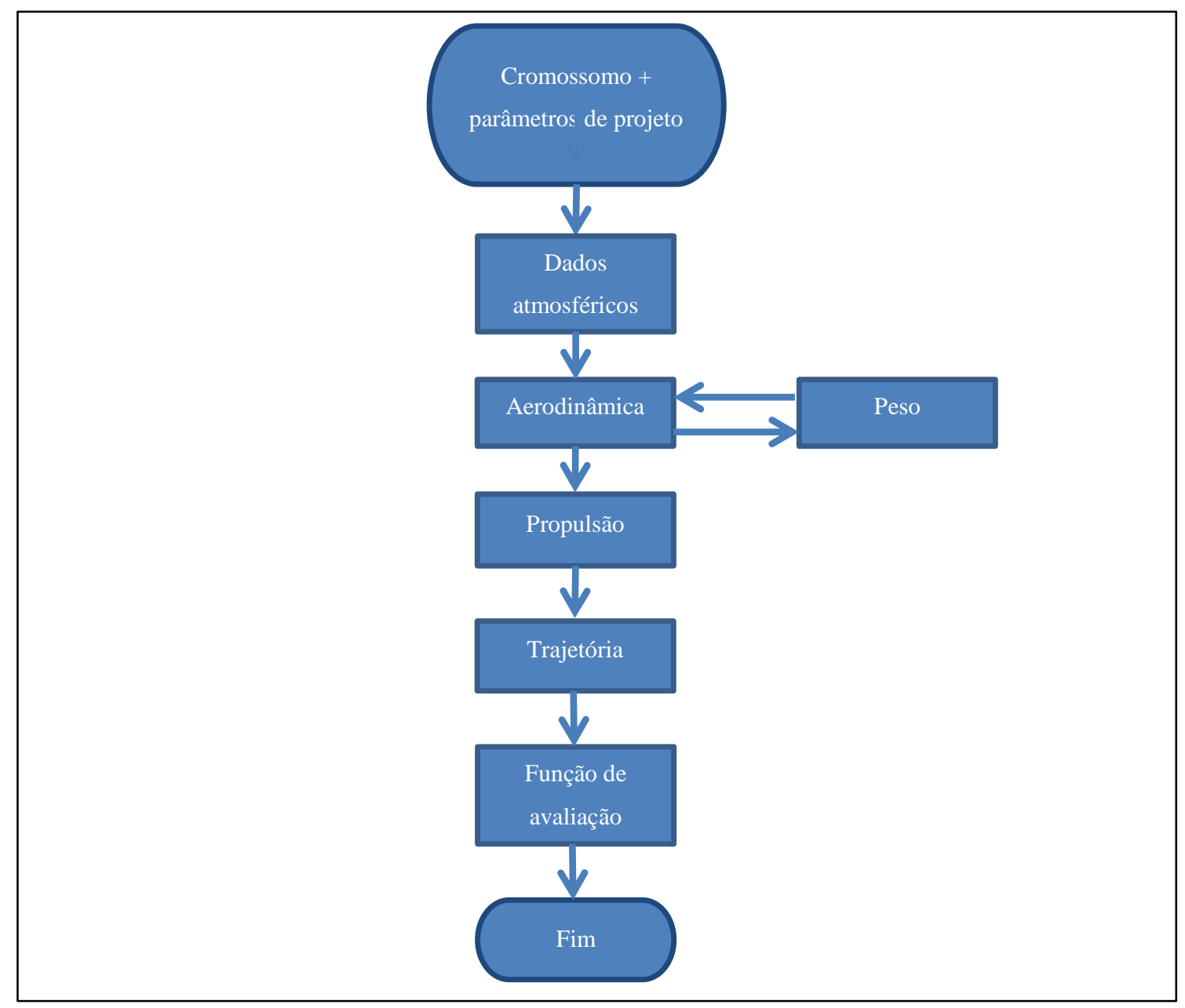

Figura 3.7 - Fluxograma da função de avaliação implementada no programa Scorpio 1.0.

O processo formado pelas rotinas no fluxograma realiza, a partir do cromossomo de entrada e juntamente com os parâmetros e requisitos de projeto, o dimensionamento dos elementos do míssil, que são dependentes dos genes do cromossomo do míssil e o avalia 
conforme os requisitos de desempenho. O processo mostrado no fluxograma acima é repetido para cada míssil avaliado durante a execução do Scorpio 1.0.

\subsubsection{1 - Cromossomo de um míssil}

Como já mencionado, o cromossomo de um míssil tático será formado por vinte e dois genes. Esse genes, listados abaixo e mostrados esquematicamente na forma de um cromossomo (Figura 3.8), foram escolhidos de forma a representar as principais variáveis de projeto para o processo de otimização.

Tabela 3.2 - Genes componentes do cromossomo de um míssil.

\begin{tabular}{cl}
\hline Gene $\mathbf{n}^{\mathbf{0}}$ & Variável de projeto \\
\hline $\mathbf{1}$ & Altitude de voo de cruzeiro (m) \\
$\mathbf{2}$ & Diâmetro externo do míssil (m) \\
$\mathbf{3}$ & Comprimento do míssil (m) \\
$\mathbf{4}$ & Comprimento do nariz do míssil (múltiplo do diâmetro) \\
$\mathbf{5}$ & Taper ratio da asa (adimensional) \\
$\mathbf{6}$ & Taper ratio da cauda (adimensional) \\
$\mathbf{7}$ & Corda aerodinâmica da raiz da asa (m) \\
$\mathbf{9}$ & Corda aerodinâmica da raiz da cauda (m) \\
$\mathbf{1 0}$ & Enflechamento da asa (graus) \\
$\mathbf{1 1}$ & Ângulo total da seção do bordo de ataque das sup. Aerodinâmicas (graus) \\
$\mathbf{1 2}$ & Envergadura total da asa (m) \\
$\mathbf{1 3}$ & Envergadura total da cauda (m) \\
$\mathbf{1 4}$ & Número de painéis da asa (adimensional) \\
$\mathbf{1 6}$ & Número de painéis da cauda (adimensional) \\
$\mathbf{1 7}$ & Número de Mach de voo em cruzeiro (adimensional) \\
$\mathbf{1 8}$ & Posição longitudinal da raiz da asa (múltiplo do comprimento do corpo) \\
$\mathbf{1 9}$ & Temperatura de combustão (K) \\
$\mathbf{2 0}$ & Ângulo inicial de voo após o cruzeiro (graus) \\
$\mathbf{2 1}$ & Fração mássica do combustível de cruzeiro (adimensional) \\
$\mathbf{2 2}$ & Relação de pressões no compressor (adimensional) \\
\hline
\end{tabular}

Ressalta-se que podem ser aplicadas outras variáveis para projeto de mísseis táticos em função da forma como são implementadas as rotinas de cálculo e dimensionamento do 
míssil. A Figura 3.8 mostra esquematicamente um cromossomo de um míssil conforme utilizado neste trabalho.

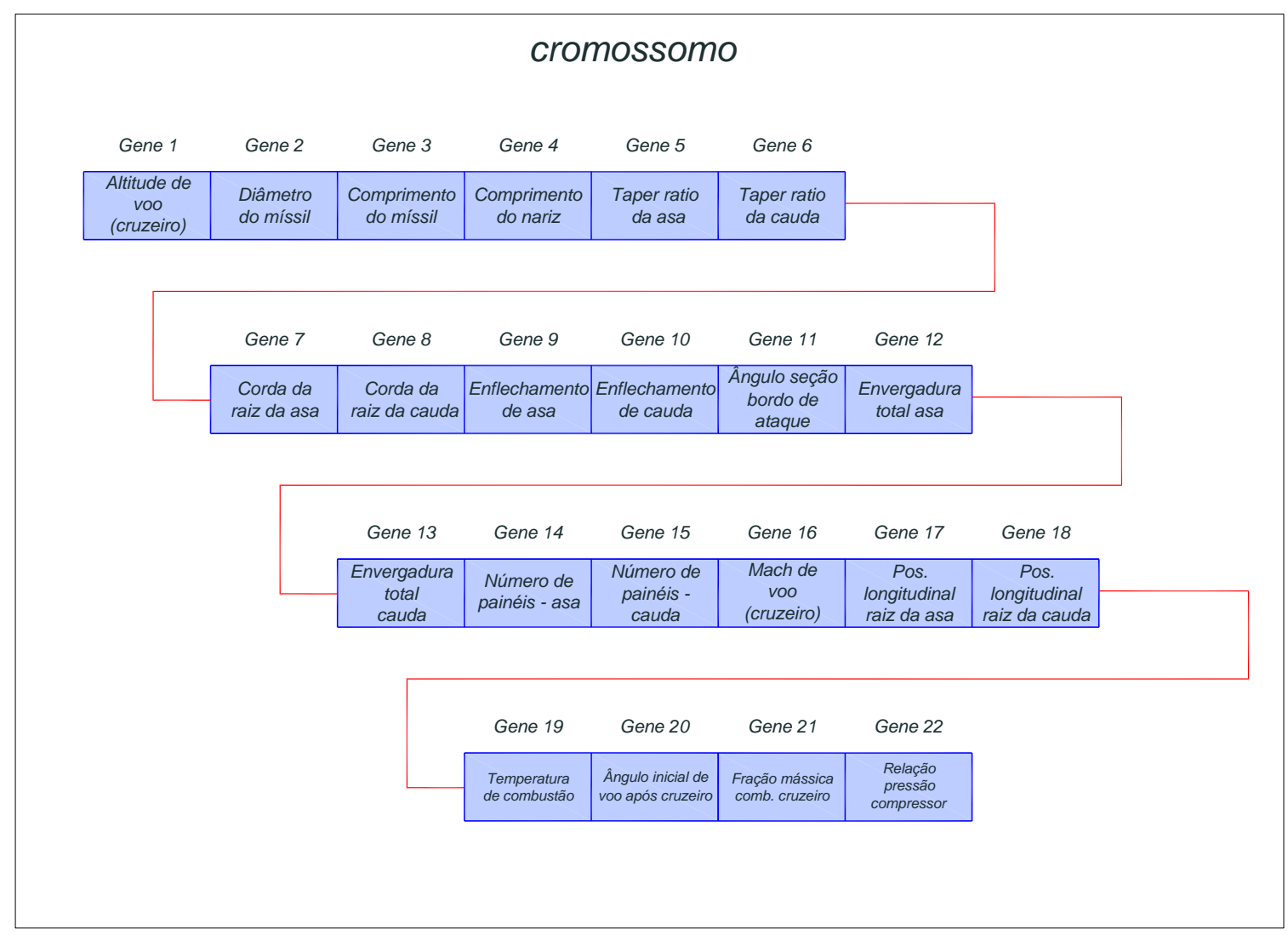

Figura 3.8 - Cromossomo de um míssil tático.

Os valores dos genes do cromossomo representado acima são escolhidos dentre os valores possíveis a partir da definição dos limites inferior e superior para cada variável de projeto, bem como do incremento de variação da respectiva variável. Novamente, esses valores são definidos pelo usuário. Ressalta-se que, caso a diferença entre os valores dos limites inferior e superior seja muito grande e o valor do incremento da variação seja muito pequeno, o número total de possíveis valores será muito grande, tendo implicações importantes no tempo de processamento, como será discutido mais adiante. Portanto, devese, sempre que possível, restringir o espaço de busca para uma região onde se espera encontrar os valores ótimos. Além disso, a escolha dos limites pode representar valores proibidos em determinada variável. Cita-se como exemplo, o caso em que o diâmetro do míssil deva ser menor que determinado valor. Logicamente o limite superior dessa variável deverá ser menor ou igual a diâmetro máximo permitido. 


\subsubsection{2 - Parâmetros de projeto}

Os parâmetros de projeto (constantes) são utilizados principalmente para dimensionar o míssil, a partir das variáveis de projeto, sendo valores determinados pelo usuário do programa Scorpio 1.0. Diversos outros termos são calculados a partir dos parâmetros de projeto. Neste trabalho os parâmetros de projeto são:

1. Quanto ao lançamento e impacto:
a. Altitude de lançamento (m);
b. Altitude de impacto (m);
c. Velocidade de lançamento $(\mathrm{m} / \mathrm{s})$;
d. Velocidade de impacto $(\mathrm{m} / \mathrm{s})$;
e. Razão de calores específicos do ar ambiente (adimensional);

2. Quanto às massas fixas para todos os mísseis:
a. Massa da cabeça de guerra $(\mathrm{kg})$;
b. Massa dos sistemas de guiamento, controle e enlace de dados $(\mathrm{kg})$;
c. Massa dos atuadores das superfícies de controle $(\mathrm{kg})$;
d. Massa da fonte de energia $(\mathrm{kg})$;

3. Dados aerodinâmicos:
a. Ângulo de ataque máximo para a asa (graus);
b. Ângulo de ataque máximo para ao corpo do míssil (graus);
c. Ângulo de ataque máximo para as superfícies de cauda (graus);
d. Incremento na variação dos ângulos de ataque (graus) ${ }^{50}$;
e. Parcela do arrasto de base desprezada em cruzeiro (adimensional) ${ }^{51}$;
f. Erro máximo admitido nas equações de equilíbrio em voo ${ }^{52}$;

4. Tipo de controle utilizado (canard, asa ou cauda);

5. Presença de boattail (sim ou não);

\footnotetext{
${ }^{50} \mathrm{O}$ incremento da variação dos ângulos de ataque é utilizado para aumentar o valor dos ângulos de ataque (corpo, asa ou canard e cauda), quando da busca das condições de equilíbrio em voo.

${ }^{51}$ Considerando que em voo de cruzeiro a área do bocal de exaustão do motor deve ser subtraída da área da seção transversal do míssil.

52 O erro máximo é necessário uma vez que o sistema de equações de equilíbrio tem mais incógnitas que equações, e é utilizado um método iterativo para encontrar uma solução aproximada para os ângulos de ataque de cada componente do míssil (corpo, asa e cauda).
} 
6. Tipo de motor de cruzeiro (foguete, turbojato, ramjet, nenhum);

7. Perfil de voo após cruzeiro (planeio ou balístico);

8. Dados do sistema de propulsão - Foguete (boost ou sustain)
a. Pressão de combustão (MPa);
b. Velocidade característica na garganta da tubeira $(\mathrm{m} / \mathrm{s})$;
c. Aceleração da gravidade $\left(\mathrm{m} / \mathrm{s}^{2}\right)$;
d. Razão de calores específicos na tubeira (adimensional);
e. Fator de aceleração durante boost (adimensional);
f. Constante do gás (J/kg.K);
g. Coeficiente de descarga da tubeira (adimensional);
h. Ângulo da trajetória de voo em boost (graus);

9. Dados do sistema de propulsão - Motor de cruzeiro - Ramjet
a. Razão de pressões de estagnação no difusor de admissão (adimensional);
b. Razão de pressões de estagnação no combustor (adimensional);
c. Razão de pressões de estagnação no bocal de exaustão (adimensional);
d. Eficiência de combustão (adimensional);
e. Poder calorífico do combustível $(\mathrm{kJ} / \mathrm{kg})^{53}$;
f. Calor específico a pressão constante do ar (kJ/kg.K);

10. Dados do sistema de propulsão - Motor de cruzeiro - Turbojato
a. Eficiência isentrópica do difusor de admissão de ar (adimensional);
b. Eficiência isentrópica de compressor (adimensional);
c. Eficiência isentrópica da turbina (adimensional);
d. Eficiência isentrópica do bocal de exaustão (adimensional);
e. Razão de calores específicos no difusor de admissão de ar (adimensional);
f. Razão de calores específicos no compressor (adimensional);
g. Razão de calores específicos na turbina (adimensional);
h. Razão de calores específicos no bocal de exaustão (adimensional);
i. Relação de pressões no combustor (adimensional);

\footnotetext{
${ }^{53} \mathrm{O}$ mesmo valor de poder calorifico do combustível é utilizado para o ramjet e o turbojato.
} 


\subsubsection{3 - Requisitos de projeto}

Os requisitos de projeto são utilizados principalmente para avaliar o míssil sob análise, sendo valores determinados pelo usuário do programa Scorpio 1.0. Neste trabalho os requisitos de projeto são:

1. Alcance máximo ${ }^{54}(\mathrm{~m})$;

2. Alcance mínimo ${ }^{55}(\mathrm{~m})$;

3. Tempo máximo de voo até o alvo (s);

4. Massa de lançamento máxima $(\mathrm{kg})$;

5. Estabilidade estática mínima (adimensional);

6. Fator de carga em manobra mínimo (adimensional).

\subsubsection{4 - Dados atmosféricos}

O bloco Dados atmosféricos (Figura 3.7) representa a função ATMOSFERA_ICAO do programa Scorpio 1.0. Essa função informa dados atmosféricos relativos às altitudes de lançamento, voo e impacto do míssil, conforme as entradas e saídas informadas na Tabela 3.3. Os valores indicados são interpolados da tabela apresentada no ANEXO F deste trabalho. Os dados de saída são a temperatura, pressão, massa específica do ar e velocidade do som para as altitudes mencionadas. Esses dados servem como valores de entrada para módulos seguintes (aerodinâmica, propulsão e trajetória). O valor máximo de altitude de voo utilizado deve ser de $70.000 \mathrm{~m}$.

Tabela 3.3 - Dados de entrada e saída da função ATMOSFERA_ICAO.

\begin{tabular}{|lll|}
\hline Módulo & Entradas & Saídas \\
\hline \multirow{4}{*}{ Atmosfera } & Altitude de lançamento do míssil & Temperatura atmosférica \\
& Altitude de voo em cruzeiro do míssil & Pressão atmosférica \\
& Altitude de impacto do míssil & Massa específica do ar \\
& & Velocidade do som \\
\hline
\end{tabular}

\footnotetext{
${ }^{54}$ Alcance superior requerido para o míssil. Dessa forma, caso deseje-se um míssil com alcance de $150 \mathrm{~km}$, o valor do alcance máximo ajustado no programa deverá ser de $150 \mathrm{~km}$.

55 Alcance inferior requerido para o míssil. Neste trabalho, o valor do alcance mínimo é considerado como a distância percorrida pelo míssil quando este atinge o fim do voo em boost.
} 


\subsubsection{5 - Aerodinâmica}

O bloco Aerodinâmica (Figura 3.7) representa a função AERODINAMICA do programa Scorpio 1.0. Essa é a parte que consome maior parte do tempo de execução do Scorpio 1.0. Essa função calcula propriedades aerodinâmicas do míssil com base em dados de entrada e informa valores de saída que são utilizados pelas funções seguintes (propulsão, trajetória e função de avaliação). Na Tabela 3.4 são mostrados os principais dados calculados por essa função do programa. Não são mostrados todos os parâmetros calculados por esta função para fins de concisão.

Essa função tem, dentre muitas outras, a capacidade de avaliar mísseis em condições de voo subsônico e supersônico, com controle por canard, asa ou por superfícies de cauda, adaptando as equações de equilíbrio (apresentadas na Seção Equilíbrio em voo deste trabalho) conforme a situação aplicável. É capaz de simular mísseis com diferentes formatos de nariz, com ou sem o emprego de boattail. É capaz ainda de processar superfícies aerodinâmicas de formatos variados. A função calcula o valor de estabilidade estática do míssil, determina os ângulos de ataques do corpo e das superfícies aerodinâmicas para as variadas fases do voo, inclusive determinando o máximo fator de carga em voo. Alguns outros dados calculados por esta e as demais funções do Scorpio 1.0 podem ser encontradas nos ANEXOS H - RELATÓRIO DE EXECUÇÃO DO SCORPIO 1.0: MÍSSIL HARPOON e I - RELATÓRIO DE EXECUÇÃO DO SCORPIO 1.0: MÍSSIL ASTROS 2020. 
Tabela 3.4 - Dados de entrada e saída da função AERODINAMICA.

\begin{tabular}{|c|c|c|}
\hline Módulo & Entradas & Saídas \\
\hline Aerodinâmica & $\begin{array}{l}\text { Diâmetro do míssil } \\
\text { Comprimento do míssil } \\
\text { Comprimento do nariz do míssil } \\
\text { Taper ratio da asa } \\
\text { Taper ratio da cauda } \\
\text { Corda aerodinâmica da raiz da asa } \\
\text { Corda aerodinâmica da raiz da cauda } \\
\text { Espessura máxima da corda média } \\
\text { aerodinâmica da asa } \\
\text { Espessura máxima da corda média } \\
\text { aerodinâmica da cauda } \\
\text { Distância da ponta do míssil até CG } \\
\text { Ângulo de enflechamento da asa } \\
\text { Ângulo de enflechamento da cauda } \\
\text { Ângulo total do bordo de ataque } \\
\text { Envergadura da asa } \\
\text { Envergadura da cauda } \\
\text { Número de superfícies da asa } \\
\text { Número de superfícies da cauda } \\
\text { Número de Mach do voo } \\
\text { Velocidade de lançamento do míssil } \\
\text { Massa específica do ar ambiente } \\
\text { Relação de calores específicos do ar } \\
\text { Distância entre nariz e bordo de ataque } \\
\text { da corda aerodinâmica média da asa } \\
\text { Distância entre nariz e bordo de ataque } \\
\text { da aerodinâmica média da cauda } \\
\text { Massa da carga paga } \\
\text { Massa dos atuadores das superfícies de } \\
\text { controle } \\
\text { Massa da fonte de energia } \\
\text { Máximo ângulo de ataque da asa } \\
\text { Máximo ângulo de ataque do corpo } \\
\text { Máximo ângulo de ataque da cauda } \\
\text { Temperatura ambiente de lançamento } \\
\text { Temperatura ambiente de cruzeiro } \\
\text { Temperatura ambiente de impacto } \\
\text { Tipo de controle } \\
\text { Fração mássica do combustível de cruzeiro } \\
\text { Fator de aceleração em boost }\end{array}$ & $\begin{array}{l}\text { Coeficiente de arrasto parasita } \\
\text { (corpo, asa, cauda, total) } \\
\text { Coeficiente de força normal } \\
\text { (corpo, asa, cauda, total) } \\
\text { Coeficiente de sustentação (corpo, } \\
\text { asa e caua) para os nos pontos } \\
\text { notáveis do voo (início e fim de: } \\
\text { boost, cruzeiro e coast) } \\
\text { Coeficiente de arrasto (corpo, asa } \\
\text { e caua) para os nos pontos } \\
\text { notáveis do voo (início e fim de: } \\
\text { boost, cruzeiro e coast) } \\
\text { Distancia da ponta do míssil até } \\
\text { centro aerodinâmico (corpo, asa, } \\
\text { cauda, total) Razão } \\
\text { sustentação/arrasto (cruzeiro e } \\
\text { coast) } \\
\text { Estabilidade estática } \\
\text { Arrasto nos pontos notáveis do } \\
\text { voo (início e fim de: boost, } \\
\text { cruzeiro e coast) } \quad \text { Máximo } \\
\text { fator de carga em voo } \\
\text { Massa do míssil (início e fim de: } \\
\text { boost, cruzeiro e coast) } \\
\text { Massa dos componentes do míssil } \\
\text { Área da seção transversal do } \\
\text { míssil } \\
\text { Espessura média da raiz da asa e } \\
\text { cauda } \\
\text { Razão de aspecto, corda média, } \\
\text { corda da ponta, espessura média } \\
\text { da raiz etc (asa e cauda) } \\
\text { Ângulo de ataque (corpo, asa e } \\
\text { caua) para os nos pontos notáveis } \\
\text { do voo (início e fim de: boost, } \\
\text { cruzeiro e coast) }\end{array}$ \\
\hline
\end{tabular}




\subsubsection{6 - Peso}

O bloco Peso (Figura 3.7) representa a função ESTRUTURA do programa Scorpio 1.0. Essa função realiza o dimensionamento estrutural do corpo, de acordo com a metodologia apresenta na Seção 2.4 -. São utilizados os carregamentos das forças normal e de arrasto parasita no corpo, asa e cauda e seus respectivos centros de pressão, no momento de máximo fator de carga em voo. Para esse dimensionamento, considera-se a massa do míssil no início do voo de cruzeiro (o máximo fator de carga em voo também é calculado para essa condição) e que o corpo do míssil possui seção transversal circular, e calcula o valor do máximo momento fletor atuante no corpo para o momento de voo com máximo fator de carga, de acordo com a técnica descrita no ANEXO C - CÁLCULO DE MOMENTO FLETOR NO CORPO DO MÍSSIL. É feita também a combinação da espessura requerida para suportar o máximo momento fletor com as espessuras requeridas por outros tipos de esforços.

Tabela 3.5 - Dados de entrada e saída da função ESTRUTURA.

\begin{tabular}{|lll|}
\hline Módulo & Entradas & Saídas \\
\hline & $\begin{array}{l}\text { Forças normal e arrasto } \\
\text { (corpo, asa e cauda) }\end{array}$ & \\
& Peso do míssil no início do cruzeiro & \\
Peso & $\begin{array}{l}\text { Centro aerodinâmico } \\
\text { (corpo, asa e cauda) }\end{array}$ & $\begin{array}{l}\text { Diâmetro interno, espessura e } \\
\text { massa do corpo do míssil }\end{array}$ \\
& Máximo fator de carga em voo & \\
& Fator de aceleração & \\
& Compr. e diâmetro externo do míssil & \\
\hline
\end{tabular}

\subsubsection{7 - Propulsão}

O bloco Propulsão (Figura 3.7) representa a função PROPULSAO do programa Scorpio 1.0. Essa função realiza o dimensionamento do motor de aceleração e cruzeiro de acordo com os dados de saída da função AERODINAMICA e com as premissas de projeto. Utiliza as metodologias discutidas neste trabalho. Essa função tem a capacidade de avaliar motores foguete, ramjet e turbojato.

A Tabela 3.6 apresenta os principais dados de entrada e saída dessa função. 
Tabela 3.6 - Dados de entrada e saída da função PROPULSÃO.

\begin{tabular}{|c|c|c|}
\hline Módulo & Entradas & Saídas \\
\hline Propulsão & $\begin{array}{l}\text { Tipo de motor de cruzeiro } \\
\text { Número de Mach do voo } \\
\text { Arrasto máximo em cruzeiro } \\
\text { Massa de lançamento } \\
\text { Pressão de descarga - booster } \\
\text { Pressão de combustão - booster } \\
\text { Velocidade específica na garganta da tubeira - } \\
\text { booster } \\
\text { Velocidade de lançamento do míssil } \\
\text { Relação de calores específicos do ar } \\
\text { Constante de gravidade } \\
\text { Razão de calores específicos médio na tubeira - } \\
\text { booster } \\
\text { Fator de aceleração - booster } \\
\text { Temperatura ambiente em cruzeiro } \\
\text { Constante do gás ambiente } \\
\text { Coeficiente de descarga da tubeira - booster } \\
\text { Arrasto médio durante - booster } \\
\text { Peso médio durante - booster } \\
\text { Peso de lançamento } \\
\text { Razão de pressões de estagnação do difusor - } \\
\text { ramjet } \\
\text { Razão de pressões de estagnação do combustor } \\
\text { - ramjet } \\
\text { Razão de pressões de estagnação do nozzle - } \\
\text { ramjet } \\
\text { Eficiência de combustão - ramjet } \\
\text { Temperatura média no combustor - ramjet ou } \\
\text { turbojato } \\
\text { Poder calorífico do combustível - ramjet ou } \\
\text { turbojato } \\
\text { Calor específico a pressão const. (ar) } \\
\text { Empuxo de cruzeiro de pressões no compressor e câmara de } \\
\text { Eficiência adiabática (difusor, compressor, } \\
\text { turbina, bocal) } \\
\text { Relação de calores específicos do gás e } \\
\text { eficiências isentrópicas (difusor de entrada, } \\
\text { compressor, turbina, bocal) } \\
\text { Temperatura média no combustor } \\
\text { Poder calófico do combustível } \\
\text { Calo arestível de cruzeiro }\end{array}$ & $\begin{array}{l}\text { Empuxo - booster } \\
\text { Impulso Específico - booster } \\
\text { Máxima velocidade incremental } \\
\text { - booster } \\
\text { Peso médio do míssil durante } \\
\text { aceleração } \\
\text { Tempo de combustão durante } \\
\text { aceleração } \\
\text { Dimensões tubeira (garganta e } \\
\text { exaustão) } \\
\text { Empuxo específico do motor de } \\
\text { cruzeiro - turbojato ou ramjet } \\
\text { Impulso Específico do motor de } \\
\text { cruzeiro - turbojato, ramjet ou } \\
\text { foguete } \\
\text { Velocidade de cruzeiro } \\
\text { Dimensões do bocal de exaustão }\end{array}$ \\
\hline
\end{tabular}




\subsubsection{8 - Trajetória}

O bloco Trajetória (Figura 3.7) representa a função TRAJETORIA do programa Scorpio 1.0. Essa função calcula o alcance de voo e tempo de voo, a partir da metodologia apresentada na Seção 2.5 -.

Nessa função são calculados principalmente o alcance e o tempo em cada fase de voo (aceleração, cruzeiro e coast).

Tabela 3.7 - Dados de entrada e saída da função TRAJETORIA.

\begin{tabular}{|lll|}
\hline Módulo & Entradas & Saídas \\
\hline & Empuxo do booster & \\
Impulso específico do booster & \\
Incremento de velocidade devido ao & \\
booster & \\
& Peso médio durante aceleração & \\
Tempo de combustão durante aceleração & \\
& Massa de lançamento do míssil & \\
Velocidade de lançamento do míssil & \\
Tempo de combustão durante aceleração & \\
Razão sustentação/arrasto em cruzeiro & Alcance total \\
Razão sustentação/arrasto em aproximação & Alcance durante aceleração \\
Velocidade de voo em cruzeiro & Alcance durante cruzeiro \\
Impulso específico de cruzeiro & Alcance durante coast \\
Aceleração da gravidade & Tempo total de voo \\
Flight path angle & Tempo de voo durante \\
Arrasto médio durante boost & aceleração \\
Peso de lançamento & Tempo de voo durante cruzeiro \\
Massa de combustível consumida em & Tempo de voo durante coast \\
cruzeiro & \\
Massa do míssil no início do cruzeiro & \\
Massa do míssil no final do cruzeiro & \\
Altitude de voo de cruzeiro & \\
Altitude de voo de impacto & \\
Flight path angle inicial para aproximação & \\
com trajetória balística & \\
Área da seção transversal do míssil & \\
Dados aerodinâmicos ao longo do voo & \\
(saída do módulo Aerodinâmica) & \\
& \\
\hline
\end{tabular}


$\mathrm{O}$ bloco Função de avaliação (Figura 3.7) representa a função FUNCAO_DE_AVALIACAO do programa Scorpio 1.0. Essa função calcula o valor da avaliação do míssil com base em seu desempenho. Os dados de entrada e saída desta função estão mostrados na Tabela 3.8.

Tabela 3.8 - Dados de entrada e saída da função FUNCAO_DE_AVALIACAO.

\begin{tabular}{|c|c|c|}
\hline Módulo & Entradas & Saídas \\
\hline $\begin{array}{l}\text { Função de } \\
\text { avaliação }\end{array}$ & $\begin{array}{l}\text { Requisitos do míssil } \\
\text { Alcance total } \\
\text { Alcance durante aceleração } \\
\text { Tempo total de voo } \\
\text { Massa de lançamento } \\
\text { Coeficiente de arrasto - sustentação nula } \\
\text { Coeficiente de força normal } \\
\text { Distancia da ponta do míssil até centro } \\
\text { aerodinâmico } \\
\text { Razão sustentação/arrasto de cruzeiro } \\
\text { Razão sustentação/arrasto de aproximação } \\
\text { Estabilidade estática } \\
\text { Arrasto máximo em cruzeiro } \\
\text { Sustentação máxima em cruzeiro } \\
\text { Massa de lançamento do míssil } \\
\text { Massa de combustível de voo em cruzeiro } \\
\text { Massa total no início do voo em cruzeiro } \\
\text { Massa total no início do voo em cruzeiro } \\
\text { Área da seção transversal do míssil } \\
\text { Espessura média da raiz da asa } \\
\text { Espessura média da raiz da cauda } \\
\text { Distância entre nariz e bordo de ataque da } \\
\text { corda aerodinâmica média da asa } \\
\text { Distância entre nariz e bordo de ataque da } \\
\text { corda aerodinâmica média da cauda } \\
\text { Espessura média da raiz da asa Espessura } \\
\text { média da raiz da cauda }\end{array}$ & $\begin{array}{l}\text { Valor da função de avaliação } \\
\text { do indivíduo }\end{array}$ \\
\hline
\end{tabular}

A função de avaliação utilizada foi escrita na forma da Equação ( 3.1), definindo-se pesos para as diversos requisitos de projeto bem como criando formas de bonificar soluções mais 
adequadas e penalizar mísseis com características indesejáveis. Isso foi necessário uma vez que a grande variedade de combinações possíveis das variáveis de projeto frequentemente podem gerar mísseis tecnicamente inviáveis.

A função de avaliação para mísseis táticos foi escrita de tal forma que pudesse apresentar um valor igual ou superior a 1 para mísseis tecnicamente viáveis e que atendessem ao requisitos de projeto. Assim, conforme será visto mais adiante, sempre que for encontrada uma solução com avaliação igual ou maior que 1, esta será uma solução viável (não necessariamente a melhor solução).

Foi criada uma função de avaliação na forma a seguir.

$$
\text { Avaliação }=\text { Avaliação } o_{\text {parcial }}+\text { Bonificações }- \text { Penalizações }
$$

O termo referente à avaliação parcial na Equação (3.2) é calculado através da verificação do atendimento aos requisitos de voo, na forma que se segue.

$$
\text { Avaliaçã } o_{\text {parcial }}=\frac{\sum_{i=1}^{7} \sigma_{i} \tau_{i}}{\sum_{i=1}^{7} \sigma_{i}}
$$

onde:

Tabela 3.9 - Valores dos coeficientes da equação de avaliação parcial.

\begin{tabular}{cc}
\hline Coeficiente & Peso \\
\hline$\sigma_{1}$ & 1 \\
$\sigma_{2}$ & 1 \\
$\sigma_{3}$ & 1 \\
$\sigma_{4}$ & 1 \\
$\sigma_{5}$ & 1 \\
$\sigma_{6}$ & 1 \\
$\sigma_{7}$ & 2 \\
\hline
\end{tabular}


Tabela 3.10 - Verificação do atendimento aos requisitos de voo na equação de avaliação parcial.

\begin{tabular}{|c|c|}
\hline Variável & Valor \\
\hline$\tau_{1}$ & $\begin{array}{l}\text { Se Alcance máx. } \geq \text { Alcance máx } x_{\text {requerido }} \\
\qquad \tau_{1}=1 \text {, caso contrário, } \tau_{1}=0\end{array}$ \\
\hline$\tau_{2}$ & $\begin{array}{l}\text { Se Alcance mín. } \leq \text { Alcance mín } n_{\text {requerido }} \\
\qquad \tau_{2}=1 \text {, caso contrário, } \tau_{2}=0\end{array}$ \\
\hline$\tau_{3}$ & $\begin{array}{c}\text { Se Tempo voo } \leq \text { Tempo voo máx } \\
\tau_{3}=1 \text {, caso contrário, } \tau_{3}=0\end{array}$ \\
\hline$\tau_{4}$ & $\begin{array}{l}\text { Se Massa lançamento } \leq \text { Massa lançamento máx } x_{\text {requerida }} \\
\qquad \tau_{4}=1 \text {, caso contrário, } \tau_{4}=0\end{array}$ \\
\hline$\tau_{5}$ & $\begin{array}{l}\text { Se Estabilidade Estática } \geq \text { Estabilida Estática mín } \mathrm{n}_{\text {requerida }}, \\
\qquad \tau_{\mathbf{5}}=1 \text {, caso contrário, } \tau_{\mathbf{5}}=0\end{array}$ \\
\hline$\tau_{6}$ & $\begin{array}{l}\text { Se Fator de carga } \geq \text { Fator de carga mín }{ }_{\text {requerido }} \\
\qquad \tau_{6}=1 \text {, caso contrário, } \tau_{\mathbf{6}}=0\end{array}$ \\
\hline$\tau_{7}$ & $\begin{array}{l}\text { Se Míssil atinge equilíbrio em voo, } \\
\tau_{7}=1 \text {, caso contrário, } \tau_{7}=0\end{array}$ \\
\hline
\end{tabular}

O termo referente às bonificações na Equação (3.3) foi implementado para graduar as soluções, de acordo com a massa de lançamento, o alcance máximo e mínimo do míssil, quando comparados com os requisitos de projeto.

$$
\text { Bonificações }=0,1 \frac{\sum_{i=1}^{3} \omega_{i} \gamma_{i}}{\sum_{i=1}^{3} \gamma_{i}}
$$

onde:

Tabela 3.11 - Valores dos coeficientes da equação de bonificações.

\begin{tabular}{cc}
\hline Coeficiente & Peso \\
\hline$\omega_{1}$ & 400 \\
$\omega_{2}$ & 10 \\
$\omega_{3}$ & 0,1 \\
\hline
\end{tabular}

É possível perceber na Tabela 3.11 aplicação de coeficientes com valores de diferentes ordens de grandeza para diferentes objetivos. O objetivo principal da função de avaliação 
(minimização da massa de lançamento) recebeu coeficiente no valor 400. O segundo objetivo (maximização do alcance máximo) recebeu coeficiente igual a 10. O terceiro objetivo (minimização do alcance mínimo - alcance após a fase de boost) recebeu coeficiente no valor 0,1 . A escolha desses coeficientes se deu de forma a que o objetivo principal dominasse completamente os demais objetivos. Assim, o processo evolutivos dos mísseis ao longo da execução do algoritmo seria dominada pelo objetivo da redução da massa de lançamento. Não obstante, os outros dois objetivos ainda operam sobre as soluções. Na hipotése do programa Scorpio 1.0 avaliar dois mísseis que atendam aos requisitos, de modo que obtenham a mesma Avaliação $o_{\text {parcial }}$, e além disso possuam a mesma massa de lançamento, possivelmente será melhor avaliado aquele que possui o maior alcance de voo. Na hipótese de ambos possuírem o mesmo alcance de voo, será melhor avaliado o que possuir o menor alcance mínimo. Esse processo decorre da escolha dos coeficientes da Tabela 3.11 com diferentes ordens de grandeza.

A escolha do valor dos coeficientes aplicados na Equação de Bonificações foi arbitrária, não precedida de estudos analíticos quanto à variação dos resultados obtidos mediante a alteração da magnitude dos coeficientes. Aplicou-se porém a adoção de coeficientes com diferentes ordens de grandeza para os diferentes objetivos, o que (espera-se) promoverá o efeito desejado no processo evolutivo dos mísseis.

Tabela 3.12 - Verificação do atendimento aos requisitos de voo na equação de bonificações.

\begin{tabular}{|c|c|}
\hline Variável & Valor \\
\hline \multirow[b]{2}{*}{$\gamma_{1}$} & Massa Lançamento Máxima Requerida - Massa Lançamento Míssil \\
\hline & Massa Lançamento Máxima ${ }_{\text {Requerida }}$ \\
\hline \multirow{2}{*}{$\gamma_{2}$} & Alcance Máximo $_{\text {Míssil }}-$ Alcance Máximo Requerido $_{\text {and }}$ \\
\hline & $\overline{\text { Alcance Máximo }}$ Requerido \\
\hline \multirow{2}{*}{$\gamma_{3}$} & Alcance Mínimo $_{\text {Requerido }}-$ Alcance Mínimo ${ }_{M i ́ s s i l}$ \\
\hline & $\overline{\text { Alcance Mínimo }}$ Requerido \\
\hline
\end{tabular}

O termo referente às penalizações na Equação(3.2) foi implementado para graduar as soluções e evitar soluções tecnicamente inviáveis ou indesejáveis. Cita-se como exemplo de um míssil tecnicamente inviável um que tenha massa específica muito diferente do 
valor médio (ver Seção 2.4.3 -). Um míssil indesejável pode ocorrer, por exemplo, se o bordo de fuga das superfícies de cauda estiverem localizadas muito distantes da base do míssil (isso certamente faria que fosse utilizada uma superfície maior para obter a estabilidade estática necessária, aumentando o peso e o arrasto do míssil).

A forma geral da equação de penalizações é:

$$
\text { Penalizações }=\sum_{i=1}^{6} \theta_{i}
$$

onde:

Tabela 3.13 - Valores dos coeficientes da equação de penalizações.

\begin{tabular}{cc}
\hline Penalização & Valor \\
\hline Leve & 0,08 \\
Média & 0,16 \\
Pesada & 0,24 \\
\hline
\end{tabular}

Os critérios decisórios da aplicação da penalização dos mísseis estão mostrados na Tabela 3.14 .

Após o encerramento da execução do programa, gera-se automaticamente um relatório contendo dados da execução (entradas, saídas, informações do grupo de elite, gráficos etc). Alguns relatórios de casos de estudo deste trabalho estão disponíveis em anexo. 
Tabela 3.14 - Verificação dos critérios da equação de penalizações.

\begin{tabular}{|c|c|}
\hline Variável & Valor \\
\hline$\theta_{1}$ & $\begin{array}{l}\text { Se posição do bordo de fuga da asa > comprimento do corpo, } \\
\boldsymbol{\theta}_{\mathbf{1}}=\text { Penalização pesada; caso contrário, } \boldsymbol{\theta}_{\mathbf{1}}=0 \text {. }\end{array}$ \\
\hline$\theta_{2}$ & $\begin{array}{l}\text { Se posição do bordo de fuga da cauda }>\text { comprimento do corpo, } \\
\qquad \boldsymbol{\theta}_{2}=\text { Penalização pesada; caso contrário, } \boldsymbol{\theta}_{2}=0 .\end{array}$ \\
\hline$\theta_{3}$ & $\begin{array}{c}\text { Se (espessura/corda })_{a s a} \leq 0,1, \boldsymbol{\theta}_{3}=0 \\
\text { Se } 0,1 \leq(\text { espessura/corda })_{a s a}<0,2, \boldsymbol{\theta}_{3}=\text { Pena média; } \\
\text { Se (espessura/corda })_{a s a} \geq 0,2, \boldsymbol{\theta}_{3}=\text { Pena pesada. }\end{array}$ \\
\hline$\theta_{4}$ & $\begin{array}{c}\text { Se (espessura/corda })_{c a u d a} \leq 0,1, \boldsymbol{\theta}_{\mathbf{4}}=0 \\
\text { Se } 0,1 \leq(\text { espessura/corda })_{c a u d a}<0,2, \boldsymbol{\theta}_{\mathbf{4}}=\text { Pena média; } \\
\text { Se (espessura/corda) })_{c a u d a} \geq 0,2, \boldsymbol{\theta}_{\mathbf{4}}=\text { Pena pesada. }\end{array}$ \\
\hline $\boldsymbol{\theta}_{5}$ & $\begin{array}{l}\text { Se posição do bordo de fuga da asa } \geq \text { posição do bordo de ataque da cauda, } \\
\qquad \boldsymbol{\theta}_{5}=\text { Penalização pesada; caso contrário, } \boldsymbol{\theta}_{\mathbf{5}}=0\end{array}$ \\
\hline$\theta_{6}$ & $\begin{array}{c}\operatorname{Se}(0,95.1384) \leq(\text { Massa específica })_{M i ́ s s i l} \leq(1,05.1384), \boldsymbol{\theta}_{\mathbf{6}}=0 ; \\
\operatorname{Se}(0,90.1384) \leq(\text { Massa específica })_{M i ́ s s i l} \leq(1,10.1384), \boldsymbol{\theta}_{\mathbf{6}}=\text { Pena Leve/2; } \\
\operatorname{Se}(0,85.1384) \leq(\text { Massa específica })_{M i ́ s s i l} \leq(1,15.1384), \boldsymbol{\theta}_{\mathbf{6}}=\text { Pena Leve; } \\
\operatorname{Se}(0,80.1384) \leq(\text { Massa específica })_{M i ́ s s i l} \leq(1,20.1384), \boldsymbol{\theta}_{\mathbf{6}}=\text { Pena Média; } \\
\operatorname{Se}(0,70.1384) \leq(\text { Massa específica })_{M i ́ s s i l} \leq(1,30.1384), \boldsymbol{\theta}_{\mathbf{6}}=\text { Pena Pesada; } \\
\text { senão, } \boldsymbol{\theta}_{\mathbf{6}}=\text { Pena Pesada . 1,5. }\end{array}$ \\
\hline $\boldsymbol{\theta}_{7}$ & $\begin{array}{l}\text { Se posição do bordo de fuga da asa } \geq 0,98 \text {. comprimento do corpo, } \\
\qquad \boldsymbol{\theta}_{\mathbf{7}}=0 \\
\text { Se posição do bordo de fuga da asa } \geq 0,95 \text {. comprimento do corpo, } \\
\qquad \boldsymbol{\theta}_{\mathbf{7}}=\text { Pena Leve } / 4 \\
\text { Se posição do bordo de fuga da asa } \geq 0,92 \text {. comprimento do corpo, } \\
\qquad \boldsymbol{\theta}_{\mathbf{7}}=\text { Pena Leve } / 2 ; \\
\text { Se posição do bordo de fuga da asa } \geq 0,90 \text {. comprimento do corpo, } \\
\qquad \boldsymbol{\theta}_{\mathbf{7}}=\text { Pena Leve; } \\
\text { senão, } \boldsymbol{\theta}_{\mathbf{7}}=\text { Pena Média. }\end{array}$ \\
\hline
\end{tabular}




\section{4 - RESULTADOS E DISCUSSÃO}

A apresentação dos resultados seguirá etapas distintas com a seguinte estrutura:

1. Verificação do algoritmo genético. $\mathrm{O}$ AG implementado no programa Scorpio 1.0 é verificado pelo uso de uma função de teste amplamente utilizada, que contém diversos máximos e mínimos locais. Essa função não está relacionada com mísseis táticos, mas permite a verificação das funcionalidades do AG. O objetivo desta etapa é demostrar a capacidade evolutiva e de busca de boas soluções do AG implementado, com uso de uma função da qual se conhece o espaço de busca e o mínimo global (ou máximo, como será discutido), antes que se inicie a aplicação deste AG com os modelos teóricos adequados para mísseis táticos.

2. Verificação das equações de modelagem apresentadas para o caso de míssil de cruzeiro subsônico. O programa Scorpio 1.0 é utilizado para o dimensionamento de um míssil de cruzeiro existente, a partir do uso de informações relativas a este míssil como dado de entrada. O desempenho informado pelo programa é comparado com o desempenho do míssil existente declarado pelo fabricante. $\mathrm{O}$ objetivo desta etapa é a verificação do funcionamento da rotina de cálculo e da precisão das equações teóricas apresentadas para previsão do desempenho de um míssil.

3. Verificação de repetibilidade de resultados para casos com os mesmos parâmetros e variáveis de projeto. Devido à natureza aleatória dos algoritmos genéticos, os resultados obtidos após sucessivas execuções do Scorpio 1.0 não são idênticos, mesmo para iguais dados de entrada. Contudo, uma medida da confiabilidade dos resultados fornecidos pelo programa é a capacidade de produzir resultados próximos, para execuções diferentes com dados de entrada iguais. Esta etapa objetiva demonstrar esta capacidade do Scorpio 1.0.

4. Utilização demonstrativa do programa para o caso de um míssil de cruzeiro subsônico em desenvolvimento. O programa Scorpio 1.0 é utilizado para o estudo do caso de um míssil que se encontrava em fase de desenvolvimento à época da elaboração deste trabalho. Para isso são utilizados dados preliminares divulgados pelos participantes do projeto (fabricante e operador). 


\section{1 - VERIFICAÇÃO DO ALGORITMO GENÉTICO IMPLEMENTADO}

\subsection{1 - A função de Rastrigin}

Em matemática aplicada, funções de teste são utilizadas para avaliar características de algoritmos de otimização, tais como velocidade de convergência, precisão, robustez e desempenho geral.

Para avaliar e validar o algoritmo genético desenvolvido utiliza-se como teste a função de Rastrigin. Esta foi inicialmente proposta por Rastrigin (1974) como uma função com duas variáveis independentes (dimensões) e foi posteriormente generalizada para $n$ dimensões (Mühlembein, Schomisch \& Born, 1991). A função de Rastrigin é frequentemente utilizada para testar o desempenho de algoritmos genéticos devido ao fato de ser uma função nãoconvexa. Também é um exemplo típico de função multimodal não-linear. Esta função constitui um problema particularmente difícil devido a seu relativamente amplo espaço de busca $^{56}$ e grande número de mínimos locais.

O caso geral da equação é definido por

$$
f(x)=A n+\sum_{i=1}^{n}\left[x_{i}^{2}-A \cos \left(\omega x_{i}\right)\right],
$$

onde $A=10, n=$ número de variáveis ou dimensões da função, $\omega=2 \pi$ e $x_{i} \in$ $[-5,12,5,12]$. A superfície da função é determinada pelas variáveis externas $A$ e $\omega$, que controlam amplitude e frequência, respectivamente. O mínimo global dessa função está localizado em $x_{i}=0$, onde $f(x)=0$.

O caso particular para duas variáveis independentes, proposto por Rastrigin, é dado por

\footnotetext{
${ }^{56} \mathrm{O}$ espaço de busca está relacionado não somente com a distância entre limites inferiores e superiores das variáveis independentes (genes), mas também com tamanho dos incrementos finitos entre opções possíveis e adjacentes destas variáveis. Assim, quanto menor for o incremento destas variáveis, maior será o espaço de busca que o algoritmo genético deverá explorar.
} 


$$
\operatorname{Ras}(x)=20+x_{1}^{2}+x_{2}^{2}-10\left(\cos 2 \pi x_{1}+\cos 2 \pi x_{2}\right)
$$

A Figura 4.1 mostra o comportamento da variável dependente com a mudança das variáveis independentes. Como pode ser visto, a função de Rastrigin possui diversos mínimos locais, representados pelos vales da superfície (curvas de nível da função estão projetadas no plano $x_{1}-x_{2}$ ). Todavia, a função tem apenas um mínimo global, que ocorre no ponto $(0,0)$ no plano $x_{1}-x_{2}$, onde o valor de função é nulo. Quanto mais distante da origem estiver o mínimo local, maior será o valor da função neste ponto.

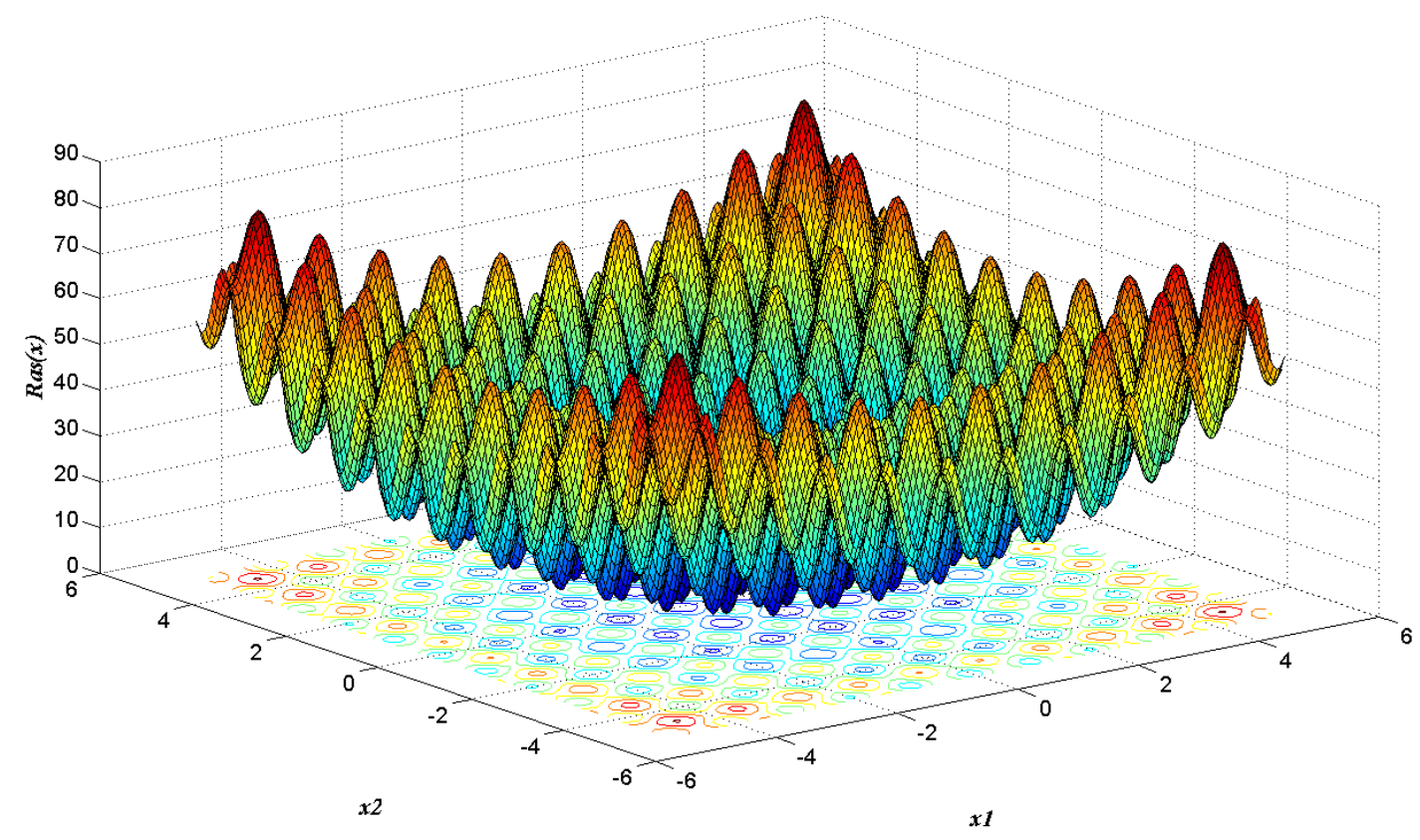

Figura 4.1 - Função de Rastrigin.

Conforme explicado anteriormente através da Figura 3.1, métodos tradicionais de otimização, baseados em gradientes têm dificuldade de encontrar o mínimo global de funções como a de Rastrigin. Além disso, a alternância entre mínimos e máximos locais torna ainda mais complexa a tarefa do algoritmo de otimização para esta situação. 


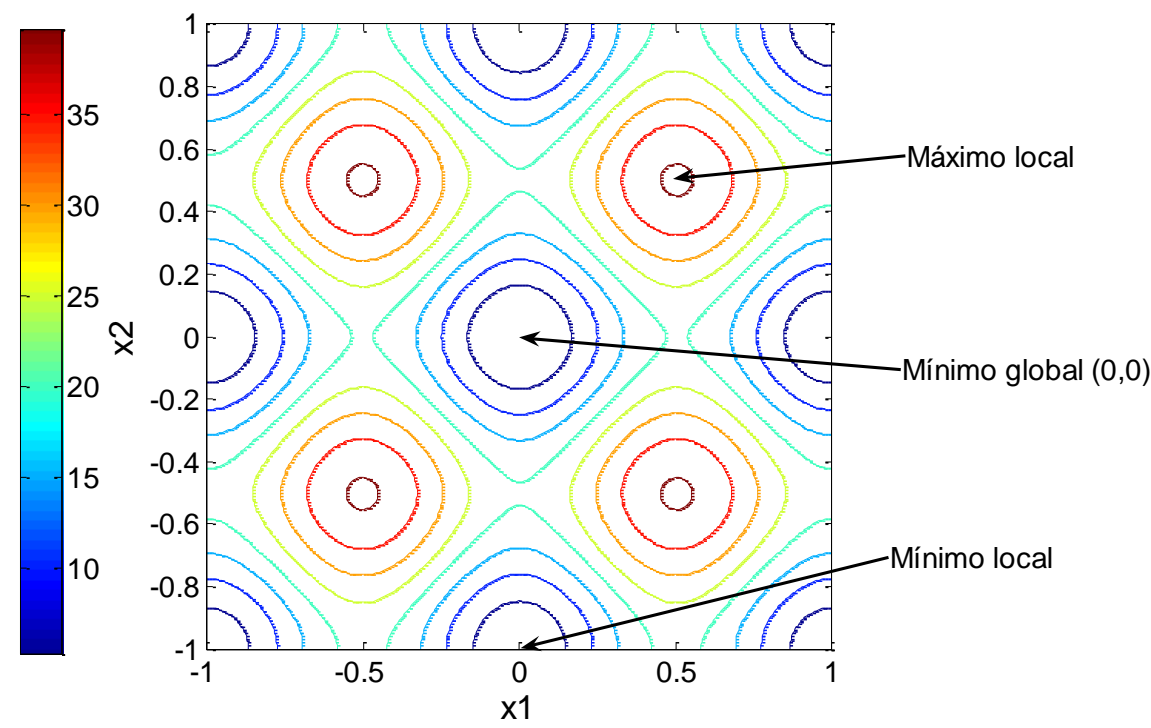

Figura 4.2 - Contornos (curvas de nível) da função de Rastrigin.

Além da complexidade da função em si, considere-se ainda a não aparente extensão deste caso, representada pelos seguintes fatores a respeito do espaço de busca:

1. Variáveis $x_{1}$ e $x_{2} \in[-5,12,5,12]$

2. Incremento na variação de $x_{1}$ e $x_{2}: 10^{-6}$;

3. Número aproximado de soluções possíveis: $1,049 \times 10^{14}$;

4. Tempo de processamento necessário para avaliar todas as soluções possíveis, considerando 100000 soluções avaliadas por segundo ${ }^{57}: 33,3$ anos.

\footnotetext{
${ }^{57}$ Durante as execuções do algoritmo genético para avaliação do inverso da função de Rastrigin, verificou-se que o tempo de processamento necessário para calcular o valor da função de avaliação, com o computador utilizado, era da ordem de $10^{-5}$ segundo. A estimativa de tempo de processamento necessário para avaliar todas as soluções possíveis foi feita com base no computador utilizado durante as execuções de teste do GA, a saber, processador Intel ${ }^{\circledR}$ Core ${ }^{\mathrm{TM}} 2$ Quad CPU Q6600 2,40 GHz, 2,99 GB de memória RAM, sistema operacional Microsoft Windows XP versão 2002 Service Pack 3.
} 


\subsection{2 - Aplicação do AG desenvolvido para busca do mínimo global da função de Rastrigin}

Para fins de verificação do algoritmo genético implementado, este foi submetido a execuções de teste através da busca do ponto mínimo global da função de Rastrigin. Contudo o algoritmo foi implementado com foco na solução do problema de maximização da função de avaliação de mísseis. Assim, considerando que a função de Rastrigin deve ser minimizada, foi utilizada como função de avaliação deste caso o inverso ${ }^{58}$ da função de Rastrigin, ou seja:

$$
\text { Função de avaliação }=[\operatorname{Ras}(x)]^{-1} \text {, }
$$

logo, na função de avaliação o ponto de mínimo se transforma em um ponto de máximo, tendendo a um valor infinito, ocorrendo também nas coordenadas $(0,0)$ no plano $x_{1}-x_{2}$.

A Figura 4.3 mostra o resultado de determinada execução do AG para o caso da função de Rastrigin. A figura mostra contornos ou curvas de nível desta função, projetados no plano $x_{1}-x_{2}$, bem como a projeção da posição dos melhores indivíduos ao longo desta execução do AG. Para esta mesma execução, a Figura 4.4 apresenta a variação da função de avaliação ao longo de gerações para minimização da função de Rastrigin, através da maximização de seu inverso $[\operatorname{Ras}(x)]^{-1}$. Nota-se desta última que o valor da avaliação do melhor indivíduo e da média da população aumenta ao longo das gerações, ao passo que a solução se aproxima do mínimo global da função de Rastrigin.

A análise das Figuras 4.3 e 4.4 permite extrair algumas conclusões a respeito do algoritmo desenvolvido. A primeira delas é que o evidente aumento da avaliação (Figura 4.4) do melhor indivíduo ao longo das gerações demonstra a capacidade evolutiva do programa. Esta propriedade é notória também na Figura 4.3, onde as coordenadas do melhor indivíduo se aproximam da solução ótima, sabidamente $x_{1}=x_{2}=0$, ao longo da execução do algoritmo.

\footnotetext{
${ }^{58}$ Um problema de minimização pode ser transformado em um problema de maximização (ou vice-versa) com o uso da função inversa.
} 


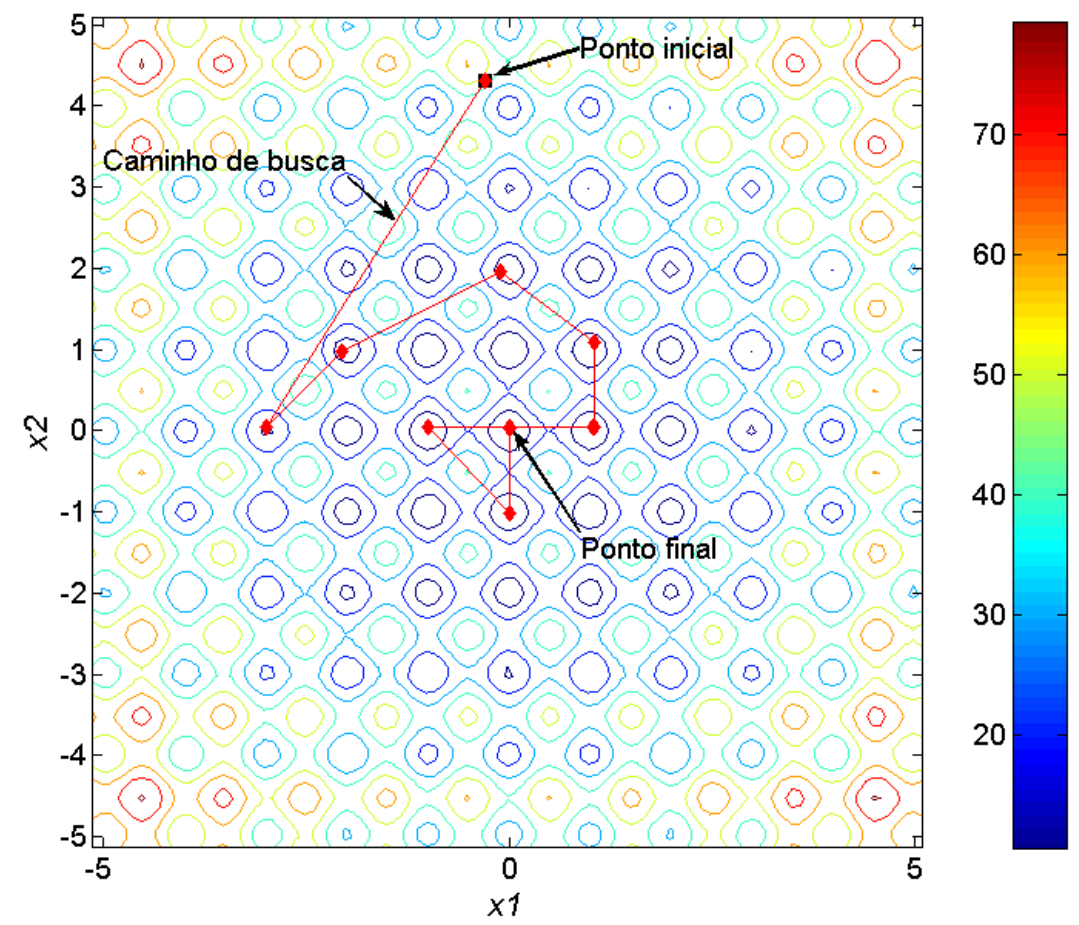

Figura 4.3 - Contornos da função de Rastrigin. Caminho de busca típico percorrido pelo melhor indivíduo da população durante execução do algoritmo genético. População composta por 80 indivíduos.

Há que se destacar ainda a capacidade do algoritmo de escapar de mínimos locais e chegar até à região onde se encontra o mínimo global, evidenciada pela passagem de melhores indivíduos de distintas gerações por diversos vales contento mínimos locais (Figura 4.3) e esclarecido pela Figura 4.2. Vale lembrar que é necessário e esperado que o algoritmo genético se comporte dessa maneira, possuindo tanto a capacidade evolutiva como a de fuga de mínimos / máximos locais.

Outra conclusão que pode ser extraída, porém de forma menos evidente, é que pontos completamente diferentes, ou seja, cromossomos compostos por genes distintos, podem, dependendo da função de avaliação utilizada, ter avaliações muito próximas ou idênticas (como no caso de curvas de nível). Além disso, é possível concluir que, dependendo do ponto em que o melhor indivíduo se encontre quando a execução do algoritmo genético for encerrada, a solução final indicada pode ser completamente distinta da solução indicada por outra execução do programa com as mesmas configurações iniciais. Este último efeito é indesejável e pode ser evitado, como será visto adiante. 
É possível perceber pela Figura 4.4 uma intensa convergência genética, representada pela rápida aproximação entre o valor da função de avaliação média da população e o valor da função de avaliação do melhor indivíduo. Nota-se também que o algoritmo genético atingiu o número de cem gerações, limite prévio estabelecido para esta execução particular do programa. Ao longo destas gerações, a população sofreu evolução e, muito provavelmente, continuaria evoluindo caso a execução do algoritmo não fosse interrompida.

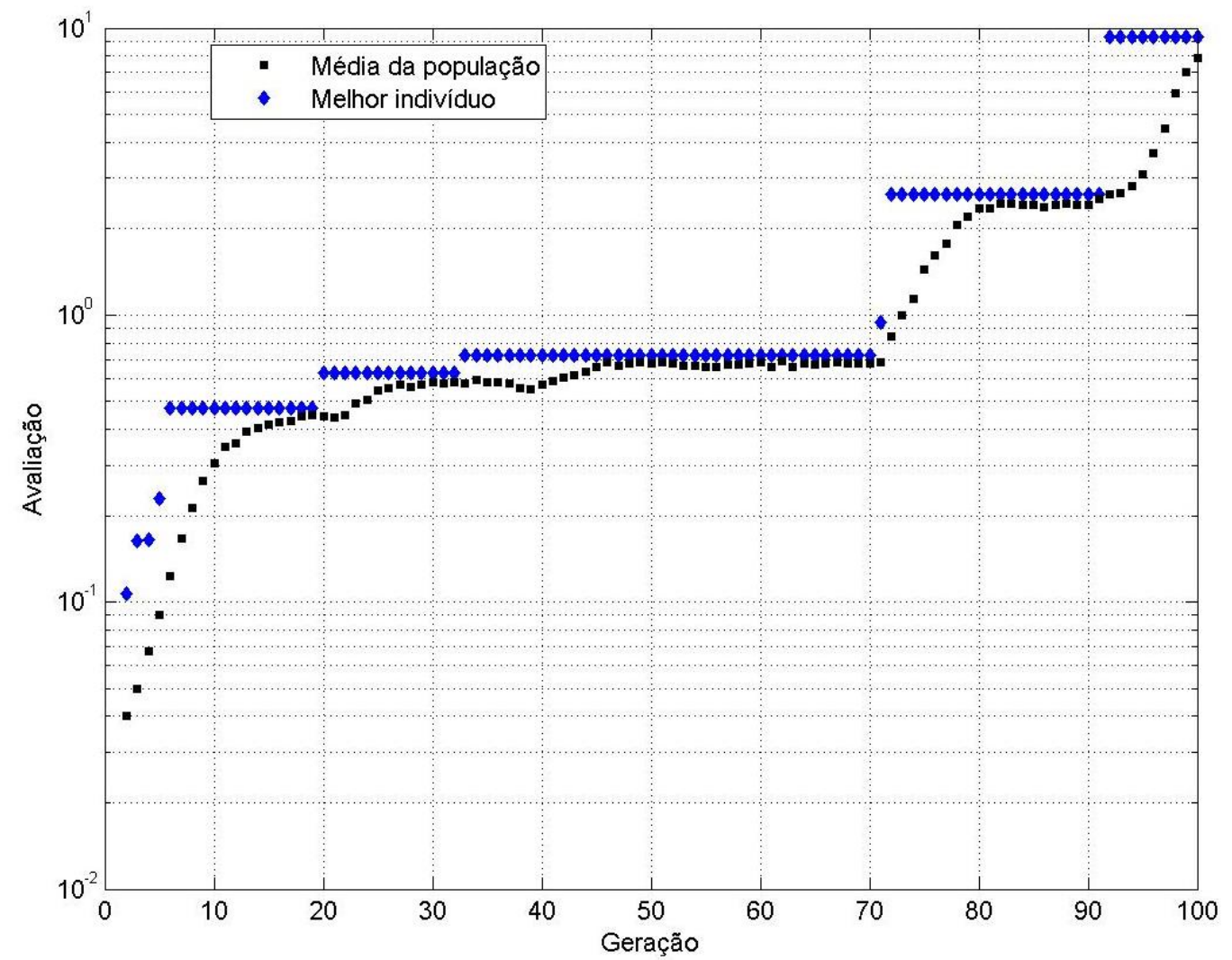

Figura 4.4 - Variação da avaliação ao longo de gerações para minimização da função de Rastrigin, através da maximização de seu inverso $[\operatorname{Ras}(x)]^{-1}$. População com 80 indivíduos, taxa de mutação de $2 \%$.

A Tabela 4.1 contém dados do melhor indivíduo após cem gerações para duas execuções do AG com mesmas configurações iniciais exceto a taxa de mutação, fixada em $2 \%$ no caso representado pela Figura 4.4 e em $30 \%$ no caso da Figura 4.5. A configuração inicial em ambos os casos foi:

1. Número de indivíduos na população: 80; 
2. Número de indivíduos no grupo de elite: 01;

3. Número de indivíduos no grupo de imigrantes: 08;

4. Número máximo de gerações (critério de parada): 100;

5. Valor de $\operatorname{Ras}(x)$ suficiente (critério de parada): 0,005.

Embora a simples análise dos resultados obtidos após execução de dois casos isolados de um programa com funcionamento regido por fatores estocásticos (como no caso do AG) não permita a extração de dados definitivos ou absolutos, expõe-se aqui estes dois exemplos para ilustrar o efeito da modificação da taxa de mutação na obtenção do resultado final. Não obstante, resultados semelhantes foram encontrados para dezenas de execuções do algoritmo, todas apresentando resultados compatíveis com estes apresentados aqui (ver Tabela 4.2). Embora o valor de $30 \%$ para a taxa de mutação seja alto se comparado a 0,5\% conforme citado por Linden (2012), ainda assim, aquele apresentou melhor resultado que este.

Através da análise da Figura 4.5 nota-se que com o aumento da taxa de mutação o efeito da convergência genética é reduzido, tendo ainda o efeito de apresentar melhores resultados ao proporcionar maior variedade genética ou possibilidade de combinações que resultem em soluções mais aptas dentro da população. Contudo, é preciso cautela para a determinação da melhor taxa de mutação (se existente) para determinado problema. Neste caso de teste, alta taxa de mutação apresentou melhores resultados, mas esse pode não ser o caso para outras funções de avaliação, o que estabelece a necessidade de análise para cada situação. Logo, no caso de mísseis táticos, como será visto adiante, é utilizada taxa de mutação mais conservadora.

Tabela 4.1 - Dados da solução final de execução do algoritmo genético para minimização da função de Rastrigin dos casos representados nas Figuras 4.4 e 4.5.

\begin{tabular}{|ccccc|}
\hline Caso & \multicolumn{3}{c|}{ Melhor indivíduo da última geração } & \\
\hline & {$[\operatorname{Ras}(\boldsymbol{x})]^{-\mathbf{1}}$} & $\boldsymbol{R a s}(\boldsymbol{x})$ & $\boldsymbol{x}_{\mathbf{1}}$ & $\boldsymbol{x}_{\mathbf{2}}$ \\
\hline Figura 4.4 & 9,31266220 & 0,10738068 & 0,00662500 & 0,02232000 \\
\hline Figura 4.5 & 36,20215265 & 0,02762267 & $-0,00069300$ & $-0,01178200$ \\
\hline
\end{tabular}


Considera-se melhor resultado não somente a proximidade entre o melhor indivíduo e o mínimo global, mas também a velocidade de convergência da solução. A diferença na velocidade de convergência para diferentes configurações iniciais, nesta situação da função de Rastrigin, é pouco relevante devido à simplicidade da função e do tempo de processamento necessário para avaliar a função (da ordem de $10^{-5}$ segundo), fazendo com que configurações iniciais que pudessem convergir rápida ou lentamente, mesmo que tivessem velocidade de execução de uma ordem de grandeza de diferença, tivessem tempo de execução medido em fração de segundo, como pode ser verificado na Tabela 4.2. Contudo quando é empregada função de avaliação com maior complexidade, como ocorre no caso de mísseis táticos, o tempo de convergência do resultado pode ser grandemente influenciado pelas configurações iniciais adotadas e não mais medido em segundos, mas em horas, justificando a cuidadosa escolha das configurações iniciais de execução do programa.

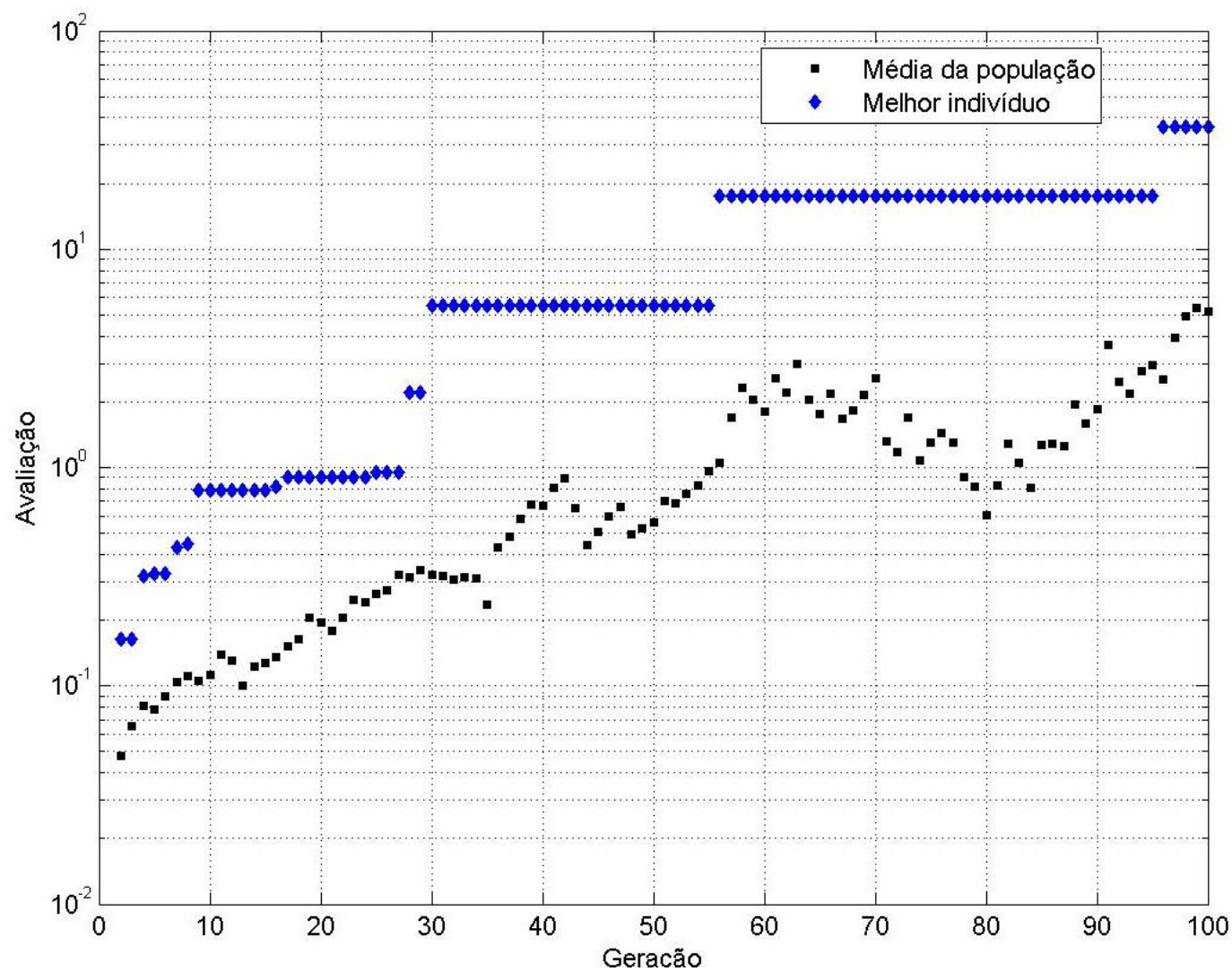

Figura 4.5 - Variação da avaliação ao longo de gerações para minimização da função de Rastrigin, através da maximização de seu inverso $[\operatorname{Ras}(x)]^{-1}$. População com 80 indivíduos, taxa de mutação de $30 \%$. 
Para fins de comparação qualitativa do comportamento do AG com o aumento da população, a Figura 4.6 apresenta o gráfico de convergência da solução para situação semelhante à da Figura 4.4, exceto que foi utilizada população composta por 3000 indivíduos. Chama atenção o fato de o algoritmo ter executado apenas 10 gerações, obtendo indivíduo com avaliação suficiente $\left([\operatorname{Ras}(x)]^{-1}=412,2\right.$ e $\operatorname{Ras}(x)=$ 0,002426), consequentemente interrompendo sua execução. A rápida convergência do resultado é atribuída à grande diversidade genética inicial, esperada em grandes populações. Novamente, muito provavelmente a população continuaria evoluindo caso a execução do algoritmo não fosse interrompida, fazendo com que o resultado se aproximando ainda mais do ponto ótimo global.

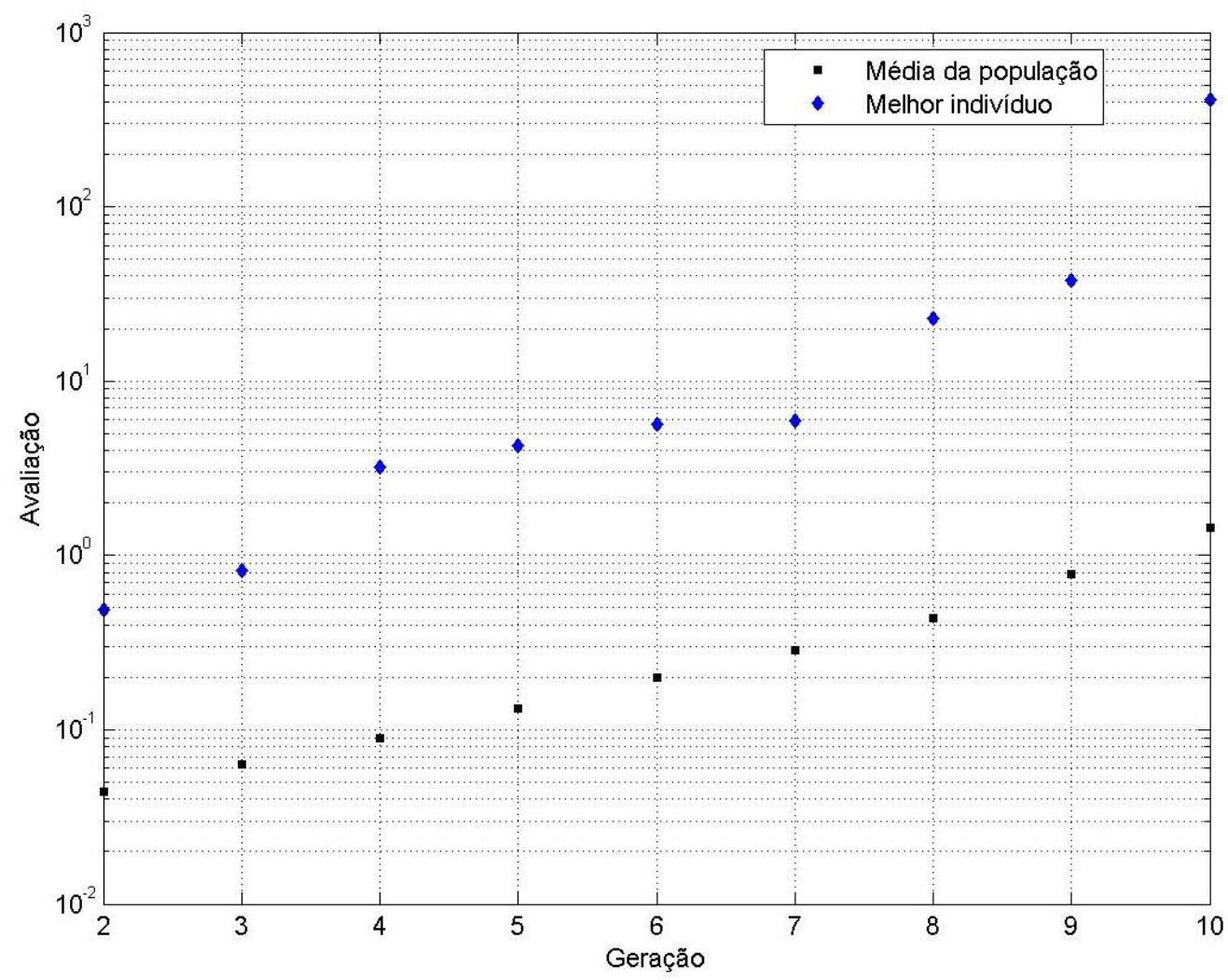

Figura 4.6 - Variação da avaliação ao longo de gerações para minimização da função de Rastrigin, através da maximização de seu inverso $[\operatorname{Ras}(x)]^{-1}$. População com 3000 indivíduos, taxa de mutação de $2 \%$.

A Figura 4.7 mostra o processo de busca da solução durante a execução do caso representada pela Figura 4.6. Comparando a figura abaixo com a Figura 4.3 percebe-se 
que, com grandes populações, o AG tem maior facilidade de chegar ao resultado final (caso a função de avaliação seja relativamente simples e rapidamente calculada).
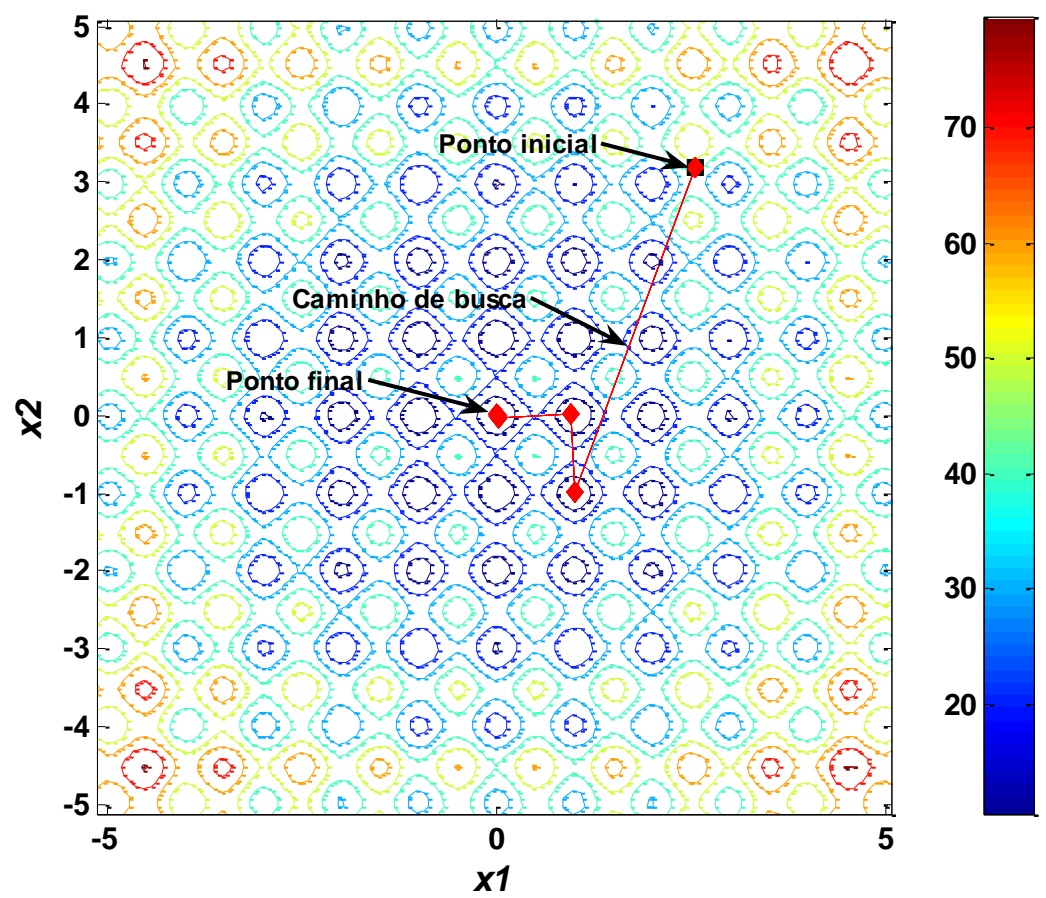

Figura 4.7 - Contornos da função de Rastrigin. Caminho de busca típico percorrido pelo melhor indivíduo da população durante execução do algoritmo genético. População composta por 3000 indivíduos.

A Figura 4.8 mostra os mesmos resultados da Figura 4.7, porém com redução da amplitude das variáveis independentes, de forma a ser possível visualizar o comportamento da busca próximo do ponto de mínimo global. A contínua aproximação entre o melhor indivíduo da população e o ponto com coordenadas $(0,0)$ representa a capacidade do programa buscar o ponto ótimo, de forma semelhante ao indicado pela Figura 3.2. Com relação à Figura 4.8, esclarece-se que a resolução utilizada para a plotagem das curvas de nível da função de Rastrigin não foi a mesma utilizada para as variáveis independentes, por isso as curvas mostradas nesta figura apresentam irregularidades não condizentes com a realidade, embora isto não tenha qualquer efeito sobre a qualidade da solução final, somente sobre a apresentação gráfica do resultado. O mesmo pode ser afirmado sobre a Figura 4.1, onde as variáveis independentes foram discretizadas em intervalos relativamente grandes, para permitir adequada visualização da superfície. 


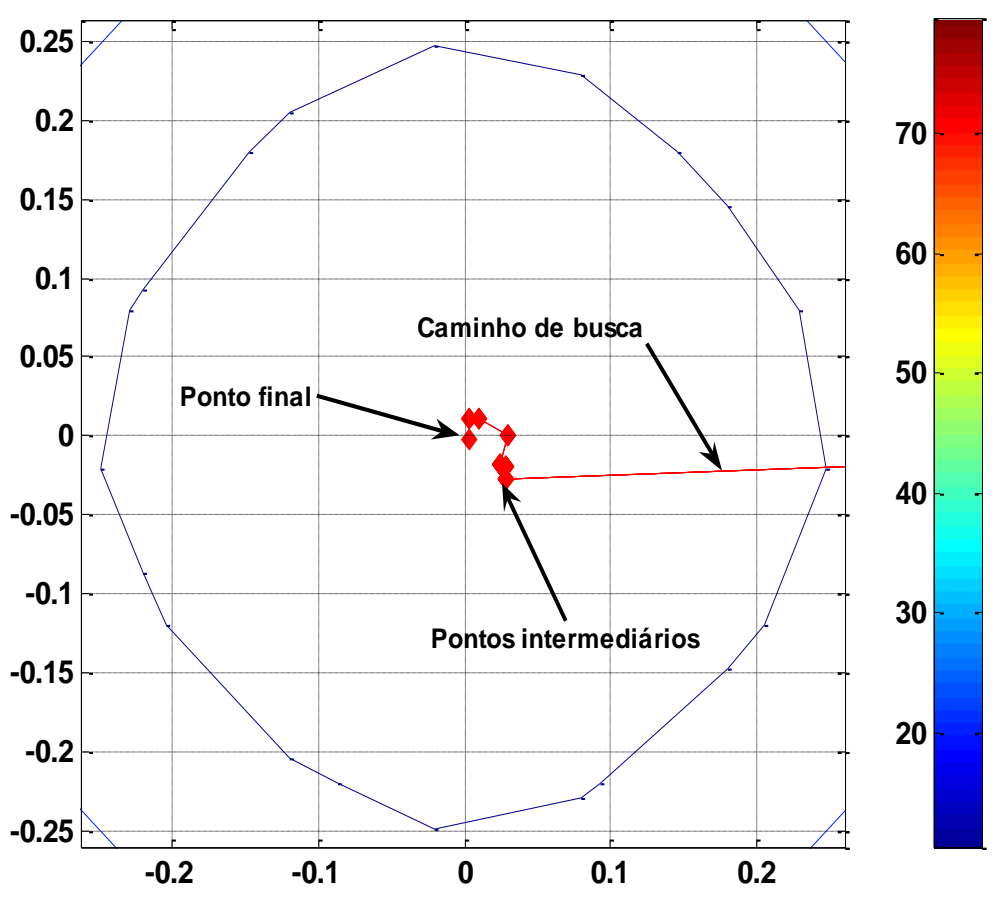

Figura 4.8 - Contornos da função de Rastrigin. Caminho de busca típico percorrido pelo melhor indivíduo da população durante execução do algoritmo genético. População composta por 3000 indivíduos.

A Figura 4.9 contém resultados médios de dezenas de execuções do algoritmo desenvolvido, utilizado para avaliação da função de Rastrigin, inclusive os dados representados pelas figuras acima. Cada ponto da Figura 4.9 representa o valor médio do resultado final (melhor indivíduo) após 10 execuções do algoritmo com condições iniciais idênticas. Desta forma, o único fator que sofreu variação ao longo de todas as execuções foi o tamanho da população. As demais condições permaneceram inalteradas e seus valores foram:

1. Taxa de mutação: $2,0 \%$;

2. Número de indivíduos no grupo de elite: 01;

3. Número de indivíduos no grupo de imigrantes: $10,0 \%$ da população;

4. Número máximo de gerações (critério de parada): 100;

5. Valor de $\operatorname{Ras}(x)$ suficiente (critério de parada): 0,005.

Nota-se que na Figura 4.9 é utilizada, na abscissa, o tamanho da população dividido pelo número de genes. Considerando que a função de Rastrigin tem duas variáveis 
independentes, o número de genes é igual a dois. Esse parâmetro foi escolhido por facilitar a escolha de população inicial para casos com diferentes números de genes (como o caso de mísseis táticos). A linha horizontal indicada representa o valor de $\operatorname{Ras}(x)$ suficiente estabelecido inicialmente $(\operatorname{Ras}(x)=0,005)$.

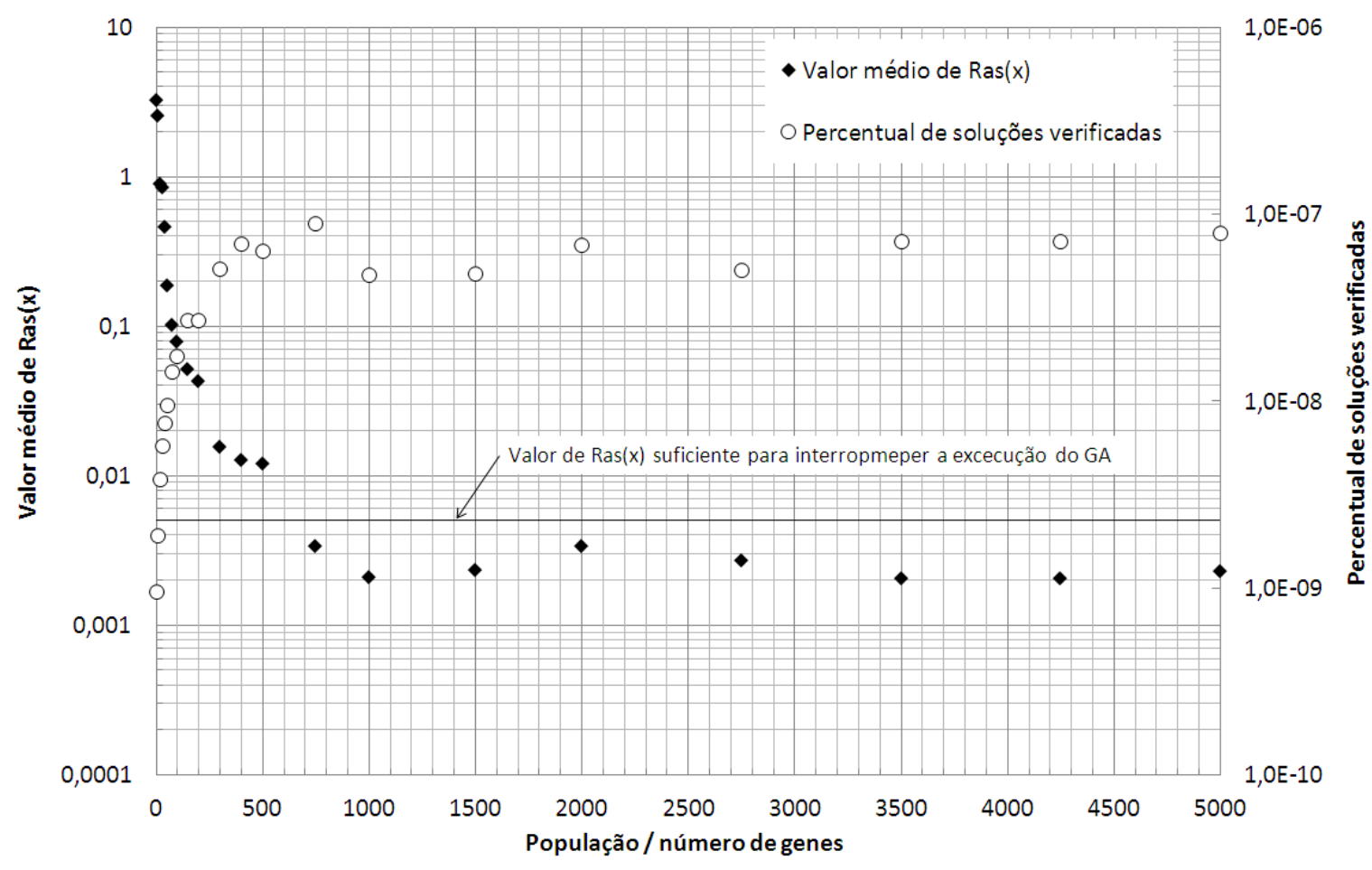

Figura 4.9 - Resultados compilados para 210 execuções do AG para avaliação da função de

Rastrigin. Cada ponto representa a média de 10 execuções com configurações iniciais idênticas com exceção da população utilizada.

Embora não indicado na Figura 4.9, até o ponto que representa População/número de genes = 75 (inclusive) todas as execuções do AG pararam por atingirem número máximo de gerações definido (100), ao passo que a partir de População/número de genes $=1000$ (inclusive), todas as simulações pararam ao obterem indivíduo com avaliação suficiente estabelecida $(0,005)$. No intervalo intermediário houve gradual transição do modo de parada da execução do AG. Observa-se que a partir de População/número de genes = 1000, tanto o percentual de soluções verificadas como o valor médio final de $\operatorname{Ras}(x)$ permanecem em patamares quase constantes a despeito do aumento da população. Isso significa que a partir desse tamanho de população a solução final indicada por diferentes execuções do $A G$ com as mesmas configurações iniciais é muito próxima da solução 
indicada por outra execução do programa com as mesmas configurações iniciais, o que é desejável, ilustrando a consistência dos resultados obtidos. Estes resultados também sugerem que para a obtenção do resultado final, com o aumento da população utilizada, o número de gerações executadas tende a cair, fazendo com que o número total de indivíduos avaliados seja praticamente independente do tamanho da população.

A Figura 4.9 indica que, ao longo das execuções de teste, o AG avaliou uma parcela extremamente pequena do espaço de soluções, por volta de $10^{-7} \%$ das soluções possíveis a cada execução. Isso representa algo entorno de uma solução testada para cada conjunto de um bilhão de soluções possíveis. Não obstante, o algoritmo foi capaz de se aproximar rapidamente e com razoável precisão do ponto de mínimo global.

A Tabela 4.2 aponta o tempo médio necessário para execução do AG em função da população utilizada. Nota-se que, mesmo com populações grandes, em média, o AG necessitou de menos de 1 segundo para se aproximar do resultado final, o que merece destaque considerando os 33,3 anos estimados para avaliação de todas as soluções possíveis, conforme explicado anteriormente. Além disso, esta tabela mostra que, com o aumento da população, ou da razão População/número de genes, juntamente com a diminuição do valor médio de $\operatorname{Ras}(x)$ ocorre também a diminuição do desvio padrão da amostra. Lembrando que o desvio padrão é uma medida comum de dispersão estatística (representa a dispersão das amostras em relação à média e um baixo desvio padrão indica que os dados tendem a estar próximos da média), é possível concluir que com o aumento da população, além da diminuição do valor médio de $\operatorname{Ras}(x)$ ocorrem menores desvios entre execuções distintas do algoritmo genético. Assim, é possível eliminar o problema de obtenção de resultados completamente diferentes a cada execução do AG, conferindo robustez aos resultados encontrados pelo algoritmo. 
Tabela 4.2 - Dados médios e desvio padrão de 200 execuções do AG.

\begin{tabular}{|c|c|c|c|c|}
\hline \multirow{2}{*}{$\begin{array}{c}\text { População / número } \\
\text { de genes }\end{array}$} & \multicolumn{2}{|c|}{ Ras $(\boldsymbol{x})$} & \multicolumn{2}{c|}{ Tempo de execução (s) } \\
\cline { 2 - 5 } & Média & $\begin{array}{c}\text { Desvio } \\
\text { Padrão }\end{array}$ & Média & $\begin{array}{c}\text { Desvio } \\
\text { Padrão }\end{array}$ \\
\hline $\mathbf{5}$ & 3,2148 & 1,8117 & 0,01 & 0,00 \\
\hline $\mathbf{1 0}$ & 2,5355 & 1,6293 & 0,02 & 0,00 \\
\hline $\mathbf{2 0}$ & 0,8966 & 0,4609 & 0,04 & 0,00 \\
\hline $\mathbf{3 0}$ & 0,8441 & 0,6264 & 0,06 & 0,00 \\
\hline $\mathbf{4 0}$ & 0,4620 & 0,3981 & 0,08 & 0,00 \\
\hline $\mathbf{5 0}$ & 0,1859 & 0,1889 & 0,10 & 0,00 \\
\hline $\mathbf{7 5}$ & 0,1012 & 0,1085 & 0,15 & 0,00 \\
\hline $\mathbf{1 0 0}$ & 0,0777 & 0,1243 & 0,18 & 0,06 \\
\hline $\mathbf{1 5 0}$ & 0,0517 & 0,0556 & 0,28 & 0,04 \\
\hline $\mathbf{2 0 0}$ & 0,0427 & 0,0764 & 0,33 & 0,09 \\
\hline $\mathbf{3 0 0}$ & 0,0155 & 0,0095 & 0,53 & 0,14 \\
\hline $\mathbf{4 0 0}$ & 0,0126 & 0,0128 & 0,73 & 0,13 \\
\hline $\mathbf{5 0 0}$ & 0,0120 & 0,0149 & 0,67 & 0,41 \\
\hline $\mathbf{7 5 0}$ & 0,0034 & 0,0029 & 0,93 & 0,51 \\
\hline $\mathbf{1 0 0 0}$ & 0,0021 & 0,0018 & 0,49 & 0,40 \\
\hline $\mathbf{1 5 0 0}$ & 0,0023 & 0,0012 & 0,50 & 0,53 \\
\hline $\mathbf{2 0 0 0}$ & 0,0034 & 0,0012 & 0,72 & 0,48 \\
\hline $\mathbf{2 7 5 0}$ & 0,0027 & 0,0015 & 0,52 & 0,16 \\
\hline $\mathbf{3 5 0 0}$ & 0,0020 & 0,0016 & 0,75 & 0,30 \\
\hline $\mathbf{5 0 0 0}$ & 0,0023 & 0,0017 & 0,83 & 0,23 \\
\hline & & & \\
\hline
\end{tabular}

Através da análise dos resultados apresentados é possível notar a capacidade do algoritmo desenvolvido de indicar soluções muito próximas do mínimo global da função de Rastrigin, independentemente dos membros da população inicial utilizada e do "caminho" percorrido até chegar à solução final, a cada vez que ele é executado com configurações semelhantes. Esta consistência de resultados ilustra a capacidade do algoritmo de escapar de mínimos locais e se aproximar do mínimo global da função. Cabe ressaltar que, devido à natureza aleatória dos algoritmos genéticos (durante a criação da população inicial, seleção de pares de pais, pontos de corte para crossover, aplicação de mutação e inserção de imigrantes), é praticamente impossível repetir com exatidão resultados encontrados. Porém é possível verificar grande proximidade entre as soluções indicadas a cada execução, comprovando a confiabilidade do algoritmo, conquanto sejam utilizadas configurações apropriadas para o algoritmo e função de avaliação utilizada. 
Vale lembrar que a discretização do espaço de soluções, definido numericamente pelo usuário e representado por intervalos finitos entre as variáveis independentes, estabelece um limite de proximidade entra a solução obtida e a solução verdadeira. De forma geral, quanto menor for a diferença entre os pontos do espaço de busca, maior poderá ser a proximidade entre a solução encontrada e a verdadeira (ótima). Esta propriedade se reflete não somente neste caso de verificação (função de Rastrigin), mas também no objeto de estudo deste trabalho (otimização de mísseis táticos em fase de projeto conceitual). Por outro lado, a intensa discretização do espaço de busca implica no aumento do número de soluções possíveis, podendo ocorrer que este número seja limitado pela memória da máquina (computador) utilizada para execução do AG. Uma abordagem para contornar esse problema em uma situação onde o nível de excelência da solução apontada seja extremamente relevante (quando a expressão "otimização" é considerada em sentido estrito) pode ser o refinamento do espaço de soluções ao redor da primeira solução encontrada, conjuntamente com a redução do distanciamento entre os limites inferiores e superiores das variáveis independentes. Embora essa estratégia esteja disponível ao usuário do algoritmo ora desenvolvido, ela não faz parte do objetivo deste trabalho e, portanto, não será explorada.

Outro ponto que deve ser considerado é que, quando se trata de um caso real de otimização (e por consequência não se conhece o valor do ponto ótimo e por esta razão nem sempre a determinação do valor de avaliação suficiente para encerramento da execução do AG é tarefa trivial), o critério de parada da execução do algoritmo deve ser escolhido com cautela. Recomenda-se que em situações como a que ocorre na Figura 4.6, onde a solução está evidentemente em intenso processo evolutivo, a execução não seja interrompida, deixando que a execução do AG continue até que seja atingido limite de tempo (número de gerações) aceitável ${ }^{59}$, ou que não seja verificada evolução significativa do melhor indivíduo, conforme ilustrado pela Figura 4.10.

\footnotetext{
${ }^{59}$ A definição de limite de tempo aceitável para a execução do GA certamente é influenciada pelo objeto de estudo para o qual é empregado o algoritmo. Em problemas práticos em que usualmente se trabalha com limitação de recursos (naturais, financeiros, humanos, etc) e que soluções otimizadas podem representar aumento significativo na eficiência do emprego destes recursos, pode ser aceitável trabalhar com tempo de execução do GA da ordem de dias ou semanas. Em contraste, podem existir situações onde é preciso obter
} 


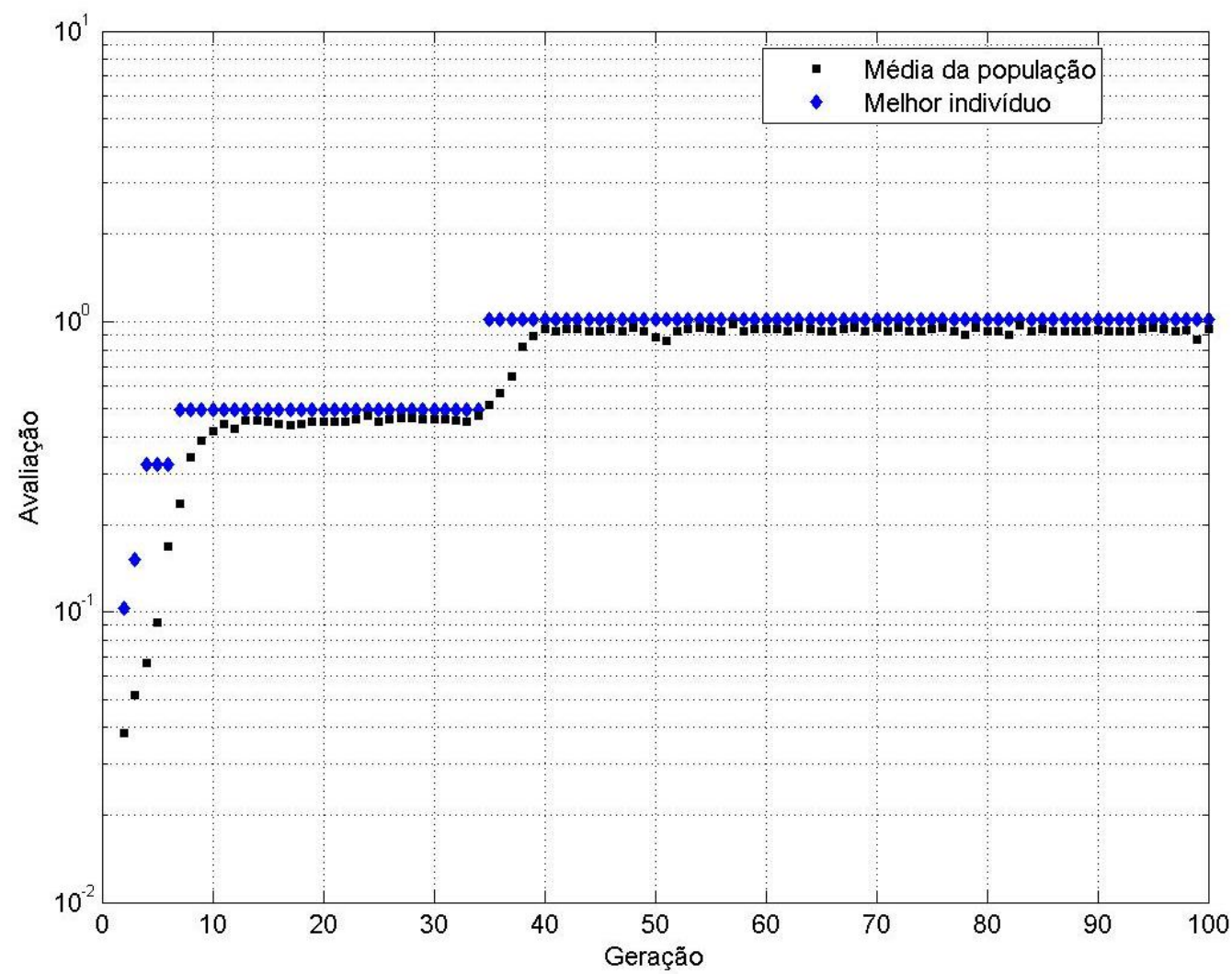

Figura 4.10 - Variação da avaliação ao longo de gerações para minimização da função de

Rastrigin, através da maximização de seu inverso $[\operatorname{Ras}(x)]^{-1}$. População com 40 indivíduos, taxa de mutação de $2 \%$. O melhor indivíduo permanece inalterado nas últimas 65 gerações, devido, possivelmente, à baixa diversidade genética presente na população.

Em situações em que a função de avaliação represente um problema multidimensional (como no caso de mísseis táticos), a visualização gráfica da função de avaliação pode ser inviável, exigindo que sejam realizados estudos para determinação das melhores condições de execução do AG (tamanho mínimo da população, taxa de mutação, etc) para obtenção de resultados consistentes, de forma análoga ao que foi feito para a função de Rastrigin. Não obstante, considera-se que o algoritmo desenvolvido tem plena capacidade de otimizar soluções de problemas diversos, dependendo apenas do adequado ajuste e uso dos parâmetros do AG e da função de avaliação utilizada.

soluções em questão de segundos ou minutos, ou ainda, situações que simplesmente não justifiquem longas esperas por resultados ótimos (casos didáticos, por exemplo). 


\section{2 - VERIFICAÇÃO DAS EQUAÇÕES DE MODELAGEN PARA O CASO DE UM MÍSSIL DE CRUZEIRO SUBSÔNICO}

\subsection{1 - O míssil Harpoon}

Nesta seção o programa desenvolvido será utilizado para o dimensionamento de um míssil a partir de dados de um míssil de cruzeiro subsônico existente. O míssil selecionado para esta etapa foi o AGM-84D Harpoon ${ }^{60}$.

O Harpoon tem corpo cilíndrico, possui asas e o controle de voo é feito pelas superfícies de cauda. As asas têm geometria trapezoidal. Para voo em cruzeiro, utiliza um motor turbojato. As versões lançadas a partir de navios e submarinos possuem booster para aceleração inicial, que são alijados antes do voo em cruzeiro. As versões lançadas por aeronaves não utilizam booster. A tomada de ar da turbina é localizada na região central inferior, entre dois painéis da asa .

A versão de interesse do Harpoon tem 3,848 m de comprimento, diâmetro de $343 \mathrm{~mm}$, envergadura total de $915 \mathrm{~mm}$ (dois painéis da asa mais o diâmetro do corpo), peso no lançamento de 556 kgf e alcance de 220 km (Castro, 2014). A versão AGM-84D é lançada por aeronaves.

A Figura 4.11 mostra duas imagens do míssil. À esquerda, o míssil é lançado a partir de um navio. É possível observar o booster na região posterior do míssil. À direita, o míssil é mostrado em voo de cruzeiro.

\footnotetext{
${ }^{60}$ O Harpoon é um míssil de cruzeiro anti-navio de médio alcance, sea-skimming, tipo "dispare-e-esqueça", com guiamento final por radar ativo, lançado por aeronaves, navios e submarinos. O míssil Harpoon foi desenvolvido pela empresa norte-americana McDonnell Douglas para a marinha daquele país. O míssil possui diversas variantes (versões). A primeira versão entrou em serviço em 1977. Segundo o atual fabricante do míssil (Boeing), já foram produzidas mais de 7.200 unidades do míssil nas diversas versões.
} 

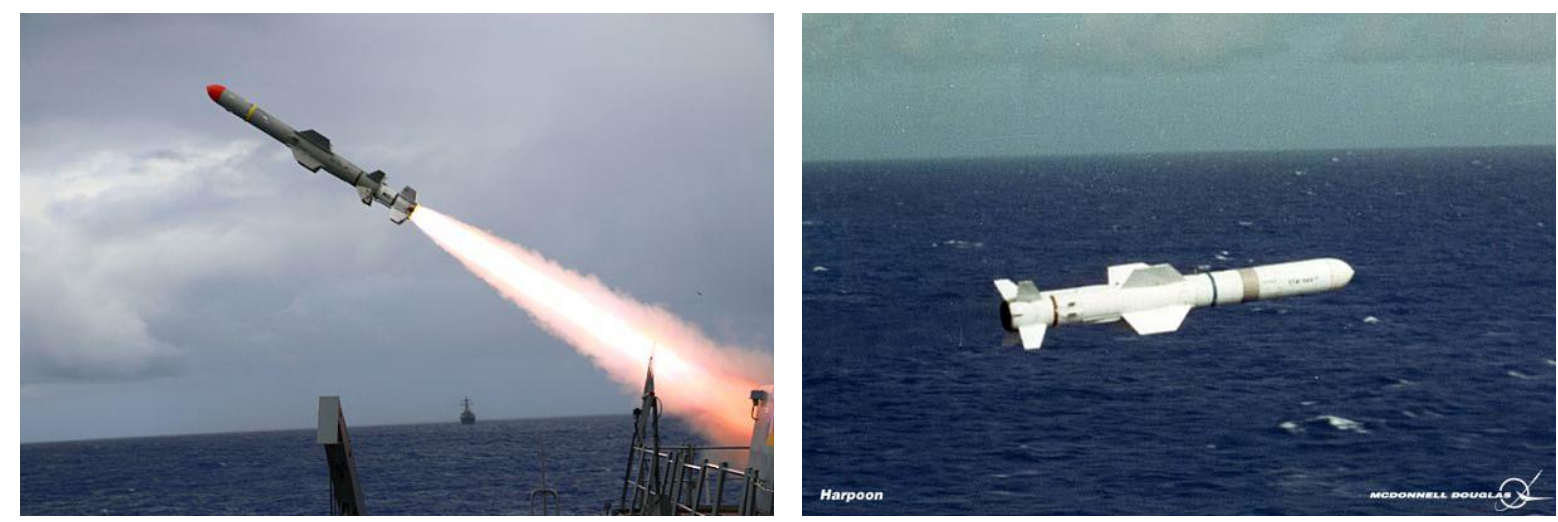

Figura 4.11 - O míssil AGM-84 Harpoon em dois momentos. À esquerda o lançamento a partir de um navio (US Navy, 2015). Notar o booster na parte posterior do míssil. A imagem à direita mostra o míssil em voo de cruzeiro, sem booster (Kopp, 2014).

Para que fosse possível fazer a análise do Harpoon com o programa Scorpio 1.0, foram necessários maiores detalhes a respeito do míssil. Para isso, foram considerados os dados informados por Bithell \& Stoner (1982). Estes dados foram utilizados como valores de entrada no programa e constam na Tabela 4.3.

Tabela 4.3 - Variáveis de projeto para dimensionamento do míssil AGM-84D Harpoon.

\begin{tabular}{lr}
\hline Variável & Valor \\
\hline Altitude de voo de cruzeiro (m) & 50 \\
Diâmetro do corpo do míssil (m) & 0,343 \\
Comprimento do corpo do míssil (m) & 3,848 \\
Comprimento do nariz do míssil (múlt. diâm.) & 0,86 \\
Taper ratio da asa (adimensional) & 0,512 \\
Taper ratio da superfície de cauda (adim.) & 0,517 \\
Corda aerodinâmica da raiz da asa(m) & 0,744 \\
Corda aerodinâmica da raiz da cauda (m) & 0,295 \\
Ângulo de enflechamento da asa (graus) & 45 \\
Ângulo de enflechamento da superfície de cauda (graus) & 34 \\
Âng. tot. bordo de ataque seção transv. da asa e cauda (graus) & 30 \\
Envergadura total da asa (soma dos 2 painéis) (m) & 0,572 \\
Envergadura total das superfícies de cauda - soma 2 painéis (m) & 0,572 \\
Núm. painéis da asa (simples = 1; cruciforme = 2; etc) & 2 \\
Núm. painéis da cauda (simples = 1; cruciforme = 2; etc) & 2 \\
Número de Mach em voo de cruzeiro (adimensional) & 0,7 \\
Dist. bordo ataque da raiz da asa - nariz (múlt. comp. - adimens.) & 0,49 \\
Dist. bordo ataque da cauda - nariz (múlt. comp. - adimens.) & 0,92 \\
Temperatura de combustão (K) & 816 \\
Ângulo de voo inicial após cruzeiro (graus) & 45 \\
Fração mássica de combustível (comb./início cruzeiro) (adimens.) & 0,1 \\
Relação de pressões no compressor (adimensional) & 5,4 \\
\hline
\end{tabular}


Além dos dados Tabela 4.3, foram utilizados como parâmetros de projeto as informações contidas na Tabela 4.4 .

Os valores utilizados na Tabela 4.4 referentes às massas da cabeça de guerra, sistemas de guiamento, controle e enlace de dados, atuadores das superfícies de controle e fonte de energia foram extraídos de Bithell \& Stoner (1982).

A limitação dos ângulos de ataque em $10,0^{\circ}$ foi decorrência dos modelos teóricos utilizados (ver Equações (2.14) e (2.15)). O incremento na variação dos ângulos de ataque é o valor utilizado para a mudança dos ângulos de ataque dos elementos do míssil (corpo, asa e cauda), quando da busca das condições de equilíbrio e voo. A parcela de arrasto de base desprezada em cruzeiro considera uma estimativa inicial da relação entre a área de exaustão do motor e a área da base do míssil. O valor do erro máximo nas equações de equilíbrio em voo se refere às Equações (2.47) e ( 2.56). O valor do erro pode ser reduzido, ou mesmo anulado, caso a variação dos ângulos de ataque fosse infinitesimal. Numericamente isso resultaria em tempo de execução demasiadamente longo, inviabilizando o uso do algoritmo. Mesmo com a tolerância de erros nas equações de equilíbrio, os resultados obtidos são adequados para projeto conceitual.

Conforme mencionado, o míssil em análise utiliza controle por superfícies de cauda móveis e motor turbojato. O míssil apresenta reduzido boattail, sendo considerado, neste trabalho, que o mesmo é inexistente.

Os valores utilizados para eficiência isentrópica dos componentes do motor (difusor, compressor, turbina, bocal de exaustão) e para a razão de calores específicos do fluido de trabalho foram baseados nos valores das Tabelas 2.3 e 2.4 deste trabalho e valores indicados por Fleeman (2012).

As informações da Tabela 4.3 foram utilizadas no programa na forma de variáveis de projeto, sendo que cada variável da tabela foi adotada como limite inferior e superior do respectivo gene. Assim, os genes disponíveis eram iguais e o programa, ao ser executado, simulou apenas este míssil. Considerando que neste caso não foi utilizada a capacidade 
evolutiva do Scorpio 1.0, o número de gerações foi ajustado para o valor mínimo. A partir dessas informações foi possível executar o Scorpio 1.0 e obter os resultados a seguir.

Tabela 4.4 - Parâmetros de projeto para simulação do míssil AGM-84D Harpoon.

\begin{tabular}{lr}
\hline Parâmetro & Valor \\
\hline Dados de lançamento e impacto & 50 \\
Altitude de lançamento (m) & 0 \\
\hline Altitude de impacto (m) & 231,5 \\
Velocidade de lançamento (m) & 200,0 \\
Velocidade de impacto (m) & \\
Dados de massa do míssil & 231,0 \\
Massa da cabeça de guerra (kg) & 42,9 \\
Massa dos sistemas de guiamento, controle e enlace de dados (kg) & 13,6 \\
Massa dos atuadores das superfícies de controle (kg) & 13,6 \\
Massa da fonte de energia (kg) & \\
Dados aerodinâmicos & 10,0 \\
Máximo ângulo de ataque da asa (graus) & 10,0 \\
Máximo ângulo de ataque do corpo (graus) & 10,0 \\
\hline Máximo ângulo de ataque da superfície de cauda (graus) & 0,25 \\
Incremento na variação dos ângulos de ataque (graus) & 25,0 \\
\hline Parcela do arrasto de base desprezada em cruzeiro (\%) & 3,0 \\
Erro máximo nas equações de equilíbrio em voo (\%) & Cauda \\
Tipo de controle & $\mathrm{Não}$ \\
Presença de boattail & Turbojato \\
Tipo de motor de cruzeiro & Balístico \\
Perfil de voo após cruzeiro & \\
Dados do sistema de propulsão - Motor de cruzeiro - Turbojato & 0,91 \\
\hline Eficiência isentrópica do difusor de admissão de ar (adimensional) & 0,89 \\
Eficiência isentrópica do compressor (adimensional) & 0,90 \\
Eficiência isentrópica da turbina (adimensional) & 0,95 \\
Eficiência isentrópica do bocal de exaustão (adimensional) & 1,4 \\
Razão de calores específicos no difusor de entrada (adimensional) & 1,37 \\
Razão de calores específicos no compressor (adimensional) & 1,33 \\
Razão de calores espećficos na turbina (adimensional) & 1,33 \\
Razão de calores específicos no bocal de exaustão (adimensional) & 0,95 \\
\hline Relação de pressões no combustor (adimensional) & \\
\hline
\end{tabular}

\subsection{2 - Previsão de desempenho do míssil Harpoon pelo programa Scorpio 1.0}

A Figura 4.12 foi gerada pelo programa Scorpio 1.0 com base nos dados de entrada do míssil de referência, e mostra as dimensões principais e o perfil do míssil. Essa figura contém duas imagens iguais (mesmo míssil). Comparando-se visualmente as imagens da Figura 4.11 e da Figura 4.12, é possível notar a semelhança entre elas. Na imagem abaixo não são mostrados todos os painéis das superfícies aerodinâmicas. A Figura 4.12 indica 
ainda a posição longitudinal dos centros aerodinâmicos do corpo (quadrado verde), da asa (quadrado azul próximo ao centro do míssil) e das superfícies de cauda (quadrado azul na região posterior do míssil). São indicados ainda o centro aerodinâmico do míssil (losango magenta) e o centro de massa do míssil (círculo vermelho). Visualmente é possível perceber que este míssil é estaticamente estável, dado que o centro aerodinâmico do míssil se encontra à jusante do centro de massa. Embora a mera visualização da imagem do míssil não forneça muitos elementos de análise, ela permite rapidamente entender a configuração geral do míssil, ao passo que as informações contidas no relatório a respeito do míssil (ANEXO H - RELATÓRIO DE EXECUÇÃO DO SCORPIO 1.0: MÍSSIL HARPOON) permitem uma compreensão e análise crítica sobre o resultado apontado pelo Scorpio 1.0. Esse relatório dá um conjunto de informações a respeito do míssil e, por ser relativamente extenso, foi inserido como anexo deste trabalho.

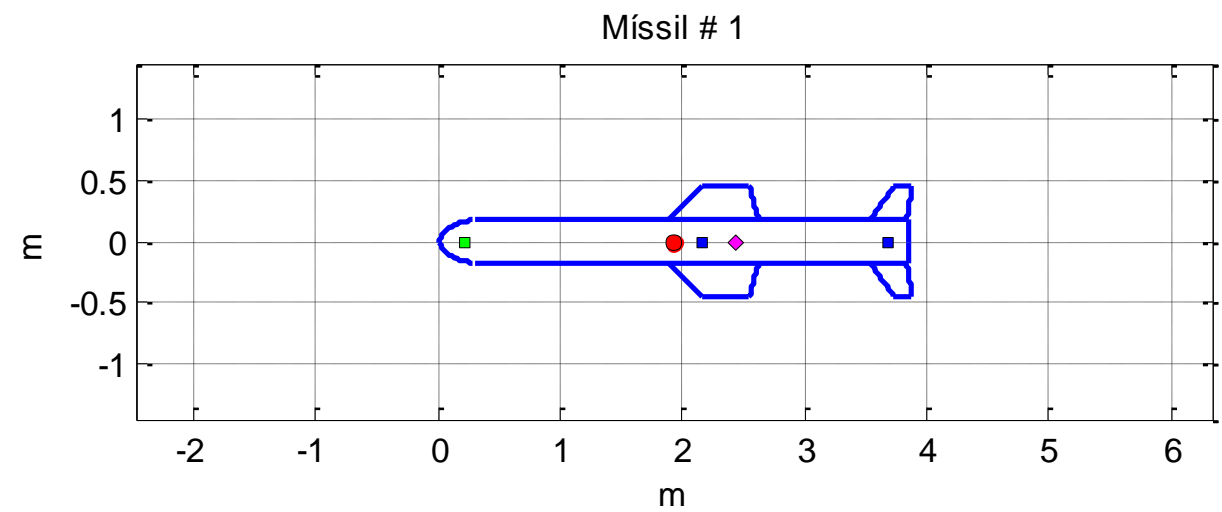

Míssil \# 2

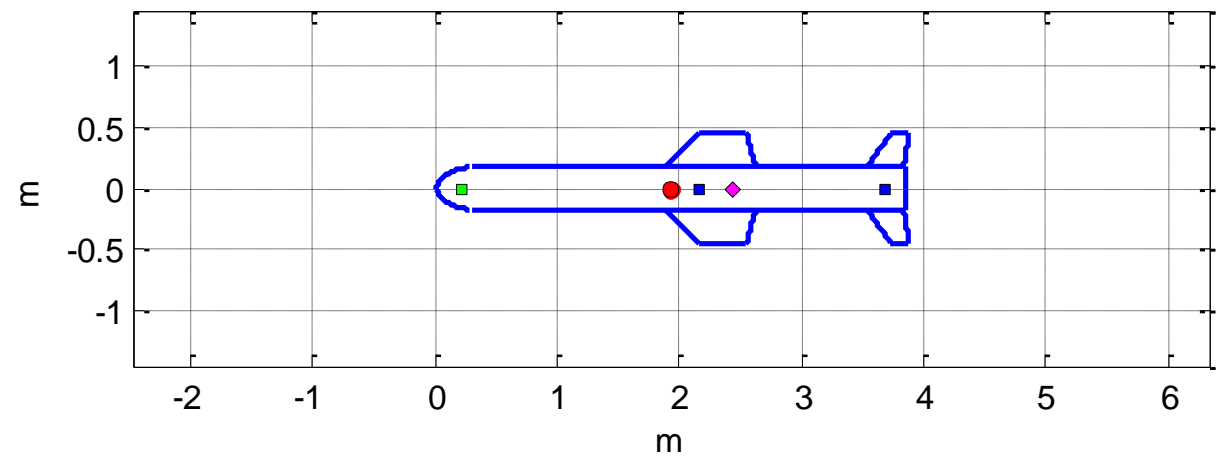

Figura 4.12 - Imagens representativas do míssil AGM-84D Harpoon.

Apesar de a literatura informar alguns dados dimensionais e operacionais sobre o míssil AGM-84D Harpoon, não foram encontradas informações com maior detalhamento a 
respeito do desempenho de voo (p.ex. estabilidade estática, fator de carga em voo, ângulos de ataque para equilíbrio em voo etc). Não obstante, a Tabela 4.5 e o ANEXO H RELATÓRIO DE EXECUÇÃO DO SCORPIO 1.0: MÍSSIL HARPOON apresentam os valores dos aludidos dados, na forma como foram previstos pelo Scorpio 1.0. Esses valores de estabilidade estática e fator de carga em voo serão utilizados como referência nos estudos realizados e apresentados mais adiante nessa dissertação (verificação de repetibilidade e dimensionamento de um míssil tático de cruzeiro).

Tabela 4.5 - Dados de desempenho do AGM-84D Harpoon conforme calculado pelo programa Scorpio 1.0.

\begin{tabular}{lr}
\hline Variável & Valor \\
\hline Alcance máximo $(\mathrm{km})$ & 221,63 \\
Tempo até o alvo (s) & 942,61 \\
Massa de lançamento (kg) & 515,44 \\
Estabilidade estática (adimensional - múltiplos do diâmetro) & 1,476 \\
Máximo Fator de carga em voo (adimensional - múltiplos de g) & 1,713 \\
\hline
\end{tabular}

O valor de alcance máximo calculado pelo programa $(221,63 \mathrm{~km})$ apresenta excelente precisão, para fins de projeto conceitual, quando comparados com o valor verificado na literatura $(220 \mathrm{~km})$.

A massa de lançamento prevista $(515,44 \mathrm{~kg})$ é 7,29\% menor que o valor encontrado na literatura $(556 \mathrm{~kg})$. Considerando a natureza dos complexos fenômenos físicos que se tenta prever pelo pequeno conjunto de equações mostradas neste trabalho, e, além disso, pelas simplificações e aproximações discutidas, pode-se considerar também, que o valor de massa de lançamento previsto pelo programa apresenta resultado satisfatório para projeto conceitual.

A posição longitudinal dos centros aerodinâmicos estimados pelo Scorpio 1.0 para cada elemento do míssil e para todo o conjunto estão mostrados na Tabela 4.6. A posição longitudinal é referenciada com relação ao nariz do míssil e no caso da asa e cauda, utiliza também o respectivo bordo de ataque. Os centros aerodinâmicos e o centro de massa do míssil, apresentados na Tabela 4.6 então presentes também na Figura 4.12. O centro aerodinâmico do míssil é situado a 2430,3 mm à jusante do nariz, ao passo que o centro de massa do míssil (CG) se localiza a 1924,0 $\mathrm{mm}$ do mesmo referencial. Isso indica que o 
míssil é estaticamente estável. A relação da distância entre o centro aerodinâmico do míssil e o CG (506,3 mm) com o diâmetro do míssil $(343 \mathrm{~mm})$, é justamente o valor da estabilidade estática do míssil $(1,476)$.

A Tabela 4.7 contém dados de relação sustentação/arrasto média em cruzeiro e em coast. Esses dados consideram o início e fim de cada fase de voo e são utilizados para o cálculo do alcance de voo. A menor relação sustentação/arrasto verificada em coast é devido principalmente ao aumento do arrasto de base do corpo, uma vez que o motor de cruzeiro não opera nessa fase do voo. Destaca-se que o arrasto e a sustentação são calculados a partir das condições de equilíbrio em voo e levam em consideração o ângulo de ataque de cada componente aerodinâmico do míssil (corpo, asa e cauda). No relatório a respeito do míssil (ANEXO H - RELATÓRIO DE EXECUÇÃO DO SCORPIO 1.0: MÍSSIL HARPOON), constam os ângulos de ataque para equilíbrio no início do cruzeiro e para máximo fator de carga em voo. Os ângulos de ataque para todos os componentes aerodinâmicos do míssil são limitados pelo valor informado pelo usuário do programa (neste caso, 10 graus). Conforme explicado na seção deste trabalho que trata de modelagem aerodinâmica, o emprego de ângulos de ataque maiores resultaria no aumento da força normal nos elementos e, assim, maior fator de carga em voo. Contudo, a limitação em 10 graus considerou a restrição da aplicabilidade da teoria adotada.

O programa Scorpio 1.0 não considera o efeito do downwash produzido pela asa sobre as superfícies de cauda. Na prática o ângulo de ataque das superfícies de cauda pode ser alterado devido a esse fenômeno.

A Tabela 4.8 apresenta valores da massa estimada dos principais componentes do míssil. Alguns desses valores foram dados de entrada (cabeça de guerra, sistema de guiamento, controle e enlace de dados, atuadores das superfícies de controle e fonte de energia). Os demais componentes tiveram sua massa estimada com a metodologia apresentada anteriormente. No ANEXO H - RELATÓRIO DE EXECUÇÃO DO SCORPIO 1.0: MÍSSIL HARPOON o valor dessas massas são indicados também na forma de um percentual da massa total do míssil. A massa da estrutura do corpo do míssil (104,74 kg) representou cerca de 20,3\% da massa total do míssil, sendo que Fleeman (2012) aponta uma relação típica de $22 \%$ para mísseis táticos. 
A massa do motor de cruzeiro estimada pelo programa $(45,21 \mathrm{~kg})$ apresentou excelente aproximação da massa do motor real do míssil (46,0 kg), uma diferença inferior a $2 \%$ (Smithsonian National Air and Space Museum, 2015). A massa de combustível de cruzeiro prevista pelo Scorpio 1.0 foi de $51,29 \mathrm{~kg}$ ao passo que a massa de combustível de cruzeiro do Harpoon é de 49,21 kg (Bithell \& Stoner, 1982), um discrepância de cerca de 4\%.

A Tabela 4.9 mostra informações sobre dados de entrada utilizados para o dimensionamento do motor e valores calculados. Os dados de entrada são mostrados em vermelho e são parâmetros de projeto, com exceção da relação de pressões no compressor que, apesar de fixa nesse caso, é uma variável de projeto. Os demais dados foram calculados a partir do dimensionamento do míssil.

A temperatura de entrada na turbina $(816 \mathrm{~K})$ e a relação de pressões no compressor $(5,4)$ foi extraídas de Fleeman $(2012)^{61}$. O poder calorífico do combustível (43 MJ/kg) considerou um valor típico de um hidrocarboneto (para esta situação, o querosene). A eficiência isentrópica e os calores específicos do fluido de trabalho nos diferentes pontos do motor, foram baseados em valores típicos da literatura. Esses mesmos valores serão mantidos constantes nas demais execuções do programa, comentadas mais adiante.

Com esses dados, e partir dos características aerodinâmicas e peso do míssil, foi possível fazer a estimativa de empuxo necessário em Mach 0,7 no início e fim de voo em cruzeiro (1469,8 e 1342,7 N, respectivamente) e empuxo necessário para voo em regime constante, com máximo fator de carga possível $(2216,8 \mathrm{~N})$. A Tabela 5.9 apresenta ainda valores de pressão e temperatura média em cada ponto notável do motor e dados relativos à operação do motor. Esses dados consideram o momento de início de voo em cruzeiro. De acordo com Fleeman (2012), o motor do míssil Harpoon possui empuxo máximo de cerca de 2900 $\mathrm{N}$, sendo que esse autor estimou que o míssil requeira empuxo da ordem de $2050 \mathrm{~N}$ em voo nivelado ao nível do mar e com número de Mach igual a 0,8. Considerando que o arrasto é função quadrática da velocidade de voo, seria possível estimar o empuxo desse míssil voando em Mach 0,7 (também ao nível do mar) como sendo da ordem de 1570 N. Esse

\footnotetext{
${ }^{61}$ Esse valor de temperatura é estimado para a operação do motor em carga parcial. A temperatura de operação em carga plena (“ponto de projeto”) é de cerca de $1000 \mathrm{~K}$ (Fleeman, 2012).
} 
valor é cerca de $7 \%$ maior que o estimado pelo programa Scorpio 1.0, uma boa aproximação para projeto conceitual.

A velocidade de exaustão do turbjato é de $436,35 \mathrm{~m} / \mathrm{s}$, enquanto a velocidade de cruzeiro é de 238,0 m/s. Conforme dito anteriormente, a eficiência global do sistema de propulsão é aproximadamente maximizada quando a velocidade de exaustão é o dobro da velocidade de voo. Isso mostra que as configurações utilizadas resultam em um motor com boa eficiência. O fluxo de gases no bocal de exaustão atinge número de Mach máximo igual a 0,9712 no plano de exaustão, expandido completamente os gases antes da exaustão.

O bocal de exaustão possui diâmetro mínimo estimado de aproximadamente $179 \mathrm{~mm}$. O motor real do míssil Harpoon possui bocal convergente com diâmetro de exaustão de cerca de 213 mm (Fleeman, 2012). Essa é uma boa aproximação diante das considerações feitas sobre bocal de exaustão de motor turbojato (Seção 2.3.3.2 -).

O consumo de combustível para o início do voo em cruzeiro é de cerca de 0,059 kg/s, enquanto o fluxo de ar é estimado em $7,283 \mathrm{~kg} / \mathrm{s}$. O impulso específico do motor foi calculado como sendo próximo de 2550,7 s. Esse valor de impulso específico foi utilizado para o cálculo do alcance de voo em cruzeiro.

Diante dos os dados obtidos, conclui-se que o programa Scorpio 1.0 foi capaz de prever, com razoável precisão, informações acerca do míssil AGM-84D Harpoon, apresentando, assim, resultados satisfatórios no dimensionamento de um míssil de cruzeiro subsônico. Essas informações podem ser representadas de forma significativa pelo alcance de voo previsto, uma vez que o alcance de voo é afetado por todos os outros parâmetros como, por exemplo, as massa dos componentes individuais, os ângulos de ataque do corpo, asa e cauda, o arrasto médio em cruzeiro, o empuxo necessário, o consumo específico de combustível, o impulso específico do sistema de propulsão e assim por diante. Outros dados de voo como máximo fator de carga em voo e estabilidade estática não foram encontrados na literatura. Não obstante, os valores obtidos neste caso de dimensionamento do Harpoon serão utilizados como valores referenciais nos casos seguintes do presente trabalho. 
Tabela 4.6 - Centro aerodinâmico do míssil Harpoon (estimado pelo Scorpio 1.0).

\begin{tabular}{ll}
\hline Centro aerodinâmico & \\
Centro aerodinâmico do corpo do míssil $(\mathrm{mm})$ & 230,2 \\
\hline Centro aerodinâmico da asa (bordo de ataque) $(\mathrm{mm})$ & 145,5 \\
\hline Centro aerodinâmico da cauda (bordo de ataque) $(\mathrm{mm})$ & 57,8 \\
\hline Centro aerodinâmico da asa (nariz do míssil) $(\mathrm{mm})$ & 2158,6 \\
Centro aerodinâmico da cauda (nariz do míssil) $(\mathrm{mm})$ & 3684,2 \\
Centro aerodinâmico do míssil (mm) & 2430,3 \\
Centro de massa (CG) do míssil (mm) & 1924,0 \\
Estabilidade estática (adimensional - múltiplos do diâmetro) & 1,476 \\
\hline
\end{tabular}

Tabela 4.7 - Dados de voo do míssil Harpoon (estimado pelo Scorpio 1.0).

\begin{tabular}{lc}
\hline Relação Sustentação/Arrasto & \\
\hline Relação Sustentação/Arrasto média em cruzeiro (adimensional) & 3,397 \\
\hline Relação Sustentação/Arrasto média em coast (adimensional) & 2,978 \\
\hline Arrasto médio em voo & 465,47 \\
\hline Arrasto médio em boost $(\mathrm{N})$ & 1396,67 \\
Arrasto médio em cruzeiro (N) & 1483,57 \\
\hline Arrasto médio em coast $(\mathrm{N})$ &
\end{tabular}

Tabela 4.8 - Massa dos componentes do míssil Harpoon (estimado pelo Scorpio 1.0).

\begin{tabular}{|c|c|}
\hline \multicolumn{2}{|l|}{ Massas dos componentes do míssil } \\
\hline Massa da Cabeça de Guerra (kg) & 231,00 \\
\hline Massa dos Sistemas de Guiamento, Controle e Enlace de Dados (kg): & 42,90 \\
\hline Massa de combustível de cruzeiro $(\mathrm{kg})$ & 51,29 \\
\hline Massa da estrutura (corpo) do míssil (kg) & 104,74 \\
\hline Massa total da Asa (kg) & 7,25 \\
\hline Massa total da Cauda (kg) & 3,33 \\
\hline Massa do motor de cruzeiro $(\mathrm{kg})$ & 45,21 \\
\hline Massa total dos atuadores das superfícies de controle $(\mathrm{kg})$ & 13,60 \\
\hline Massa total da fonte de energia $(\mathrm{kg})$ & 13,60 \\
\hline
\end{tabular}


Tabela 4.9 - Dados do motor de cruzeiro do míssil Harpoon (estimado pelo Scorpio 1.0).

\begin{tabular}{|c|c|}
\hline \multicolumn{2}{|l|}{ Sistema de Propulsão - Motor de Cruzeiro } \\
\hline \multicolumn{2}{|l|}{ Tipo de motor de cruzeiro: Turbojato } \\
\hline Empuxo necessário - início do cruzeiro (N) & 1469,8 \\
\hline Empuxo necessário - fim do cruzeiro $(\mathrm{N})$ & 1342,7 \\
\hline Empuxo necessário máx. Fator de Carga (N) & 2216,8 \\
\hline \multicolumn{2}{|l|}{ Condições de operação início voo cruzeiro } \\
\hline \multicolumn{2}{|l|}{ Temperatura } \\
\hline Temp. estagnação entrada compressor (K) & 316,0 \\
\hline Temp. estagnação saída do compressor (K) & 520,9 \\
\hline Temp. estagnação entrada na turbina $(\mathrm{K})$ & 816,0 \\
\hline Temperatura estagnação saída da turbina (K) & 611,2 \\
\hline \multicolumn{2}{|l|}{ Pressão } \\
\hline Relação de pressões no compressor $(\mathrm{Pa} / \mathrm{Pa})$ : & 5,4 \\
\hline Relação de pressões no combustor $(\mathrm{Pa} / \mathrm{Pa})$ & 0,95 \\
\hline Pressão estagnação entrada compressor (kPa) & 135,8 \\
\hline Pressão estagnação saída compressor (kPa) & 733,5 \\
\hline Pressão de estagnação entrada turbina (kPa) & 696,8 \\
\hline Pressão de estagnação saída da turbina (kPa) & 186,5 \\
\hline Pressão na saída do bocal de exaustão (kPa) & 100,7 \\
\hline \multicolumn{2}{|l|}{ Eficiência isentrópica (dados de entrada) } \\
\hline Efic. isentrópica difusor de ar (adimens.) & 0,91 \\
\hline Efic. isentrópica compressor (adimens.) & 0,89 \\
\hline Efic. isentrópica turbina (adimens.) & 0,90 \\
\hline Efic. isentrópica bocal exaustão (adimens.) & 0,95 \\
\hline \multicolumn{2}{|l|}{ Calor específico do fluido de trabalho } \\
\hline Razão calores específicos difusor (adimens.) & 1,40 \\
\hline Razão calores espec. compressor (adimens.) & 1,37 \\
\hline Razão calores específicos turbina (adimens.) & 1,33 \\
\hline Razão calores espec. bocal exaus. (adimens.) & 1,33 \\
\hline Razão combustível/ar (kg/kg): & 0,008069 \\
\hline Poder calorífico do combustível (kJ/kg) & 43000 \\
\hline Velocidade na saída bocal de exaustão (m/s) & 436,35 \\
\hline Área da saída do bocal de exaustão $\left(\mathrm{m}^{2}\right)$ & 0,025149 \\
\hline Área seção transversal corpo do míssil $\left(\mathrm{m}^{2}\right)$ & 0,0924 \\
\hline Razão área da saída do bocal de exaustão / seção do míssil (adm.) & 0,2722 \\
\hline Diâmetro saída do bocal de exaustão (mm) & 178,95 \\
\hline Mach saída bocal de exaustão (adimens.) & 0,9712 \\
\hline Fluxo de ar pela turbina $(\mathrm{kg} / \mathrm{s})$ & 7,2825 \\
\hline Consumo de combustível (kg/s) & 0,0588 \\
\hline Empuxo Específico (kN.s/kg) & 0,2018 \\
\hline Consumo específico de comb. $(\mathrm{kg} / \mathrm{s} . \mathrm{kN})$ & 0,0400 \\
\hline Impulso Específico (s) & 2550,7 \\
\hline
\end{tabular}




\section{3 - VERIFICAÇÃO DE REPETIBILIDADE DE RESULTADOS}

\subsection{1 - Testes de repetibilidade}

Os resultados produzidos pelo programa Scorpio 1.0 só possuem utilidade caso sejam confiáveis. Uma forma de verificar a confiabilidade do programa é através da comparação dos resultados gerados pelo programa com mísseis reais ou dados de ensaios experimentais (túnel de vento, ensaio em voo etc), como o procedimento mostrado na seção anterior. Além disso, a confiabilidade do Scorpio 1.0 deve ser verificada através de testes para constatar se o programa produz resultados semelhantes sempre que é executado com as mesmas configurações iniciais ${ }^{62}$.

Foram realizados testes de repetibilidade com o programa Scorpio 1.0 onde o programa foi executado quatro vezes com as mesmas configurações iniciais ${ }^{63}$. Os resultados são descrito a seguir.

\subsection{2 - Configurações iniciais do Scorpio 1.0 para os testes de repetibilidade}

As configurações iniciais usadas no programa para os testes de repetibilidade estão indicadas nas Tabelas 4.10 a 4.15. Os valores de entrada utilizados foram essencialmente o mesmos utilizados no caso anterior (AGM-84D Harpoon), com a exceção que o lançamento do míssil nestes testes de repetibilidade foi feito a partir de velocidade nula, fazendo com que o programa realizasse o dimensionamento de um motor de aceleração (booster) capaz de levar o míssil até a velocidade de cruzeiro com o fator de aceleração informado pelo usuário. Os valores de estabilidade estática e fator de carga em voo do

\footnotetext{
${ }^{62}$ As configurações iniciais levam em conta não somente os dados de entrada para dimensionamento do míssil, mas também os dados de funcionamento do algoritmo genético. Como discutido anteriormente, o tamanho da população, taxa de mutação, número de imigrantes etc, tem forte ingerência no desempenho do programa.

63 Não é o objetivo deste teste produzir resultados iguais em todas as execuções, mas resultados razoavelmente parecidos.
} 
AGM-84D Harpoon previstos pelo programa (Tabela 4.5), foram utilizados como requisitos de projeto para os testes seguintes. Portanto, além da verificação da repetibilidade de resultados, o uso desses dados iniciais faz com que o programa busque um míssil otimizado, dentro dos limites das variáveis de projeto e que atenda aos requisitos e parâmetros de projeto seguintes.

Tabela 4.10 - Configurações de ajuste do AG para testes de repetibilidade.

\begin{tabular}{lr}
\hline Parâmetro & Valor \\
\hline Número de indivíduos na população & 200 \\
Número de indivíduos no grupo de elite & 4 \\
Número de indivíduos no grupo de imigrantes & 20 \\
Número de genes no cromossomo (incluindo função de avaliação) & 25 \\
Probabilidade de mutação inicial (\%) & 2,00 \\
Probabilidade de mutação final (\%) & 15,00 \\
Número máximo de gerações & 100 \\
Avaliação suficiente para terminar execução (critério de parada) & 1,5 \\
\hline
\end{tabular}

Para estes testes foi utilizada uma população contendo 200 indivíduos ${ }^{64}$. Diferentemente dos estudos com a função de Rastrigin, onde a simplicidade dessa função de avaliação permitiu o uso de populações maiores (p. ex. 10000 indivíduos), a metodologia utilizada para o dimensionamento de mísseis táticos tornou inviável o uso de populações dessa ordem de grandeza durante o desenvolvimento deste trabalho. Essa limitação não aconteceu devido a limite de memória computacional disponível, mas porque a função de avaliação adotada necessitava de 1,5 a 2,2 segundos para ser executada, dependendo do cromossomo avaliado, fazendo com que o tempo de execução do programa fosse demasiadamente longo para o escopo deste trabalho ${ }^{65} 66$.

\footnotetext{
${ }^{64}$ O programa Scorpio 1.0 foi executado algumas vezes com populações maiores (p.ex. 500, 800, 1000 e 2000 indivíduos). Foi possível concluir que o uso de populações maiores tornava o processo evolutivo muito lento, apesar da maior diversidade genética disponível na população. Considerando que um estudo abrangente acerca do tamanho populacional mais adequado para o caso de mísseis táticos, conforme foi feito com a função de Rastrigin, requereria longo tempo de processamento, optou-se por adotar uma população composta por 200 indivíduos, pois esta configuração se mostrou mais promissora durante os testes realizados. ${ }^{65}$ Nos casos de execução do programa Scorpio 1.0 para avaliação de mísseis, foi utilizado um computador pessoal com processador Intel ${ }^{\circledR}$ Core $^{\mathrm{TM}}$ i7-4790 CPU 3,60 GHz, 16,0 GB de memória RAM, sistema operacional Windows 8 de 64 bits.

${ }^{66}$ Para fins de exemplificação, uma execução do programa com uma população de 10000 indivíduos e 100 gerações, com tempo médio consumido de 2 segundos para avaliar 1 indivíduo, seriam necessários pouco
} 
Tabela 4.11 - Requisitos de voo para testes de repetibilidade.

\begin{tabular}{lr}
\hline Requisito de desempenho & Valor \\
\hline Alcance máximo $(\mathrm{km})$ & 210 \\
Alcance mínimo $(\mathrm{km})$ & 30 \\
Tempo máximo até o alvo (s) & 1000 \\
Massa de lançamento máxima (kg) & 620 \\
Estabilidade estática mínima (adimens. - múltiplos do diâmetro) & 1,47 \\
Fator de carga em manobra mínima (adimens. - múltiplos de g) & 1,70 \\
\hline
\end{tabular}

mais de 23 dias para finalizar a execução. Esse tempo pode ser aceitável para usos práticos do programa (além do meramente acadêmico), quando o custo de desenvolvimento do produto justifique o tempo de processamento. 
Tabela 4.12 - Variáveis de projeto para testes de repetibilidade.

\begin{tabular}{|c|c|}
\hline Variáveis de projeto (genes) & Valor \\
\hline \multicolumn{2}{|l|}{ Altitude de voo de cruzeiro } \\
\hline Altitude mínima de voo (m) & 50 \\
\hline Altitude máxima de voo $(\mathrm{m})$ & 50 \\
\hline Incremento de variação da altitude de voo (m) & 50 \\
\hline \multicolumn{2}{|l|}{ Diâmetro do corpo do míssil } \\
\hline Diâmetro mínimo (m) & 0,3 \\
\hline Diâmetro máximo (m) & 0,5 \\
\hline Incremento de variação do diâmetro (m) & 0,001 \\
\hline \multicolumn{2}{|l|}{ Comprimento do corpo do míssil } \\
\hline Comprimento mínimo (m) & 3,5 \\
\hline Comprimento máximo (m) & 4 \\
\hline Incremento de variação do comprimento (m) & 0,001 \\
\hline \multicolumn{2}{|l|}{ Comprimento do nariz do míssil (múltiplo do diâmetro) } \\
\hline Comprimento mínimo do nariz (adimensional) & 0,86 \\
\hline Comprimento máximo do nariz (adimensional) & 0,86 \\
\hline Incremento de variação do comprimento do nariz (adimensional) & 0,5 \\
\hline \multicolumn{2}{|l|}{ Taper ratio da asa } \\
\hline Valor mínimo (adimensional) & 0,3 \\
\hline Valor máximo (adimensional) & 0,7 \\
\hline Incremento de variação do taper ratio (adimensional) & 0,001 \\
\hline \multicolumn{2}{|l|}{ Taper ratio da superfície de cauda } \\
\hline Valor mínimo (adimensional) & 0,3 \\
\hline Valor máximo (adimensional) & 0,7 \\
\hline Incremento de variação do taper ratio (adimensional) & 0,001 \\
\hline \multicolumn{2}{|l|}{ Corda aerodinâmica da raiz da asa } \\
\hline Valor mínimo (m) & 0,3 \\
\hline Valor máximo (m) & 1 \\
\hline Incremento de variação da corda da raiz da asa (m) & 0,001 \\
\hline \multicolumn{2}{|l|}{ Corda aerodinâmica da raiz da superfície de cauda } \\
\hline Valor mínimo (m) & 0,1 \\
\hline Valor máximo (m) & 0,5 \\
\hline Incremento de variação da corda da raiz da superfície de cauda (m) & 0,001 \\
\hline \multicolumn{2}{|l|}{ Ângulo de enflechamento da asa } \\
\hline Valor mínimo (graus) & 30 \\
\hline Valor máximo (graus) & 50 \\
\hline Incr. de variação do enflechamento da asa (graus) & 5 \\
\hline \multicolumn{2}{|l|}{ Ângulo de enflechamento da superfície de cauda } \\
\hline Valor mínimo (graus) & 30 \\
\hline Valor máximo (graus) & 50 \\
\hline Incr. de variação do enflechamento da superfície de cauda (graus) & 5 \\
\hline
\end{tabular}


Tabela 4.13 - Variáveis de projeto para testes de repetibilidade (continuação 1).

\begin{tabular}{|c|c|}
\hline Variáveis de projeto (genes) & Valor \\
\hline \multicolumn{2}{|l|}{ Ângulo total de bordo de ataque da seção transversal da asa e cauda } \\
\hline Valor mínimo (graus) & 30 \\
\hline Valor máximo (graus) & 30 \\
\hline Incremento de variação do ang. total de bordo de ataque (graus) & 5 \\
\hline \multicolumn{2}{|l|}{ Envergadura total da asa (soma dos 2 painéis) } \\
\hline Valor mínimo (m) & 0,3 \\
\hline Valor máximo $(\mathrm{m})$ & 0,6 \\
\hline Incremento de variação da envergadura de asa (m) & 0,001 \\
\hline \multicolumn{2}{|l|}{ Envergadura total das superfícies de cauda (soma dos 2 painéis) } \\
\hline Valor mínimo (m) & 0,3 \\
\hline Valor máximo (m) & 0,6 \\
\hline Incremento de variação da envergadura de cauda (m) & 0,001 \\
\hline \multicolumn{2}{|l|}{ Número de painéis da asa (Asa simples $=1 ;$ cruciforme $=2 ;$ etc ) } \\
\hline Valor mínimo (adimensional) & 2 \\
\hline Valor máximo (adimensional) & 2 \\
\hline Incremento de variação do número de painéis da asa (adimensional) & 1 \\
\hline \multicolumn{2}{|c|}{ Número de painéis superf. de cauda (Cauda simples = 1 ; cruciforme = 2 ; etc) } \\
\hline Valor mínimo (adimensional) & 2 \\
\hline Valor máximo (adimensional) & 2 \\
\hline Incremento de variação do número de painéis da cauda (adim.) & 0,5 \\
\hline \multicolumn{2}{|l|}{ Número de Mach em voo de cruzeiro } \\
\hline Valor mínimo (adimensional) & 0,7 \\
\hline Valor máximo (adimensional) & 0,7 \\
\hline Incr. de variação do número de Mach de cruzeiro (adimensional) & 0,1 \\
\hline \multicolumn{2}{|c|}{ Distância do bordo de ataque da raiz da asa até nariz (múlt. do comprimento) } \\
\hline Valor mínimo (adimensional) & 0,4 \\
\hline Valor máximo (adimensional) & 0,6 \\
\hline Incremento de variação (adimensional) & 0,01 \\
\hline \multicolumn{2}{|c|}{ Dist. bordo de ataque da superfície de cauda até nariz (múlt. do comprimento) } \\
\hline Valor mínimo (adimensional) & 0,87 \\
\hline Valor máximo (adimensional) & 0,95 \\
\hline Incremento de variação (adimensional) & 0,01 \\
\hline \multicolumn{2}{|l|}{ Temperatura de combustão } \\
\hline Valor mínimo $(\mathrm{K})$ & 816 \\
\hline Valor máximo $(\mathrm{K})$ & 816 \\
\hline Incremento da temperatura de combustão $(\mathrm{K})$ & 50 \\
\hline \multicolumn{2}{|l|}{ Ângulo de voo inicial após cruzeiro } \\
\hline Valor mínimo (graus) & 45 \\
\hline Valor máximo (graus) & 45 \\
\hline Incremento (graus) & 5 \\
\hline
\end{tabular}


Tabela 4.14 - Variáveis de projeto para testes de repetibilidade (continuação 2).

\begin{tabular}{lr}
\hline Variáveis de projeto (genes) & Valor \\
\hline Fração mássica de combustível (massa de comb./massa início do cruzeiro) & \\
\hline Valor mínimo (adimensional) & 0,05 \\
\hline Valor máximo (adimensional) & 0,25 \\
\hline Incremento de variação (adimensional) & 0,003 \\
Relação de pressões no compressor (adimensional) & \\
Valor mínimo (adimensional) & 5,4 \\
\hline Valor máximo (adimensional) & 5,4 \\
Incremento de variação (adimensional) & 0,1 \\
\hline
\end{tabular}

Tabela 4.15 - Parâmetros de projeto para os testes de repetibilidade.

\begin{tabular}{|c|c|}
\hline Parâmetro & Valor \\
\hline \multicolumn{2}{|l|}{ Dados de lançamento e impacto } \\
\hline Altitude de lançamento (m) & 0 \\
\hline Altitude de impacto (m) & 0 \\
\hline Velocidade de lançamento (m) & 0 \\
\hline Velocidade de impacto (m) & 200,0 \\
\hline \multicolumn{2}{|l|}{ Dados de massa do míssil } \\
\hline Massa da cabeça de guerra $(\mathrm{kg})$ & 231,0 \\
\hline Massa dos sistemas de guiamento, controle e enlace de dados $(\mathrm{kg})$ & 42,9 \\
\hline Massa dos atuadores das superfícies de controle (kg) & 13,6 \\
\hline Massa da fonte de energia $(\mathrm{kg})$ & 13,6 \\
\hline \multicolumn{2}{|l|}{ Dados aerodinâmicos } \\
\hline Máximo ângulo de ataque da asa (graus) & 10,0 \\
\hline Máximo ângulo de ataque do corpo (graus) & 10,0 \\
\hline Máximo ângulo de ataque da superfície de cauda (graus) & 10,0 \\
\hline Incremento na variação dos ângulos de ataque (graus) & 0,25 \\
\hline Parcela do arrasto de base desprezada em cruzeiro (\%) & 25,0 \\
\hline Erro máximo nas equações de equilíbrio em voo (\%) & 3,0 \\
\hline Tipo de controle & Cauda \\
\hline Presença de boattail & Não \\
\hline Tipo de motor de cruzeiro & Turbojato \\
\hline \multicolumn{2}{|l|}{ Dados do sistema de propulsão - foguete - Booster } \\
\hline Pressão de combustão (Mpa) & 7,00 \\
\hline Velocidade característica (m/s) & 1560,0 \\
\hline Razão de calores específicos na tubeira (adimensional) & 1,18 \\
\hline Fator de aceleração durante boost (múltiplo da acel. gravidade) & 9,00 \\
\hline Coeficiente de descarga (adimensional) & 0,96 \\
\hline Ângulo de voo (graus) & 45,0 \\
\hline \multicolumn{2}{|l|}{ Dados do sistema de propulsão - Motor de cruzeiro - Turbojato } \\
\hline Eficiência isentrópica do difusor de admissão de ar (adimensional) & 0,91 \\
\hline Eficiência isentrópica do compressor (adimensional) & 0,89 \\
\hline Eficiência isentrópica da turbina (adimensional) & 0,90 \\
\hline Eficiência isentrópica do bocal de exaustão (adimensional) & 0,95 \\
\hline Razão de calores específicos no difusor de entrada (adimensional) & 1,4 \\
\hline Razão de calores específicos no compressor (adimensional) & 1,37 \\
\hline Razão de calores específicos na turbina (adimensional) & 1,33 \\
\hline Razão de calores específicos no bocal de exaustão (adimensional) & 1,33 \\
\hline Relação de pressões no combustor (adimensional) & 0,95 \\
\hline
\end{tabular}




\subsection{3 - Resultados dos testes de repetibilidade}

Com os dados descritos nas Tabelas 4.10 a 4.15, o programa Scorpio 1.0 foi executado quatro vezes, obtendo os resultados a seguir descritos.

Nas Figuras 4.13 a 4.16 são mostrados resultados das quatro execuções do programa. Cada uma delas é formada por quatro gráficos. O gráfico do canto superior esquerdo mostra a avaliação atribuída ao melhor individuo (vermelho) e a avaliação média da população (azul) ao longo das gerações. No canto superior direito é indicado o alcance máximo (azul) e mínimo (verde) para o melhor indivíduo ao longo das gerações. Canto inferior esquerdo apresenta o tempo de voo até o alvo do melhor indivíduo ao longo das gerações. Por fím, o gráfico do canto inferior direito indica a massa de lançamento do melhor indivíduo em cada geração.
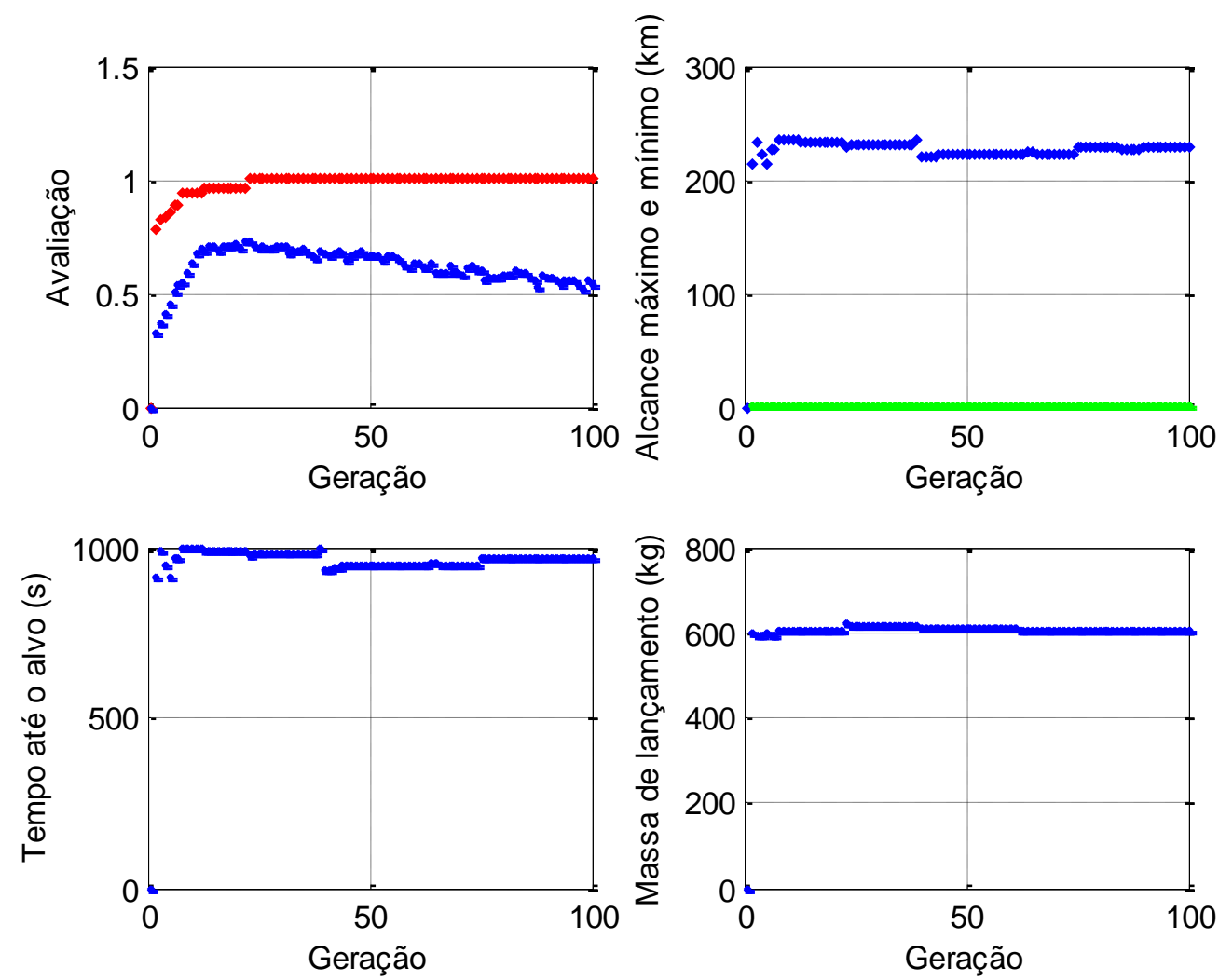

Figura 4.13 - Gráficos da primeira execução do Scorpio 1.0 para os testes de repetibilidade. 

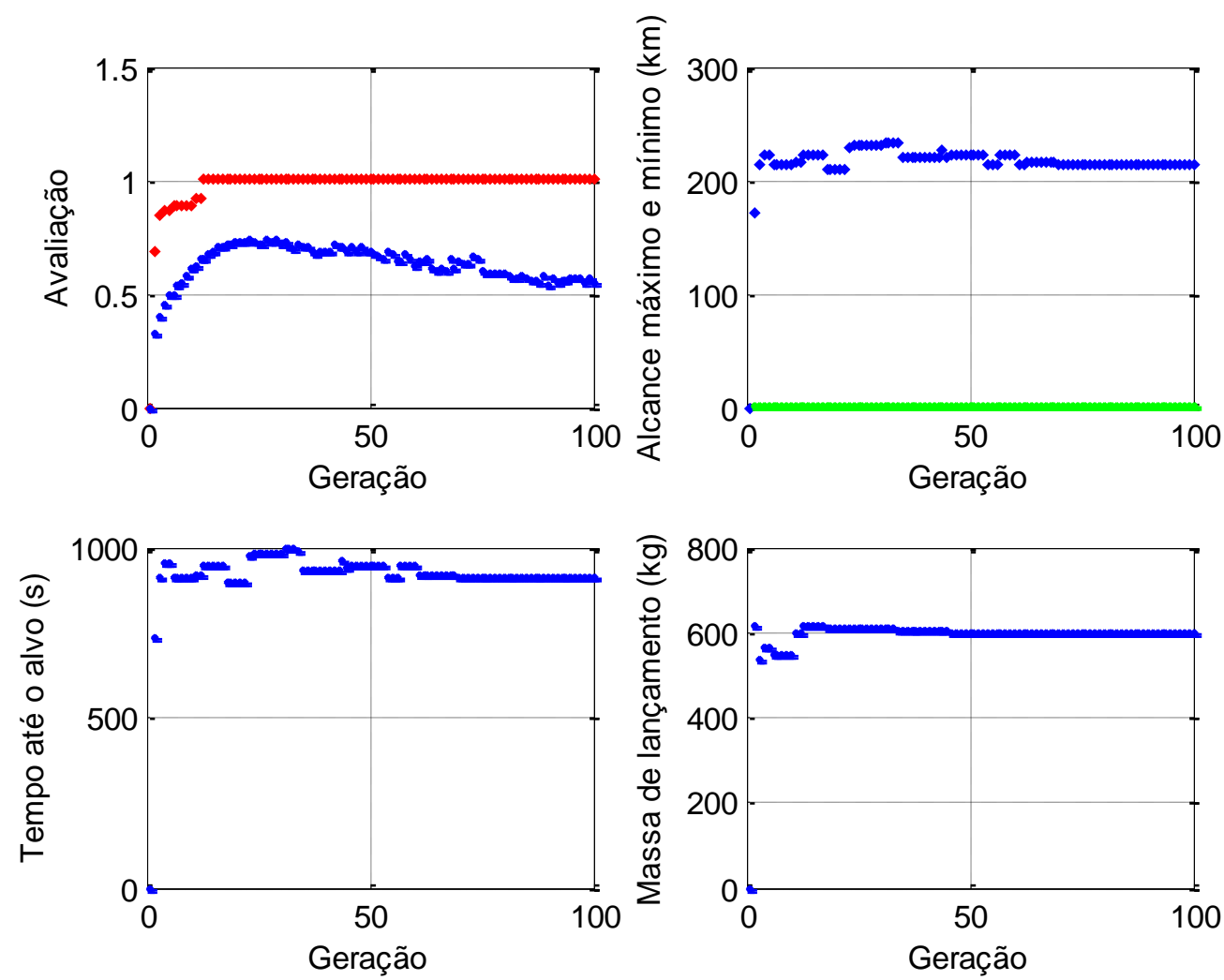

Figura 4.14 - Gráficos da segunda execução do Scorpio 1.0 para os testes de repetibilidade.
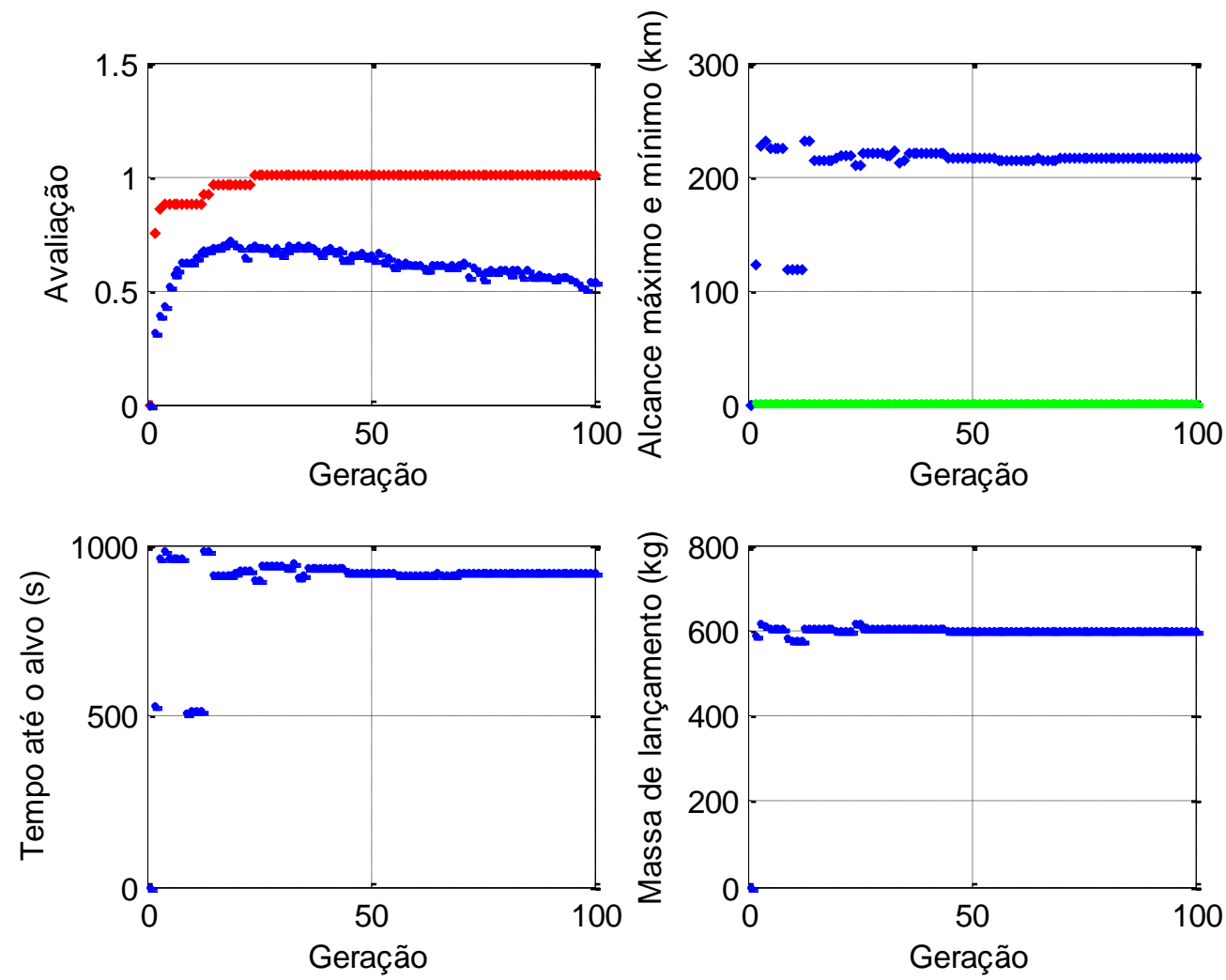

Figura 4.15 - Gráficos da terceira execução do Scorpio 1.0 para os testes de repetibilidade. 

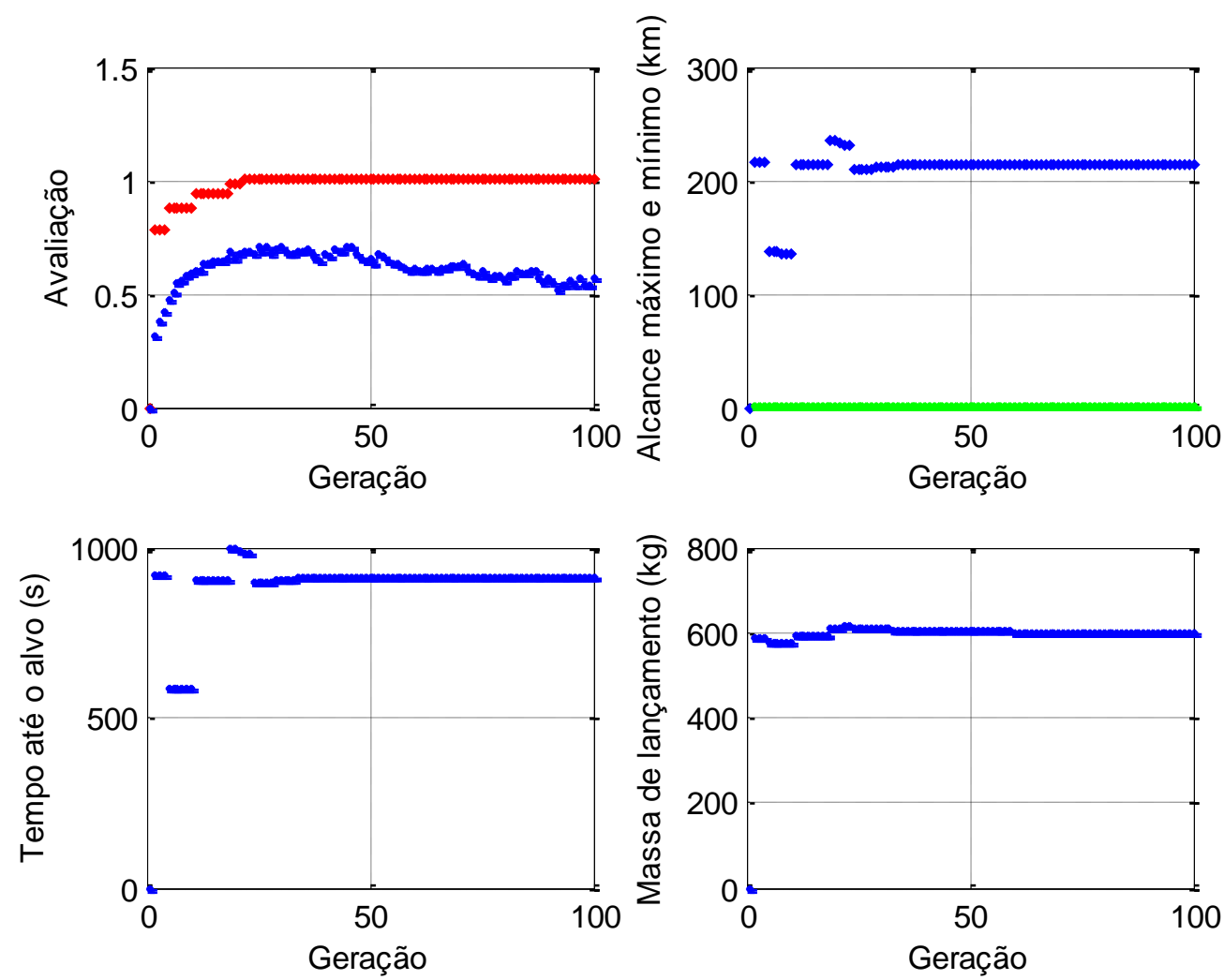

Figura 4.16 - Gráficos da quarta execução do Scorpio 1.0 para os testes de repetibilidade.

Conforme explicado, a função de avaliação para mísseis táticos foi composta de tal forma que uma avaliação igual ou superior a um indica um míssil tecnicamente viável e que atende aos requisitos de projeto. Com isso em mente e a partir da análise dos gráficos de avaliação do melhor indivíduo (pontos vermelhos) das Figuras 4.13 a 4.16, é possível concluir que em nenhuma das quatro execuções do programa foi encontrada uma solução adequada desde a primeira geração. É possível notar ainda que em todas as execuções, o Scorpio 1.0 foi capaz de encontrar uma solução que atendesse aos requisitos de projeto até aproximadamente a $25^{\mathrm{a}}$ geração. Isso mostra a capacidade evolutiva do programa. Salientase que, a cada vez que o gráfico indica um ponto diferente do ponto da geração anterior, o algoritmo encontrou uma solução melhor (maior avaliação) que a melhor solução anterior. Além disso, percebe-se um comportamento onde ocorre um forte aumento da avaliação nas primeiras gerações e um comportamento aparentemente assintótico posteriormente. Isso resulta da forma da função de avaliação (pesos, bonificações e penalizações). A análise dos demais gráficos permite inferir que o programa continuou a encontrar melhores soluções 
após encontrar a primeira solução viável, ou seja, conseguiu proceder com o processo de otimização (melhoramento) da solução.

Ainda com relação ao gráfico superior esquerdo, os pontos azuis mostram os valores da avaliação média da população. É interessante notar em todas as Figuras 4.13 a 4.16 um comportamento geral semelhante: aumento da avaliação média nas primeiras gerações, em decorrência do operador crossover do GA e sua posterior diminuição, devido ao aumento da taxa de mutação ao longo das gerações. Embora o aumento da taxa de mutação tenha esse efeito aparamente indesejado sobre a avaliação média da população, ele é benéfico na busca da melhor solução, pois permite explorar melhor o espaço de soluções após encontrar uma solução viável, escapando de máximos locais, conforme já discutido.

Todas as curvas referentes ao alcance máximo do melhor indivíduo mostram uma oscilação inicial, na região anterior à obtenção de um indivíduo satisfatório. Após esse fenômeno, o alcance máximo em todos os casos varia, porém, dentro de uma faixa compreendida aproximadamente entre 210 e $235 \mathrm{~km}$.

Nas Figuras 4.17 a 4.20 são mostrados dados dos mesmos casos representados nas Figuras 4.13 a 4.16, com escalas diferentes. O gráfico do canto superior esquerdo mostra apenas a avaliação atribuída ao melhor individuo ao longo das gerações. No canto superior direito é indicado somente o alcance máximo do melhor indivíduo, no canto inferior esquerdo, o tempo de voo até o alvo, e no canto inferior direito, a massa de lançamento do melhor indivíduo em cada geração.

Da análise das Figuras 4.17 a 4.20 é possível concluir que, embora o míssil melhor avaliado cumpra os requisitos operacionais, sendo suficiente para o objetivo a que o programa se propõe, os resultados encontrados não são o melhor possível (o resultado ótimo). Basta ver que, se o míssil melhor avaliado em cada execução tem alcance superior ao máximo exigido $(210 \mathrm{~km})$, ele é passível de ser otimizado e ter seu alcance reduzido até o valor exigido. Isso faria com que a massa de lançamento fosse reduzida. Também já foi mencionada uma estratégia que não será utilizada neste trabalho, embora seja simples de ser adotada, que é a redução do espaço de busca para uma região ao redor do melhor ponto encontrado (melhor indivíduo). Possivelmente isso traria resultados ainda melhores. 

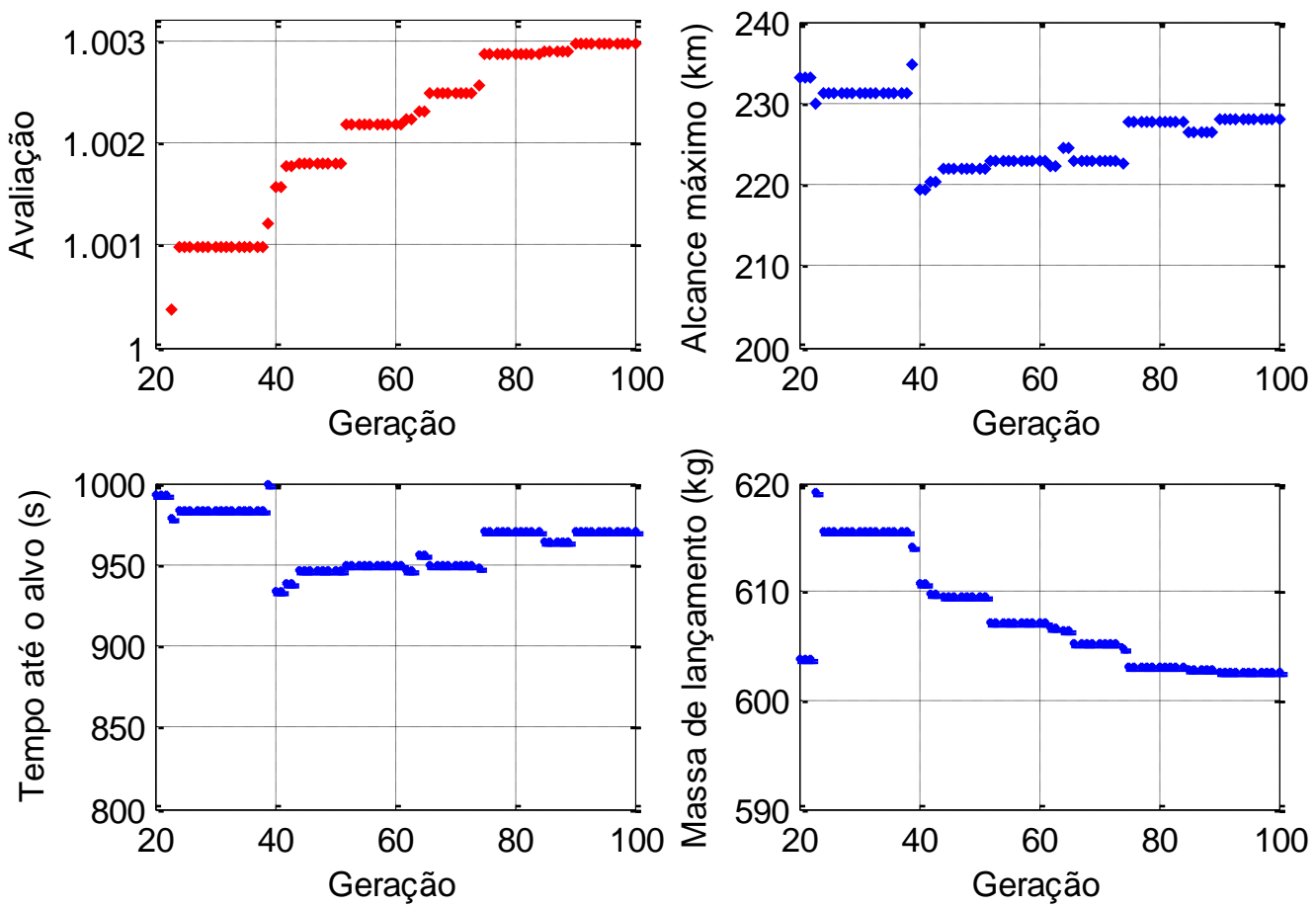

Figura 4.17 - Gráficos da primeira execução do Scorpio 1.0 para os testes de repetibilidade (diferentes escalas).
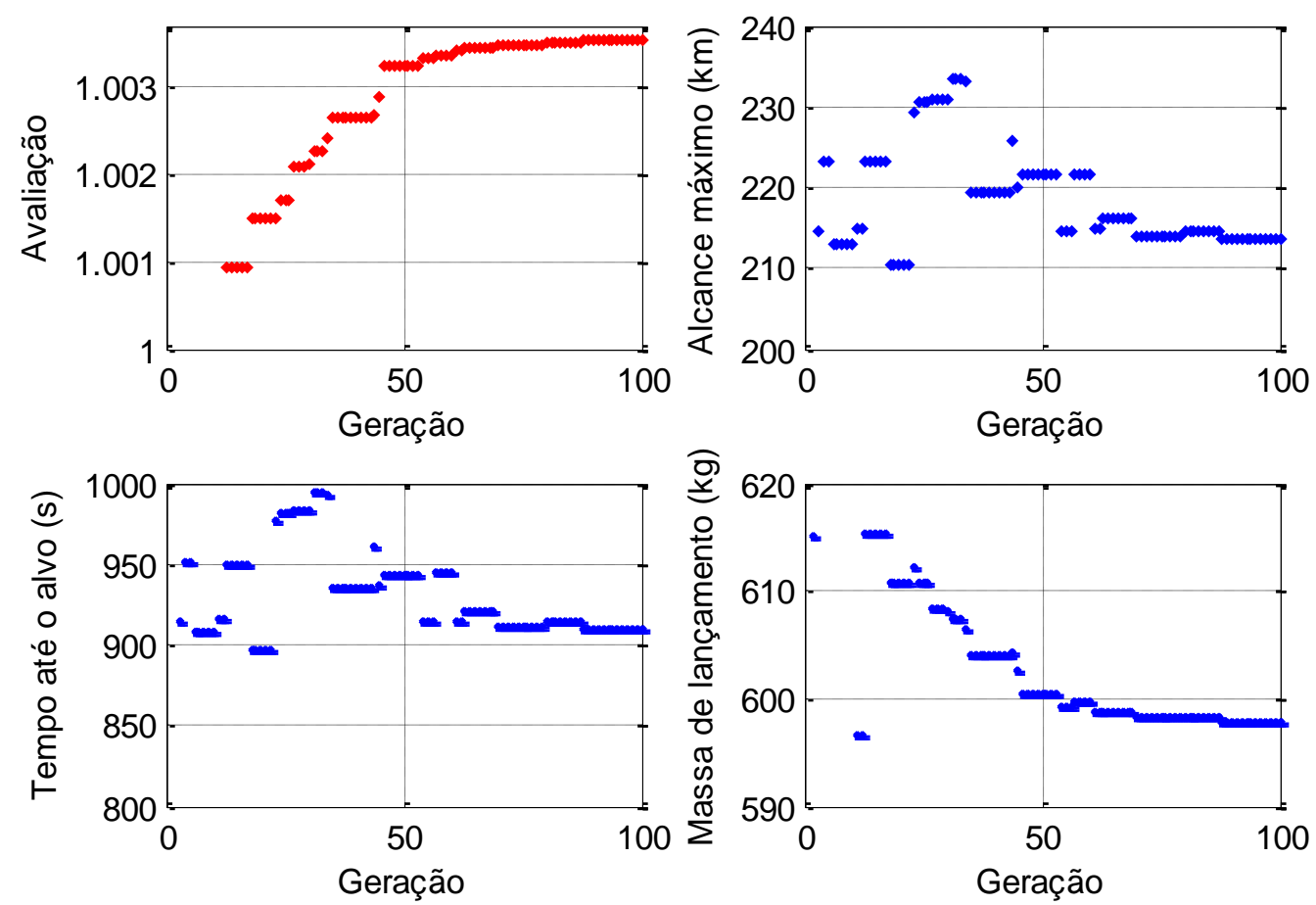

Figura 4.18 - Gráficos da segunda execução do Scorpio 1.0 para os testes de repetibilidade (diferentes escalas). 

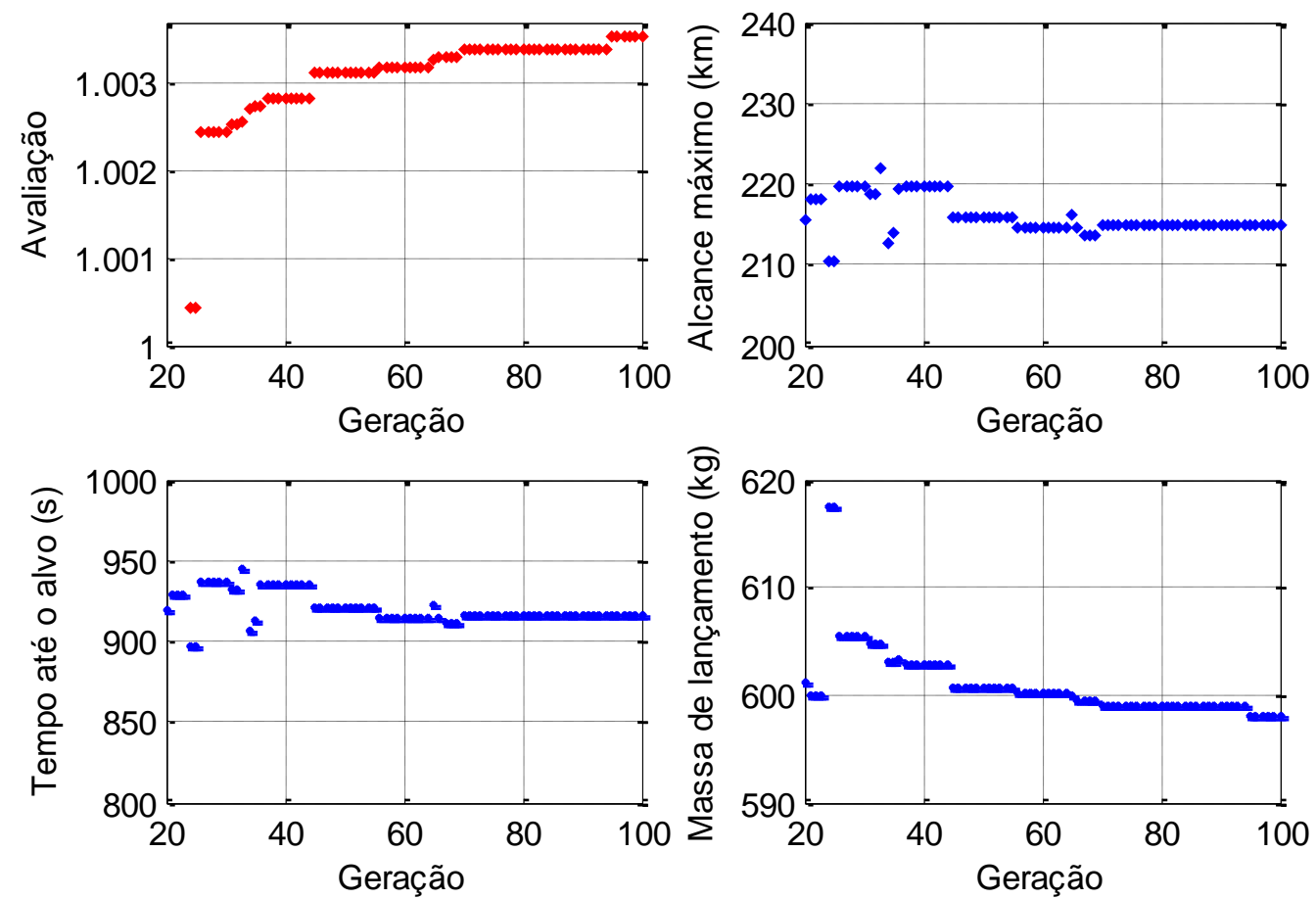

Figura 4.19 - Gráficos da terceira execução do Scorpio 1.0 para os testes de repetibilidade (diferentes escalas).
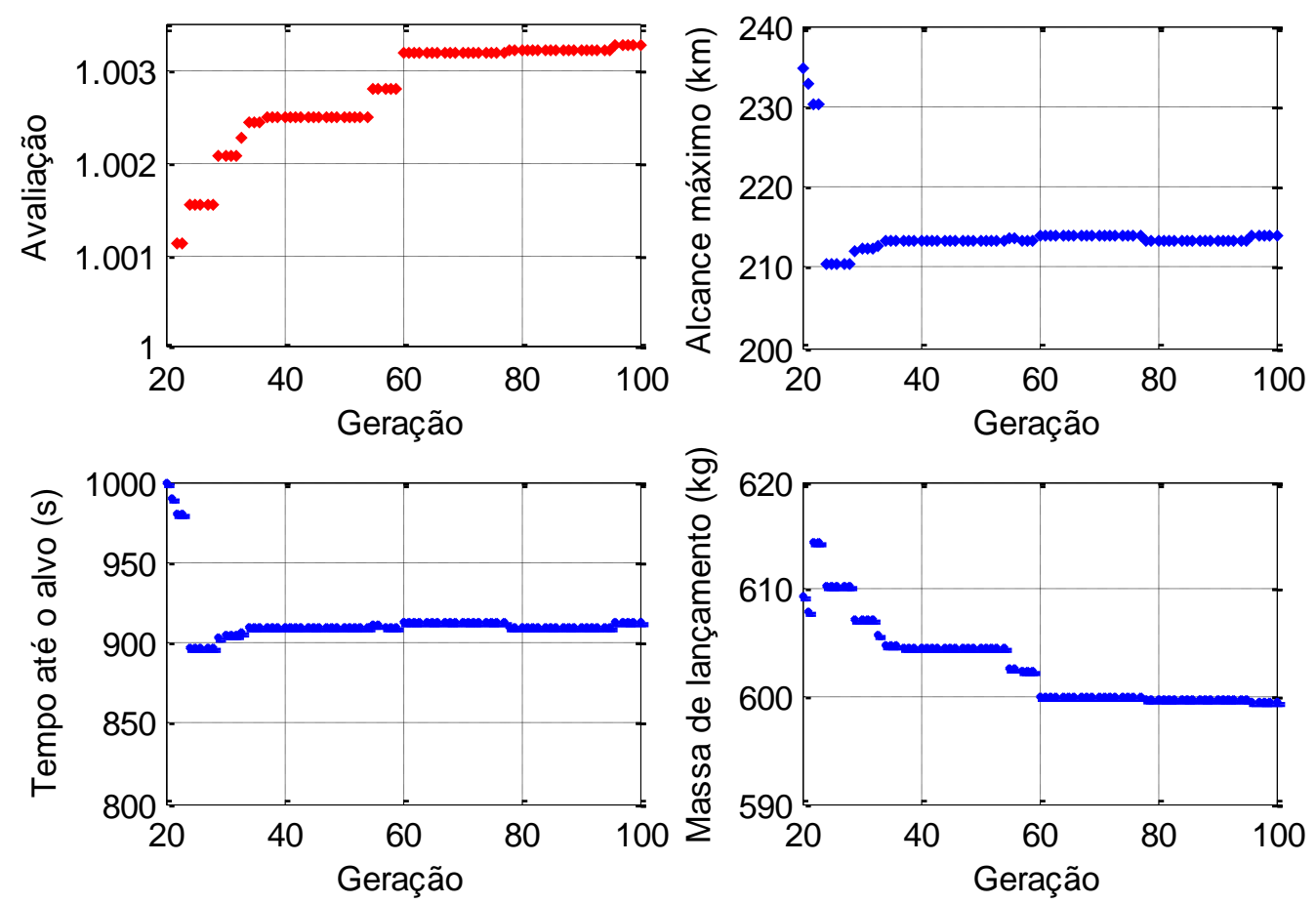

Figura 4.20 - Gráficos da quarta execução do Scorpio 1.0 para os testes de repetibilidade (diferentes escalas). 
O tempo de voo até o alvo (canto inferior esquerdo de cada figura) é menos importante nesse caso onde a velocidade de voo é constante. O tempo de voo é praticamente dominado pela distância percorrida, uma vez que a velocidade é mantida constante em Mach 0,7 . O tempo de voo até o alvo é crítico em determinadas situações e terá grande variação quando for utilizada velocidade variável, diferentemente deste caso em análise.

No canto inferior direito das Figuras 4.17 a 4.20 são mostradas as massas de lançamento dos melhores mísseis em cada geração de cada execução do programa. Os valores mostrados nos gráficos estão próximos de $600 \mathrm{~kg}$. Esse valor é superior à massa de lançamento do caso anterior, onde foi dimensionado o míssil AGM-84D Harpoon (515,44 $\mathrm{kg}$ ). A diferença entre ambos é fundamentalmente devido à massa do booster necessário para os mísseis deste teste de repetibilidade. Estes últimos apresentaram massa no início do voo em cruzeiro de aproximadamente $500 \mathrm{~kg}$, como será visto adiante, sendo $3 \%$ menor que o estimado para o míssil AGM-84D Harpoon. Isso permite concluir que o míssil AGM-84D Harpoon já apresenta uma configuração que não deixa margem significativa para otimização, considerando as restrições aplicadas ${ }^{67}$.

As Figuras 4.21 a 4.24 foram geradas pelo programa Scorpio 1.0 e são referentes aos mísseis integrantes do grupo de elite da última geração em cada uma das quatro execuções. Elas mostram a configuração geral dos mísseis.

Assim como na Figura 4.12, nas Figuras 4.21 a 4.24 estão indicados:

1. Centro aerodinâmico do corpo (quadrado verde);

2. Centro aerodinâmico da asa (quadrado azul próximo ao centro do míssil);

3. Centro aerodinâmico das superfícies de cauda (quadrado azul na região posterior do míssil);

4. Centro aerodinâmico do míssil (losango magenta);

5. Centro de massa do míssil (círculo vermelho).

\footnotetext{
${ }^{67} \mathrm{O}$ míssil existente pode ser otimizado modificando-se as restrições aplicadas e os parâmetros de projeto. Por exemplo, é possível, dentre outras formas, incrementar o alcance em voo aumentando-se a relação sustentação/arrasto com o uso de asas com maior razão de aspecto ou com a adoção de motor mais eficiente ou ainda com o uso de combustível com maior poder calorífico.
} 


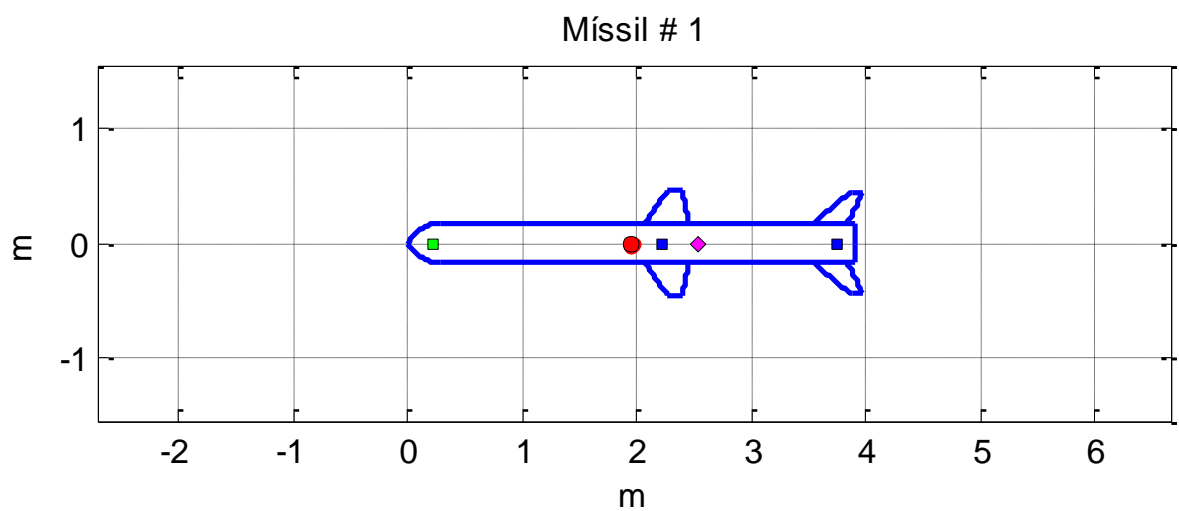

Míssil \# 2

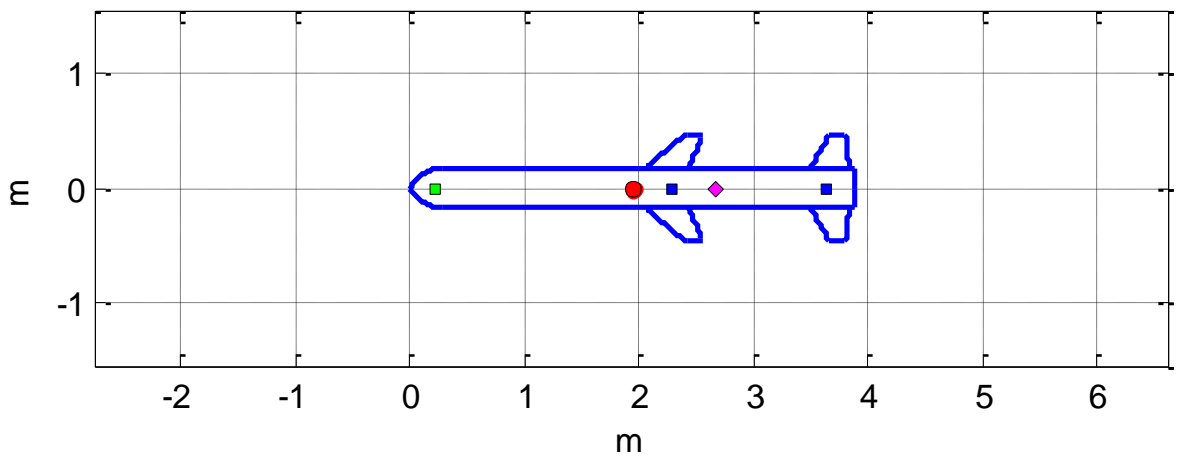

Míssil \# 3

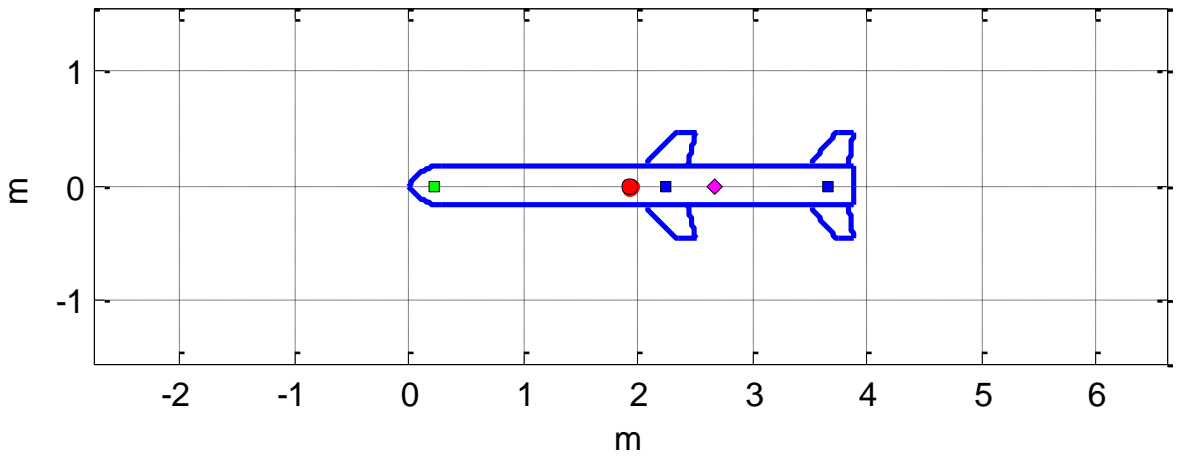

Míssil \# 4

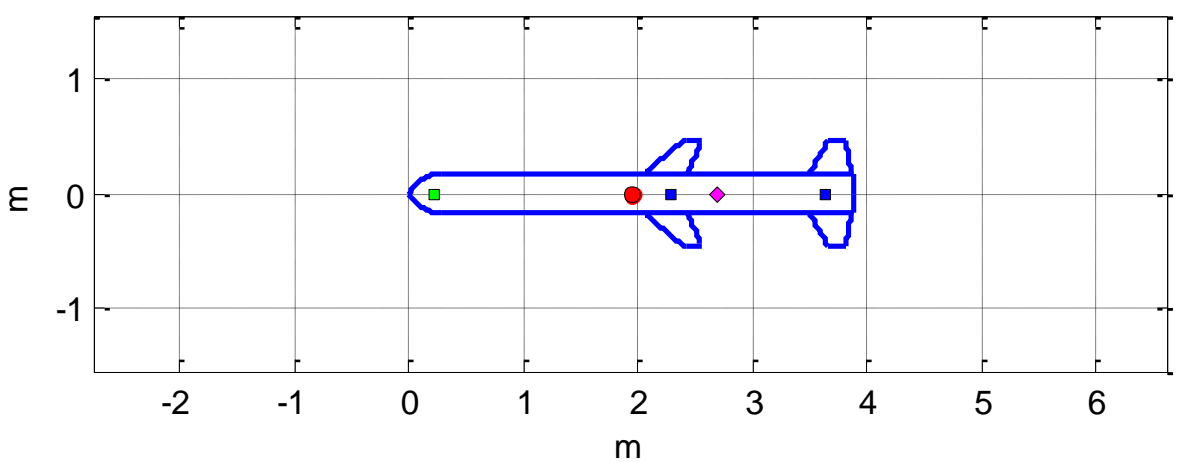

Figura 4.21 - Imagens representativas dos melhores mísseis a partir das configurações mostradas nas Tabelas 4.10 a 4.15. Primeira execução do programa Scorpio 1.0. 

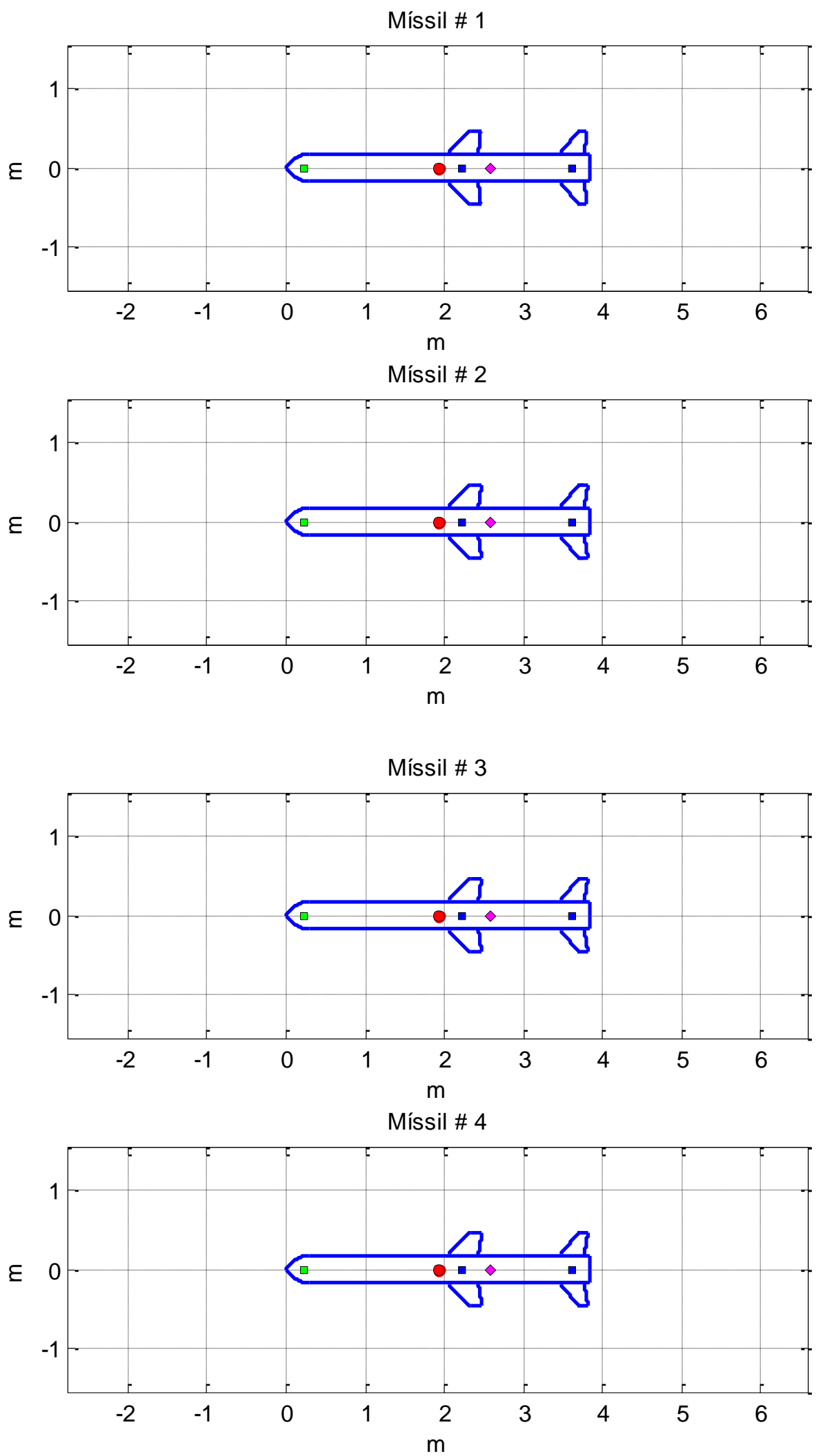

Figura 4.22 - Imagens representativas dos melhores mísseis a partir das configurações mostradas nas Tabela 4.10 a Tabela 4.15. Segunda execução do programa Scorpio 1.0 


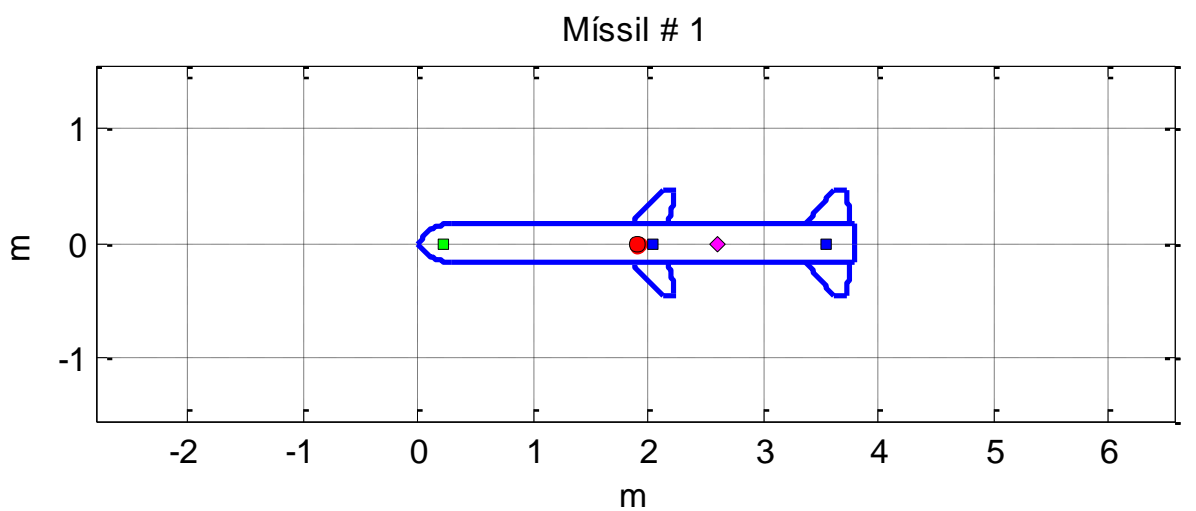

Míssil \# 2

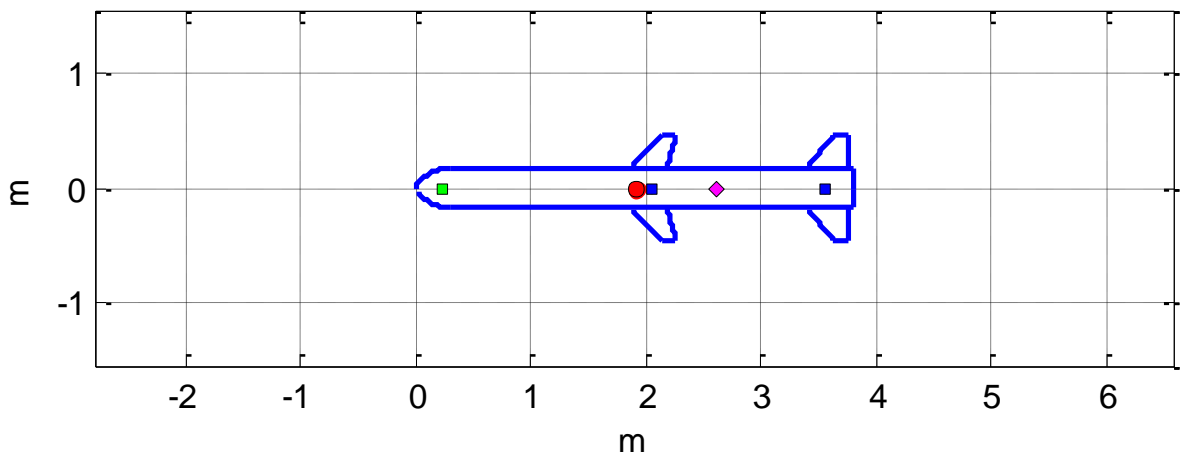

Míssil \# 3

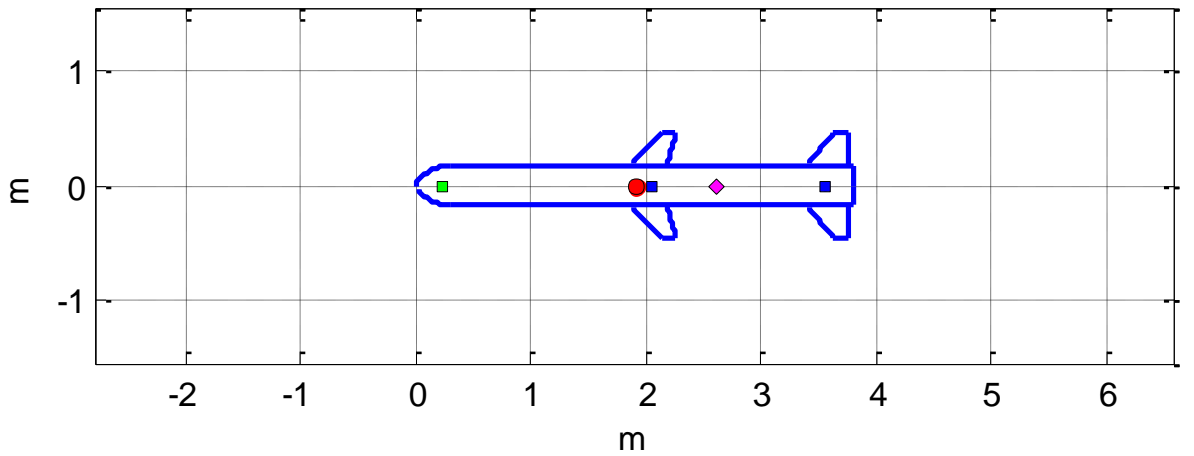

Míssil \# 4

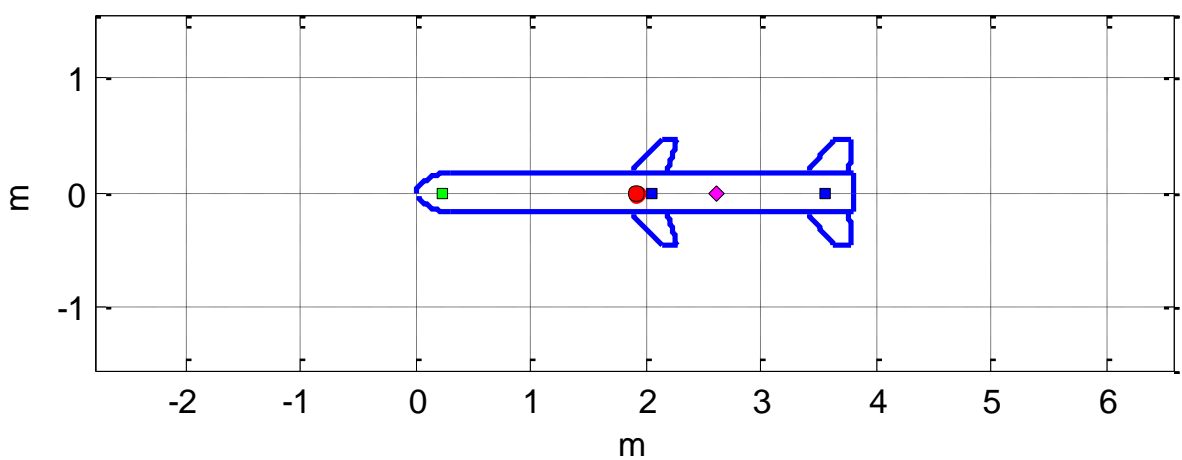

Figura 4.23 - Imagens representativas dos melhores mísseis a partir das configurações mostradas nas Tabelas 4.10 a 4.15. Terceira execução do programa Scorpio 1.0. 


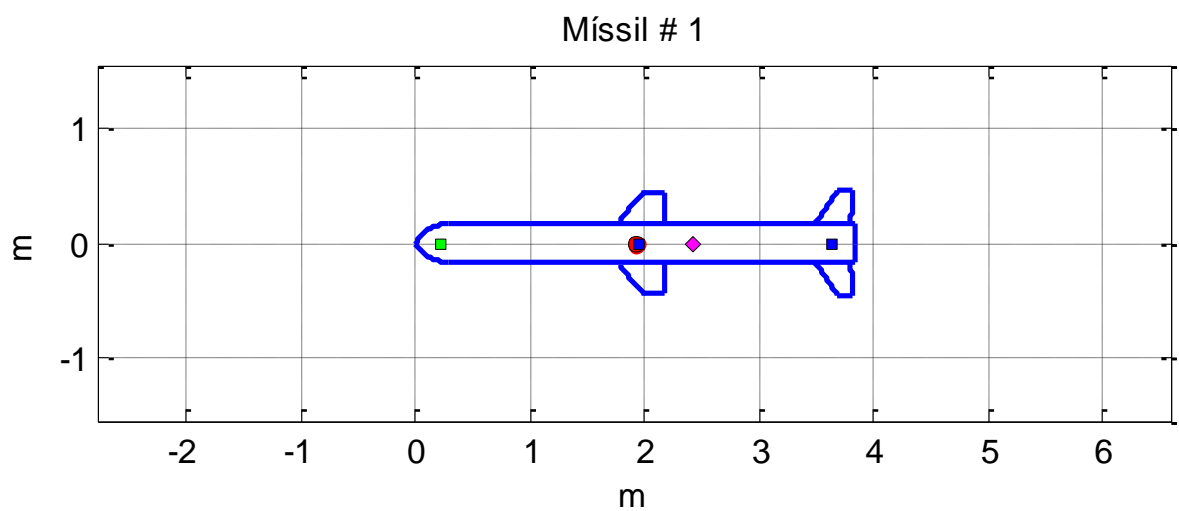

Míssil \# 2

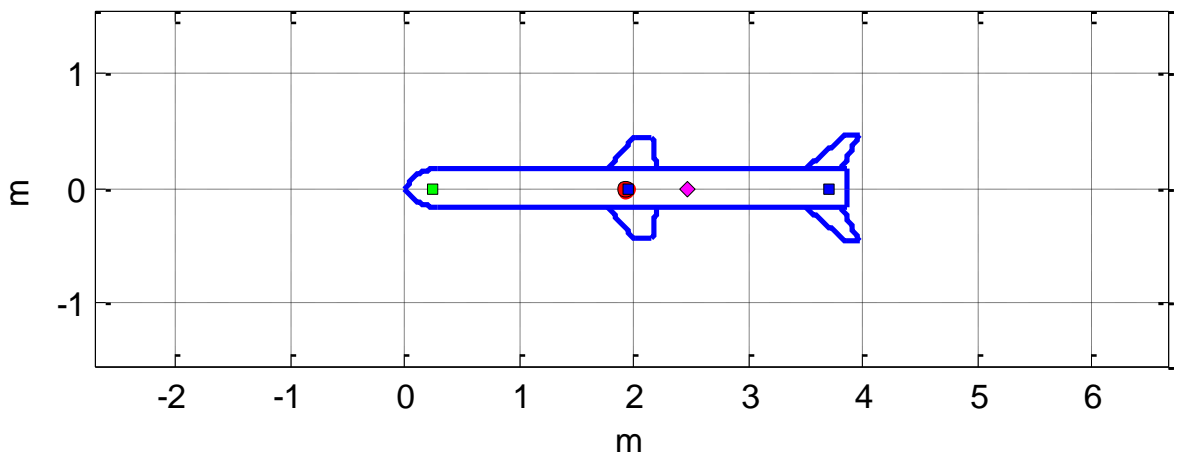

Míssil \# 3

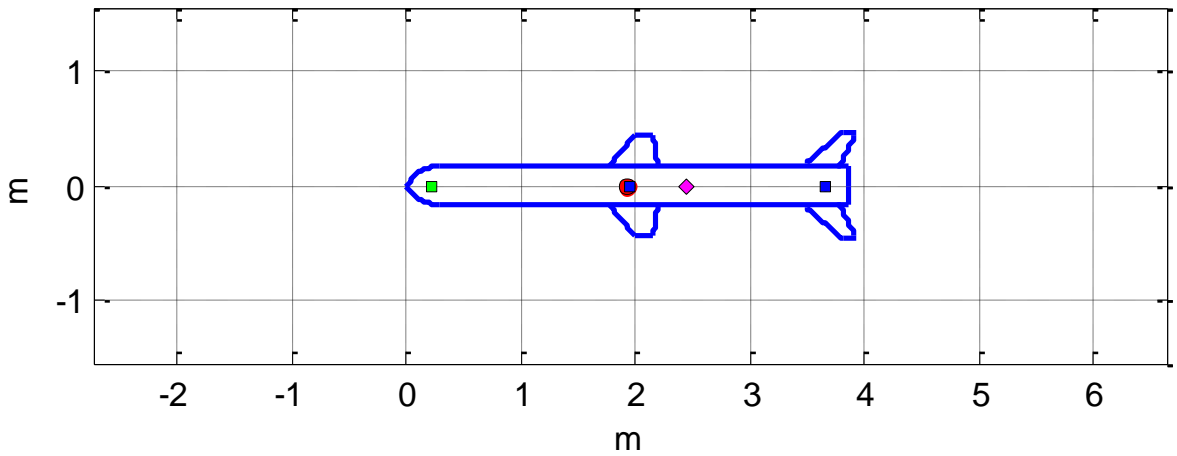

Míssil \# 4

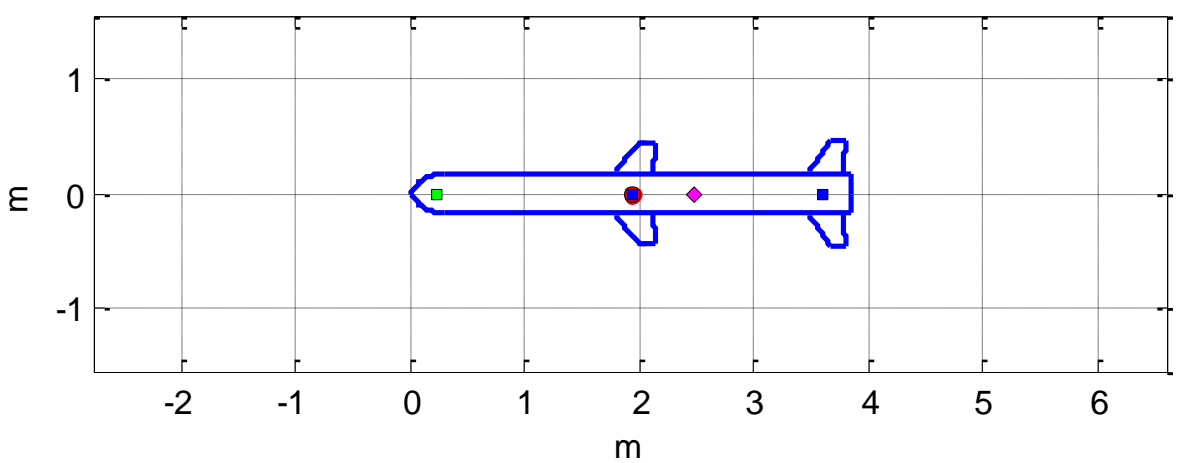

Figura 4.24 - Imagens representativas dos melhores mísseis a partir das configurações mostradas nas Tabelas 4.10 a 4.15. Quarta execução do programa Scorpio 1.0. 
As Tabelas 4.17 a 4.26 contém os dados dos melhores indivíduos de cada caso teste (Mísseis \#1).

De acordo com os dados informados na Tabela 4.16, o tempo de execução do programa para os casos teste variou entre 10 e 11 horas aproximadamente. Em cada caso, foram avaliados 20000 mísseis distribuídos ao longo de 100 gerações. Embora o número de mísseis avaliados pareça alto em um primeiro momento, ele representa uma parcela extremamente pequena do número de soluções possíveis, correspondendo a aproximadamente $1,27 \times 10^{-20} \%$ do número de configurações possíveis, de acordo com as variáveis de projeto utilizadas (Tabela 4.12 a Tabela 4.14$)^{68}$.

A Tabela 4.17 mostra dados de alcance máximo, alcance mínimo (após aceleração inicial), massa de lançamento e máximo fator de carga em voo com valores aproximados para as quatro execuções do programa. O fator que apresentou maior variação entre os casos teste foi a estabilidade estática, em decorrência, principalmente da variação das áreas das superfícies aerodinâmicas (asa e cauda) e suas posições longitudinais em relação ao corpo do míssil, alterando a posição do centro aerodinâmico do conjunto (observar as Figuras 4.23 e 4.24). Contudo, cabe ressaltar que todos os mísseis apresentados atenderam aos requisitos impostos para os casos do teste.

A Tabela 4.17 mostra ainda o valor da avaliação do melhor indivíduo ao fim de cada uma das execuções do programa. Percebe-se que os valores das avaliações atribuídas não são o mesmos em todos os casos, uma vez que os melhores indivíduos encontrados ao fim de cada execução são diferentes em cada caso. Devido à natureza aleatória dos algoritmo genéticos, a avaliação do melhor indivíduo da população tenderia a crescer (até a obtenção

\footnotetext{
${ }^{68}$ A título de ilustração da inviabilidade de avaliar todas as soluções possíveis de um caso como aqueles dos testes de repetibilidade, faz-se a análise a seguir. Considerando o número de soluções possíveis (cerca de $1,578 \times 10^{26}$ ) e o tempo aproximado de 2 segundos para que o programa manipule (pelo algoritmo genético) e avalie uma solução (pelas equações de modelagem teórica), seriam necessários aproximadamente $10^{19}$ anos para que o programa avaliasse todas as soluções possíveis. Conforme dito anteriormente, a idade do universo mais aceita pela comunidade científica é estimada em aproximadamente $13,8 \times 10^{9}$ anos. Portanto, seria necessário um tempo superior a 700 milhões de vezes a idade do universo para que o computador utilizado avaliasse todas as soluções possíveis. É interessante notar que, apesar do pequeno número de soluções avaliadas, o programa tenha indicado soluções razoavelmente próximas em diferentes execuções.
} 
do melhor individuo possível) caso o processo evolutivo continuasse. Isso provavelmente faria com que os melhores indivíduos das diferentes execuções fossem ainda mais parecidos. Isso poderá ser feito mediante uma exploração mais abrangente do espaço de soluções, através da adoção de uma população maior e/ou um maior número de gerações. Isso exigiria maior tempo de processamento. Para os fins dessa dissertação, os resultados apresentados mostram boa concordância, sendo suficiente para demonstrar a capacidade de repetibilidade de resultados por parte do programa Scorpio 1.0, mesmo com as configurações iniciais utilizadas.

Da análise das Figuras 4.21 a 4.24 e da Tabela 4.18Tabela 4.18 - Dados dimensionais do corpo do míssil dos casos de teste de repetibilidade., é possível notar que, para as quatro execuções do Scorpio 1.0 para os testes de repetibilidade, o programa indicou mísseis com dimensões de corpo muito próximas, sendo que a diferença entre o maior e o menor comprimento indicados é inferior a 3\%, ao passo que a diferença entre o maior e o menor diâmetro externo é inferior a 1\% (ver Tabela 4.18 - Dados dimensionais do corpo do míssil dos casos de teste de repetibilidade.). A espessura requeria para a estrutura do corpo do míssil em todos os casos foi praticamente a mesma $(9 \mathrm{~mm})$.

As Tabelas 4.19 e 4.20 mostram dados dimensionais das asas e superfícies de cauda para os melhores mísseis de cada caso teste. Com relação à forma geométrica das superfícies, nota-se uma variação mais acentuada que em relação ao corpo do míssil. Esse comportamento era esperado, uma vez que, conforme explicado na Seção 2.2.5 (Geometria e características das superfícies planas do míssil), a área da superfície tem maior impacto na estabilidade aerodinâmica, controle e desempenho que a geometria da superfície. As diferenças entres os maiores e os menores valores verificados para área de asa e cauda foram, respectivamente, cerca de $41 \%$ e $25 \%$. A diferença nestas áreas aliada à posição de cada elemento em relação ao centro de massa do míssil, resultou na variação verificada nos valores de estabilidade estática (ver Tabela 4.21).

As Tabelas 4.22 a 4.26 mostram dados de voo, massa do míssil e de seus componentes, dados do booster e do motor de cruzeiro para os melhores mísseis em cada um dos quatro casos dos testes de repetibilidade. Essas tabelas mostram excelente aproximação entre os valores obtidos para os diferentes casos. 
Assim, a partir da análise dos dados contidos nas Tabelas 4.16 a 4.26, é possível inferir que o programa Scorpio 1.0 possui capacidade de indicar mísseis parecidos (resultados próximos), cada vez que ele é executado com as configurações iniciais semelhantes. Portanto, considera-se que o programa é capaz de produzir resultados confiáveis quando se analisa o critério de repetibilidade.

Tabela 4.16 - Dados da execução do Scorpio 1.0 para os casos de teste de repetibilidade.

\begin{tabular}{|c|c|c|c|c|c|}
\hline & 1 & 2 & 3 & 4 & Média \\
\hline $\begin{array}{l}\text { Tempo transcorrido durante execução } \\
\text { do programa (s) }\end{array}$ & $36.063,9$ & $40.020,7$ & 39.931 & $38.633,5$ & $38.662,28$ \\
\hline Número de gerações avaliadas & 100 & 100 & 100 & 100 & 100 \\
\hline Número de soluções avaliadas: & 20.000 & 20.000 & 20.000 & 20.000 & 20.000 \\
\hline $\begin{array}{l}\text { Parcela avaliada do espaço de } \\
\text { soluções possíveis }(\%):\end{array}$ & $\begin{array}{l}1,27 \\
\times 10^{-20}\end{array}$ & $\begin{array}{l}1,27 \\
\times 10^{-20}\end{array}$ & $\begin{array}{l}1,27 \\
\times 10^{-20}\end{array}$ & $\begin{array}{l}1,27 \\
\times 10^{-20}\end{array}$ & $\begin{array}{l}1,27 \\
\times 10^{-20}\end{array}$ \\
\hline $\begin{array}{l}\text { Tempo médio consumido para avaliar } \\
\text { uma solução (s) }\end{array}$ & 1,8031 & 2,0010 & 1,9965 & 1,9316 & 1,9331 \\
\hline Critério de parada: & $\begin{array}{l}\text { Máx. } \\
\text { ger. }\end{array}$ & $\begin{array}{l}\text { Máx. } \\
\text { ger. }\end{array}$ & $\begin{array}{l}\text { Máx. } \\
\text { ger. }\end{array}$ & $\begin{array}{l}\text { Máx. } \\
\text { ger. }\end{array}$ & - \\
\hline
\end{tabular}

Tabela 4.17 - Dados de desempenho em voo para os casos de teste de repetibilidade.

\begin{tabular}{|c|c|c|c|c|c|}
\hline Desempenho do míssil & 1 & 2 & 3 & 4 & Média \\
\hline Alcance máximo (km) & 228,03 & 213,45 & 215,04 & 214 & 217,63 \\
\hline Alcance mínimo (km) & 0,33 & 0,33 & 0,33 & 0,33 & 0,33 \\
\hline Tempo até o alvo (s) & 970,97 & 909,72 & 916,4 & 912,04 & 927,28 \\
\hline Massa de lançamento (kg) & 602,56 & 597,83 & 598,07 & 599,53 & 599,49 \\
\hline $\begin{array}{l}\text { Estabilidade estática (adimensional - } \\
\text { múltiplos do diâmetro) }\end{array}$ & 1,757 & 1,992 & 2,091 & 1,509 & 1,837 \\
\hline $\begin{array}{l}\text { Máximo Fator de Carga em voo } \\
\text { (adimensional - múltiplos de g) }\end{array}$ & 1,7 & 1,711 & 1,724 & 1,737 & 1,718 \\
\hline Avaliação do indivíduo (adimensional): & 1,002977 & 1,003551 & 1,003535 & 1,00329 & 1,00333 \\
\hline
\end{tabular}


Tabela 4.18 - Dados dimensionais do corpo do míssil dos casos de teste de repetibilidade.

\begin{tabular}{|c|c|c|c|c|c|}
\hline & 1 & 2 & 3 & 4 & Média \\
\hline \multicolumn{6}{|l|}{$\begin{array}{l}\text { Dados dimensionais do corpo do míssil } \\
\text { (Alumínio 2219-T81) }\end{array}$} \\
\hline Comprimento do corpo do míssil (mm) & 3.899 & 3.841 & 3.788 & 3.834 & $3.840,5$ \\
\hline Comprimento do nariz do míssil (mm) & 289,8 & 290,7 & 292,4 & 290,7 & 290,9 \\
\hline $\begin{array}{l}\text { Diâmetro externo da estrutura do corpo } \\
\text { do míssil (mm) }\end{array}$ & 337 & 338 & 340 & 338 & 338,25 \\
\hline $\begin{array}{l}\text { Diâmetro interno da estrutura do corpo do } \\
\text { míssil (mm) }\end{array}$ & 319 & 320 & 321,9 & 320 & 320,2 \\
\hline $\begin{array}{l}\text { Espessura da estrutura do corpo do míssil } \\
\text { (mm) }\end{array}$ & 9 & 9 & 9,1 & 9 & 9,03 \\
\hline $\begin{array}{l}\text { Área de referência - seção transversal do } \\
\text { corpo do míssil }\left(\mathrm{m}^{2}\right)\end{array}$ & 0,0892 & 0,0897 & 0,0908 & 0,0897 & 0,0899 \\
\hline Comprimento do boattail do míssil (mm) & 0 & 0 & 0 & 0 & 0 \\
\hline $\begin{array}{l}\text { Diâmetro da parte posterior do boattail do } \\
\text { míssil(mm) }\end{array}$ & 337 & 338 & 340 & 338 & 338,3 \\
\hline
\end{tabular}

Tabela 4.19 - Dados dimensionais da asa do míssil dos casos de teste de repetibilidade.

\begin{tabular}{|c|c|c|c|c|c|}
\hline & 1 & 2 & 3 & 4 & Média \\
\hline \multicolumn{6}{|l|}{$\begin{array}{l}\text { Dados dimensionais da asa do míssil } \\
\text { (Alumínio 2219-T81) }\end{array}$} \\
\hline Corda da ponta da asa $(\mathrm{mm})$ & 119 & 126,5 & 96,7 & 173,5 & 128,9 \\
\hline Corda da raiz da asa $(\mathrm{mm})$ & 389 & 393 & 313 & 420 & 378,8 \\
\hline Corda Aerodinâmica média da asa (mm) & 277,9 & 282,5 & 223,9 & 313,8 & 274,5 \\
\hline $\begin{array}{l}\text { Distância entre corda aerod. média e a } \\
\text { raiz da asa }(\mathrm{mm})\end{array}$ & 122,8 & 123,3 & 117 & 119,3 & 120,6 \\
\hline Taper ratio da asa (adimensional) & 0,306 & 0,322 & 0,309 & 0,413 & 0,3375 \\
\hline Envergadura asa - soma 2 painéis (mm) & 597 & 595 & 568 & 554 & 578,5 \\
\hline Razão de aspecto da asa (adimensional) & 2,3502 & 2,2905 & 2,7726 & 1,8670 & 2,3200 \\
\hline Ângulo de enflechamento da asa (graus) & 35 & 45 & 45 & 40 & 41,25 \\
\hline Área planiforme da asa $\left(\mathrm{m}^{2}\right)$ & 0,1516 & 0,1546 & 0,1164 & 0,1644 & 0,1468 \\
\hline Espessura média da raiz da asa $(\mathrm{mm})$ & 6,8 & 6,7 & 7 & 6 & 6,6 \\
\hline Âng. bordo ataque seção asa (graus) & 30 & 30 & 30 & 30 & 30 \\
\hline $\begin{array}{l}\text { Número de painéis da asa }(\text { simples }=1 \text {; } \\
\text { cruciforme }=2 ; \text { etc }) \text { : }\end{array}$ & 2 & 2 & 2 & 2 & 2 \\
\hline $\begin{array}{l}\text { Dist. bordo ataque da raiz da asa - nariz } \\
(\mathrm{mm}) \text { : }\end{array}$ & 2066,5 & 2035,7 & 1856,1 & 1763,6 & 1930,4 \\
\hline
\end{tabular}


Tabela 4.20 - Dados dimensionais da cauda do míssil dos casos de teste de repetibilidade.

\begin{tabular}{|c|c|c|c|c|c|}
\hline & 1 & 2 & 3 & 4 & Média \\
\hline \multicolumn{6}{|l|}{$\begin{array}{l}\text { Dados dimensionais das superfícies de } \\
\text { cauda do míssil (Alumínio 2219-T81) }\end{array}$} \\
\hline Corda da ponta da cauda $(\mathrm{mm})$ : & 100,2 & 95,5 & 141,8 & 106,6 & 111,0 \\
\hline Corda da raiz da cauda (mm): & 293 & 309 & 375 & 309 & 321,5 \\
\hline $\begin{array}{l}\text { Corda Aerodinâmica média da cauda } \\
(\mathrm{mm})\end{array}$ & 212,4 & 221 & 275,9 & 224,2 & 223,3 \\
\hline $\begin{array}{l}\text { Distância entre corda aerod. média e a } \\
\text { raiz da cauda (mm) }\end{array}$ & 116,5 & 123,2 & 122,5 & 120 & 120,5 \\
\hline $\begin{array}{l}\text { Taper ratio da superfície das superfícies } \\
\text { de cauda (adimensional): }\end{array}$ & 0,342 & 0,309 & 0,378 & 0,345 & 0,343 \\
\hline $\begin{array}{l}\text { Envergadura total das superfícies de } \\
\text { cauda-soma } 2 \text { painéis-(mm): }\end{array}$ & 557 & 598 & 577 & 573 & 576,2 \\
\hline Razão de aspecto da cauda (adimens.) & 2,833 & 2,957 & 2,233 & 2,757 & 2,695 \\
\hline $\begin{array}{l}\text { Ângulo de enflechamento das superfícies } \\
\text { de cauda (graus) }\end{array}$ & 50 & 40 & 40 & 35 & 41,25 \\
\hline Área planiforme da cauda $\left(\mathrm{m}^{2}\right)$ & 0,1095 & 0,1409 & 0,1491 & 0,1191 & 0,1296 \\
\hline Espessura média da raiz da cauda (mm) & 5,4 & 5,4 & 5,4 & 6,1 & 5,58 \\
\hline $\begin{array}{l}\text { Âng. tot. bordo de ataque seção transv. da } \\
\text { cauda (graus) }\end{array}$ & 30 & 30 & 30 & 30 & 30 \\
\hline $\begin{array}{l}\text { Núm. painéis cauda (simples }=1 ; \\
\text { cruciforme }=2 ; \text { etc } \text { (adimens.) }\end{array}$ & 2 & 2 & 2 & 2 & 2 \\
\hline Dist. bordo ataque da cauda - nariz (mm) & 3548,1 & 3456,9 & 3371,3 & 3488,9 & 3466,3 \\
\hline
\end{tabular}

Tabela 4.21 - Centro aerodinâmico do míssil dos casos de teste de repetibilidade.

\begin{tabular}{|c|c|c|c|c|c|}
\hline & 1 & 2 & 3 & 4 & Média \\
\hline \multicolumn{6}{|l|}{ Centro aerodinâmico } \\
\hline $\begin{array}{l}\text { Centro aerodinâmico do corpo do míssil } \\
(\mathrm{mm})\end{array}$ & 228,6 & 228,2 & 228,3 & 228,1 & 228,3 \\
\hline $\begin{array}{l}\text { Centro aerodinâmico da asa (bordo de } \\
\text { ataque) }(\mathrm{mm})\end{array}$ & 69,5 & 70,6 & 56 & 78,4 & 68,6 \\
\hline $\begin{array}{l}\text { Centro aerodinâmico da cauda (bordo de } \\
\text { ataque) }(\mathrm{mm})\end{array}$ & 53,1 & 55,3 & 69 & 56,1 & 58,4 \\
\hline $\begin{array}{l}\text { Centro aerodinâmico da asa (nariz do } \\
\text { míssil })(\mathrm{mm})\end{array}$ & 2221,9 & 2229,7 & 2029,1 & 1942,2 & 2105,7 \\
\hline $\begin{array}{l}\text { Centro aerodinâmico da cauda (nariz do } \\
\text { míssil) }(\mathrm{mm})\end{array}$ & 3740 & 3615,5 & 3543,1 & 3629 & 3631,9 \\
\hline Centro aerodinâmico do míssil (mm) & 2541,7 & 2593,9 & 2605 & 2426,9 & 2541,8 \\
\hline Centro de massa (CG) do míssil (mm) & 1949,5 & 1920,5 & 1894 & 1917 & 1920,3 \\
\hline $\begin{array}{l}\text { Estabilidade estática (adimensional } \\
\text { múltiplos do diâmetro) }\end{array}$ & 1,757 & 1,992 & 2,091 & 1,509 & 1,837 \\
\hline
\end{tabular}


Tabela 4.22 - Dados de voo do míssil dos casos de teste de repetibilidade.

\begin{tabular}{|c|c|c|c|c|c|}
\hline & 1 & 2 & 3 & 4 & Média \\
\hline \multicolumn{6}{|l|}{ Relação Sustentação/Arrasto } \\
\hline $\begin{array}{l}\text { Relação Sustentação/Arrasto média em } \\
\text { cruzeiro (adimensional) }\end{array}$ & 3,582 & 3,538 & 3,565 & 3,549 & 3,559 \\
\hline $\begin{array}{l}\text { Relação Sustentação/Arrasto média em } \\
\text { coast (adimensional) }\end{array}$ & 3,183 & 3,109 & 3,137 & 3,129 & 3,139 \\
\hline \multicolumn{6}{|l|}{ Arrasto médio em voo } \\
\hline Arrasto médio em boost $(\mathrm{N})$ & 204,13 & 206 & 202,96 & 206,74 & 204,96 \\
\hline Arrasto médio em cruzeiro (N) & 1321,42 & 1299,72 & 1304,13 & 1299,74 & 1306,25 \\
\hline Arrasto médio em coast $(\mathrm{N})$ & 1425,29 & 1388,6 & 1408,68 & 1401,46 & 1406,00 \\
\hline
\end{tabular}

Tabela 4.23 - Massa do míssil dos casos de teste de repetibilidade.

\begin{tabular}{|c|c|c|c|c|c|}
\hline & 1 & 2 & 3 & 4 & Média \\
\hline \multicolumn{6}{|l|}{ Massa - principais momentos voo } \\
\hline Massa total de lançamento (kg) & 602,56 & 597,83 & 598,07 & 599,53 & 599,50 \\
\hline Massa do míssil - início do cruzeiro (kg) & 502,07 & 498,11 & 498,28 & 499,53 & 499,50 \\
\hline Massa do míssil - fim do cruzeiro (kg) & 453,12 & 452,04 & 452,19 & 453,33 & 452,67 \\
\hline $\begin{array}{l}\text { Massa espec. do míssil - início do } \\
\text { cruzeiro - ref.: } 1384-\left(\mathrm{kg} / \mathrm{m}^{3}\right)\end{array}$ & 1443,6 & 1415,3 & 1448,1 & 1452,1 & 1439,8 \\
\hline
\end{tabular}

Tabela 4.24 - Massa dos componentes dos casos de teste de repetibilidade.

\begin{tabular}{|c|c|c|c|c|c|}
\hline & 1 & 2 & 3 & 4 & Média \\
\hline \multicolumn{6}{|l|}{ Massas dos componentes do míssil } \\
\hline Massa do Booster com propelente (kg) & 92,72 & 91,99 & 92,01 & 92,23 & 92,23 \\
\hline $\begin{array}{l}\text { Massa de propelente necessária para o } \\
\text { Booster (kg) }\end{array}$ & 60,27 & 59,79 & 59,81 & 59,95 & 59,96 \\
\hline Massa do Booster sem propelente $(\mathrm{kg})$ & 32,45 & 32,2 & 32,2 & 32,28 & 32,283 \\
\hline Massa da Cabeça de Guerra (kg) & 231 & 231 & 231 & 231 & 231 \\
\hline $\begin{array}{l}\text { Massa dos Sistemas de Guiamento, } \\
\text { Controle e Enlace de Dados (kg): }\end{array}$ & 42,9 & 42,9 & 42,9 & 42,9 & 42,9 \\
\hline Massa de combustível de cruzeiro (kg) & 48,95 & 46,08 & 46,09 & 46,21 & 46,83 \\
\hline Massa da estrutura (corpo) do míssil (kg) & 102,57 & 101,62 & 101,37 & 101,44 & 101,75 \\
\hline Massa total da Asa (kg) & 4,19 & 4,27 & 3,31 & 4,23 & 4,00 \\
\hline Massa total da Cauda (kg) & 2,45 & 2,68 & 3,4 & 2,99 & 2,88 \\
\hline Massa do motor de cruzeiro $(\mathrm{kg})$ & 42,8 & 42,35 & 42,99 & 43,55 & 42,92 \\
\hline $\begin{array}{l}\text { Massa total dos atuadores das superfícies } \\
\text { de controle }(\mathrm{kg})\end{array}$ & 13,61 & 13,61 & 13,61 & 13,61 & 13,61 \\
\hline Massa total da fonte de energia $(\mathrm{kg})$ & 13,61 & 13,61 & 13,61 & 13,61 & 13,61 \\
\hline
\end{tabular}


Tabela 4.25 - Dados do booster dos casos de teste de repetibilidade.

\begin{tabular}{|c|c|c|c|c|c|}
\hline & 1 & 2 & 3 & 4 & Média \\
\hline \multicolumn{6}{|l|}{ Sistema de Propulsão - Booster } \\
\hline Empuxo $(\mathrm{N}):$ & 53178,2 & 52761,2 & 52782,5 & 52911,2 & 52908,3 \\
\hline \multicolumn{6}{|l|}{ Dados de entrada } \\
\hline Pressão de combustão (MPa): & 7 & 7 & 7 & 7 & 7 \\
\hline Velocidade característica $(\mathrm{m} / \mathrm{s})$ : & 1560 & 1560 & 1560 & 1560 & 1560 \\
\hline $\begin{array}{l}\text { Razão de calores específicos na tubeira } \\
\text { (adimensional): }\end{array}$ & 1,18 & 1,18 & 1,18 & 1,18 & 1,18 \\
\hline $\begin{array}{l}\text { Fator de aceleração durante boost } \\
\text { (múltiplo da acel. gravidade): }\end{array}$ & 9 & 9 & 9 & 9 & 9 \\
\hline Constante do gás (ar) (J/kg.K): & 287 & 287 & 287 & 287 & 287 \\
\hline Coeficiente de descarga (adimensional) & 0,96 & 0,96 & 0,96 & 0,96 & 0,96 \\
\hline Flight path angle (graus): & 45 & 45 & 45 & 45 & 45 \\
\hline $\begin{array}{l}\text { Razão de expansão da tubeira - Booster } \\
\text { (adimensional): }\end{array}$ & 9,386 & 9,386 & 9,386 & 9,386 & 9,386 \\
\hline Área da garganta da tubeira $\left(\mathrm{m}^{2}\right)$ & 0,00491 & 0,00487 & 0,00488 & 0,00489 & 0,00488 \\
\hline Diâmetro da garganta da tubeira (mm) & 79,1 & 78,8 & 78,8 & 78,9 & 78,9 \\
\hline Diâmetro da exaustão da tubeira (mm) & 242,3 & 241,3 & 241,4 & 241,7 & 241,6 \\
\hline Velocidade de cruzeiro $(\mathrm{m} / \mathrm{s})$ & 238 & 238 & 238 & 238 & 238 \\
\hline $\begin{array}{l}\text { Máxima velocidade incremental devido } \\
\text { ao Booster }(\mathrm{m} / \mathrm{s})\end{array}$ & 238 & 238 & 238 & 238 & 238 \\
\hline Massa de propelente mínima $(\mathrm{kg})$ & 56,61 & 56,17 & 56,19 & 56,33 & 56,33 \\
\hline Tempo de combustão mínimo (s) & 2,57 & 2,57 & 2,57 & 2,57 & 2,57 \\
\hline Massa de propelente necessária $(\mathrm{kg})$ & 60,27 & 59,79 & 59,81 & 59,95 & 59,96 \\
\hline Tempo de combustão necessário (s) & 2,73 & 2,73 & 2,73 & 2,73 & 2,73 \\
\hline Peso médio do míssil durante Boost $(\mathrm{N})$ & 5613,2 & 5569,2 & 5571,5 & 5585,1 & 5584,75 \\
\hline Fluxo Mássico de Propelente (kg/s) & 22,04 & 21,87 & 21,88 & 21,93 & 21,93 \\
\hline Impulso Específico - Booster (s) & 246,04 & 246,04 & 246,04 & 246,04 & 246,04 \\
\hline
\end{tabular}


Tabela 4.26 - Dados do motor de cruzeiro dos casos de teste de repetibilidade.

\begin{tabular}{|c|c|c|c|c|c|}
\hline Sistema de Propulsão - Motor de Cruzeiro & 1 & 2 & 3 & 4 & Média \\
\hline \multicolumn{6}{|l|}{ Tipo de motor de cruzeiro: Turbojato } \\
\hline Empuxo necessário - início do cruzeiro $(\mathrm{N})$ & 1371,3 & 1365,6 & 1334,9 & 1351,4 & 1355,8 \\
\hline Empuxo necessário - fim do cruzeiro $(\mathrm{N})$ & 1290,3 & 1251,6 & 1291,2 & 1264,5 & 1274,4 \\
\hline Empuxo necessário máx. Fator de Carga $(\mathrm{N})$ & 2098,5 & 2076,4 & 2108,1 & 2135,6 & 2104,65 \\
\hline \multicolumn{6}{|l|}{ Condições de operação início voo cruzeiro } \\
\hline \multicolumn{6}{|l|}{ Temperatura } \\
\hline Temp. estagnação entrada compressor (K) & 316 & 316 & 316 & 316 & 316 \\
\hline Temp. estagnação saída do compressor (K) & 520,9 & 520,9 & 520,9 & 520,9 & 520,9 \\
\hline Temp. estagnação entrada na turbina $(\mathrm{K})$ & 816 & 816 & 816 & 816 & 816 \\
\hline Temperatura estagnação saída da turbina (K) & 611,2 & 611,2 & 611,2 & 611,2 & 611,2 \\
\hline \multicolumn{6}{|l|}{ Pressão } \\
\hline Relação de pressões no compressor $(\mathrm{Pa} / \mathrm{Pa})$ : & 5,4 & 5,4 & 5,4 & 5,4 & 5,4 \\
\hline Relação de pressões no combustor $(\mathrm{Pa} / \mathrm{Pa})$ & 0,95 & 0,95 & 0,95 & 0,95 & 0,95 \\
\hline Pressão estagnação entrada compressor $(\mathrm{kPa})$ & 135,8 & 135,8 & 135,8 & 135,8 & 135,8 \\
\hline Pressão estagnação saída compressor (kPa) & 733,5 & 733,5 & 733,5 & 733,5 & 733,5 \\
\hline Pressão de estagnação entrada turbina (kPa) & 696,8 & 696,8 & 696,8 & 696,8 & 696,8 \\
\hline Pressão de estagnação saída da turbina (kPa) & 186,5 & & & 186,5 & 186,5 \\
\hline Pressão na saída do bocal de exaustão (kPa) & 100,7 & 100,7 & 100,7 & 100,7 & 100,7 \\
\hline \multicolumn{6}{|l|}{ Eficiência isentrópica (dados de entrada) } \\
\hline Efic. isentrópica difusor de ar (adimens.) & 0,91 & 0,91 & 0,91 & 0,91 & 0,91 \\
\hline Efic. isentrópica compressor (adimens.) & 0,89 & 0,89 & 0,89 & 0,89 & 0,89 \\
\hline Efic. isentrópica turbina (adimens.) & 0,9 & 0,9 & 0,9 & 0,9 & 0,9 \\
\hline Efic. isentrópica bocal exaustão (adimens.) & 0,95 & 0,95 & 0,95 & 0,95 & 0,95 \\
\hline \multicolumn{6}{|l|}{ Calor específico do fluido de trabalho } \\
\hline Razão calores específicos difusor (adimens.) & 1,4 & 1,4 & 1,4 & 1,4 & 1,4 \\
\hline Razão calores espec. compressor (adimens.) & 1,37 & 1,37 & 1,37 & 1,37 & 1,37 \\
\hline Razão calores específicos turbina (adimens.) & 1,33 & 1,33 & 1,33 & 1,33 & 1,33 \\
\hline Razão calores espec. bocal exaus. (adimens.) & 1,33 & 1,33 & 1,33 & 1,33 & 1,33 \\
\hline Razão combustível $/ \mathrm{ar}(\mathrm{kg} / \mathrm{kg})$ : & 0,00807 & 0,00807 & 0,00807 & 0,00807 & 0,00807 \\
\hline Poder calorífico do combustível (kJ/kg) & 43000 & 43000 & 43000 & 43000 & 43000 \\
\hline Velocidade na saída bocal de exaustão $(\mathrm{m} / \mathrm{s})$ & 436,35 & 436,35 & 436,35 & 436,35 & 436,35 \\
\hline Área da saída do bocal de exaustão $\left(\mathrm{m}^{2}\right)$ & 0,02346 & 0,02336 & 0,02284 & 0,02312 & 0,02319 \\
\hline Área seção transversal corpo do míssil $\left(\mathrm{m}^{2}\right)$ & 0,0892 & 0,0897 & 0,0908 & 0,0897 & 0,0899 \\
\hline $\begin{array}{l}\text { Razão área da saída do bocal de exaustão / } \\
\text { seção do míssil (adm.) }\end{array}$ & 0,2631 & 0,2604 & 0,2516 & 0,2577 & 0,2582 \\
\hline Diâmetro saída do bocal de exaustão (mm) & 172,8 & 172,5 & 170,5 & 171,6 & 171,9 \\
\hline Mach saída bocal de exaustão (adimens.) & 0,9712 & 0,9712 & 0,9712 & 0,9712 & 0,9712 \\
\hline Fluxo de ar pela turbina $(\mathrm{kg} / \mathrm{s})$ & 6,7945 & 6,7666 & 6,6141 & 6,6962 & 6,7178 \\
\hline Consumo de combustível (kg/s) & 0,0548 & 0,0546 & 0,0534 & 0,0540 & 0,0542 \\
\hline Empuxo Específico (kN.s/kg) & 0,2018 & 0,2018 & 0,2018 & 0,2018 & 0,2018 \\
\hline Consumo específico de comb. (kg/s.kN) & 0,04 & 0,04 & 0,04 & 0,04 & 0,04 \\
\hline Impulso Específico (s) & 2550,7 & 2550,7 & 2550,7 & 2550,7 & 2550,7 \\
\hline
\end{tabular}




\section{4 - DEMONSTRAÇÃO DO USO DO SCORPIO 1.0 PARA O CASO DE UM MÍSSIL DE CRUZEIRO SUBSÔNICO EM DESENVOLVIMENTO}

O programa Scorpio 1.0 foi utilizado para o estudo do caso de um míssil que se encontrava em fase de desenvolvimento à época da elaboração deste trabalho. Para isso serão utilizados dados preliminares divulgados pelos participantes do projeto (fabricante e operador) na forma que se segue.

\subsection{1 - Míssil Tático de Cruzeiro para o Sistema ASTROS 2020}

O Projeto do Sistema Míssil Tático de Cruzeiro tem como objeto a pesquisa e o desenvolvimento de um Sistema Míssil Tático de Cruzeiro com uma faixa de alcance de 30 $\mathrm{km}$ a $300 \mathrm{~km}$, com capacidade de ser disparado a partir da plataforma do Sistema ASTROS em uso pelo Exército Brasileiro (Exército Brasileiro, 2014).

O sistema ASTROS (Artillery Saturation Rocket System) é um sistema de lançadores múltiplos de foguetes desenvolvido e fabricado pela empresa brasileira Avibras e utilizado pelo Exército Brasileiro (EB). É um sistema de artilharia de foguetes para saturação de área (Figura 4.25). Atualmente o EB, juntamente com o fabricante do sistema, desenvolve o projeto ASTROS 2020, que abrange, dentre outros pontos, o desenvolvimento de um míssil tático de cruzeiro e as modificações necessárias no sistema ASTROS para torná-lo compatível com o míssil.

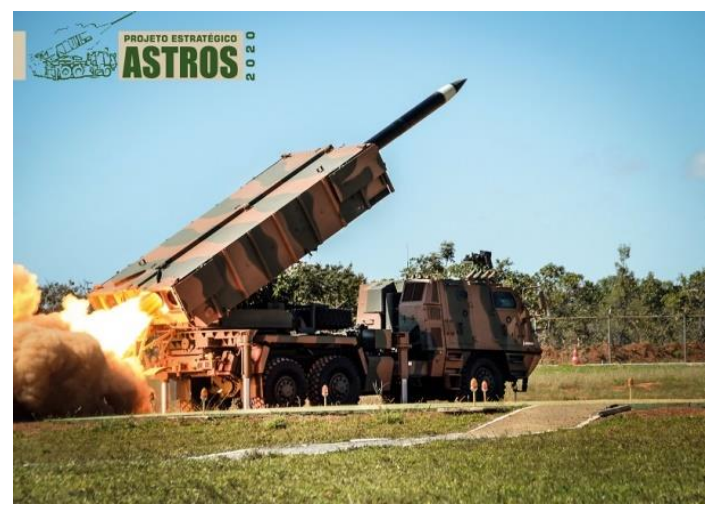

Figura 4.25 - Unidade lançadora do sistema ASTROS no momento do disparo de um foguete (Exército Brasileiro, 2016). 
Segundo o EB, o Sistema Míssil Tático de Cruzeiro do Sistema ASTROS 2020 será dotado de booster para aceleração inicial e motor turbojato para voo em cruzeiro subsônico. Deverá ainda atender às limitações impostas pelo Regime de Controle de Tecnologia de Mísseis (Missile Technology Control Regime) e ser desenvolvido e produzido por empresa nacional. Requisitos técnico-operacionais básicos e dados preliminares do Míssil Tático de Cruzeiro do sistema ASTROS 2020 estão disponíveis na Tabela 4.27 (Exército Brasileiro, 2015; Exército Brasileiro, 2012).

Tabela 4.27 - Características iniciais do míssil tático de cruzeiro do sistema ASTROS 2020.

\begin{tabular}{|l|c|}
\hline Faixa de alcance (ao nível do mar) & 30 a $300 \mathrm{~km}$ \\
\hline Massa da cabeça de guerra & $\geq 200 \mathrm{~kg}$ \\
\hline Altitude de cruzeiro (acima do nível do solo) & $200-800 \mathrm{~m}$ \\
\hline Altitude de lançamento (em relação ao nível do mar) & $0-2500 \mathrm{~m}$ \\
\hline Número de Mach em cruzeiro & 0,8 \\
\hline Velocidade nominal de cruzeiro & $275 \mathrm{~m} / \mathrm{s}$ \\
\hline Combustível de cruzeiro & 1801 \\
\hline Volume de combustível (previsão) & $5480 \mathrm{~mm}$ \\
\hline Comprimento com booster & $450 \mathrm{~mm}$ \\
\hline Diâmetro & $1100 \mathrm{kgf}$ \\
\hline Peso total de lançamento & 2 \\
\hline Mísseis por lançador ASTROS 2020 & Aprox. 4 km do local de lançamento \\
\hline Local de queda do booster
\end{tabular}

\subsection{2 - Configurações iniciais do Scorpio 1.0 para o caso do Míssil Tático de Cruzeiro do Sistema ASTROS}

Para a execução do programa Scorpio 1.0 para o caso do Míssil Tático de Cruzeiro do Sistema ASTROS 2020 foram utilizadas os dados mostrados nas Tabelas 4.28 a 4.33. As características do míssil tático de cruzeiro do sistema ASTROS 2020 descritas anteriormente foram empregadas. As configurações de ajuste para o algoritmo genético tais como tamanho da população, taxa de mutação e número máximo de gerações foram as mesmas dos casos teste de repetibilidade (ver Tabela 4.28). Contudo, os requisitos de voo foram alterados, de forma a atender ao maior alcance $(300 \mathrm{~km})$ e massa de lançamento 
(1100 kg), bem como um aumento no fator de carga em manobra (o que permite curvas com menor raio), conforme mostrado na Tabela 4.29.

Tabela 4.28 - Configurações de ajuste do AG para o caso do míssil tático de cruzeiro do sistema ASTROS 2020.

\begin{tabular}{lr}
\hline Parâmetro & Valor \\
\hline Número de indivíduos na população & 200 \\
Número de indivíduos no grupo de elite & 4 \\
Número de indivíduos no grupo de imigrantes & 20 \\
Número de genes no cromossomo (incluindo função de avaliação) & 25 \\
Probabilidade de mutação inicial (\%) & 2,00 \\
Probabilidade de mutação final (\%) & 15,00 \\
Número máximo de gerações & 100 \\
Avaliação suficiente para terminar execução (critério de parada) & 1,5 \\
\hline
\end{tabular}

Tabela 4.29 - Requisitos de voo para o caso do míssil tático de cruzeiro do sistema ASTROS 2020.

\begin{tabular}{lr}
\hline Requisito de desempenho & Valor \\
\hline Alcance máximo $(\mathrm{km})$ & 300 \\
Alcance mínimo $(\mathrm{km})$ & 30 \\
Tempo máximo até o alvo (s) & 1500 \\
Massa de lançamento máxima (kg) & 1100 \\
Estabilidade estática mínima (adimens. - múltiplos do diâmetro) & 1,48 \\
Fator de carga em manobra mínima (adimens. - múltiplos de g) & 2,00 \\
\hline
\end{tabular}

As variáveis de projeto foram ajustadas de forma a permitir a busca de um míssil otimizado dentro dos limites impostos. Dessa maneira, as Tabelas 4.30 a 4.32 expõe os limites inferior e superior aplicados para cada variável de projeto, bem como a variação aplicada. Destaca-se que alguma variáveis foram ajustadas de forma que os limites superior e inferior sejam iguais. Por exemplo, a altitude de voo de cruzeiro (foi considerado o valor médio da altitude de voo para um lançamento ao nível do mar), número de Mach em voo de cruzeiro, temperatura de combustão do motor (temperatura de entrada na turbina) etc. O limite superior de comprimento do corpo $(4500 \mathrm{~mm})$ foi estabelecido considerando uma estimativa do comprimento do booster (estimado em aproximadamente $1 \mathrm{~m}$ ), sendo, portando, menor que o comprimento máximo indicado na Tabela $4.27(5480 \mathrm{~mm})$. Essa aproximação se fez necessária, pois o programa atua com o comprimento do corpo do míssil em voo de cruzeiro, considerando a ejeção do booster. Não obstante, o programa Scorpio 1.0 é capaz de estimar a massa do booster, conforme será mostrado. O diâmetro máximo utilizado foi o indicado na Tabela 4.27 . 
Tabela 4.30 - Variáveis de projeto para o caso do míssil tático de cruzeiro do sistema ASTROS 2020.

\begin{tabular}{|c|c|}
\hline Variáveis de projeto (genes) & Valor \\
\hline \multicolumn{2}{|l|}{ Altitude de voo de cruzeiro } \\
\hline Altitude mínima de voo (m) & 500 \\
\hline Altitude máxima de voo (m) & 500 \\
\hline Incremento de variação da altitude de voo (m) & 50 \\
\hline \multicolumn{2}{|l|}{ Diâmetro do corpo do míssil } \\
\hline Diâmetro mínimo (m) & 0,330 \\
\hline Diâmetro máximo (m) & 0,450 \\
\hline Incremento de variação do diâmetro (m) & 0,001 \\
\hline \multicolumn{2}{|l|}{ Comprimento do corpo do míssil } \\
\hline Comprimento mínimo (m) & 3,800 \\
\hline Comprimento máximo (m) & 4,500 \\
\hline Incremento de variação do comprimento (m) & 0,001 \\
\hline \multicolumn{2}{|l|}{ Comprimento do nariz do míssil (múltiplo do diâmetro) } \\
\hline Comprimento mínimo do nariz (adimensional) & 1,00 \\
\hline Comprimento máximo do nariz (adimensional) & 1,00 \\
\hline Incremento de variação do comprimento do nariz (adimensional) & 0,5 \\
\hline \multicolumn{2}{|l|}{ Taper ratio da asa } \\
\hline Valor mínimo (adimensional) & 0,500 \\
\hline Valor máximo (adimensional) & 0,900 \\
\hline Incremento de variação do taper ratio (adimensional) & 0,001 \\
\hline \multicolumn{2}{|l|}{ Taper ratio da superfície de cauda } \\
\hline Valor mínimo (adimensional) & 0,500 \\
\hline Valor máximo (adimensional) & 0,900 \\
\hline Incremento de variação do taper ratio (adimensional) & 0,001 \\
\hline \multicolumn{2}{|l|}{ Corda aerodinâmica da raiz da asa } \\
\hline Valor mínimo (m) & 0,400 \\
\hline Valor máximo $(\mathrm{m})$ & 0,900 \\
\hline Incremento de variação da corda da raiz da asa (m) & 0,001 \\
\hline \multicolumn{2}{|l|}{ Corda aerodinâmica da raiz da superfície de cauda } \\
\hline Valor mínimo (m) & 0,300 \\
\hline Valor máximo (m) & 0,600 \\
\hline Incremento de variação da corda da raiz da superfície de cauda (m) & 0,001 \\
\hline \multicolumn{2}{|l|}{ Ângulo de enflechamento da asa } \\
\hline Valor mínimo (graus) & 20 \\
\hline Valor máximo (graus) & 50 \\
\hline Incr. de variação do enflechamento da asa (graus) & 5 \\
\hline \multicolumn{2}{|l|}{ Ângulo de enflechamento da superfície de cauda } \\
\hline Valor mínimo (graus) & 20 \\
\hline Valor máximo (graus) & 50 \\
\hline Incr. de variação do enflechamento da superfície de cauda (graus) & 5 \\
\hline
\end{tabular}


Tabela 4.31 - Variáveis de projeto para o caso do míssil tático de cruzeiro do sistema

ASTROS 2020. (continuação 1).

\begin{tabular}{|c|c|}
\hline Variáveis de projeto (genes) & Valor \\
\hline \multicolumn{2}{|l|}{ Ângulo total de bordo de ataque da seção transversal da asa e cauda } \\
\hline Valor mínimo (graus) & 30 \\
\hline Valor máximo (graus) & 30 \\
\hline Incremento de variação do ang. total de bordo de ataque (graus) & 5 \\
\hline \multicolumn{2}{|l|}{ Envergadura total da asa (soma dos 2 painéis) } \\
\hline Valor mínimo (m) & 0,600 \\
\hline Valor máximo $(\mathrm{m})$ & 1,200 \\
\hline Incremento de variação da envergadura de asa (m) & 0,001 \\
\hline \multicolumn{2}{|l|}{ Envergadura total das superfícies de cauda (soma dos 2 painéis) } \\
\hline Valor mínimo (m) & 0,400 \\
\hline Valor máximo (m) & 0,600 \\
\hline Incremento de variação da envergadura de cauda (m) & 0,001 \\
\hline \multicolumn{2}{|l|}{ Número de painéis da asa (Asa simples $=1$; cruciforme $=2 ;$ etc ) } \\
\hline Valor mínimo (adimensional) & 2 \\
\hline Valor máximo (adimensional) & 2 \\
\hline Incremento de variação do número de painéis da asa (adimensional) & \\
\hline \multicolumn{2}{|c|}{ Número de painéis superf. de cauda (Cauda simples $=1$; cruciforme $=2 ;$ etc ) } \\
\hline Valor mínimo (adimensional) & 2 \\
\hline Valor máximo (adimensional) & 2 \\
\hline Incremento de variação do número de painéis da cauda (adim.) & 0,5 \\
\hline \multicolumn{2}{|l|}{ Número de Mach em voo de cruzeiro } \\
\hline Valor mínimo (adimensional) & 0,8 \\
\hline Valor máximo (adimensional) & 0,8 \\
\hline Incr. de variação do número de Mach de cruzeiro (adimensional) & 0,1 \\
\hline \multicolumn{2}{|c|}{ Distância do bordo de ataque da raiz da asa até nariz (múlt. do comprimento) } \\
\hline Valor mínimo (adimensional) & 0,400 \\
\hline Valor máximo (adimensional) & 0,600 \\
\hline Incremento de variação (adimensional) & 0,01 \\
\hline \multicolumn{2}{|c|}{ Dist. bordo de ataque da superfície de cauda até nariz (múlt. do comprimento) } \\
\hline Valor mínimo (adimensional) & 0,87 \\
\hline Valor máximo (adimensional) & 0,95 \\
\hline Incremento de variação (adimensional) & 0,01 \\
\hline \multicolumn{2}{|l|}{ Temperatura de combustão } \\
\hline Valor mínimo $(\mathrm{K})$ & 816 \\
\hline Valor máximo $(\mathrm{K})$ & 816 \\
\hline Incremento da temperatura de combustão (K) & 50 \\
\hline \multicolumn{2}{|l|}{ Ângulo de voo inicial após cruzeiro } \\
\hline Valor mínimo (graus) & 45 \\
\hline Valor máximo (graus) & 45 \\
\hline Incremento (graus) & \\
\hline
\end{tabular}


Tabela 4.32 - Variáveis de projeto para o caso do míssil de cruzeiro do sistema ASTROS 2020. (continuação 2).

\begin{tabular}{lc}
\hline Variáveis de projeto (genes) & Valor \\
\hline Fração mássica de combustível (massa de comb./massa início do cruzeiro) & \\
\hline Valor mínimo (adimensional) & 0,050 \\
Valor máximo (adimensional) & 0,250 \\
\hline Incremento de variação (adimensional) & 0,003 \\
Relação de pressões no compressor (adimensional) & \\
Valor mínimo (adimensional) & 5,2 \\
Valor máximo (adimensional) & 5,8 \\
Incremento de variação (adimensional) & 0,1 \\
\hline
\end{tabular}

Tabela 4.33 - Parâmetros de projeto para o caso do míssil de cruzeiro ASTROS 2020.

\begin{tabular}{lr}
\hline Parâmetro & Valor \\
\hline Dados de lançamento e impacto & \\
Altitude de lançamento (m) & 0 \\
\hline Altitude de impacto (m) & 0 \\
Velocidade de lançamento (m) & 0 \\
\hline Velocidade de impacto (m) & 200,0 \\
Dados de massa do míssil & 200,0 \\
Massa da cabeça de guerra (kg) & 70,0 \\
Massa dos sistemas de guiamento, controle e enlace de dados (kg) & 30,0 \\
Massa dos atuadores das superfícies de controle (kg) & 25,0 \\
Massa da fonte de energia (kg) & \\
Dados aerodinâmicos & 10,0 \\
Máximo ângulo de ataque da asa (graus) & 10,0 \\
\hline Máximo ângulo de ataque do corpo (graus) & 10,0 \\
\hline Máximo ângulo de ataque da superfície de cauda (graus) & 0,25 \\
Incremento na variação dos ângulos de ataque (graus) & 25,0 \\
\hline Parcela do arrasto de base desprezada em cruzeiro (\%) & 3,0 \\
Erro máximo nas equações de equilíbrio em voo (\%) & Cauda \\
Tipo de controle & Não \\
Presença de boattail & Turbojato \\
Tipo de motor de cruzeiro & \\
\hline Dados do sistema de propulsão - foguete - Booster & 7,00 \\
\hline Pressão de combustão (Mpa) & 1560,0 \\
\hline Velocidade característica (m/s) & 1,18 \\
\hline Razão de calores específicos na tubeira (adimensional) & 9,00 \\
Fator de aceleração durante boost (múltiplo da acel. gravidade) & 0,96 \\
Coeficiente de descarga (adimensional) & \\
Dados do sistema de propulsão - Motor de cruzeiro - Turbojato & 0,91 \\
Eficiência isentrópica do difusor de admissão de ar (adimensional) & 0,89 \\
Eficiência isentrópica do compressor (adimensional) & 0,90 \\
Eficiência isentrópica da turbina (adimensional) & 0,95 \\
Eficiência isentrópica do bocal de exaustão (adimensional) & 1,4 \\
Razão de calores específicos no difusor de entrada (adimensional) & 1,37 \\
Razão de calores específicos no compressor (adimensional) & 1,33 \\
Razão de calores específicos na turbina (adimensional) & 1,33 \\
Razão de calores específicos no bocal de exaustão (adimensional) & 0,95 \\
Relação de pressões no combustor (adimensional) & \\
\hline
\end{tabular}


Os parâmetros de projeto aplicados para a otimização do míssil tático de cruzeiro do sistema ASTROS 2020 (ver Tabela 4.33) diferem daqueles utilizados nos casos teste de repetibilidade apenas em relação às massas invariáveis do míssil. Para a massa da cabeça de guerra foi utilizado o valor constante na Tabela 4.27. Os demais componentes de massa invariável no programa, ou seja, sistemas de guiamento, controle e enlace de dados, atuadores das superfícies de controle e fonte de energia, tiveram aumento arbitrário da estimativa de massa considerando que os requisitos do míssil resultariam em;

1. Míssil com maior massa e maiores cargas nas superfícies de controle (atuadores com maior torque e peso);

2. Maior potência requerida para transmissão de dados pelo sistema de enlace de dados, devido ao maior alcance de voo (maior peso e consumo de energia elétrica);

3. Maior potencia requerida e tempo de fornecimento por parte da fonte de energia do míssil (fonte de energia maior e mais pesada).

Salienta-se que os valores de massa dos referidos componentes foram arbitrados a partir dos valores referenciados na literatura para o míssil AGM-84D Harpoon. Note-se que esse último tem dimensões e características técnico-operacionais que permitiram fazer essa aproximação, conforme será visto nos resultados obtidos.

\subsection{3 - Resultados do caso do Míssil Tático de Cruzeiro do Sistema ASTROS 2020}

A Figura 4.26 mostra resultados da execução do Scorpio 1.0 para o caso do Míssil Tático de Cruzeiro do Sistema ASTROS 2020. Analogamente ao caso do míssil AGM-84D Harpoon e aos casos de repetibilidade descritos anteriormente, a Figura 4.26 é formada por quatro gráficos. O gráfico do canto superior esquerdo mostra a avaliação atribuída ao melhor individuo (vermelho) e a avaliação média da população (azul) ao longo das gerações. No canto superior direito é indicado o alcance máximo (azul) e mínimo (verde) para o melhor indivíduo ao longo das gerações. No canto inferior esquerdo é mostrado o tempo de voo até o alvo do melhor indivíduo ao longo das gerações. Por fim, o gráfico do canto inferior direito indica a massa de lançamento do melhor indivíduo em cada geração. 

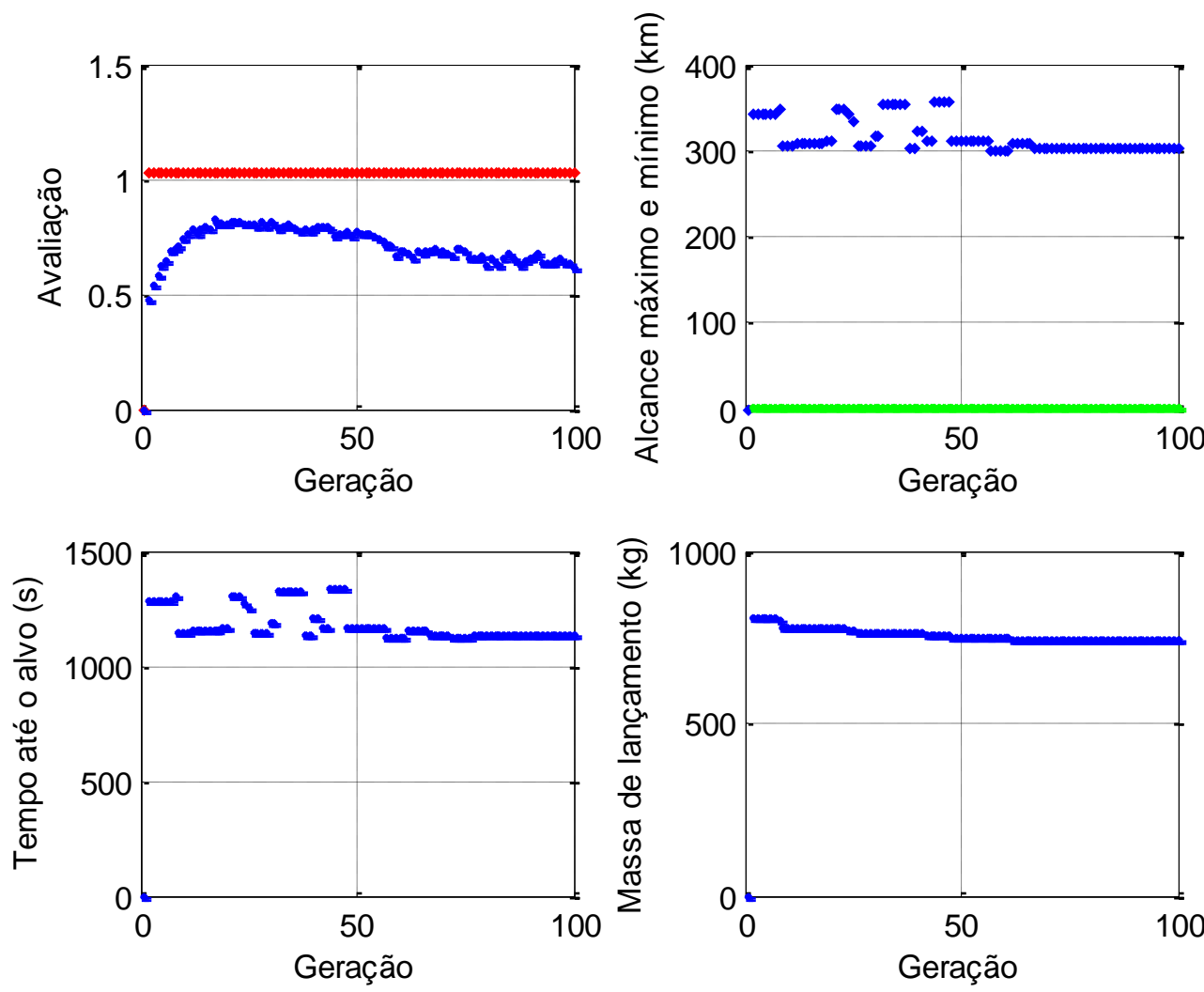

Figura 4.26 - Gráficos da execução do Scorpio 1.0 para o caso do sistema ASTROS 2020.

Foi explicado anteriormente que a função de avaliação para mísseis táticos foi composta de tal forma que uma avaliação igual ou superior a um indica um míssil tecnicamente viável e que atende aos requisitos de projeto. Logo, a partir da análise dos gráfico de avaliação do melhor indivíduo (pontos vermelhos) da Figura 4.26, é possível concluir que o programa encontrou uma solução adequada desde a primeira geração e que o processo evolutivo ocorreu ao longo desta execução. Isso pode ser constatado uma vez que a variação ocorrida nos outros três gráficos dessa figura indica que o melhor individuo da população foi alterado diversas vezes, especialmente nas primeiras cinquenta gerações. Os pontos azuis mostram os valores da avaliação média da população, que mostram o mesmo comportamento verificado nos testes de repetibilidade, ou seja, um aumento inicial do valor médio, com um decaimento posterior. Os motivos desse fenômenos são os mesmos que aqueles apontados quando se comentou sobre os testes de repetibilidade.

Na Figura 4.27 são mostrados dados do mesmo caso representado na Figura acima, com escalas diferentes. O gráfico do canto superior esquerdo mostra apenas a avaliação 
atribuída ao melhor individuo ao longo das gerações. No canto superior direito é indicado somente o alcance máximo do melhor indivíduo, no canto inferior esquerdo, o tempo de voo até o alvo, e no canto inferior direito, a massa de lançamento do melhor indivíduo em cada geração.
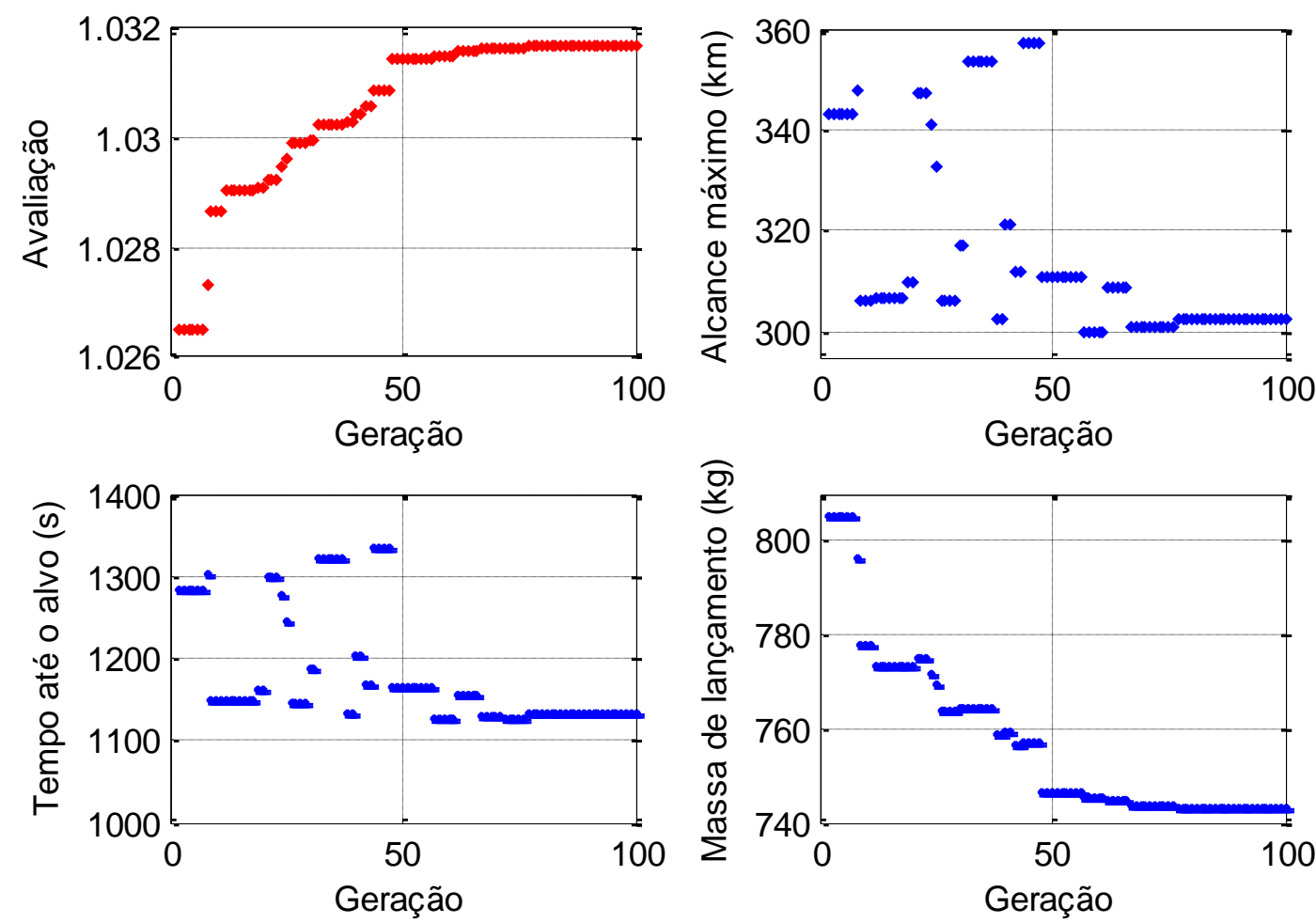

Figura 4.27 - Gráficos da execução do Scorpio 1.0 para o caso do sistema ASTROS 2020 (diferentes escalas).

A curva referente ao alcance máximo do melhor indivíduo mostra uma intensa variação inicial seguido de um trecho com valores tendendo a $300 \mathrm{~km}$, conforme esperado, dado o conjunto de requisitos de projeto. O gráfico do canto inferior esquerdo mostra o tempo de voo, que é dominado pela distância percorrida, uma vez que a velocidade é mantida constante em Mach 0,8. Por fim, no canto inferior direito são mostradas as massas de lançamento em casa geração de casa execução do programa. Os valores de massa de lançamento apresentaram comportamento com tendência decrescente a partir da primeira geração, culminando na massa de 742,99 kg na última geração. 
As imagens da Figura 4.28 foram geradas pelo programa Scorpio 1.0 e são referentes aos mísseis integrantes do grupo de elite da última geração da execução do caso do Míssil Tático de Cruzeiro do sistema ASTROS 2020. Elas mostram a configuração geral dos mísseis. Na Figura 4.28 estão indicados:

1. Centro aerodinâmico do corpo (quadrado verde);

2. Centro aerodinâmico da asa (quadrado azul próximo ao centro do míssil);

3. Centro aerodinâmico das superfícies de cauda (quadrado azul na região posterior do míssil);

4. Centro aerodinâmico do míssil (losango magenta);

5. Centro de massa do míssil (círculo vermelho).

Pela escala presente nas imagens, percebe-se que o míssil otimizado para o caso do sistema ASTROS 2020 tem comprimento superior ao míssil AGM-84D Harpoon (ver Figura 4.12). A posição relativa do centro aerodinâmico do míssil (losango magenta) em região posterior ao centro de massa do míssil (circulo vermelho) indica que o míssil é estaticamente estável. As Tabelas 4.35 a 4.44 a seguir dão maiores informações a respeito do míssil otimizado, ao passo que o relatório de execução do programa Scorpio 1.0, para o caso presente, está disponível no ANEXO I - RELATÓRIO DE EXECUÇÃO DO SCORPIO 1.0: MÍSSIL ASTROS 2020 e apresenta informações mais abrangentes. 


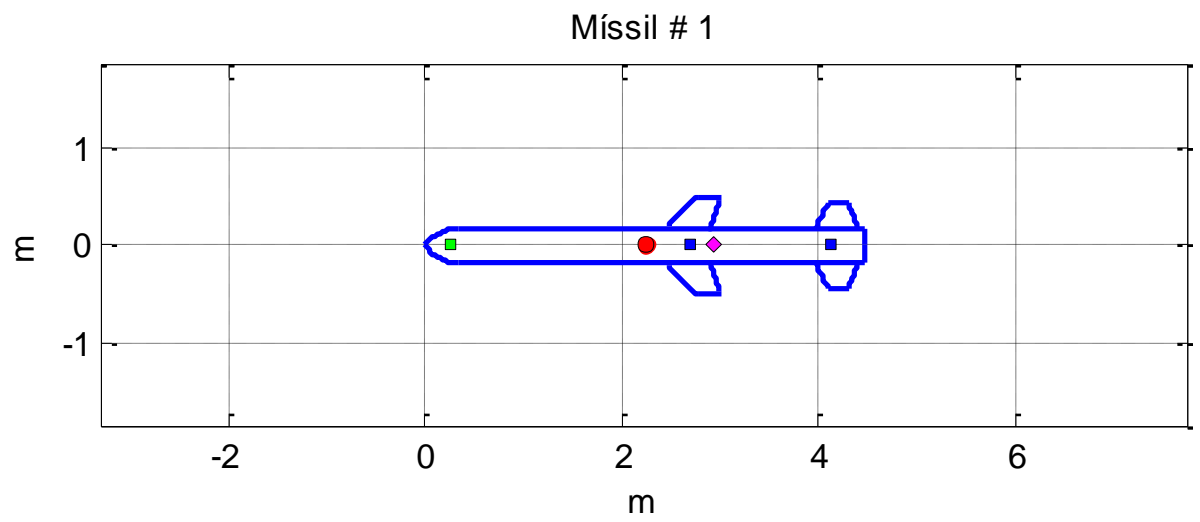

Míssil \# 2
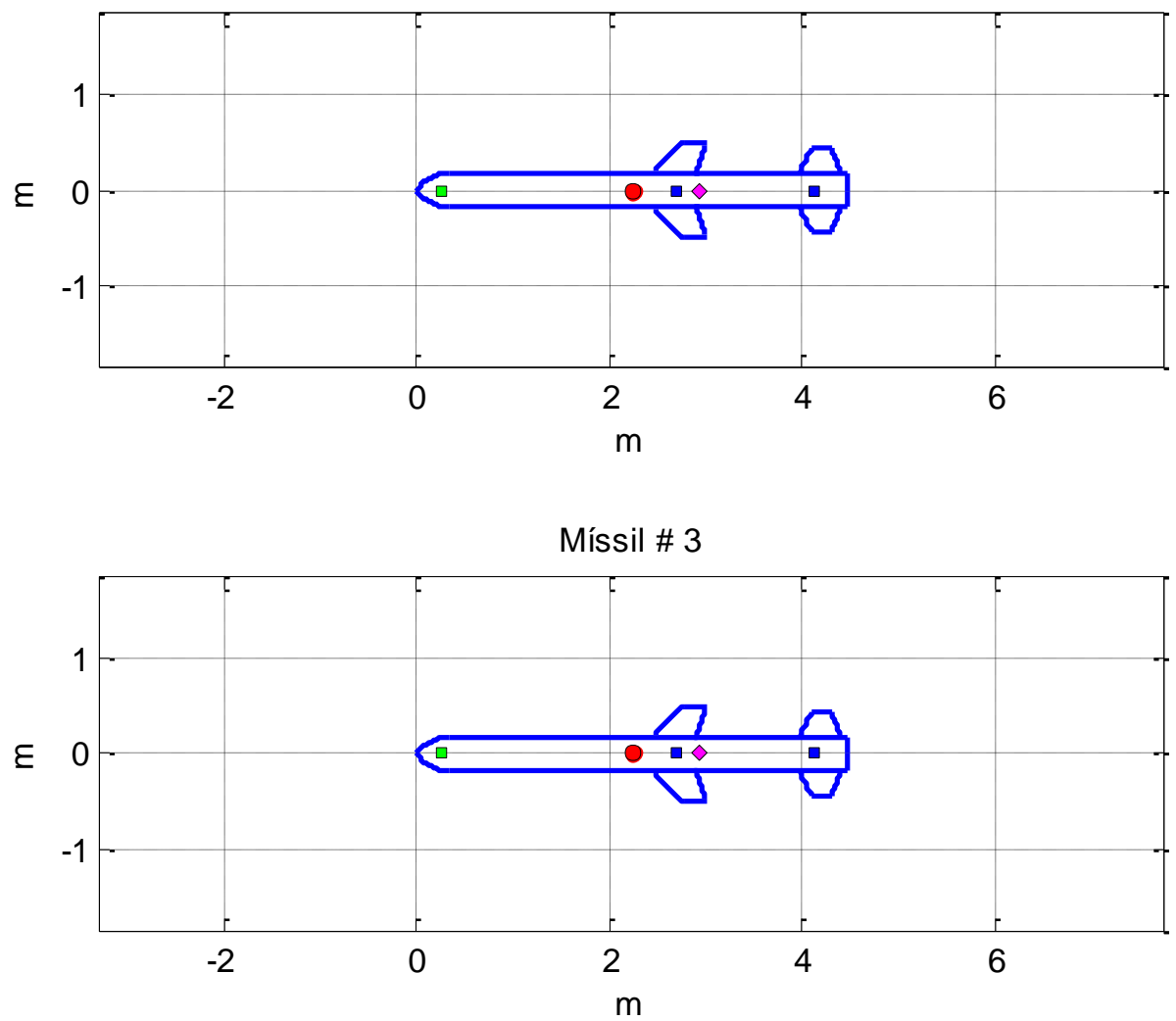

Míssil \# 4

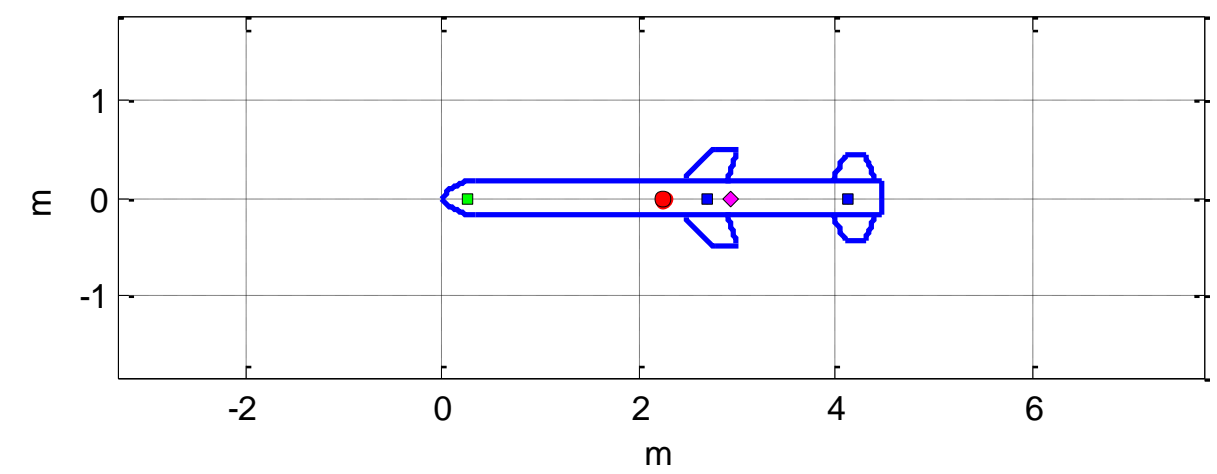

Figura 4.28 - Imagens representativas dos melhores mísseis a partir das configurações mostradas nas Tabelas 4.28 a 4.33. 
A Tabela 4.34 indica que, para esse estudo de otimização também foram avaliados 20000 mísseis distribuídos em 100 gerações. As considerações sobre a parcela avaliada do espaço de soluções, feitas quando foram apresentados os resultados dos casos de repetibilidade, também se aplicam nesse caso, sendo que, devido ao maior número de configurações possíveis na execução atual (devido à modificação das variáveis de projeto), o percentual de soluções avaliadas nessa última execução do programa foi menor.

Como visto na Tabela 4.35, o míssil otimizado atendeu aos requisitos de projeto constantes na Tabela 5.29, tendo alcance máximo de 302,6 km (superior a $300 \mathrm{~km}$ ), alcance mínimo de 0,42 km (inferior a $30 \mathrm{~km}$ ), massa de lançamento de 742,99 (inferior a $1100 \mathrm{~kg}$ ), estabilidade estática igual a 2,046 (superior a 1,48), máximo fator de carga em voo de 2,014 (superior a 2,00).

Vale esclarecer que o alcance mínimo calculado pelo programa Scorpio 1.0 representa apenas a distância percorrida pelo míssil durante a fase de aceleração (booster acionado). O alcance mínimo real de um míssil será superior a essa distância. Considerando que o valor calculado $(0,42 \mathrm{~km})$ é muito inferior ao valor requerido $(30 \mathrm{~km})$, esse requisito não é crítico no processo de dimensionamento e otimização do míssil, portanto não será dada maior atenção a este dado.

Um dado notório obtido nos resultados é o míssil configurado pelo programa Scorpio ter massa de lançamento que representa cerca de 67,5\% da massa de lançamento máxima indicada na Tabela 4.27. Esse resultado é significativo uma vez que o custo de um míssil tático pode ser diretamente relacionado com sua massa (Fleeman, 2012). O ANEXO G ESTIMATIVA DE CUSTOS DE MÍSSEIS TÁTICOS contém equações para estimativas de custo de desenvolvimento e de produção de mísseis táticos com base em registros históricos.

Além do custo, um outro aspecto que pode ser discutido a partir desse resultado, é a possibilidade inicial de instalação de três mísseis em cada unidade lançadora ao invés de dois, conforme previsão mostrada na Tabela 4.27. Isso representaria um aumento de 50\% no poder de fogo de cada unidade lançadora, mantendo-se virtualmente a mesma 
estimativa inicial de peso (2.229 kgf vs $2.200 \mathrm{kgf}$ ). Embora o peso de lançamento não seja a única limitação relacionada à plataforma de lançamento (podem existir outras limitações, como por exemplo, limitações de espaço físico), esse resultado sugere que um míssil otimizado traria características superiores ao sistema ASTROS 2020, tais como menor custo e/ou maior poder de fogo.

A Tabela 4.36 mostra dados dimensionais do corpo do míssil otimizado para o sistema ASTROS 2020. O resultado apresentado pelo programa indicou um míssil com diâmetro próximo do limite inferior para diâmetro $(345 \mathrm{~mm}$ vs $330 \mathrm{~mm}$ ) e comprimento próximo do limite superior para o comprimento (4462 mm $v s 4500 \mathrm{~mm}$ ), conforme pode ser constatado pela confrontação dos dados da Tabela 4.36 e das Tabelas 4.30 a 4.32. Isso provavelmente decorreu do fato de um míssil com essa configuração apresentar menor arrasto e requerer menor empuxo. Contudo, é preciso evidenciar que podem existir outras restrições que não foram aplicadas neste estudo, que implicam na imposição de um diâmetro mínimo para o míssil, tais como diâmetro mínimo interno necessário para instalação do motor turbojato ou do sistema de guiamento e controle, dentre outras.

A Tabela 4.41 apresenta estimativas das massas de lançamento do míssil e nos instantes de início e fim do voo em cruzeiro. Considera-se a ejeção do booster antes do início do voo em cruzeiro. A diferença entre a massa de início e fim de cruzeiro é a massa de combustível. Essa tabela apresenta também o valor estimado da massa específica do míssil. O valor estimado para massa específica do míssil $\left(1.446 \mathrm{~kg} / \mathrm{m}^{3}\right)$ é próximo do valor de referência $(1.384 \mathrm{~kg} / 3$ ), indicado por Fleeman (2012). A Tabela 4.42 apresenta de forma individualizada a massa estimada dos principais componentes do míssil.

Na Tabela 4.43 são indicados dados para o booster do míssil. Um dos parâmetros de projeto utilizados foi a aceleração durante boost igual a nove vezes o valor da aceleração da gravidade. Obviamente esse parâmetro tem forte influência no empuxo requerido, dimensões da turbeira, tempo de combustão, fluxo mássico de propelente etc. 
A Tabela 4.44 é composta por informações a respeito do motor turbojato para voo em cruzeiro. Essa Tabela indica três valores distinto de empuxo; nos momentos de início e fim de cruzeiro e considerando um voo em máximo fator de carga. O cálculo do empuxo necessário no início e fim de cruzeiro consideram a altitude e velocidade de cruzeiro, com as respectivas condições atmosféricas. Consideram ainda os ângulos de ataque de cada elemento aerodinâmico do míssil (corpo, asa e cauda) na determinação da configuração de equilíbrio em voo, para então determinar o arrasto total e, posteriormente, o empuxo necessário. Apesar do programa considerar as mesmas condições de voo no início e fim do cruzeiro, o programa indica valores diferentes no empuxo necessário para cada momento. Isso decorre da diferença de massa do míssil entre esses momentos de voo, devido ao consumo do combustível disponível. Essa diferença de massa resulta em diferentes condições de equilíbrio em voo, diferentes forças de arrasto e, portanto, diferentes valores de empuxo.

O valor de empuxo necessário em máximo fator de carga em voo mostrado na Tabela 4.44 considera voo em regime permanente nessa situação. Sendo assim, o míssil poderia manter velocidade constante mesmo executando uma curva horizontal no fator de carga calculado. Esse valor de empuxo é utilizado para o cálculo da massa do motor de cruzeiro, ao passo que o valor do empuxo no início do cruzeiro é utilizado para o cálculo da velocidade e área de saída do bocal de exaustão, fluxo de ar pela turbina, consumo de combustível etc.

É importante enfatizar que os valores de eficiência isentrópica dos componentes (difusor, compressor, turbina e bocal de exaustão) bem como os valores de razão de calores específicos, considerados para o fluxo nesses componentes, têm forte influência no desempenho do motor e afetam grandemente seu dimensionamento. É desejável que esses componentes tenham a maior eficiência isentrópica possível para que o desempenho do motor, e consequentemente do míssil, seja penalizado o mínimo possível. Além disso, deve ser dada especial atenção quando do projeto de um motor para determinado míssil ou na seleção de um motor existente para instalação em um míssil em desenvolvimento, quanto ao "ponto de projeto", ou seja, o conjunto de condições de operação considerado para o dimensionamento do motor. Isso se faz necessário haja vista a acentuada queda de 
desempenho verificada em motores turbojato (e ramjet) quando em operação diferente daquelas consideradas em projeto. Os valores de eficiência isentrópica mostrados na Tabela 4.44 se baseiam em referências da literatura. Assim, a melhor abordagem para uma otimização com fins práticos (como o projeto real do programa ASTROS 2020), seria o uso de valores conhecidos de um motor existente ou um estudo abrangente acerca do efeito das ineficiências específicas de cada componente sobre o desempenho do míssil, para que fosse possível embasar um conjunto de requisitos técnicos para o projeto do motor. No âmbito deste trabalho e para fins demonstrativos do uso do programa Scorpio 1.0, é suficiente adotar valores fixos e típicos para cada componente do motor.

Vale esclarecer que o programa Scorpio 1.0 não faz um estudo de todo o envelope de voo do míssil. Isso pode refletir na configuração geral do míssil. Para ilustrar, pode-se citar duas situações que não são tratadas a priori pelo programa: a necessidade de o míssil voar com velocidade inferior à velocidade nominal de cruzeiro e na máxima altitude requerida (3300 m acima do nível do mar), exigindo que o míssil disponha de maior área de asa e cauda para compensar o efeito da menor pressão dinâmica sobre as superfícies, ou ainda, a necessidade de o míssil voar com velocidade superior à nominal de cruzeiro, requerendo maior empuxo do motor. O estudo do envelope de voo pode ser feito com o programa Scorpio 1.0 de forma iterativa pelo usuário, mas não de forma automática e otimizada pelo programa.

De modo geral, o resultado obtido representa um míssil adequado para as configurações utilizadas no programa e que representam determinado cenário. Alterações nos requisitos, parâmetros e variáveis de projeto, bem assim na função de avaliação, certamente importariam um cenário diferente ${ }^{69}$. Logo, um estudo de otimização mais realista poderia ser feito caso todas as limitações reais do projeto ASTROS 2020 fossem conhecidas.

\footnotetext{
${ }^{69}$ Rememorando a analogia do problema em estudo com um processo de evolução biológica na natureza, é razoável concluir que qualquer alteração no meio ambiente teria alguma ingerência sobre o processo evolutivo e consequentemente sobre os indivíduos ao longo da gerações.
} 
Tabela 4.34 - Dados da execução do Scorpio 1.0 para o caso do sistema ASTROS 2020.

Tempo transcorrido durante execução do programa (s)

$32.573,5$

Número de gerações avaliadas

100

Número de soluções avaliadas:

20.000

Parcela avaliada do espaço de soluções possíveis (\%):

$1,53 \times 10^{-21}$

Tempo médio consumido para avaliar uma solução (s)

1,6286

Critério de parada:

Máx. ger.

Tabela 4.35 - Dados de desempenho em voo para o caso do sistema ASTROS 2020.

\begin{tabular}{ll}
\hline Desempenho do míssil & \\
\hline Alcance máximo (km) & 302,6 \\
\hline Alcance mínimo (km) & 0,42 \\
\hline Tempo até o alvo (s) & 1134,1 \\
\hline Massa de lançamento (kg) & 742,99 \\
\hline Estabilidade estática (adimensional - múltiplos do diâmetro) & 2,046 \\
\hline Máximo Fator de Carga em voo (adimensional - múltiplos de g) & 2,014 \\
\hline Avaliação do indivíduo (adimensional): & 1,031701 \\
\hline
\end{tabular}

Tabela 4.36 - Dados dimensionais do corpo do míssil do caso do sistema ASTROS 2020.

Dados dimensionais do corpo do míssil (Alumínio 2219-T81)

Comprimento do corpo do míssil (mm)

$4.462,0$

Comprimento do nariz do míssil (mm) 345,0

Diâmetro externo da estrutura do corpo do míssil (mm)

345,0

Diâmetro interno da estrutura do corpo do míssil (mm) 326,6

Espessura da estrutura do corpo do míssil (mm) 9,2

Área de referência - seção transversal do corpo do míssil $\left(\mathrm{m}^{2}\right)$ 0,0935

Comprimento do boattail do míssil (mm) 0

Diâmetro da parte posterior do boattail do míssil(mm) 345,0 
Tabela 4.37 - Dados dimensionais da asa do míssil do caso do sistema ASTROS 2020.

Dados dimensionais da asa do míssil (Alumínio 2219-T81)

$\begin{array}{ll}\text { Corda da ponta da asa }(\mathrm{mm}) & 224,5\end{array}$

$\begin{array}{ll}\text { Corda da raiz da asa }(\mathrm{mm}) & 436,0\end{array}$

$\begin{array}{ll}\text { Corda Aerodinâmica média da asa }(\mathrm{mm}) & 341,6\end{array}$

$\begin{array}{ll}\text { Distância entre corda aerod. média e a raiz da asa }(\mathrm{mm}) & 146,9\end{array}$

$\begin{array}{ll}\text { Taper ratio da asa (adimensional) } & 0,515\end{array}$

$\begin{array}{ll}\text { Envergadura asa - soma } 2 \text { painéis }(\mathrm{mm}) & 658,0\end{array}$

$\begin{array}{lr}\text { Razão de aspecto da asa (adimensional) } & 1,9923\end{array}$

Ângulo de enflechamento da asa (graus) 45

$\begin{array}{ll}\text { Área planiforme da asa }\left(\mathrm{m}^{2}\right) & 0,2173\end{array}$

$\begin{array}{lr}\text { Espessura média da raiz da asa }(\mathrm{mm}) & 8,7\end{array}$

$\begin{array}{ll}\text { Âng. bordo ataque seção asa (graus) } & 30\end{array}$

Número de painéis da asa (simples $=1$; cruciforme $=2$; etc): 2

$\begin{array}{ll}\text { Dist. bordo ataque da raiz da asa - nariz }(\mathrm{mm}) \text { : } & 2.454,1\end{array}$

Tabela 4.38 - Dados dimensionais da cauda do míssil do caso do sistema ASTROS 2020.

\begin{tabular}{ll}
\hline Dados dimensionais das superfícies de cauda do míssil (Alumínio 2219-T81) & \\
\hline Corda da ponta da cauda (mm): & 272,4 \\
\hline Corda da raiz da cauda (mm): & 427,0 \\
\hline Corda Aerodinâmica média da cauda (mm) & 355,4 \\
\hline Distância entre corda aerod. média e a raiz da cauda (mm) & 117,2 \\
\hline Taper ratio da superfície das superfícies de cauda (adimensional): & 0,638 \\
\hline Envergadura total das superfícies de cauda -soma 2 painéis-(mm): & 506,0 \\
\hline Razão de aspecto da cauda (adimens.) & 1,447 \\
\hline Ângulo de enflechamento das superfícies de cauda (graus) & 25 \\
\hline Área planiforme da cauda (m²) & 0,1770 \\
\hline Espessura média da raiz da cauda (mm) & 5,0 \\
\hline Âng. tot. bordo de ataque seção transv. da cauda (graus) & 30 \\
\hline Núm. painéis cauda (simples $=1 ;$ cruciforme = 2; etc) (adimens.) & 2 \\
\hline Dist. bordo ataque da cauda - nariz (mm) & $3.971,2$ \\
\hline
\end{tabular}


Tabela 4.39 - Centro aerodinâmico do míssil do caso do sistema ASTROS 2020.

Centro aerodinâmico

Centro aerodinâmico do corpo do míssil (mm)

260,3

Centro aerodinâmico da asa (bordo de ataque) ( $\mathrm{mm}$ )

85,4

Centro aerodinâmico da cauda (bordo de ataque) (mm)

88,9

Centro aerodinâmico da asa (nariz do míssil) (mm)

Centro aerodinâmico da cauda (nariz do míssil) (mm)

$4.114,7$

Centro aerodinâmico do míssil (mm)

Centro de massa (CG) do míssil (mm)

Estabilidade estática (adimensional - múltiplos do diâmetro)

Tabela 4.40 - Dados de voo do míssil do caso do sistema ASTROS 2020.

\begin{tabular}{lc}
\hline Relação Sustentação/Arrasto & \\
\hline Relação Sustentação/Arrasto média em cruzeiro (adimensional) & 3,207 \\
\hline Relação Sustentação/Arrasto média em coast (adimensional) & 2,710 \\
\hline Arrasto médio em voo & 304,16 \\
\hline Arrasto médio em boost $(\mathrm{N})$ & $1.734,08$ \\
\hline Arrasto médio em cruzeiro (N) & $1.879,63$ \\
\hline Arrasto médio em coast $(\mathrm{N})$ &
\end{tabular}

Tabela 4.41 - Massa do míssil do caso do sistema ASTROS 2020.

\begin{tabular}{|c|c|}
\hline Massa - principais momentos voo & \\
\hline Massa total de lançamento (kg) & 742,99 \\
\hline Massa do míssil - início do cruzeiro (kg) & 603,15 \\
\hline Massa do míssil - fim do cruzeiro (kg) & 523,23 \\
\hline Massa espec. do míssil - início do cruzeiro - ref.:1384 -(kg/m³) & 1446,0 \\
\hline
\end{tabular}


Tabela 4.42 - Massa dos componentes do caso do sistema ASTROS 2020.

\begin{tabular}{|c|c|}
\hline \multicolumn{2}{|l|}{ Massas dos componentes do míssil } \\
\hline \multicolumn{2}{|l|}{ Massa do Booster com propelente $(\mathrm{kg})$} \\
\hline Massa de propelente necessária para o Booster $(\mathrm{kg})$ & 83,45 \\
\hline Massa do Booster sem propelente (kg) & 44,93 \\
\hline Massa da Cabeça de Guerra (kg) & 200,00 \\
\hline Massa dos Sistemas de Guiamento, Controle e Enlace de Dados (kg): & 70,00 \\
\hline Massa de combustível de cruzeiro $(\mathrm{kg})$ & 79,92 \\
\hline Massa da estrutura (corpo) do míssil (kg) & 122,84 \\
\hline Massa total da Asa $(\mathrm{kg})$ & 8,40 \\
\hline Massa total da Cauda $(\mathrm{kg})$ & 4,23 \\
\hline Massa do motor de cruzeiro $(\mathrm{kg})$ & 62,76 \\
\hline Massa total dos atuadores das superfícies de controle $(\mathrm{kg})$ & 30,00 \\
\hline Massa total da fonte de energia $(\mathrm{kg})$ & 25,00 \\
\hline
\end{tabular}

Tabela 4.43 - Dados do booster do caso do sistema ASTROS 2020.

\begin{tabular}{ll}
\hline Sistema de Propulsão - Booster & \\
\hline Empuxo (N): & $65.572,1$ \\
\hline Dados de entrada & \\
\hline Pressão de combustão (MPa): & 7 \\
\hline Velocidade característica (m/s): & 1560 \\
Razão de calores específicos na tubeira (adimensional): & 1,18 \\
\hline Fator de aceleração durante boost (múltiplo da acel. gravidade): & 9 \\
\hline Constante do gás (ar) (J/kg.K): & 287 \\
\hline Coeficiente de descarga (adimensional) & 0,96 \\
\hline Flight path angle (graus): & 45 \\
\hline Razão de expansão da tubeira - Booster (adimensional): & 9,779 \\
\hline Área da garganta da tubeira (m²) & 0,00603 \\
\hline Diâmetro da garganta da tubeira (mm) & 87,9 \\
\hline Diâmetro da exaustão da tubeira (mm) & 274,0 \\
\hline Velocidade de cruzeiro (m/s) & 270,7 \\
\hline Máxima velocidade incremental devido ao Booster (m/s) & 270,7 \\
\hline Massa de propelente mínima (kg) & 78,52 \\
\hline Tempo de combustão mínimo (s) & 2,90 \\
\hline Massa de propelente necessária (kg) & 83,45 \\
\hline Tempo de combustão necessário (s) & 3,08 \\
\hline Peso médio do míssil durante Boost (N) & $6.876,6$ \\
\hline Fluxo Mássico de Propelente (kg/s) & 27,06 \\
\hline Impulso Específico - Booster (s) & 247,14 \\
\hline
\end{tabular}


Tabela 4.44 - Dados do motor de cruzeiro do caso do sistema ASTROS 2020.

\begin{tabular}{|c|c|}
\hline \multicolumn{2}{|l|}{ Sistema de Propulsão - Motor de Cruzeiro } \\
\hline \multicolumn{2}{|l|}{ Tipo de motor de cruzeiro: Turbojato } \\
\hline Empuxo necessário - início do cruzeiro $(\mathrm{N})$ & $1.818,3$ \\
\hline Empuxo necessário - fim do cruzeiro $(\mathrm{N})$ & $1.668,6$ \\
\hline Empuxo necessário máx. Fator de Carga $(\mathrm{N})$ & $3.077,1$ \\
\hline \multicolumn{2}{|l|}{ Condições de operação início voo cruzeiro } \\
\hline \multicolumn{2}{|l|}{ Temperatura } \\
\hline Temp. estagnação entrada compressor (K) & 321,4 \\
\hline Temp. estagnação saída do compressor (K) & 526,8 \\
\hline Temp. estagnação entrada na turbina (K) & 816,0 \\
\hline Temperatura estagnação saída da turbina (K) & 610,6 \\
\hline \multicolumn{2}{|l|}{ Pressão } \\
\hline Relação de pressões no compressor $(\mathrm{Pa} / \mathrm{Pa})$ : & 5,3 \\
\hline Relação de pressões no combustor $(\mathrm{Pa} / \mathrm{Pa})$ & 0,95 \\
\hline Pressão estagnação entrada compressor $(\mathrm{kPa})$ & 140,4 \\
\hline Pressão estagnação saída compressor (kPa) & 744,0 \\
\hline Pressão de estagnação entrada turbina (kPa) & 706,8 \\
\hline Pressão de estagnação saída da turbina $(\mathrm{kPa})$ & 188,3 \\
\hline Pressão na saída do bocal de exaustão (kPa) & 98,3 \\
\hline \multicolumn{2}{|l|}{ Eficiência isentrópica (dados de entrada) } \\
\hline Efic. isentrópica difusor de ar (adimens.) & 0,91 \\
\hline Efic. isentrópica compressor (adimens.) & 0,89 \\
\hline Efic. isentrópica turbina (adimens.) & 0,90 \\
\hline Efic. isentrópica bocal exaustão (adimens.) & 0,95 \\
\hline \multicolumn{2}{|l|}{ Calor específico do fluido de trabalho } \\
\hline Razão calores específicos difusor (adimens.) & 1,40 \\
\hline Razão calores espec. compressor (adimens.) & 1,37 \\
\hline Razão calores específicos turbina (adimens.) & 1,33 \\
\hline Razão calores espec. bocal exaus. (adimens.) & 1,33 \\
\hline Razão combustível/ar (kg/kg): & 0,007907 \\
\hline Poder calorífico do combustível (kJ/kg) & 43000 \\
\hline Velocidade na saída bocal de exaustão (m/s) & 447,27 \\
\hline Área da saída do bocal de exaustão $\left(\mathrm{m}^{2}\right)$ & 0,033427 \\
\hline Área seção transversal corpo do míssil $\left(\mathrm{m}^{2}\right)$ & 0,0935 \\
\hline Razão área da saída do bocal de exaustão / seção do míssil (adm.) & 0,3576 \\
\hline Diâmetro saída do bocal de exaustão $(\mathrm{mm})$ & 206,3 \\
\hline Mach saída bocal de exaustão (adimens.) & 1,000 \\
\hline Fluxo de ar pela turbina $(\mathrm{kg} / \mathrm{s})$ & 9,7668 \\
\hline Consumo de combustível (kg/s) & 0,0772 \\
\hline Empuxo Específico (kN.s/kg) & 0,1862 \\
\hline Consumo específico de comb. $(\mathrm{kg} / \mathrm{s} . \mathrm{kN})$ & 0,0425 \\
\hline Impulso Específico (s) & 2401,2 \\
\hline
\end{tabular}




\section{5 - CONCLUSÕES}

No primeiro capítulo dessa dissertação foi feita breve introdução à temática da importância atual dos mísseis táticos, uma abordagem sobre fases projeto de engenharia e sobre projeto conceitual de mísseis táticos. Lá também foi estabelecido o objetivo geral deste trabalho, que foi o desenvolvimento de um programa de computador, que possa ser utilizado como ferramenta de auxílio no projeto conceitual de mísseis táticos, segundo uma estratégia de otimização multiobjectivo, com objetivo principal de minimização de massa de lançamento. Os objetivos específicos também foram delineados no primeiro capítulo.

No segundo capítulo foi apresentado o conjunto de equações e considerações utilizado para modelagem e dimensionamento de mísseis táticos. Foram apresentadas formulações relativas às áreas de aerodinâmica, propulsão, peso e trajetória de voo.

Foi feita uma exposição sistemática das equações de modelagem de forças de arrasto parasita e força normal em cada elemento aerodinâmico do míssil (corpo, asa e cauda), com a posterior transformação em componentes de arrasto e sustentação. Foram mostradas as equações usualmente utilizadas para dimensionamento das superfícies de cauda. Fez-se considerações sobre técnicas de controle do míssil, forma planar das superfícies aerodinâmicas, estabilidade estática e fator de carga em manobra.

Os modelos utilizados para a análise termodinâmica dos motores foguete, turbojato e ramjet foram discutidos, ressaltando-se os principais aspectos técnicos de interesse de cada tipo de motor, o comportamento típico e seus impactos sobre o desempenho do míssil.

No segundo capítulo também foi apresentada a abordagem empregada para a estimativa de massa dos diversos componentes do míssil. Posteriormente, no programa de computador desenvolvido, alguns componentes foram considerados com massa constante, não alterada pelo processo de otimização (cabeça de guerra, sistemas de guiamento, controle e enlace de dados, atuadores das superfícies de controle e fonte de energia do míssil). Outros itens tinham a massa dependente do míssil sob análise. Esses itens foram separados em dois grupos, um composto por aqueles componentes que tinham sua massa estimada a partir de dados estatísticos de massa de mísseis táticos apresentados pela literatura (motor de 
cruzeiro e booster sem propelente), e outro grupo formado por itens que tinham a massa calculada em função das dimensões, desempenho de voo do míssil etc (propelente do booster, combustível de cruzeiro, estrutura do corpo do míssil, asa e superfícies de cauda).

Foram apresentados os perfis usuais de trajetória de voo de mísseis táticos (voo balístico e de cruzeiro) e suas decomposições em diferentes fases de voo (aceleração inicial, cruzeiro e coast). Os respectivos equacionamentos e considerações técnicas foram discutidos.

No terceiro capítulo foi feita uma exposição da técnica evolucionária baseada em algoritmos genéticos (AG), que posteriormente foi empregada no programa desenvolvido, acoplada aos modelos utilizados para dimensionamento de mísseis táticos. Foram abordados os principais parâmetros dos AG, tais como: tamanho da população, população inicial, número de gerações, operadores mutação e crossover, número de pontos de corte, inserção de imigrantes da população, manutenção de um grupo de elite, avaliação suficiente para interromper o processo evolutivo, método de seleção de pais para produzir indivíduos para a geração seguinte, a função de avaliação etc. Foram feitos comentários sobre como cada um desses aspectos pode influenciar no desempenho do algoritmo genético.

Para o estudo e solução do problema proposto, descrito pelos objetivos deste trabalho, foi desenvolvido um programa de computador, escrito na linguagem MATLAB R2013a e baseado na técnica de algoritmos genéticos, com a capacidade de avaliar representações de projeto conceitual de mísseis táticos, de acordo com os modelos teóricos apresentados neste trabalho, e produzir um processo evolutivo que fornece características gerais de mísseis adequados para atender a determinados requisitos técnico-operacionais. $\mathrm{O}$ programa, desenvolvido inteiramente no âmbito deste projeto, foi denominado Scorpio 1.0.

O algoritmo genético, contido no programa Scorpio 1.0, utiliza representação de cromossomos com números reais. Como forma de seleção de pais, aplica o método do torneio, utiliza taxa de mutação fixa ou variável, sendo que o cruzamento genético entre indivíduos é feito por operador crossover com dois pontos de corte. Além disso, a população inicial é escolhida randomicamente entre os limites estabelecidos pelo usuário para cada variável de projeto (gene do cromossomo). O tamanho da população, definido 
pelo usuário, é mantido constante ao longo da execução do caso. O número máximo de gerações e avaliação suficiente também são definidos pelo usuário do programa. O AG tem a possibilidade de inserir um grupo de imigrantes em cada geração, além de preservar inalterados um grupo de melhores indivíduos (elitismo).

O programa Scorpio 1.0 engloba o equacionamento apresentado nessa dissertação para modelagem nas área de aerodinâmica, propulsão, peso e trajetória de voo de mísseis táticos, tendo a funcionalidade de indicar soluções otimizadas para mísseis subsônicos e supersônicos, com perfil de voo balístico ou de cruzeiro, que adotem sistema de propulsão com motor foguete, turbojato ou ramjet, com sistema de controle por superfícies de causa, asa ou canard, segundo requisitos de desempenho inseridos pelo usuário, com a aplicação de restrições e premissas de projeto, também determinados pelo usuário.

Os resultados do trabalho foram gerados e apresentados de maneira gradual, separados em quatro etapas de forma a verificar as funcionalidades do programa gerado.

$\mathrm{Na}$ primeira etapa foi realizada uma série de execuções para avaliar exclusivamente o comportamento do algoritmo genético desenvolvido e implementado no programa Scorpio 1.0, de forma a estudar seu comportamento e capacidade de indicar soluções otimizadas para determinado problema. Para isso foi empregada uma conhecida função de teste (função de Rastrigin), adequada para esse tipo de estudo por conter diversos mínimos e máximos locais, sendo útil para testar capacidade do AG de escapar desses mínimos e máximos locais e encontrar o mínimo (ou máximo) global. A partir desses estudos, foram apresentadas discussões sobre tamanho populacional, taxa de mutação, número de gerações, percentual de soluções avaliadas em relação ao número total de soluções possíveis, tempo de processamento e intratabilidade do problema. Diante dos resultados obtidos, considerou-se que o algoritmo genético desenvolvido e implementado no programa Scorpio 1.0 tem plena capacidade de otimizar soluções de problemas diversos, dependendo apenas do adequado ajuste e uso dos parâmetros do AG e da função de avaliação utilizada.

Na segunda etapa de testes, o programa Scorpio 1.0 foi utilizado para o dimensionamento de um míssil de cruzeiro existente (AGM-84 D Harpoon), a partir do uso de informações 
relativas a esse míssil como dado de entrada. O desempenho informado pelo programa foi comparado com o desempenho do míssil existente encontrado na literatura. O objetivo desta etapa foi a verificação do funcionamento da rotina de cálculo e da precisão das equações teóricas apresentadas para previsão do desempenho de um míssil existente.

O programa Scorpio $1.0 \mathrm{fez}$ previsões de alcance máximo de 221,63 km, enquanto o alcance do míssil AGM-84D Harpoon, verificado na literatura, é de $220 \mathrm{~km}$ (desvio inferior a 1\%). A massa de lançamento, prevista pelo programa foi de $515,44 \mathrm{~kg}$, ao passo que o valor real é de $556 \mathrm{~kg}$ (desvio inferior a 8\%). A massa do motor de cruzeiro estimada pelo programa $(45,21 \mathrm{~kg})$ apresentou excelente aproximação da massa do motor real do míssil (46,0 kg), com diferença inferior a 2\%. A massa de combustível de cruzeiro prevista pelo Scorpio 1.0 foi de $51,29 \mathrm{~kg}$, sendo que a massa de combustível de cruzeiro do Harpoon é de 49,21 kg, (discrepância de cerca de 4\%). Os valores de arrasto e empuxo também apresentaram boa proximidade dos valores informados na literatura. Estes foram apenas alguns dos valores indicados pelo programa. Considerando os resultados obtidos nesta etapa e os dados do míssil AGM-84D Harpoon, concluiu-se que o programa Scorpio 1.0 foi capaz de prever, com boa precisão em termos de projeto conceitual, informações acerca do referido míssil, apresentando, assim, resultados satisfatórios no dimensionamento de um míssil de cruzeiro subsônico.

Devido à natureza aleatória inerente ao processo evolutivo dos algoritmos genéticos, era esperado que os resultados obtidos após sucessivas execuções do Scorpio 1.0 não fossem idênticos, mesmo para iguais dados de entrada. Contudo, uma métrica da confiabilidade do programa é sua capacidade de produzir resultados próximos, para distintas execuções com dados de entrada iguais. Por esse motivo, na terceira etapa de testes do programa, foram realizados testes de repetibilidade com o Scorpio 1.0, quando este foi executado quatro vezes com as mesmas configurações iniciais para o dimensionamento de um míssil. Nessas execuções foram empregadas equações de dimensionamento de mísseis táticos apresentadas nessa dissertação, bem como uma função de avaliação escrita especificamente para isso. A função de avaliação adotada foi escrita de forma a otimizar simultaneamente múltiplos objetivos, sendo eles a minimização da massa de lançamento, a maximização do alcance superior e minimização do alcance inferior. A priorização entre 
cada um desses objetivos conflitantes foi feita por meio da aplicação de diferentes pesos a cada um deles.

Em cada execução durante os testes de repetibilidade, o programa Scorpio 1.0 avaliou vinte mil mísseis. O conjunto de variáveis de projeto permitiam um arranjo combinatório tal que esse valor representou apenas $1,27 \times 10^{-20} \%$ do número total de mísseis possíveis. Apesar de avaliar uma parcela extremamente reduzida do espaço total de busca, o programa apontou mísseis razoavelmente próximos ao fim de cada uma das quatro execuções. Foram apresentadas também curvas com informações de cada execução ao longo das gerações (melhor avaliação, avaliação média da população, alcance do míssil, tempo de voo até o alvo e massa de lançamento), imagens representativas dos mísseis integrantes do grupo de elite da última geração de cada execução e tabelas contendo dados variados sobre os melhores mísseis de cada execução. A partir da análise de todas essas informações, foi possível inferir que o programa Scorpio 1.0 possui capacidade de indicar mísseis parecidos (resultados próximos) cada vez que ele é executado com as configurações iniciais semelhantes. Dessa forma, concluiu-se que o programa é capaz de produzir resultados confiáveis quando se analisa o critério de repetibilidade.

$\mathrm{Na}$ quarta etapa foi feita uma utilização demonstrativa das capacidades do programa Scorpio 1.0, sendo ele utilizado para o estudo do caso de um míssil que se encontrava em fase de desenvolvimento à época da elaboração deste trabalho (Míssil Tático de Cruzeiro do programa ASTROS 2020 do Exército Brasileiro). Foram utilizados dados preliminares divulgados pelos participantes do projeto (fabricante e operador) na forma de dados de entrada do programa, juntamente com outros valores que foram arbitrados por não estarem disponíveis na literatura. O míssil otimizado para os requisitos, variáveis e parâmetros de projeto adotados foi apresentado e discutido.

Um fato de destaque a respeito dos resultados obtidos nessa etapa é o míssil configurado pelo programa Scorpio ter massa de lançamento que representa cerca de 67,5\% da massa de lançamento estimada pelo operador do míssil. Esse resultado é significativo uma vez que o custo de um míssil tático pode ser diretamente relacionado com sua massa. Portanto o programa desenvolvido se mostrou eficaz em seu objetivo de otimizar um míssil tático para determinada missão, atendendo aos requisitos e restrições impostas. Além do custo, 
um outro aspecto que pode ser discutido a partir desse resultado, é a possibilidade inicial de instalação de três mísseis em cada unidade lançadora ao invés de dois, conforme previsão do fabricante e operador do sistema. Isso representaria um aumento de $50 \%$ no poder de fogo de cada unidade lançadora, mantendo-se virtualmente a mesma estimativa inicial de peso. Embora o peso de lançamento não seja a única limitação relacionada à plataforma de lançamento (podem existir outras limitações, como por exemplo, limitações de espaço físico), esse resultado sugere que um míssil otimizado pode conferir características superiores ao sistema ASTROS 2020, tais como menor custo e/ou maior poder de fogo.

Ainda com relação aos resultados obtidos nessa simulação, foram feitas ponderações sobre a validade dos modelos teóricos utilizados e afirmou-se que os resultados obtidos representam um míssil adequado para as configurações utilizadas no programa e que contemplam determinado cenário. Alterações nos requisitos, parâmetros e variáveis de projeto, bem assim na função de avaliação, certamente importariam um cenário diferente. Concluiu-se que um estudo de otimização mais adequado poderia ser feito caso todas as limitações reais do projeto ASTROS 2020 fossem conhecidas.

Diante dos resultados obtidos e discutidos conclui-se que o programa desenvolvido foi capaz de atender ao objetivo proposto para este trabalho, sendo passível de ser utilizado como ferramenta de auxílio no projeto conceitual de mísseis táticos.

Conforme declarado anteriormente, o programa Scorpio 1.0 tem ainda a capacidade de dimensionar mísseis com características diferentes daqueles analisadas neste trabalho, tais como, perfil de voo balístico, velocidade supersônica, propulsão com motor ramjet, controle por canard etc. Para fins de concisão e brevidade, nem todas as funcionalidades do programa foram executadas e discutidas nesse trabalho, estando, contudo, disponíveis ao usuário do programa.

De maneira a aprimorar e estender as capacidades do programa Scorpio, suas versões posteriores podem contemplar os seguintes aspectos:

1. Inclusão de modelagem para motor turbofan; 
2. Dimensionamento geométrico do motor foguete, de maneira a incluir o comprimento e diâmetro do booster no comprimento total do míssil no momento do lançamento;

3. Cálculo estimativo de torque requerido e peso dos atuadores das superfícies de controle, com base nos esforços aerodinâmicos nas superfícies de controle;

4. Modelos aerodinâmicos que permitam a adoção de asas com maiores razões de aspecto, para a obtenção de maiores relações sustentação/arrasto;

5. Cálculo de efetividade de controle do míssil;

6. Implementação de modelos com mais graus de liberdade (GDL) para simulação de comportamento em voo;

7. Simulação de todo o envelope de voo do míssil;

8. Estudo dos efeitos da variação dos coeficientes (pesos) empregados na função de avaliação adotada;

9. Inclusão de capacidade de simulação de diferentes configurações de cauda para o estudo da efetividade de controle do míssil;

10. Inclusão de efeitos de downwash nas superfícies de cauda. 


\section{REFERÊNCIAS BIBLIOGRÁFICAS}

Anderson, J. D. (2001). Fundamentals of Aerodynamics - 3rd Edition. New York: McGraw-Hill.

Army Technology. (2015). Astros II Artillery Saturation Rocket System, Brazil. Acesso em 27 de novembro de 2015, disponível em Army Technology: http://www.armytechnology.com/projects/astros/astros1.html

Ashley, H. (1974). Engineering Analysis of Flight Vehicles. Dover Publications. Inc.

Ashley, H., \& Landahl, M. (1956). Aerodynamics of Wings and Bodies. Cambridge, Massachusetts: Dover.

Ashwood, P. F. (1957). A review of the performance of exhaust systems for gas turbine aero-engines. Proceedings of the Institution of Mechanical Engineers, 129 - 58.

ASME. (1959). American National Standard Letter Symbols for Rocket Propulsion. ASME Publication Y10.14.

Beggs Aerospace. (28 de julho de 2015). V-2. Acesso em 14 de dezembro de 2015, disponível em Post War V-2: http://www.postwarv2.com/usa/ws/photo03.html

Bithell, R. A., \& Stoner, R. C. (Março de 1982). Rapid Approach for Missiles Synthesis. AFWAL TR 81-3022.

Blickle, T., \& Thiele, L. (1997). A comparison of selection schemes used in evolutionary algorithms. Zurich, Suiça.

Bonney et al. (1956). Aerodynamicas, Propulsion, Structures, and Design Practice "Principles of Guided Missile Design". D. Vab Nostrand Company, Inc.

BrahMos Aerospace . (2012). Classification of Missile. Acesso em 3 de novembro de 2015, disponível em BrahMos Aerospace http://www.brahmos.com/content.php?id=10\&sid=9\#launch-mode

Bruns, K., Moore, M., Stoy, S., Vukelich, S., \& Blake, W. (Abril de 1991). Missile DATCOM. AFWAL-TR-91-3039.

Bureau of Naval Personnel. (1959). Principles of Guided Missiles and Nuclear Weapons. Washington D.C.: NAVPERS 10784.

Bureau of Naval Personnel. (1966). Principles of Guided Missiles and Nuclear Weapons. Washington D.C.: NAVPERS-10784-A. 
Carvalho, A., Braga, A., \& Ludermir, T. (2003). Computação Evolutiva. In: S. Rezend, Sistemas Inteligentes - Fundamentos e Aplicações. São Paulo, Brasil: Manole.

Castro, F. (2014). Míssil anti-navio Harpoon. Acesso em 3 de novembro de 2015, disponível em Sistemas de Armas: http://www.sistemasdearmas.com.br/asv/harpoon.html

Chin, S. (1961). Missile Configuration Design. Orlando, Florida: McGraw-Hill Company, Inc.

Chin, S. (1961). Missile Configuration Design. Orlando, Florida: McGraw-Hill Company, Inc.

Darwin, C. R. (1859). On The Origin of Species by Means of Natural Selection or the Preservation of Favoured Races in the Struggle for Life. Londres.

Exército Brasileiro. (21 de setembro de 2012). Portaria n.137-EME de 14 de stembro de 2012. Boletim do Exército n.38, pp. 16-19.

Exército Brasileiro. (2 de maio de 2014). Portaria n. 38-DCT de 31 de março de 2014. Boletim do Exército n.18, pp. 69-79.

Exército Brasileiro. (5 de outubro de 2015). Emprego da Artilharia de Mísseis e Foguetes de Longo Alcance. Nota de Coordenação Doutrinária n.03/2015 - Centro de Doutrina do Exército, pp. 1-16.

Exército Brasileiro. (2016). Escritório de Projetos do Exército Brasileiro. Acesso em 15 de agosto de 2016, disponível em Escritório de Projetos do Exército Brasileiro: http://www.epex.eb.mil.br/index.php/astros-2020

Fleeman, E. (2012). Missile Design and System Engineering. Liuburn, Georgia: AIAA.

Fleeman, E. L. (2006). Tactical Missile Design. Blacksburg, Virginia: American Institute of Aeronautics and Astronautics.

Fleeman, E. L. (2012). Missile Design and System Engineering. Reston, Virginia: American Institute of Aeronautics and Astronautics.

Fleeman, E. L. (2012). Missile Design and System Engineering. Liuburn, Georgia: AIAA.

Frits, A., \& et al. (2002). A Conceptual Sizing Tool for Tactical Missiles. AIAA Missile Sciences Conference.

Gen, M., \& Cheng, R. (1997). Genetic Algorithms and Engineering Optimization. New York: John Wiley \& Sons.

Gordon, S., \& McBride, B. (1994). Computer Program for Calculation of Complex Equilibrium Compositions and Applications. NASA Reference Publication 1311. 
Gormley, D. M. (2008). Missile Contagion - Cruise Missile Proliferation and the Threat to International Security. Annapolis, Maryland: Naval Institute Press.

Hill, P. G., \& Peterson, C. R. (1992). Mechanics and Thermodynamics of Propulsion. Cambridge: Addison Wesley.

Hindes, J. W. (1993). Advanced Design of Aerodynamic Missiles (ADAM).

Hoak, D. E. (1978). USAF Stability and Control DATCOM. St. Louis, Missouri: Global Engineering.

Holdaway, G. H. (1953). Comparison of Theoretical and Experimental Zero-Lift DragRise Characteristics of Wng-Body-Tail Combinations Near the Speed of Sound. Washngton: National Advisory Committee for Aeronautics.

Jerger, J.J. (1960). Systems Preliminary Design. In: J. Jerger, Principles od Guided Missile Design.

Jorgensen, L. H. (1973). Prediction of Static Aerodynamic Characteristics for SpaceShuttle-Like and Other Bodies at Angles of Attack from $0^{\circ}$ to $180^{\circ}$. NASA, Ames Research Center, Moffet Field, California.

Kinroth, G., \& Anderson, W. (1980). Ramjet Design Handbook. CPIA Pub.319 e AFWAL TR 80-2003.

Kopp, C. (27 de janeiro de 2014). Expanding the Envelope - Stealth and Other Strike Roles. Acesso em 2 de novembro de 2015, disponível em Air Power Australia: http://www.ausairpower.net/ASPC-Expand-Mirror.html

Linden, R. (2012). Algoritmos Genéticos - $3^{a}$ Edição. Rio de Janeiro: Ciência Moderna Ltda.

Loader, \& Gums. (2014). AGM-84 Harpoon Anti-Ship Missile. Acesso em 29 de novembro de 2015, disponível em F-16.net: http://www.f-16.net/f16_armament_article12.html

Mindling, G., \& Bolton, R. (2011). U.S. Air Force Tactical Missiles 1949 - 1969 The Pioneers. Morrisville, North Carolina, United States: Lulu.

Missile Technology Control Regime. (2015). The Missile Technology Control Regime. Acesso em 14 de dezembro de 2015, disponível em Missile Technology Control Regime: http://www.mtcr.info/english/index.html

Moore, F., \& Moore, L. (2009). The 2009 Version of the Aerprediction Code. AIAA Aerospace Sciences Meeting. AIAA 2009-309. 
Mühlembein, H., Schomisch, D., \& Born, J. (1991). The Parallel Genetic Algorithm as Function Optmizer. Parallel Computing, pp. 619 - 632.

NEAR Inc. (2016). NIelsen Engineering \& Research, Inc. Acesso em 1 de Junho de 2016, disponível em NEAR Inc: http://nearinc.com/

Nicholas , T., \& Rossi, R. (1999). US Missile Data Book. Data Search Associates.

Nicholls, D. J. (2000). Cruise Missiles and Modern War: Strategic and Technical Implications. Maxwell Air Force Base, AL: Center for Strategy and Technology, Air War College.

North American Rockwell Corporation. (1970). Technical Aerodynamics Manual. DTIC AD 723823.

Phillips, W. F. (2010). Mechanics of Flight. New Delhi: Wiley India Pvt. Ltd.

Pitts, Nielsen, \& Kaatari. (1957). Lift and Center of Pressure of Wing-Body-Tail Combinations at Subsonic, Transonic and Supersonic Speeds. NACA Report 1307.

Rastrigin, L. A. (1974). Systems of External Control. Moscow, Russia: Nauka.

Raymer, D. P. (2004). Aircraft Design: A Conceptual Approach. Washington, D.C.: American Institute of Aeronautics and Astronautics.

Saravanamuttoo, H., Rogers, G., Cohen, H., \& Straznicky, P. (2008). Gas Turbine Theory (Sixth Edition ed.). Pearson Prentice Hall.

Simberg, R. (7 de abril de 2009). How Hard Is It to Fire a Rocket? Acesso em 14 de dezembro de 2015, disponível em The New York Times: http://roomfordebate.blogs.nytimes.com/2009/04/07/how-hard-is-it-to-fire-arocket/?_r=1

Smithsonian National Air and Space Museum. (2015). Teledyne CAE J402-CA-400 Turbojet Engine. Acesso em 29 de novembro de 2015, disponível em Smithsonian National Air and Space Museum: http://airandspace.si.edu/collections/artifact.cfm?object=nasm_A19900069000

Sutton, G. P., \& Biblarz, O. (2010). Rocket Propulsion Elements (Eighth Edition). New Jersy: John Wiley \& Sons.

Tanil, Ç. (2009). Optimal External Configuration Design of Missiles. Ankara, Turquia: Middle East Technical University.

Tawancy, H. M., Ul-Hamid, A., \& Abbas, N. M. (2004). Practical Engineering Failure Analysis. New York: Marcel Dekker. 
Toscani, L., \& Veloso, P. (2009). Complexidade de Algoritmos: análise, projeto e métodos. Porto Alegre: Bookman.

TPUB. (2016). Integrated Publishing. Acesso em 5 de Junho de 2016, disponível em Guided Missile and Rocket Designations: http://navyaviation.tpub.com/14014/css/Typical-Air-To-Surface-Guided-Missile191.htm

Turns, S. R. (2000). An Introduction to Combustion - Concepts and Applications - $2^{a}$ Edition. Singapore: McGraw-Hill.

US Inflation Calculator. (2016). US Inflation Calculator. Acesso em 9 de Junho de 2016, disponível em US Inflation Calculator: http://www.usinflationcalculator.com/

US Navy. (2015). Photo Gallery. Acesso em 2 de novembro de 2015, disponível em Official Website of the United States Navy: http://www.navy.mil/viewGallery.asp

Van Riper, A. B. (2004). Rockets and Missiles: The Life Story of a Technology. Baltmore, Maryland: Johns Hopkins.

Venkataraman, P. (2008). Applied Optimization with MATLAB Programming - Second Edition. Rochester, New York: John Wiley \& Sons.

Von Mises, R. (1944). Theory of Flight. Cambridge, Massachussets: Dover.

Vose, M. D. (2004). The Simple Genetic Algorithm. New Dheli, Índia: Prentice-Hall of India.

Warry, J. (1995). Warfare in the Classical World. Londres: Reino Unido: Salamander Books Ltd.

Wikipédia. (10 de novembro de 2015). Idade do Universo. Acesso em 13 de dezembro de 2015, disponível em Wikipédia A enciclopédia livre: https://pt.wikipedia.org/wiki/Idade_do_universo\#cite_note-5 
ANEXOS 


\section{A - FORMAS DE CLASSIFICAÇÃO DE MÍSSEIS}

Mísseis geralmente são classificados com base nos seguintes parâmetros (BrahMos Aerospace , 2012):

1. Perfil de voo;

2. Modo de lançamento;

3. Alcance;

4. Propulsão;

5. Cabeça de guerra;

6. Sistema de guiamento.

\section{Quanto ao perfil de voo.}

1.1. Míssil de cruzeiro: É um veículo guiado não-tripulado e autopropelido que mantém voo através de sustentação aerodinâmica por grande parte de sua trajetória e cuja principal missão é levar uma carga-paga até um alvo. Mísseis de cruzeiro voam dentro da atmosfera terrestre e geralmente utilizam propulsão a ar-aspirado (existem exceções). Esses mísseis variam grandemente em velocidade e habilidade em penetrar sistemas de defesa. Mísseis de cruzeiro podem ser divididos em categorias com base em tamanho, velocidade (subsônico, supersônico ou hipersônico), alcance e plataforma de lançamento (terra, ar, navio de superfície ou submarino). Os mísseis de cruzeiro subsônicos voam com velocidade abaixo da do som, normalmente abaixo de Mach 0,8. São exemplos desse grupo os mísseis norte-americanos Tomahawk e Harpoon e o míssil francês Exocet. Mísseis de cruzeiro supersônicos voam em velocidades próximas a Mach 2 - 3. A combinação de velocidade supersônica e cabeça de guerra promove alta energia cinética no impacto. O míssil indo-russo BrahMos é um míssil de cruzeiro supersônico em serviço nos dias atuais. Misseis de cruzeiro hipersônicos voam a Mach 5 ou mais. Diversos países têm trabalhado no desenvolvimento dessa tecnologia.

1.2. Míssil balístico: é um míssil que tem trajetória de voo balística ao longo de maior parte de seu percurso. Pode ser caracterizado de acordo com seu alcance, (distância 
máxima medida sobre a superfície da Terra do ponto de lançamento até o ponto de impacto do último elemento de sua cabeça de guerra). Mísseis balísticos podem ter parte de sua trajetória fora da atmosfera terrestre e geralmente utilizam motor foguete.

\section{Quanto ao modo de lançamento.}

2.1. Míssil terra - terra: é um projétil guiado e lançado de uma instalação fixa ou móvel. Frequentemente é propelido por motor foguete.

2.2. Míssil terra - ar: é projetado para ser lançado a partir do solo para destruir alvos aéreos como aviões, helicópteros e até mesmo mísseis balísticos. Estes misseis são genericamente chamados de sistemas de defesa aérea, dado que eles têm a missão de defender qualquer ataque aéreo inimigo.

2.3. Míssil terra - mar: é projetado para ser lançado a partir do solo e tem navios como principal alvo.

2.4. Míssil ar - ar: é lançado de uma aeronave para destruir outra aeronave inimiga.

2.5. Míssil ar - terra: é disparado a partir de aeronaves militares, com o intuito de causar avarias em alvos em terra ou mar. Pode utilizar guiamento a laser, infravermelho, guiamento ótico ou guiamento por sinais de GPS (Global Positioning System). O tipo de guiamento depende do tipo de alvo.

2.6. Míssil mar - mar: lançado de navio com o objetivo de atingir embarcação inimiga;

2.7. Míssil mar - terra: disparado a partir de navios para destruição de alvos em terra;

2.8. Míssil anti-tanque: é um míssil guiado projetado para atingir e destruir veículos blindados. Pode ser lançado de aeronaves, helicópteros, tanques e também de lançadores transportados por um único homem. 


\section{Quanto ao alcance}

3.1. Míssil de curto alcance (até $1000 \mathrm{~km}$ );

3.2. Míssil de médio alcance (1000 - 3500 km);

3.3. Míssil balístico de alcance intermediário (3500 - $5500 \mathrm{~km})$;

3.4. Míssil balístico intercontinental (> $5500 \mathrm{~km})$.

\section{Quanto ao tipo de propulsão}

4.1. Motor foguete a propelente sólido: utiliza propelente sólido. Usualmente o combustível principal é alumínio. Esse tipo de propulsão tem a vantagem de ser facilmente armazenado e poder ser manuseado com combustível pronto para uso. Não permite controlar a intensidade do empuxo, nem desligar o motor após seu acionamento. Permite atingir altas velocidades rapidamente. Sua simplicidade também é uma vantagem quando um grande empuxo é necessário.

4.2. Motor foguete a propelente líquido: esta tecnologia utiliza propelentes armazenados em estado líquido. $\mathrm{O}$ armazenamento de mísseis com combustível líquido é difícil e complexa. Além disso, a preparação dos mísseis antes do disparado pode precisar de tempo considerável. Possui alto impulso específico quando comparado com propulsão sólida, além da capacidade de controlar a intensidade do empuxo, ativar e desativar o motor quando necessário;

4.3. Motor foguete híbrido: tem propelentes armazenados em diferentes estados (por exemplo, sólido e líquido). Combina as vantagens da propulsão sólida e líquida. Essa tecnologia tem evoluído de maneira relativamente rápida nos últimos anos, contornando problemas encontrados em décadas passadas.

4.4. Turbojato/Turbofan: é um motor a ar-aspirado, do tipo turbina a gás. Possui, conectados por um eixo, um compressor e uma turbina. Pode operar em velocidade nula até velocidades supersônicas. Mísseis que utilizam esse tipo de propulsão são exclusivamente mísseis de cruzeiro. Possui alto impulso específico, permitindo ao míssil grandes alcances operacionais. 
4.5. Ramjet: é um tipo de motor a ar-aspirado que, diferentemente de uma turbina a gás, não possui turbina ou compressor. O ramjet realiza a compressão do ar aspirado através da alta velocidade de voo, portanto, esse precisa estar em velocidade supersônica. Assim, o míssil deve estar voando em velocidade também supersônica. Motores ramjet precisam ser acelerados a partir do repouso até voo supersônico por outros meios. São utilizados quase que exclusivamente em mísseis de cruzeiro. Devido à sua grande velocidade, reduz grandemente o tempo de reação do alvo.

\section{Quanto à cabeça de guerra}

5.1. Convencional: uma cabeça de guerra convencional com explosivos de alta energia (grande velocidade de explosão). É composto por explosivos químicos e depende da detonação do explosivo e fragmentação do involucro metálico como mecanismo de destruição.

5.2. Estratégica: em uma cabeça de guerra estratégica (nuclear), materiais radioativos estão presentes e, quando acionados, iniciam intensas atividades nucleares com imensa liberação de energia, que podem devastar cidades inteiras. São usualmente projetadas para destruição em massa.

\section{Quanto ao sistema de guiamento}

6.1. Guiamento por cabo (fio): este sistema é similar ao comando via rádio, mas é menos suscetível a contramedidas. Os sinais de comando são transmitidos por um ou mais cabos que fazem conexão entre plataforma de lançamento e míssil, durante todo o voo.

6.2. Guiamento por comando: envolve o rastreamento do projétil a partir da plataforma de lançamento e transmissão de comandos por radiofrequência, radar, pulsos de luz laser. O rastreamento pode ser realizado por radar ou instrumentos óticos pela plataforma de lançamento ou imagem de televisão emitida pelo míssil. 
6.3. Guiamento por comparação de terreno: é uma tecnologia invariavelmente utilizada por mísseis de cruzeiro. O sistema utiliza altímetros para medir o perfil do solo diretamente abaixo do míssil e comparar o resultado com informações armazenadas em seu sistema de guiamento, alterando a rota se necessário.

6.4. Guiamento terrestre: esse sistema monitora constantemente a posição de estrelas e compara com posições pré-programadas esperadas para a trajetória do míssil. O sistema de guiamento direciona o sistema de controle quando preciso.

6.5. Guiamento inercial: é um sistema totalmente contido no míssil e é programado antes do lançamento. Três acelerômetros, montados em uma plataforma estabilizada por giroscópios, medem aceleração ao longo de três eixos mutuamente perpendiculares; esses componentes de acelerações são integradas duas vezes, a primeira integração fornece a velocidade e a segunda, a posição. O sistema então direciona o sistema de controle para preservar a trajetória pré-programada. Este sistema é utilizado em mísseis terra - terra e mísseis de cruzeiro.

6.6. Guiamento beam rider: o conceito desse sistema recai sobre uma estação de radar, baseada em solo ou mar, que transmite um feixe de energia eletromagnética (radar) na direção do alvo. O radar de superfície faz a busca do alvo e também transmite um feixe de guiamento que ajusta seu direcionamento na medida em que o alvo se movimenta.

6.7. Guiamento a laser: um feixe de luz laser é focado no alvo e é refletido pelo mesmo. O míssil deve possuir um sensor que detecta radiação. O sistema de busca do míssil fornece a direção do alvo ao sistema de guiamento. O míssil é lançado em direção ao alvo, o buscador procura por reflexão de luz laser e o sistema de guiamento orienta o voo do míssil na direção da fonte de reflexão de laser (alvo).

6.8. Guiamento por GPS: o míssil utiliza sinais de GPS para determinar sua localização e a do alvo. Ao longo do voo, estas informações são utilizadas para enviar comandos para as superfícies de controle e ajustar sua trajetória. 


\section{B - CONTROLE E PROLIFERAÇÃO DE MÍSSEIS}

A proliferação de mísseis no mundo teve início ainda na Guerra Fria. As duas superpotências de então disponibilizaram mísseis de curto e médio alcance a seus aliados europeus e ambos forneceram mísseis a países tecnologicamente menos desenvolvidos. Países como França e Alemanha também contribuíram para essa proliferação, fornecendo mísseis completos, componentes e componentes de "uso dual" que poderiam ser utilizados paras fins civis ou adaptados para uso militar.

Ao longo do tempo, a proliferação de mísseis expandiu. A China, um dos primeiros países a absorver tecnologia dos mísseis soviéticos, desenvolveu seus próprios mísseis balísticos ao copiar projetos soviéticos. Ela subsequentemente se transformou em um grande fornecedor, vendendo seus mísseis derivados dos soviéticos a países em desenvolvimento. Vários países seguiram o exemplo chinês, notavelmente Coréia do Norte, Paquistão, Irã e Iraque. Esses países começaram adquirindo mísseis de outros países e copiando, modificando e produzindo seus próprios mísseis. Outros países como Israel, Índia e Argentina desenvolveram mísseis para uso próprio. Israel desenvolveu o míssil Jericho, a Índia o Agni e a Argentina o míssil Condor. O resultado final foi um comércio global de mísseis que havia contornado os Estados Unidos, União Soviética e outros países industrializados de liderança política. Os mísseis disparados na guerra entre Irã e Iraque (1980-1988), por exemplo, foram construídos no Iraque, Irã, China, Coréia do Norte e Líbia (Van Riper, 2004).

Diversos países em desenvolvimento que construíram, venderam ou buscavam adquirir mísseis passavam por momentos de instabilidade política. Outros eram regidos por governos militares com históricos de agressão contra nações vizinhas e seus próprios cidadãos. Muitos dos mais ativos estados fabricantes e compradores de mísseis possuíam ou tentavam adquirir armas de destruição em massa. A perspectiva de governos autoritários em países politicamente instáveis armados com mísseis que pudessem transportar armas químicas, biológicas ou nucleares, deixaram alarmados líderes dos Estados Unidos, da União Soviética e boa parte da Europa. Nesse contexto surgiu, ao final da década de 1980, o Regime de Controle de Tecnologia de Mísseis, cuja sigla em língua inglesa é MTCR (Missile Technology Control Regime). 
As diretrizes com as quais os países membros do MTCR concordam em aderir declaram que eles limitarão estritamente suas exportações de mísseis completos, subsistemas de mísseis (cabeça-de-guerra, sistemas de guiamento e controle, motor foguete ou a ar aspirado, etc), projetos de mísseis e equipamentos para fabricação de mísseis. As diretrizes também estabelecem uma segunda categoria de materiais e equipamentos que, embora tenham uso pacífico legítimo, poderiam ser adaptados para uso em mísseis. Membros do MTCR têm maior liberdade para exportar itens da segunda categoria, mas devem avaliar com critério o parceiro comercial (Missile Technology Control Regime, 2015).

O termo "míssil" é definido vagamente nas diretrizes do MTCR. Ele inclui mísseis balísticos, mísseis de cruzeiro, foguetes de sondagem, veículos lançadores de satélites, aeronaves remotamente controladas - qualquer veículo aéreo não tripulado capaz de exceder os limites de $300 \mathrm{~km}$ de alcance e $500 \mathrm{~kg}$ de carga paga. Grande parte dos veículos lançadores de satélites se enquadra neste cenário. As diretrizes permitem explicitamente a transferência de tecnologia desenvolvida para apoiar programas espaciais nacionais, mas reconhece existir uma linha pouco definida que distingue veículos lançadores de satélites e mísseis balísticos. Membros do MTCR que exportam tecnologia de lançamento espacial exigem, portanto, a obtenção e monitoramento de garantias do importador que a tecnologia será usada apenas para propósitos pacíficos.

O MTCR foi e ainda é uma barreira significativa à proliferação de armas de destruição em massa e mísseis capazes de transportá-las. A Rússia encerrou suas vendas de sistemas de mísseis balísticos a outros países (como fez a União Soviética por toda a Guerra Fria), e países tecnologicamente avançados como França e Alemanha não mais exportam sistemas de guiamento de mísseis e outras tecnologias críticas (como fizeram empresas alemãs ao Iraque no fim da década de 1980 e início dos anos 90). Pelo menos dois países membros (Argentina e África do Sul) oficialmente abandonaram programas de mísseis balísticos.

Apesar dessas importantes conquistas, o MTCR tem grandes limitações. Uma que se destaca é que poucos países em desenvolvimento, que estão fortemente relacionados com a proliferação de mísseis, são membros do MTCR (Van Riper, 2004). 


\section{C - CÁlCULO DE MOMENTO FLETOR NO CORPO DO MÍSSIL}

De modo a facilitar a determinação de momento fletor ao longo do corpo do míssil, utilizase a analogia de uma viga simples. Nesta técnica, o corpo do míssil é representado por uma viga apoiada sobre os pontos de sustentação positiva, conforme mostrado na Figura G.1. A distribuição de cargas externas é aplicada à viga. Por conveniência, as cargas aerodinâmicas da asa e cauda (carregamento distribuídos) são substituídas por cargas concentradas em seus respectivos centros de pressão. Assume-se que o míssil está em condição de voo trimado. Assim, o somatório de momentos em relação ao centro de massa da viga devido às cargas externas atuantes sobre o míssil é nulo. Uma vez que não existe momento externo desbalanceado, o míssil não sofre aceleração angular. Logo a força resultante age sobre o centro de massa do míssil contra a aceleração da gravidade. Considera-se também que o peso interno do corpo tem a forma de um carregamento distribuído uniforme.

Com o conhecimento dos carregamentos interno e externos, o míssil é colocado em equilíbrio dinâmico ao opor a força externa vertical ascendente com a força de inércia vertical descendente. Esse procedimento, no âmbito deste trabalho, considera o peso do míssil com máximo fator de carga em voo e com a massa do míssil no início do cruzeiro. Um diagrama de esforços cisalhantes é então construído ao se somar as cargas externas e de inércia sobre o míssil. Por fim, o diagrama de momentos é feito ao considerar o somatório das forças cisalhantes sobre o centro de massa do míssil. Matematicamente, o cisalhamento e o momento podem ser expressos como:

$$
s=\int w d x \quad \text { e } \quad M_{b}=\int S d x=\iint w d x d x
$$

Onde

$s=$ força cisalhante;

$M_{b}=$ momento fletor;

$w=$ carregamento sobre a viga;

$x=$ um ponto qualquer ao longo da viga; 


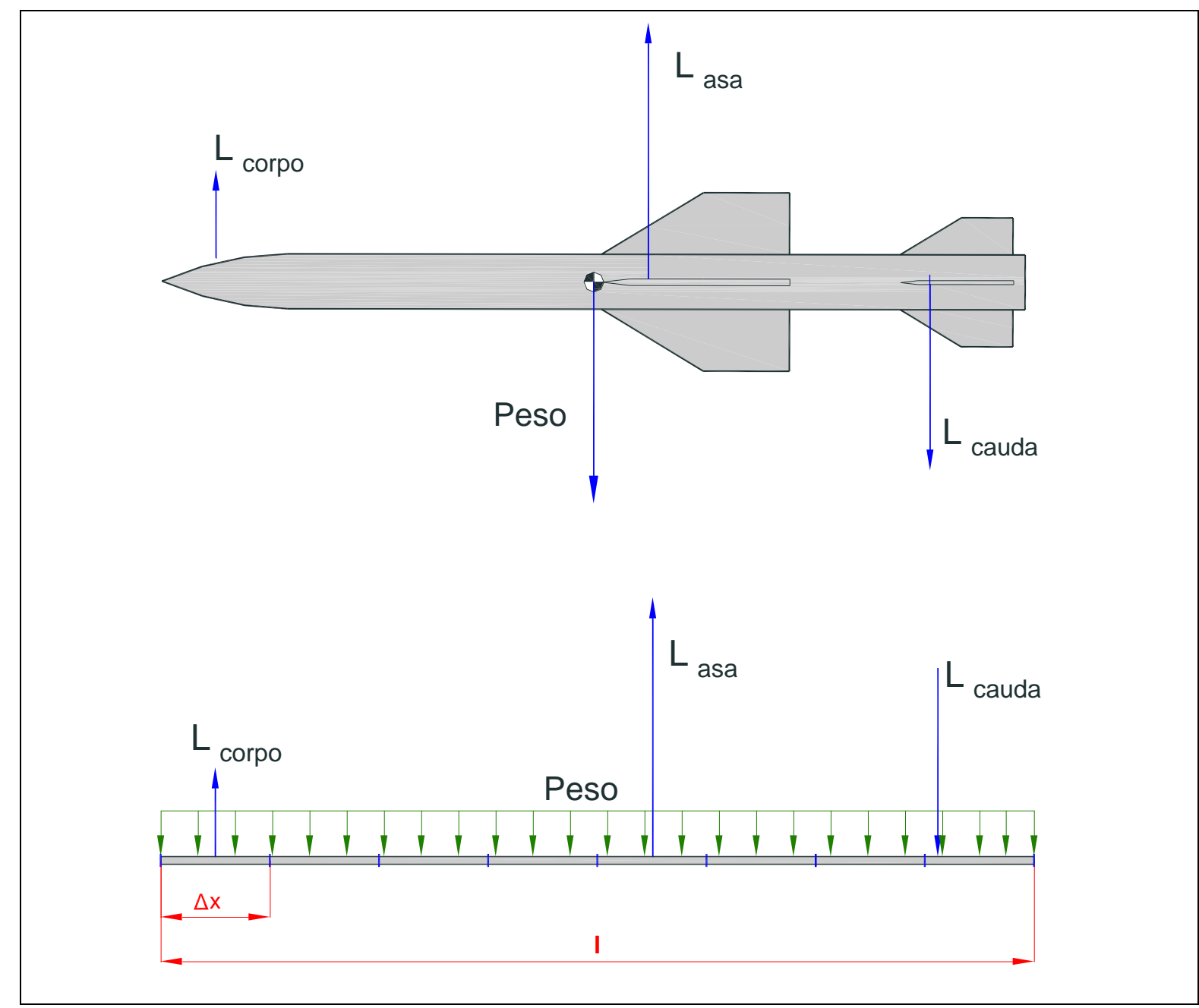

Figura C.1 - Representação dos esforços atuantes sobre o míssil. Analogia de uma viga simples.

Determinada a distribuição de momentos fletores ao longo da via (corpo do míssil), utilizase o valor de máximo módulo para o dimensionamento da espessura da estrutura do corpo para suportar o esforço de flexão, conforme descrito na Seção2.4.4.5 - que trata de dimensionamento estrutural.

Como uma solução aproximada das integrais acima, neste trabalho são aplicados elementos discretos ao invés de infinitesimais, permitindo que seja obtida uma solução numérica para o caso, conforme a Figura G.2: 


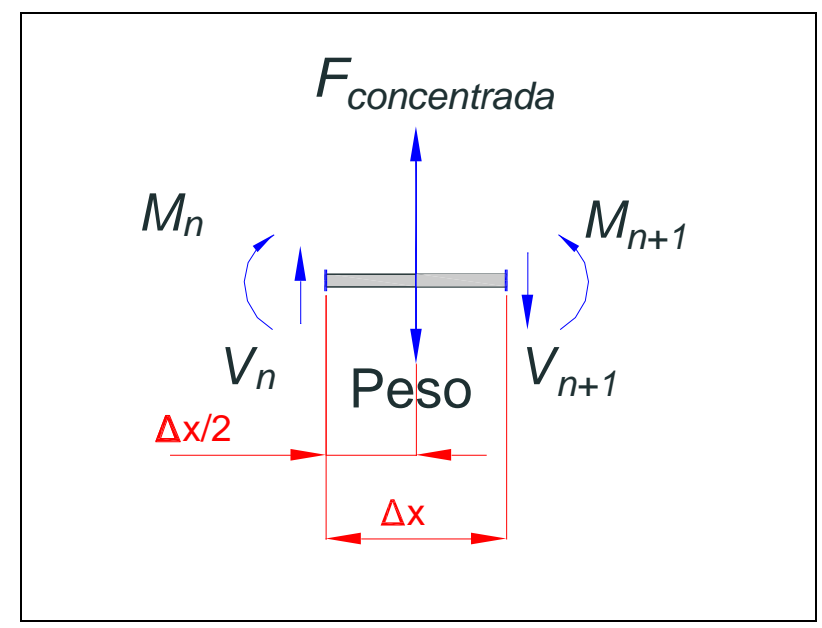

Figura C.2 - Esforços atuantes sobre elemento discreto.

Para determinar a condição de equilíbrio em um elemento infinitesimal, deve-se considerar que os somatórios de forças verticais e de momentos atuantes sobre o elemento sejam nulos. Assim, considerando o elemento mais à esquerda da viga e aplicando as equações de equilíbrio, é possível escrever as equações abaixo:

$$
\sum F_{y}=0
$$

$$
(1) V_{0}+(-1) V_{1}-\operatorname{Peso}\left(\frac{\Delta x}{l}\right)+F_{c n}=0
$$

e

$$
\begin{aligned}
\sum M_{0}= & 0 ; \\
& (-1) M_{0}+(1) M_{1}+\left\{-\left[\operatorname{Peso}\left(\frac{\Delta x}{l}\right)\left(\frac{\Delta x}{2}\right)\right]+\left[F_{c n}\left(\frac{\Delta x}{2}\right)\right]-\left(V_{1} \Delta x\right)\right\}=0,
\end{aligned}
$$

Onde:

Peso $=$ peso do míssil (considerando a massa de início de cruzeiro e o máximo fator de carga em voo);

$F_{c n}$ = força concentrada atuante sobre o elemento (força aerodinâmica sobre o corpo, canard, asa ou cauda). Considera a aplicação da força normal no centro aerodinâmico do corpo, canard, asa e cauda;

$\Delta x=$ comprimento do elemento infinitesimal;

$l=$ comprimento do corpo do míssil;

$M=$ momento fletor em um dado nó; 
$V=$ momento cortante em um dado nó.

Considerando os sistemas de equações resultantes da aplicação das equações de equilíbrio em todos os elementos infinitesimais do corpo, é possível escrever esses sistemas de equações na forma vetorial abaixo:

$$
A X=B
$$

$\mathrm{E}$

$$
C Y=D
$$

Onde:

$A=$ matriz de coeficientes do sistema de equações de forças verticais;

$B=$ vetor composto por forças de campo (peso) e forças concentradas;

$X=$ vetor composto por esforços cortantes nos nós;

$C=$ matriz de coeficientes do sistema de equações de momentos;

$D=$ vetor composto por momentos gerados pelas forças de campo (peso) e forças concentradas;

$Y=$ vetor composto por momentos fletores nos nós;

Os entes vetoriais acima têm a forma geral conforme se segue.

A matriz de coeficientes do sistema de equações de forças verticais $A$ é uma matriz quadrada (dimensões $n \times n$ ), com os elementos iguais a zero com as seguintes exceções:

$$
\begin{gathered}
A_{i i}=-1, \\
A_{i(i-1)}=1 .
\end{gathered}
$$

Assim, considerando um caso em que a matriz $A$ seja de dimensões $6 \times 6$, ela teria a forma mostrada abaixo

$$
A=\left(\begin{array}{rrrrrr}
-1 & 0 & 0 & 0 & 0 & 0 \\
1 & -1 & 0 & 0 & 0 & 0 \\
0 & 1 & -1 & 0 & 0 & 0 \\
0 & 0 & 1 & -1 & 0 & 0 \\
0 & 0 & 0 & 1 & -1 & 0 \\
0 & 0 & 0 & 0 & 1 & -1
\end{array}\right)
$$


O vetor $B$, composto por forças de campo (peso) e forças concentradas, é um vetor coluna (dimensões $n \times 1$ ), com os elementos iguais a Peso $\left(\frac{\Delta x}{l}\right)$ com as seguintes exceções:

$$
B_{n_{k} 1}=\operatorname{Peso}\left(\frac{\Delta x}{l}\right)-F_{c n} .
$$

Onde $n_{k}$ se refere à posição no vetor (nó) onde é aplicada a força concentrada resultante das forças aerodinâmicas resultantes no corpo, canard, corpo e cauda $\left(F_{c n}\right)$.

Assim, considerando um caso em que o vetor $B$ seja de dimensões $6 \times 1$, ele teria a forma mostrada abaixo. Ressalta-se que o sentido e a posição da força aerodinâmica no vetor deve ser considerado sobre o elemento pertinente, sendo que a forma (dimensão do vetor e sentido das forças aerodinâmicas) mostrada abaixo tem caráter meramente ilustrativo. No vetor abaixo todas as forças aerodinâmicas mostradas têm sentido positivo (ascendente).

$$
B=\left(\begin{array}{c}
\operatorname{Peso}\left(\frac{\Delta x}{l}\right)-F_{\text {corpo }} \\
\operatorname{Peso}\left(\frac{\Delta x}{l}\right) \\
\operatorname{Peso}\left(\frac{\Delta x}{l}\right) \\
\operatorname{Peso}\left(\frac{\Delta x}{l}\right)-F_{\text {asa }} \\
\operatorname{Peso}\left(\frac{\Delta x}{l}\right) \\
\operatorname{Peso}\left(\frac{\Delta x}{l}\right)-F_{\text {cauda }}
\end{array}\right) .
$$

O vetor $X$ composto por esforços cortantes nos nós é um vetor coluna (dimensões $n \times 1$ ). Assim, considerando um caso em que o vetor $X$ seja de dimensões $6 \times 1$ :

$$
X=\left(\begin{array}{l}
V_{1} \\
V_{2} \\
V_{3} \\
V_{4} \\
V_{5} \\
V_{6}
\end{array}\right)
$$

A partir da determinação do esforço cortante em cada nó, é possível determinar a distribuição de momento fletor ao longo do corpo do míssil. 
A matriz de coeficientes do sistema de equações de momentos fletores $C$ é uma matriz quadrada (dimensões $n \times n$ ), com os elementos iguais a zero com as seguintes exceções:

$$
\begin{gathered}
C_{i i}=1, \\
C_{i(i-1)}=-1 .
\end{gathered}
$$

Assim, considerando um caso em que a matriz $C$ seja de dimensões $6 \times 6$, ela teria a forma mostrada abaixo:

$$
C=\left(\begin{array}{cccccc}
1 & 0 & 0 & 0 & 0 & 0 \\
-1 & 1 & 0 & 0 & 0 & 0 \\
0 & -1 & 1 & 0 & 0 & 0 \\
0 & 0 & -1 & 1 & 0 & 0 \\
0 & 0 & 0 & -1 & 1 & 0 \\
0 & 0 & 0 & 0 & -1 & 1
\end{array}\right)
$$

O vetor $D$, composto pelos momentos das forças de campo (peso) e forças concentradas, é um vetor coluna (dimensões $n \times 1$ ). Assim, considerando um caso em que o vetor $D$ seja de dimensões $6 \times 1$, ele teria a forma mostrada abaixo. Ressalta-se que o sentido e a posição da força aerodinâmica no vetor devem ser considerados sobre o elemento pertinente, sendo que a forma mostrada abaixo tem caráter meramente ilustrativo. No vetor abaixo todas as forças aerodinâmicas mostradas têm sentido positivo (ascendente).

$$
D=\left(\begin{array}{c}
\left\{-\left[\operatorname{Peso}\left(\frac{\Delta x}{l}\right)\left(\frac{\Delta x}{2}\right)\right]+\left[F_{\text {corpo }}\left(\frac{\Delta x}{2}\right)\right]-\left(V_{1} \Delta x\right)\right\} \\
\left\{-\left[\operatorname{Peso}\left(\frac{\Delta x}{l}\right)\left(\frac{\Delta x}{2}\right)\right]-\left(V_{2} \Delta x\right)\right\} \\
\left\{-\left[\operatorname{Peso}\left(\frac{\Delta x}{l}\right)\left(\frac{\Delta x}{2}\right)\right]-\left(V_{3} \Delta x\right)\right\} \\
\left\{-\left[\operatorname{Peso}\left(\frac{\Delta x}{l}\right)\left(\frac{\Delta x}{2}\right)\right]+\left[F_{\text {asa }}\left(\frac{\Delta x}{2}\right)\right]-\left(V_{4} \Delta x\right)\right\} \\
\left\{-\left[\operatorname{Peso}\left(\frac{\Delta x}{l}\right)\left(\frac{\Delta x}{2}\right)\right]-\left(V_{5} \Delta x\right)\right\} \\
\left\{-\left[\operatorname{Peso}\left(\frac{\Delta x}{l}\right)\left(\frac{\Delta x}{2}\right)\right]+\left[F_{\text {cauda }}\left(\frac{\Delta x}{2}\right)\right]-\left(V_{6} \Delta x\right)\right\}
\end{array}\right) .
$$

$\mathrm{O}$ vetor $Y$, composto por esforços cortantes nos nós, é um vetor coluna (dimensões $n \times 1$ ). Assim, considerando um caso em que o vetor $Y$ seja de dimensões $6 \times 1$ : 


$$
Y=\left(\begin{array}{l}
M_{1} \\
M_{2} \\
M_{3} \\
M_{4} \\
M_{5} \\
M_{6}
\end{array}\right)
$$

A resolução dos sistemas lineares dados por

$$
A X=B
$$

$\mathrm{e}$

$$
C Y=D
$$

é feita através de

$$
X=B A^{-1}
$$

$\mathrm{e}$

$$
Y=D C^{-1}
$$

O valor de máximo módulo no vetor de momentos fletores $(Y)$ é utilizado para o dimensionamento da espessura do corpo do míssil.

Nos casos de execução do programa Scorpio 1.0 apresentados neste trabalho, foram utilizados discretização com 200 elementos, pois essa configuração apresentou boa relação entre tempo de processamento e precisão nos resultados indicados, quando comparada com discretizações mais ou menos "refinadas". 


\section{D - PROBLEMAS INTRATÁVEIS}

Um problema é dito intratável se o tempo necessário para resolvê-lo é considerado inaceitável para os requerimentos do usuário da solução (Linden, 2012). Em termos práticos, um problema é tratável se o seu limite superior de complexidade é polinomial, e é intratável se o limite superior de sua complexidade é exponencial (Toscani \& Veloso, 2009), isto é, se seu tempo de execução é da ordem de uma função exponencial (como $2^{n}$, por exemplo) ou fatorial $(n !)$.

Para perceber a dificuldade de lidar com tempo de execução associado a qualquer uma dessas funções, basta analisar os tempos de execução associados a algumas das principais funções, descritos na Tabela D.1.

Tabela D.1 - Quantidade de operações associadas a funções exponenciais.

\begin{tabular}{ccccc}
\hline $\boldsymbol{n}$ & $\boldsymbol{n}^{\mathbf{2}}$ & $\boldsymbol{n}^{\mathbf{3}}$ & $\mathbf{2}^{\boldsymbol{n}}$ & $\boldsymbol{n} !$ \\
\hline $\mathbf{1 0}$ & $10^{2}$ & $10^{3}$ & $\approx 10^{3}$ & $\approx 10^{6}$ \\
$\mathbf{1 0 0}$ & $10^{4}$ & $10^{6}$ & $\approx 10^{30}$ & $\approx 10^{158}$ \\
$\mathbf{1 0 0 0}$ & $10^{6}$ & $10^{9}$ & $\approx 10^{300}$ & $\approx 10^{1500}$ \\
$\mathbf{1 0 0 0 0}$ & $10^{8}$ & $10^{12}$ & $\approx 10^{3000}$ & $\approx 10^{10000}$ \\
\hline
\end{tabular}

Considerando que uma máquina moderna possa realizar cerca de $10^{10}$ operações em um segundo e puder ser determinado que, se tiverem que ser realizadas $10^{30}$ operações (o suficiente para se tentar resolver um problema cujo tempo seja proporcional a $2^{n}$ com $n=100$ elementos ou variáveis), será preciso um tempo da ordem de $10^{20}$ segundos para que as operações sejam concluídas. Isso representa aproximadamente $10^{12}$ anos, um intervalo de tempo com ordem de grandeza cem vezes maior que a idade do universo (considerando que a idade do universo mais aceita pela comunidade científica é estimada em aproximadamente 13,8 $\times 10^{9}$ anos (Wikipédia, 2015)). Ainda que no futuro consiga-se elevar ao quadrado ou ao cubo a velocidade das máquinas modernas, um problema com esse tempo de execução continuaria inaceitavelmente lento. Torna-se evidente que uma busca aleatória não é uma solução razoável para esse problema específico ou algum semelhante a ele (Linden, 2012). 
Nesse contexto o desempenho dos algoritmos genéticos (AG) se destaca. Os algoritmos genéticos são uma técnica de busca extremamente eficiente no seu objetivo de varrer o espaço de soluções e encontrar soluções próximas da solução ótima (ou mesmo a solução ótima), quase sem necessitar interferência humana. O principal problema dos AG é que eles requerem tempo de processamento relativamente elevado (Linden, 2012). Logo, eles são mais adequados em problemas especialmente difíceis (como, por exemplo, o objeto de estudo desse trabalho). 


\section{E - ELEMENTOS DE BIOLOGIA FUNDAMENTAL}

\section{Bases da teoria da evolução}

A teoria da evolução propõe que na natureza todos os indivíduos dentro de um ecossistema competem entre si por recursos limitados, tais como alimento e água. Aqueles dentre os indivíduos (animais, vegetais etc) de uma mesma espécie que não obtêm êxito na busca por estes recursos tendem a ter menor prole, e essa descendência tem reduzida probabilidade de ter suas características propagadas ao longo de sucessivas gerações, processo este que é denominado de seleção natural. Esta teoria foi proposta por Darwin (Darwin, 1859).

A combinação entre as características dos indivíduos que sobrevivem pode produzir um novo individuo mais adaptado às características de seu meio ambiente ao mesclar propriedades desejáveis de cada um dos reprodutores. Este processo implica nos descendentes de indivíduos serem variações de seus pais. Assim, um descendente é ligeiramente diferente de seus pais, podendo esta diferença ser benéfica ou prejudicial. Portanto, é presumível que haverá uma mudança gradual e progressiva nas características da população de indivíduos.

Todavia, essa evolução natural não é um processo dirigido, com o intuito de maximizar alguma característica das espécies. $\mathrm{Na}$ verdade, não existe nenhuma garantia de que os descendentes de pais muito bem adaptados também o sejam. Ocorre que o processo de seleção nesse meio tende a gerar indivíduos cada vez mais adaptados ao meio. É possível afirmar que a evolução é um processo no qual os seres vivos são alterados por um conjunto de modificações que eles sofrem através do tempo, podendo ser explicada por alguns fatores como mutação gênica, recombinação gênica, seleção natural e isolamentos.

\section{Genética básica}

Fundamentalmente, todo indivíduo, seja ele animal, vegetal ou mesmo organismos dito inferiores, como vírus e bactérias, é formado por uma ou mais células, e dentro de cada uma delas, o organismo possui uma cópia completa do conjunto de um ou mais cromossomos que descrevem o organismo, conjunto este denominado genoma. 
Um cromossomo consiste de pares de genes, que são blocos de sequências de DNA, sendo que cada gene é uma região do DNA que tem uma posição específica no cromossomo, chamada de locus, e controla (sozinho ou em conjunto com outros genes) uma ou mais características hereditárias características.

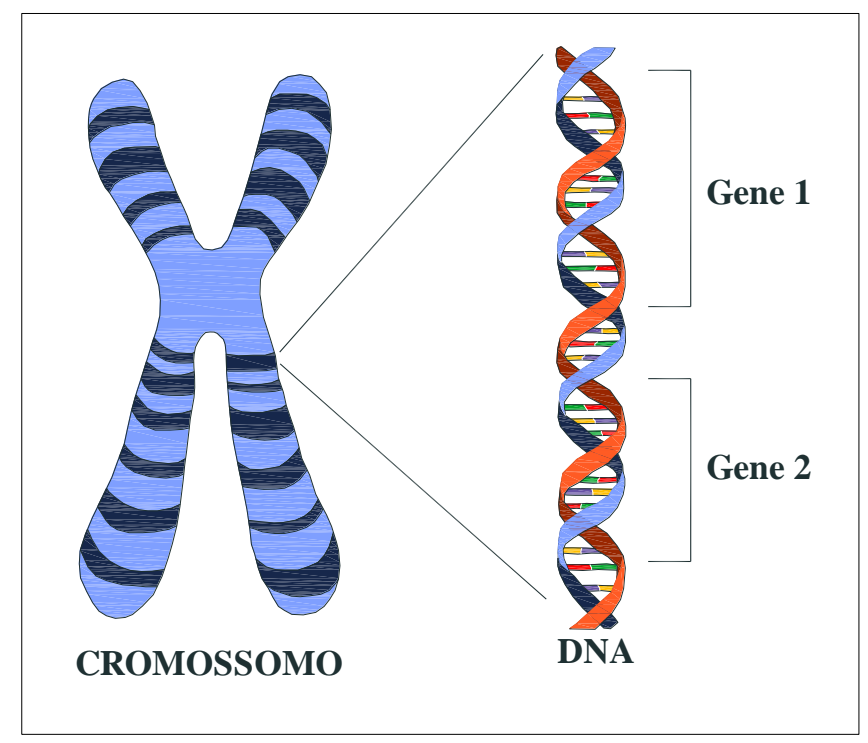

Figura E.0.1 - Diagrama esquemático de um cromossomo.

No processo de reprodução, cada progenitor fornece uma parte de material genético chamado gametas. Estes gametas participam de um processo denominado crossover (recombinação), que permite que os filhos herdem características do ambos os pais, mas não sejam exatamente iguais a estes.

O processo se inicia com a duplicação dos cromossomos. Após serem duplicados, os cromossomos realizam o crossover, processo no qual um pedaço de cada cromossomo é trocado com seu par. Em seguida a este processo, existem quatro cromossomos potencialmente diferentes que são separados para os gametas.

O processo de crossover recebe este nome porque fisicamente um cromossomo se cruza sobre o outro para realizar a operação.

É importante considerar que o processo de replicações do DNA é extremamente complexo. Pequenos erros podem ocorrer ao longo do tempo, gerando mutações dentro do código genético. Além dos erros, essas mutações podem ser causadas por fatores aleatórios tais 
como presença de radiação ambiente, causando pequenas mudanças nos genes dos indivíduos. Estas mutações podem ser benéficas, prejudiciais ou neutras.

É esperado que indivíduos com fenótipo mais adequado ao meio ambiente sobrevivam por mais tempo e reproduzam mais. Ao reproduzirem mais, existe maior probabilidade de que seus genes sejam repassados à próxima geração. Entretanto, por intervenção dos operadores genéticos (recombinação e mutação) os cromossomos dos filhos não são exatamente iguais aos dos pais, mas sim uma combinação de seus genes. Assim, as gerações seguintes podem evoluir e se adaptar cada vez mais ao meio que os cerca. 


\section{F - ATMOSFERA PADRÃO}

\begin{tabular}{|c|c|c|c|c|c|c|}
\hline $\begin{array}{l}\text { Altitude, } \mathbf{H} \\
\quad(\mathrm{m})\end{array}$ & $\begin{array}{l}\text { Temperatura, } \mathbf{T} \\
(\mathbf{K})\end{array}$ & $\begin{array}{l}\text { Pressão, } \mathbf{P} \\
(\mathbf{P a})\end{array}$ & $\begin{array}{c}\text { P/P0 } \\
\text { (adimen.) }\end{array}$ & $\begin{array}{c}\text { Massa específica, } \rho \\
\left(\mathrm{kg} / \mathrm{m}^{3}\right)\end{array}$ & $\begin{array}{c}\rho / \rho 0 \\
\text { (adimen.) }\end{array}$ & $\begin{array}{c}\text { Velocidade do } \\
\text { som, } \\
\text { a (m/s) }\end{array}$ \\
\hline O & 288,15 & 101325 & 1 & 1,225 & 1 & 340,263 \\
\hline 2000 & 275,154 & 79501 & 0,7846 & 1,0066 & 0,8217 & 332,501 \\
\hline 4000 & 262,166 & 61660 & 0,6085 & 0,81935 & 0,6689 & 324,559 \\
\hline 6000 & 249,187 & 47217 & 0,466 & 0,66011 & 0,5389 & 316,423 \\
\hline 8000 & 236,215 & 35651 & 0,3518 & 0,52579 & 0,4292 & 308,077 \\
\hline 10000 & 223,252 & 26500 & 0,2615 & 0,41351 & 0,3376 & 299,504 \\
\hline 12000 & 216,65 & 19399 & 0,1915 & 0,31194 & 0,2546 & 295,042 \\
\hline 14000 & 216,65 & 14170 & 0,1398 & 0,22786 & 0,186 & 295,042 \\
\hline 16000 & 216,65 & 10353 & 0,1022 & 0,16647 & 0,1359 & 295,042 \\
\hline 18000 & 216,65 & 7565 & 0,0747 & 0,12165 & 0,0993 & 295,042 \\
\hline 20000 & 216,65 & 5529 & 0,0546 & 0,08891 & 0,0726 & 295,042 \\
\hline 22000 & 218,574 & 4042 & 0,0399 & 0,06451 & 0,0527 & 296,35 \\
\hline 24000 & 220,56 & 2955 & 0,0292 & 0,046938 & 0,0383 & 297,693 \\
\hline 26000 & 222,544 & 2163 & 0,0213 & 0,034257 & 0,028 & 299,029 \\
\hline 28000 & 224,527 & 1595 & 0,0157 & 0,025076 & 0,0205 & 300,358 \\
\hline 30000 & 226,509 & 1186 & 0,0117 & 0,01841 & 0,015 & 301,681 \\
\hline 32000 & 228,49 & 889 & 0,00877 & 0,013555 & 0,01107 & 303,02 \\
\hline 34000 & 233,744 & 663 & 0,00654 & 0,009887 & 0,00807 & 306,49 \\
\hline 36000 & 239,282 & 498 & 0,00491 & 0,007258 & 0,00592 & 310,1 \\
\hline 38000 & 244,818 & 377 & 0,00372 & 0,005366 & 0,00438 & 313,67 \\
\hline 40000 & 250,35 & 287 & 0,00283 & 0,003995 & 0,00326 & 317,19 \\
\hline 42000 & 255,878 & 220 & 0,00217 & 0,002994 & 0,00244 & 320,67 \\
\hline 44000 & 261,406 & 169 & 0,00167 & 0,002258 & 0,00184 & 324,12 \\
\hline 46000 & 266,925 & 131 & 0,00129 & 0,001714 & 0,00140 & 327,52 \\
\hline 48000 & 270,65 & 102 & 0,00101 & 0,001316 & 0,00107 & 329,8 \\
\hline 50000 & 270,65 & 79 & 0,00078 & 0,001026 & 0,00084 & 329,8 \\
\hline 52000 & 270,65 & 62 & 0,00061 & 0,0008 & 0,00065 & 329,8 \\
\hline 54000 & 267,56 & 48 & 0,00047 & 0,000631 & 0,00052 & 327,91 \\
\hline 56000 & 263,628 & 37 & 0,00037 & 0,0004976 & 0,00041 & 325,49 \\
\hline 58000 & 259,699 & 29 & 0,00029 & 0,00039085 & 0,00032 & 323,06 \\
\hline 60000 & 255,772 & 22 & 0,00022 & 0,0003059 & 0,00025 & 320,61 \\
\hline 62000 & 251,045 & 17 & 0,00017 & 0,0002393 & 0,00020 & 317,63 \\
\hline 64000 & 243,202 & 13 & 0,00013 & 0,0001883 & 0,00015 & 312,63 \\
\hline 66000 & 235,363 & 9,9 & 0,00010 & 0,0001471 & 0,00012 & 307,55 \\
\hline 68000 & 227,529 & 7,4 & 0,00007 & 0,0001139 & 0,00009 & 302,39 \\
\hline 70000 & 219,7 & 5,5 & 0,00005 & 0,0000875 & 0,00007 & 297,14 \\
\hline
\end{tabular}




\section{G - ESTIMATIVA DE CUSTOS DE MÍSSEIS TÁTICOS}

De acordo com Fleeman (2012), como uma aproximação de primeira ordem, o custo de um programa de desenvolvimento de um míssil tático pode ser estimado por sua duração. Um programa de desenvolvimento de baixo risco usualmente requer menos de quatro anos de duração. Um programa de risco moderado é geralmente mais longo, possuindo quatro a seis anos de duração. Um programa de desenvolvimento de alto risco tem usualmente mais que seis anos de duração. Esse autor afirma, com base em dados compilados de Nicholas \& Rossi (1999), que o custo de um programa de desenvolvimento de mísseis táticos pode ser estimado pela Equação $(\mathrm{G} .1)^{70}$. Nesta equação, o a extensão do programa de desenvolvimento ( $\left.t_{\text {desenvolvimento }}\right)$ é expresso em anos.

$$
C_{\text {desenvolvimento }}=\$ 24.500 .000,00 t_{\text {desenvolvimento }}^{2,02} .
$$

Aplicando a correção para a inflação verificada do ano 1999 até 2016 - aproximadamente 43,6\% (US Inflation Calculator, 2016) - a equação acima pode ser atualizada para:

$$
C_{\text {desenvolvimento }}=\$ 35.182 .000,00 t_{\text {desenvolvimento }}^{2,02} .
$$

Fleeman (2012) apresenta também uma estimativa de primeira ordem para o custo de produção de mísseis táticos, como uma função de seu peso de lançamento. Essa estimativa é dada pela Equação (G.3) abaixo.

$$
C_{1000} \approx \$ 13.000,00 W_{L}^{0,596}
$$

A equação acima também é baseada em dados compilados de Nicholas \& Rossi (1999). Nela $C_{1000}$ representa o custo de produção do milésimo míssil ${ }^{71}$. O peso de lançamento do míssil $W_{L}$ é dado em libras. A correlação apresentada pelo autor abrange mísseis com peso variando em duas ordens de magnitude, de $27 \mathrm{lb}$ a $3200 \mathrm{lb}$.

\footnotetext{
${ }^{70}$ Essa equação considera o dólar conforme o ano fiscal de 1999 (Fleeman 2012).

${ }^{71}$ Essa equação considera o dólar conforme o ano fiscal de 2011 (Fleeman 2012).
} 
Aplicando a correção para a inflação verificada do ano 2011 até 2016 - aproximadamente 6,4\% (US Inflation Calculator, 2016) - a Equação (G.3) pode ser atualizada para:

$$
C_{1000} \approx \$ 13.832,00 W_{L}^{0,596} .
$$




\section{H - RELATÓRIO DE EXECUÇÃO DO SCORPIO 1.0: MÍSSIL HARPOON}

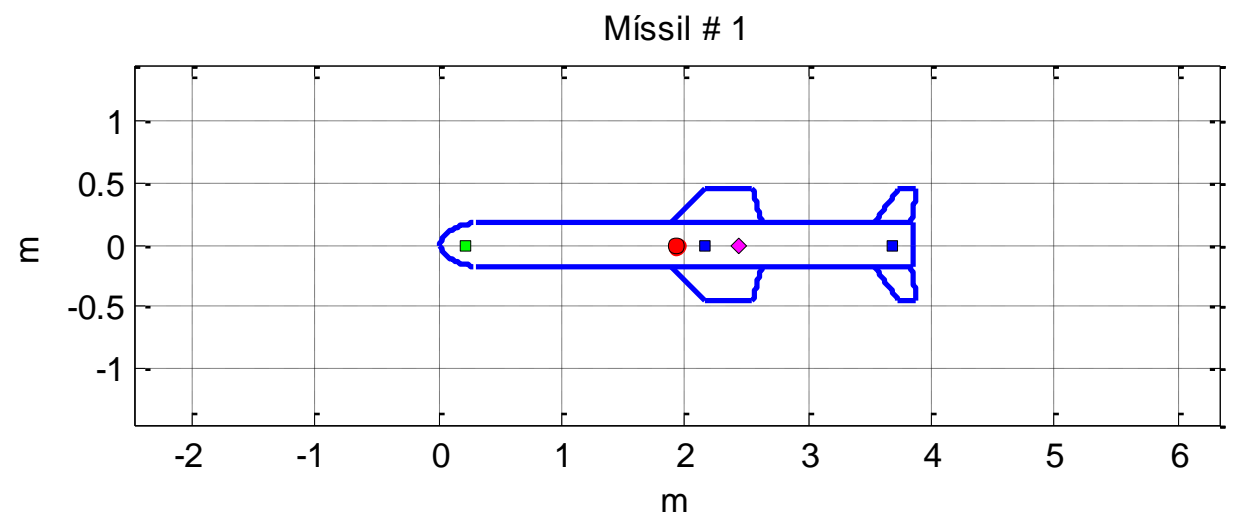

Míssil \# 2

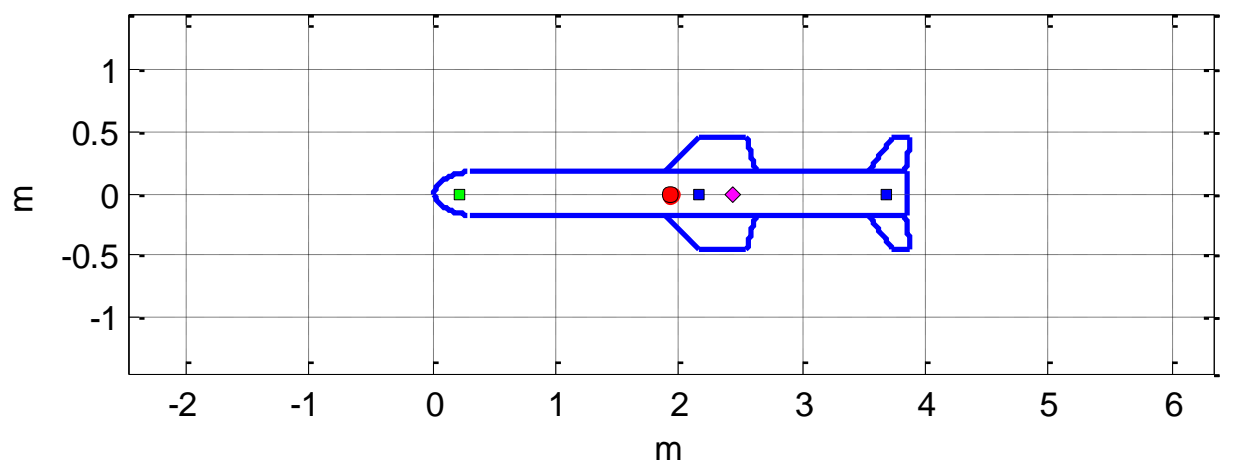

RELATÓRIO DE EXECUÇÃO DO PROGRAMA SCORPIO 1.0

Dados de operação do algoritmo genético

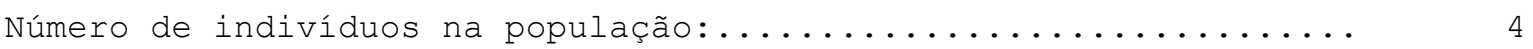

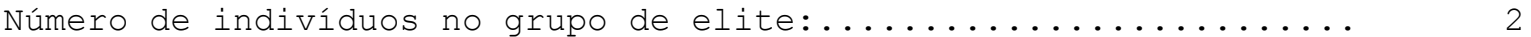

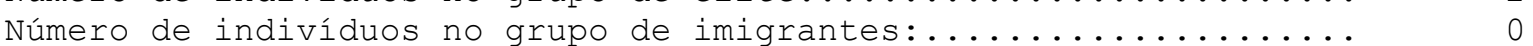

Número de genes no cromossomo (incluindo função de avaliação) : ... 25

Probabilidade de mutação inicial (\%) :.................... 2.00

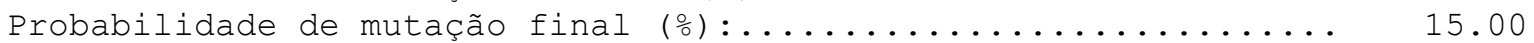

Número máximo de gerações:............................ 4

Avaliação suficiente p/ terminar execução (critério de parada):.. 1.50000

Requisitos de desempenho do míssil

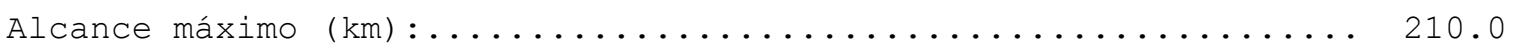

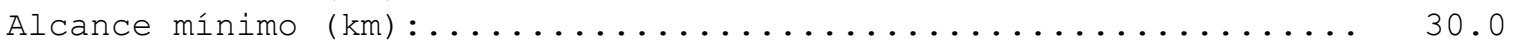

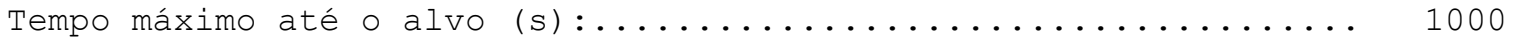

Máxima massa de lançamento $(\mathrm{kg})$ :........................620.00

Estabilidade Estática mínima (adim. - múltiplos do diâmetro):... 1.47

Fator de Carga em manobra mínimo (adim. - múltiplos da gravidade): 1.70 
Variáveis de projeto (genes)

Altitude de voo de cruzeiro

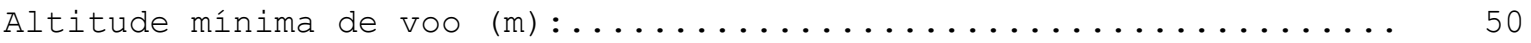

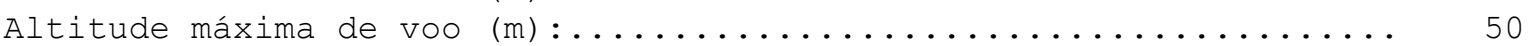

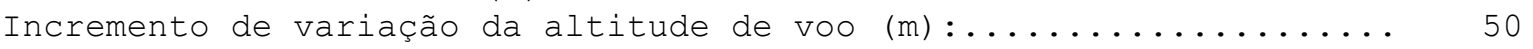

Diâmetro do corpo do míssil

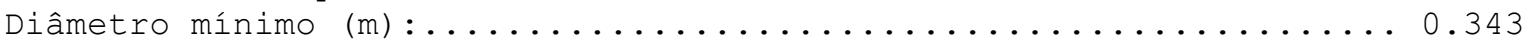

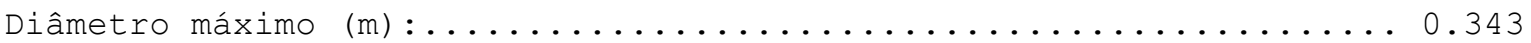

Incremento de variação do diâmetro $(\mathrm{m}): \ldots \ldots \ldots \ldots \ldots \ldots \ldots \ldots . \ldots \ldots 1$

Comprimento do corpo do míssil

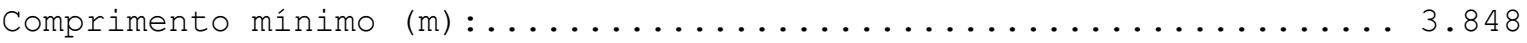

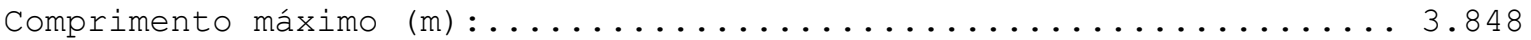

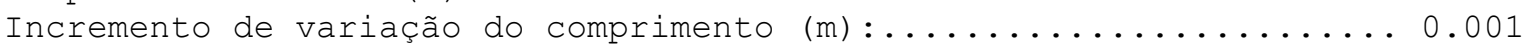

Comprimento do nariz do míssil (múltiplo do diâmetro)

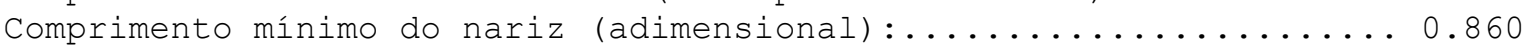

Comprimento máximo do nariz (adimensional) :............... 0.860

Incremento de variação do comprimento do nariz (adimensional) :.... 0.500

Taper ratio da asa

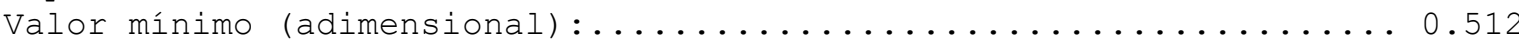

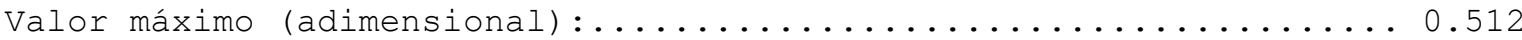

Incremento de variação do taper ratio (adimensional) :..........0.001

Taper ratio da superfície de cauda

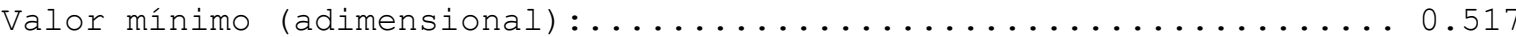

Valor máximo (adimensional) :......................... 0.517

Incremento de variação do taper ratio (adimensional):......... 0.001

Corda aerodinâmica da raiz da asa

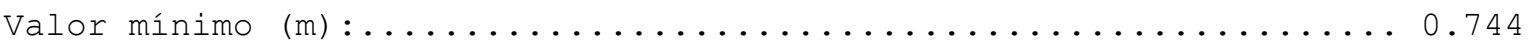

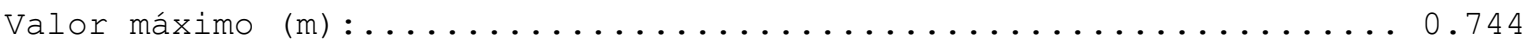

Incremento de variação da corda da raiz da asa (m) ............ 0.001

Corda aerodinâmica da raiz da superfície de cauda

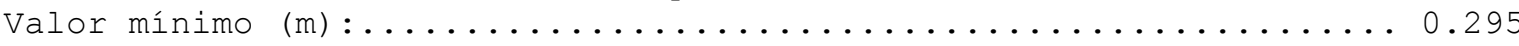

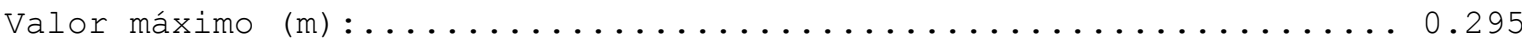

Incremento de variação da corda da raiz da superfície de cauda (m): 0.001

Ângulo de enflechamento da asa

Valor mínimo (graus) :........................... 45.0

Valor máximo (graus) :.......................... 45.0

Incr. de variação do enflechamento da asa (graus) :............ 5.0

Ângulo de enflechamento da superfície de cauda

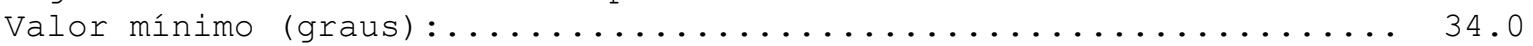

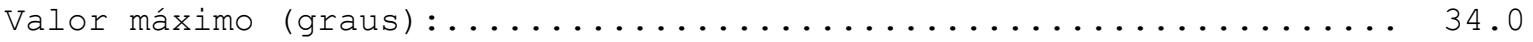

Incr. de variação do enflechamento da superfície de cauda (graus) :. 5.0

Ângulo total de bordo de ataque da seção transversal da asa e cauda

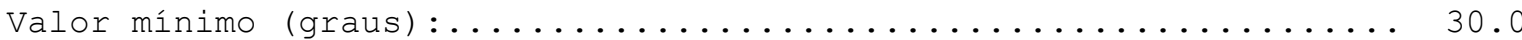

Valor máximo (graus) :............................ 30.0

Incremento de variação do ang. total de bordo de ataque (graus) :... 5.0

Envergadura total da asa (soma dos 2 painéis)

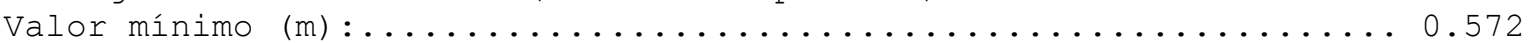

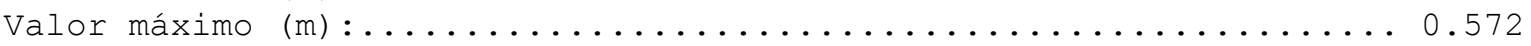


Incremento de variação da envergadura de asa $(m)$............. 0.001

Envergadura total das superfícies de cauda (soma dos 2 painéis)

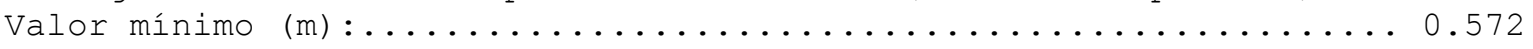

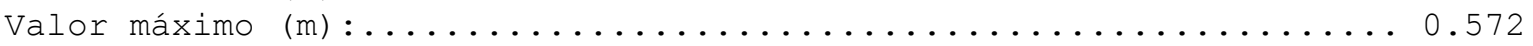

Incremento de variação da envergadura de cauda $(\mathrm{m})$............. 0.001

Número de painéis da asa (Asa simples $=1$; cruciforme = 2; etc)

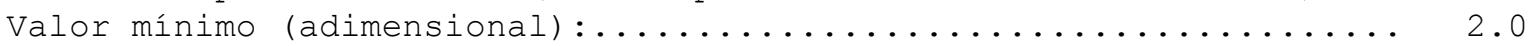

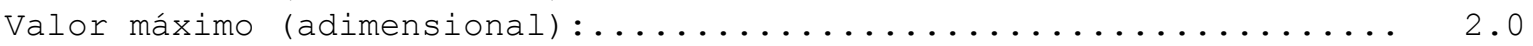

Incremento de variação do número de painéis da asa (adimensional):. 1.0

Número de painéis superf. de cauda (Cauda simples = 1 ; cruciforme = 2; etc)

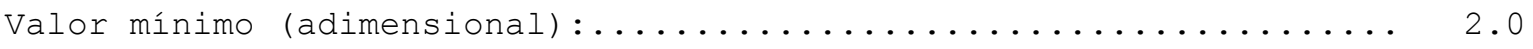

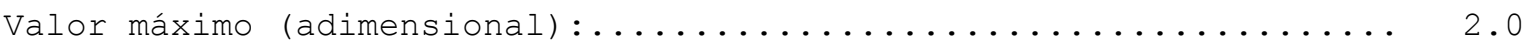

Incremento de variação do número de painéis da cauda (adim.) :..... 0.5

Número de Mach em voo de cruzeiro

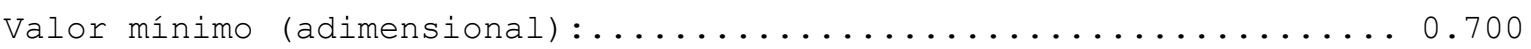

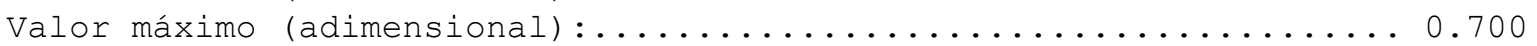

Incr. de variação do número de Mach de cruzeiro (adimensional):... 0.100

Distância do bordo de ataque da raiz da asa até nariz (múlt. do comprimento)

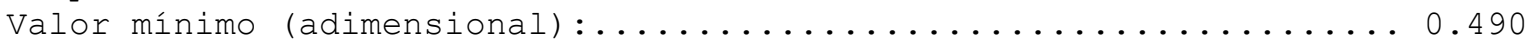

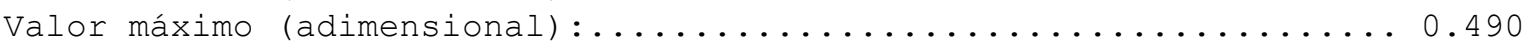

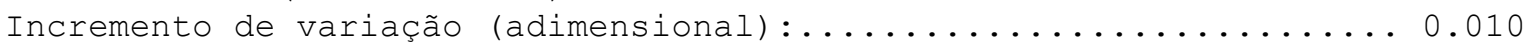

Distância do bordo de ataque da superfície de cauda até nariz (múlt. do comprimento)

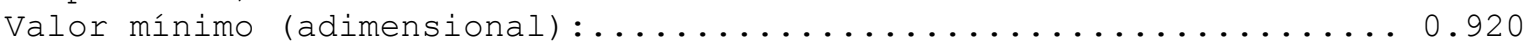

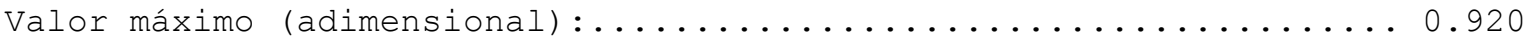

Incremento de variação (adimensional) :................... 0.010

------------------------------------------------------------------------

Temperatura de combustão

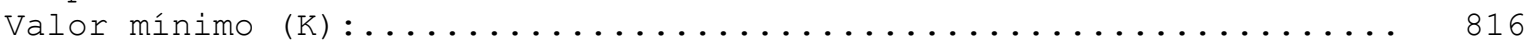

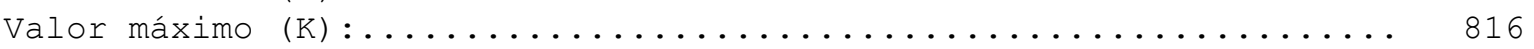

Incremento da temperatura de combustão $(\mathrm{K})$................ 50

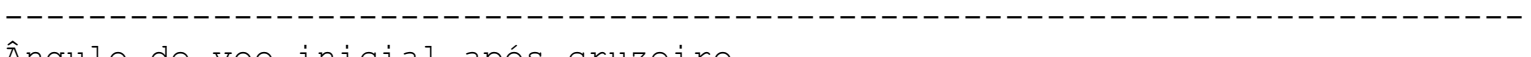

Ângulo de voo inicial após cruzeiro

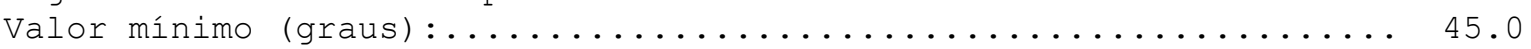

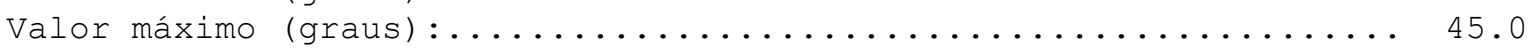

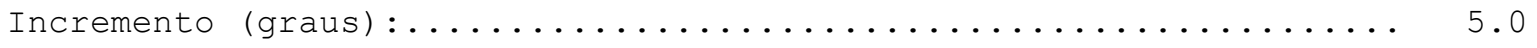

Fração mássica de combustível (massa de comb./massa início do cruzeiro)

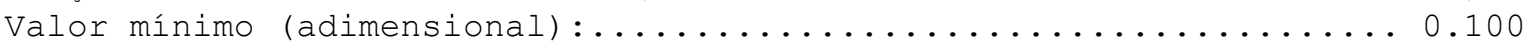

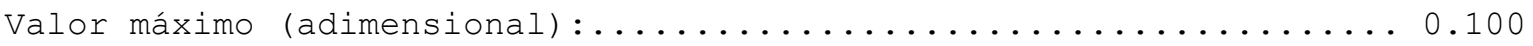

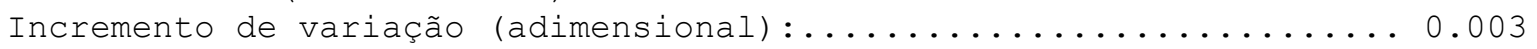

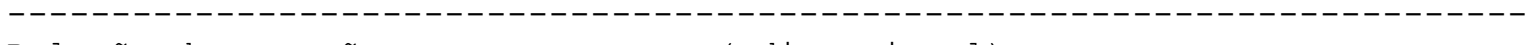

Relação de pressões no compressor (adimensional)

Valor mínimo (adimensional) :........................ 5.40

Valor máximo (adimensional) :........................ 5.40

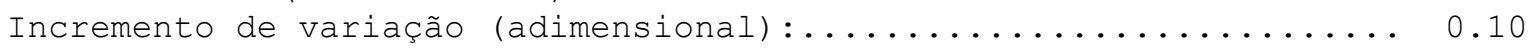


Dados de lançamento e impacto

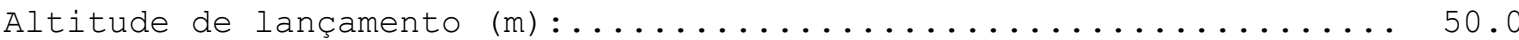

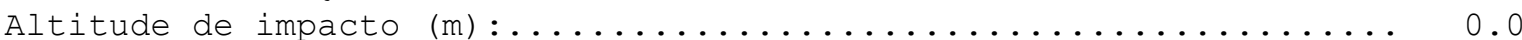

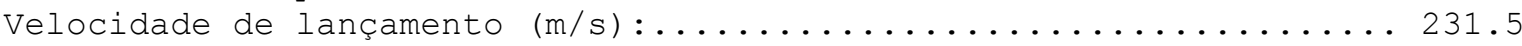

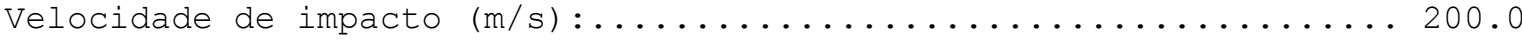

Razão de calores específicos ambiente (adimensional) :.......... 1.40

Dados de massa do míssil

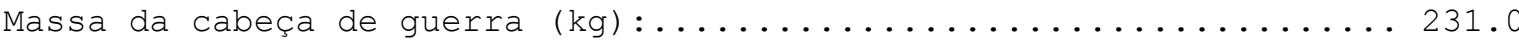

Massa dos sistemas de guiamento, controle e enlace de dados (kg) :.. 42.9

Massa dos atuadores das superfície de controle (kg) :........... 13.6

Massa da fonte de energia (power supply) (kg) :............. 13.6

Dados aerodinâmicos

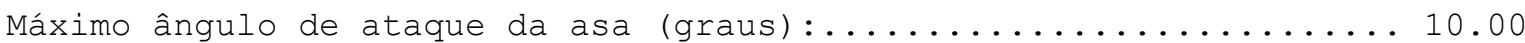

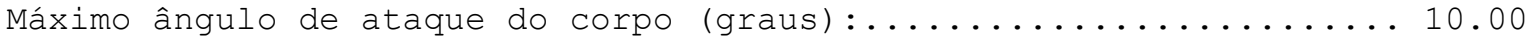

Máximo ângulo de ataque da superfície de cauda (graus) :........ 10.00

Incremento na variação dos ângulos de ataque (graus) :.......... 0.25

Parcela do arrasto de base desprezada em cruzeiro (\%) :......... 25.00

Erro máximo nas equações de equilíbrio em voo ( $\left.\frac{\circ}{0}\right)$............... 3.0

Tipo de controle:................... Superfícies de cauda móveis

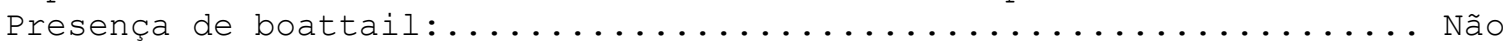

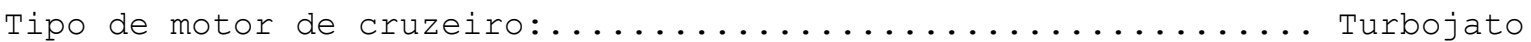

Perfil de voo após cruzeiro (Planeio $=1$; Balístico $=2$ ) $\ldots \ldots \ldots . . .2$

Dados do sistema de propulsão - foguete - Booster e Sustain

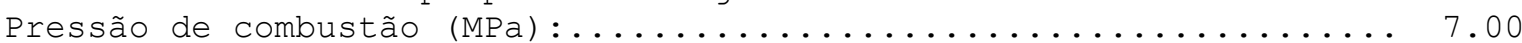

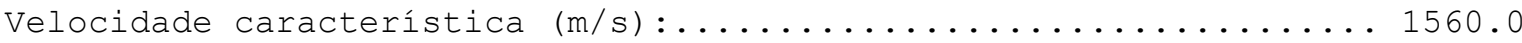

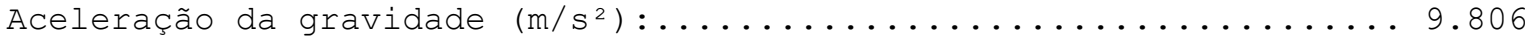

Razão de calores específicos na tubeira (adimensional) :........ 1.180

Fator de aceleração durante boost (múltiplo da acel. gravidade) :.. 0.00

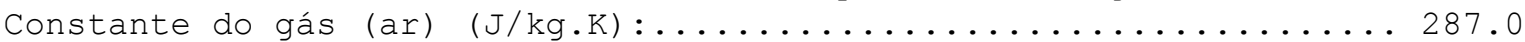

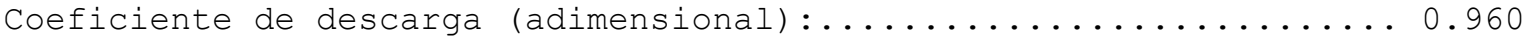

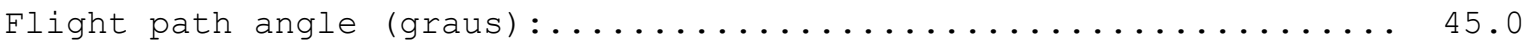

Dados do sistema de propulsão - Motor de cruzeiro - Ramjet

Razão de pressões de estagnação no difusor (adimensional):....... 0.700

Razão de pressões de estagnação no combustor (adimensional) :...... 0.950

Razão de pressões de estagnação no bocal de exaustão (adim.) :..... 0.980

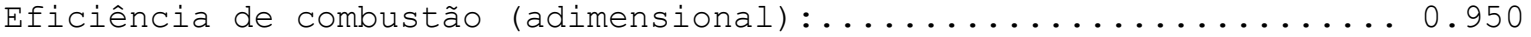

Poder calorífico do combustível (kJ/kg):...............43000.0

Calor espec. a pressão const. do ar (temp. combustão) (KJ/kg.K) :... 1.150

Dados do sistema de propulsão - Motor de cruzeiro - Turbojato

Eficiência isentrópica do difusor de admissão de ar (adimensional): 0.91

Eficiência isentrópica do compressor (adimensional) ........... 0.89

Eficiência isentrópica da turbina (adimensional) .............. 0.90

Eficiência isentrópica do bocal de exaustão (adimensional):...... 0.95

Razão de calores específicos no difusor de entrada (adimensional):. 1.40

Razão de calores específicos no compressor (adimensional) :...... 1.37

Razão de calores específicos na turbina (adimensional) :......... 1.33

Razão de calores específicos no bocal de exaustão (adimensional) :.. 1.33

Relação de pressões no combustor (adimensional) :.............. 0.95 
Estatísticas da execução do programa

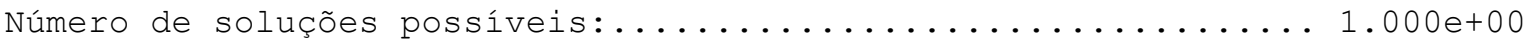
Tempo de processamento necessário para avaliar todas as soluções possíveis, considerando 2 soluções avaliadas por segundo: $1.585 e-08$ anos.

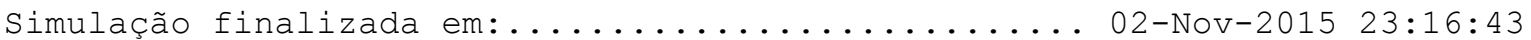

Tempo transcorrido durante execução do programa (s) : ......... 34.8

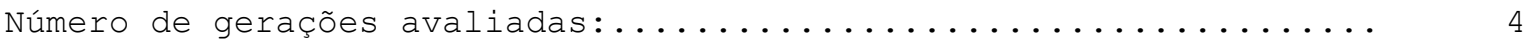

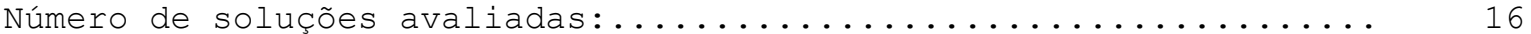

Parcela avaliada do espaço de soluções possíveis (o ) . . . . . . . . . . 1600

Tempo médio consumido para avaliar uma solução (s) : . . ....... 2.177034

Critério de parada: simulação atingiu número máximo de gerações.

Resultados da simulação

Resultados apresentados são referentes aos 2 melhores indivíduos da última geração. 


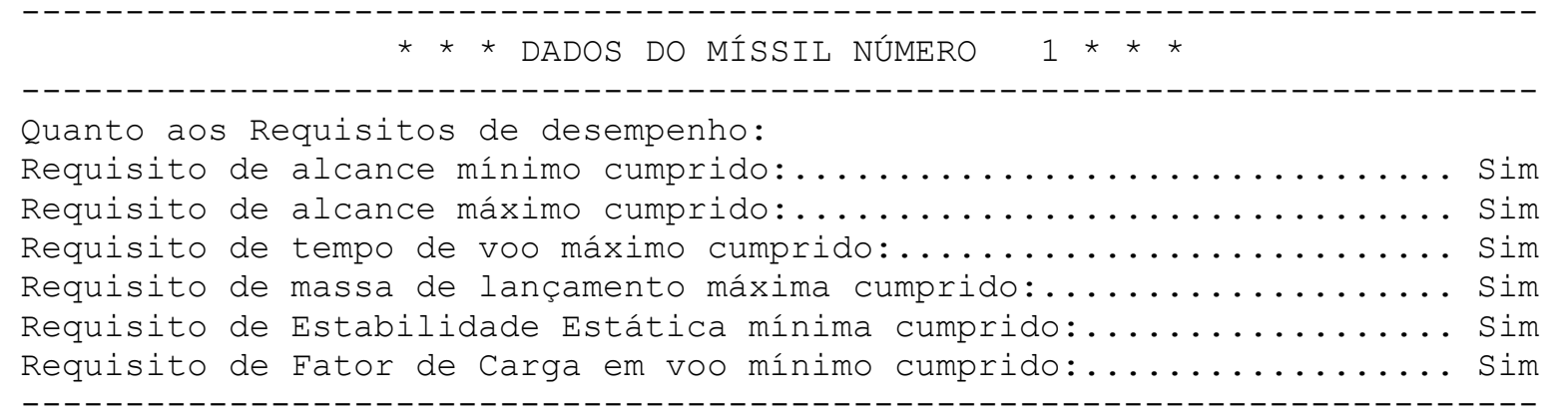

Desempenho do míssil

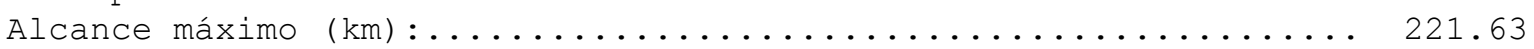

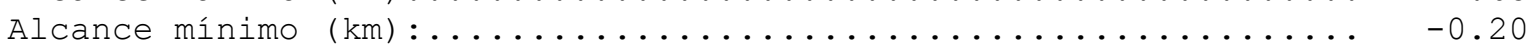

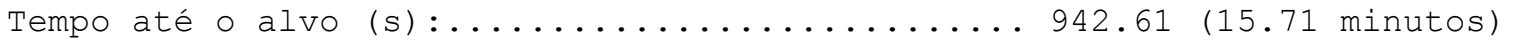

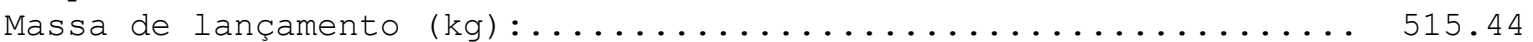

Estabilidade estática (adimensional - múltiplos do diâmetro) :... 1.476

Máximo Fator de Carga em voo (adimensional - múltiplos de g) :... 1.713

Avaliação do indivíduo (adimensional) :................ 1.016609

Dados do Míssil (genes do cromossomo)

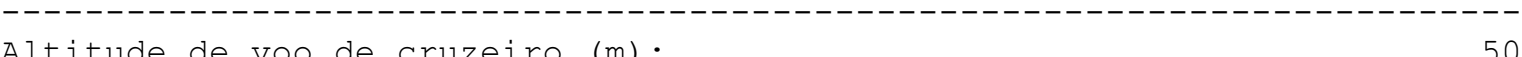

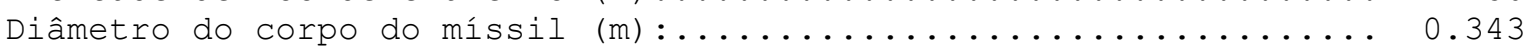

Comprimento do corpo do míssil $(\mathrm{m})$ :................... 3.848

Comprimento do nariz do míssil (múltiplo do diâmetro) : ........ 0.860

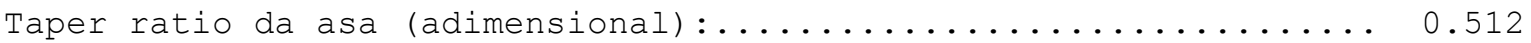

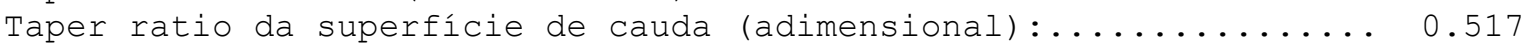

Corda aerodinâmica da raiz da asa $(m)$.................... 0.744

Corda aerodinâmica da raiz da superfície de cauda (m) :........ 0.295

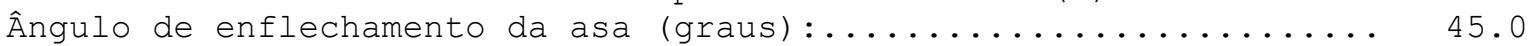

Ângulo de enflechamento da superfície de cauda (graus) :......... 34.0

Âng. tot. bordo de ataque seção transv. da asa e cauda (graus) : .. 30.0

Envergadura total da asa (soma dos 2 painéis) (m) ............ 0.572

Envergadura total das superfícies de cauda (soma 2 painéis) (m) :.. 0.572

Núm. painéis da asa (simples $=1$; cruciforme $=2$; etc) (adimens.): 2

Núm. painéis da cauda (simples= 1 ; cruciforme $=2$; etc) (adimens.): 2

Número de Mach em voo de cruzeiro (adimensional) ............. 0.700

Dist. bordo ataque da raiz da asa - nariz (múlt. comp. - adimens.) : 0.490

Dist. bordo ataque da cauda - nariz (múlt. comp. - adimens.) :.... 0.920

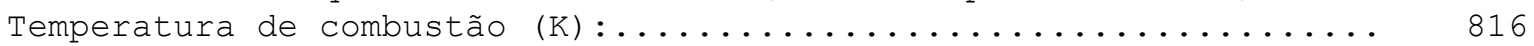

Ângulo de voo inicial após cruzeiro (graus) :................ 45.0

Fração mássica de combustível (comb./início cruzeiro) (adimens.):. 0.100

Relação de pressões no compressor (adimensional) .............. 5.40 
Dados dimensionais do corpo do míssil (Alumínio 2219-T81)

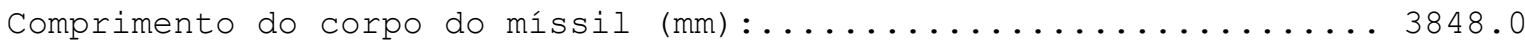

Comprimento do nariz do míssil $(\mathrm{mm})$ :.................... 295.0

Diâmetro externo da estrutura do corpo do míssil (mm) :........ 343.0

Diâmetro interno da estrutura do corpo do míssil (mm) : ........ 324.7

Espessura da estrutura do corpo do míssil $(\mathrm{mm})$................. 9.1

Área de referência - seção transversal do corpo do míssil (m²) :.. 0.0924

Comprimento do boattail do míssil $(\mathrm{mm})$ :.................... 0.0

Diâmetro da parte posterior do boattail do míssil (mm) :........ 343.0

Dados dimensionais da asa do míssil (Alumínio 2219-T81)

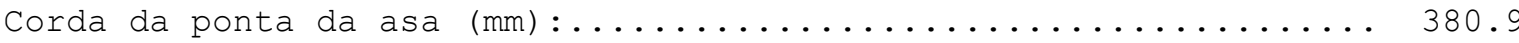

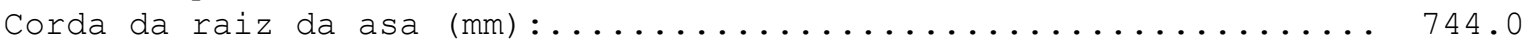

Corda Aerodinâmica média da asa $(m)$.................... 582.0

Distância entre corda aerod. média e a raiz da asa (mm) :....... 127.6

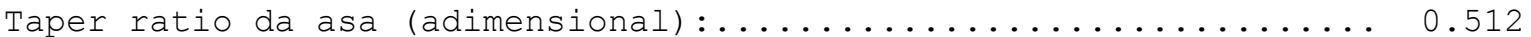

Envergadura total da asa - soma dos 2 painéis $-(\mathrm{mm})$........... 572.0

Razão de aspecto da asa (adimensional) :................... 1.0170

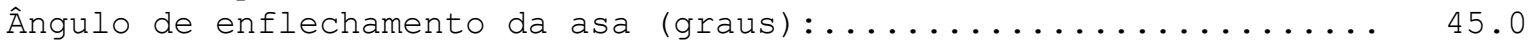

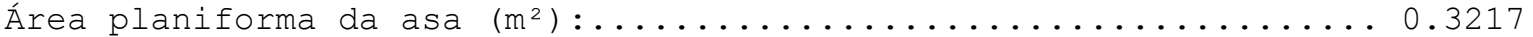

Espessura média da raiz da asa $(\mathrm{mm})$....................... 5.1

Âng. tot. bordo de ataque seção transv. da asa (graus) : ....... 30.00

Número de painéis da asa (simples $=1$; cruciforme $=2$; etc) $\ldots \ldots 2.00$

Dist. bordo ataque da raiz da asa - nariz $(\mathrm{mm})$ :............ 1885.5

Dados dimensionais das superfícies de cauda do míssil (Alumínio 2219-T81)

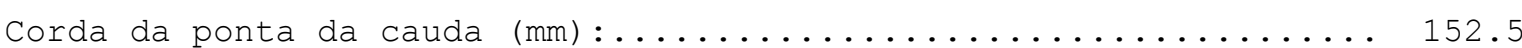

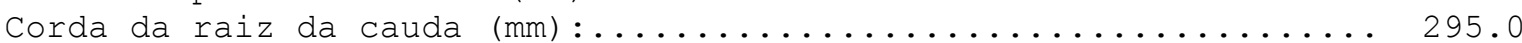

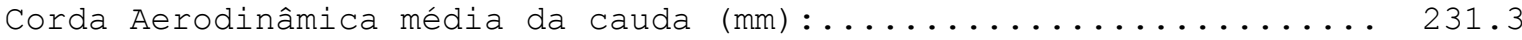

Distância entre corda aerod. média e a raiz da cauda (mm) :...... 127.8

Taper ratio da superfície das superfícies de cauda (adimensional): 0.517

Envergadura total das superfícies de cauda -soma 2 painéis-(mm) :.. 572.0

Razão de aspecto da cauda (adimensional) :................ 2.556

Ângulo de enflechamento das superfícies de cauda (graus) :....... 34.0

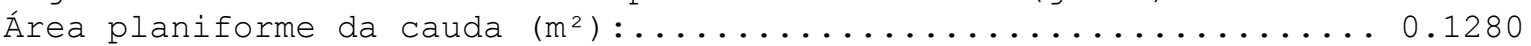

Espessura média da raiz da cauda $(\mathrm{mm}): \ldots \ldots \ldots \ldots \ldots \ldots \ldots \ldots \ldots \ldots . \ldots \ldots$

Âng. tot. bordo de ataque seção transv. da cauda (graus) :....... 30.0

Núm. painéis cauda (

Dist. bordo ataque da cauda - nariz $(\mathrm{mm})$................. 3540.2

Centro aerodinâmico

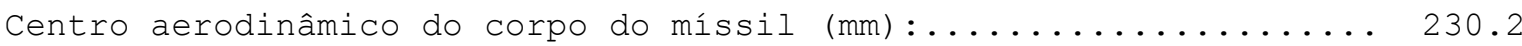

Centro aerodinâmico da asa (bordo de ataque) (mm) ............. 145.5

Centro aerodinâmico da cauda (bordo de ataque) (mm) :.......... 57.8

Centro aerodinâmico da asa (nariz do míssil) (mm) ............ 2158.6

Centro aerodinâmico da cauda (nariz do míssil) (mm) ........... 3684.2

Centro aerodinamico do míssil $(\mathrm{mm})$ :....................... 2430.3

Centro de massa (CG) do míssil (mm) :.................. 1924.0

Estabilidade estática (adimensional - múltiplos do diâmetro) :.... 1.476

Estabilidade estática (adimensional - múltiplos do diâmetro) : . . $\cdot 1.476$ 
Dados do voo do míssil

Lançamento

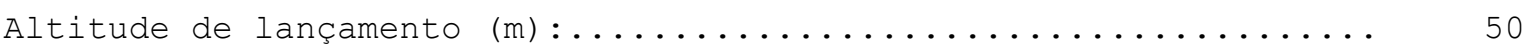

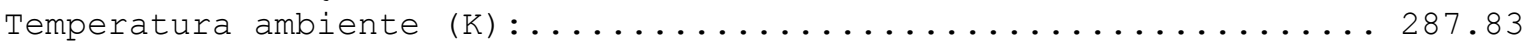

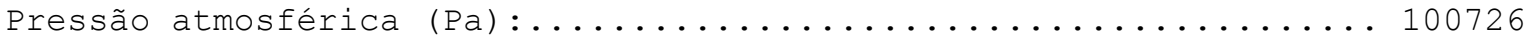

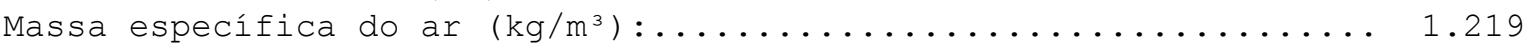

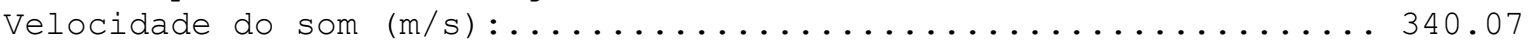

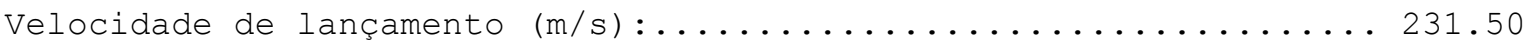

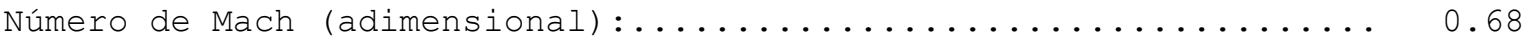

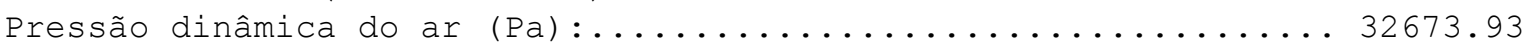

------------------------------------------------------------------

Cruzeiro

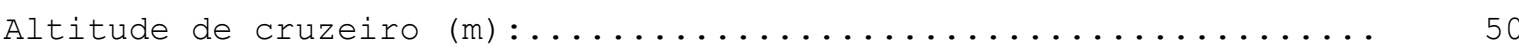

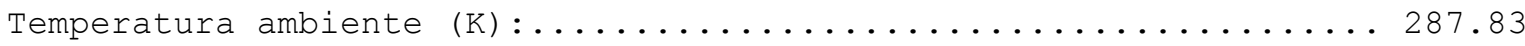

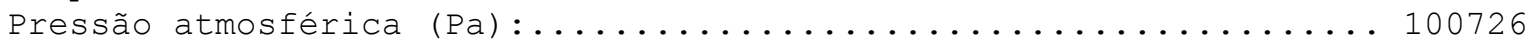

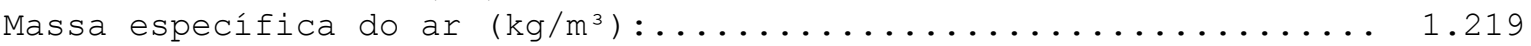

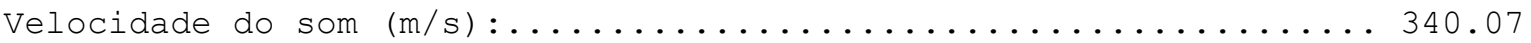

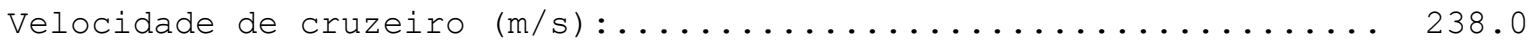

Número de Mach em voo de cruzeiro (adimensional) ............. 0.700

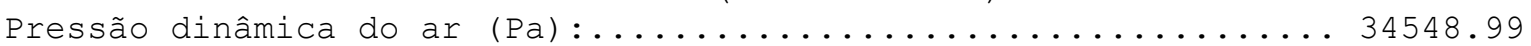

Impacto

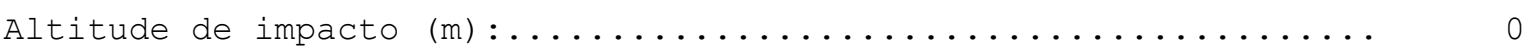

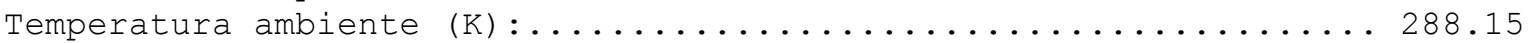

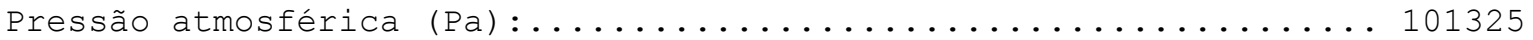

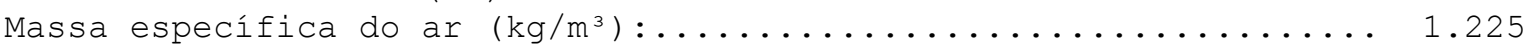

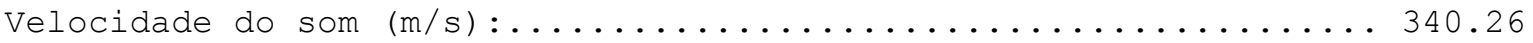

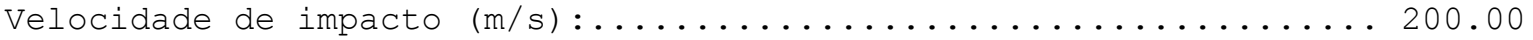

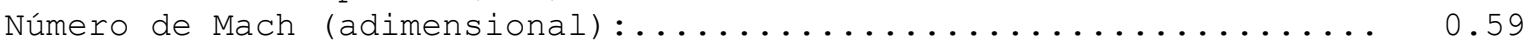

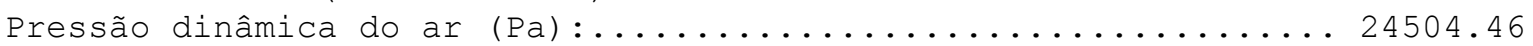

Ângulo de voo inicial após cruzeiro (graus) . .................. 45.0

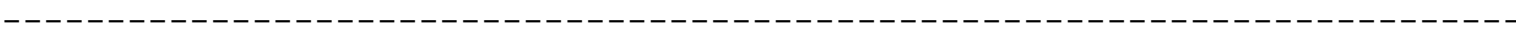

Tempo de voo

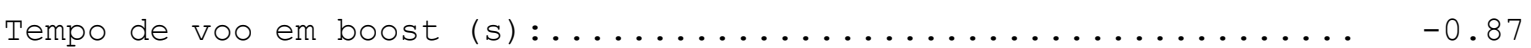

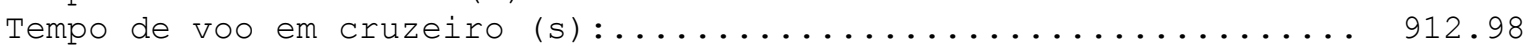

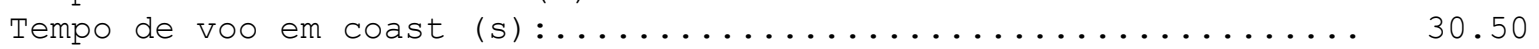

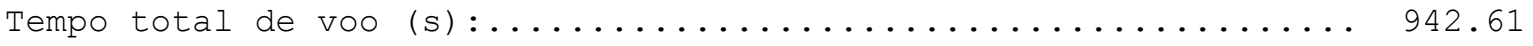

Distância de voo

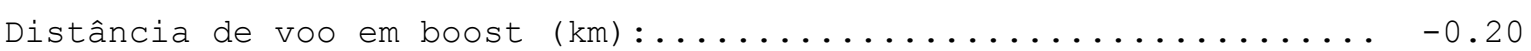

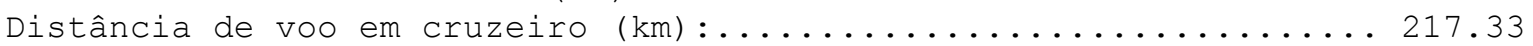

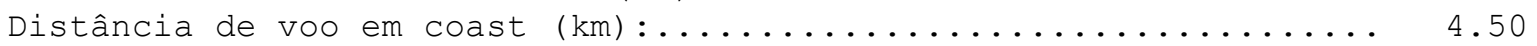

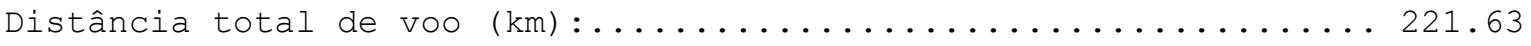


Dados de Coeficiente de Arrasto Parasita Médio em Boost

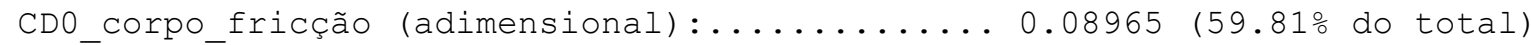

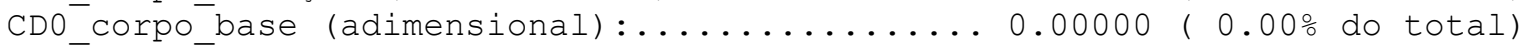

CD0_corpo_onda (adimensional) :................00000 ( $0.00 \%$ do total)

Coef́. Arrásto Parasita de CORPO (adimensional): 0.08965 (59.81\% do total)

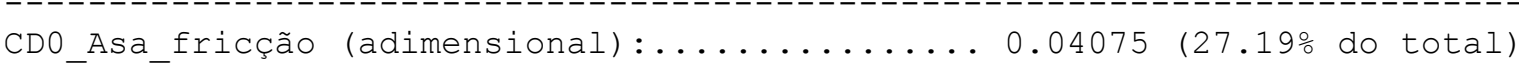

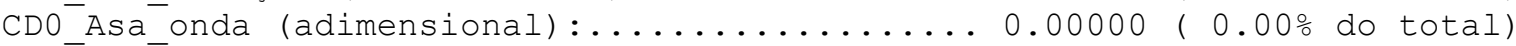

Coeff. Arrrasto Parasita de ASA (adimensional):.. 0.04075 (27.19\% do total)

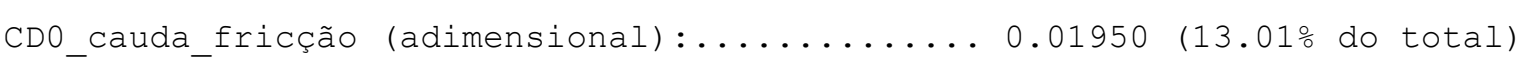

CDO cauda onda (adimensional) :................00000 ( $0.00 \%$ do total)

coef $\bar{f}$. Arrásto Parasita de CAUDA (adimensional): 0.01950 (13.01\% do total)

Coef. Arrasto Parasita Global em boost (adimensional) :........ 0.14990

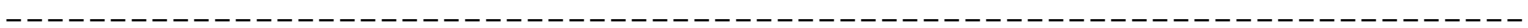

Dados de Coeficiente de Arrasto Parasita em Cruzeiro

CD0 corpo fricção (adimensional) : ......... 0.08940 (31.12\% do total)

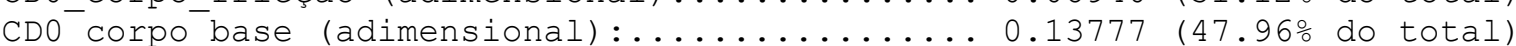

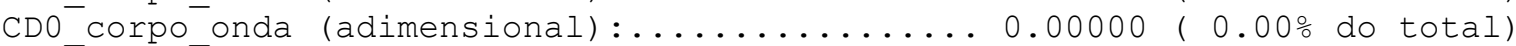

Coef. Arrāsto Parasita de CORPO (adimensional): 0.22717 (79.09\% do total)

CDO Asa friç̧ão (adimensional) :.................................... do total)

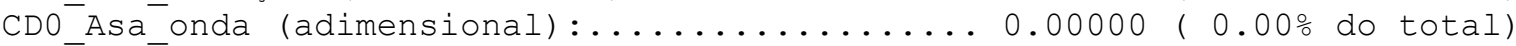

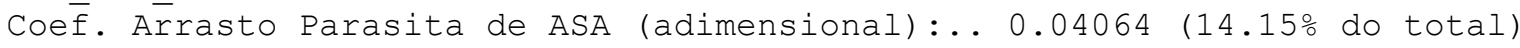

CDO cauda friç̧ão (adimensional) :................................ do total)

CDO_cauda_onda (adimensional) :.................00000 ( $0.00 \%$ do total)

Coes. Arrāsto Parasita de CAUDA (adimensional): 0.01944 ( $6.77 \%$ do total)

-------------------------------------------------------------------

Coef. Arrasto Parasita Global em cruzeiro (adimensional):...... 0.28725

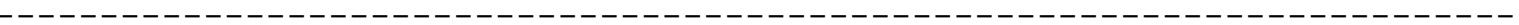

Dados de Coeficiente de Arrasto Parasita Médio em Coast

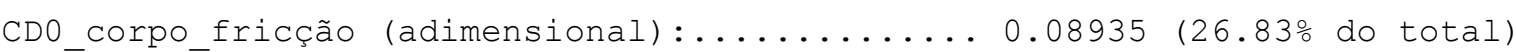

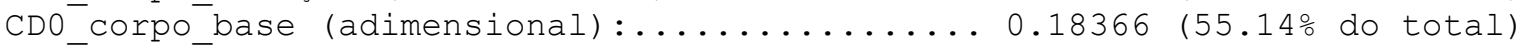

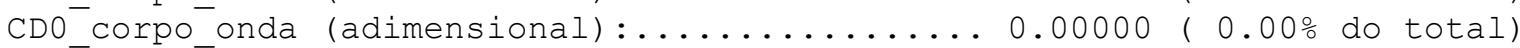

Coef̄. Arrāsto Parasita de CORPO (adimensional): 0.27302 (81.97\% do total)

CD0 Asa_friç̧ão (adimensional) :..............04061 (12.19\% do total)

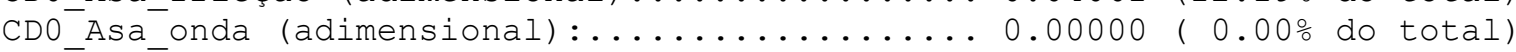

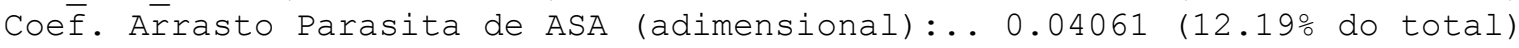

CDO_cauda_fricção (adimensional) .............0.01943 ( $5.83 \%$ do total)

CDO_cauda_onda (adimensional) :.................................

Coēf. Arrásto Parasita de CAUDA (adimensional): 0.01943 ( 5.83\% do total)

coef. Arrasto Parasita Global em coast (adimensional) ......... 0.33306

Coef. Arrasto Parasita Global em coast (adimensional) ............ 0.33306 
Dados de Coeficiente de Força Normal e sua derivada

--ー-ー-

Coeficiente de Força Normal (Início do Cruzeiro)

Coeficiente de força normal no Corpo (adimensional) ............ 0.458

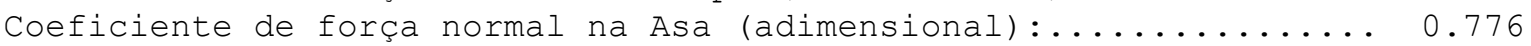

Coeficiente de força normal na Cauda (adimensional) :.......... 0.349

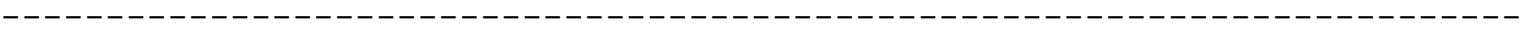

Derivada do Coeficiente de Força Normal (Início do Cruzeiro)

Derivada do Coeficiente de força normal no Corpo (1/rad) :....... 2.00

Derivada do Coeficiente de força normal na Asa (1/rad) :....... 5.56

Derivada do Coeficiente de força normal na Cauda (1/rad) :....... 5.56

$-----------------------------------------------------------------------$

Coeficiente de Força Normal (Máximo Fator de Carga em voo)

Coeficiente de força normal no Corpo (adimensional) ............ 0.780

Coeficiente de força normal na Asa (adimensional) :..............161

Coeficiente de força normal na Cauda (adimensional) :.......... 0.608

Derivada do Coeficiente de Força Normal (Máximo Fator de Carga em voo)

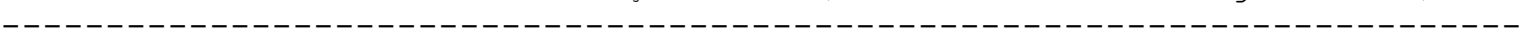

Derivada do Coeficiente de força normal no Corpo (1/rad) :....... 2.00

Derivada do Coeficiente de força normal na Asa (1/rad) :........ 5.56

Derivada do Coeficiente de força normal na Cauda (1/rad) :....... 5.56

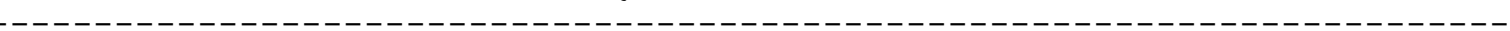

Relação Sustentação/Arrasto

Relação Sustentação/Arrasto média em cruzeiro (adimensional) : ... 3.397

Relação Sustentação/Arrasto média em coast (adimensional):...... 2.978

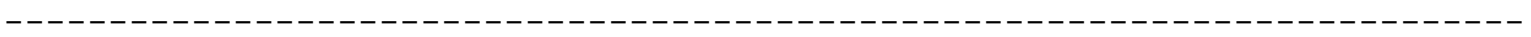

Arrasto médio em voo

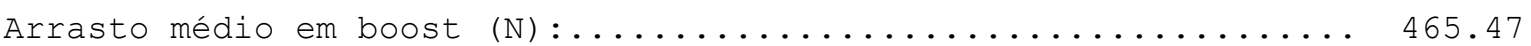

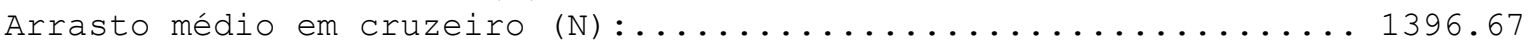

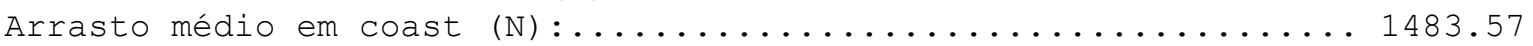

----------------------------------------------------------------------- 
Massa do míssil nos principais momentos de voo

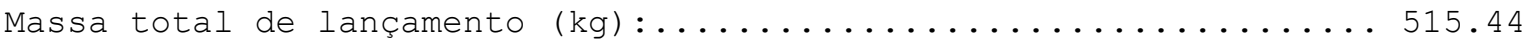

Massa do míssil no início do cruzeiro $(\mathrm{kg})$.................. 512.93

Massa do míssil no fim do cruzeiro $(\mathrm{kg})$ :................. 461.63

$-----------------------------------------------------------------------$

Massa espec. do míssil no início do cruzeiro - ref.:1384 - (kg/m³): 1442.6

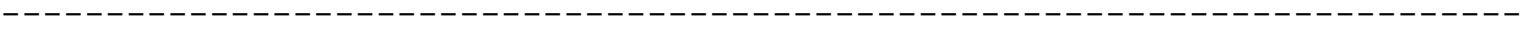

Massas dos componentes do míssil

Massa do Booster com propelente $(\mathrm{kg})$ :..................... -0.00

Massa de propelente necessária para o Booster $(\mathrm{kg})$............ -0.00

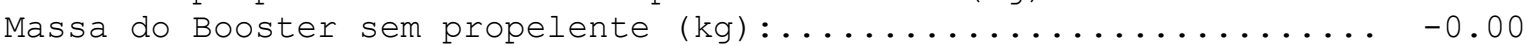

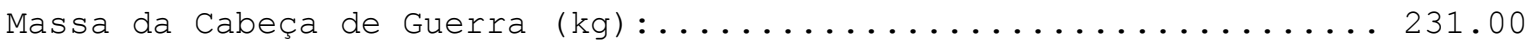

Massa dos Sistemas de Guiamento, Controle e Enlace de Dados (kg):. 42.90

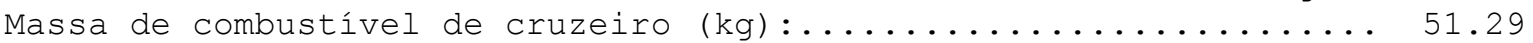

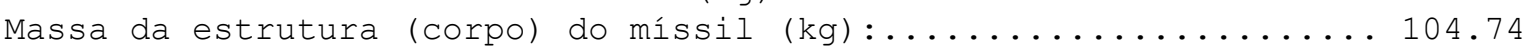

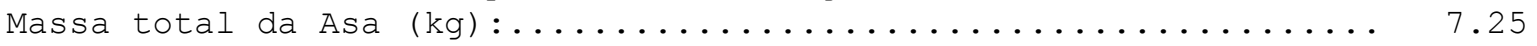

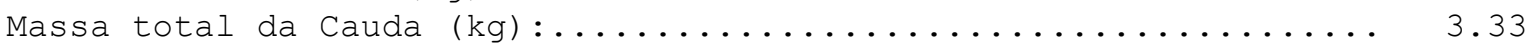

Massa do motor de cruzeiro (kg) :...................... 45.21

Massa total dos atuadores das superfícies de controle (kg) :..... 13.60

Massa total da fonte de energia (power supply) (kg) :.......... 13.60

Parcela da massa dos componentes em relação à massa de Lançamento

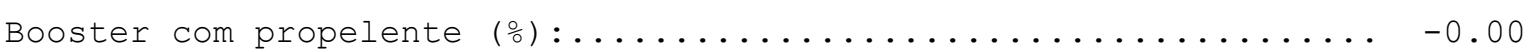

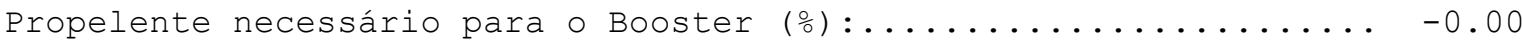

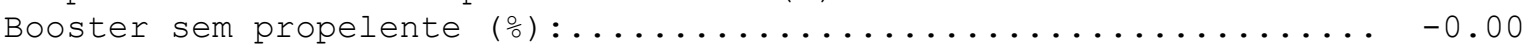

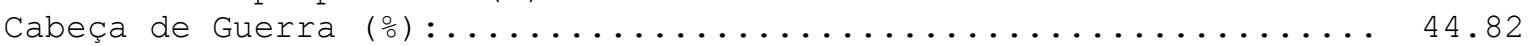

Sistemas de Guiamento, Controle e Enlace de Dados (은 :......... 8.32

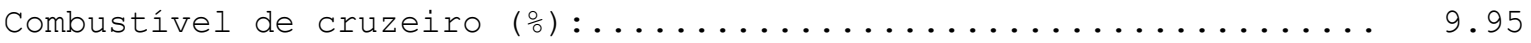

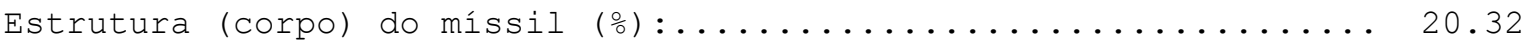

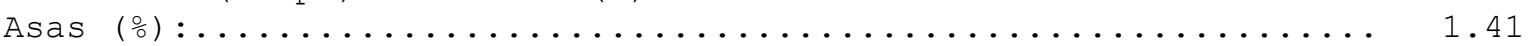

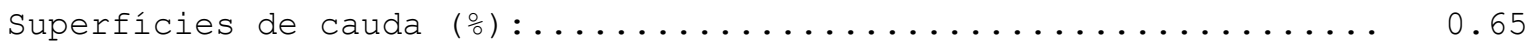

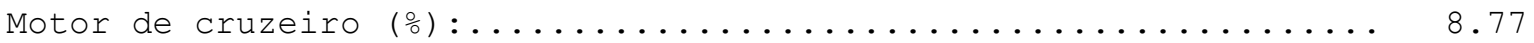

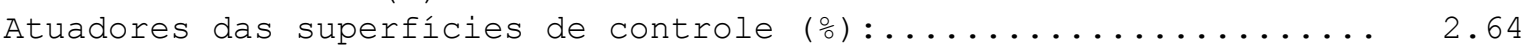

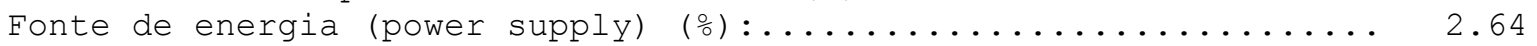

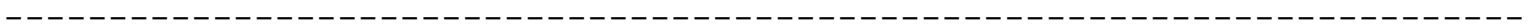

Parcela da massa dos componentes em relação à massa no início do cruzeiro

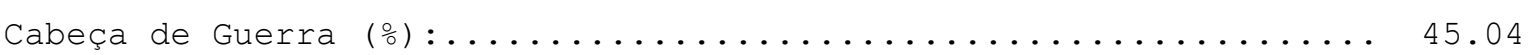

Sistemas de Guiamento, Controle e Enlace de Dados (\%) :......... 8.36

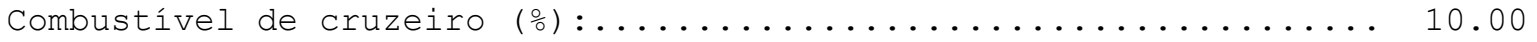

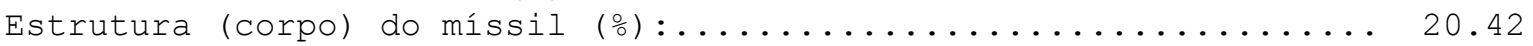

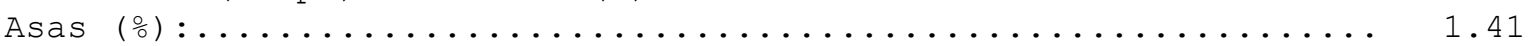

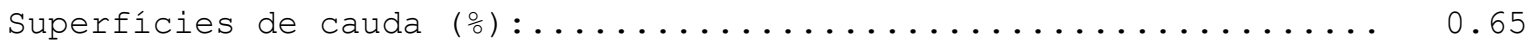

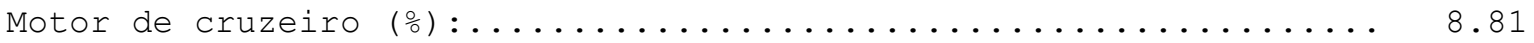

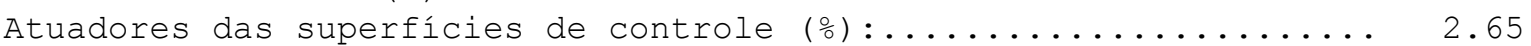

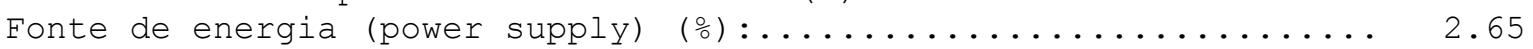


Condição de voo nivelado no início do cruzeiro

Ângulo de Ataque dos elementos do míssil

Ângulo de Ataque do corpo (graus) :....................... 7.00

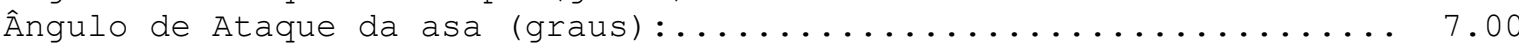

Ângulo de Ataque da cauda (graus) :...................... 3.50

Força normal nos elementos do míssil

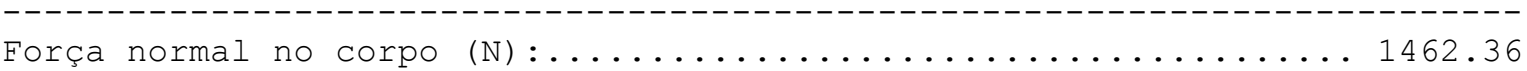

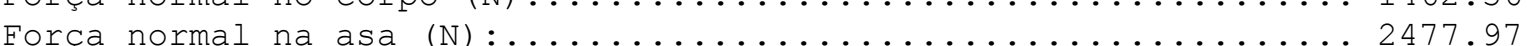

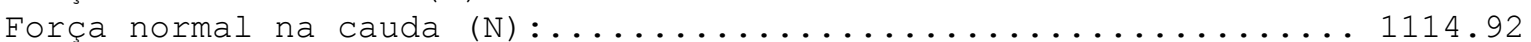

Peso do míssil em voo nivelado (início do cruzeiro) (N) : ...... 5030.11

Erro na aplicação das equações de equilíbrio

Erro no balanço de forças verticais (응..................... 1.29

Erro no balanço de momentos em relação ao CG (\%) .............

Valor residual na aplicação das equações de equilíbrio

Valor residual do balanço de forças verticais - inclui o peso (N): 64.83 Valor residual do somatório de momentos em relação ao CG (N.m) :... -37.05

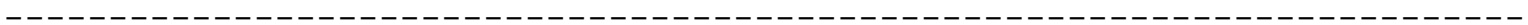

Condição de máximo Fator de Carga em voo (n máximo)

Máximo Fator de Carga em voo (adimensional) :............... 1.713

--------------------------------------------------------------------

Ângulo de Ataque dos elementos do míssil

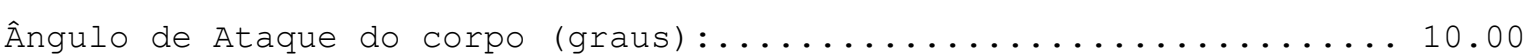

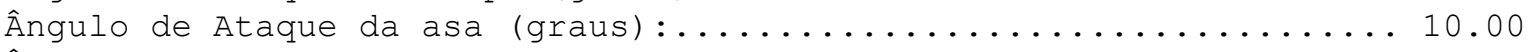

Ângulo de Ataque da cauda (graus) :....................... 6.00

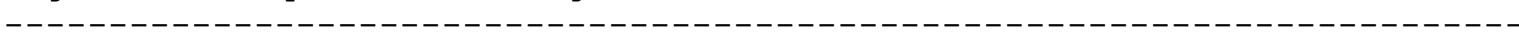

Força normal nos elementos do míssil

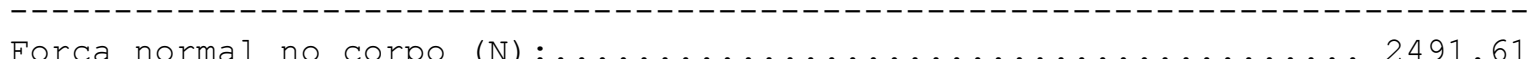

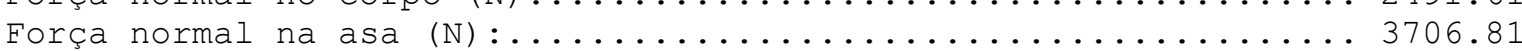

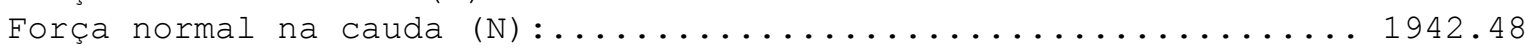
Peso do míssil em máximo fator de carga de voo (n máximo) (N) : ... 8616.04

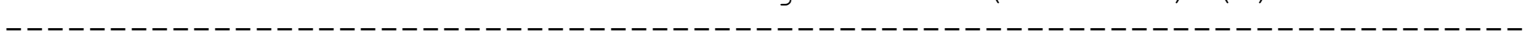

Erro na aplicação das equações de equilíbrio

Erro no balanço de momentos em relação ao CG (\%) ............ - 1.58

Valor residual na aplicação das equações de equilíbrio

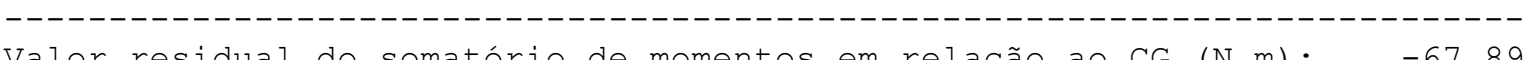

Valor residual do somatório de momentos em relação ao CG (N.m) :... -67.89

------------------------------------------------------------------------


Sistema de Propulsão - Booster

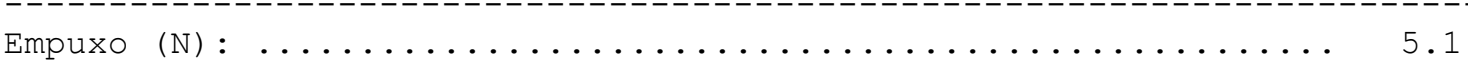

Dados de entrada

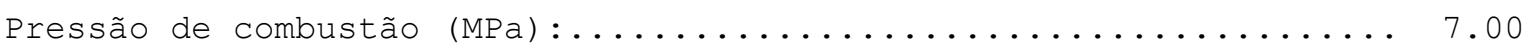

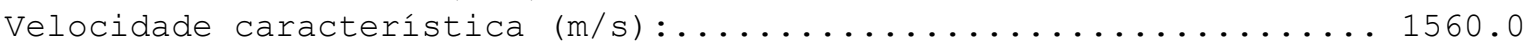

Razão de calores específicos na tubeira (adimensional) :........ 1.180

Fator de aceleração durante boost (múltiplo da acel. gravidade) :... 0.00

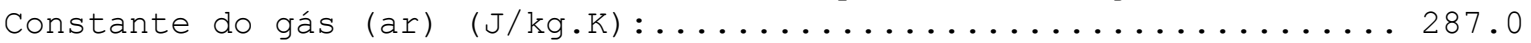

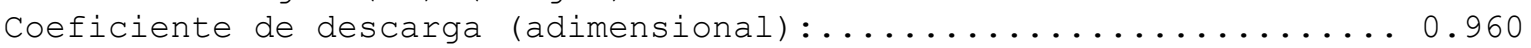

Flight path angle (graus) :........................ 45.0

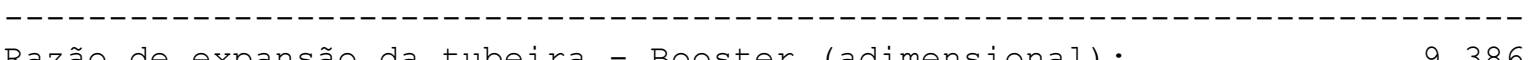

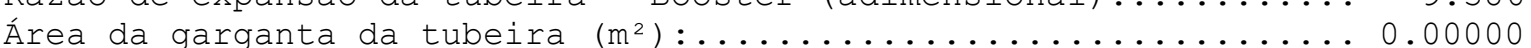

Diâmetro da garganta da tubeira $(\mathrm{mm}): \ldots \ldots \ldots \ldots \ldots \ldots \ldots \ldots \ldots \ldots . \ldots \ldots$

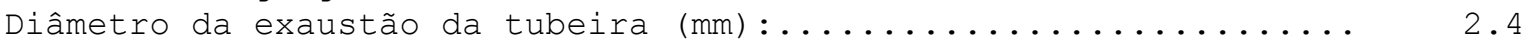

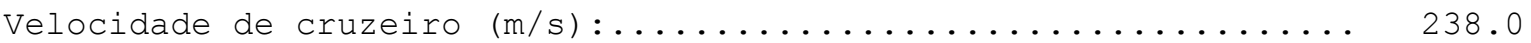

Máxima velocidade incremental devido ao Booster (m/s) . ....... 6.5

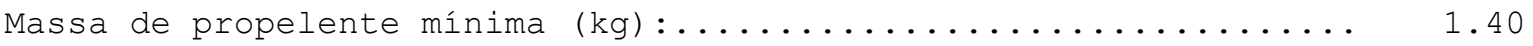

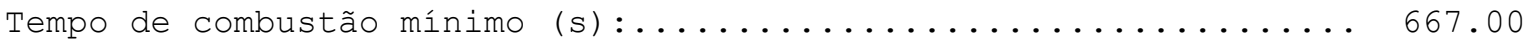

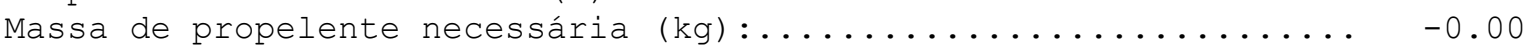

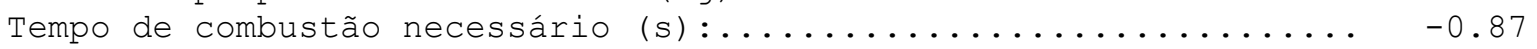

Peso médio do míssil durante Boost (N) :........... 5054.4 (515.44 kgf)

Fluxo Mássico de Propelente $(\mathrm{kg} / \mathrm{s})$....................... 0.00

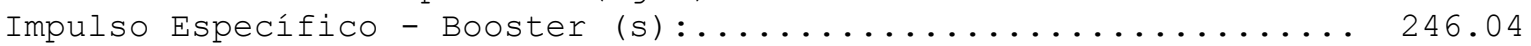


Sistema de Propulsão - Motor de Cruzeiro

Tipo de motor de cruzeiro: Turbojato

Empuxo necessário em voo nivelado - início do cruzeiro (N) : . . . . 1469.8 Empuxo necessário em voo nivelado - fim do cruzeiro (N) : ...... 1342.7 Empuxo necessário no instante de máximo Fator de Carga (N) :..... 2216.8

Condições de operação no início do voo em cruzeiro

Temperatura

Temperatura de estagnação na entrada do compressor (K) : ........ 316.0 Temperatura de estagnação na saída do compressor (K) : ......... 520.9 Temp. de estagnação na entrada na turbina (K) - dado de entrada:... 816.0 Temperatura de estagnação na saída da turbina (K) :........... 611.2

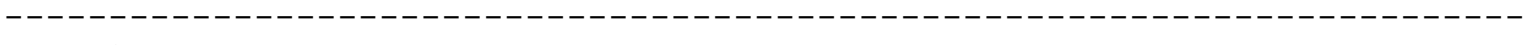

Pressão

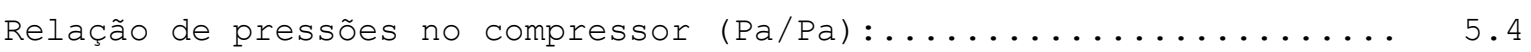

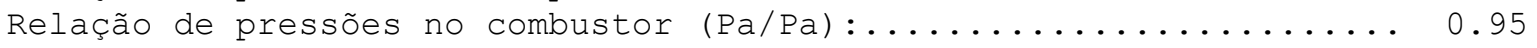

Pressão de estagnação na entrada do compressor $(\mathrm{kPa})$. . . . . . . 135.8

Pressão de estagnação na saída do compressor (kPa) :.......... 733.5

Pressão de estagnação na entrada na turbina (kPa) :........... 696.8

Pressão de estagnação na saída da turbina (kPa) ............. 186.5

Pressão na saída do bocal de exaustão $(\mathrm{kPa}): \ldots \ldots \ldots \ldots \ldots \ldots \ldots . \ldots 10 . \ldots 1$

---------------------------------------------------------------------

Eficiência isentrópica (dados de entrada)

Eficiência isentrópica do difusor de admissão de ar (adimensional): 0.91

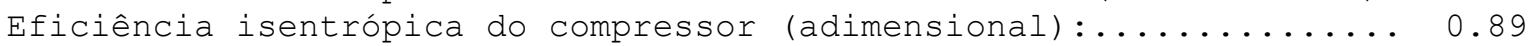

Eficiência isentrópica da turbina (adimensional) ............. 0.90

Eficiência isentrópica do bocal de exaustão (adimensional) :...... 0.95

Calor específico do fluido de trabalho (dados de entrada)

Razão de calores específicos no difusor de entrada (adimensional) : . 1.40

Razão de calores específicos no compressor (adimensional) :...... 1.37

Razão de calores específicos na turbina (adimensional) :........ 1.33

Razão de calores específicos no bocal de exaustão (adimensional):.. 1.33

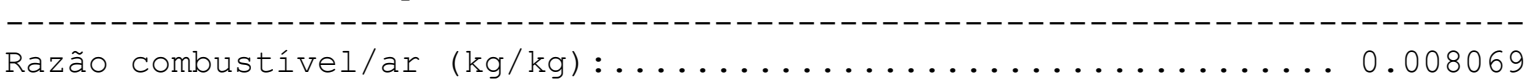

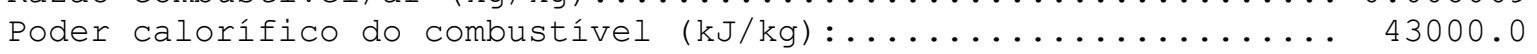

Velocidade na saída do bocal de exaustão (m/s) :............ 436.35

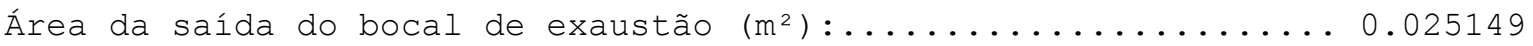

Área de referência - seção transversal do corpo do míssil (m²) : .. 0.0924

Razão área da saída do bocal de exaustão / seção do míssil (adm.): 0.2722

Diâmetro da saída do bocal de exaustão $(\mathrm{mm})$ :.............. 178.95

Número de Mach na saída do bocal de exaustão (adimensional):.... 0.9712

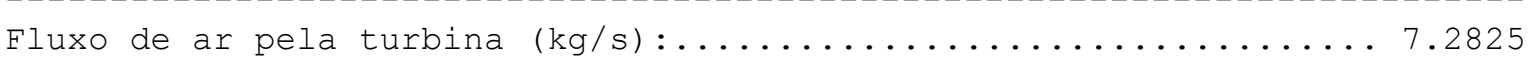

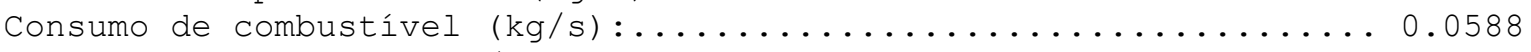

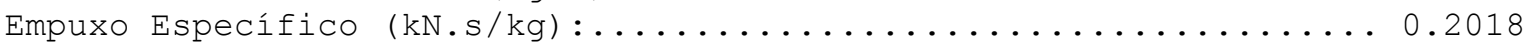

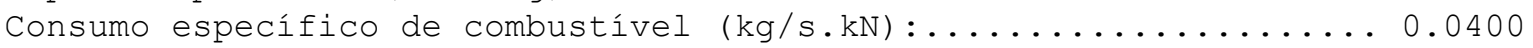

Impulso Específico $(\mathrm{s}): \ldots \ldots \ldots \ldots \ldots \ldots \ldots \ldots \ldots \ldots \ldots \ldots \ldots \ldots \ldots$ 
Dados da Avaliação do Míssil

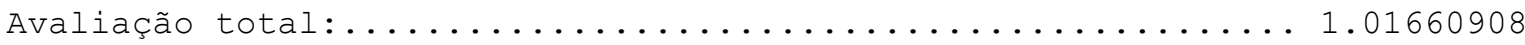

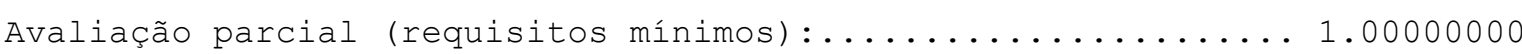

-------------------------------------------------------------------------

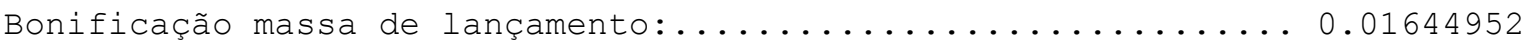

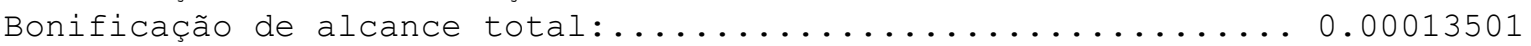

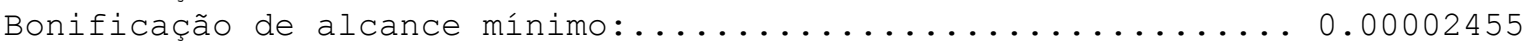

$-----------------------------------------------------------------------$

Penalização nariz maior que o comprimento do míssil:.......0.0000000

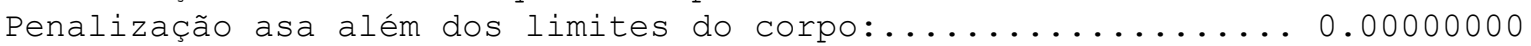

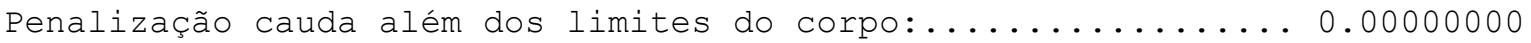

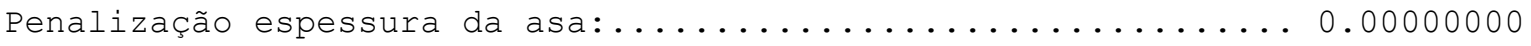

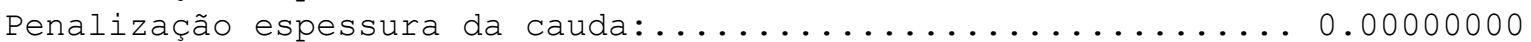

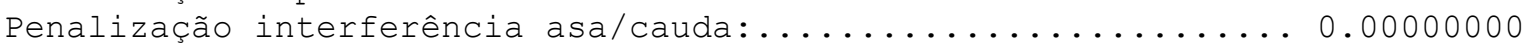

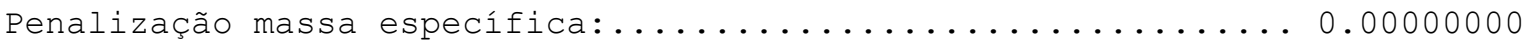

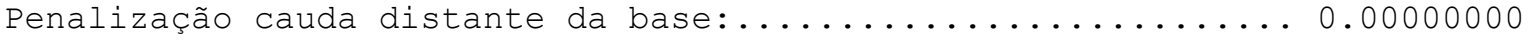




\section{I - RELATÓRIO DE EXECUÇÃO DO SCORPIO 1.0: MÍSSIL ASTROS 2020}
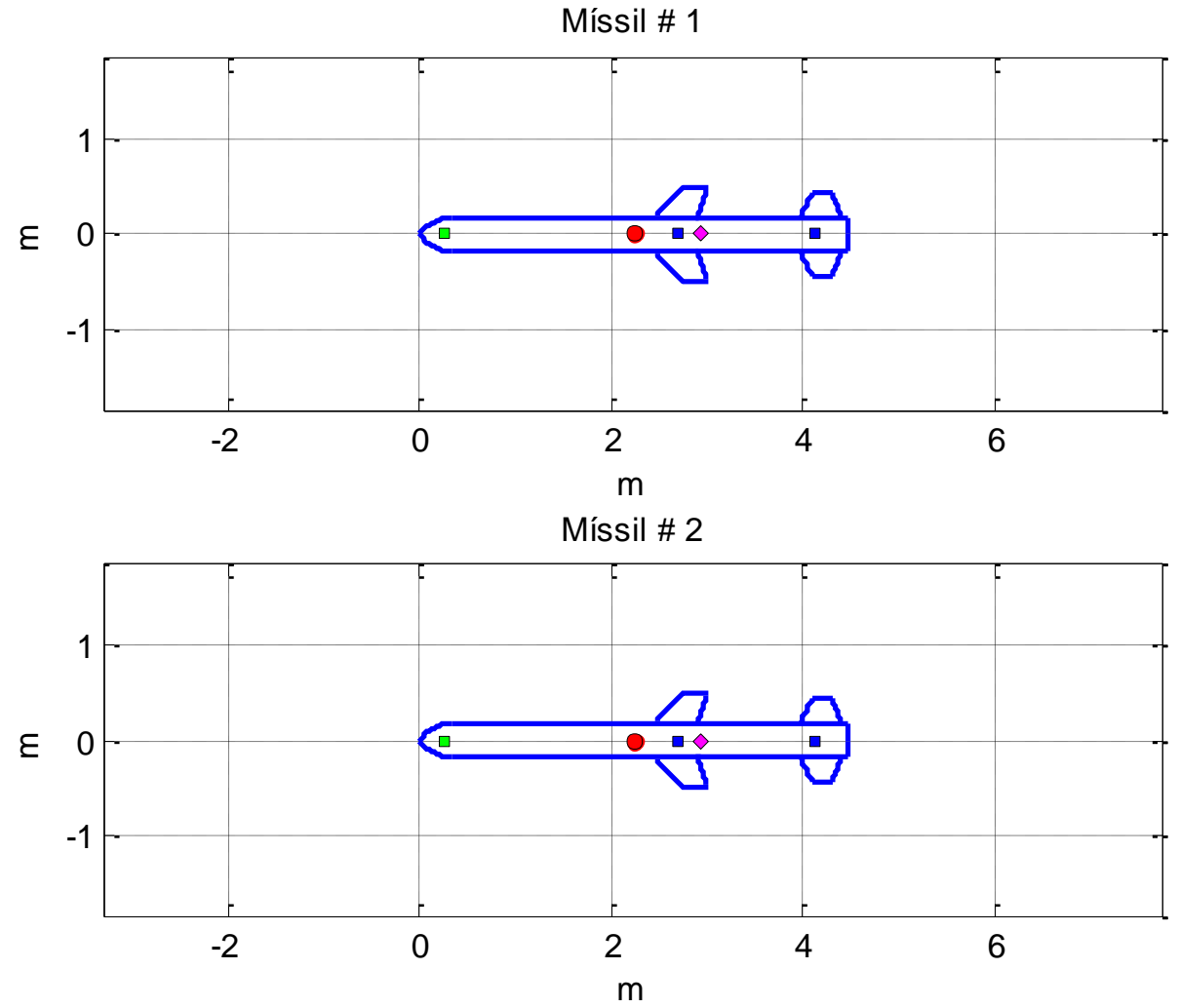

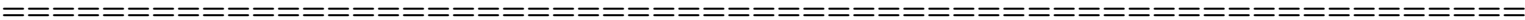

RELATÓRIO DE EXECUÇÃO DO PROGRAMA SCORPIO 1.0

Dados de operação do algoritmo genético

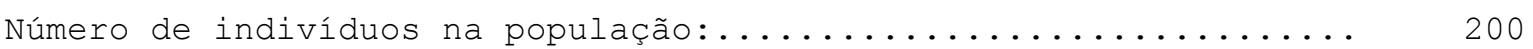

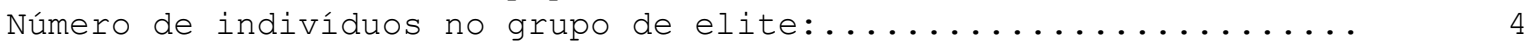

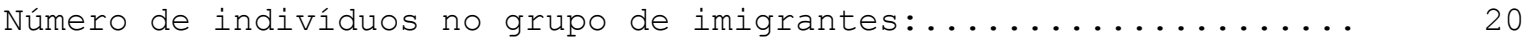

Número de genes no cromossomo (incluindo função de avaliação) :... 25

Probabilidade de mutação inicial (\%) :..................... 2.00

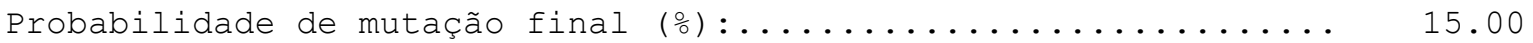

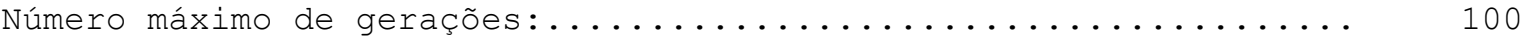

Avaliação suficiente p/ terminar execução (critério de parada) :.. 1.50000

Requisitos de desempenho do míssil

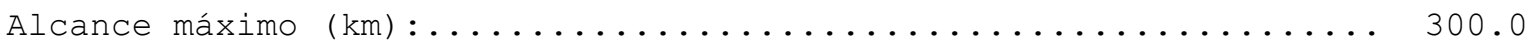

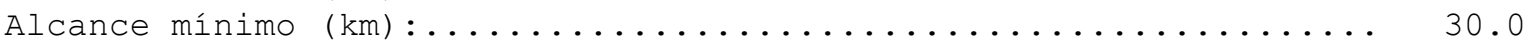

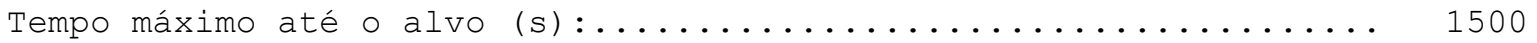

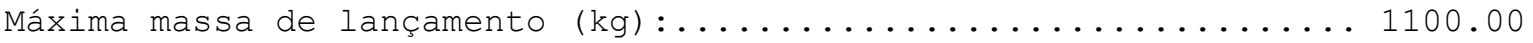

Estabilidade Estática mínima (adim. - múltiplos do diâmetro) :.... 1.48

Fator de Carga em manobra mínimo (adim. - múltiplos da gravidade):. 2.00 
Altitude de voo de cruzeiro

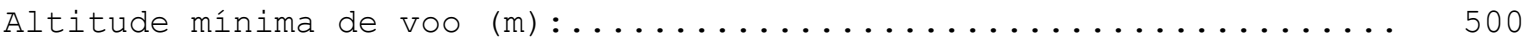

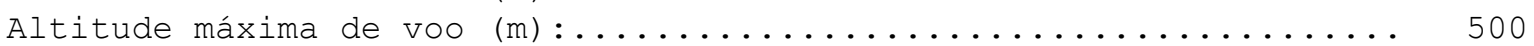

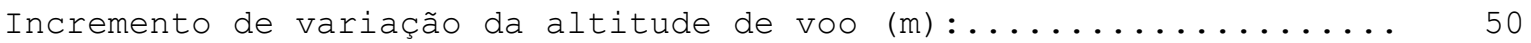

Diâmetro do corpo do míssil

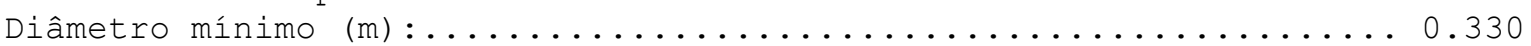

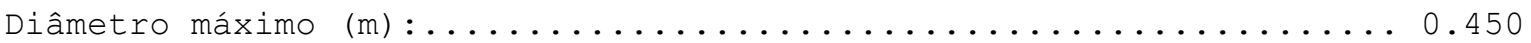

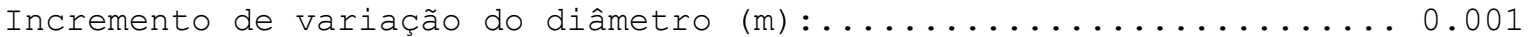

Comprimento do corpo do míssil

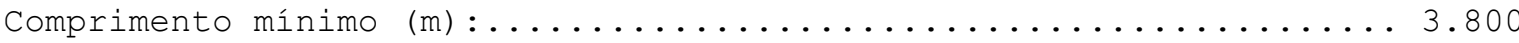

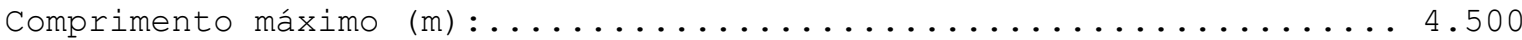

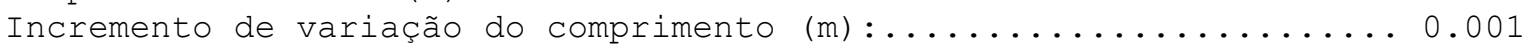

Comprimento do nariz do míssil (múltiplo do diâmetro)

Comprimento mínimo do nariz (adimensional) ................. 1.000

Comprimento máximo do nariz (adimensional) :............... 1.000

Incremento de variação do comprimento do nariz (adimensional) :.... 0.500

Taper ratio da asa

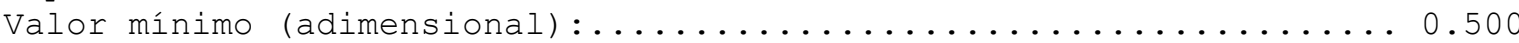

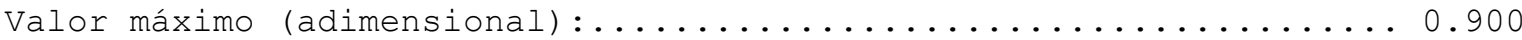

Incremento de variação do taper ratio (adimensional) :..........0.001

Taper ratio da superfície de cauda

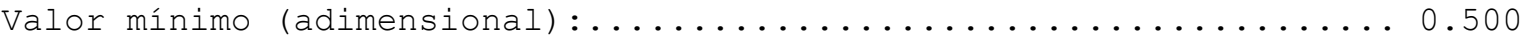

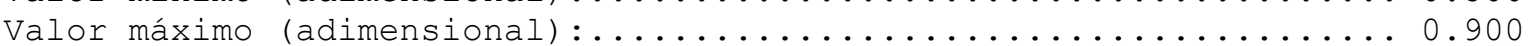

Incremento de variação do taper ratio (adimensional) .......... 0.001

Corda aerodinâmica da raiz da asa

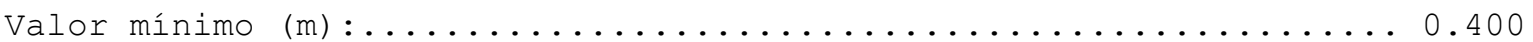

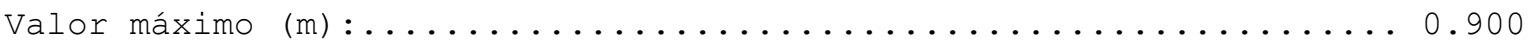

Incremento de variação da corda da raiz da asa (m) ............ 0.001

Corda aerodinâmica da raiz da superfície de cauda

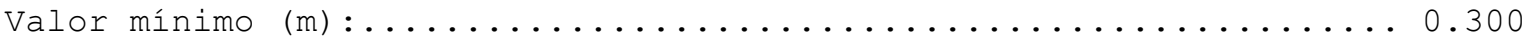

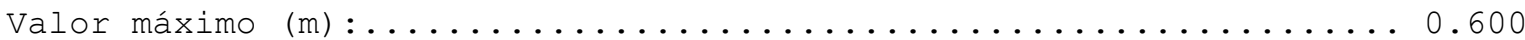

Incremento de variação da corda da raiz da superfície de cauda (m): 0.001

Ângulo de enflechamento da asa

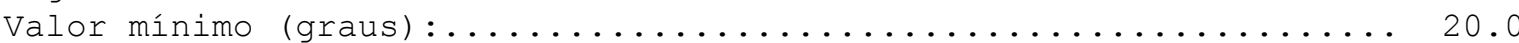

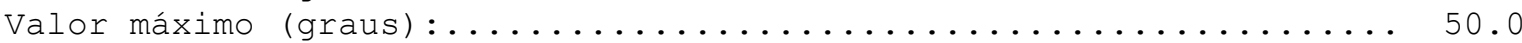

Incr. de variação do enflechamento da asa (graus) ............. 5.0

Ângulo de enflechamento da superfície de cauda

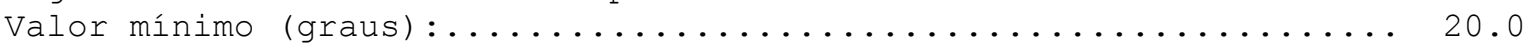

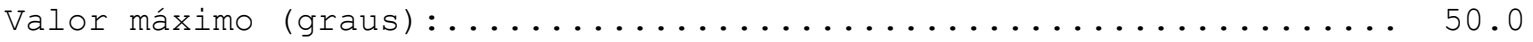

Incr. de variação do enflechamento da superfície de cauda (graus) :. 5.0

Ângulo total de bordo de ataque da seção transversal da asa e cauda

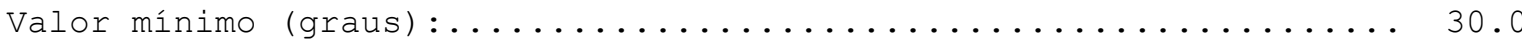

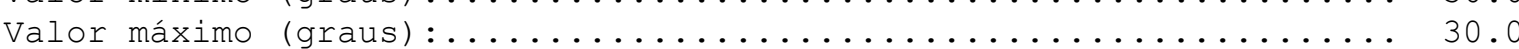

Incremento de variação do ang. total de bordo de ataque (graus) :... 5.0

Envergadura total da asa (soma dos 2 painéis)

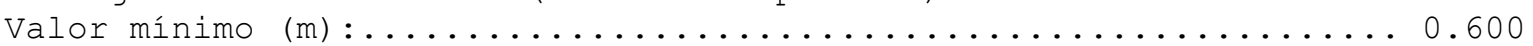

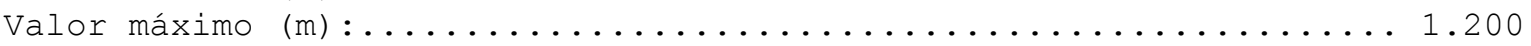


Incremento de variação da envergadura de asa $(m)$............. 0.001

Envergadura total das superfícies de cauda (soma dos 2 painéis)

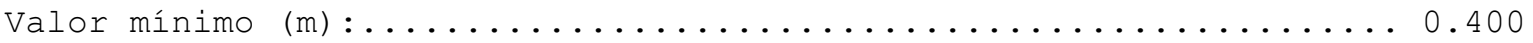

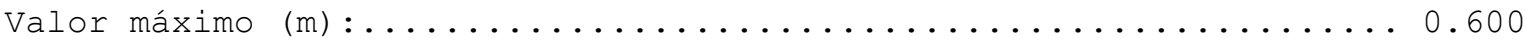

Incremento de variação da envergadura de cauda $(m)$............ 0.001

Número de painéis da asa (Asa simples $=1$; cruciforme = 2; etc)

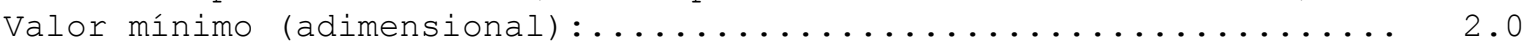

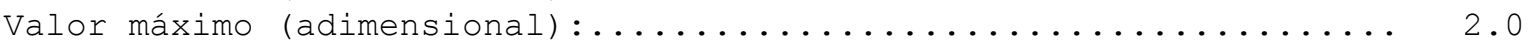

Incremento de variação do número de painéis da asa (adimensional):. 1.0

Número de painéis superf. de cauda (Cauda simples = 1; cruciforme = 2; etc)

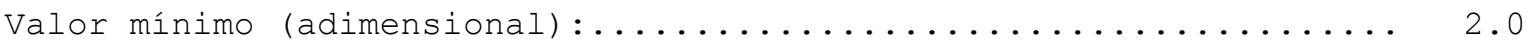

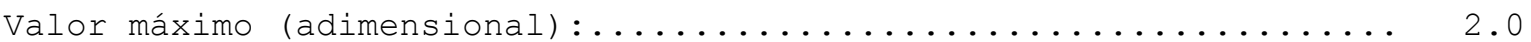

Incremento de variação do número de painéis da cauda(adim.) :..... 0.5

Número de Mach em voo de cruzeiro

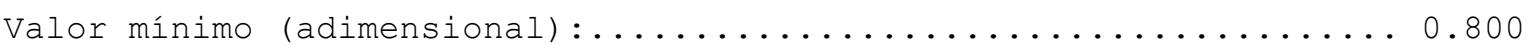

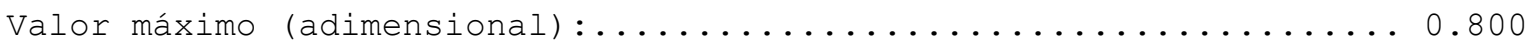

Incr. de variação do número de Mach de cruzeiro (adimensional) :... 0.100

Distância do bordo de ataque da raiz da asa até nariz (múlt. do comprimento)

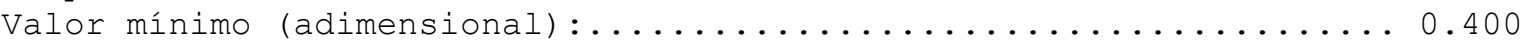

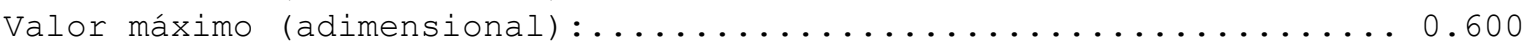

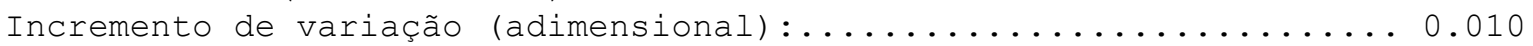

Distância do bordo de ataque da superfície de cauda até nariz (múlt. do comprimento)

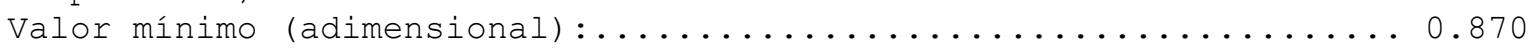

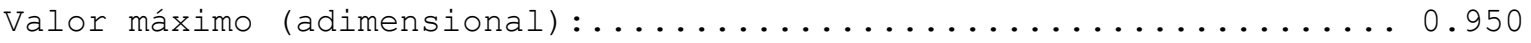

Incremento de variação (adimensional) :................... 0.010

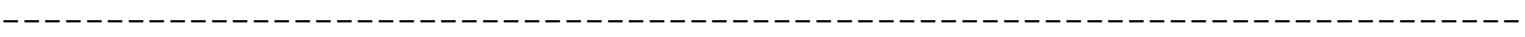

Temperatura de combustão

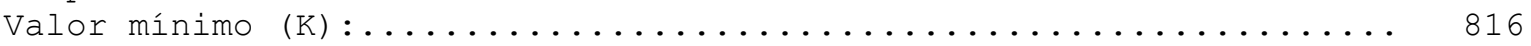

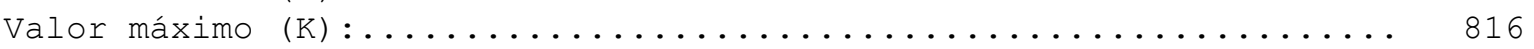

Incremento da temperatura de combustão $(\mathrm{K})$................ 50

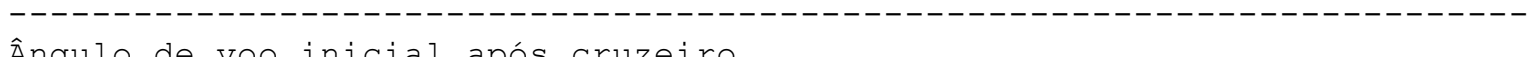

Valor mínimo (graus) :.......................... 45.0

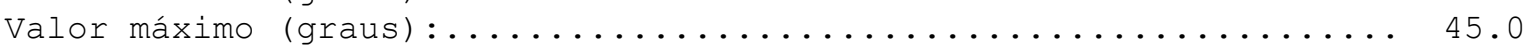

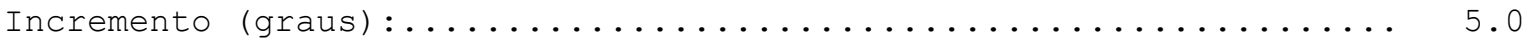

Fração mássica de combustível (massa de comb./massa início do cruzeiro)

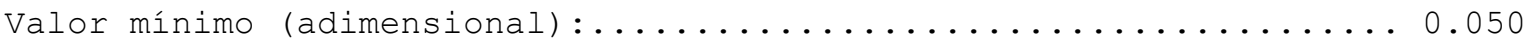

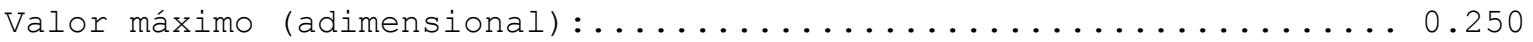

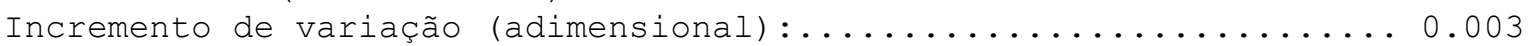

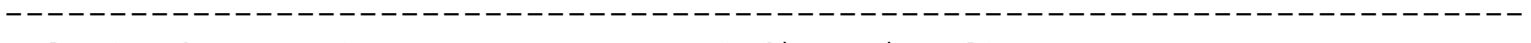

Relação de pressões no compressor (adimensional)

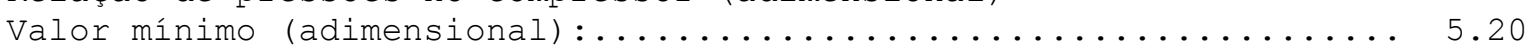

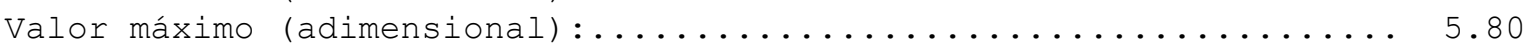

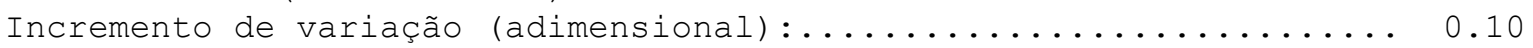


Dados de lançamento e impacto

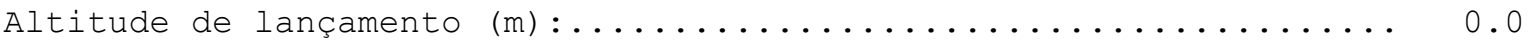

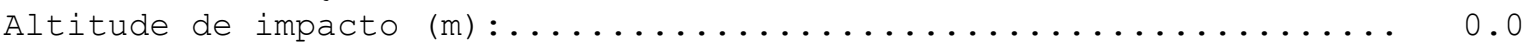

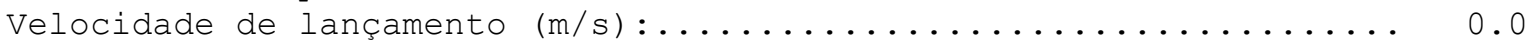

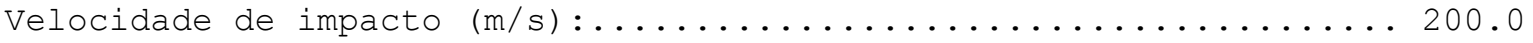

Razão de calores específicos ambiente (adimensional) :.......... 1.40

Dados de massa do mísil

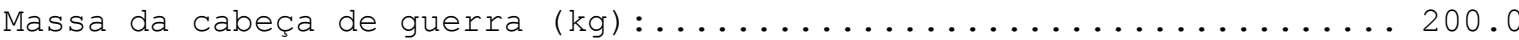

Massa dos sistemas de guiamento, controle e enlace de dados (kg) :.. 70.0

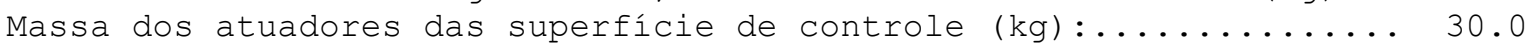

Massa da fonte de energia (power supply) (kg) ............... 25.0

Dados aerodinâmicos

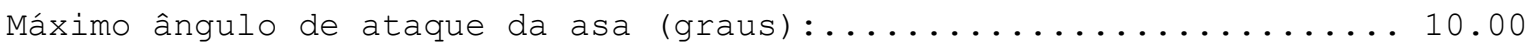

Máximo ângulo de ataque do corpo (graus) :................... 10.00

Máximo ângulo de ataque da superfície de cauda (graus) :........ 10.00

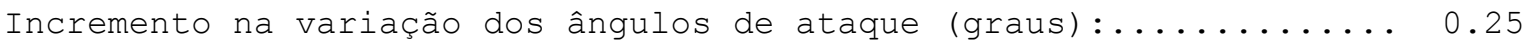

Parcela do arrasto de base desprezada em cruzeiro (o ) :........ 25.00

Erro máximo nas equações de equilíbrio em voo ( $\left.\frac{\circ}{0}\right)$............... 3.0

Tipo de controle:................... Superfícies de cauda móveis

Presença de boattail:............................. Não

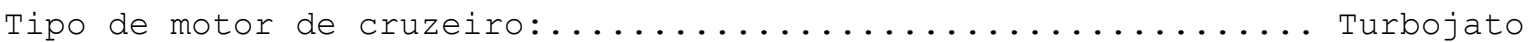
Perfil de voo após cruzeiro (Planeio $=1$; Balístico $=2$ ) $\ldots \ldots \ldots . . .2$

Dados do sistema de propulsão - foguete - Booster e Sustain

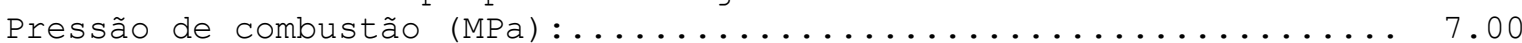

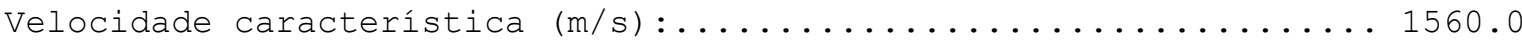

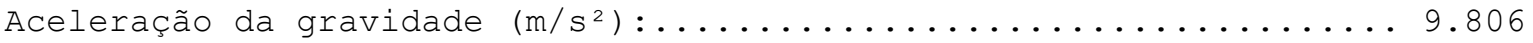

Razão de calores específicos na tubeira (adimensional) :......... 1.180

Fator de aceleração durante boost (múltiplo da acel. gravidade) :.. 9.00

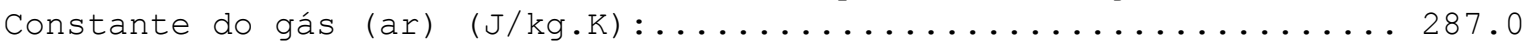

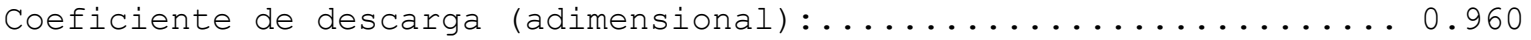

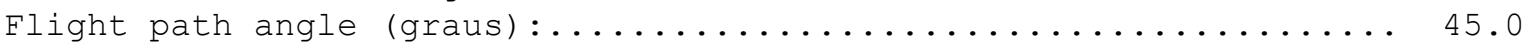

Dados do sistema de propulsão - Motor de cruzeiro - Ramjet

Razão de pressões de estagnação no difusor (adimensional) :...... 0.700

Razão de pressões de estagnação no combustor (adimensional) :...... 0.950

Razão de pressões de estagnação no bocal de exaustão (adim.) :..... 0.980

Eficiência de combustão (adimensional) :................... 0.950

Poder calorífico do combustível (kJ/kg):...............43000.0

Calor espec. a pressão const. do ar (temp. combustão) (KJ/kg.K) :... 1.150

Dados do sistema de propulsão - Motor de cruzeiro - Turbojato

Eficiência isentrópica do difusor de admissão de ar (adimensional): 0.91

Eficiência isentrópica do compressor (adimensional) ........... 0.89

Eficiência isentrópica da turbina (adimensional) .............. 0.90

Eficiência isentrópica do bocal de exaustão (adimensional) :...... 0.95

Razão de calores específicos no difusor de entrada (adimensional):. 1.40

Razão de calores específicos no compressor (adimensional) :...... 1.37

Razão de calores específicos na turbina (adimensional) :........ 1.33

Razão de calores específicos no bocal de exaustão (adimensional):.. 1.33

Relação de pressões no combustor (adimensional) :.............. 0.95 
Estatísticas da execução do programa

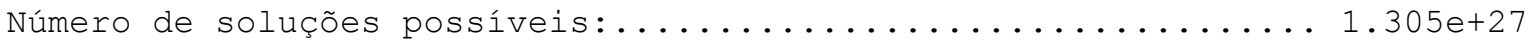
Tempo de processamento necessário para avaliar todas as soluções possíveis, considerando 2 soluções avaliadas por segundo: 2.069e+19 anos.

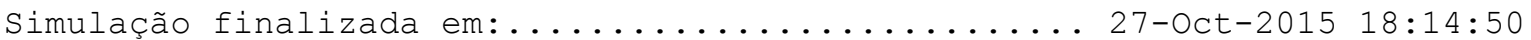

Tempo transcorrido durante execução do programa (s) : . . . . . . 32573.5

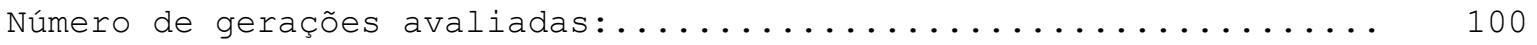

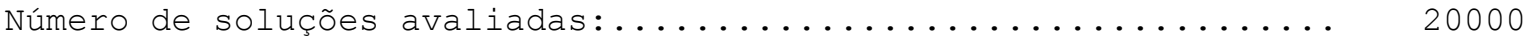
Parcela avaliada do espaço de soluções possíveis ( $\left.\frac{\circ}{0}\right)$ : $1.5329294513368418 e-21$

Tempo médio consumido para avaliar uma solução (s) : ......... 1.628674 Critério de parada: simulação atingiu número máximo de gerações.

Resultados da simulação

Resultados apresentados são referentes aos 4 melhores indivíduos da última geração. 


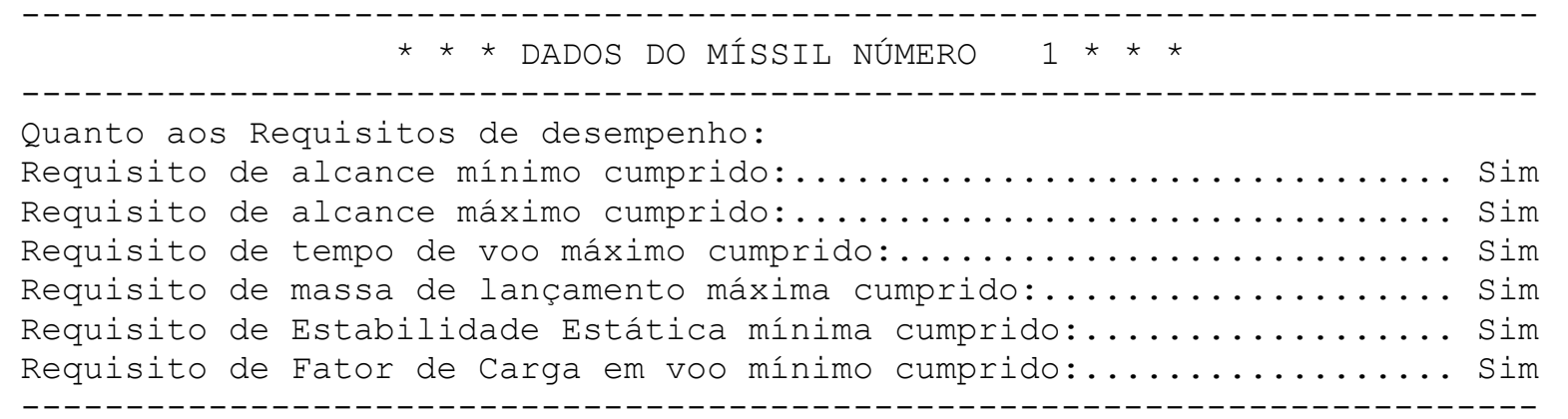

Desempenho do míssil

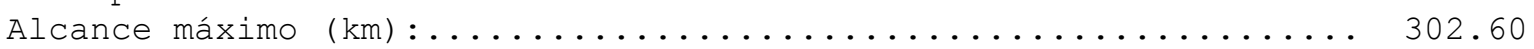

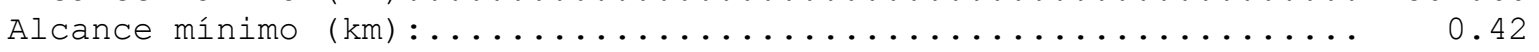

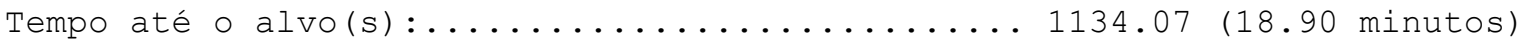

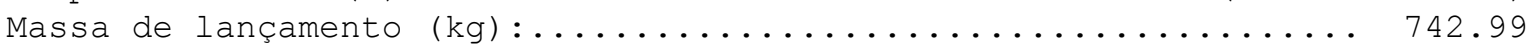

Estabilidade estática (adimensional - múltiplos do diâmetro) :... 2.046

Máximo Fator de Carga em voo (adimensional - múltiplos de g) :... 2.014

Avaliação do indivíduo (adimensional) :................ 1.031701

Dados do Míssil (genes do cromossomo)

Altitude de voo de cruzeiro $(\mathrm{m})$ :...................... 500

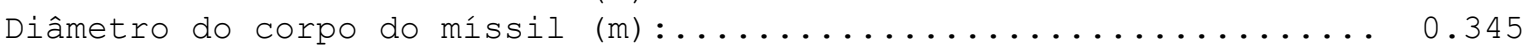

Comprimento do corpo do míssil $(\mathrm{m})$ :.................... 4.462

Comprimento do nariz do míssil (múltiplo do diâmetro) :......... 1.000

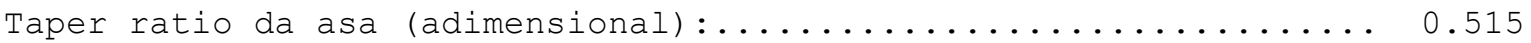

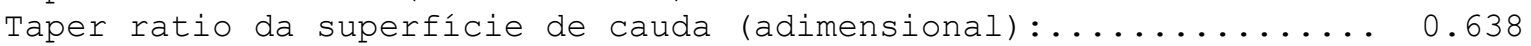

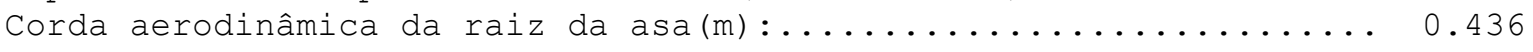

Corda aerodinâmica da raiz da superfície de cauda (m) :........ 0.427

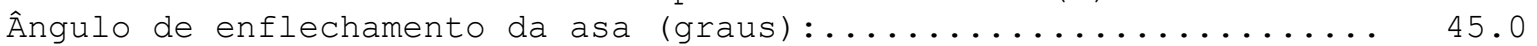

Ângulo de enflechamento da superfície de cauda (graus) :........ 25.0

Âng. tot. bordo de ataque seção transv. da asa e cauda (graus) : .. 30.0

Envergadura total da asa (soma dos 2 painéis) (m) :........... 0.658

Envergadura total das superfícies de cauda (soma 2 painéis) (m) :.. 0.506

Núm. painéis da asa (simples $=1$; cruciforme $=2$; etc) (adimens.): 2

Núm. painéis da cauda (simples $=1$; cruciforme= 2; etc) (adimens.): 2

Número de Mach em voo de cruzeiro (adimensional) :........... 0.800

Dist. bordo ataque da raiz da asa - nariz (múlt. comp. - adimens.) : 0.550

Dist. bordo ataque da cauda - nariz (múlt. comp. - adimens.) :.... 0.890

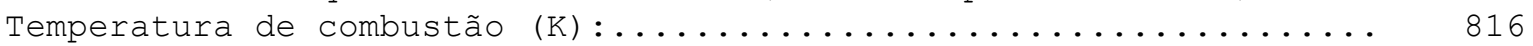

Ângulo de voo inicial após cruzeiro (graus) :................. 45.0

Fração mássica de combustível (comb./início cruzeiro) (adimens.):. 0.133

Relação de pressões no compressor (adimensional) :............ 5.30 
Dados dimensionais do corpo do míssil (Alumínio 2219-T81)

Comprimento do corpo do míssil (mm) :.................... 4462.0

Comprimento do nariz do míssil $(\mathrm{mm})$ :................... 345.0

Diâmetro externo da estrutura do corpo do míssil (mm) :........ 345.0

Diâmetro interno da estrutura do corpo do míssil (mm) ......... 326.6

Espessura da estrutura do corpo do míssil (mm) . .............. 9.2

Área de referência - seção transversal do corpo do míssil (m²) :.. 0.0935

Comprimento do boattail do míssil $(\mathrm{mm})$ :................... 0.0

Diâmetro da parte posterior do boattail do míssil (mm) :........ 345.0

Dados dimensionais da asa do míssil (Alumínio 2219-T81)

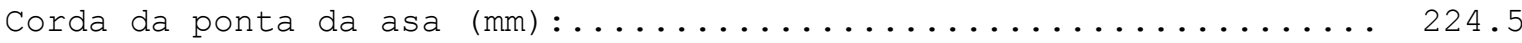

Corda da raiz da asa $(m)$............................ 436.0

Corda Aerodinâmica média da asa $(m m): \ldots \ldots \ldots \ldots \ldots \ldots \ldots . \ldots . \ldots . \ldots$

Distância entre corda aerod. média e a raiz da asa (mm) :....... 146.9

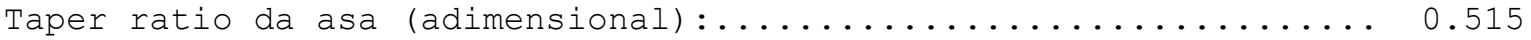

Envergadura total da asa - soma dos 2 painéis $-(\mathrm{mm})$...........6...658.0

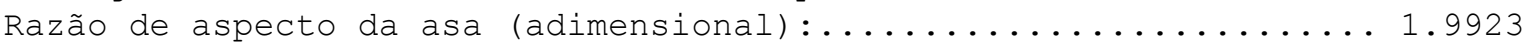

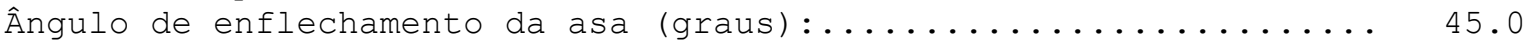

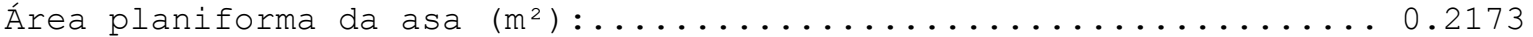

Espessura média da raiz da asa $(\mathrm{mm})$..................... 8.7

Âng. tot. bordo de ataque seção transv. da asa (graus) : ....... 30.00

Número de painéis da asa (simples $=1$; cruciforme $=2$; etc) $\ldots \ldots \ldots$ 2.00

Dist. bordo ataque da raiz da asa - nariz $(\mathrm{mm})$ :............. 2454.1

Dados dimensionais das superfícies de cauda do míssil (Alumínio 2219-T81)

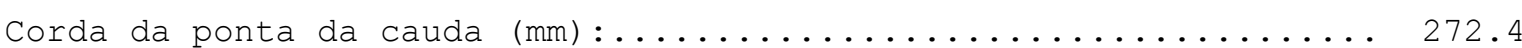

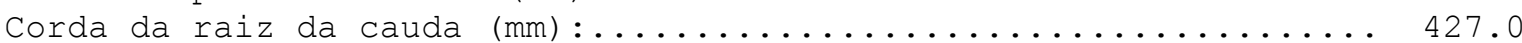

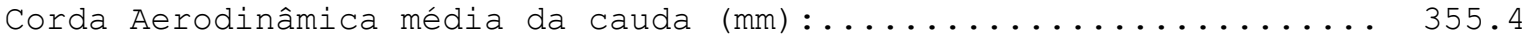

Distância entre corda aerod. média e a raiz da cauda (mm) :...... 117.2

Taper ratio da superfície das superfícies de cauda (adimensional): 0.638

Envergadura total das superfícies de cauda -soma 2 painéis-(mm) :.. 506.0

Razão de aspecto da cauda (adimensional) ................. 1.447

Ângulo de enflechamento das superfícies de cauda (graus) :....... 25.0

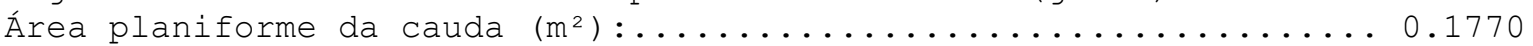

Espessura média da raiz da cauda $(\mathrm{mm}): \ldots \ldots \ldots \ldots \ldots \ldots \ldots \ldots \ldots \ldots . \ldots \ldots . \ldots \ldots$

Âng. tot. bordo de ataque seção transv. da cauda (graus) :....... 30.0

Núm. painéis cauda (

Dist. bordo ataque da cauda - nariz $(\mathrm{mm})$................. 3971.2

Centro aerodinâmico

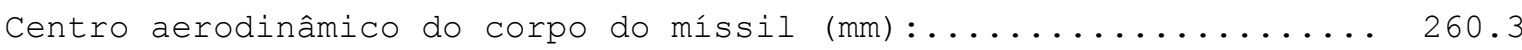

Centro aerodinâmico da asa (bordo de ataque) (mm) ............. 85.4

Centro aerodinâmico da cauda (bordo de ataque) (mm) :.......... 88.9

Centro aerodinâmico da asa (nariz do míssil) (mm) :........... 2686.4

Centro aerodinâmico da cauda (nariz do míssil) (mm) .......... 4114.7

Centro aerodinamico do míssil $(\mathrm{mm})$ :...................... 2937.0

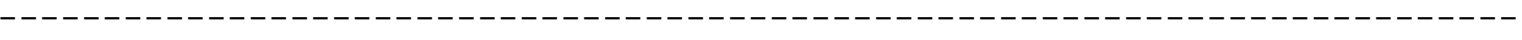

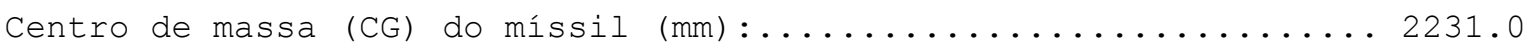

Estabilidade estática (adimensional - múltiplos do diâmetro):.... 2.046 
Dados do voo do míssil

Lançamento

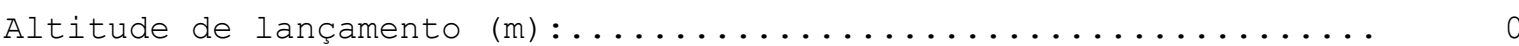

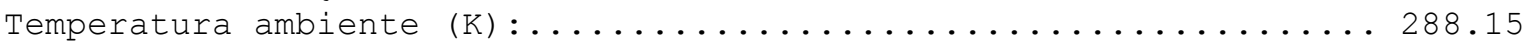

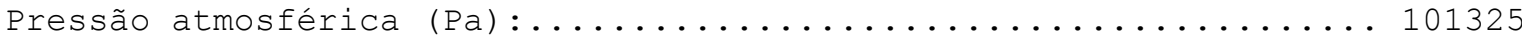

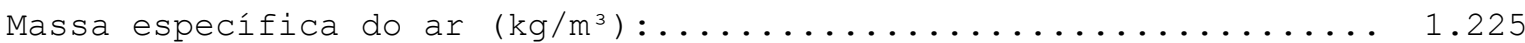

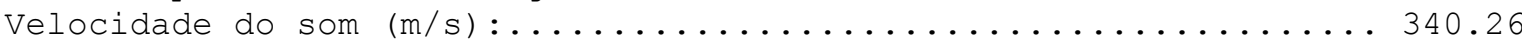

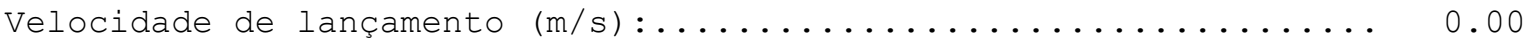

Número de Mach (adimensional) :........................ 0.00

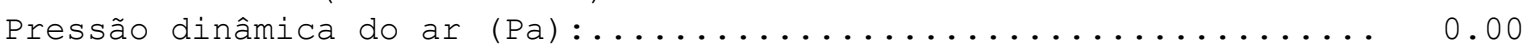

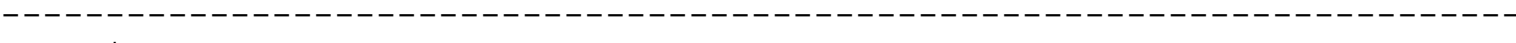

Cruzeiro

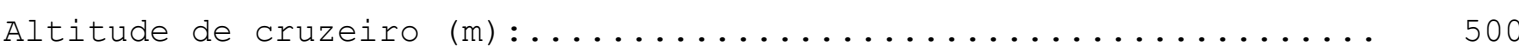

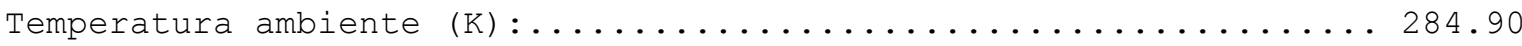

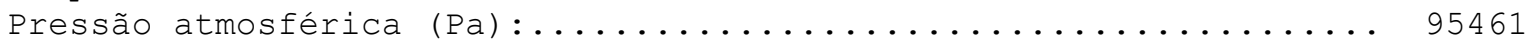

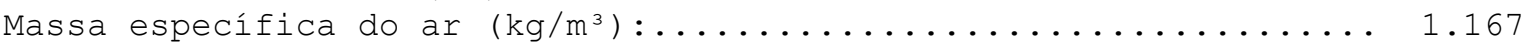

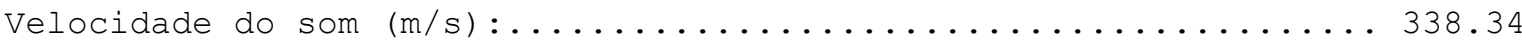

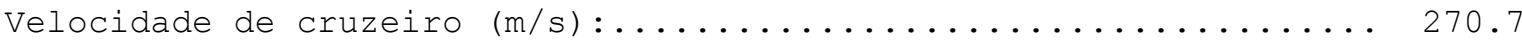

Número de Mach em voo de cruzeiro (adimensional) ............. 0.800

Pressão dinâmica do ar $(\mathrm{Pa})$......................... 42766.70

Impacto

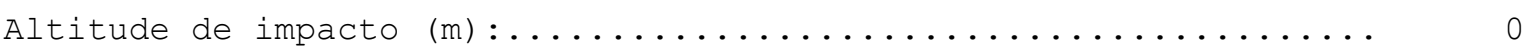

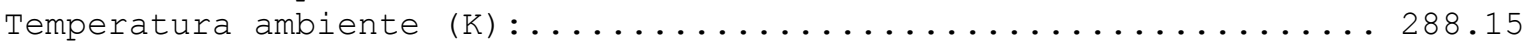

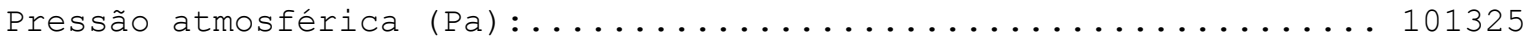

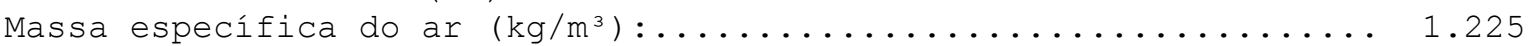

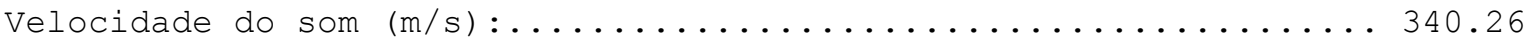

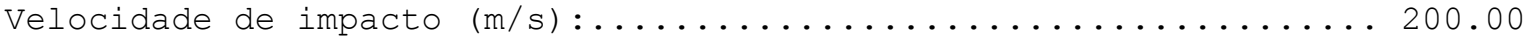

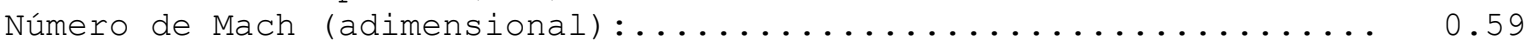

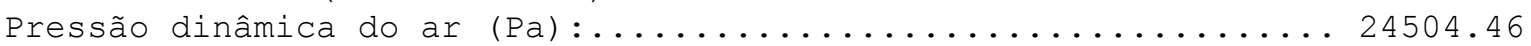

Ângulo de voo inicial após cruzeiro (graus) .................... 45.0

Tempo de voo

Tempo de voo em boost (s) :........................ 3.08

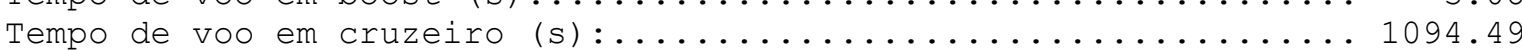

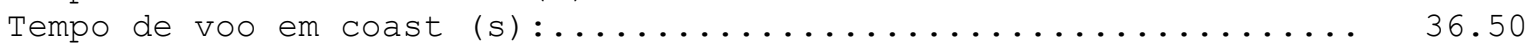

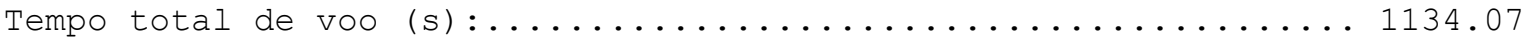

Distância de voo

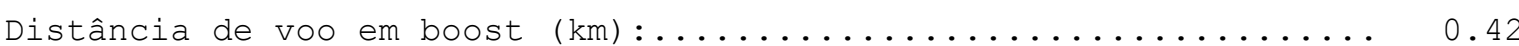

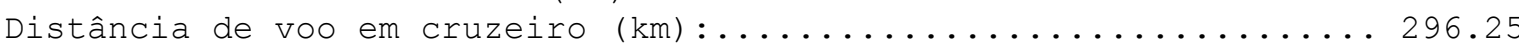

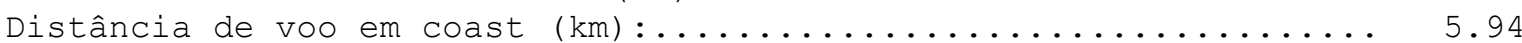

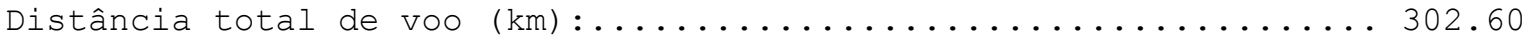


Dados de Coeficiente de Arrasto Parasita Médio em Boost

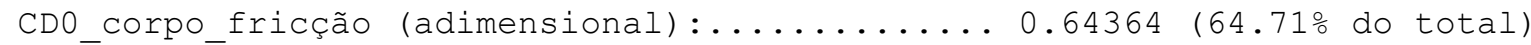

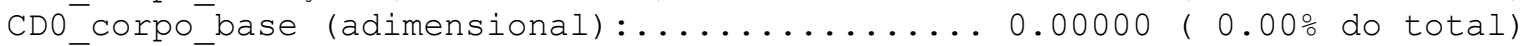

CD0_corpo_onda (adimensional) :................00000 ( $0.00 \%$ do total)

Coef́. Arrāsto Parasita de CORPO (adimensional): 0.64364 (64.71\% do total)

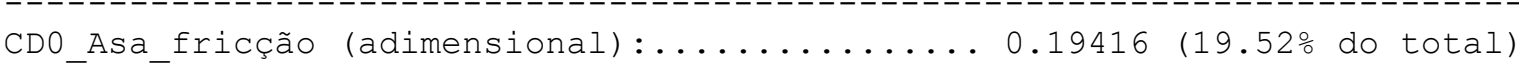

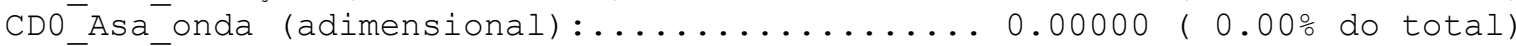

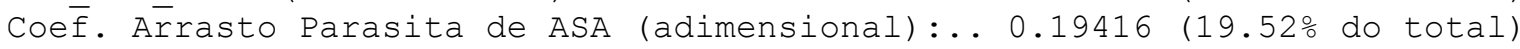

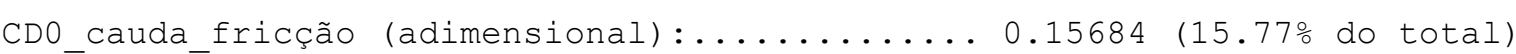

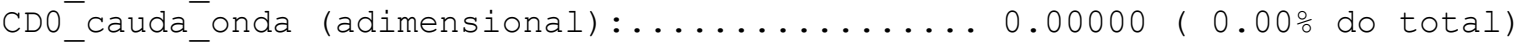

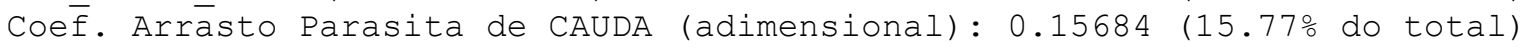

Coef. Arrasto Parasita Global em boost (adimensional) :........ 0.99464

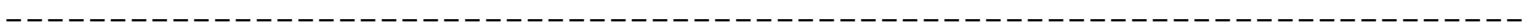

Dados de Coeficiente de Arrasto Parasita em Cruzeiro

CD0 corpo fricção (adimensional) : ............... 0.09847 (32.33\% do total)

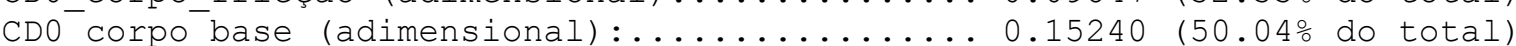

CDO ${ }^{-}$corpo onda (adimensional) :..................00000 ( $0.00 \%$ do total)

Coef. Arrāsto Parasita de CORPO (adimensional): 0.25087 (82.37\% do total)

CDO Asa friç̧ão (adimensional) :...................................... do total)

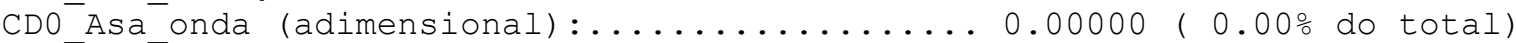

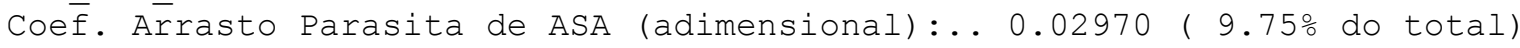

CDO cauda friç̧ão (adimensional) :................................ do total)

CDO_cauda_onda (adimensional) :.................00000 ( $0.00 \%$ do total)

Coes. Arrásto Parasita de CAUDA (adimensional): 0.02400 ( $7.88 \%$ do total)

------------------------------------------------------------------------

Coef. Arrasto Parasita Global em cruzeiro (adimensional):...... 0.30457

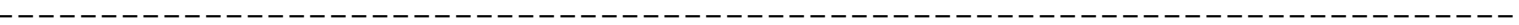

Dados de Coeficiente de Arrasto Parasita Médio em Coast

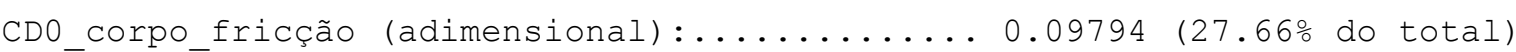

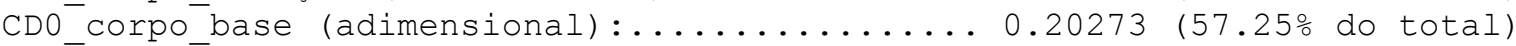

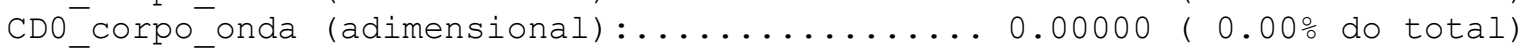

Coef̄. Arrāsto Parasita de CORPO (adimensional): 0.30067 (84.92\% do total)

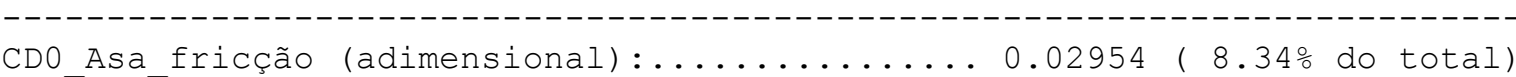

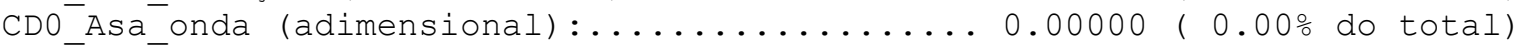

Coeff. Arrrasto Parasita de ASA (adimensional):.. 0.02954 ( $8.34 \%$ do total)

CDO_cauda_fricção (adimensional) .............0.02387 ( $6.74 \%$ do total)

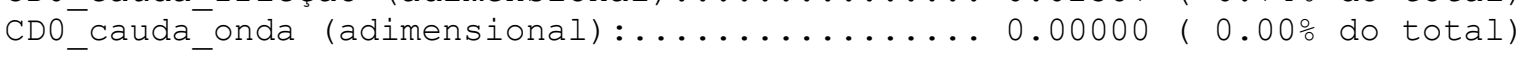

Coēf. Arrásto Parasita de CAUDA (adimensional): 0.02387 ( $6.74 \%$ do total)

Coef. Arrasto Parasita Global em coast (adimensional) :........ 0.35409

Coef. Arrasto Parasita Global em coast (adimensional) ............ 0.35409 
Dados de Coeficiente de Força Normal e sua derivada

--- -

Coeficiente de Força Normal (Início do Cruzeiro)

Coeficiente de força normal no Corpo (adimensional) ............ 0.415

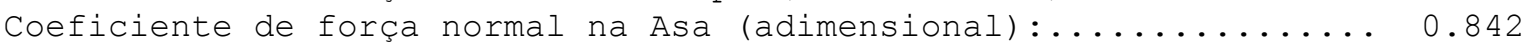

Coeficiente de força normal na Cauda (adimensional) :.......... 0.235

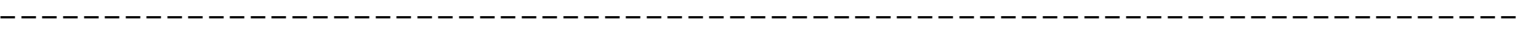

Derivada do Coeficiente de Força Normal(Início do Cruzeiro)

Derivada do Coeficiente de força normal no Corpo (1/rad) :....... 2.00

Derivada do Coeficiente de força normal na Asa (1/rad) :........ 7.28

Derivada do Coeficiente de força normal na Cauda (1/rad) :....... 4.30

$-------------------------------------------------------------------------$

Coeficiente de Força Normal (Máximo Fator de Carga em voo)

Coeficiente de força normal no Corpo (adimensional) ............ 0.848

Coeficiente de força normal na Asa (adimensional) :........... 1.384

Coeficiente de força normal na Cauda (adimensional) :.......... 0.577

--------------------------------------------------------------------

Derivada do Coeficiente de Força Normal (Máximo Fator de Carga em voo)

Derivada do Coeficiente de força normal no Corpo (1/rad) :....... 2.00

Derivada do Coeficiente de força normal na Asa (1/rad) :........ 7.28

Derivada do Coeficiente de força normal na Cauda (1/rad) :....... 4.30

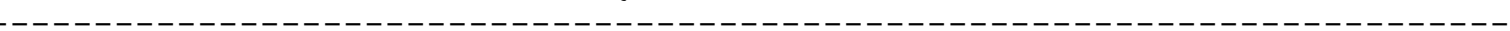

Relação Sustentação/Arrasto

Relação Sustentação/Arrasto média em cruzeiro (adimensional) :.... 3.207 Relação Sustentação/Arrasto média em coast (adimensional) :...... 2.710

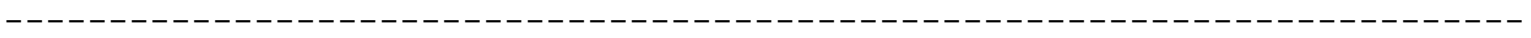

Arrasto médio em voo

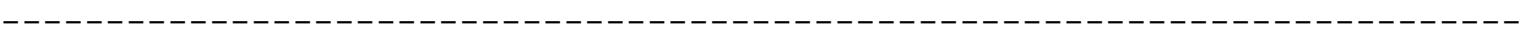

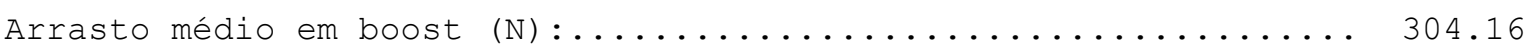

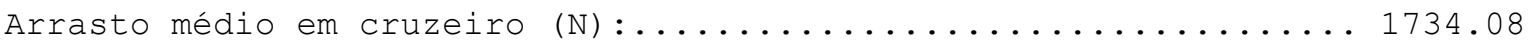

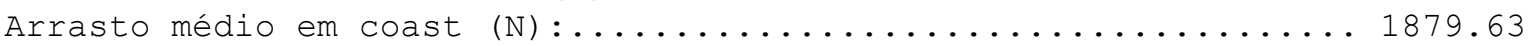


Massa do míssil nos principais momentos de voo

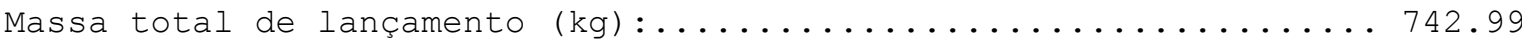

Massa do míssil no início do cruzeiro $(\mathrm{kg})$................6 603.15

Massa do míssil no fim do cruzeiro $(\mathrm{kg})$ :................. 523.23

Massa espec. do míssil no início do cruzeiro - ref.:1384 - (kg/m³): 1446.0

Massas dos componentes do míssil

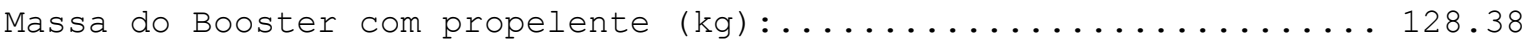

Massa de propelente necessária para o Booster (kg) :.......... 83.45

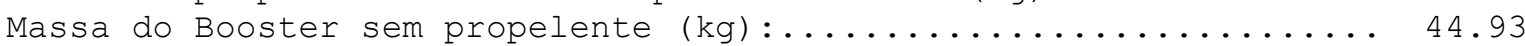

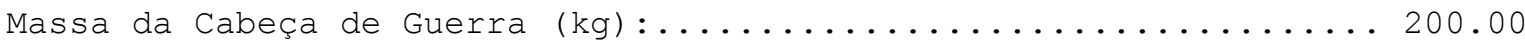

Massa dos Sistemas de Guiamento, Controle e Enlace de Dados (kg):. 70.00

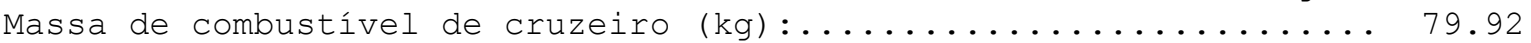

Massa da estrutura (corpo) do míssil (kg) :................. 122.84

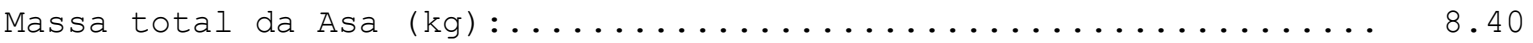

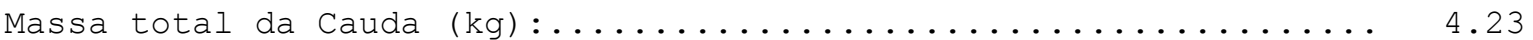

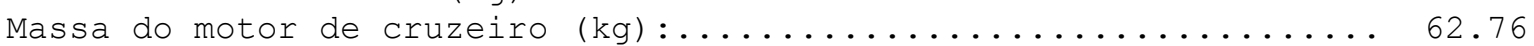

Massa total dos atuadores das superfícies de controle (kg) :.... 30.00

Massa total da fonte de energia (power supply) (kg) :.......... 25.00

Parcela da massa dos componentes em relação à massa de Lançamento

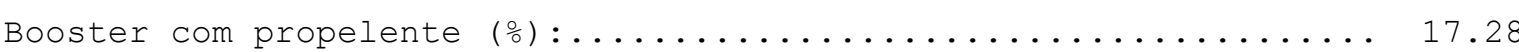

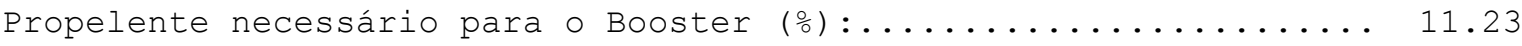

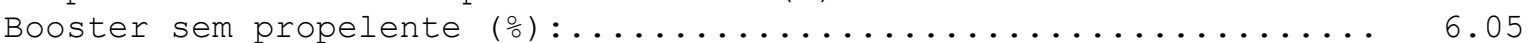

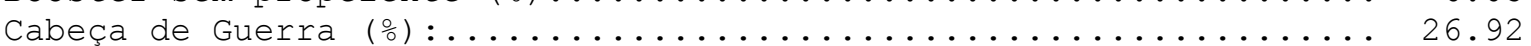

Sistemas de Guiamento, Controle e Enlace de Dados (\%) :......... 9.42

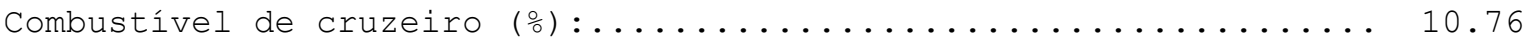

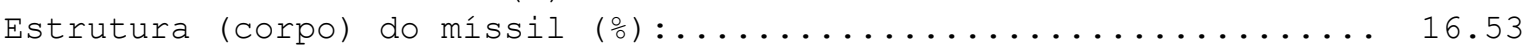

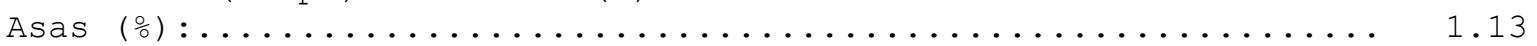

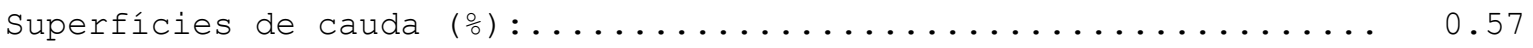

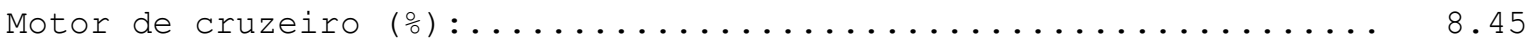

Atuadores das superfícies de controle (o) :.................. 4.04

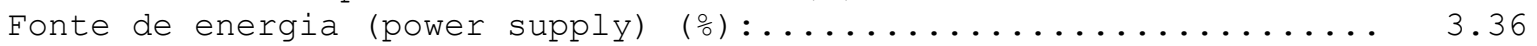

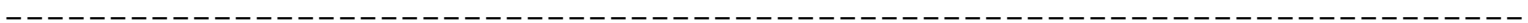

Parcela da massa dos componentes em relação à massa no início do cruzeiro

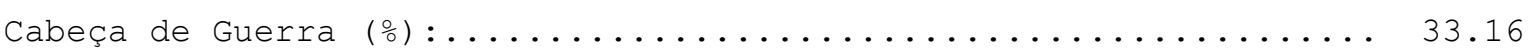

Sistemas de Guiamento, Controle e Enlace de Dados (\%) :.......... 11.61

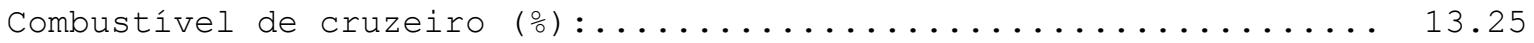

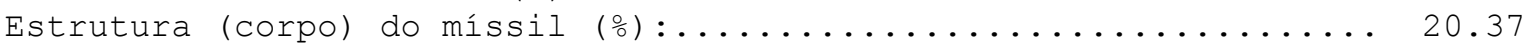

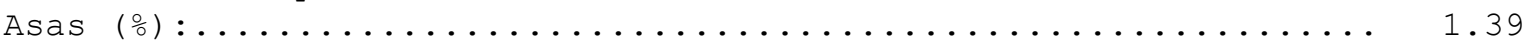

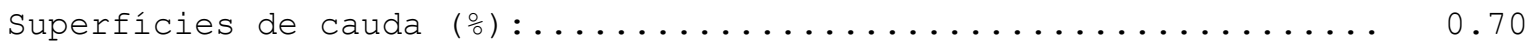

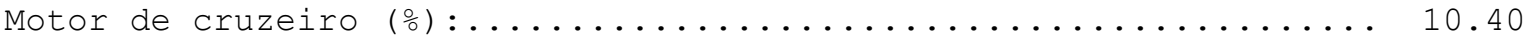

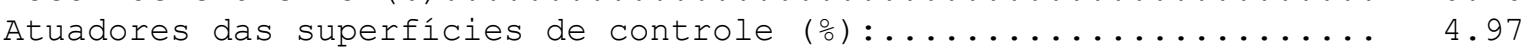

Fonte de energia (power supply) (o) :..................... 4.14 
Condição de voo nivelado no início do cruzeiro

Ângulo de Ataque dos elementos do míssil

Ângulo de Ataque do corpo (graus) :........................6.25

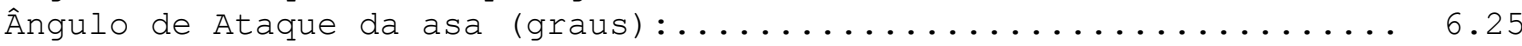

Ângulo de Ataque da cauda (graus) :...................... 3..00

Força normal nos elementos do míssil

Forca normal no corpo (N) : . -

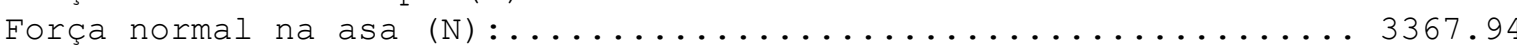

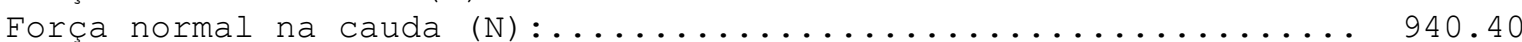

Peso do míssil em voo nivelado (início do cruzeiro) (N) : ...... 5914.86

Erro na aplicação das equações de equilíbrio

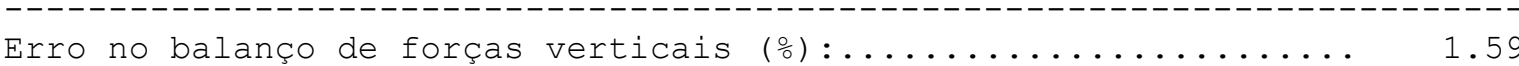

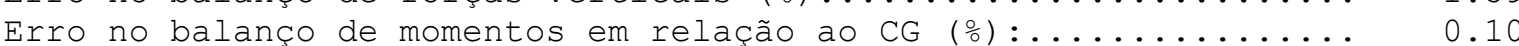

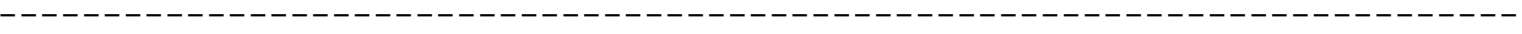

Valor residual na aplicação das equações de equilíbrio

Valor residual do balanço de forças verticais - inclui o peso (N): 93.81 Valor residual do somatório de momentos em relação ao CG (N.m) :... 3.33

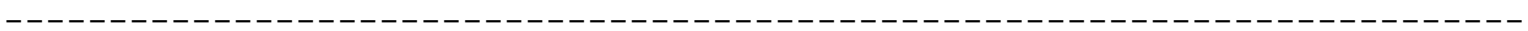

Condição de máximo Fator de Carga em voo (n máximo)

Máximo Fator de Carga em voo (adimensional) :................ 2...014

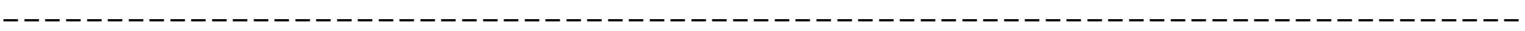

Ângulo de Ataque dos elementos do míssil

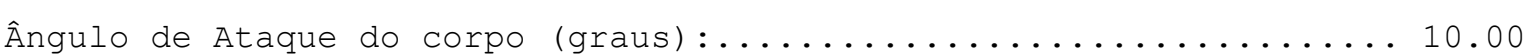

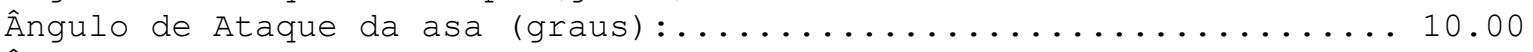

Ângulo de Ataque da cauda (graus) :...................... 7.0. 00

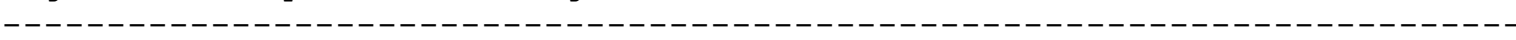

Força normal nos elementos do míssil

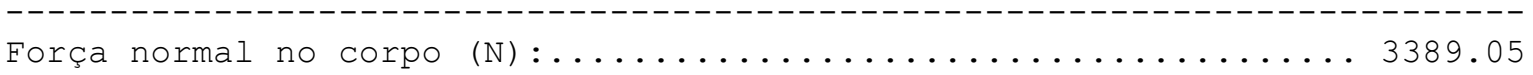

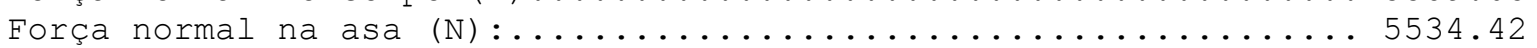

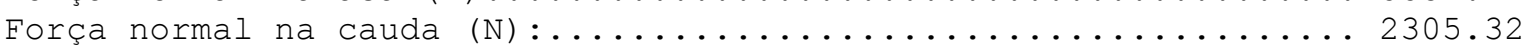
Peso do míssil em máximo fator de carga de voo (n máximo) (N) : .. 11914.73

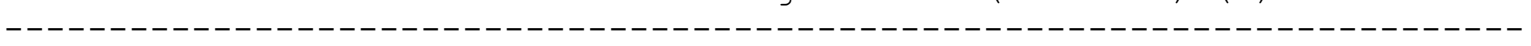

Erro na aplicação das equações de equilíbrio

Erro no balanço de momentos em relação ao CG (\%) ............ - 2.74

Valor residual na aplicação das equações de equilíbrio

---------------------------------------------------------------------

Valor residual do somatório de momentos em relação ao CG (N.m) :.. -187.81

-------------------------------------------------------------------------


Sistema de Propulsão - Booster

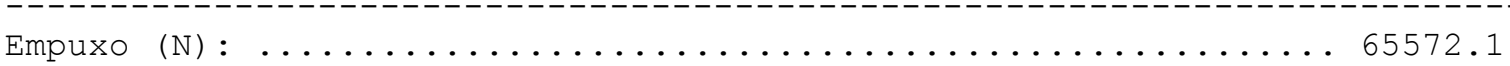

Dados de entrada

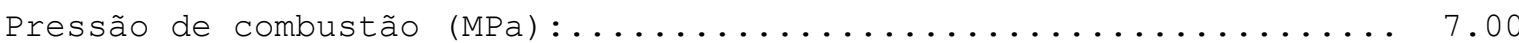

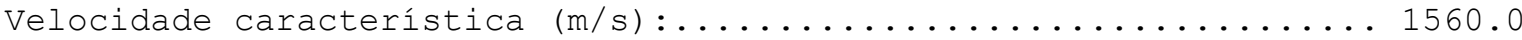

Razão de calores específicos na tubeira (adimensional) :........ 1.180

Fator de aceleração durante boost (múltiplo da acel. gravidade) :.. 9.00

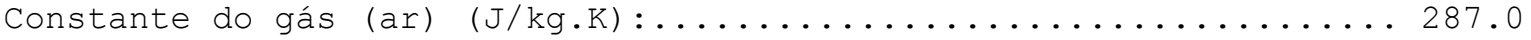

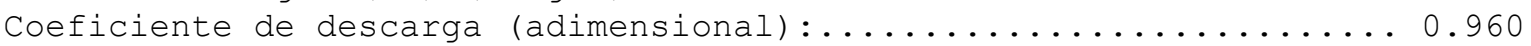

Flight path angle (graus) :........................ 45.0

Razão de expansão da tubeira - Booster (adimensional)

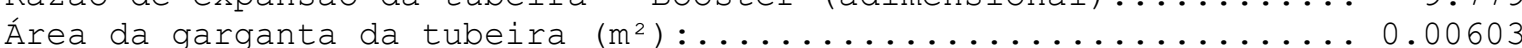

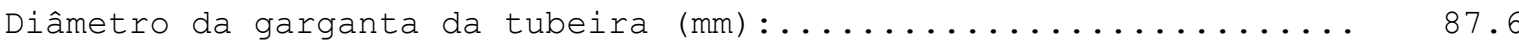

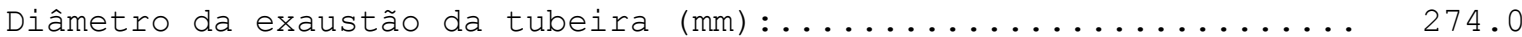

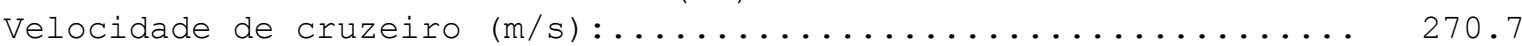

Máxima velocidade incremental devido ao Booster (m/s) : ....... 270.7

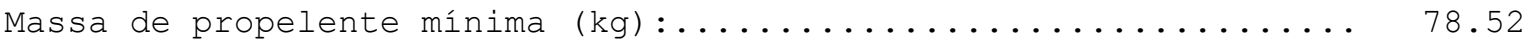

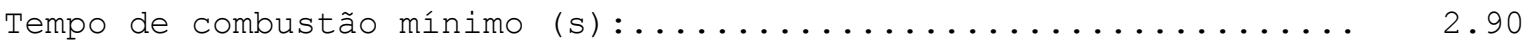

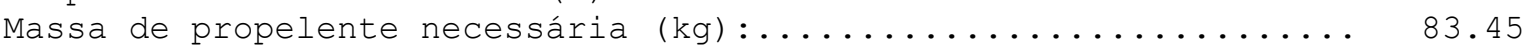

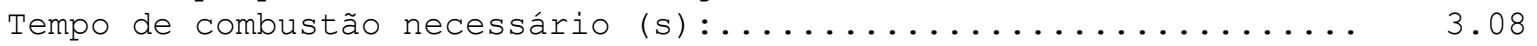

Peso médio do míssil durante Boost (N) :.......... 6876.6 (701.27 kgf)

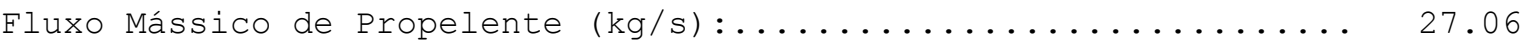

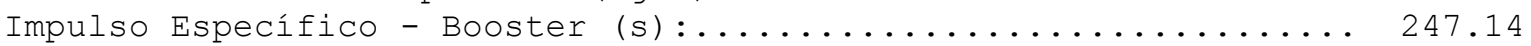


Sistema de Propulsão - Motor de Cruzeiro

Tipo de motor de cruzeiro: Turbojato

Empuxo necessário em voo nivelado - início do cruzeiro (N) :..... 1818.3 Empuxo necessário em voo nivelado - fim do cruzeiro (N) :...... 1668.6 Empuxo necessário no instante de máximo Fator de Carga (N) :..... 3077.1

Condições de operação no início do voo em cruzeiro

Temperatura

Temperatura de estagnação na entrada do compressor (K) : ........ 321.4 Temperatura de estagnação na saída do compressor (K) : ........ 526.8 Temp. de estagnação na entrada na turbina (K) - dado de entrada:... 816.0 Temperatura de estagnação na saída da turbina $(K)$............610.6

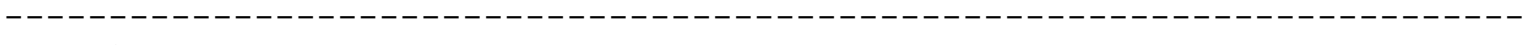

Pressão

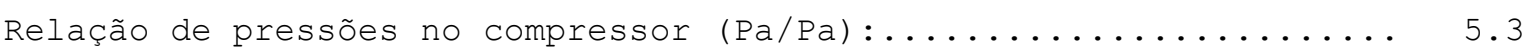

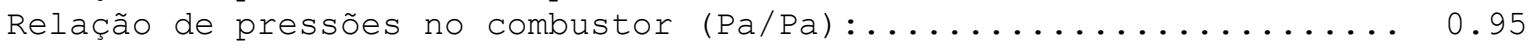

Pressão de estagnação na entrada do compressor (kPa) . . . . . . . . 140.4

Pressão de estagnação na saída do compressor (kPa) ............ 744.0

Pressão de estagnação na entrada na turbina (kPa) :.......... 706.8

Pressão de estagnação na saída da turbina $(\mathrm{kPa})$............. 188.3

Pressão na saída do bocal de exaustão $(\mathrm{kPa}): \ldots \ldots \ldots \ldots \ldots \ldots . \ldots . \ldots 9$

------------------------------------------------------------------------

Eficiência isentrópica (dados de entrada)

Eficiência isentrópica do difusor de admissão de ar (adimensional): 0.91

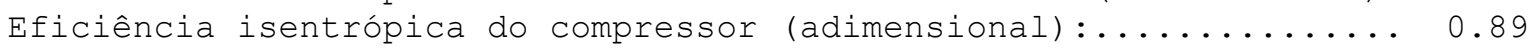
Eficiência isentrópica da turbina (adimensional) ............. 0.90 Eficiência isentrópica do bocal de exaustão (adimensional) :...... 0.95 Calor específico do fluido de trabalho (dados de entrada)

Razão de calores específicos no difusor de entrada (adimensional) : . 1.40 Razão de calores específicos no compressor (adimensional) :...... 1.37 Razão de calores específicos na turbina (adimensional) :........ 1.33 Razão de calores específicos no bocal de exaustão (adimensional):.. 1.33

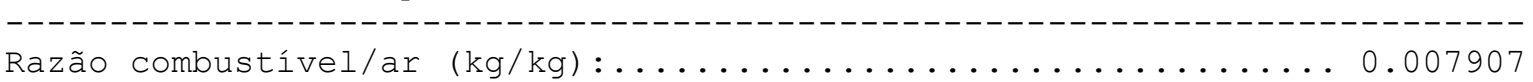
Poder calorífico do combustível (kJ/kg) :................ 43000.0

Velocidade na saída do bocal de exaustão $(\mathrm{m} / \mathrm{s})$ :............4447.27 Área da saída do bocal de exaustão $\left(\mathrm{m}^{2}\right)$ :......................0.033427 Área de referência - seção transversal do corpo do míssil (m²) : .. 0.0935 Razão área da saída do bocal de exaustão / seção do míssil (adm.): 0.3576

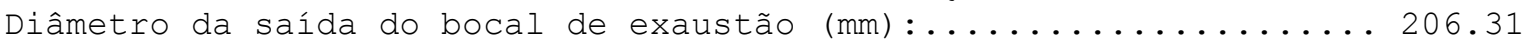
Número de Mach na saída do bocal de exaustão (adimensional):..... 1.0000

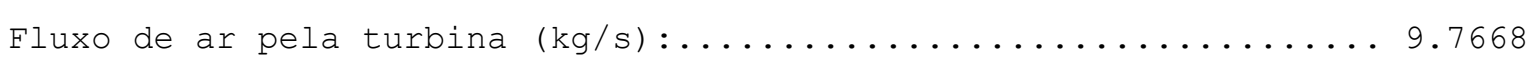

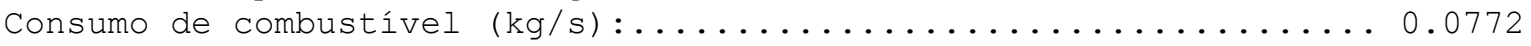

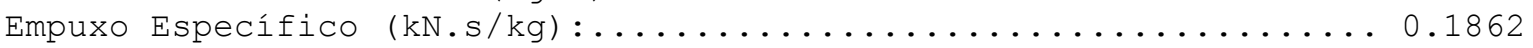

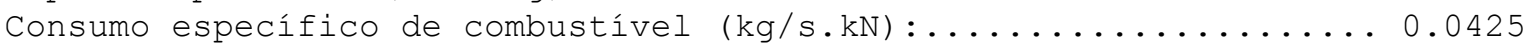
Impulso Específico $(\mathrm{s})$ : ............................. 2401.2 
Dados da Avaliação do Míssil

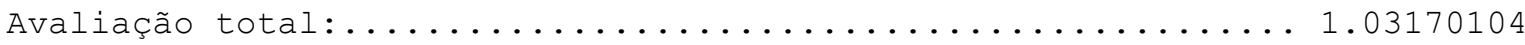

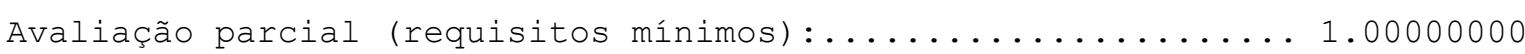

$-------------------------------------------------------------------------$

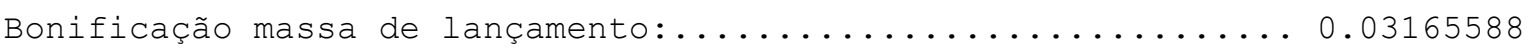

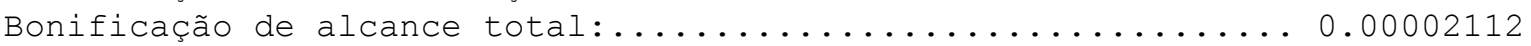

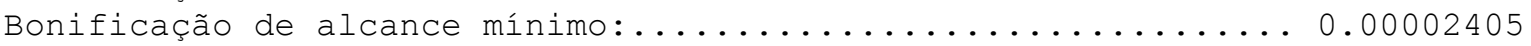

$-------------------------------------------------------------------$

Penalização nariz maior que o comprimento do míssil:.......0.0000000

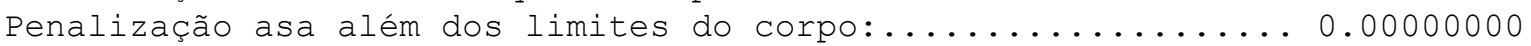

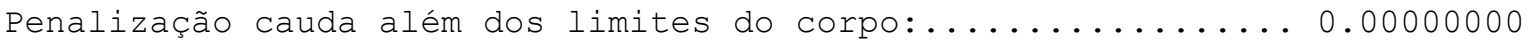

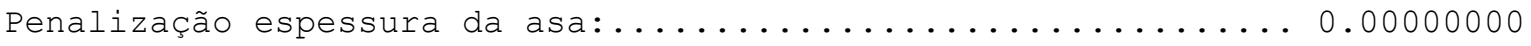

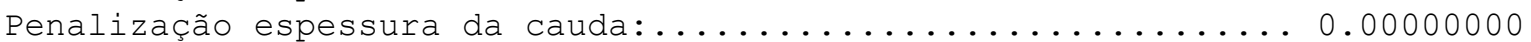

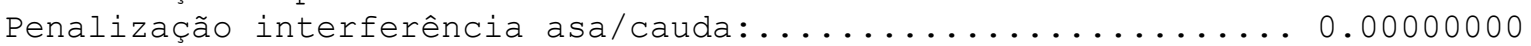

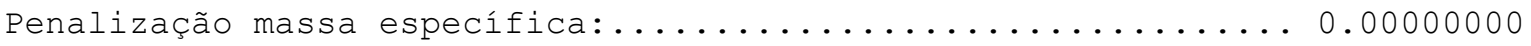

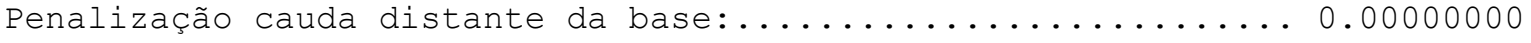

